\title{
Josef Vintr
}

\section{Die ältesten tschechischen Evangeliare}

\section{Edition, Text- und Sprachananlyse der ersten Redaktion}

Verlag Otto Sagner München · Berlin - Washington D.C.

Digitalisiert im Rahmen der Kooperation mit dem DFG-Projekt „Digi20“

der Bayerischen Staatsbibliothek, München. OCR-Bearbeitung und Erstellung des eBooks durch den Verlag Otto Sagner:

http://verlag.kubon-sagner.de

() bei Verlag Otto Sagner. Eine Verwertung oder Weitergabe der Texte und Abbildungen, insbesondere durch Vervielfältigung, ist ohne vorherige schriftliche Genehmigung des Verlages unzulässig. 


\section{SLAVISTISCHE BEITRÄGE}

BEGRÜNDET VON ALOIS SCHMAUS

HERAUSGEGEBEN VON JOHANNES HOLTHUSEN UND JOSEF SCHRENK

REDAKTION: PETER REHDER

Band 107 
JOSEF VINTR

DIE ÄLTESTEN TSCHECHISCHEN EVANGELIARE

Edition, Text- und Sprachanalyse der ersten Redaktion

VERLAG OTTO SAGNER - MÜNCHEN

1977 
ISBN 3-87690-128-6

Copyright by Verlag Otto Sagner, München 1977

Abteilung der Firma Kubon \& Sagner, München

Druck: Alexander Grossmann

Fäustlestr. 1, D-8000 München 2 
vorwort..................................... 11 EINLEITUNG

1. Aufgabenstellung der textstrukturellen Analyse........ 12

1.1. Die Stellung der Evangeliare unter den altesten tschechischen Texten..................... 12

1.2. Die Arbeitsmethode....................... 13 ERSTER TEIL

TEXTOLOGISCH-PHILOLOGISCHE CHARAKTERISTIK

2. Methodik und Einteilung der Thematik.............. 15

3. Textologische Charakteristik

3.1. Einteilung der Problematik................ 16

3.2. Literaturgeschichtliche Einfuhrung........... 16

3.3. Kodikologische Charakteristik............... 21

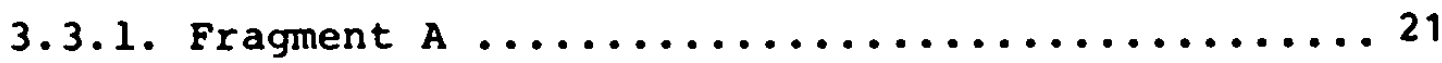

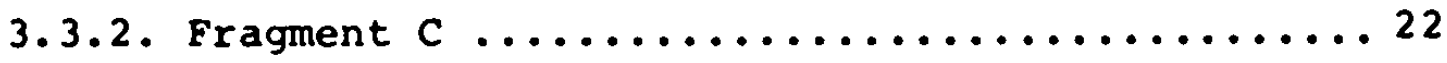

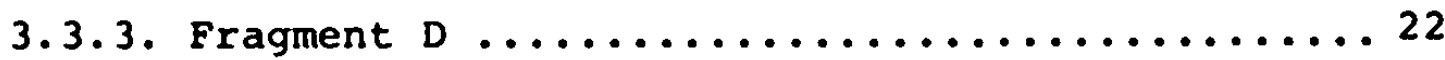

3.3.4. Seitenstettener Handschrift (S) $\ldots \ldots \ldots \ldots \ldots 23$

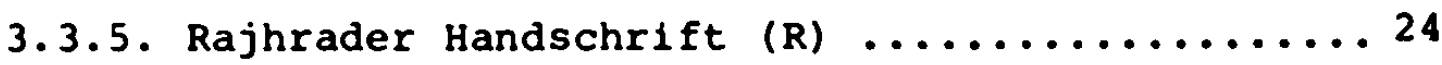

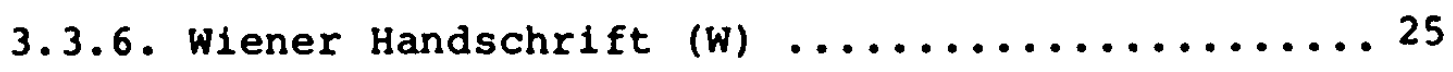

3.4. Redaktionen der tschechischen Evangeliarubersetzung. ......................... 26

3.5. Liturgische Anmerkung................... 26

4. Philologische Charakteristik der Ubersetzungstechnik..... 27

4.0. Einteilung der Problematik................ 27

4.1. Die Frage des Originals.................. 28

4.1.1. Das Verhältnis zur altkirchenslavischen Evangelienübersetzung - Ubersicht der bisherigen standpunkte................. 29

4.2. Abweichungen vom Vulgatatext und Ubersetzungs-

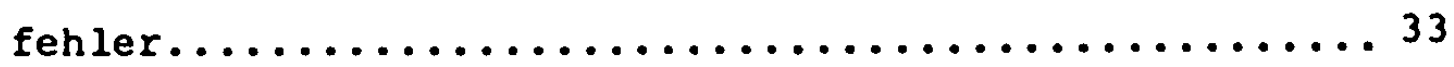

4.2.1. Abweichungen vom Vulgatatext; năhere Bestimmung des lateinischen originals....... 33

4.2.2. Ubersetzungs fehler................... 39

4.2.2.1. Abschreibfehler.................. 39

4.2.2.2. Die echten Ubersetzungsfehler..........42

4.3. Die Wiedergabe lateinischer grammatikalischer

Kategorien durch alttschechische sprachmittel......43

4.3.1. Die lateinischen Partizipialkonstruktionen.... 44 
4.3.1.1. Der, ablativus absolutus'..............44

4.3.1.1.1. Wiedergabe durch ein Part.t Akk. .......45

4.3.1.1.2. Wiedergabe durch ein Part.+ Gen. .......45

4.3.1.1.3. Wiedergabe durch einen Hauptsatz........46

4.3.1.1.4. Wiedergabe durch einen Temporalsatz......46

4.3.1.1.5. Wiedergabe mit Fehlern..............47

4.3.1.2. Die lateinischen attributiven und prădikativen Partizipien................47

4.3.1.2.1. Wiedergabe durch Indikative und Partizipien.....................47

4.3.1.2.2. Wiedergabe durch absolutive Partizipien... 49 4.3.1.2.3. Wiedergabe durch einen Infinitiv (bzw.

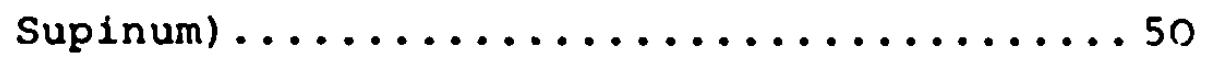

4.3.2. Das lateinische Tempussystem..............50 4.3.2.1. Wiedergabe des Präsens, Imperfekts,Perfekts, Plusquamperfekts.................. 50

4.3.2.1.1. Wiedergabe des Futurs.............. 51

4.3.2.1.2. Wiedergabe der lateinischen, coniugatio periphrastica activa'...............51

4.3.2.2. Die wichtigsten lateinischen Nebensätze.... 52

4.3 .2 .2 .1 . Finalsätze....................5 5

4.3 .2 .2 .2 . Temporalsätze................... 53

4.3.2.2.3. Konditionalsätze.................53

4.3.3. Die lateinischen Infinitivkonstruktionen.....54

4.3.3.1. Der, accusativus cum infinitivo'........54

4.3.3.2. Der, nominativus cum infinitivo'........56

4.3.4. Andere lateinische Konstruktionen..........56

4.3.4.1. Der Imperativ noli + Inf. ...........57

4.3.4.2. Der adnominale Genitiv...............57

4.3.4.3. Der, ablativus temporis' ..............58

4.3.4.4. Die Nachahmungen der lateinischen Kon-

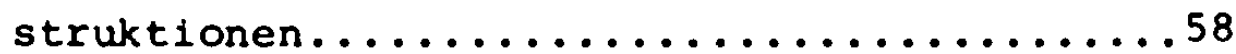

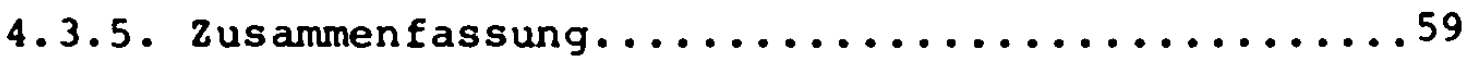

4.4. Die Wiedergabe des lateinischen wortschatzes.......60

4.4.1. Die biblischen Termini.................60

4.4.2. Die Ze1t- und Massangaben, die Wirtschaftstermini, die Krankheiten, die Fischereitermini, die botanischen und zoologischen Termini..........................66

4.4.3. Die Pronomina omnis und nemo.............69 4.4.4. Die Verba. 
4.4.4.1. Die typisch biblischen Zeitwörter.........70

4.4.4.2. Die unklaren Verbaíbersetzungen..........71

4.4.4.3. Die Modernisierungsversuche............71

4.4.5. Die lexikalischen Besonderheiten..........72

4.4.5.1. Die Ungenauigkeiten und Fehler bei der

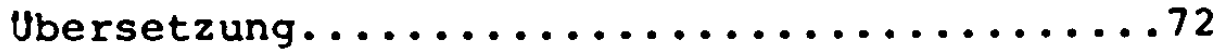

4.4.5.2. Die Archaismen und Dialektismen..........74

4.4.6. Zus ammenfassung.....................75

4.5. Ergebnisse der Ubersetzungscharakteristik.........76

4.5.1. Das lateinische Original und die alttsche-

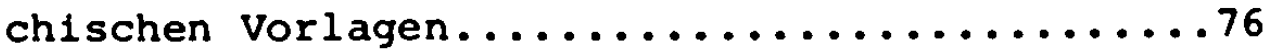

4.5.2. Uber die Qualität der alttschechischen Evangeliarijbersetzung..................79

4.5.3. Filiationsschema der ersten Ubersetzungsredaktion........................81

ZWEITER TEIL

LINGUISTISCHE CHARAKTERISTIK

5. Zur Methodik und Problemeinteilung................84

6. Lexikologische Charakteristik...................86

6.0.1. Zum Begriff 'lexikalisches Teilsystem'.........86

6.0.2. Die bisherige Literatur..................87

6.1. Die lexikalischen zentralen und peripheren

Erscheinungen......................... 88

6.2. Die Entwicklungsvorglinge im wortschatz...........89

6.2.1. Die sprachlichen Faktoren der Entwicklungs-

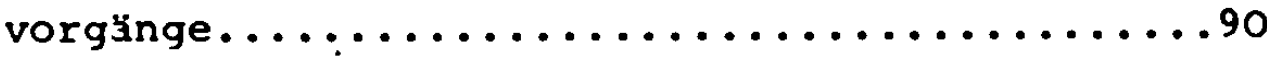

6.2.2. Die aussersprachlichen Faktoren...........91

6.3. Zusammenfassung........................92

7. Syntaktische Charakteristik....................92

7.0.1. Zum Begriff 'syntaktisches Teilsystem'.........92

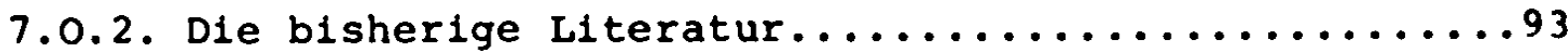

7.1. Die syntaktischen zentralen und peripheren Erscheinungen..........................94

7.2. Die Entwicklungsvorgänge im syntaktischen Teil-

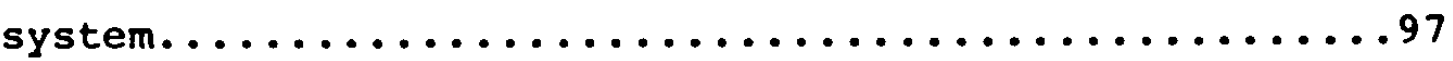

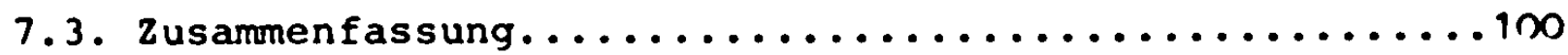

8. Morphologische Charakteristik....................100

8.0.1. Zum Begriff der diachronen Morphologie..........101

8.1. Die Deklinationsformen......................101

8.1.1. Die bisherige Literatur.................102

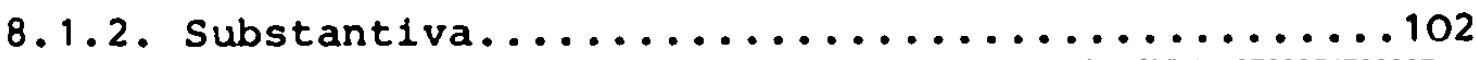


8.1.3. Pronomina ......................... 103

8.2. Die Konjugationsformen..................... 104

8.2.1. Die bisherige Literatur................ 104

8.2.2. Die Problematik des alttschechischen Kond. Fut. (des sog. 'futurum exactum') und die Funktionen der vier stämme des Hilfsverbs

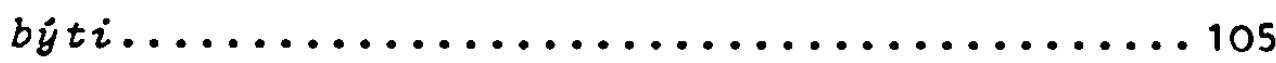

8.3. Zusammenfassung......................... 108

9. Phonologische Charakteristik.................... 108

9.1. Charakteristik der phonologischen systeme einzelner

Evangeliarhandschriften..................... 108

9.1.1. A Fragment......................... 108

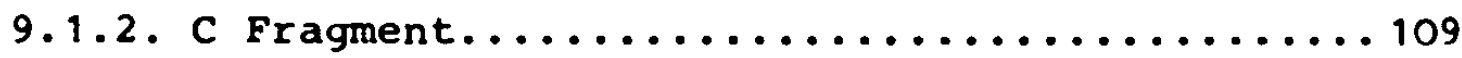

9.1.3. D Fragment......................... 109

9.1.4. S (Seitenstettener) Handschrift............ 110

9.1.5. R (Rajhrader) Handschrift............... 111

9.1.6. W (Wiener) Handschrift................. 113

9.2. Neue Einblicke in das alttschechische phonologi-

sche system............................. 114

9.2.1. Die bisherige Literatur............... 115

9.2.2. Zur hiexarchischen Gliederung der system-

elemente und die Einteilung der Problematik.. 115

9.2.3. Rekonstruktion der phonologischen Systeme einzelner Handschriften............... 116

9.2.3.1. Rekonstruktion des phonologischen Systems

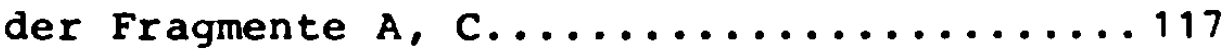

9.2.3.1.1. Die Stellung der silbischen Sonanten..... 118

9.2.3.2. Rekonstruktion des phonologischen systems der Handschriften $S, R, W, D \ldots \ldots \ldots \ldots . . . .119$

9.2.4. Die Zahlensymmetrie der systemelemente...... 120

9.2.4.1. Die bisherige Literatur................ 120

9.2.4.2. Zum Begriff eines systemmodells.......... 120

9.2.4.3. Das arithmetische systemmodell...........121

9.2.4.4. Die Grundsatze der analytischen Phonologie

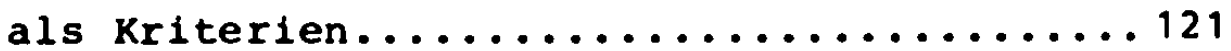

9.2.4.5. Zahlenrelationen und -symmetrie im arithmetischen Modell des alttschechischen phonologischen systems um $1300 \ldots \ldots \ldots \ldots \ldots \ldots 122$

9.2.4.5.1. C, V (Konsonanten, Vokale)-Symmetrie.... 122 9.2.4.5.2. s(silbenwert)-Symmetrie............. 123 
9.2.4.5.3. X(Farbe - alveolar, palatal, velar,

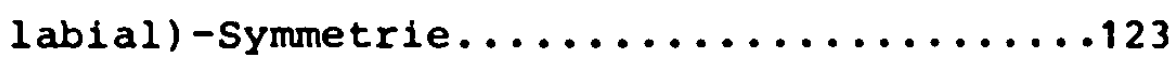

9.2.4.5.4. m(Mouillierung)-symmetrie............123

9.2.4.5.5. q(Quantitä) -symmetrie................124

9.2.4.5.6. n(Nasalität)-Symmetrie..............124

9.2.4.5.7. Zusammenfassung der Relationen..........125

9.2.4.5.8. Die Rolle der Vokalvarianten als

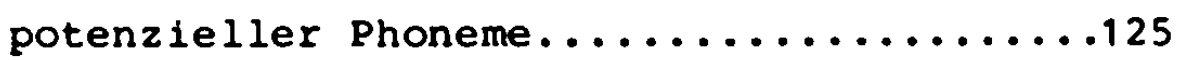

9.2.4.5.9. Die Ergebnisse der Zahlensymmetrie-

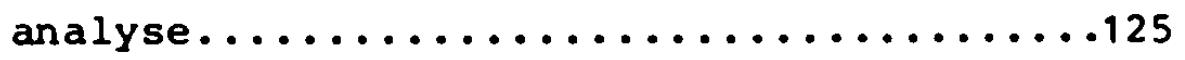

9.2.4.6. Zahlensymmetrie im arithmetischen Modell des alttschechischen phonologischen

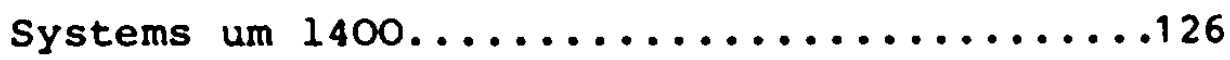

9.2.5. Die Raumsymmetrie der Systemelemente.

9.2.5.1. Das geometrische Modell eines phonologi-

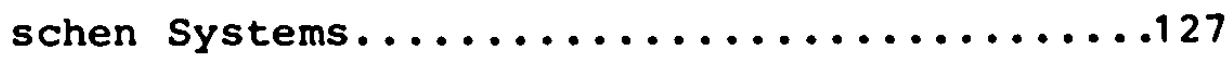

9.2.5.2. Die Unterteilung der Teilebenen und Sektoren im geometrischen Modell...........127

9.2.5.3. Die Figuren im geometrischen Modell.......128

9.2.5.4. Das Raummodell des alttschechischen phonologischen systems um $1300 \ldots \ldots \ldots . \ldots . \ldots 129$

9.2.5.5. Das Raummodell des alttschechischen phonologischen systems um 1400.............130

9.2.5.6. Die Symmetrie in Raummodellen............130

9.2.5.7. Die Konkurrenz der Symmetrien...........131 9.2.6. Parazentrische Bewegungen eines akzessorischen Elements.....................131

9.2.6.1. Gibt es ein dynamisches systemmodell?.....131

9.2.6.2. Die Beweglichkeit der akzessorischen Elemente.........................131

9.2.6.3. Konkurrenz in der Hierarchıe der akzessorischen Elemente..................132

9.2.6.4. Die parazentrischen Bewegungen eines akzessorischen Elements..............132

9.2.6.5. Die parazentrischen Bewegungen des m(Mouillierung)-Elements - Entwicklung der Mouillierungskorrelation...........133

9.2.6.6. Die parazentrischen Bewegungen als Entwicklungsfaktor..................137

9.3. zusammenfassung........................137

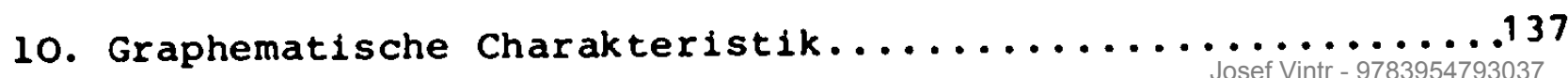


10.1. Die Digraphenorthographie............ . . . . 137

10.2. Graphematische Systeme aller Handschriften im

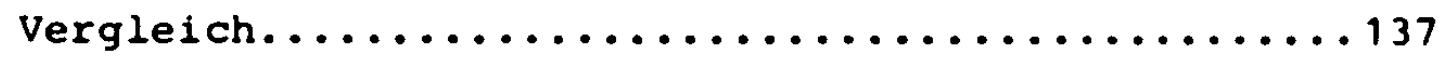

10.3. Fragment A .......................... 138

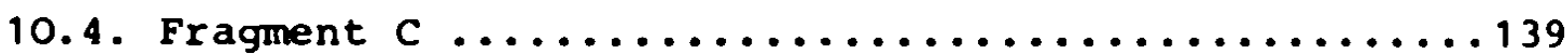

10.5. Fragment D ........................... 139

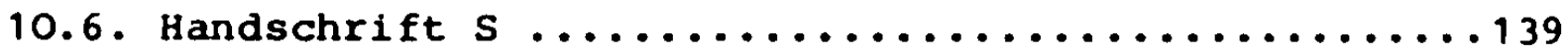

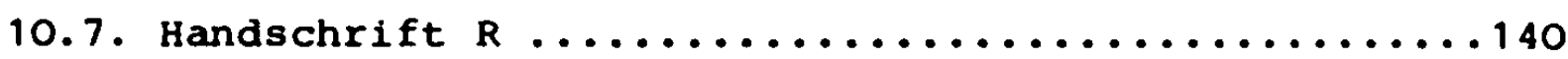

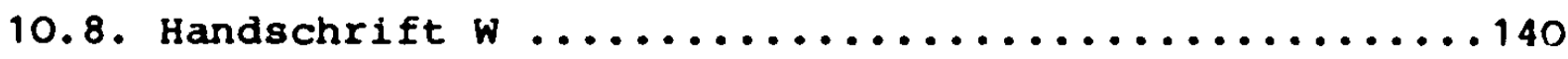

10.9. Zusammenfassung. ........................ 141

11. Die Ergebnisse der linguistischen Analyse...........141

11.1. Die lexikologische Analyse.................141

11.2. Die syntaktische Analyse..................142

11.3. Die morphologische Analyse..................143

11.4. Die phonologische Analyse...................144

11.5. Die graphematische Analyse.................145 DRITTER TEIL

12. ZUSAMMENFASSENDE KONFRONTATION DER TEXTOLOGISCH-PHILOLO-

GISCHEN UND LINGUISTISChEN ANALYSE...............146

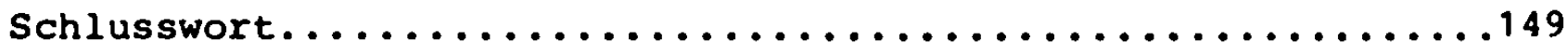

VIERTER TEIL

EDITION

13. Anmerkungen zur Editionstechnik..................151

13.1. Bibliographische Anmerkungen zu den Handschriften

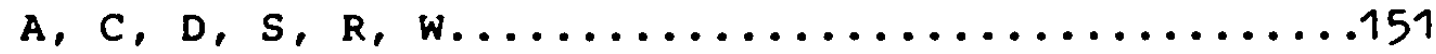

13.2. Zur Gestaltung und Transkription der edierten

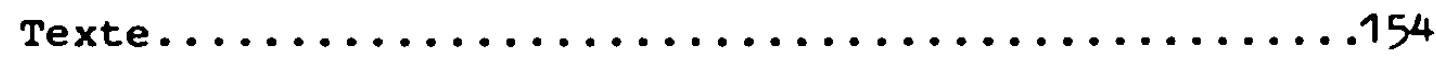

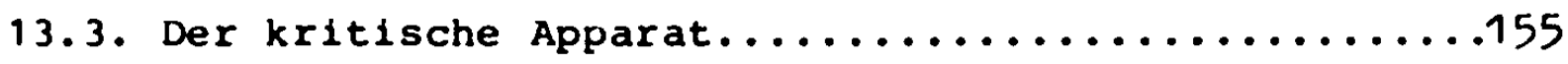

13.4. Verzeichnis der im Apparat benützten Abkürzungen...155

13.5. Verzeichnis der handschriftlichen Abkürzungen..... 157 Edition der Evangeliare $S, R, w, D(A, D) \ldots \ldots \ldots \ldots . . . . . .158$ 14. Synopsis der Perikopen........................326

14.1. Synopsis der Perikopen nach der Reihenfolge der

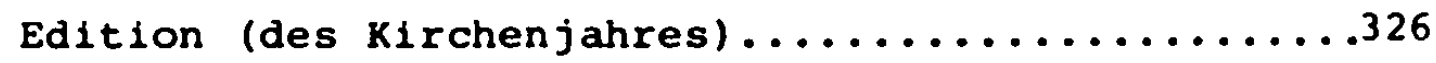

14.2. Synopsis der edierten Evangelienabschnitte in

der Reihenfolge der Evangelisten......................

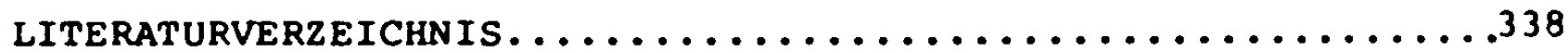

PERSONENREGISTER. . . . . . . . . . . . . . . . . . . . . . 344

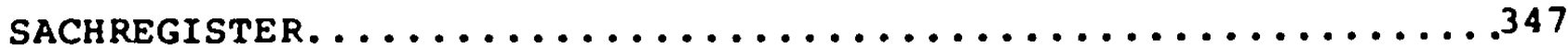

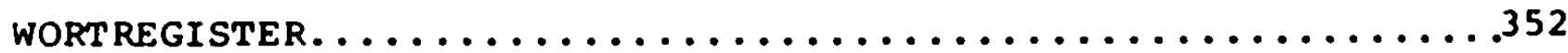

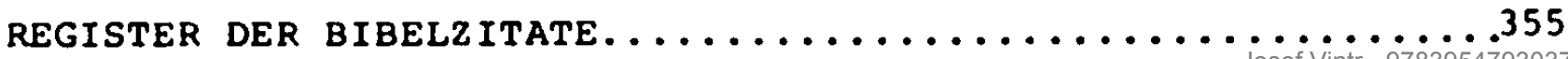




\section{VORWORT}

Aus langjährigem Interesse für die Problematik der sprachlichen Diachronie entstand der Gedanke, anhand einer inhaltich geschlossenen Gruppe von alten Sprachdenkmälern in die Entwicklungsvorgänge eines Sprachsystems vorzudringen und $z u$ versuchen, die synchronen Querschnitte (repräsentiert durch Analysen einzelner aufeinander folgender Texte) zur Aufstellung (:iner möglichst kontinuierlichen Vertikale $z u$ vereinigen. Die Wahl fiel auf die ältesten tschechischen Evangeliarhandschriften, von denen die zwei wichtigsten in den osterreichischen Bibliotheken in wien und in Seitenstetten aufbewahrt sind. Die Textanalyse und Edition dieser Ubersetzungen ermöglicht uns, eine Lücke in der Erforschung aller alttschechischer Texte, die grösstenteils aus dem Lateinischen ubersetzt wurden, $z u$ füllen. Es wird die bis jetzt fehlende Analyse der Ubersetzungstechnik durchgefuhrt und die wiedergabe der lateinischen grammatikalischen Kategorien durch Sprachmittel des tschechischen Systems beleuchtet.

Gerne benutze ich hier die Gelegenheit, um meinen Freunden aus dem Institut für Slavische Philologie der Universität Wien meinen Dank auszusprechen - Herrn Dr. G. BIRKFELLNER für seine Hilfe bei der Abschreibung des Seitenstettener Evangeliars und Herrn Dr. R. PREINERSTORFER für die sprachliche Revision des deutschen Textes meiner Abhandlung. Manchen wertvollen Rat auf dem Gebiet der Editionstechnik alttschechischer Texte verdanke ich meinem Freund Dr. J. CEJNAR aus Prag. Der Ausdruck meines aufrichtigen Dankes gehört den Herren Univ.Prof.Dr. J. HAMM und Univ. Prof.Dr. G. WYTRZENS, die sich für diese Arbeit stets interessierten. Herrn Univ.Prof.Dr. F. W. MARES bin ich im besonderen Masse für sein ausserordentliches Verständnis und Interesse und fur $z$ ahlreiche Anregungen aus vielen oft stundenlangen Konsultationen von ganzem Herzen dankbar.

Wien, im Dezember 1974 


\section{EINLEITUNG}

1. Aufgabestellung der textstrukturellen Analyse

Die Sprachdenkmäler bieten dem Sprachforscher die Moglichkeit, durch eine Analyse der in ihnen verschlüsselten sprachlichen und kulturhistorischen Informationen neue Erkenntnisse uber die betreffende Sprache und Kultur zu gewinnen. Ein mittelalterlicher Text als Quelle der Sprachgeschichte soll aber nicht nur als eine in der Diachronie isolierte synchrone sprachlich-kulturelle Teilerscheinung, sondern als ein funktionelles Ganzes in möglichst vielen sprachlichen und kulturhistorischen zusammenhängen und in seiner Entwicklung untersucht werden. Dieser Standpunkt - eine diachrone textologisch-funktionelle Auffassung des Textes - soll die Objer.tivität der Textanalyse und ihrer Ergebnisse gewährleisten und die Notwendigkeit einer einheitlichen Anwendung der Arbeitsmethoden funktioneller Sprachwissenschaft und Textologie demonstrieren.

Die synchrone Sprachwissenschaft kann sich bei ihren Analysen auf das Sprachbewusstsein eines ,native speaker', auf die mündlichen und schriftlichen Sprachäusserungen der zeitgenossen und auf die Analyse der Mundarten stützen. Bei den Rekonstruktionen eines Sprachsystems in seiner Dynamik ist die diachrone Sprachwissenschaft auf die Texte angewiesen, ihre Feststellungen können aber such bei der synchronen Sprachbeschreibung nicht übergangen werden, sie dienen sogar oft als bedeutsame methodische Anregungen.

Die folgende sprachliche Analyse der ältesten tschechischen Evangeliare und die daran anschliessende Edition hat es sich zum Hauptziel gesteckt, dem Leser den Text eines der ältesten umfangreicheren Denkmäler der alttschechischen Sprache als zeugnis der hohen sprachkultur an der wende des XIII. und XIV.Jhs. zugänglich zu machen.

1.1. Unsere Texte sind keine neu entdeckten Denkmäler. Die Fragmente A, C des Prager Nationalmuseums wurden zum Ende des XIX. Jhs. ohne sprachliche Analyse abgedruckt (vgl. 13.1.) 1, das Fragment D aus Brünn und das Evangeliar von Rajhrad (Raigern) in Măhren wurden

1 Es handelt sich um paläographische Editionen von A. PATERA, vgl. editorische Anmerkung, Ubersicht der Bibliographie, unter $A$ und C $(13.1$.$) .$

2 J. VAŠICA, Staročeské evangeliár̆e, Praha 1931, in der serie: Rozpravy Ceské akademie vèd a uméni, KI. III, Nr. 68; -

F. MENCı́, Dva evangelistáre, Praha 1893. 
von J. VAŠICA beschrieben, jedoch nicht ediert. Das wiener und das Seitenstettener Evangeliar wurden von F. MENCIK ${ }^{2}$ herausgegeben; diese veraltete, heute schwer zugängliche und leider auch ziemlich fehlerhafte Edition kann dem heutigen Sprachforscher keine geeigrete Grundlage für die bisher noch nicht durchgefürte Sprachanalyse der Evangeliare bieten. Die Evangeliartexte sind für die Erforschung der ältesten historischen Entwicklungsperiode des Alttschechischen, für das Ende des XIII. und die erste Hälfte des XIV. Jhs., von eminenter Bedeutung. Die Sprachkultur der Literaturdenkmäler aus dieser zeit, der Legenden, der Alexandreis u.a., ist ein deutliches zeugnis dafür, dass diese Poesie schon im tschechischen religiösen literarischen schaffen ihre Vorstufen hatte (die Lieder Hospodine pomizuj ny, Svatý Václave, Psalter, Evangeliar). Vašica, der bisher am ausführlichsten die alttschechischen Evangeliartexte behandelt hat, ist mit Dobrovsky der Meinung, dass es sogar schon im XI. Jh. eine tschechische Ubersetzung des Evangeliars für pastorale zwecke gab. Diese Ubersetzung sollte in den folgenden zwei Jahrhunderter mündich überliefert werden und durch diese Tradition ist auch die lebendige, orale Diktion und die dem alltäglichen Leben nahe Ausdruckweise der ältesten Evangeliaraufzeichnungen erklärbar. Wir sind, was das Alter der ersten Evangeliarübersetzung betrifft, eher vorsichtiger. Auf jeden Fall muss aber damit gerechnet werden, dass das Bedurfinis eines in die heimische sprache ubertragenen, textus sacer' schon vor dem Beginn der tschechischen welt11 chen Literatur vorhanden war.

1.2. Die Erforschung der alttschechischen Evangeliare ist ein offenes Gebiet, auf dem man $z u$ aufschlussreichen Ergebnissen über die Entwicklungsvorgänge im alttschechischen Sprachsystem gelangen kann. Für die Lösung der von uns aufgestellten Problematik - auf Grund der Untersuchung der parallelen fast uber das ganze XIV. Jh. verteil ten Texte die diachrone (vertikale) Entwicklung im System des Alttschechischen festzustelien - bieten die Evangeliare mit ihren relativ leicht feststellbaren Lesarten (durch Vergleich untereinander und mit dem lateinischen Original) hervorragend geeignete Materialgrundlagen dar. Uber das Verhältnis des Alttschechischen zu den lateinischen Originalen bei ubersetzten Texten wurde bis heute nur sehr wenig geschrieben. Wir können aber nicht abwarten, bis solche ausführliche studien vorhanden sind, und darum müssen wir diese Pionierarbeit selbst wagen. Auf jedem grammatikalischen Teilgebiet (Lexik, Syntax, Morphologie) werden nur die typischen Erscheinungen, dj für die Ubersetzungstechnik repräsentativ erscheinen, untersucht unc 
auf Grund dieser Ubersetzungscharakteristik hoffen wir dann, eine profilierte Darstellung der Ubersetzungsvorgänge $z u$ erhalten. Wir finden es methodisch sehr angebracht, die Grundlagen für eine solche objektive und erschöpfende Textcharakteristik einer Gruppe von verwandten Textstrukturen von zwei standpunkten aus zu beurteilen - nach den Ergebnissen I. einer textologisch-philologischen und II. einer linguistischen Analyse. Die konsequente Anwendung dieser kombinierten textologisch-linguistischen Methode ist in dieser Form bei der Textanalyse nicht gelaufig. Unseren Arbeitsvorgang - mit abschliesender Konfrontation der Ergebnisse beider Analysen - könnten wir am ehesten als eine textstrukturelie Analyse bezeichnen.

Die Konfrontation von Ergebnissen beider Analysen soll die Bestätigung der Schlussfolgerungen dort, wo die beiden Analysenvorgănge übereinstimmen, bringen und die notwendigen Korrekturen oder Ergänzungen andeuten, wo sie auseinandergehen. Es kann sich aber auch zeigen, dass einige Teilprobleme noch unlobbar sind und of fen bleiben müssen.

Als Anhang zur Studie ist die wissenschaftliche Edition (mit dem kritischen und parakritischen Apparat) der ersten Ubersetzungsredaktion der alttschechischen Evangeliare gedacht (es werden die Fragmente A, C, D, die beiden österreichischen Handschriften aus Seitenstetten und Wien und das Evangeliar von Rajhrad (Raigern) in Măhren ediert; ausführliche Beschreibung dieser Handschriften siehe unter 3.3. und 13.).

1.2.1. Wir wollen diese Abhandlung nicht als eine nur textologische Studie auffassen, dazu erscheint uns die Aufgabenstellung der Textologie als einer Disziplin, die die Geschichte eines Textes untersucht, $z u$ eng $z u$ sein. Unsere Texte stellen fur uns vor allem Sprachstrukturen dar, deren komplette Analyse nicht nur eine textologische, sondern hauptsăchlich erstens eine mit Rücksicht auf die lateinische Vorlage gründich durchgefürte Ubersetzungscharakteristik und zweitens für die Darstellung des alttschechischen Sprachsystems in seiner Entwicklung noch wichtigere linguistische Charakteristik erfordert. Die Hervorhebung der sprachlichen Analyse wird auch von den modernen Textologen verlangt ${ }^{3}$, aber unseres wissens ist es noch in keiner unfangreicheren Bearbeitung einer Textgruppe zu einer solchen engen Verbindung der Textologie und der Linguistik gekommen.

$3 \mathrm{Vgl.} \mathrm{J}$. DAÑHELKA, Textologie a lingvistika, in: Miscellanea linguistica, Ostrava 1971, 211-215; - E. COSERIU, Thesen zum Thema, Sprache und Dichtung', in: Beiträge zur Textlinguistjk Münghen 1971 ,

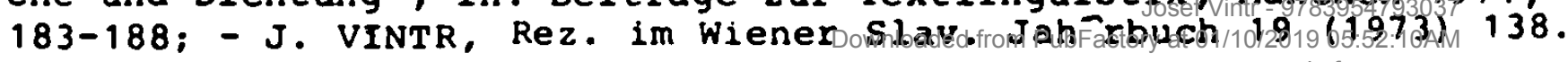


ERSTER TEIL

TEXTOLOGISCH-PHILOLOGISCHE CHARAKTERISTIK

2. Die Aufgabe eines Textologen wăre es, sich auf die Erforschung der Entstehungs-, Entwicklungs- und Uberlieferungsgeschichte unserer Handschriften zu konzentrieren. Dieses Problem wollen wir auch lösen, betrachten es aber nicht als zentrales, sondern nur als ein Nebenprodukt der textologischen Analyse, die primăr schlussfolgerungen uber die Textgestaltung ermöglichen soll. Die Ergebnisse dieses Teils I werden uns helfen, nach der darauf folgenden linguistischen Analyse (Teil II) ein solches Gesamtbild unserer Texte zu bekommen, dass man die Evangeliarhandschriften als Sprachdenkmäler genau klassifizieren kann - als zeugnisse der kulturellen und sprachlichen Entwicklungen.

2.1. Die Methodik

Im Titel dieses Teils wurde der Ausdruck "eine textologisch-philologische Charakteristik" absichtlich angeführt. Der textologische Teil der Charakteristik soll die aussere Textcharakteristik liefern - die Beurteilung der kulturgeschichtlichen Ursachen der Entstehung, die Festlegung der stellung der Handschriften innerhalb aller alttschechischen Evangeliarüberlieferungen, die vorläufigen Feststellungen über die relative Chronologie der Texte, eine kurze kodikologische Beschreibung und eine kurze paläographische Charakteristik der einzelnen Handschriften. Der philologische Teil soll die innere Textcharakteristik liefern - besonders was das Verhältnis des alttschechischen Textes zum lateinischen original betrifft. Diese Ubersetzungscharakteristik hat mehrere Aufgaben: sie soll das lateinische Original năher bestimmen, die Ubersetzungstechnik mit Fehlern und Versăumnissen beurteilen, das Niveau der Ubersetzunç bewerten und die Ergebnisse der Ersetzung der lateinischen grammatikalischen Kategorien durch die alttschechischen feststellen. Der philologische Teil der Textanalyse soll auf diese Weise Grundlagen für das Filiationsschema und auch für die linguistische systemanalyse vorbereiten. Die Ubersetzungscharakteristik wird durch Untersuchung der Transpositionsfähigkeiten des alten Ubersetzers zeigen, welche stilistische Begabung, welche Vorstellungs- und Objektivisierungskraft er besass. Die Beurteilung des sprachsystems gehört in die Kompetenz der Linguistik, aber die Beurteilung der Auswahl 
der Aquivalente und ihres Wirkens in einem anderen kulturellen und sprachlichen Milieu muss ein Philologe schaffen. Die Eingliederung einer Ubersetzung in die heimische Literatur gibt einem solchen Werk noch eine zusatzliche Funktion - es informiert uns uber das Original und über eine fremde Rultur. Die Analyse der Ubersetzungen in dieser Hinsicht wird zeigen, wie hoch die Renntnisse der fremden Realităt beim mittelalterlichen tschechischen Ubersetzer waren, und auf diese Weise wird indirekt die Breite und Qualität der damaligen Bildung auf betreffendem Gebiet charakterisiert.

\subsection{Die Kapiteleinteilung}

Die Textanalyse wird in zwei Bereiche geteilt: im textologischen (3.) werden die Voraussetzungen der Entstehung, die Funktion, die Ubersetzungsredaktionen, und die wichtigsten kodikologiscnen Merkmale der ältesten tschechischen Evangeliarhandschriften behandelt; im philologischen Bereich die Ubersetzungscharakteristik (4.), die dann gemeinsam mit den Ergebnissen der textologischen Charakteristik die ersten Schlüsse über Vorlagen und Filiation der Evangeliare erlauben wird. Die ältere Literatur zum Forschungsgegenstand und das Problem des Zusamenhanges mit der altkirchenslavischen Evangelienübersetzung werden unter 4.1 .1 . behandelt.

\section{TEXTOLOGISCHE CHARAKTERISTIR}

3.1. Die Problematik der äusseren Charakteristik unserer Evangeliarhandschriften ${ }^{4}$ wird folgendermassen aufgetollt: die kurze literaturgeschichtliche Charakteristik der Epoche(3.2.), die kodikologische Charakteristik (3.3.), die Redaktionen der alttschechischen Evangeliarubersetzung (3.4.) und eine kurze liturgische Anmerkung $(3.5$.$) .$

\subsection{Die kurze literarhistorische Charakteristik}

Die ersten häufigeren Aufzeichnungen tschechischer Texte,

4 Unter einem Evangeliar verstehen wir immer nur ein Perikopenbuch, also ein Evangeliar im julngeren Sinn (oft auch Evangelistar genannt), nicht ein älteres (im frühen Mittelalter und in der bstlichen Liturgie vorkommendes) Tetraevangelium - vgl. dazu Lexikon fur Theologie und Kirche, Freiburg (Herder-Verlag), 1961 , s.v. Lektionar. 
meist nur in Form von Marginalien und Glossen, sind erst aus dem XIII. Jh. belegt (z.B. die Glossen in Mater verborum, in Pharetra des hl. Bonaventura, Cisioianus, der glossierte Psalter, u.a.). Diese Feststellung ist schon ein zeugnis dafür, dass es vor dem XIII. Jh. kaum eine Aufzeichnung einer tschechischen Ubersetzung des Evangeliars geben konnte ${ }^{5}$.

Die Verfasser der Geschichten der alttschechischen Literatur (Vlček, Jakubec, Hrabák) sind verschiedener Meinung, was die zeit der Entstehung der ersten Evangeliarübersetzung betrifft. J. VLCEK ${ }^{6}$ behauptet, dass die Anfänge der Ubersetzungen einiger biblischer Bücher (Psalmen, Evangelien) nicht vor die zweite Hălfte des XIII. Jhs. reichen. J. JAKUBEC ${ }^{7}$ setzt ältere Vorlagen für die alttschechischen Evangeliare des XIV. Jhs, voraus, aussert sich aber über ihr Alter nicht. J. HRABAK ${ }^{8}$ formuliert das problem der Entstehung der ersten tschechischen Evangeliarübersetzung sehr allgemein und vorsichtig - die ersten Evangelienubersetzungen wurden lange zeit nur mündich iberliefert und darum war es nicht notwendig, sie aufzuzeichnen. In seiner jüngeren Arbeit ${ }^{9}$ datiert derselbe Autor die erste Ubersetzung der Evangelien ins XII. Jh., ohne jedoch năhere Gründe für diese Behauptung anzuführen.

In unseren Ausführungen zur Charakteristik der Ubersetzungstechnik kommen wir auf dieses Thema nochmals zurück (4.1.1. ff.). Es ist leider $z u$ wenig bekannt über die Geschichte der pastoralen Tätigkeit und über die Art der Priesterausbildung in den böhmischen Ländern im XII. und XIII. Jh., was uns die Erforschung der Gründe und der Funktion der tschechischen Evangeliarübersetzung erschwert. Alle Forscher, die sich mit der Problematik der alttschechischen Evangeliare befassten, setzen automatisch voraus, dass diese Texte aus der Notwendigkeit, dem Volk bei der Messe an Sonntagen und

5 Die Frage des zusammenhanges der sog. Wiener (Jagí́)-Glossen mit dem alttsch. Evangeliar wurde von J. VASICA, 0.C. (Fn.2), 126-131 endgültig gelöst - es ist kein direkter Zusammenhang nachweisbar, weil die Glossen $z u$ den Evangelienabschnitten in der Rado-Bibel nach griechischem Perikopensystem zugeschrieben sind (die alttsch. Evangeliare haben das römische Perikopensystem und darum kommen die meisten in der Radobibel glossierten Evangelienabschnitte im alttsch. Evangeliar als Lesungen gar nicht vor). Vgl. dazu auch J. HAMM, Glose u Radonovoj bibliji, Slovo 1 (1952) 19-32.

$6 \mathrm{~J}$. VLČEK, Dějiny České literatury I, 3. Aufl., Praha 1940, 19.

$7 \mathrm{~J}$. JAKUBEC, Dějiny české literatury I, Praha 1929, 215-216.

$8 \mathrm{~J}$. HRABAK et coauct., Dějiny české literatury I, Praha 1959, 69.

9 J. HRABAK, Staršl česká literatura, Praha 1964, 60. 
Feiertagen das Evangelium in heimischer Sprache vorzulesen, entstanden sind. War es aber wirklich so? Die ganze Messe im Mittelalter wurde ausschliesslich in lateinischer Sprache gelesen; sie war ein geschlossenes Ganzes, dem das Volk nur passiv beiwohnte; es waren nur wenige (etwa vier) tschechische Lieder zum singen in der Kirche zugelassen ${ }^{10}$. Die Predigt war vor der Messe. Es ist uns leider nicht gelungen, in der Fachliteratur festzustelien, ob vor der Predigt wirklich in den ersten Jahrhunderten dieses Jahrtausends den Gläubigen das Evangelium (nicht $z$ u reden von der Epistel) in heimischer Sprache vorgelesen wurde. Wir sind eher der Meinung, dass es, mindestens noch im XIII. Jh., nicht der Fall war. Die späteren tschechischen Postillen zeigen, dass zu Beginn der Predigt oft nicht die ganze Perikope, sondern nur das Rernstück oder der Anfang leinige Verse von der ganzen für die betreffende Messe in der Liturgie vorgeschriebenen Lesung) wörtlich in tschechischer Sprache zitiert wurde, der ubrige Perikopentext wurde mehr oder weniger frei in der Predigt paraphrasiert. Bei solcher Seelsorgenpraxis war es nicht notwendig, eine geschriebene Fassung der Perikopen zu haben - der Priester uber. setzte sich vor jeder predigt die gebrauchte Passage aus dem lateini. schen Lektionar (solche Ubersetzungen wurden wahrscheinlich schon bei der Ausbildung der Priester gründich und unter Berücksichtigung der mündlichen Tradition geübt), die er dann dem Volk entweder auswendig oder anhand des lateinischen Texts rezitierte. Ein kanonischej

- für das ganze Land verbindlicher tschechischer Text - war damals sicher wicht vorhanden. Schon die ziemlich unterschiedlichen Aufzeichnungen der wichtigsten Gebete (Pater noster und credo) und der Bussforme ${ }^{11}$ deuten darauf hin, dass es keine verbindliche und einheitliche alttschechische Version gab, dass nur ad hoc und von verschiedenen Personen übersetzt und redigiert wurde, ohne die Ubersetzung - besonders in der altesten zeit - aufzuzeichnen. Eine wichtigere Rolle bei der seelsorgenpraxis begann das tschechische geschriebene Evangeliar erst zur zeit der kirchlichen Reformbewegungen des Aufschwungs der tschechischen Literatur und der verbreitung des billigeren Schreibmaterials, des Papiers, um die wende des XIV. und

$10 \mathrm{z}$. NEJEDLY̊, Dějiny předhusitského zpěvu v Cechách, Praha 1904, 255-260.

11 Vgl. besonders A. SKARKA, Nejstaršl česká duchouni lyrika, Praha 1949; - J. VINTR, Das alttschechische Pater noster, Ave und Credo in einer Handschrift der Wiener Nationalbibliothek, Wiener Slavistisches Jahrbuch 17 (1972) 303-309. 
XV. Jhs. zu spielen. Diese Feststellung wird auch dadurch bestätigt, dass zu dieser zeit schon einzelne Priester tschechische Evangeliartexte im Besitz hatten (z.B. Evangeliar des Priesters Benesch - Ctenie knězě Benešovy ${ }^{12}$, Ende des XIV. Jh.), und dass der Inhalt auch um die Perikopen für die Ferialtage, um die Epistel und verschiedene Gebete erweitert wurde (vgl. z.B. das Olmützer Evangeliar aus dem $J .1421^{13}$ ).

Welchem $\mathrm{zweck}$ haben dann die ersten Aufzeichnungen der tschechischen Evangeliare gedient? Es ist merkwüdig, dass relativ viele der altesten tschechischen Glossen und Texte an das alteste Frauenkloster auf tschechischem Gebiet, an das Benediktinerinnen-kloster Sankt Georg (Svatojiřský klášter) in Prag gebunden sind (z.B. die S.Georg-Glossen einer Nonne und das sog. Kunigunde-Lied). Dieses prominente Kloster, wo die Frauen des hohen tschechischen Adels und sogar Herrschertöchter (Agnes, Kunigunde) Unterkunft fanden, gab dem tschechischen mittelalterlichen Kulturleben viele Anregungen. Man kann sich gut vorstellen, dass in der zweiten Halfte des XIII. Jhs., zur zeit des grössten Aufschwungs der ritterlichen Poesie, die auch ins Tschechische übersetzt wurde (Alexandreis), besonders die adeligen Nonnen (des Lateinischen oft nicht kundig) das Bedürfnis ausserten, uber die wichtigsten liturgischen Bücher - Psalter und Evangeliar - in tschechischer sprache $z u$ verfügen. Für die königliche Tochter, Abtissin Kunigunde, wurde eine ganze Reihe kostbarer Handschriften angefertigt, unter anderen einige bis heute erhaltenen liturgischen Gesangbücher. Aller Wahrscheinlichkeit nach muss $z u$ dieser zeit für die Abtissin und ihre Nonnen die erste Aufzeichnung des alttschechischen Evangeliars geschrieben werden sein. Der Anstoss zu der Ubersetzung konnte vom Hof könig Wenzels des zweiten gekommen sein. Wenzel II. forderte nicht nur die ritterliche Poesie, sondern auch die geistliche; sein Hof beherbergte viele Priester aus verschiedenen Ländern und Orden, sogar auch aus Russland. Der König wohnte gerne der in verschiedenen Liturgien gelesenen Messe bei, und so horte man damals in Prag nicht nur dem griechischen, sondern auch dem slavischen liturgischen Gesang zu. 14 Diese Ent-

12 V. MĔRKA, Ø̌tenie knězě Beněsovy, Prostějov 1918.

13 F. CERNY, Olomoucký evangeliáry, Praha 1902.

14 Petri, abbatis Aulae Regiae terti1, Chronicon Aulae Regiae, in: Fontes rerum Bohemicarum IV, Praha 1884, 70. Es wăre verdienstvoll, die Auswirkungen des Aufenthaltes russischer Priester und und einen eventuellen zusammenhang mit den kyrillisch geschriebenen Denkmälern aus dieser zeit auf tschechischem Boden $2 u$ unter- 
wicklung, die Förderung der tschechischen Sprache, wurde auch von dem damaligen Prager Bischof, Tobias von Bechynè, unterstüzt. Bohuslaus Balbinus feiert diesen kirchlichen würdentrăger, nachdem 1281 die Brandenburger weggezogen waren und die Tschechen wieder die oberhand im Lande behielten, als den Retter der Nation, der "Iinguam patriae, Boemiam Boemiae restituit". 15

Die ganze kulturelle und historische situation war der Entstehung der Evangeliarubersetzung um das Jahr 1300 sehr günstig. Die Aufzeichnung des Evangellars war aber nicht, wie schon angedeutet, für den pastoralen Gebrauch, sondern vielmehr als religiobse Literatur für die ständige Lektüre der adeligen Nonnen bestimmt. Die adeligen Frauen hatten ein lebendiges Interesse an Ubersetzungen der heliligen Bücher, wie es z.B. auch die vom englischen Reformator Wiclif überlieferte Nachricht über die englische Königin Anna (Tochter des Kaisers Karl des IV.), die eine tschechische und deutsche Evangelienubbersetzung nach England mitgebracht hat, bezeugt! 16 Auf die bestehende Tradition, nach der die tschechischen Texte des Evangeliars für die adeligen frommen Frauen und Nonnen bestimmt waren. scheint auch die Widmung am Fol. 1a des Konvoluts, dem auch das alttschechische Olmützer Evangeliar beigebunden ist, hinzuweisen: Tyto kniehy učinila jest panl Kačna íprol svu dceru a maji být $v$ obec vǒim sestrám ('Diese Bücher liess Frau Katschna für ihre Tochter schreiben und sie sollen allen Schwestern ein Gemeingut sein'); bei den Schwestern handelt es sich um die olmützer Klarissinnen. Wo wurde übersetzt und wo wurde der Archetyp, von dem später kopiert wurde, aufbewahrt? Das ganze mittelalterliche Wissen konzentrierte sich in den Klöstern, der Hand eines gelehrten Mónches begegnen wir bei jedem wichtigeren Unternehmen des Kulturlebens in den ersten drei Jahrhunderten unseres Jahrtausends. Die Monche, besonders die Benediktiner in den Ländern der tschechischen Krone, hatten als einzige die Möglichkelt und die Voraussetzungen gehabt, sich in der stille einer klosterzelle mit Unterstützung der Klosterbibliothek und der gelehrten Mitbruder mit einem so wichtigen und bedeutsamen Unternehmen, wie es eine Ubersetzung des heiligen Evangelientextes war, auseinanderzusetzen. Es wăre auch nicht ganz aus-

suchen (vgl, F. V. MARES, LevínskY̧ nápis - epigrafickÝ doklad cyrilice $v$ Cechách, Slavia 22 (1953) 473-483).

15 A. FRIND, Die Kirchengeschichte Brhmens II, Prag 1866, 58.

16 F. TADRA, Kulturni styky Cech s cizinou až do válek husitskych, Praha $1897,166$. 
geschlossen, dass dabei nicht nur die mündliche Tradition, sondern vielleicht auch die vorübergehend am Hof des Königs weilenden russischen Priester und die von ihnen mitgebrachten Bücher zur Konsultation herangezogen wurden. Bei fast allen unseren Evangeliartexten ist ein Zusamenhang mit dem Benediktinerorden auffällig und nachweisbar (siehe 3.3.). Das Zentralkloster der tschechischen Benediktiner war Brevnov in Prag. Wir wagen hier eine Hypothese, auf die wir noch später (vgl. 5.3., 12.) eingehen werden, auszusprechen - der Archetyp der alttschechischen Evangeliarübersetzung entstand im Kloster Břevnov und wurde dort aufbewahrt.

\subsection{Die kodikologische Charakteristik}

Die Gruppe von Evangeliarhandschriften, die von uns behandelt wird, stellt die ältesten Abschriften der alttschechischen Evangeliare aus dem XIV. Jh. dar. Hier werden nur solche Zeichen der Handschriften berücksichtigt, die für die Textanalyse, für die Datierung und für die Filiation von Bedeutung sein können (es werden aber auch die Abmessungen, die Ausstattung und der Einband beschrieben); die bibliographischen Angaben $z u$ den einzelnen Texten werden erst bei der Edition in einer editorischen Anmerkung (siehe 13.1.) zus ammenge fasst.

Unsere Evangeliare wurden bisher am besten von $\mathrm{J} \operatorname{VASICA}^{17}$ beschrieben. Wir wollen seine Angaben ergänzen und dabei passen wir die von Vašica benützten Handschriftenabkürzungen den Abkürzungen an, die im neuen Alttschechischen wörterbuch ${ }^{18}$ für diese Texte in Verwendung sind.

\subsubsection{Fragment A}

(bel Vašica A) - zwei Pergamentstreifen in der Bibliothek des Nationalmuseums in Prag, Sign. 1 Ac 47, entdeckt von V. Hanka auf den Deckelinnenseiten der lateinischen Inkunabel Gregorii opera. Das Fragment beinhaltet Texte der Perikopen aus der Fastenzeit (genaue Aufzählung der Evangelienverse s. bei Vašica, S. 2).

Anm.: Wenn man die Provenienz der Inkunabel feststellen kñnnte (was uns nicht gelungen ist), wäre auch die Provenienz des Fragments A näher bestimmbar.

17 J. VASICA, O. C., (Fn. 2), 1-12.

18 staročeský slovnik. Ovodni stati, soupis pramenů a zkratek, Praha 1968, 70-71. 
Die zwei Abschnitte stammen von einem Doppelblatt in Oktavgrösse, der erste vom oberen, der zweite vom unteren Teil des Doppelblattes (die Blattmitte fehlt); die Breite des Blattes 10,7 $\mathrm{cm}$, des Schriftspiegels $8 \mathrm{~cm}$, der breitere Abschnitt hat Schrift in 8 Zeilen, der engere in 7 zeilen auf beiden Seiten. Das erste Wort der Perikope hat immer eine einfache $2 \mathrm{~cm}$ grosse rote Initiale ohne Schmuckornament; die Rubriken wurden von einer anderen Hand in einer gut lesbaren, nur am Rand verwischten gotischer Minuskel der ersten Hälfte des XIV. Jhs. geschrieben.

\subsubsection{Fragment $C$}

(bei Vašica D) - ein Pergamentdoppelblatt (erstes und letztes Blatt eines Quaternions), jetzt in der Bibliothek des Nationalmuseums in Prag, Sign. 1 Ac 67; weitere drei Blätter dieses Restes eines alttschechischen Konvoluts beinhalten Teile des Gesprächs der hl. Jungfrau Maria mit dem hl. Anselm über das Leiden Christi und Teile des Martyriums des hl. Georgs. Alle fünf Blätter waren auf den Deckeln der Urbarbücher des XVI. Jhs. aufgeklebt. Die zwei Blätter mit dem Evangeliartext (ein Blatt 26 mal $17 \mathrm{~cm}$ ) weisen Perikopen der Karwoche auf (vgl. auch Vašica, 11-12), zweispaltig (29-31 zeilen, Spaltenschriftspiegel 22,3 mal $6,5 \mathrm{~cm}$ ) in gotischer Kursive um die Hälfte des XIV. Jhs. geschrieben; vereinzelte $3 \mathrm{~cm}$ grosse Initialen rot oder grün mit einfachem zierornament; die Rubriken rot.

\subsubsection{Fragment D}

(bei Vašica C) - ein unvollständiges ( 1 Zeile am oberen Teil des Blattes abgerissen) Papierblatt und ein Papierdoppelblatt in $4^{\circ}$ (Grösse des Blattes $23 \mathrm{mal} 18,5 \mathrm{~cm}$; zweites Blatt des Doppelblattes in der Hälfte vertikal abgeschnitten) des Staatsarchivs Brünn, Sign. G 1, Kart. 86 (aus der Boček-Sammlung Nr. 12307); die Reste des Evangeliars waren auf den Deckelinnenseiten aufgeklebt (wo, weiss man heute nicht mehr) und starmen aller wahrscheinlichkeit nach aus dem mährischen Benediktinerkloster Rajhrad (Raigern) bei Brünn. Auf den Blättern befinden sich Perikopen der Weihnachtsund der Fastenzeit (auch mit den Lesungen für Ferialtage, vgl. Vašica, 9-11). Der Text ist in zwei Spalten (Abmessungen des Spaltenschriftspiegels $20,7 \mathrm{mal} 6 \mathrm{~cm}$ ) in gotischer Kursivschrift der $2 w e i-$ ten Hälfte des XIV. Jhs. geschrieben. In der synopsissinderastarten 
Texte (siehe 14.1.) benützen wir für die Hs. D folgende Foliation: erstes Fol. des Doppelblattes mit den Perikopen der Weihnachtszeit - 1a, 1b; freies Blatt 2a, 2b und zweites Blatt des Doppelblattes mit den Perikopen der Fastenzeit $3 a, 3 b$.

\subsubsection{Handschrift $S$}

(bei Vašica S) - im lateinischen Konvolut der Bibliothek des Benediktinerstiftes Seitenstetten in Niederösterreich unter sign. CCLXXII, fol. 144a-153a (nach alter Foliation, die noch in der Edition von Menčik beibehalten wird, 139a-148a) mit Perikopen für Sonntage und Feiertage des Kirchenjahres. Die Papierhandschrift (Grösse des Blattes $30 \mathrm{mal} 21 \mathrm{~cm}$ ) war früher im aufgelassenen niederösterreichischen Kollegiatsstift Ardagger, stammt aber aus südmähren, wie es die eingebundene Pergamenturkurde vom Verkauf eines Weingartens beim südmährischen Dorf Myslice vom 6. Februar 1396 bezeugt. Der Ledereinband ist mittelalterlich, im Rücken sind Pergamentabschnitte mit einem lateinischen Text des XIII. Jhs. eingebunden. Das Vorsatzblatt ist ohne Anmerkungen, das Papierblatt des letzten Sexternions ist auf der hinteren Deckelinnenseite aufgeklebt, mit der in Kurrentschrift geschriebenen Anmerkung ,Ardagger' und mit einem von derselben Hand wie das Evangeliar geschriebenen alttschechischen Mariengebet (sein Text wird ediert in editorischer Anmerkung, siehe 13.1.). Zum übrigen Inhalt des Papierkonvoluts: 1a-43b Gregorii Magni Liber de cura pastorali, 43b-106b eiusdem Libri quattuor dialogorum, 1.07a-143b Conradi de Saxonia Holzingarii Speculum B. Mariae Virginis.

Der alttschechische Text ist in zwei Spalten (Spaltenschriftspiegel $22,3 \mathrm{mal} 7,3 \mathrm{~cm}$ ) in gotischer Minuskel der zweiten Hälte des $x I V$. Jhs. mit roten, $2 \mathrm{~cm}$ grossen Initialen und roten, von einer anderen Hand stammenden Rubriken, niedergeschrieben. Der lateinische Text hat eine jüngere von einer anderen Hand als der tschechische ausgeführte Schrift. Die Interpunktion im tschechischen Text mit roten Strichen und schwarzen Punkten durchgefüht, die Anfangsbuchstaben, die als grosse gelesen werden sollen, rot durchgestrichen.

Der lateinische Text hat am Papier ein anderes Wasserzeichen (eine stilisierte Glocke) als der früher selbständige alttschechische Text (der hat einen Ochsenkopf ohne Nasenlöcher, nur mit Augen, zwischen den Hörnern eine einkonturige stange mit Stern). Einen 
ähnlichen Ochsenkopf findet man bei BRIQUET ${ }^{19}$ unter Nr. 14645 aufgezeichnet, belegt aus würzburg und olmütz (Anfang des XV. Jhs.). Die Provenienz und das Alter des Papiers kann man aber eher mit Hilfe der Arbeit über die Ochsenkopfwasserzeichen von G. PICCARD 20 näher bestimmen, wo man (Abt. VI, Bd. 2) nicht ganz genau unseren, aber sehr ähnliche Ochsenköpfe unter den Nr. 171-173 (S. 383), 271 -273 (S. 394) findet. Es handelt sich bei allen eindeutig um Papiere aus Oberitalien. Das erste Papier mit dem Ochsenkopf, mit einkonturiger Stange und mit Stern ist aus dem J. 1369 belegt; der Stern wurde Ende des XIV. Jhs. durch eine Blume ersetzt. Der zeitraum, innerhalb dessen unser aus Italien importiertes Papier auf tschechischem Boden beschrieben wurde, erstreckt sich auf Grund dieser Feststellung auf die 70-er und 80-er Jahre des XIV. Jhs.

\subsubsection{Handschrift $R$}

(bei Vaśica R) - ein alttschechisches Evangeliar im lateinischen Konvolut der Bibliothek des Benediktinerklosters Rajhrad (Raigern) bei Brünn, jetzt in der Universitätsbibliothek Brünn, Sign. R 364 (alte Sign. D/K I aa. 4). Diese Papierhandschrift (Grösse des Blattes $27,5 \mathrm{mal} 18,5 \mathrm{~cm}$, Lagen mit 12 Blättern) im barocken Ledereinband beinhaltet: 1a-45b Sermones dominicales, $46 a-$ -95b Defensor monachus Locociaquensis Scintillarum liber, 95b-96b Auctoritates Patrum, 96b-97b Casus episcopales, 97b-98a Casus papales, 98a-99a Auctoritates, 100a-105b leer, 106a-124a altschechisches Evangeliar mit Perikopen für Sonntage und Feiertage, aber auch mit den wichtigsten Ferialperikopen (vgl. Vašica, 7-9). Die ganze Handschrift ist in zwei Spalten geschrieben (Spaltenschriftspiegel $23 \mathrm{mal} 6,5 \mathrm{~cm} \mathrm{mit}$ 53-57 zeilen), der alttschechische Text in gotischer Kursivschrift der zweiten Hälfte des XIV. Jhs., von einer anderen Hand als der lateinische Teil; rote Initialen und Rubriken nur auf den ersten drei Seiten. Das papier ist dem in der Hs. S benutzten sehr ähnlich - im R-Evangeliar haben die ersten fünf Folia (bis 110) einen Ochsenkopf ohne Augen als Wasserzeichen, die folgenden dann dasselbe Wasserzeichen wie das Evangeliar S. Das wirde bedeuten, dass die beiden Handschriften $S$ und $R$ in demselben

$19 \mathrm{CH}$. BRIQUET, Les filigranes IV, Paris 1907.

20 G. PICCARD, Die Ochsenkopfwasserzeichen, 1-3, Stuttgart 1966 , Bd. 1 (Einführung), Bd. 2, Abt. VI (Ochsenköpfe mit einkonturiger Stange und Stern). 
Skriptorium in einem nicht allzugrossen zeitabstand aufgezeichnet wurden.

\subsubsection{Handschrift $w$}

(bei Vašica V) - unvollständiges (1m Evangeliar fehlen 11 Blätter) aber trotzdem umfangreichstes Evangeliar unserer Handschriftengruppe, auf den ersten 49 Folia eines Konvoluts Sign. 4733 der Osterreichischen Nationalbibliothek in Wien. Das Evangeliar hat nach den Perikopen De tempore (wie in Hs. R) noch die Lesungen des Propriums und Commune Sanctorum. Nach dem Evangeliartext folgt im Konvolut ein lateinisch-alttschechisches Hymnarium (50a-143a, nicht ediert), Notabilia bona de biblia mit alttschechischen Glossen (143b-163b, nicht ediert) und endlich Sermones tres (168a-174b, lateinisch, unvollständig); alle Texte nach dem Evangeliar sind jünger, aus dem XV. Jh. Diese Papierhandschrift (Blattformat $21,5 \mathrm{mal} 15 \mathrm{~cm}$ ) im Ledereinband des XV. Jhs. war zuerst Eigentum des oberösterreichischen Benediktinerstiftes Lambach, dann war sie im aufgelassenen Collegium Canon. Reg. ad. S. Dorotheam in Wien, 1786 wurde sie von der damaligen Hofbibliothek gekauft. 21 Der alttschechische Evangeliartext ist in einer Spalte (Schriftspiegel $15,5 \mathrm{mal} 9,5 \mathrm{~cm}$ in $29 \mathrm{zeilen}$ ) in gotischer Buchminuskel vom Ende des XIV. Jhs. geschrieben, mit roten Initialen und Rubriken. Im ersten Sexternion fehlen die ersten fünf und die letzten vier Blatter, im zweiten Sexternion das sechste Blatt und im letzten (fünften) Sexternion das letzte Blatt. Das Wasserzeichen des Papiers ist sehr undeutlich,gerade in der Falz der Lage; das sehr schlecht erkennbare wasserzeichen war wahrscheinlich ein wappen. Nach Fol. 50 kommen im jüngeren Text mehrere Wasserzeichen vor, auch ein Ochsenkopf, zwei kreuze usw. Auf dem auf der hinteren Deckelinnenseite aufgeklebten Pergamentabschnitt ist eine Notiz Conventori in Bystre amico suo...praesens detur; für die Proventenz des Textes ist diese Notiz bedeutungslos (es gibt nämlich sehr viele orte Bystrá in den bohmischen Ländern), aber sie ist ein zeugnis dafür, dass sich die Handschrift noch im XV. Jh. auf tschechischem Gebiet befand.

Zum Text des Evangeliars gibt es zweierlei Marginalien, von

$21 \mathrm{Vgl}$. die Korrespondenz zwischen J. DOBROVSK $\mathbf{Y}$ und F. DURYCH, Bd. $I$, herausgegeben von A. PATERA, in: Sbirka pramenü, skup. II, Nr. 2, Praha 1895, 66. 
einer zeitgenössischen und von einer wesentlich jüngeren hand (nach Schriftductus aus dem XVI. Jh.).

3.4. Die erste Evangeliarübersetzungsredaktion

Die unter 3.3. beschriebenen Texte A, C, D, S, R, W stellen die erste selbständige Übersetsungsredaktion des alttschechischen Evangeliars dar. Wie schon festgestellt wurde ${ }^{22}$, sind die übrigen jüngeren alttschechischen Evangeliare alle mehr oder weniger von der alttschechischen Bibelübersetzung abhängig, also nicht selbständig und werden darum in den weiteren Analysen von uns nicht berücksichtigt.

\subsection{Kurze liturgische Anmerkung}

Die liturgische Problematik der alttschechischen Evangeliare - die Zusammenstellung, die Reihenfolge, die Unregelmässigkeiten in der Einteilung der Perikopen über das liturgische Jahr - wurde von Vašica gründlich geprüft und beschrieben. 23 seine Erkenntnisse auf diesem Teilgebiet ändert auch die neuere liturgische von uns durchgesehene Fachliteratur nicht. Wir wollen hier nur zwei Tatsachen, die für die Datierung des Archetyps von grosser wichtigkeit sind, hervorheben.

Die Fronleichnamsperikope (J 6, 56-59; das Fest wurde für die ganze Kirche erst 1311 eingeführt und 1316 synodal erneut angeordnet) ist unter unseren Handschriften nur in $R$ vorhanden. In $R$ wurde diese Perikope erst bei der Abschreibung der älteren Vorlage eingegliedert und, wie es die Sprache dieses Evangelienabschnittes bezeugt, erst nach 1350 übersetzt. Auch die Perikope Ss. Trinitatis (das fest wurde 1334 eingefuhrt) ist in keinem unserer Texte vorhanden. Dadurch wird eindeutig bestätigt, dass die erste Aufzeichnung der alttschechischen Evangeliarübersetzung, von der später kopiert wurde, vor dem Jahr 1311 entstanden ist.

Die Fragmente $A$ und $C$ haben Perikopen für die Ferialtage der Fastenzeit, die in dem kanonischen (für unsere zwecke) Text S nicht aufgezeichnet sind. Für diese Erscheinung gibt es zwei Erklärungen: 1. der Archetyp war, was die Anzahl der Perikopen betrifft, umfang-

22 J. VASICA, O. C., (Fn, 2), 12,60ff.

$23 \mathrm{~J}$. VASICA, O. C., (Fn. 2), 105-125. 
reicher als die Hs. S, die dem Archetyp nur Sonntags- und Feiertagsperikopen entnommen hat (das Proprium Sanctorum in $W$ ist jüngeren Datums): 2. es ist aber wahrscheinlicher, dass der alttschechische Evangeliartext stufenweise angewachsen ist - der älteste Teil wird durch die Perikopen der wichtigsten zeit des Kirchenjahres, der Fastenzeit, verkörpert und diese stufe wird durch die ältesten Texte $A$ und $C$ repräsentiert; eine weitere Stufe, auf der die Perikopen für die übrigen Sonntage und Feiertage des Kirchenjahres ergänzt wurden, wird durch die Hs. S repräsentiert; die nächste Stufe, auf der $z u$ den schon vorhandenen noch die wichtigsten Ferialperikopen (besonders für Vigilien und Quatemberwochen) übersetzt wurden, stellen die Handschriften D, R dar; die letzte Stufe, auf der eine allmähliche Beifügung und Ergänzung der Lesungen des Proprium Sanctorum erfolgt, wird durch die Hs. W dokumentiert.

\section{PHILOLOGISCHE CHARAKTERISTIK DER UBERSETZUNGSTECHNIK}

\subsubsection{Einteilung der Problematik}

Bei der Analyse und Beurteilung der Ubersetzungsmethode werden wir uns darauf konzentrieren, was in die Kompetenz der Sprachwissenschaft gehört - mit welchem Erfolg wurden die Einheiten und Teilstrukturen eines Sprachsystems durch andere Einheiten und Teilstrukturen eines anderen Sprachsystems ersetzt. wir wollen die fremdsprachige Vorlage näher bestimmen (4.1.), die Textabweichungen vom lateinischen original feststellen (4.2.), die Ersetzung der fremden grammatikalischen Kategorien durch die alttschechischen beurteilen (4.3.), den alttschechischen Wortschatz unserer Handschriften in seinem Verhältnis zum lateinischen Original analysieren (4.4.) und einige Schlüsse über die Filiation der Handschriften ziehen (4.5.).

Es werden uns nicht nur die Latinismen, Neologismen und Exotismen, die besonders in den älteren alttschechischen biblischen Ubersetzungen ziemlich oft vorkommen, interessieren, sondern auch weitere (extralinguistische) Umstands- und (linguistische) Kontextsituationen, die den Ubersetzer oder den Kopisten $z u$ diesen Lösungen gezwungen haben.

\subsubsection{Zur fehlenden literarischen Charakteristik}

Die ausführlichere ästhetische wertung unserer übersetzten 
Texte als literarischer Kunstwerke werden wir den Literaturwissenschaftlern überlassen. Wir beschränken uns auf diesem Gebiet nur auf eine das breite Thema gar noch nicht ausschopfende Ergănzung der kargen Äusserungen Menčlks und Vašicas besonders in zwei Richtungen: 1 . ob der Stil der Ubersetzung dem des Originals entspricht und 2. ob die alttschechischen Äquivalente nicht $z u$ naiv, farblos alltäglich und vereinfachend wirken und ob dann die Spannung zwischen dem Ausdruck und dem Gedanken durch zuviel Interpretation und Streben nach Verständlichkeit nicht vermindert oder sogar beseitigt wurde (siehe 4.5.2.). Unsere Feststellungen können und wollen nicht die immer noch fehlende und nicht leichte literarische Ubersetzungscharakteristik ersetzen, mögen aber als Wegweiser in dieser 'terra incognita' dienen.

\subsection{Die Frage des Originals}

Die ausfuhrlichere Analyse der Ubersetzungsmethode soll uns bel der Feststellung des Originals, aus dem übersetzt wurde, helfen. Schon ein erster nur flüchtiger Vergleich des alttschechischen und lateinischen Textes führt $z u$ dem schluss, dass es sich hier ganz eindeutig um eine Ubersetzung aus dem Lateinischen handelt und dass kein direktes Verhăltnis zur älteren altkirchenslavischen Übersetzung besteht (die vorhandenen ziemlich seltenen Paläoslovenismen kann man vor allem im lexikalischen Bereich auch als alte tschechische religiöse Termini, die unter den Priestern und Mönchen in ihrer Fachsprache noch indirekt aus der grossmährischen Periode durch mündiche Tradition überlebt haben und als heimisch empfunden wurden, betrachten (vgl. dazu noch 4.5.2.).

Die Entstehung der alttschechischen Evangeliarübersetzung wurde nicht mehr durch die alte kyrillomethodianische Tradition (die wichtigsten liturgischen Texte sollen dem Volk in einer ihm verständlichen Sprache verlesen werden), wenig oder auch überhaupt nicht durch die schon vorhandenen muttersprachlichen Evangeliare in benachbarten deutschsprachigen Gebieten (allemanische Ubersetzung im XII. Jh., im XIII. Jh. schon mehrere Ubersetzungen ${ }^{24}$, sondern und vor allem durch die Bedürfnisse des tschechischen Kulturlebens am Ende des XIII. Jhs.(vgl. 3.2.) beeinflusst und gefordert. Die Perikopenübersetzungen (genauso wie auch die jüngeren ubersetz-

24 G. EHRISMAN, Geschichte der deutschen Literatur bis zum Ausgang des Mittelalters, II/2/2, München 1935, 590. 
ten alttschechischen liturgischen Texte) weichen von der im Mittelalter sonst so üblichen Methode der freien Paraphrasierung ab - sie sind fast wortgetreu, denn der kanonische originaltext galt als heilig und bindend. Trotzdem findet man auch hier zahlreiche recht gute, oft aus dem Alltagsleben stamende Ausdrücke, z.B. Mt 6,26: volutilia caeli ptáčkuov pod oblaky S, ptacva pod oblaky R, ptaćsvie pod nebem $W$ (normalerweise wird ein lateinischer adnominaler Genitiv durch ein Adjektiv ersetzt, vgl. 4.3.4.2.): L 7,42: non haben-

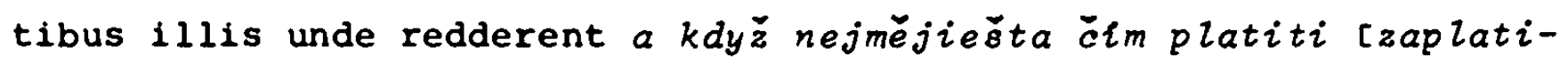
$t i$ RJ W, R; L 13,8: mittam stercora napusti okolo něho lajen $R$, hnojem pokladu W; J 5,36: testimonium perhibent de me za mé svĕď́l R, Di J 15,20: si me persecuti sunt jok lit' mné lest učinili $w$, u.a. (vgl, auch J. Vašica, o.c. Fn. 2, 91ff.). Die ersten uns uberlieferten Aufzeichnungen der ältesten alttschechischen Evangeliare stammen aus dem XIV. Jh. Alle sind Abschriften älterer Vorlagen, von denen die älteste (der Archetyp) frühestens um die Wende des XIII. und XIV. Jhs. nach unserer Uberzeugung, vgl, noch weiter, geschrieben wurde (Dobrovský setzt die erste tschechische Evangeliarubersetzung sogar ins XI. Jh.).

4.1.1. Das Verhältnis zur altkirchenslavischen Evangelienübersetzung und Ubersicht der bisherigen Literatur

Mit den Problemen des direkten Zusammenhanges der alttschechischen Ubersetzung der Evangelienperikopen und der altkirchenslavischen Ubersetzung und mit dem Verhältnis des alttschechischen Evangeliartextes und der fremdsprachigen Vorlage befassten sich schon mehrere Generationen von Slavisten. Als erste beschäfigten sich $J$. DOBROVSKY und F. DURYCH ${ }^{25}$ in ihrem langjahrigen Briefwechsel eingehend mit dem wiener Evangeliar als dem damals ăltesten bekannten alttschechischen Evangeliartext. Die scharfsinnigen Bemerkungen von Dobrovsky uber die Entstehung, das Alter und die Ubersetzungsmethode des Textes wurden bis heute nicht ubertroffen und dienten bis zur Gegenwart als Grundlage für alle späteren Ausserungen $z u$ diesem Denkmal (auch in Dobrovskýs Geschichte..., weiter bei Safarilk, Palacky, Sembera, viček, Jakubec, Hrabák, Kyas u.a.). Man kann sogar sagen, dass niemand bis heute so viele mit dieser Handschrift

25 A. PATERA, Korespondence J. Dobrovského, I. Vzájemné dopisy $\mathrm{J}$. Dobrovského a F. Durycha z let 1777-1800, in: Sblrka pramenü, skup. II, Nr. 2, Praha 1895. Vgl. Im Sachregister s.v.evangelizr. 
verbundene Fragen und Probleme so gründlich und ausführlich wie die beiden grossen Freunde löste. Das wichtigste aus diesem Dialog hat Dobrovský in seiner Abhandlung Uber den ersten Text der böhmischen Bibelübersetzung ${ }^{26}$ zusamengefasst: die alttschechischen Perikopen im Wiener Evangeliar wurden aus dem lateinischen original ubersetzt; es besteht kein dierekter zusamenhang mit einer altkirchenslavischen Evangelienübersetzung. Die präzisen Beurteilungen vorı Dotrovský und seine Datierung der ersten tschechischen Evangeliarubersetzung ins XI. Jh. inspirierten unserer Meinung nach Hanka zur Falsifizierung der angeblich uralten tschechischen Uberset$z$ ung des Johannesevangeliums. Nach einer längeren Pause wurde das Wiener Evangeliar erst vom J. JIRECEK kurz untersucht und als ein Denkmal slowakischer Provenienz klassifiziert. ${ }^{2}$ Seine Ausführungen, was die Herkunft der Handschrift betrifft, basieren meist auf den Fehllesungen von -e- als-0-, z.B. liest er som anstatt des richtigen sem, u.a. (vgl. dazu 9.1.2.). Eine scharfe Diskussion um das Verhältnis der alttschechischen Evangeliare zur altkirchenslavischen Ubersetzung entstand in den 90-er Jahren des XIX. Jhs. Im J. 1893 ist die Edition der Hss. $S$ und $w$ von F. MENCIK ${ }^{28}$ erschienen. Im Vorwort bringt er vorsichtig seine Vermutung (mit einigen Belegen) zum Ausdruck, dass der indirekte zusammenhang mit einer altkirchenslavischen Ubersetzung nicht ganz auszuschliessen wäre. Die Edition von Menčlk und sein Vorwort waren für V. VONDRAK ${ }^{29}$ der Anlass zur Studie über die Spuren der altkirchenslavischen Evangelienüberset-

$26 \mathrm{~J}$. DOBROVSKY, Uber den ersten Text der böhmischen Bibelübersetzung, in: Neuere Abhandlungen der königl. böhmischen Gesellschaft d. Wissenschaften, Bd. III, Prag 1795, 240-266.

27 J. JIRECEK, O Českém prvotnlı prekkladu sv. evangelil, in: Rozpravy Královské české spolećnosti nauk V. Praha 1859, Bd. 10, 161-196; - J. JIREČK, O zvláštnostech čeśtiny ve stárých rukopisech moravských, in: Rozpravy KXSN VII, Praha 1887, Bd. 2 , besonders die $S$. 16-18.

28 F. MENCIK, Dva evangelistáre, Praha 1893. Eine scharfe Rezension von F. CERNY, Dva evangelistáre, Listy filologické 21 (1894) 477; eine weitere, nicht gerade geistreiche, von F. KOTT, Dva evangelistáre, Casopis Xeského musea 67 (1893) 632-634.

29 V. VONDRAK, Die Spuren der altkirchenslavischen Evangelienübersetzung in der altböhmischen Literatur, in: Sitzungsberichte d. k. Akademie d. Wiss. in Wien, philos.-hist. Classe, Bd. CXXIX, 1-38 (als selbst. Druck noch 1894). Diese Studie wurde von $J$. KVICALA in einer umfangreichen Rezension in Ceské museum filologické I (1894) 77-87 positiv aufgenommen, von J. POLIVKA in Casopis Ceského musea 68 (1894) 468-470 aber schon kritischer beurteilt. 
zung in alttschechischen Evangeliar-, Bibel-, aber auch weltlichen Texten. Uber diese studie ist dann eine heftige Diskussion zwischen V. FLAJSHANS (und J. POLIVKA) auf der einen und $V$. Vondrak auf der anderen seite entflammt. 30 Flajšhans steht auf Dobrovskýs standpunkt, dass der Einfluss der altkirchenslavischen Evangelienübersetzung auf die alttschechische Ubersetzung ganz unbeträchtlich war und beweist am alttschechischen lexikalischen Material die Unrichtigkeit von Vondráks Ausführungen. Vondrák selbst sah sich dann gezwungen, seine Behauptungen über einen direkten Kontakt mit einer altkirchenslavischen Vorlage vorsichtiger zu formulieren. Die bisher ausführlichste Studie zur Problematik der alttschechischen Evangeliare hat J. VASICA 31 geschrieben. An umfangreichem Material bewiess er eindeutig, dass der alttschechische Text aus dem lateinischen übersetzt wurde und dass die Dobrovskýs Feststellung eines sehr lockeren und indirekten Verhältnisses zum altkirchenslavischen Evangelium vollkommen richtig war. Vašica analysiert als bisher einziger näher auch die Ubersetzungstechnik der Evangeliare, leider nicht besonders syste matisch und übersichtlich. Nach ihm erwähnte die Evangeliare in seinem eher bibliographischen Aufsatz über die alttschechischen liturgischen Texte A. SPALDAK. 32 Dreimal setzte sich mit den Ergebnissen der Studie von Vašica und mit den noch $z u$ erfüllenden Aufgaben der Evangeliarforschung K. JANACEK ${ }^{33}$ auseinander. In seiner umfangreichen Rezension von Vašicas Buch bringt er nicht nur eine ziemlich scharfe und nicht immer berechtigte Kritik, sondern auch zahlreiche

30 V. FLAJSHANS, VIiv literatury staroslovenské na staročeskou, Listy filologické 21 (1894) 372-378, 463-469; - V. VONDRAK, K otáce o vilivu cirkevnl slovanštiny na starou čěstinu, Casopis Ceského musea 69 (1895) 301-314; - unter demselben Titel V. FLAJS. HANS, Casopis Ceského musea 69 (1895) 487-498; - V. VONDRAK, K ná. mitkám stran vlivu církevnl slovanštiny na starou češtinu, Ċasopi: Ceského musea 69 (1895) 498-501; - J. POLIVKA. Ještè slovo k otáz ce o vlivu clirkevnl slovanštiny na starou ceš́tinu, Casopis Ceského musea 69 (1895) 501-502.

$31 \mathrm{~J}$. VASICA, O. C., (Fn. 2), $12 \mathrm{ff}$.

32 A. SPALDAK, O překládán l liturgických textú do češtiny za staršlch dob, Ćasopis Ceského musea 114 (1940), 154-180.

$33 \mathrm{~K}$. JANACEK, eine Rezension der Monographie von Vašica (Fn. 2), Ca sopis Matice moravské 55 (1931) 491-509; - K. JANACEK, K otáce jednotného pưvodu staročeských evangeliáriơ, Casopis Matice moravské 56 (1932) 445-449; - K. JANACEK, Dvě poznámky k staročeským evangeliárúm, in (Festschrift): Pocta F. Trávnićkovi a F. Wolimanov1. Brno 1948, 182-185. 
eigene Beobachtungen und Anregungen für weitere Forschung. Seine Schlüse uber die Selbständgkeit der S-, $R$ - und W-Ubersetzung und uber die zwei in der Ubersetzung verschiedenen Teile der Handschrift $W$ im Aufsatz aus dem J. $1932^{34}$ beruhen auf sehr beschränktem Material und sind unrichtig. Im J. 1948 ist er immer noch nicht mit der Vašicas These einverstanden, dass alle Handschriften der ersten Ubersetzungsredaktion der Evangeliare von einem Archetyp abstamen. zuletzt beschäftigte sich (leider ganz kurz) V. KYAS ${ }^{35}$ mit den Evangeliartexten und spricht wieder von einer kontinuität der altkirchenslavischen und alttschechischen Ubersetzung. Er zitiert dabei unrich. tigerweise eine stelle von Vašica ${ }^{36}$, wo dieser nur über die Entstehung der wiener (Jagí́)-Glossen spricht und nicht über die Entstehung der ganzen tschechischen Evangeliarubersetzung. Indirekt befasst sick mit den Problemen der Entstehung der alttschechischen Evangeliare auch die studie von F. V. MARES ${ }^{37}$, die mit dem tschechisch-kirchenslavischen Material der 40 Homilien in Evangelia Gregors des Grossen aus dem XI.-XII. Jh. versucht, eine Brücke zwischen den altkirchenslavischen und alttschechischen Evangelienübersetzungen herzustellen. Sowohl Kyas (ausdrücklich) als auch Mareš (stillschweigend) rechnet schon mit einer langen Periode (XII.-XIII. Jh.) der mündlichen Uberlieferung, womit wir wieder bei der Polemik Vondrák - Flajšhans oder sogar noch bei dem Dialog Dobrovský - Durych und letzten Endes auf dem Standpunkt von Dobrovský gelandet sind.

Aus dieser Ubersicht der Literatur zum Gegenstand kann man folgenden Schluss ziehen: es gab keinen direkten zusammenhang zwischen der alttschechischen und altkirchenslavischen Evangeliarübersetzung, die vereinzelten Paläoslovenismen im alttschechischen Evangeliartext sind als archaische Reste entweder einer mündlichen Uberlieferung der im Laufe der zeit immer mehr bohemisierten altkirchenslavischen Perikopenubersetzung oder, was realistischer ist, sind diese Paläoslovenismen als terminologische Axchaismen der Sprache der Priester anzusehen. Unten (4.5.2.) werden wir uns mit dieser Problematik, die jetzt, da es weder ein vollständiges alttschechisches worterbuch noch eine kritische Edition der Besédy (Homilien) gibt, kaum lösbar

34 K. JANACEK, K otázce...(Fn. 33).

35 V. KYAS, Prunl český překlad bible, in: Rozpravy CsAV 81 (1971) Heft 1, Praha 1971, 39.

$36 \mathrm{~J}$. VAS̆ICA, O.C., (Fn. 2), 131.

37 F. V. MARES, Ceská redakce clrkevnl slovanštiny v světle Besěd Rehoře Velikého (Dvojeslova), Slavia 32(1963) 418, 445-451. 
ist, noch kurz befassen.

4.2. Abweichungen vom Vulgatatext und Ubersetzungsfehler

Schon unsere Vorgänger stellten eindeutig fest, dass die Perikopen aus dem Lateinischen übersetzt wurden. Eine Aufgabe wurde aber noch nicht gelöst: man sollte die Abweichungen vom Vulgatatext finden, die nicht als Ubersetzungsfehler, sondern als Textabweichungen der lateinischen Vorlage $z u$ erklären sind. Zuerst werden die wichtigsten von der Vulgata abweichenden stellen (4.2.1.) und dann die häufigsten Ubersetzungsfehler $(4.2 .2$.$) behandelt.$

\subsubsection{Die Abweichungen vom Vulgatatext}

Einige wenige Abweichungen stellte schon Vašica ${ }^{38}$ fest. Wir werden sein Verzeichnis um mehrere neue stellen erweitern, die uns ermöglichen, das lateinische Original näher zu bestimmen. Die Belege werden in der Reihenfolge der Evangelisten (Mt, Mc, I, J) angeführt.

Mt 3,17: hic est Filius meus... in quo mihi conplacui jenż sem vzvoli l /sobè add. W/ S, R, W; Mt 17,5: in quo mihi bene conplacuit

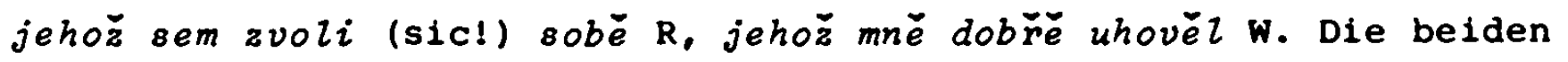
Stellen zeigen, dass dem Ubersetzer die lateinischen Texte so geläufig waren, dass oft nach dem Gedächtnis übersetzt wurde (ohne im lateinischen Text nachzusehen) und auf diese Weise ist auch die Verwechslung mit L 9,35: hic est Filius meus electus erklärbar. Es wäre aber auch möglich, dass an beiden stellen in der für die älteste Ubersetzung benutzten lateinischen Vorlage schon fehlerhaft electus stand. Die Handschrift $w$, die bei der Abschreibung mit einem lateinischen Text kollationiert wurde, kompilierte im zweiten Beleg (Mt 17,5 ) die ältere Ubersetzung mit dem richtigen Text - jeho $\vec{z}$ (alt, siehe R) und mné dobr̆ĕ uhovĕz. Im ersten Beleg hat aber auch $w$ die alte Ubersetzung. Das beweist, dass nicht alle Perikopen in $w$ nach einem lateinischen Text korrigiert wurden.

Mt 5,22: qui autem dixerit fratri suo racha reus erit concilio qui autem dixerit fatue reus erit gehennae ignis Jeñ̆e die bratru svému vilo vinen jest muky ohñové $\mathrm{S}$, Nebo ktö́ die svêmu bratru vilo bude hoden suzenie A ktoż die blazne bude vinen muky pekelne R, kto brat-

$38 \mathrm{~J}$. VASICA, O.C. (Fn. 2), 13-18. 
ru svêmu die zle bude vinen muku ohnēvu $\mathrm{w}$ - merkwürdig, dass die Stelle in $S$ und $W$ gekürzt vorkommt und die sonst ziemlich fehlerhafte Hs. $R$ den vollkommenen Text hat. Keine lateinische Handschrift hat eine solche verkürzte Lesart - es bedeutet also, dass die Hss. $S$, $W$ von einer Vorlage abgeschrieben wurden, die diese verkürzte Lesart gehabt hat, und dass dagegen die Hs. R schon eine durch Eintragungen korrigierte alttschechische Vorlage benutzte. Dies deutet folgende Filiation an:

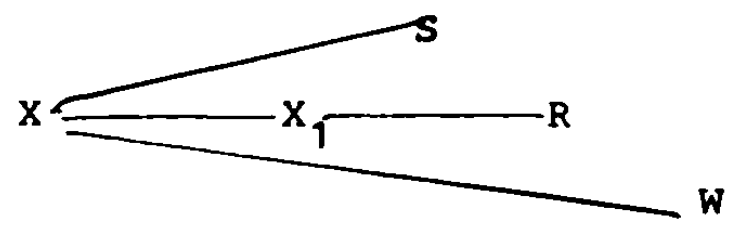

Mt 20,2: fehlt in den Hss. S, $R$ (A, C, D, W haben nicht diese Perikope) - das bedeutet, die beiden Texte $S, R$ mussten einen gemeinsamen Archetyp gehabt haben:

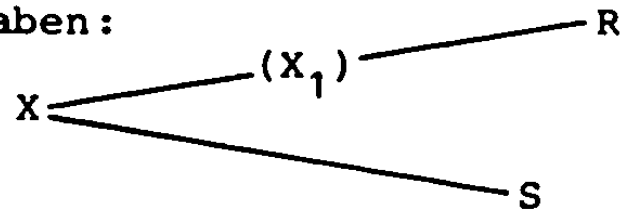

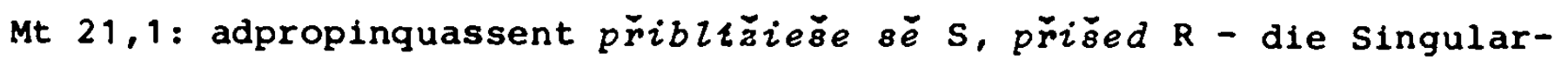
formen im tschechischen Text deuten auf ein lateinisches original hin, das nicht mit der Vulgata identisch war. Die Variante adpropinquasset haben die lateinischen Texte $M, D^{39}$ (Kodex Marianus hat auch sing.!).

Mt 21,17: abiit foras extra civitatem in Bethaniam ibique mansit vynide ven $z$ mésta do Betané tu učľ̆e je o královstvĕ Bořiem W (nur in dieser Handschrift belegt). Die freie Ubersetzung von $i b i-$ que mansit stammt sicher noch aus der Vorlage, weil die Handschrift W sonst ziemlich wörtlich den lateinischen Text wiedergibt.

Mc 16,17: signa autem eos qui crediderint haec sequentur znamenajte je /znamenaj W/ kto vériec toto prijijmu S, ähnlich R, W; vom Archetyp übernommen, der fehlerhaft signa, ev. signate (beim Lesen von signa auté zu signate kontaminiert) als einen Imperativ übersetzte. Das ist ein weiterer Beweis für einen gemeinsamen Archetyp unserer Handschriften.

L 2,2: facta est praeside... Cyrino stalo së od sudce Cyrina S, R. Es wurde aus einem mit der Vulgata nicht ganz identischen Text ubersetzt - die lateinischen biblischen Handschriften S, Z, P, C, ๑, c 39 haben a praeside.

39 R. WEBER, Biblia sacra iuxta Vulgatam versionem, Stuttgart 1969, siehe dort Handschriftenindex. 
L 8,4: turba plurima conveniret et de civitatibus properarent ad

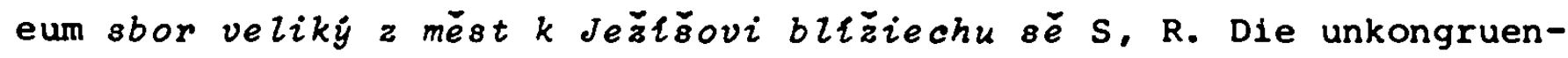
te Form im Prädikat (PI. im Prädikat vs. Sing. beim Subjekt) wurde durch das Weglassen von conveniret vom Ubersetzer des tschechischen Archetyps verursacht.

L 11,8: et ille perseveraverit pulsans $A$ on 8 tane $t$ luka $S, W, A \check{z}$ ten dokoná tluka R. Dieser lateinische Passus ist nicht in der Vulgata, sondern nur in den lateinischen Handschriften S, A, Z, P, C, vorhanden; diese Stelle beweist dieselbe Filiation bei den Abschriften $S, R, W$, wie schon oben (hier Mt 5,22) angedeutet wurde.

L 11,25: invenit[domum] scopis mundatam /et ornatam add. lateinische Handschriften $\mathrm{P}, \mathrm{c}^{39} /$ naleze umeten $i$ ukrás̆len $\mathrm{S}, \mathrm{W}$, chvostištém okråsilen $\mathrm{R}$ ( $\mathrm{vgl}$. auch Mt 12,44: scopis mundatam et ornatam umeten a ukråzlen $A, W)$. Die Vorlage für $R\left(x_{1}\right)$ wurde von einem tschechischen Glossator um 1350 - und nicht nur an dieser stelle - nach einem Vergleich mit einem lateinischen Text durch genaue und zeitgemässe Glossen verbessert (das Wort chvostï̈të ist relativ jung, erst bei Stîtný um 1350 belegt, vgl. das alttschechische worterbuch von J. Gebauer, s.v.). Dies konnte aber erst nach dem Abschreiben zumindest der Handschrift A (aus dem ersten Drittel des XIV. Jhs.) geschehen, denn diese stellen sind in den auch vom Archetyp $x$ abgeschriebenen (etwa um 1350-1370) Handschriften C, D nicht erhalten und wir wissen daher nicht, ob dort die Glosse chvostǐ̈tém übernommen wurde. Der Kopist von $R$ liess umeten aus, weil er die jüngere ergänzende Glosse chvostï̌tĕm für einen Ersatz von umeten hielt. Das jüngere alttschechische Evangeliar aus olmütz hat an beiden Stellen schon pometzami učiščený a pr̈ipravený, genau nach lateinischem Text. Die Handschriften $A, S, W$ behielten an diesen wohlbekannten und leicht $z u$ merkenden stellen eine mündich tradierte und bereits bohemisierte altkirchenslavische Ubersetzung des griechischen oeoapwhévos (CodMar: pometenb $i$ ukrasenb). Das Filiationsschema (unter 5,22 Mt) wird wieder bestätigt und der Hyparchetyp $x_{1}$ mit ungefähr 1350 datiert.

L 14,20: uxorem duxi et ideo non possum venire 21 . et reversus servus

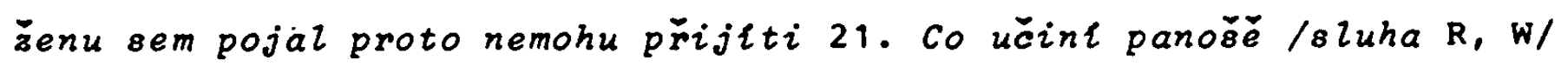

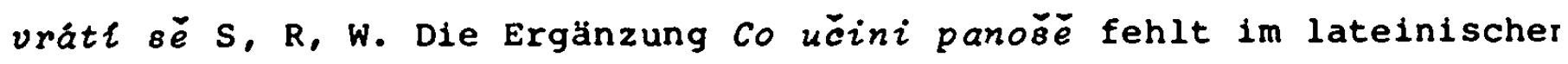
Text; es hängt mit einer in den mittelalterlichen Ubersetzungen ubli. chen (in unseren Handschriften aber nur selten $z$ um Vorschein kommenden) Tendenz zusammen, das fremdsprachige original dem Leser durch 
Erklärungen und Ergänzungen näher zu bringen. In diesem Fall ist es sogar wahrscheinlich, dass es sich um eine Redewendung noch aus der Zeit handelt, in der die Perikopen nur mündlich tradiert wurden. Ein solcher Verbindungsausdruck ist bei einer Predigt, wo es darum geht, die Aufmerksamkeit der Gläubigen aufrechtzuerhalten, recht gut verständlich. Aus diesen Gründen wăre diese Stelle als eine der älteste: zu betrachten.

L 14, 21: in plateas et vicos civitatis $v$ ulice méscké $\mathrm{S}, \mathrm{W}$, na rynk; i ulice u méstské $\mathrm{R}$ - der mangels eines geeigneten Ausdrucks vereinfachte Text in $S, W$ bestätigt wieder die Filiation unter Mt 5,22.

L 16,1: homo quidam erat dives človēk jeden biěse S, R, člověk jeden bieše bohatý $W$. Bei diesem Beleg kann man voraussetzen, dass der w-Text bei der Abschreibung mindestens teiweise (bei einigen Perikopen oder nur Versen) noch mit dem lateinischen kollationiert und eventuell ergänzt wurde.

L 16,6: accipe cautionem tuam vezmi jistost tvu R, om. in $S, W-$ die Filiation unter Mt 5,22 wieder bestätigt.

L 16, 21: a nikte jemu dodadiěse $\mathrm{S}$, ale žádný jemu nedadiěse $\mathrm{R}$, ähnlich $w$. Die Vulgata hat diese stelle nicht, sie ist nur in den lateinischen Handschriften $P, \Phi, c^{39}$ vorhanden: nemo illi dabat.

L 18,14: descendit hic iustificatus etúpil jest apraven $S$, vystupil spravedlny tuto $W$, vstupiz jest zde utësitel R. Die Abweichung in der Handschrift $R$ ist in keinem lateinischen Text zu finden. Die Lesart utésitel $\mathbf{l}$ entstand nach aller Wahrscheinlichkeit auf folgende Weise: der Kopist entzifferte das betreffende in der Vorlage abgekürzte Wort ( $\left.{ }^{\star} \S \tilde{p} w e n\right)$ als spiritus und übersetzte dann dieses durch utēöite 2 ; das übriggebliebene wen, das als ven 'hinaus' verstanden und nicht mit dem vorangehenden $z$ de 'hier' in Einklang gefunden wurde, liess der schreiber einfach weg.

L 18,35: cum adpropinquaret Hiericho ẳ pojdiē̌e $k$ Jeruzalemu /do Je. ruzalema R/ S, R. Ein gemeinsamer noch aus dem Archetyp stammender Fehler.

L 19,42: quia si cognovisses et tu et quidem in hac die tua quae ad pacem tibi nunc autem abscondita sunt ab oculis tuis Nebo by poznalo a ty $A$ ješto den tento jenż $k u$ pokoji tobé a nynie skryto jest p̆́red očima tvyma S, ähnlich w; die Hs. R hat zuerst etwas, das wahrscheinlich auch in der Vorlage nicht war und als fehlerhafte Kon tamination des Kopisten $z u$ bezeichnen wăre, die irrtümlicherweise 
nicht gestrichen wurde; erst dann folgt die alttschechische Version des Vulgatatextes: by by $l$ poznal dar tento jeřto tobé ku pokánl uči-

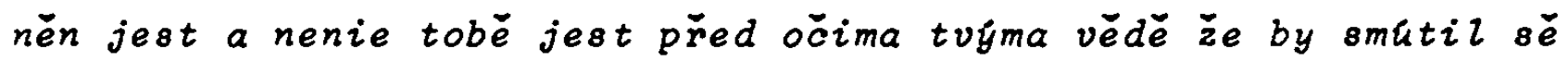
a nebo by bylo poznalo ty a jersto den tento jenżto ku pokank učinén tobé ale nenie skryto jest pr̈ed očima tuyma R. Die Handschrift $R$ wurde nicht anhand des lateinischen Textes kontrolliert, sie wurde nur abgeschrieben und nach dem Sprachgefühl des Kopisten oder nach den um 1350 eingetragenen Marginalien modernisiert, damit sie verständlicher werde. Mit welchem Text hat der Kopist hier kontaminiert? Die R-Ergänzung (by by $l$ poznal...smutiz sè a) ist in keinem Evangelium zu finden. Es wurde entweder eine Marginalie übernommen oder, was wahrscheinlicher ist, der Schreiber hat den Passus unvollständig und fehlerhaft abgeschrieben und nach der Feststellung, dass er einen Fehler gemacht hat, schrieb er den Passus nochmals richtig $a b$, den fehlerhaften vergass er aber durchzustreichen.

L 19,44: quod non cognoveris tempus visitationis tuae że neviés ča-

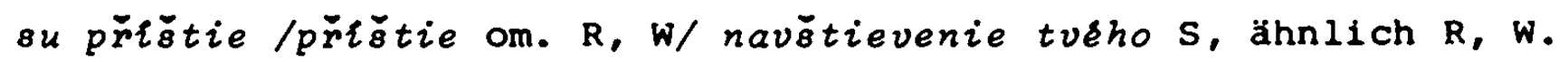
Das Wort $p \bar{r} \mathfrak{s}$ tie in $S$ zeigt, dass oft aus dem Gedächtnis ergänzt wurde - der Kopist von $S$ kannte die stelle Mt 24,3: dic.nobis... quod signum adventus tui auswendig, die er zur Ergänzung der seiner Meinung nach nicht vollständigen Ubersetzung benützte.

L 24,27: interpretabatur illis in omnibus scripturis quae de ipso

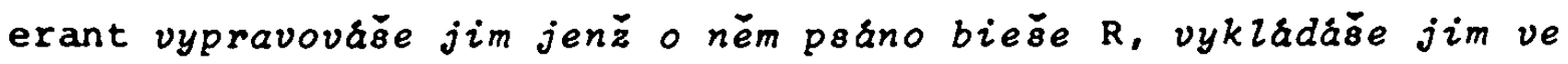

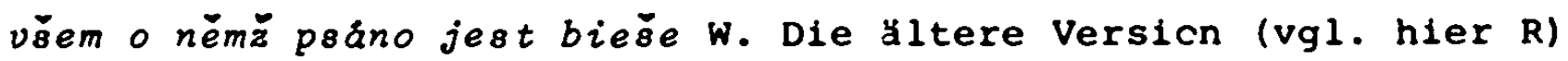
wurde in $w$ nach dem lateinischen original nicht gerade glücklich korrigiert.

J 1,7: de lumine o človéce S, D, R - ein lateinischer Lesefehler des Archetypsübersetzers (gelesen: de homine).

J 4,12: filil elus et pecora elus synové jeho R; pecora eius wurde entweder schon im Hyparchetyp $x_{1}$ nicht ubersetzt oder die dort vorhandene Ubersetzung vom Kopisten der Hs. $R$ übersehen.

J 11,33: Iudaeos qui venerant cum ea plorantes Zidé jenż $s$ nl biechu

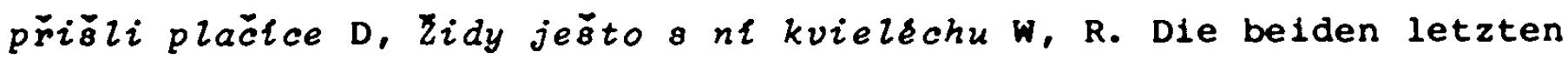
Handschriften haben eine unvollständige, aber wahrscheinlich ältere Version beibehalten. Dies würde folgendes Filiationsschema voraussetzen :

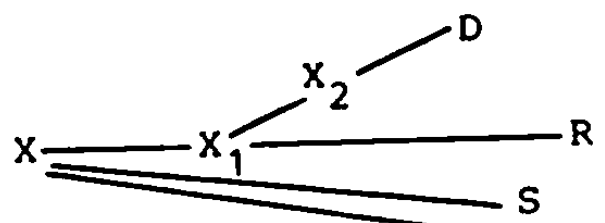


J 11,39: ait Iesus tollite lapidem die Jež̃̌̆ zdvihněte kómen W, ve-

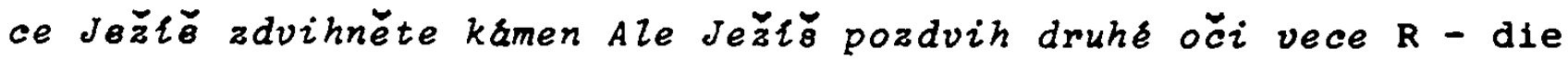
Ergănzung in $R$ schon kontaminiert mit dem folgenden Vers 41 : tulerunt ergo lapidem Iesus autem elevatis sursum oculis dixit.

Aus den oben angeführten vom Vulgatatext abweichenden stellen geht nicht eindeutig hervor, welcher lateinischer Evangelientext als Vorlage für die alttschechische Ubersetzung diente. Man kann aber folgendes feststellen: diese Vorlage war mit keiner bekannteren altel lateinischen Evangelienhandschrift voll identisch ${ }^{39}$, am nächsten stand sie der Alcuinbibe ${ }^{40}$, die bis zur Pariser Sorbonne-Bibel (im XIII. Jh.) als Grundtext für die meisten Messbücher und Lektionare in West- und Mitteleuropa diente. Die Sorbonne-Bibel war auf tschechischem Gebiet erst un die Hälfte des XIV. Jhs. bekannt. 41 Diese Feststellung ist auch ein weiterer Beweis dafür, dass die erste alttschechische Evangeliarübersetzung sehr alt sein muss. 42 schon die zweite Redaktion der alttschechischen Evangeliare, repräsentiert vor allem durch tetenie zimnieho času ${ }^{43}$ aus der zweiten Hälfte des XIV. Jhs., wurde durch die älteste tschechische Bibelübersetzung beeinflusst 44 und dadurch auch schon von der Sorbonne-Bibel abhängig (die älteste tschechische Bibelübersetzung geht von der Sorbonne. Bibel aus). Vašica untersuchte über 90 alte lateinische Handschriftel von Messbüchern, Brevieren, Lektionaren und Bibeln tschechischer Pro. venienz in Prag, Brünn, Olmütz, Raigern und wien, aber es gelang ihm nicht, die lateinische Vorlage für die alteste alttschechische Evangeliarubersetzung zu finden; er gibt auch uber den Charakter der lateinischen Vorlage nichts näheres an. Bei unserer Feststellung,dass es sich um einen lateinischen Text handelte, der sich auf die Alcuin. bibel stützte, muss uns aber klar sein, dass es bei der Fehlerhaftig. keit und relativ grossen Variierbarkeit der mittelalterlichen lateinischen liturgischen Handschriften fast unmöglich erscheint, die un-

40 Die Handschrift 0 in der Weber-Vulgata (vgl. Fq. 39); nach findet man im altsch. Text die Lesarten 2 . B. in $L 2,2$; 16,21 u.a.

41 V. KYAS, O.c. (Fn. 35), 54.

42 Die alttschechische Bibelubersetzung der zweiten Redaktion wurde dagegen schon aus der Sorbonne-Bibel übersetzt, vgl. S.GRACIOTTI, La bibbia paleoboema della Biblioteca di Brera, Milano 1964, $28 f f$. (vgl. auch V. KYAS, 0.C. Fn. 35, SS. 6, 54).

43 Ed.: A. PATERA, Ctenie zimnieho Času, in: Sblrka pram. 11t. I/1, 7. Praha 1905.

$44 \mathrm{Vgl}$. J. VASICA, o.c. (Fn. 2), 61. 
mitteluare, vielleicht auch nicht mehr erhaltene lateinische Vorlage zu finden.

Für die Filiation der alttschechischen Evangeliare der ersten Ubersetzungsredaktion gilt nach diesen ersten Textuntersuchungen das unter $J 11,33$ (S. 37) aufgestellte Schema. Die Evangeliartexte A, C kommen in den unter 4.2.1. zitierten stellen nicht vor; wir werden sie erst später $(4.2 .2,5.3$.$) bei der Filiation berücksichtigen.$

\subsubsection{Die Ubersetzungsfehler}

Einige Fehler wurden schon unter 4.2.1. angeführt, andere findet man bei Vašica ${ }^{45}$; wir werden aber noch eine ganze Menge von anderen Belegen behandeln und im Gegensatz zum blossen Verzeichnis von Vašica auch derer Erklärung suchen. Es wird nicht immer leicht zu unterscheiden, ob es sich un Fehler eines unaufmerksamen Kopisten oder um seine Fehllesungen (siehe 4.2.2.1.), um Ubersetzungsfehler des ersten Ubersetzers durch mangelhaftes Verstehen der lateinischen Vorlage (siehe 4.2.2.2.), oder auch un Fehler und Abweichungen des lateinischen Originals handelt.

\subsubsection{Die Abschreibefehler}

können wichtige Aussagen über die alten alttschechischen Vorlagen (Hyparchetype) liefern. Oft, besonders in der Hs. $R$, findet man deformierte worter, die durch schlechte Lesung der älteren einfachen orthographie, die vor allem im Bereich der $\mathrm{zischlaute}$ andere Grapheme als die jüngere alttschechische Digraphenorthographie benützte, entstanden sind.

Anm.: Die älteste tschechische Orthographie bedient sich der Buchstaben des lateinischen Alphabets, wobel besonders $c, z$, 8 mehrere Funktionen haben; $c=$ alttschechisch $c, c, k ; 8=$ alttschechisch 8,8 , ev. $z ; z=z, 8$; in der älteren Variante der alttschechischen Digraphenorthggraphie - um 1350 - bedeutet $z=z, 8=\dot{z}, z z=8$, $\S$ und $\delta \oint=\delta$.

Mt 2,1: in Rama $v$ chrámé $R, D, u$ vģsosti $S$. Der Fehler in $R, D$ ist durch eine unrichtige Ergänzung des ch-im Hyparchetyp zu erklären, im Archetyp stand richtig $w$ ramie (die Ubersetzung in $S$ deutet auf

$45 \mathrm{Vgl}$. J. VAŠICA, O.C. (Fn. 2), 13-18.

46 Dazu B. HAVRANEK, VY̧voj spisouného jazyka Českého, in: Ceskoslovenská vlastivèda I I (Jazyk), Praha 1936, 21-23; - J. CEJNAR, Odraz znělostni asimilace sykavek $v$ spřežkových pravopisných systémech $v$ čštinè, Slovo a slovesnost 30 (1969) 150-156. 
Teilkenntnisse des Hebräischen beim S-Kopisten an - 'rama' bedeutet wirklich 'die Höhe'.

Mt 11,30: iugum enim meum suave est et onus meum leve est nebo jeho (anstatt jho) mé jest a br̆iemĕ lehké W. Diese stelle (die Perikope gehört in das Proprium Sanctorum, das nur in $W$ vorhanden ist) liefert einen Beweis dafür, dass auch die Perikopen des proprium Sanctorum in der Hs. W von einem Hyparchetyp $\left(x_{3}\right)$ abgeschrieben wurden und dass sie nicht alle mit einem lateinischen Text kollationiert wurden (wie sonst die meisten in dieser Handschrift), sonst müsste diese Stelle dem Lateinischen entsprechen (jho in $x_{3}$ vom Kopisten unrichtigerweise für einen älteren Gen. von Pron. on 'er' gehalten und auf einen geläufigen Gen. jeho korrigiert).

Mt 21,5: pullum filium subiugalis dietĕ syna podlé sebe S, R - im Archetyp war offensichtlich ${ }^{\star}$ pod Sedle = pod sedlem 'unter dem Sattel'.

L 5,2: lavabant retia prăchu /brăchu $W$, promýváchu R/...sieti $S, R$, W. Dem Schreiber der Vorlage für die Handschrift $W$ wurde wahrscheinlich vorgelesen (die stimmbeteiligungskorrelation war dem Kopisten oder dem Vorlesenden fremd, in seinem sprachbewusstse in nicht fest verankert und dadurch kam es $z u$ dieser $p-b$ Verwechslung).

L 9,5: pulverem pedum vestrorum excutite prach nohami vaśimi prắte $\mathrm{R}$, nohami vašimi prorazte $\mathrm{W}$. In $\mathrm{R}$ geht es um eine schlechte lesung des Hyparchetyps $x_{1}$, wo bestimmt "praßte $(p=$ pro-) stand; der Kopist von $w$ entzifferte die Abkürzung in seiner Vorlage richtig, liess aber das Wort prach weg.

L 13,16: filiam Abrahae quam alligavit Satanas dcêr Abrahamovu jižto uvåzal /priviázal (przy§wal ms.) R/ sám Satanas W, R. Das Wort przySwal in $R$ wurde vom Hyparchetyp (*priua\$al), der noch in der älteren Orthographie geschrieben wurde $(z=z, s)$, schlecht interpretiert.

L 16,1: dissipasset utratil S, W, vrátil R - das erste -t-wurde beim Abschreiben in $R$ vergessen.

L 16,8: in...generatione v...pokoleni S, $W, v \ldots$...pokoji $R$ - das alte *pocolei (so etwa im Hyparchetyp) wurde in $\mathrm{R}$ fehlerhaft gelesen. I 19,43: vallo moct $S, W$, noct $R$.

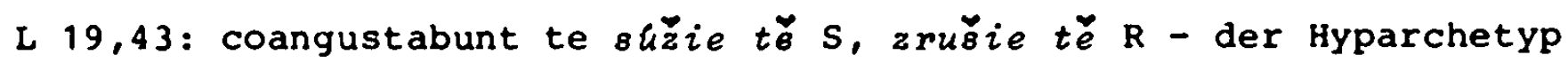
mit etwa ${ }^{2} z u \S \S i e$ wurde für $R$ fehlerhaft entziffert.

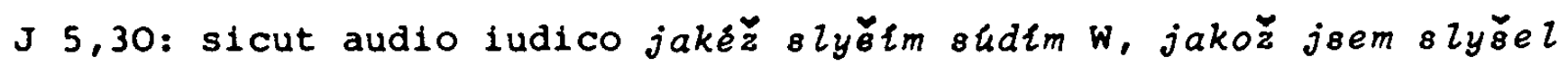

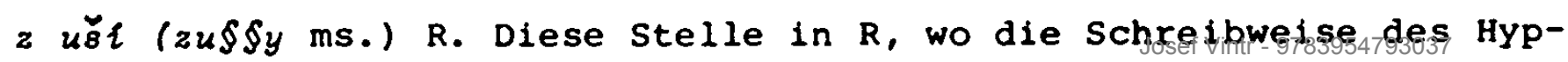


archetyps versehenlich buchstäblich übernommen wurde (bedeutet nicht

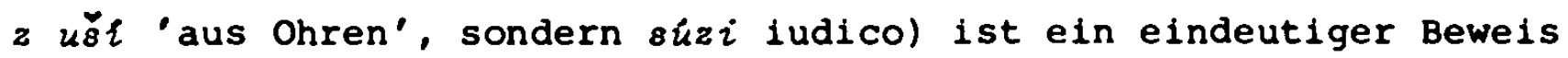
dafür, dass die Hs. $R$ aus einer noch in der älteren Orthographie geschriebenen Vorlage kopiert wurde; der durch geführte Lautwandel $u>i\left(\star^{*} u z u>s u z i\right)$ datiert die unmittelbare vorlage für $R$ etwa zur Hălfte des XIV. Jhs. (vor 1350 wuirde man $z z u z u$ oder $\$ u z u$ schreiben). J 5,39: scrutamini scripturas zvězte plsmo W, v svaté płsmo R - der Kopist von $R$ verstand das wawiezte des Hyparchetyps nicht.

J 5,44: gloriam ab invicem chv\&lu narüzno $\mathrm{W}$, chvalu narozeného ('des Geborenen') $R$ - der Hyparchetyp (etwa *narozno) unrichtig in R korrigiert.

J 8,7: erexit se skloni se w. Die Vorlage hatte etwa *wzcloni; wzwurde, wie damals üblich, auf $8-\left(z_{-}\right)$vereinfacht, in diesem Fall aber ohne die dabei entstandene Bedeutungsverschiebung $2 \mathrm{u}$ berücksichtigen (Präfix $v z$ - bezeichnet eine Bewegung nach oben, Präfix sdagegen eine Bewegung nach unten!).

L 8,12: in tenebris $v$ temnosti $W$, ve tmĕ $\mathrm{D}$, věčnĕ $\mathrm{R}$ - die fehlerhafte Abschreibung in $R$ wurde dadurch verursacht, dass das $t$ und $c$ in den mittelalterlichen Handschriften sehr ähnlich geschrieben wurden und dass ein $c$ von der älteren orthographie auch als ein $\grave{c}$ interpretiert werden konnte.

J 16,2: obsequium obĕt $S$, opět $R, W-\operatorname{der}$ Fehler in $R, W$ lopět = 'wieder') weist auf einen Protograph $\left(\mathrm{x}_{0}\right)$ der Hss. $\mathrm{R}, \mathrm{W}$ hin, der nach einem Diktat eines Fremden (oder einem Fremden) geschrieben wurde und infolgedessen konnte $b$ und $p$ beim Horen leicht verwechselt werden. Den zeitpunkt des Entstehens dieses Protographs kann man durch die Erkenntnis, dass dieser Text noch in der älteren Version der Digraphenorthographie aufgezeichnet wurde, noch näher bestimmen. Diese orthographie ist meist in den Handschriften im ersten Drittel des XIV. Jhs. zu finden. Als, terminus post quem non' für die Entstehung dieses Textes setzen wir die 30-er Jahre des XIV. Jhs. Es ist weiter noch bemerkenswert, dass die gemeinsamen Abschreibefehler in $R$ und $w$ recht selten sind, was auch das grössere Alter des Protographs indirekt bestätigt. Aus dieser Erwägung ergibt sich folgendes ergänztes Filiationsschema:

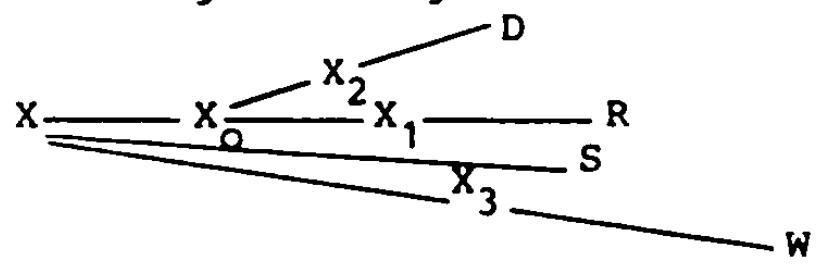


4.2.2.2. Die echten Ubersetzungsfehler

(die durch ein schlechtes Lesen oder Interpretieren des lateinischen originals entstanden sind):

Mt 11,$7 ; 11,8 ; 11,9$ : quid existis videre co $z$ těohto...vidĕste /vidt. te $\mathrm{R} / \mathrm{S}, \mathrm{R}$ - gelesen und übersetzt ex istis.

Mt 16,13: in partes Cesareae Philippi do kraje clsarova Filipova W. Mt 18,7: vae mundo hoře světu čistému $n$ - světu von der Vorlage abgeschrieben und mundo dazu nochmals falsch übersetzt.

Mc 7,31: inter medios fines Decapoleos mezi pol vlastน... Dekapoleos W, mezi vlasti...Kapoleos S, R. Die Hs. W korrigierte zwar Kapoleos auf Dekapoleọ, beging aber beim allzu wortgetreuen kollationieren mit dem lateinischen Text einen grösseren Fehler - medios fines über. setzte sie als pol viasti.

Mc 7,35: aures uši ('Ohre') S, W, üsta ('Mund') R. Da die Hs. R nich1 mit dem lateinischen Text kollationiert wurde, entstand die Verwechs: lung ores vs. aures schon bei der Ubersetzung des Archetyps, wobei die wenigstens stellenweise mit dem lateinischen Text kollationierter Handschriften $S, W$ diesen Fehler schon beseitigt hatten.

L 5,4: duc in altum vaved' vahoru S, W, R - hier wurde durch mangelhafte Kenntnis der Seeterminologie 'führe hinauf' anstatt des richtigen ved' na hlubinu 'fahr hinaus ins tiefe Wasser' ubersetzt.

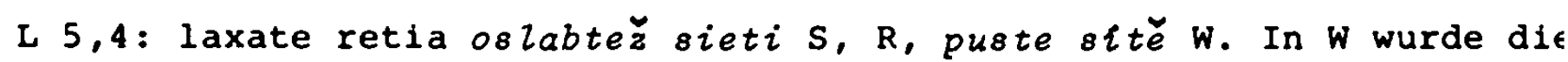
treue, aber nicht richtige Ubersetzung des Archetyps (Zaxare bedeutet auch os labiti 'abschwächen', aber nicht in diesem terminologischen Gebrauch) schon korrigiert.

L 5,5: laxabo rete upusti siet $\mathrm{S}$, ähnlich $\mathrm{W}$, os lavimy (sic ms. anstat $0 s$ lablmy) sieti R. Es ist interessant, dass in der Hs. S um einen Vers früher (s. oben) noch die alte unrichtige Ubersetzung vorkommt. L 6,17: ab maritimae Tyri z maritima a z Styrska W. Der Schreiber von $W$ war nicht nur in der biblischen, sondern auch in der europäischen Topographie nicht besonders bewandert, wenn er die steiermark (Styria, Styrsko) in Palästina placierte.

L 13, 15-16: non solvit bovem...non oportuit solvi a vinculo neodviż volu...nebylo jie zprostiti $w$, nezaplati vol...nemohl vyplatiti $z$ okov R. Das lateinische solvo bedeutet beides, der Archetypfehler wurde nur in $\mathrm{W}$ korrigiert. 
J 5,21: suscitat mortuos et vivificat zkr̆iesl mrtvého $i$ ořivl W,

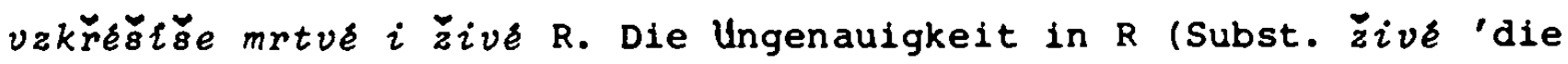
Lebenden' anstatt Verb. (0) živi) entstand durch eine Fehlabschreibung des etwa $\$ i \omega i$ 'macht lebendig' des Hyparchetyps $x_{1}$.

J 9,7: Siloae quod interpretatur Missus abiit Sizoe jenžto s l6ve pos lán jide R, Siloe jenžto poslán jide odšed W. Bei einer eher flüchtigen Kollation der älteren Vorlage $\left(x_{3}\right)$ mit dem Lateinischen wurde $a b i i t$ irrtumlich nochmals übersetzt.

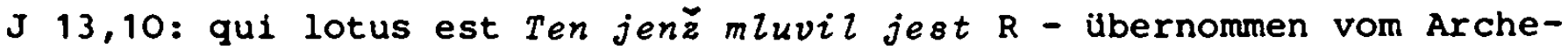
typ - der alte Ubersetzer las im Original Zocutus.

J 21,11: magnis piscibus... centum quinquaginta tribus ryb velikých sto a padesát bez tr̆́ W, R. Der gemeinsame Fehler (bez 'weniger' anstatt $a$ 'und') war noch im Archetyp und ist durch die Lesung a tribus entstanden.

J 21,12: venite prandete pod'te ob ědujte $\mathrm{W}$, pod'te obědnlci R. Der Ubersetzer des Archetyps hatte prandetae verstanden und ubersetzt.

Es zeigt sich, dass die meisten Fehlübersetzungen nur beim ersten Blick eine Fehlleistung des Archetypsübersetzers darstellen. In vielen Fällen geht es um Fehlablesungen der Kopisten, denen die älteren in einer damals nicht mehr benutzten Orthographie geschriebenen Vorlagen des ofteren schon grössere Schwierigkeiten bereiteten. Eine besondere Gruppe von Fehlern bilden diejenigen Stellen in der Hs. $W$, die erst nachträglich nach einem Vergleich der Vorlage $x_{3}$ mit dem lateinischen Text fehlerhaft korrigiert wurden. Die Fehler des Archetyps, die durch unrichtige Interpretlerung des lateinischen Originals (z.B. existis als ex istis, prandete als prandetae u.a) oder durch mangelhaftes Verstehen und unzureichende Kenntnisse der fremden Realität entstanden, kommen relativ selten vor. Man muss freilich damit rechnen, dass einige Fehler des Archetyps in den Abschriften (wie es vor allem in $W$, teilweise auch in $S$ feststellbar ist) ausgebessert wurden. Die überraschend kleine Anzahl von alten Ubersetzungsfehlern ist auf jeden Fall ein sehr bedeutsames zeugnis der hohen Qualität der ältesten alttschechischen Evangeliarübersetzung.

4.3. Die lateinischen grammatikalischen Kategorien und ihre Ubersetzungsweise

Unsere bisherigen Analysen zeigten, dass die meisten von unseren Handschriften (mit Ausnahme von $w$, teilweise auch von S) bei der 
Abschreibung nicht anhand des lateinischen Textes korigiert wurden. Die festgestellten lexikalischen Abweichungen und Fehler hăngen fast alle von den Kopisten $a b$, von ihren Abschreibequalitäten und von ihrem Sprachgefühl. Die gramatikalische Struktur der alttschechischen Evangeliartexte stammt noch aus den Hyparchetypen und bei vielen Konstruktionen setzen wir voraus, dass sie noch vom Archetyp abstammen. Der erste Ubersetzer wurde bel seiner Arbeit mit ziemlich grossen Schwierigkeiten konfrontiert - er musste die verschiedenen spezifisch lateinischen Konstruktionen (ablativus absolutus, accusativus und nominativus cum infinitivo, das lateinische Tempussystem usw.) durch Mittel des alttschechischen grammatikalischen systems ersetzen. Nachdem wir festgestellt haben, dass es 1. keine direkte Verbindung mit der altkirchenslavischen Ubersetzung gab und dass 2. aus einem lateinischen Text übersetzt wurde, konnte sich daher der erste Ubersetzer nur auch die vorhandene mündliche Uberlieferunc stützen. $\mathrm{Zu}$ der $\mathrm{ze}$ it der ersten Evangeliarübersetzung gab es noch keine alttschechische Hilfstexte wie Worterbücher oder Mammotrekte, er könnte höchstens eine mit tschechischen Glossen ergänzte lateini. sche liturgische Handschrift benutzt haben.

Wir werden die lateinischen grammatikalischen Kategorien und ihre alttschechische Uoersetzungsweise in dieser Reihenfolge analysieren: die Partizipialkonstruktionen (4.3.1.), das lateinische Tempussystem (4.3.2.), dann weitere typisch lateinische Konstruktio. nen wie der Akk. mit Inf., Nom. mit Inf. (4.3.3.) und endilch auch die Imperativkonstruktionen mit noli und die adnominalen Genitive (siehe unter 4.3.4.).

\subsubsection{Die Partizipialkonstruktionen}

Wir werden uns vor allem auf zwei Gruppen konzentrieren: Konstruktionen des lateinischen, ablativus absolutus' (4.3.1.1.) und besondere lateinische Partizipialkonstruktionen (4.3.1.2.). Die Pro. blematik des lateinischen Partizips auf -urus wird beim Tempussystem $(4.3 .2 .1 .2$.$) behandelt.$

4.3.1.1. Ablativus absolutus 47

Diese lateinische Konstruktion wird in den meisten Fallen durcl

47 Vgl. dazu J. BAUER, Vliv řečtiny a latiny na vY̧voj syntaktické stavby slovanských jazykư, in:Syntactica slavica, Brno 1972,58- 
alttschechische Partizipialkonstruktion Part.Prăs./Prăt. + Akk. (siehe 4.3.1.1.1.) oder seltener + Gen. (siehe 4.3.1.1.2.) übersetzt. Die Substanz dieser lateinischen Konstruktion wird durch ein alttschechisches Partizip wiedergegeben, die Formen der objekte sind dann von der Rektion des betreffenden Grundverbs abhăngig. Bei dem alttschechischen Partizip wird nur selten auf die relative zeit des lateinischen Partizips Rücksicht genommen - oft wird das lateinische Part. Perf. durch das alttschechische Part.Prăs. und ungekehrt ubersetzt.

4.3.1.1.1. Die Akkusativformen des Objekts beim Partizip in der alttschechischen Ubersetzung einer abl.abs.-Konstruktion kormen am haufigsten vor - Mt 2,11: apertis thesauris otvořiv̌se /odkryvše R/ zbožie S, R; Mt 4,20: relictis retibus ostavivăe sieti W; Mt 21,35: adprehensis servis popadre sluhy $W$; Mt 22,18: cognita...nequitia poznav zlost /nevěru R/ S, R; Mt 22,41: congregatis...Pharisaeis sebrav zåkonnlky S, R, W; Mt 25,3: acceptis lampadibus vzemb̆e lampy W: Mc 6,29: quo audito discipuli To us lyšěše učenntci W: Mc 16,20: sequentibus signis divy /znamenie W/ činiece S, R, W; L 2,43: consummatisque diebus dokonavöe dny $\mathrm{S}$, ăhnlich $\mathrm{R}, \mathrm{W} ; \mathrm{J}$ 5,13: declinavit turba constituta in loco vzdăli sĕ od $l i d u$ ostaviv jej na miestĕ $W, R$; nach der Negation kommt ein Gen. - L 24,23: non invento corpore elus nenaleš̀e tèla jeho W, R.

4.3.1.1.2. Die Genitivformen des Objekts sind meist regelmăssige Rektionen des alttschechischen Verbs: a) als Gen. der Trennung -

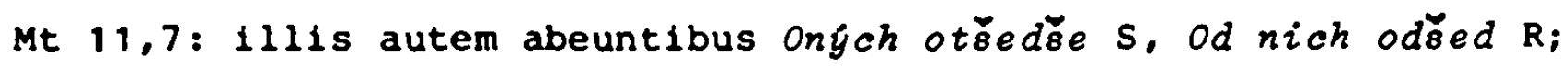

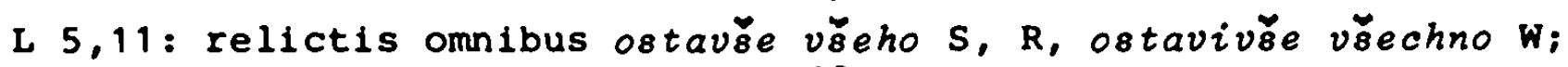
b) nach Verben mit dem Prafix po- ${ }^{48}$, z.B. Mc 8,1: convocatis disci-

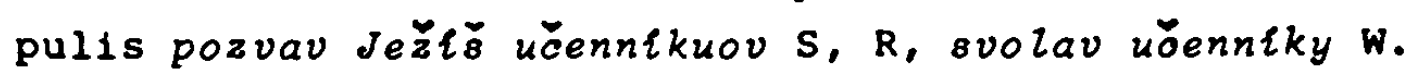

Die alttschechischen Nachahmungen der lateinischen abl.abs.Konstruktion werden meist durch einen genitivus absolutus repräsentiert. Der alttschechische gen. abs. entstand durch eine syntaktisch-semantische Analogie - die syntaktischen Funktionen eines Genitivs und eines Ablativs liegen ziemlich nahe - Mt 2,23: ascen-

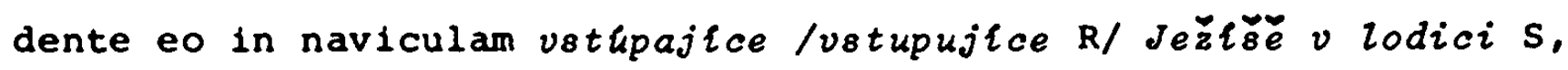
R; L 3,1: procurante Pontio Pilato viadaŕstvie (Gen.!) Ponského Piláta W; L 24,41: illis non credentibus et mirantibus jich nedo-

$48 \mathrm{Vgl.} \mathrm{J.} \mathrm{GEBAUER,} \mathrm{Historická} \mathrm{mluvnice} \mathrm{jazyka} \mathrm{českého,} \mathrm{IV.} \mathrm{Skladba,}$ Praha $1929,343$. 


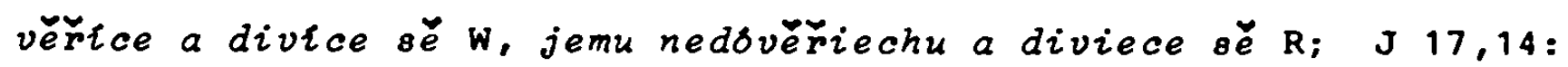
iam die festo mediante $j i \check{z}$ dně hodnieho přrichodiece $W, K d y \check{z}$ dne hodinneho príchodiece R; Mt 1,20: haec autem eo cogitante To jeho mysleše /richtig in R: myslece/ $\mathrm{S}, \mathrm{R}$.

4.3.1.1.2.1. Vereinzelt findet man eine Dativform des objekts in der alttschechischen Ubersetzung. An der stelle L 21,20: his autem fieri incipientibus Tehdy tomu búti počrnajlce $S, R$ geht es um eine tschechische Redewendung byti tomu (bis heute sagt man je tomu tak 'so ist es'). An der zweiten stelle - Mc 16,14: recumbentibus illis undecim apparuit jĕductm jedenácte /jedenăcti $\mathrm{R} /$ učenntkuom zjevil se jim S, R, odpočrvajłc jedenádcet učennŁkovv zjevil se jim W-wurde recumbentibus iliis für einen Dativ gehalten und die Dativübersetzun durch die Dativrektion des Verbs zjeviti sĕ komu'sich offenbaren jemandem' unterstützt. Es ist aber unserer Meinung nach keine Reflexion des altkirchenslavischen, dativus absolutus'.

4.3.1.1.3. An einigen Stellen, meist durch den Satzkontext verursach erscheint anstatt einer alttschechischen Partizipkonstruktion nur ei alter konjunktionsloser Satz mit einer Indikativform der Vergangenheit: anstatt eines lateinischen Part.präs./Perf. eine alttschechische Aorist; Imperfekt- oder Perfektform - Mt 2,7: Herodes clam voca tis magis Herodes tajné zavola králuo S, W, R; Mt 21,17: relictis illis abiit... in Bethantam ostavi jě vynide...do Betanĕ W; Mt 22,7: rex...missis exercitibus suis kr\&l...posla zástupy $S, W, R ; \quad L 2,42$ : cum factus esset annorum duodecim ascendentibus 111 s in Hierusalem

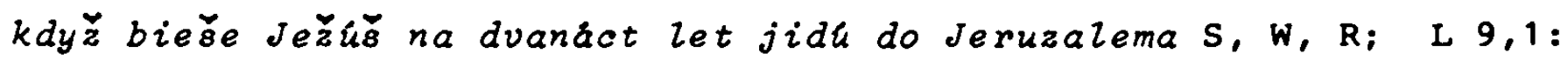
convocatis duodecim apostolis dedit illis...potestatem pozval Je ż duanaste učennłkov dal jim moc $\mathrm{W}, \mathrm{R} ; \mathrm{J} 2,3$ : deficiente vino dicit mater Iesu Nedosta /nedostăvăše R, Nestăvăse W/ se vina vece máti $k$ nӗmu S, R, W.

4.3.1.1.4. Durch einen alttschechischen Temporalnebensatz wird diese lateinische Konstruktion in unseren Handschriften noch sehr selten

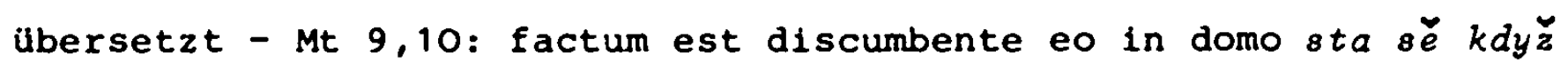
jediěse $v$ domu $W_{;} L$ 7,42: non habentibus 1111 s unde redderent $k d y \check{z}$ nejmějiěsta člm platıti W, R; J 13,2: cena facta cum diabolus iam

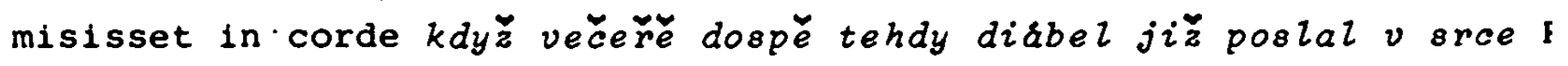
Noch seltener kommt als Ubersetzung eines, ablativus absolutus' eint gewohnte alttschechische nominale Redewendung vor, z.B. MC 16,20: DC 
mino cooperante $s$ pomoct Božl $S, R$, W.

Sowohl die Partizipiaübersetzungen (4.3.1.1.2.) als auch die konjunktionslosen Sătze (4.3.1.1.3.) betrachten wir als ein Ubergangsstadium zur Ubersetzung durch einen konjunktionalen temporalen Nebensatz. Die Vergangenheitsformen der Verba unter 4.3.1.1.3. bezeugen, dass sich der Ubersetzer der temporalen Funktion dieser lateinischen Konstruktion bewusst war, obwohl wir nicht immer genau entsprechende und gleiche alttschechische Formalmittel zum Ausdruck der relativen zeit vorfinden. Diese Inkonsequenz erklăren wir dadurch, dass die von Korrektoren und Kopisten als veraltet angesehenen, aber funktionell von dem alten Ubersetzer genau angesetzten Imperfekt- und Aoristformer durch funktionell noch nicht ausgeprägte Perfektformen ersetzt wurden.

4.3.1.1.5. Es ist merkwirdig, dass die lateinische Konstruktion des ,ablativus absolutus' schon zu dieser zeit so gut und fehlerfrei ins Alttschechische ubersetzt wurde. Wir haben keine einzige fehlerhaft interpretierte stelle gefunden.

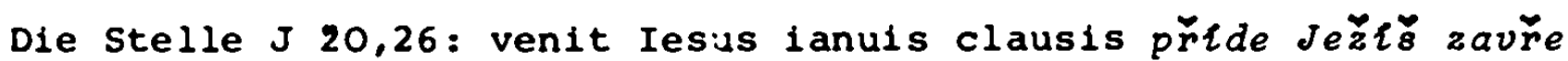
své rány $R$ hat in $R$ einen Kopisten-fehler (rány 'Wunden' anstatt des richtigen brany 'Tore'). Wie die (stellenweise mit einem lateinischen Text kollationierten) Handschriften $S$ und $w$ zeigen, wurde im Archetyp clausus als Partizip, in $S_{\text {und }} W$ aber als Adjektiv interpretiert (Pa-

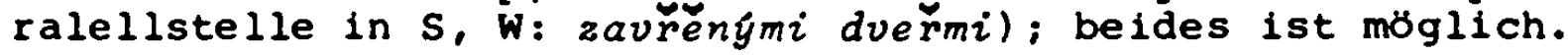

Die Analyse der Ubersetzungsweise dieser lateinischen Konstruktion zeigt die Entwicklung der alttschechischen Äquivalentenausdrücke in der altesten zeit wurde ein ,abl. abs.' durch alttschechische Partizipien, dann auch durch einen Hauptsatz mit finiten Verbformen und erst zuletzt (im XIV. Jh., meist in der spät verbesserten $W-H s$. ) durc konjunktionale Temporalsätze übersetzt.

4.3.1.2. Die lateinischen Partizipien als Attribute oder Prädikate

werden durch alttschechische Partizipien oder Hauptsätze mit Ind kativformen (4.3.1.2.1.), durch alttschechische sog. absolute partizi pien (4.3.1.2.2.) oder sejtener durch andere Formen (4.3.1.2.3.) über setzt.

4.3.1.2.1. Die lateinischen prädikativen und attributiven Part.Präs. werden in unseren Texten meist durch alttschechische Vergangenheitsformen (finite oder infinite) ubersetzt. Die erwarteten alttschechischen - nt-Part.Prăs. fehlen (bis auf vereinzelte Ausnahmen in $R, 2.1$ Mc 6,48: videns eos laborantes vidiěse je těřě plovúce $R ; \quad J$ 21,12:

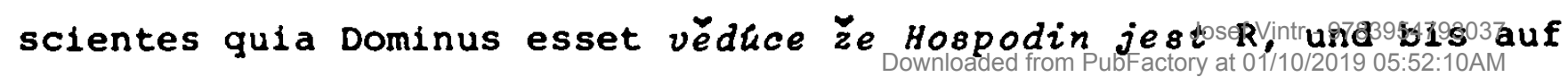


die alttschechischen absolutiven -nt-Partizipien, vgl. 4.3.1.2.2.). Der Ubersetzer gab sich gerade mit der Wiedergabe der lateinischen Partizipien und ihrer relativen zeit grosse Muhe; nur dort, wo ihm ein Partizip im alttschechischen Satzkontext nicht erträglich schien wurde durch eine Form des Präteritums (Imperfekt oder Aorist) ersetz Die Imperfektformen kommen dort vor, wo es sich aus dem kontext um Gleichzeitigkeit handelt, die Aoristformen bezeichnen nur eine (aus dem Kontext verstandene) Handlung in der Vergangenheit, z.B. - Mt 2,18: vox in Rama audita est... Rachel plorans filios suos et noluit consolari Hlas u výsosti /v Ramĕ R/s sy̆̌săn jest... Rachel plakăse synov svỵch a nerodiěse utěšiti $S, R$; Mt 21,6: euntes autem discipuli fecerunt sicut praecepit illis Tehdy jidu/jidechu R/ učenlci učinichu jakože kazal jim S, R; Mc 6,48: erat navis in medio mari...et

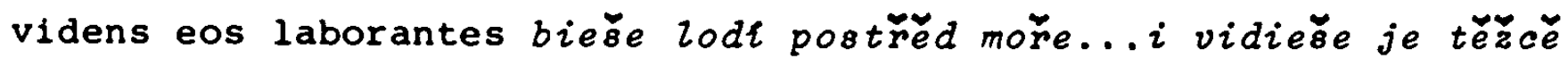
plovuce $R ; \quad L 2,46$ : invenerunt illum in templo sedentem in medio doctorum audientem 11 los et interrogantem naleznu/nalezli w/ jeho $v$ chrămě mezi mistry sediece (Part. abs., vgl. 4.3.1.2.2.) posiuchaje /poslúchăse W, R/ jich i tázăbe /tăže W/ jich S, R, W.

An Stellen, wo der Ubersetzer loder Korrektor der Handschriften $S$, W) von der Vorzeitigkeit der durch ein lateinisches Part.Präs. ausgedrückten Handlung uberzeugt war, benutzte er ein alttschechisches aktives kongruentes - 8 - Partizip des Perfekts, 2.B. - Mt 2,8: Herodes mittens eos/magos/ in Betlehem dixit Herodes...poslav/posla R, poslal W/ je do Betléma vece /a rka $\mathrm{R}, \mathrm{W} / \mathrm{S}, \mathrm{R}, \mathrm{W}$; Mt 11,4: respondens Iesus ait 111 is euntes renuntiate Iohanni quae auditis

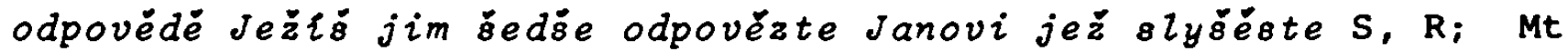
17,6: audientes discipuli ceciderunt in faciom suam slysévỉe učenntci...padechu /padnú R/ na svú tvár W, R; L 24,27: incipiens a Mose

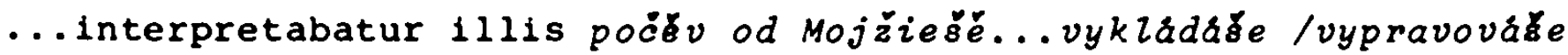
R/ jim W, R; J 21,12: nemo audebat discentium interrogare eum... scientes quia Dominus esset nižrdný nesmél z nich jeho otázati...védèvə̌e /vĕduce R/ że Hospodin jest W, R. Es ist nicht auszuschliesen, dass durch diese Ubersetzungsweise versucht wurde, die Abgeschlossen heit (Perfektivităt) der Handlung (z.B. von jiti 'gehen', slyéti 'hören' u.a., siehe oben) auszudrücken.

Einige der angeführten stellen deuten darauf hin (Mc 6,48 in $R$, $\mathrm{J} 21,12$ in $\mathrm{R}, \mathrm{L} 2,46$ in $\mathrm{S}$ ), dass in der älesten alttschechischen Ubersetzung doch die meisten lateinischen Part.Prăs. durch alttschechische Part.Präs. ubersetzt wurden und dass der beschriebene zustand mit den verschiedenen Ubersetzungsvarianten des lateinischen 
Part.Präs. erst durch Eingriffe der Korrektoren entstand.

4.3.1.2.2. Das lateinische Partizip im Attribut wird weiter durch das alttschechische absolutive Part.Präs. $(=$ durch eine nicht kongruente Partizipkonstruktion = eine Konstruktion mit verschiedenen Subjekten) 49 ubersetzt - Mt 21,4: dictun est per prophetam dicentem jenž povèdĕno jest prorokem praviece $S, R$; Mt 2,15: dictum est... per prophetam dicentem jest povédéno...prorokem řkuce $S, R, D$; Mt 3,16: vidit Spiritum Dei descendentem sicut columbam venientem super se vidél Duch Božl /Ducha svatého w/ schodiece jako holub /ho-

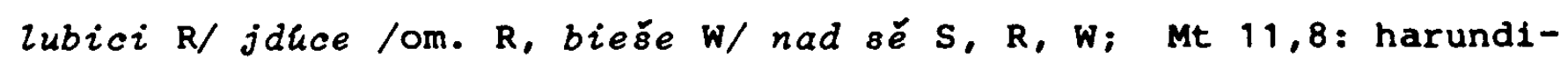
nem vento agitatam trest vétrem hyblce $S$; Mt 15,20: non lotis autem manibus manducare neumyvajlc ruku/neumytyma rukama R/ jlsti chléb W, R; L 12,36: similes hominibus expectantibus podobni lidem cékajice $W_{;}$L 15,10: super uno peccatore poenitentiam agente nad jednim hriešným pokănie diniece $S, W, R$ (ăhnlich auch L 15,7); I 21,27: videbunt Filium hominis venientem uzr̈ie syna človęcieho prichodrc /pr̆ijduce R/ S, R; J 1,9: omnem hominem venientem všelikého člověka přldúce $S, D ; J$ 5,19: nisi quod viderit Patrem facientem jedno což uzr̆l otcé čintce $W, R$.

Die alttschechischen absolutiven partizipien kommen nur in gewissen Positionen vor, wie schon von Gebauer 50 festgestellt wurde: nach ,verba percipiendi' und bei bestimmten Infinitivkonstruktionen. Die unkongruenten alttschechischen partizipien sind relativ jung, vor dem Ende des XIV. Jhs. nur selten zu finden ${ }^{51}$. Die ziemlich häufigen Belege dieser Erscheinung in unseren Texten, die alle aus dem XIV. Jh. stammen, sind alle als Neuerungen der Kopisten und Korrektoren $z u$ beurteilen. Der Archetyp hatte kongruente Formen gehabt, wie es z.B. die die älteren Formen gut bewahrenden Handschriften $S$ und besonders $R$ bezeugen - Mt 15,20: non lotis...manibus neumytyma rukama $R$, die voneiner jüngeren Vorlage abgeschriebene Hs. $W$ hat aber schon neumývajic ruku; L 11,13: Pater...dabit spiritum bonum petentibus se otec d\& duch dobry prostclm/aber: prosice W/ sebe S, R, W. So stellt sich auch in dieser Hinsicht die Hs. W als die jüngste heraus.

$49 \mathrm{Vgl.}$ J. GEBAUER, Hist. ml. IV (s. Fn. 48), 601ff.; - E. DVOKAK, V̧́voj prechodnikovłch konstrukcl ve staršl ceštinè, Praha 1970, $24 \mathrm{ff}$.

50 J. GEBAUER, Hist. ml. IV (s. Fn. 48), 629.

$51 \mathrm{~J}$. GEBAUER, Hist. ml. IV (s. Fn. 48), 601. 
4.3.1.2.3. Die lateinische Partizipkonstruktion wird in den Evangeliartexten nur vereinzelt durch andere Formen als das alttschechische Partizip und den Indikativ ubersetzt - durch einen Infinitiv oder durch ein Supinum (nach, verba movendi'), 2.B. Mc 9,22: omnia possibilia credenti vzeckno jenz byti moze jiz věriti R; L 11,14: erat elciens daemonium Biere Jezłళ chtieße vyhnati /vypuditi W/ berac Ibés R, diábla W/ S, R, W (im Archetyp musste ein alttschechisches Part. Fut. *chté vyhnati in der Bedeutung eines lateinischen Part. Fut. ,eiecturus' sein): L 2,45: regressi sunt...requirentes eum vratichu se...hledat $\mathrm{S}, \mathrm{R}, \mathrm{W}$.

4.3.1.2.3.1. Das lateinische Gerundium wird durch einen Infinitiv ubersetzt - I 8,8: qui habet aures audiendi Jenz m\& u\&i sly 8 ti $\mathrm{S}$, A, jenz maji vichni (die Vorlage fehlerhaft verstanden und abgeschrieben anstatt má $u \delta i)$ s $z y \delta \varepsilon t i R_{i}$ L 14,28: si habet ad perficiendum jmę $\imath i$ by doskondert $i$ w.

\subsubsection{Das lateinische Tempussystem}

bereitete dem tschechischen Ubersetzer keine grösseren Schwierigkeiten vor. Die grössere Variierbarkeit der alttschechischen Ausdrucksweise für die lateinische, coniugatio periphrastica activa' und für die Konjunktivformen der Nebensätze deutet darauf hin, dass das syntaktische System des Alttschechischen im Bereich. der Hypotaxt noch nicht konstituiert wurde und die geeigneten Formalmittel erst gesucht wurden. Es wird hier zuerst die Ubersetzungsweise der lateinischen Tempora (4.3.2.1.) mit einigen typischen Beispielen und danr die Ubersetzung der hăufigsten lateinischen konjunktionalen Nebensätze (4.3.2.2.) beschrieben.

4.3.2.1. Die lateinischen Zeiten werden ohne grössere Probleme (ausser dem Futurum, siehe 4.3.2.1.1.) wiedergegeben - Präsens durch Prăsens, lateinisches Imperfektum oder Plusquamperfektum durch alttschechisches Imperfektum (und erst spater als Folge der Korrekturen der jüngeren Abschriften durch die alttschechischen Per. fektformen), z.B. J 11,31: consolabantur utęovłchu R, utęovali D

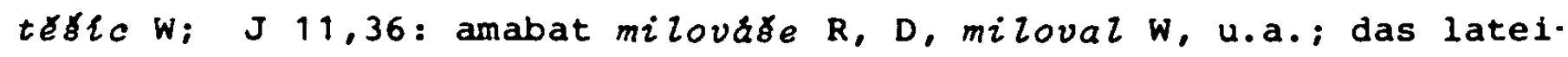
nische Perfektum durch alttschechische Aoristformen (in unseren Hss. nur vereinzelt durch die jüngeren alttschechischen Perfektformen, 2.B. J 11,34: ubi posuistis eum kde ste jeho položili R, Di J 11,: 
lacrimatus est plakal jest R, D, poze slzeti w, u.a.).

4.3.2.1.1. Das lateinische Futurum wird meist durch ein alttschechisches Futurum (budu + Inf., oder Prăsensformen der Perfektiva) ersetzt; das alttschechische periphrastische "modale" Futurum (jmåm, chcu + Inf.) ist in unseren Texten nicht belegt, denn diese Formen werden anders ausgenützt (vgl. 4.3.2.1.2.). Das sogenannte alttschechische ,futurum exactum' (siehe dazu ausführlich bei der Konjugation, 8.2.2.) kommt aber sfters anstatt eines lateinischen Konj.Fut. in den Konditionalsatzen vor - Mt 18,15: si te audierit bude $l_{i}$ té uslybal $\mathrm{R}$, poslechne $l_{i}$ tebe $\mathrm{w}_{\text {; }} \mathrm{J}$ 3,3: nisi quis natus fuerit denuo jedno ktol znova narodil se bude $W ; J$ 8,55: si dixero quia non scio eum ero similis vobis mendax ${ }^{r} k u \quad l i$ neznal sem /jeho add. C, R, D, W/ budu \& vămi v roveñ /zarovno C, D, R, W/ selhal /Lhăr W, nazván Lhaŕ C, D, R/ S, C, D, R, W; J 12,24: nisi...granum...mortuum fuerit jedno ad zrno...umrlo /umrelo R/ bude $W, R$ (aber eine Paralellstelle in J 12,25: si...mortuum fuerit pakli umr̆e /neumře $R / W, R$ - schon durch ein einfaches Futurum).

4.3.2.1.2. Die lateinische, coniugatio periphrastica activa' (Part. -urus + Formen von esse) bereitete dem alttschechischen Ubersetzer schon grössere schwierigkeiten. GEBAUER ${ }^{52}$ gibt an, dass in den alteren Texten diese lateinische Formen durch eine alttschechische Konstruktion Part.Prăs. chté + Inf. wiedergegeben wurden. In unseren Texten, die ein sehr altes stadium der alttschechischen Sprache repräsentieren, findet man aber keinen einzigen klaren Beleg für diese Konstruktion (vgl. aber 4.3.1.2.3.). Die vorhandenen Ubersetzungen solcher lateinischer konstruktionen in unseren Texten bezeugen die grosse Verlegenheit des Ubersetzers (und auch der späteren Verbesserer), wenn sie für diese lateinische Formen ein entsprechendes alttschechisches Aquivalent finden sollten. Die Handlung 'ich beabsichtige etwas zu tun' wird durch altere Formen des alttschechischen ,futurum periphrasticum modale' ausgedrückt, durch Formen von jmám + Inf., chcu + Inf., jsem + Inf. (bei der letzten Moglichkeit für einen Subjektnominativ auch durch jsem + Dat. + Inf., entsprechend in der Bedeutung der lateinischen Konstruktion ,mihi est laborandum') - Mt 11,3: qui venturus es jemuz prijiti /jest add. R/ S, R; Mt 16,2 venturus est prijiti jm\& W; L 10,1: quo erat ipse venturus jamže jen.

52 J. GEBAUER, Hist, ml. IV (siehe Fn. 48), 576. 
jti bieše $w_{i} J 16,14$ : qui venturus est jemuz/jest add. $R / \ldots$ r $_{i}$ jiti S, R, jenz prisel jest W: $J$ 7,35: quo hic iturus est kam chce tento jiti W, R, C, D; J 7,39: quem accepturi erant jenz chtiechu vaieti D, C, R, jenz valti mejłchu $w$; $J 11,51$ : quia Iesus moriturus erat aby Jezlłovi bylo umrieti R, D, aby Jezls umrę W; J 16,13: quae ventura sunt jemuż býti $S, R$, jenż ma prijiti $W$.

Relativ oft wird das lateinische part. auf -urus unrichtig durcl alttschechische l-Partizipien wiedergegeben. Es handelt sich nicht un alte Ubersetzungen, sondern un Eingriffe der Kopisten, die die richtigen, von ihnen oft im Kontext als unpräzise (oder veraltet?) angesehenen Formen des periphrastischen modalen Futurums durch Part. ersetzten (vgl. auch 4.3.2.1. uber die alttschechischen Perfektformen und die dort zitierten Belege, besonders die Varianten der Handschrift $W$ bei $J 16,14$ und $J 11,51)$ - Mt 20,22: potestis bibe. re calicem quem ego bibiturus sum možete $l_{i}$ plti kalich jenz̆ jă sem pil $W$, budu plti R; Mt 21,9: benedictus qui venturus est blakený jenz prizel S, R; J 12,4: qui erat eum traditurus jenž biełe jeho zradil $R ; J$ 12,33: hoc autem dicebat significans qua morte esset mo. riturus ale tot' pravlse znamenavaje kterú by smrti umrél $/$ by $l$ add. R/ W, R (im letzten Beleg in potenzieller Bedeutung als Äquivalent möglich). Durch ein alttschechisches Part.Präs. wird nur an einer Stelle fehlerhaft übersetzt - J 17,20: qui credituri sunt ješto vertict su $R$.

Die angeführten Belege zeigen, dass die älteste alttschechische ziemlich genau entsprechende Ubersetzungsform für die lateinische , coniugatio periphrastica activa' die Konstruktion chcu + Inf. war, dann folgt bald oder gleichzeltig jmám + Inf.; alle andere Ubersetzungen der lateinischen Konstruktion mit einem Part. auf -urus sind jüngeren Datums.

\subsubsection{Die lateinischen Nebensäze werden im Alttschechischen} nicht einheitlich ubersetzt. Wir behandeln hier an einigen typischen Beispielen nur die Satztypen, die die Entwicklung der alttschechischen Hypotaxe durch ihre grosse Frequenz am meisten beeinflussten: die Finalsätze (4.3.2.2.1.), die Konditionalsätze (4.3.2.2.2.) und die Temporalsătze (4.3.2.2.3.). Es besteht eine ziemlich starke Tendenz zur Vereinheitlichung der Ubersetzungsformen bei einzelnen Satz. typen ( $a b y$ bei Finalsätzen, kdyz̆ bei Temporalsätzen), aber in unseren Texten wurden noch $z$ ahlreiche andere Ubersetzungsmöglichkeiten ausgenützt. 
4.3.2.2.1. Die lateinischen Finalsäze mit ut werden ins Altschechische am hăufigsten durch die Verbindung $a b y+$ Part.Perf., aber auch noch durch einen Paralellhauptsatz oder durch eine Infinitiv- oder Supinkonstruktion übertragen - J 4,8: abierant...ut cibos emerent biechu $8 l_{i}$ atravy kupovat $R ; J$ 8,59: tulerunt ergo lapides ut iacerent in eum vaechu /podvihachu $\mathrm{W}$, proti nemu zdvizechu R, C, D/ zidové kamenie aby nañ metali /luceli $w, i$ luceli nañ $\mathrm{R}, \mathrm{C}, \mathrm{D} / \mathrm{S}, \mathrm{C}, \mathrm{D}$, R, W; J 11,29: cogitaverunt ut interficerent eum pocéchu mysliti aby jeho zabili D, R, pocéchu mysliti zabiti jejw, u.a. Die paralelle Angliederung eines Hauptsatzes anstatt einer hypotaktischen Beifügung kommt nur in unseren ältesten Handschriften (C, D, R) vor und dadurch wird die schon bekannte Tatsache über die Unterentwicklung der Hypotaxe in der altesten Periode des (geschriebenen) Alttschechischen bestätigt. Es ist gleichzeitig ein weiteres zeugnis für das betrăchtilche Alter der alttschechischen Evangeliarubersetzung.

4.3.2.2.2. Der lateinische Temporalsatz mit einem, cum historicum' wird vor allem durch einen alttschechischen Nebensatz mit der Konjunktion $k d y \dot{z}+$ Vergangenheitsform übersetzt, nur vereinzelt (und nur in der jüngsten Handschrift $w)$ auch durch einen Hauptsatz oder durch eine Partizipkonstruktion - Mt 21,1: cum adpropinquassent Hierosoly-

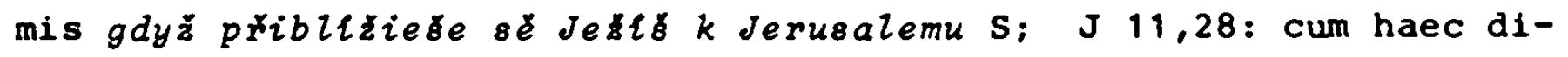
xisset /Martha/ abilt kdyz to povedé odejde $R$, řeknuci to jde $w$;

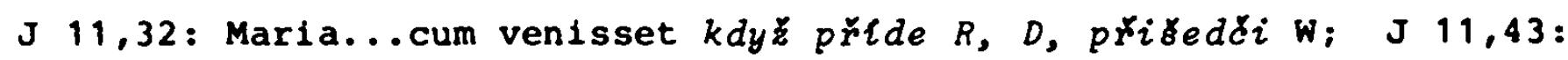
haec cum /Iesus/ dixisset kdyz to poverdé R, D, Rekl to W, u.a.

4.3.2.2.3. Die lateinischen realen Konditionalsätze werden als alttschechische Nebensätze mit $l_{i}, a d, p a k l_{i}+$ Ind. wiedergegeben, $z . B$. Mt 18,15: si autem peccaverit in te frater tuus vade et corripe eum ...si te audierit...si autem non te audierit ad provint protiv /provint $l_{i}$ se $k \mathrm{R} /$ tobe bratr tuoj di a treskci jej...poslechne $l_{i}$ tebe lbude $l_{i}$ te uslysal R/...pakli tebe neposlechne /neuslyst R/ W, R; $J$ 8,46: si veritatem dico quare vos non creditis mihi ad pravdu pravi /vám add. C, D, R, W/ proc mi neverite S, C, D, R, Wi J 8,55: si dixero quia non scio eum ero similis vobis mendax $\$ k u l_{i} / p a k l_{i} k_{k} u$ R, C, D/ neznal sem /jeho add. C, D, R, W/ budu o vámi v roveñ /zarovno $\mathrm{C}, \mathrm{D}, \mathrm{R}, \mathrm{W} /$ selhal / Lhat $\mathrm{W}$, nazuán lhax $\mathrm{R}, \mathrm{C}, \mathrm{D} / \mathrm{S}, \mathrm{R}, \mathrm{C}, \mathrm{D}$, W, u.a. Die Konjunktion jest $l i$, jest $l i z e$ kommt nicht vor.

Die lateinischen irrealen Konditionalsatze ubersetzt man in unseren Texten mit ad + Kond., z.B. L 16,31: neque si quis ex mortuis re- 
surrexerit credent ani ax by kto $z$ mrtvých votal uvérie $R, W$ (aber in $S$ interessanterweise durch ein absolutives Partizip - ani komu $z$ mrtvých votanuce uver rie S): J 5,46: si enim crederetis Mosi crederetis forsitan et mihi at byste /a byste R/ vexili Mojzfsovi snad byste $i$ mné verili $w$, R. Hăufiger wird aber durch blossen Konditional übersetzt, z.B. J14,28: si diligeretis me gauderetis utique byste milovali mé radovali byste se vłeliky $S, R, W ; J$ 15,19: si de mundo fuissetis mundus quod suum erat diligeret byste s sveta by $l_{i}$ svet coz jeho miloval by $w ; J$ 8,42: si Deus pater vester esset diligeretis utique me by Buoh otec va's by $l$ milovali byste me $w$, R, usw. Die Konjunktion kdyby kommt noch nicht vor.

4.3.3. Accusativus und nominativus cum infinitivo

Bei den typisch lateinischen Konstruktionen wie, accusativus cum infinitivo' (4.3.3.1.) und, nominativus cum infinitivo' (4.3.3.2. erhebt sich die Frage, welchen Einfluss die lateinische Vorlage auf die Art der alttschechischen wiedergabe ausubte und ob diese Verbindungen ins Alttschechische übernommen oder durch heimische Ausdrücke ersetzt wurden.

4.3.3.1. Der, accusativus cum infinitivo' kommt im lateinischen Original ziemlich häufig vor und wird in unseren Texten auf verschiedene Weise übersetzt. Wie schon GEBAUER ${ }^{53}$ festgestellt hat, wird diese Konstruktion meist durch eine Verbindung Akk. + Part. wiedergegeben, z.B. Mt 16,13: quem dicunt homines esse Filium hominis Koho pravl lidé Syna Bozieho jouce W; Mc 16,14: qui viderant eum resurrexisse jenz videli jeho vstav\&e $z$ mrtvých $S, R, W$; L 21,31: cum videritis hoc fieri kdyz uzilte/uslysite $\mathrm{s} /$ to budice R, Si L 24,39: sicut me videtis habere jakoz me vidite majlce $W$, $R_{i} J$ 12,18: audierunt eum fecisse hoc signum slyłechu divy jeho Ciniece R.

Eine andere Möglichkelt, die besonders nach den, verba existimandi' fast regelmassig vorkommt, ist die Ubersetzung mit dem Konditional, z.B. Mc 6,49: putaverunt fantasma esse mnéchu by by $l$ pielud R; L 2,4i: existimantes autem illum esse in comitatu domniece oe by byl na çate z druzinu S, W, R.

Durch die lateinische Vorlage stark beeinflusst ist die ver-

53 J. GEBAUER, Hist. ml. IV (siehe Fn. 48), 331. 
einzelte Ubersetzung durch einen alttschechischen Akk. + Ind. mit einer Elipse des es8e in der Handschrift $W$ - Mt 16,15: vos autem quem me esse dicitis koho vy me pravite $w$.

Die alttschechische Konstruktion Akk. + Inf. als eine Nachahmung der lateinischen finden wir in unseren Texten nur an einer einzigen Stelle - L 11,18: dicitis eicere me daemonia pravite me diably vyhoniti $\mathrm{S}$. Durch dieses vereinzelte Vorkommen wird auch die These von Gebauer ${ }^{54}$ bestätigt, dass diese Nachahmungen der lateinischen Konstruktion jüngeren Datums sind.

Fehlerhafte oder ungenaue Ubersetzungen dieser Konstruktion kommen selten und nur in den Hss. $R$, ev. $S$ vor. Wir haben schon oben festgestellt, dass der Schreiber der Handschrift $R$ bei der Abschrift vieles fehlgelesen und den lateinischen Text nicht konsultiert hat. Er hat des ofteren versucht, die altere (richtige) Ubersetzung zu verbessern, aber nicht immer ist es ihm gelungen, 2.B. L 24,37: existimabant se spiritum videre mniechu se oblúsenie duch viduce duch videli $\mathrm{R} / m n i e c h u$ by videli duch odzuzent $\mathrm{W} /$ vom Kopisten in $\mathrm{R}$ duch videli in diesem Rontext unrichtig (einer Glosse nach, die setzte voraus, dass $\$ \$ \sum_{e}$ in $x_{1}$ als $z e$ 'dass' interpretiert wird, also 8 ...duch videli) verbessert; die alte Ubersetzung durch Akk. ( $8 E$ ) und Part. (viduce) war ublich und richtig. Die folgende Stelle zeigt, dass der Kopist der Handschrift $S$ bei der Abschrift nur stellenweise einen lateinischen Text konsultierte. Er korrigierte nămlich auch eine Stelle, wo er eine (im Lateinischen allerdings nicht vorhandene) Konstruktion Akk. + Inf. vermutete - L 17,15: ut vidit quia mundatus est kdyz̆ vidiere sé zdrá-

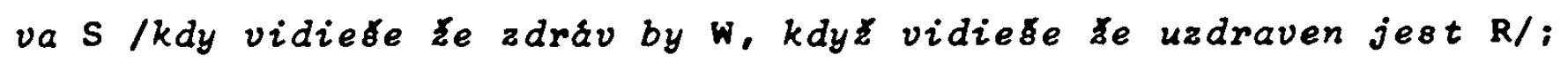
dieser Fehler ware auch durch Verlesung der Vorlage für $S$ erklärbar, wo (vgl. Hs. W!) stand etwa "Se \$draw by, was, mit dem Fehler in die Digraphenorthographie transponiert und nach der Elipse von by in $S$ se $z d r a v a$ ergibt. Die Handschrift $R$ korrigierte fehlerhaft auch eine andere Stelle - Mc 6,55: ubi audiebant eum esse kdyż $8 l_{y-}$ siechu jeho $\mathrm{R}$; in der Vorlage war etwa "cdeई zzli\$§lechu geho gzzu$c e$. Es wurde vom Kopistender Hs. R, der keinen lateinischen Text zur Kontrolle benützte, nicht verstanden und darum ohne das part. abgeschrieben. Ein Fehler an einer anderen Stelle, der schon in der Vorlage für $R$, $W$ war, wurde ähnlich wie der vorangehende Beleg in der $R$-Abschrift noch vergrössert - J 16,2: arbitretur obsequium se

54 J. GEBAUER, Hist. ml. IV (siehe Fn. 48), 330. 
praestare Deo ukládal obét' sobé vráciti Bohu S, ukládali opét sebe vrătiti Bohu W, ukläst uklad opét vratt Bohu R.

Unsere Beispiele zeigen auch ganz genau die Entwicklungstendenzen der Ubersetzungen der lateinischen Akk. + Inf.-Konstruktionen. Wir können aber die Behauptung J. BAUERs "meist werden die lateinischen Akk. + Inf.-Konstruktionen durch einen alttschechischen Nebensatz übersetzt" 55 nicht bestätigen - diese Formulierung würde eher für spătere Entwicklungsphasen des Alttschechischen, etwa für das XV. Jh., gelten. Unsere Belege zeigen eindeutig, dass in der altesten Zeit durch einen Akk. + Part. , dann durch einen Nebensatz mit by + Ind., und erst Ende des XIV. Jhs. durch einen Nebensatz mit 弓e + Ind. (Beispiele s. oben) oder seltener durch das Ubernehmen der lateinischen Konstruktion mit einem alttschechischen Akk. + Inf. ubersetzt wurde. Zwei Belege mit ihren Varianten werden unsere These klar demonstrieren - L 24,37: existimabant se spiritum videre mniechu se obluzenie duch viduce duch videli $R$, miechu by videli duch odluzent (anstatt ob-) W (vgl. auch oben); L 11,18: dicitis ...eicere me daemonia pravtte mé...bésy vyhontce R, pravtte mé... diábly vyhoniti s.

4.3.3.2. Der, nominativus cum infinitivo' komnt nur an einer einzigen Stelle vor - L 10,37: quis videtur tibi proximus fuisse $k$ to $t i$ sé vidi bliznt /jemu add. R/ $\mathrm{S}, \mathrm{R}$, kto...bližnt tober se ad\& W. GEBAUER ${ }^{56}$ gibt an, dass diese lateinische Konstruktion durch Beifügung des Inf. býti ubersetzt wird. Diese Feststellung von Gebauer gilt, wie unser Beleg zeigt, erst für die jüngeren Handschriften (im XV. Jh.).

4.3.4. Die Imperativkonstruktion noli + Inf., der adnominale Genitiv, der temporale Ablativ, die Nachahmungen

Die Analyse der Ubersetzungstechnik der Imperativkonstruktion noli $i$ Inf. (4.3.4.1.), des adnominalen Genitivs (4.3.4.2.), des temporalen Ablativs (4.3.4.3.) und der wort- und formgetreuen Nachahmungen lateinischer Wortverbindungen (4.3.4.4.) soll helfen, das relative Alter unserer Texte năher $z u$ bestimmen, vielleicht auch neue Erkenntnisse für alttschechische syntax zu bringen.

55 J. BAUER, Vliv... (siehe Fn. 47), 59.

$56 \mathrm{~J}$. GEBAUER, Hist. ml. IV (siehe Fn. 48), 309. 
4.3.4.1. Der lateinische negative Imperativ noli + Inf. wird in den Evangeliartexten am hăufigsten durch eine Konstruktion nerod" + Inf. wiedergegeben. Das Verb nerod' hat keine semantische, sondern nur eine formale grammatische Funktion. Aber in den jüngeren Handschriften, seltener in $S, R$ und häufiger in $W$, findet man schon Belege für einen einfachen, nicht zusammengesetzten, negativen Imperativ (negative Vorsilbe ne- + Imperativform, z.B. nebojte sé). Dazu einige Beispiele - Mt 17,7 und L 24,36: nolite timere nerod'te $8 \dot{ }$ báti $W$, nebojte sé $R$; Mt 28,5: nerod'te sé báti $W$, nebojte sé $R, S$; Mc 6,50: nerod'te sé báti R; L 2,10: nejmejje strachu S; L 6,37: nolite iudicare nerod'te suditi S, R, W; J 7,24: nesud'te W, R; L 11,7: noli mihi molestus esse nezalost' mne $S, R$, nerod' se (anstatt mé) hnévati $W_{;} L 21,9$ : nolite terreri nelekajte se $W_{i} J$ 19, 21: noli scribere nerod' paati $C_{i} J$ 20,17: noli me tangere nerod' mne dotykati $w, R$. Nur an einer einzigen stelle in allen Texten ist die genaue Bedeutung dieser lateinischen Konstruktion - ein Verbot - durch eine Umschreibung im alttschechischen Text wiedergegeben - L 10,4: nolite portare jå zapovldaji vám nésti $\mathrm{W}$.

Die zwe 1 verschiedenen Ubersetzungsarten dieser lateinischen Konstruktion kann man nicht als ein absolut festes Kriterium für das Alter unserer Handschriften ansetzen, weil die bestimmt neuere einfache Form (nebojte $s e$ ) auch in der mittleren Gruppe unserer Handschriften (S, R) vorkommt. Man kann nur eines feststellen, nämlich dass die zusammengesetzte Form älter und die einfache jung ist.

4.3.4.2. Der lateinische adnominale Genitiv (als inkongruentes Attribut) wird ins Alttschechische meist mit einem Adjektiv (als kongruentes Attribut) úbersetzt, z.B. Mt 11,8: in domibus regum $v$ kralových domiech S: MC 6,7: dabat illis potestatem spirituum immundorum d\&våze jim moc duchounú $W$ (nicht ganz genau!): L 11,15: principe daemoniorum kniezete bésověho /diăbelského W/ S, R, W; L 21,25: pressura gentium dåvenie pohanské $S, R ; J 5,29$ : in resurrectionem iudicil $v$ ohen vẻný nebo vakíiełenie budové $R ; J$ 6,4: dies festus Iudaeorum den hodní zidovekí W, $R ;$ J 11,13: de dormitione somni o spani snovém R, D, o snu W, U.a. Diese Ubersetzungsweise kann aber auch $z u$ Missverstăndnissen führen, z.B. Mt 21,12: cathedras vendentium columbas stolice prodajnie holuby $\mathrm{W}$ (nicht genau, weil es 'Taubenverkaufsstände' anstatt 'Sitze der Taubenverkäufer' bedeutet); J 19,38: propter metum Iudaeorum pro hrozu zidovskí C (nicht genau, weil es 'wegen der Furcht der Juden' anstatt 'aus Furcht vor den Juden' bedeutet). 
Relativ selten (nicht in den zwei ältesten Texten $A$ und $C$ ) wird durch einen alttschechischen, genitivus possesivus' ubersetzt (in so: chen Fallen bleiben besonders bei den Eigennamen hie und da sogar noch die fremdsprachigen Genitivendungen) - Mt 15,21: in partes Tyri et Sidonis do vlasti Tyri a Sidona /Sidonis W/ $\mathrm{S}$, $\mathrm{W}$, do mesta Tyri a Sidona R; Mt 15,26: sumere panem filiorum vaieti chléb synuov/sy. nom $W$, synovsky R/ S, R, W; Mc 16,14: duritiam cordis tvrdosti srdcé /srdedné $S / R, W, S ; L$ 8,13: in tempore temptationis $v$ cas pokhsenie $\mathrm{R}, v$ casu pokưeném $\mathrm{A}, \mathrm{S}$; $J$ 5,33: testimonium veritatis sverdedstuie pravdy /pravé W/ R, W; J 14,30: princeps mundi huius knieże tohoto sverta R, W, kniere suetské $\mathrm{S}$.

Ganz vereinzelt findet man die Ubersetzung durch einen Dativ (nach einem Substantiv, das eine Handlung bezeichnet) - Mt 13,50: stridor dentium skřĕhot zubuom w (vgl. dazu 7.1.).

4.3.4.3. Der lateinische, ablativus temporis' wird nicht einheitlich übersetzt - entweder mit einem Genitiv oder durch präpositionale Ver. bindungen, z.B. Mt 21,41: temporibus suis v casu svêm W; Mt 28,20: vobiscum sum omnibus diebus 8 vami sem ve vł̌̉ch dnech $W$, sem s vámi po v\&e dny R; L 24,18: quae facta sunt...his diebus co se stalo... téch dni /v téch dnech R/W, R.

4.3.4.4. Die Nachahmungen der lateinischen Konstruktionen, die man als Latinismen im alttschechischen Text bewerten konnte, kommen an dem Umfang der Texte gemessen merkwürdigerweise vereinzelt vor.

Eindeutige Latinismen, obwohl selten, findet man bei den Eigennamen (vgl. schon 4.3.4.2.). Die undeklinierten Formen oder auch lateinische Kasusendungen werden ubernommen, z.B. Mt 21,1: ad montem Oliveti k...horé oliveti lolivetské R/ S, R; Mt 23,35: a sanguine Abel iusti usque ad sanguinem Zacchariae filii Barachiae od krve Abel /Abelovy R, D/ pravého az do krve Zacharie /Zachaŕovy R, D/ 8yna Barachie S, R, D; MC 6,17: propter Herodiadem pro Herodiadem $W$; Mt 1, 2-26: Abraham genuit Isaac... Abraham porodil Izaak... W, und immer mit einer lateinischen (ev. hebräischen) Form anstatt eines alttschechischen Akk. (auf -a), nur bei den bekannteren und auch im Alltag schon gebrauchten Namen findet man eine Akkusativendung, z.B. ...porodil Jakuba... w, u.a.

In vereinzelten Fällen wird der lateinische Kasus ohne Rücksicht auf den alttschechischen Gebrauch übernommen, z.B. L 11,5: quis vestrum $k$ to vås $\mathrm{S}, k$ to $\mathrm{z}$ vås $\mathrm{R}$, $\mathrm{W}$; $\mathrm{L} 21,15$ : ego enim dabo vo- 
bis os et sapientiam cui non poterunt resistere...adversaril nebo já vem dám hsta a múdrost jemuz nebudú moci svitéziti...protivnfoi W; dem Ausdruck jemuz entspricht in syntaktischer Funktion das demuz (Dat.Pron.N.Rel. von co 'was'). Es zeigt sich, wie es schon bei den früher angefuhrten Beispielen $z u$ bemerken war, dass sich die messten Latinismen in der jüngsten Handschrift $w$ befinden. Dies ist auch dadurch erklärbar, dass der Schreiber versuchte, den Text dieser Handschrift dem lateinischen anzunähern. Seine Bemuhungen waren aber nicht immer erfolgreich und oft weisen die alteren Handschriften eine dem Geist des Tschechischen besser entsprechende Ubersetzung aus (nur ein kleines Beispiel - J 7,35: dixerunt ergo Iudaei ad se ipsos proto vecechu iidie mezi sebu C, D, R, povedechu Zidové sami $k$ sobe W).

Die lateinischen Redewendungen werden im Tschechischen fast immer gut ausgedrückt. Nur in den drei folgenden Belegen sieht man gleich, lass die lateinische Vorlage (wenigstens von einigen Handschriften) wörtlich übernommen wurde - Mt 22,17: quid tibi videatur co ee tobe vidl R, co sé tobé podobno $i$ vidl $S$; ăhnlich Mt 22,41: quid vobis videatur de Christo Co /které $\mathrm{S} / 8 \theta$ vam vidl o Kristu R, S, co sé vǻm zd̊́ o Kristu W; L 14,18: habe me excusatum méj mé omluvena $\mathrm{R}$, omluv $i$ me $S, W ; J$ 2,4: quid tibl et mihi est mulier co tobe a mne jest zeno S, R, W.

\subsubsection{Zusammenfassung}

Die Analyse der Ubersetzungstechnik lateinischer grammatikalischer Kategorien und Redewendungen ins Alttschechische zeigte, dass jer Jbersetzer ein sehr gutes Sprachgefül für die eigene Sprache hatte und ihm nur selten, bei schwierigeren stellen, einige Latinismen unterliefen. Die alttschechische Evangeliarübersetzung ist bei der wiedergabe lateinischer Konstruktionen erstaunlicherweise (im altesten Stadium der Entwicklung der tschechischen Kultursprache) formell nicht vom lateinischen Vorbild abhängig, sondern bedient sich syntaktischer Mittel der eigenen Sprache, durch die (im Archetyp oft besser als in den jüngeren von Korrektoren abgeänderten Abschriften) das lateinische Original dem tschechischen Benützer in hoher Vollendung dargeboten wird. Die Untersuchungen bestätigten die Ergebnisse des vorigen Kapitels (Abweichungen von der Vulgata und Ubersetzungsfehler, s. 4.2.), obwohl die Schlüsse, die man im Hinblick auf das Alter der einzelnen Handschriften ziehen kann, 
nicht so präzise und eindeutig wie oben (siehe 4.2.) sein können. Unsere Handschriften kann man in zwei Gruppen teilen: in der ersten Gruppe sind die älteren Handschriften A, C, D, S, R, die die ältere alttschechische Vorlage relativ treu wiedergeben, wenige Latinismen und gute Ubersetzungen aufweisen; die zweite Gruppe, die Handschrif 1 $w$, weist zahlreiche Latinismen auf und ihre Ubersetzung, obwohl bei der Abschreibung durch Vergleich mit dem lateinischen Text verbesser bedeutet oft als Reaktion auf bereits existierenden Evangeliartext eher einen schritt zurück.

4.4. Die biblischen lexikalischen Einheiten und Termini und die Art ihrer alttschechischen Ubersetzung

Es 1 st vor allem die Art, wie die biblischen Termini übersetzt wurden, festzustellen. Es wird uns weiter interessieren, welche alttschechischen lexikalischen Einheiten die älteste Ubersetzung repräsentieren und welche durch Eingriffe der Kopisten in die Texte gekommen sind. Schon beim ersten Durchlesen der alttschechischen Perikopen sieht man, dass verscheidene lateinische Termini und biblische Ausdrücke an den konkordanten stellen nicht einheitlich wiedergegeben werden. Die Analyse solcher Belege sollte es uns ermöglichen genauere Schlüse über die relative Chronologie und den Filiationsbaum $z$ u ziehen.

Zuerst (4.4.1.) werden die häufigsten biblischen Termini (Dominus, Pharisaeus, publicanus, discipulus, similitudo, usw.), dann (4.4.2) die Ubersetzungen von verschiedenen semantischen Gruppen (Zeit- und Massangaben, Fischereiausdrücke, usw.), weiter die Ubersetzungen einiger Pronomina (4.4.3.), typische Ubersetzungen von Verben (4.4.4.) und letzten Endes verschiedene lexikalische Besonderheiten $(4.4 .5$.$) analysiert.$

\subsubsection{Die biblischen Termini}

D O $\mathrm{m}$ i n u $\mathrm{s}$ - Mt 28,6:Hospodin S, R, W; J 11,21: Hospodine $R$, $D$, Pane $W ; J ~ 11,32$ : Hospodine R, D, Pane $W ; J$ 11,34: Hospodine D, Pane R, W: J 11,39: Hospodine R, D, Pane W; J 20,13: Hospodina W, Păna R, ăhnlich $\mathrm{J} 20,28$ u.a. Die älteren Hss. D, $S$ haben konsequent immer Hospodin, in $R$ und $W$ gemischt Hospodin und Pán, wobei Hospodin in $R$ und $P$ án in $W$ häufiger vorkommt.

d a e m ○ n 1 u m - L 9,1: bessy R, diăbly W; L 11,14: bęsa S, bęs R, diábla W; L 11,15: kniezete 
ského W; L 11,18: běsy R, diábly S, W; J 7,20: bësa R, diábla W; J 8,48: bĕs S, běsa C, D, R, diábla W; u.a. Die ălteren Handschriften haben meist bess (in $S, R$ nur vereinzelt, z.B. in der Perikope Mt 4,1-11 nur diábe 2$)$, die Handschrift $W$ hat nur das jüngere diabbe Einmal wurde durch das Wort diábel auch temptator ubersetzt (Mt 4,3 S, R) - erstens dem Kontext nach und zweitens hatte der alte Ubersetzer noch keinen anderen, besseren Ausdruck gehabt.

d 1 s c 1 p u $l$ u $s$ - wird meist durch das alte ucentk (in $R$ jüngeres uzedln\{k) ubersetzt, z.B. Mt 5,2: ucen\{kuom S, W, R, ibid. Mt 7,15; L 14,16; L 16,1; L 16,19; J 10,1, u.a. Die meisten Belege für dieses wort findet man in der einleitenden Formel vieler Perikopen dixit Iesus discipulis suis, die als rein liturgische Formel im Vulgatatext selbstverständich nicht enthalten ist. Vereinzelt wird ucenik/ucedlnik auch zur Ubersetzung anderer lateinischer worter benützt - I 9,1: apostolis ucenntkov W, R; J 6,45: docibiles uEennfei $W, R$. Ziemlich hăufig, vor allem in den Einleitungsformeln der Lesungen, findet man schon in den älteren Handschriften $S$ und $R$, weniger in der Handschrift $w$ (keinen Beleg haben wir von $A, C$, D, wo die Einleitungsformeln nicht belegt sind - auch ein zeugnis dafür, dass die alttschechische Evangeliarubersetzung in der ersten niedergeschriebenen Form noch nicht den Predigern als Hilfsmittel gedient hat; erst die jüngeren Abschriften $S, R$ - und die auch noch nicht regelmässig - und vor allem Hs. W für die seelsorgenpraxis mit den liturgischen Einleitungsformeln In illo tempore dixit Iesus discipulis suis ausgestattet wurden) die Ubersetzung mladcl aus dem deut-

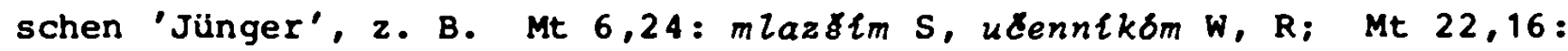
mlazile R, udentky S; L 6,36: mLad8lm R, uđentkuom S, W; L 11,5:

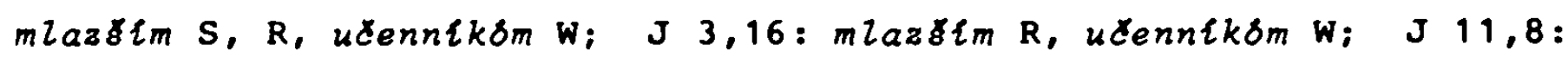

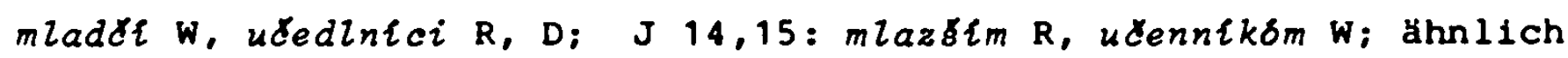
auch $J 14,23 ; J 16,5 ; J 16,23 ; J 16,29$. Auffallend sind die wenigen Belege für mladef in der Hs $W$; dieses wort kommt hier besonders in den Lesungen des Proprium Sanctorum, von denen die meisten in $w$ jünger als die Lesungen aus dem Proprium de Tempore sind, vor (Mt 5,1; Mt 5,13; Mt 9,11; Mt 10,16; L 14,27; L 22,24). In den Lesungen des Proprium de Tempore erscheint in $W$ das wort mladde nur an dre1 Stellen - Mt 18,23; Mc 8,4; J 16,17 (hier auch in S, R!). Diese beschrănkte Anzahl von identischen Ubersetzungen durch mZad\&l (nur drei stellen in $S, R, W$ ) und dagegen ziemlich viele stellen mit

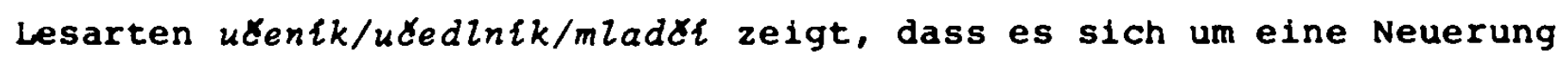
der zweiten Halfte des XIV. Jhs. handeln muss, die am meisten von 
der Handschrift $R$, mässig von $S$ und schon beschränkt von $W$ ubernommen wurde. Es stellen sich zwei Fragen, die man mit unseren jetzigen Kenntnissen noch nicht beantworten kann: wăre die Hăufigkeit des Vorkommens von mladdf in $R$ durch die Deutschkenntnisse des Kopisten erklärbar? 808 der Ubersetzungen durch mladę kommen in den Einleitubgsformeln der Lesungen vor. Wurden diese Formeln aus deutschen Liturgiebüchern übernommen?

p u b 1 i c a n u s - wird meist durch zjêuntk ubersetzt, z.B. Mt 5,46: zeunici $R$; Mt 9,10: mnoho zjeunikov $w$; von dieser alteren Ubersetzung fuhrt ein direkter Weg zum zjevný, zjevný hriesnlk und endlich zum hriesnlk - L 15,1: publicani et peccatores ajevnie $i$ hriesnt w, hriesntci zevnt R, hxiesntci s; L 18,10 und 11,13:

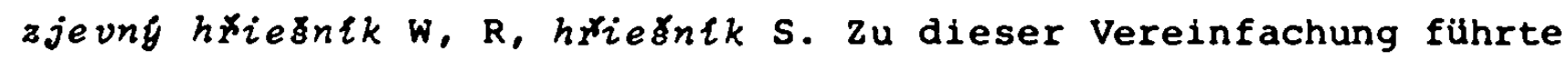
auch die Ubersetzungsweise von $e t h \mathrm{n} i \mathrm{c}$ u zevnlk $\mathrm{s}$ (Mt 5,47) - Mt 18,17: ethnicus et publicanus zjevný hisierntk w, R. Eine alte Ubersetzung hat die Hs. $S$ in $L$ 19,2: publicanorum obecnlkuov, dagegen Mt 9,11: publicanis s vypovedln£ky in $w$ soll wesentlich jünger sein. Die alten Aquivalente sind obecnlk, zjevntk.

P h a r i s a e u s - wird meist durch zákonnlk übersetzt - Mt 12,38: W, A; Mt 15,1:W, R; L 5,17:W, R; L 5,21:W, R; L 15,2: $S, W, R ; J 11,47: W, R$. Nur zweimal in $W$ und in $R$ kommt für Pharisaeus das alttschechische licomernik (vgl. unten bei hypocrita) vor - Mt 21,45: Zicomernkci W; L 18,10: z\&konntk S, W, licomernik R; J 1,24: Zicomérnłci R; J 7,32: zákonntci R, C, D, zákonnłci a lisomerntci $w$.

$h y p \circ c r i t$ a - wird in unseren Texten meist durch licomer$n \ell k$, aber auch anders ubersetzt - Mt 15,7: 2icomérnlci $w$, pokntFent R; Mt 22,18: Zicomerntci R, pokrtnici S; L 6,42: ZicomerntCe S, W, pokrytze R; L 13,15: pokrytci R, pokryti w; (*poknúreny war offensichtlich die Grundlage für poknurnkk im olmutzer Evangeliar und hängt weiter mit dem deutschen 'knurren' zusammen, vgl. dazu V. MACHEK, Etymologický slovnik jazyka Ceského, 2.Aufl.. Pra-

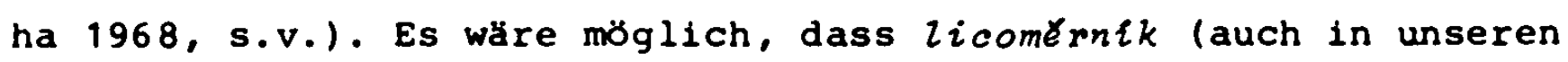
Hss. scheint der Ausdruck nicht besonders alt $2 u$ sein) aus der kirchenslavischen Evangelienübersetzung (von licemerz) übernommen wurde 57 .

$57 \mathrm{Vgl}$. V. KYAS, O.C. (siehe Fn. 35), 40, der vom Einfluss des Prager Emaus-Klosters spricht; - J. HAMM, Hrvatski glagoljasi u Pragu, Zbornik za slavistiku 1 (1970) 84-99. 
s c r 1 b a - wird regelmässig durch plsał (Mt 2,4; Mt 13,52; Mt 21,15 usw.) übersetzt. Nur an einer stelle anders - Mt 23,34: scribas a åkonnŁky S, R. D.

$s$ a $c$ e $r$ o s - wird noch mit dem alten pop, aber auch schon knezz übersetzt - L 17,14: popuom S, knëziem W, R; J 1,10: knez S, R; ähnlich auch principes sacerdotum - Mt 2,4: kniezata popová R, W, kniezata z popóv S; Mt 21,15: kniezata popovå W; Mt $21,45: k n e z t$ W.

p o $\mathrm{t}$ i f e $x$ - alte Ubersetzung war pop - J 19,15 und 21: popové $C_{\text {; }}$ neuere findet man in $W$ und $R-J 11,47:$ biskupi $W, R$.

p r a e c p tor - machte dem Ubersetzer Schwierigkeiten; die älteste und beste Ubersetzung mistr gefiel den Kopisten nicht mehr und so suchte jeder einen anderen Ausdruck - L 5,5: mistye S, R, prikazateli.W (Kalqueübersetzung!); L 17,13: kazateli S, prikazateliw, spasiteli R.

s y n a g o g a - wird meist durch das alte modla (Mt 23,6: W; Mt 23,34: S, R, D; L 13,10: W; J 16,2: S, W, R), nur selten anders übersetzt - Mc 3,1: v skolu S, R, W; Mt 6,2: v chrámiech R. Das letzte Wort chram ist relativ jung, vgl. L 18,10: in templum do kostela S, do kostela t. do chrámu R, do chrámu W; mit dem Wort kostel wird auch e c c l e s i a übersetzt - Mt 16,18: k08tel W; Mt 18,17: kostelu W, cierkvi R.

Die rhetorischen Termini (sermo, mandatum, similitudo, proverbium, parabola) werden vor allem in der Handschrift $R$ ziemlich einheitlich übersetzt; dagegen hat die Handschrift $S$ noch viele alte Ausdrücke.

m a n d a t u m - Mt 22,36: kázanie S, príkázanie R, W; Mt 22,38: prikázanie S, R, W; J 14,21: płikázanie R, kázanie W; J 14,31: kázanie S, W, prikázanie R.

se r mo - J 4,41: pro kăzanie R, pro kazen W; J 8,37: kázanie $R, W ; J$ 8,43: slova mého R, W; J 14,24: prikázanie S, R, slovo W. p a r a b o l a - Mt 15,15: povesst R, W; L 14,7: poverst $S, R, W$; L 15,3: povest S, R, W.

s i m i l i t u d o - L 6,39: podobenstuie S, R, W; L 8,4: rovenstuie (alt!) S, A, podobenstvie R.

prove r b i u m - J 10,6: prislovie R, slovo W; J 16,25: $u$ prikladiech $\mathrm{S}, \mathrm{W}, u$ prislovi R. 
Die abstrakten religiobsen Termini (gloria, veritas, iustitia, pax) werden meist noch mit den alten Ausdrücken (chvala, pravdal viera, pravda, $m(r)$ übersetzt, nur in $R$ und $w$ dringen neue worter durch:

g $1 \circ \mathrm{r} 1 \mathrm{a}$ - chvala Mt 6,29; Mt 16,27; L 2,14; L 2,32; L 14, 10; J 1,14; J 2,11 usw., nur einmal in $W$ anders - I 24,26:v kraLovstuie sve.

V e $r$ i a $s$ - pravda L 4,25; J 1,14; J 3,21; J 4,23 usw.; aber Mt 22,16: v spravedlnosti $R, u$ pravde $S$; $J$ 8,32: viera (alt!) A, R, pravda W.

i u s $t$ t 1 a - pravda Mt 3,15; Mt 5,20; J 16,8; J 16,10; aber Mt 6,1: odplaty R; Mt 6,33: spravedlnosti S, W.

p a x - älter mir, neu pokoj - L 2,14: mir S, pokoj R, D; L 10,5: mier W; I 10,6: pokoj W; J 14,27: mlr...mlr S, R, mir..pokoj W; J 20,19: mir S,W, R; J 20,21: pokoj a mir S, W, R; J 20,26: mir R, mir a pokoj w.

m y s t e r 1 u m - L 8,10: mysterium regni Dei vĕst/celost $R /$ kralovstuie Bozieho S, R. Der Schreiber der Handschrift R, der keinen lateinischen Text $z$ um Vergleich benüzte, brachte das Wort vĕst der Vorlage mit dem Adj. verst, - $a,-0$ 'sicher' (vgl. z.B. die alttschechische Alexandreis, Veiter Bruchstück, Vers 5966 řð věstu) in Verbindung und darum ersetzte er es durch celost 'Sicherheit'.
a $m$ e $n$ (a m e $n$ a m e $n$ )
C - zaverrné zajisté (1x, J 8,51)
D - zavěrné zajisté $(1 \mathrm{x})$, zajisté $(1 \mathrm{x})$, vèrnè $(1 \mathrm{x})$
S - vèrnè jisté $(2 \mathrm{x})$, cele jisté $(1 \mathrm{x})$, jisté $(2 \mathrm{x})$, zaverrné $(1 \mathrm{x})$
$\mathrm{R}$ - zavèrné zajisté $(11 \mathrm{x})$, vèrnè zajisté $(2 \mathrm{x})$, zajisté a zapravé $(1 \mathrm{x})$, jiste $(3 \mathrm{x})$, cele $(1 \mathrm{x})$
w - zavěrné zajisté $(11 x)$, věrnè jistè $(4 x)$, jistè $(2 x)$, zajisté cèle $(1 \mathrm{x})$

Am häufigsten kommen die Ausdrücke zaverrné zajisté (etwa 30x) vor: die Verbindung zavérné zajisté war dem Schreiber der Handschrift $R$ (oder schon des Hyparchetyps $x_{1}$ ) so geläufig, dass er auch den anderen lateinischen Text so ubersetzte - J 6,56: vere...vere zajisté zavërné $R_{i}$ am ältesten sind wahrscheinlich cẻle und jisté (vgl. auch Gebauer, slovnik starocesky, s.v.). Auf die Filiation der Handschriften unserer Evangeliarübersetzung kann man aus dieser lexikalischen, obwohl interessanten und gewisse Anhaltspunkte doch darbietenden 
Teilanalyse (also aus der Verteilung der Lesarten) keine genaueren Schlüsse ziehen ${ }^{58}$. Die Anzahl der Ubersetzungsmöglichkeiten in den Hss. $R, W$ bestätigt aber doch unsere Feststellung, dass diese beiden Handschriften im lexikalischen Bereich die meisten Neuerungen (und nicht nur bei amen-Ubersetzungen) gegenüber den Vorlagen und der ălteren Ubersetzung eingeführt haben.

e c c e

$A-\operatorname{ova}(1 \mathrm{x})$

$C-a j(1 \mathrm{x})$

$D-a j(4 x)$, tehdy $(1 x)$, nebo zajisté (1x)

S - sĕova $(18 \mathrm{x})$, tehdy $(2 \mathrm{x}), v$ tu dobu $(3 \mathrm{x})$, tede $(1 \mathrm{x})$

$\mathrm{R}-a_{i}(21 \mathrm{x})$, tehdy $(2 \mathrm{x}), v$ tu dobu $(3 \mathrm{x})$, tede $(2 \mathrm{x})$, jakoz $(1 \mathrm{x})$

$w-e \bar{z}(5 x), t^{\prime}(10 x), t e h d y(3 x), v$ tu dobu $(1 x), v i z(2 x)$, aj $z x_{i}(1 x), t u(1 x)$

Im Gegensatz zu JANACEK 58 wagen wir nicht, aus den Verschiedenheiten in der Ubersetzung von ecce für die Filiation der Handschriften irgendwelche Schlusse zu ziehen. Es ist aber interessant, dass in der Hs. $W$ in den Lesungen des Proprium Sanctorum, das unserer Meinung nach (wenigstens bei einigen Perikopen) jüger als die Lesungen des proprium de Tempore ist, das Wort ecce einmal ez̃ (Mt 19,27) und einmal tot' (Mt 12,46)- also durch typische W-Ubersetzungen - wiedergegeben wurde. Dies ist ein Zeugnis dafür, dass die meisten Perikopen des Proprium Sanctorum von demselben Autor wie die Perikopen des Proprium de Tempore stammen, oder genauer gesagt, von demselben Korrektor, der die unmittelbare Vorlage $x_{3}$ mit Hilfe eines lateinischen Textes uberarbeitete. Bei diesen korrekturen der Vorlage, die vielleicht schon einige Lesungen des proprium Sanctorum hatte (die Ubersetzung von einigen Perikopen im Proprium Sanctorum ist eindeutig älter, einige sind wieder jünger, vgl. 4.4.6. und 5.1.), wurden wahrscheinlich anhand eines Missals auch die anderen übersetzt. Die Meinung Janáceks ${ }^{58}$, dass die Hs. $W$ in zwei verschiedenen Ubersetzungsteile zerfällt und die Lesungen des Proprium Sanctorum in $w$ zur Gănze von einem anderen Ubersetzer stammen, können wir nicht bestätigen. Die Lesungen des Proprium Sanctorum in der Handschrift $w$ wurden mindestens in zwei, vielleicht auch in mehreren Etappen ubersetzt und zusammengestellt.

58 K. JANAČK, K otázce... (Fn. 33), 445-449, wagt auch nicht, auf Grund ăhnlicher amen-Ubersetzungen und ihrer Analyse irgendeine Hypothese über die Filiation der Evangeliarhandschriften aufzustellen (schon aber auf Grund der ecce-Ubersetzungen!). 
4.4.2. Die Zeit- und Massangaben, die Wirtscheftstermini, die Krankheiten, die Fischereitermini, die botanischen und zoologischen Termini

Die Massangaben werden durch die alttschechischen Ausdrücke wiedergeben - Mt 18,24: decem milia talenta deset tisicóv funtuov S, $W$, deset tisicóv $R$ (funt aus dem mhd. pfunt = talentum, libra); J 19,39: libras centum liber sto $C_{i}$ L 16,7: centum choros tritici sto kuorcuov płenice /t. mĕr add. $R / S, R, W$. Nicht genau wird dann übersetzt, wenn man für die biblische Massangabe keinen entsprechenden alttschechischen Ausdruck oder kein entsprechendes Mass kannte - L 16,6: centum cados olei sto varent/vah R, fontoov W/ oleje $S$, $R$, $W$; auch bei den Entfernungsangaben stimmen die biblischen Angaben mit den alttschechischen nicht überein, z.B. das alttschechische mile 'Meile' in der Hs. W entspricht nicht (als zu grosse Entfernung، vgl. Gebauer, Slovnik staročeský, s.v.) dem lateinischen stadium L 24,13: stadiorum sexaginta sestdesat mil/honöv R/ W, $\mathrm{R}$ (richtig schon in $J 11,18$ : stadiis quindecim $u$ patndcti honech $R, D, W$ ).

Die Zeitangaben, die allgemein bekannt waren, wurden durch entsprechende alttschechische übersetzt, die weniger oder nur ungefahr verstandenen durch nicht immer genau entsprechende Ausdrücke ersetzt - J 19,31: parasceve patek C (es geht schon un einen Freitag, aber um einen bestimmten - um den Rüsttag vor Pascha). Sabbatum wird immej als sobota 'Samstag' úbersetzt (als jüdischer Festtag, obwohl man in christlichen Milieu nedele 'Sonntag' erwarten würde), nur an zwei Stellen anders - J 5,9: den nedélsky W ('Ruhetag, Sonntag'); L 18, 12: bis in sabbato dua dny z nedéle $\mathrm{S}$, dua dny nedele $\mathrm{R}$, dua dny $v$ tyden $(=$ 'in der Woche'). Die lateinischen Bezeichnungen der zeitabschnitte des Tages nach Erscheinungen, die fur den bestimnten zeitabschnitt typisch waren (galli cantu, vigilia noctis usw.) werden geschickt und mit Bewahrung der Semantik des lateinischen originals ubersetzt - Mc 6,48: circa quartam vigiliam noctis ve ztvrtej ciesti R ('im vierten Teil'); Mc 13,35: galli cantu v kury W ('zum Hahn', es versteht sich 'zum Hahnschrei'); J 8,2: na zabredeni $W$ ('in der Morgendämmerung'). Das lateinische hora wird durch das alttschechische cas und hodina (vereinzelt durch doba, chvile) übersetzt. Es gibt 36 stellen in unseren Handschriften (nur konkordante Stellen, nicht insgesamt), wo hora vorkommt. Wir werden in der folgenden Ubersichtstabelle die Hăufigkeit der alttschechischen Aquivalente von hora in einzelnen Evangeliarhandschriftenndemonstosieren: 


$\begin{array}{lrrrr} & \text { cas } & \text { hodina } & \text { chvile } & \text { doba } \\ \text { C } & - & 1 \mathrm{x} & - & - \\ \mathrm{D} & 3 \mathrm{x} & 1 \mathrm{x} & - & - \\ \mathrm{S} & 8 \mathrm{x} & 5 \mathrm{x} & - & - \\ \mathrm{R} & 12 \mathrm{x} & 14 \mathrm{x} & - & 1 \mathrm{x} \\ \mathrm{W} & 11 \mathrm{x} & 4 \mathrm{x} & 1 \mathrm{x} & 2 \mathrm{x}\end{array}$

Diese Ubersicht zeigt, dass $c_{a s}$ (mit Ausnahme von R) immer noch häufiger als hodina ist. Diese Feststellung ist darum wichtig, weil in der ersten Redaktion der alttschechischen Bibelubersetzung (aus der zweiten Hälfte des XIV. Jhs.) das Verhältnis der Frequenz von cas und hodina gerade umgekehrt ist. ${ }^{59}$ Durch die festgestellte Aufteilung dieser zwei Ubersetzungen von hora in unseren Texten wird ein weiterer Beweis des hohen Alters dieser Evangeliarübersetzung geliefert. Die Frequenz von $\chi_{a s}$ und hodina in der Hs. $\mathrm{R}$ bestatigt wieder, wie schon in anderen Fällen, dass diese Handschrift, was den Wortschatz betrifft, die am meisten fortgeschrittene und modernisierte ist. Es wäre noch hinzufügen, dass nur wenige von VRASTIL 59 zitierte Belege für das alttschechische $c_{a s}$ (er betrachtet es als einen Palăoslovenismus in der Bedeutung 'Stunde') wirklich die Bedeutung 'Stunde' haben - meist handelt es sich bei ihm um Belege in der Bedeutung 'zeit, Weile' und daher um keine Paläoslovenismen. An solchen Stellen, wo es um eine genaue zeitangabe geht (in Verbindung mit einem Numerale), haben die Evangeliare immer nur hodina - J 4,6: sesta hodina $R_{i} J$ 4,52: heri hora septima viera $v$ sedmu hodinu $W$, 8 noci s poledne (?) $S, R$; $J$ 11,9: dvankst jest hodin $W, R, D$, usw.

Die Wirtschaftstermini sind nicht so haufig; nehmen wir zur Illustration nur den Bereich 'ein Herr und sein Diener': das lateinische pater familias wird noch mit den alten alttschechischen Wortverbindungen otec deledinny/otec delednt (Mt 13,52: W; Mt 20,1: W, R; L 12,39: W; L 14,21: R, W) oder otec domovity (Mt 20,11: S, R) übersetzt. Die anderen alttschechischen Ausdrücke wie pan (L 14,21: S) und hospodar (Mt 21,33: W) sind in dieser Bedeutung wesentlich jünger, vor allem das Wort hospodar. Das lateinische minister wird am häufigsten durch das alttschechische sluha übersetzt - J 7,45: $R, D ; J 7,46: D, R, W$; es kommt aber als Aquivalent auch služebnik (Mt 23,11: W; J 12,26: R), panoze (J 7,45: W) und pos lužntk

$59 \mathrm{Vgl}$. J. VRASTIL, Vyznam nejstrých starođeských souvislych textú evangelijnich pro otázku o vlivu bible staroslovénské na staroCeskou, in: Slovanske studie (Vajs' Festschrift), Praha 1948, 169-173, besonders S. 171 . 
(Mt 23,11: R) vor.

Die Bezeichnungen der Krankheiten waren dem ersten Ubersetzer oft nicht verständlich und darum findet man in den alteren Evangeliaren S, R Lösungsversuche entweder entsprechend den ältesten medizinischen Vorstellungen, z.B. hydropicus vodné tele ('Wasserwurm'), oder verallgemeinernde Ausdrücke (paralyticus, leprosus = nuzný). Erst die jüngere Hs. W bringt falls noch nicht schon Termini, dann wenigstens entsprechende erklärende Umschreibungen (hydropicus nemoc vodna mezi masem a közil.

l e p r o s u s - nuzný (Mt 8,2: S, R; L 4,27: R; L 17,12: S, $\mathrm{R})$; malomocny an denselben stellen in $\mathrm{W}$; pracny Mt 10,8: $\mathrm{W}$.

I e p r a - Mt 8,3: mundata est lepra elus by ¿ist zivot jeho

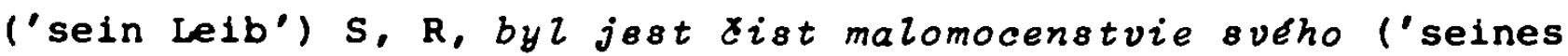
Aussatzes') W. Der Archetyp übersetzte dem Kontext nach, die Bedeutung des Ausdrucks Lepra war noch nicht bekannt.

p a $r$ a 1 y $t$ i u $s$ - Mt 9,2: nemocný $S, R$ (die Hs. $S$ hat hier noch eine Ergănzung, die in Latein und in $\mathrm{R}$ fehlt - jmejjieze nemoc jesto slóve dna); I 5,18: nuzný R, nemocny W; L 5,24: pracny $R$, nemocny $w$.

hy d $r \circ p i$ c u s - I 14,2: hydropicus erat mejieze v sobe vodné tele ('einen Wasserwurm' vgl. dazu MACHEK, EtymologickÝ slovnlk jazyka Ceského, s.v.) S, R, nemoc vodnú mezi masem a köž ('Wassersucht') $w$.

Die Fischereiterminologie war nicht nur dem alten Ubersetzer, sondern auch den spateren Kopisten und Korrektoren fremd. Nur auf diese Welse ist es erklärbar, dass gerade in solchen stellen Archaismen (z.B. I 5,2: piscatores rybitvi S) vorkommen; die Kopisten waren mit dieser Materie sehr wenig vertraut und darum fürchteten sie, die Vorlage zu ändern. Es wurden dabei aber nicht nur Archaismen, sondern auch Ubersetzungsfehler und Ungenauigkeiten ubernommen - L 5.3: a terra reducere pusillum aby pristúpil malo $k$ ze$m i \mathrm{~S}, a b y$ pristripil k nému mdlo R, W (vgl. Mc 6,53: adplicuerunt pristupichu R!): I 5,4: duc in altum et laxate retia vaved' vahoru oslabtez sieti /puste site W/ S, R, W; Mt 4,21: reficientes retia dospievajice elte $W$ (gelesen und ubersetzt: perficientes).

Die botanischen und zoologischen Termini wurden nicht genau und einheitlich wiedergegeben - besonders in solchen Fällen, wo es 
sich un fremde Realien handelte - Mt 7,16: de tribulis s 8lpku S, $z$ hlozie R, z rostu W; L 21,19: flculneam fik S, vinice R; L 11,

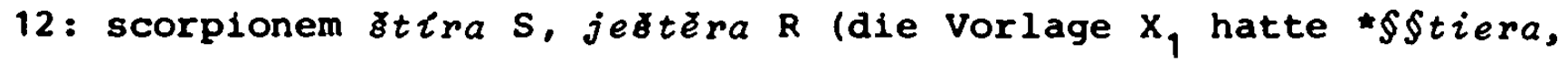
unrichtig korrigiert), skerupinu $\mathrm{w}$.

\subsubsection{Die Pronomina}

Die Analyse der Art ihrer Ubersetzung wird den zwei am hăufigsten vorkommenden pron., nămlich dem Pron. Indef. omnis und Pron. Neg. nemo, gewidmet.

- $\mathrm{m} n \mathrm{~s}$ als ,pronomen indefinitum' kommt in den Evangelien recht hăufig vor und wird in der alttschechischen Ubersetzung vielfälig

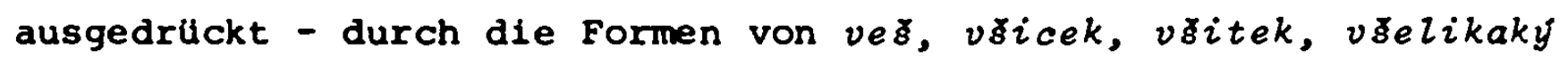
(letztes öfters in $R$ ) und im Plural dann besonders durch die Formen $v 8 i c h n i$ (oft in $\mathrm{S}, \mathrm{R}$ ), $v z_{i}{ }^{\mathrm{c} k n i}$ (besonders in $\mathrm{W}$ ). Fur Masc.Sing. wird in der Hs. $R$ vorwiegend kazdy (nur selten in $S, W$ ), in $W$ dagegen $v z_{e}-$ liky, in $S$ oft (teilweise auch in $w$, aber nicht mehr in $R$ ) noch ein Archaismus proknt (2.B. Mt 5,22: S; Mt 19,29: W; L 14,11: S; L 18, 14: S; J 3,8: W) benützt.

$n$ e $m$ o wird in unseren Texten durch füf alttschechische pron. Neg. Ubersetzt: nikte ijeden izadny nizddny zadny D

S

$\mathbf{R}$ $2 \mathrm{x} \quad 1 \mathrm{x}$ $3 x \quad 3 x$

R $\quad-9 x$

W $12 x \quad 2 x$

$x$

$\begin{array}{rrr}- & - & - \\ - & - & - \\ 4 \times & - & 5 x \\ - & 7 x & 2 x\end{array}$

Die zwei älteren Hss. D und $s$ haben nur die älteren worter nikte, ijeden; die Hs. W hat eher noch die alteren worter und meldet dabei die pronominale Negation durch $t$-; Die Hs. R bevorzugt die Negation durch $n i-$, und bedient sich schon relativ oft des jüngsten Negativpronomens żdný. Für die Filiation der Evangeliarhandschriften: aus der Ubersetzungsweise der Pronomina omnis und nemo kann man feststellen, dass die Hss. D und $S$ alter als die $R$ und $W$ sind. Die Hs. R benützt mehrere jüngere Ausdrücke im Vergleich mit der Hs. W, die - obwohl jünger als $R$ - in dieser Hinsicht eher konservativ ist. Die konservativsten Hss. sind $D$ und $S$.

\subsubsection{Die Verba}

Die Analyse der Ubersetzungen der Verba wird sich vor allem

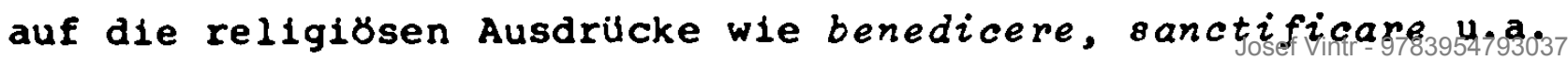


(unter 4.4.4.1.) und auf einige unklare Belege (4.4.4.2.) konzentrieren. Die anschliessende Ubersicht (4.4.4.3.) soll zeigen, ob die einzelnen Hss. bei den Verba Modernisierungsversuche unternomen haben.

4.4.4.1. Es ist anzunehmen, dass gerade bel den Verba, die für die Evangelien typisch sind, ziemlich alte Ubersetzungen erhalten blieben.

a $\mathrm{d}$ o $\mathrm{a} \mathrm{r}$ wird überwiegend durch nasledovati übersetzt - $3 x$ in $S, 1 x$ in $D, 9 x$ in $R, 6 x$ in $W$. Es kommen aber auch viele andere Ubersetzungen vor - Mt 2,8: chvalu vzdam S; Mt 2,11: poruęchu se S, R, pomodlichu se W; Mt 4,9: pokloniz se S, R; Mt 8,2: prosi S, R, W; Mt 20,20: nazievajici W, R; J 12,20: modlizi se R. Die alten Ausdrúcke (chvalu vadati, modliti ser, pokloniti sel) findet man in $s$ und R. Es könnte sich um die durch eine lange phase nur mulndlicher Uberlieferung schon selten gewordenen Bindeglieder der alttschechischen und alttschechischen Perikopenubersetzung handeln.

b e n e d i c e r e - L 2,34: blahoslavieže S, blaze R, D (sehr alt); alle anderen Belege weisen schon jüngere Aquivalente aus Mt 5,44: dobre diñte R; L 1,64: chvale W; L 2,28: chvalése W; L 24,30: požehna W, $R ;$ b e $n$ e d $i$ t u $s$ wird meist blažený, selten blahos laveny übersetzt.

c l a $r i$ f $i$ a $r$ e wird in den älteren Hss. durch oslaviti übersetzt, in der Hs. W wurde aber dieses Verb unrichtig nach der konkreten Bedeutung des lateinischen Wortes auf odistiti ausgebessert - J 12,23: aby oslaven by Z R; J 12,28: oslav..oslavil sem ..oslavim R; J 16,14: oslavi S, R, odistl W; J 17,1: oslav... oslavil D, R, odisti...odistil W; ibid. J 17,4; J 17,5; auch in der Wortfamilie wurde in $\mathrm{W}$ korrigiert - J 17,10: clarificatus os $l a-$ ven D, R, odiżen W; J 17,5: claritatem slavenim D, R, distotú W. Nur einmal findet man in $W$ das altere Wort oslavil $(J 21,19)$. Dieser Beleg ist sehr wichtig und erlaubt uns folgenden schluss: die betreffende stelle befindet sich im nur in $W$ vorhandenen Proprium Sanctorum und beweist, dass die Lesungen des Proprium Sanctorum nicht alle erst für $w$ übersetzt wurden, sondern dass es schon eine altere Ubersetzung wenigstens einiger Perikopen des Proprium Sanctorum gab. Gleichzeitig zeigt diese stelle, dass nicht alle Perikopen der Hs. W im denselben Masse verbessert worden sind.

s a l u $t$ a $r$ kommt nur dreimal vor, aber alle alttschechischen Aquivalente sind alt - Mt 5,47: pakli sdravie vdabat Rat 


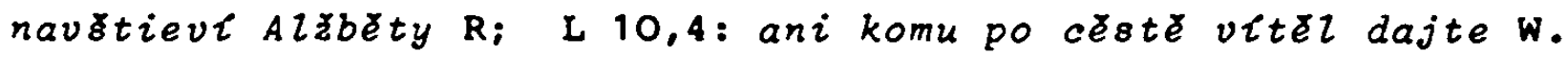
s a $n$ c $t i$ f $i$ a $r$ e hat ebenfalls nur drei Belege - J 10,36: osvětil W, R; J 17,17: svĕt' $R ; J$ 17,19: osvěcuji..osvéceni $R$. s e $q u i$ wird meist durch die Verbindung jiti po + Lok. 'jemandem nachgehen' und seltener durch ndsledovati + Akk. 'jemandem folgen' übersetzt. Die zwei folgenden Belege zeigen, wie die Ubersetzungen verschiedener stellen aufeinander Einfluss ausüben und wie aus einer Rektion eine neue entstehen kann - J 12,19: mundus totus post eum abiit suet vesken jde po nĕm $R_{i} J$ 8,12: qui sequitur me ktoz $j d e$ po mne R, D, kto nasleduje po mer $W$.

4.4.4.2. Die semantisch unklaren Stellen bei den Ubersetzungen der Verba sind auf solche beschrănkt, die auch im lateinischen Original nur wenig frequentiert sind - Mt 18,8: si...pes tuus scandalizet te pakli...noka tvd te tixl $w$; das lateinische scandalizare wird in unseren Texten sonst anders übersetzt - Mt 18,6: obludil W; Mt 18,9: prezlżije W: Mt 15,12: zrazeni süW, zradu jmajl R; J 16,1: nezbluzovali S, R, nezrazovali w. Das Verb tiřeti kann man mit dem alttschechischen tirati 'treiben' in zusammenhang setzen, aber es könnte auch týrsti sein und dann von týrati 'quălen' stammen. Eine andere unklare stelle - L 24,16: oculi autem illorum tenebantur obi jejich biechu pozly (in marg. von späterer Hand zaderzeny) $w$; das Wort poßly ist schwer erklärbar, vielleicht hatte die lateinische Vorlage anstatt tenebantur eine andere Lesart (interibantur, peribantur?), denn Fehlabschreibungen aus der alttschechischen Vorlage findet man in $w$, im Gegensatz $z u$, gar nicht. Die Form porokovdchu in Mt 22,19: obtulerunt ei porokovdchu jemu R, prines $l i m u S$, wăre wahrscheinlich als eine fehlerhafte Abschreibung zu erklären; in der noch mit der alteren Orthographie geschriebenen $x_{1}$ alttschechischen Vorlage für $R$ stand etwa *porucowachu (= porucovachu 'darbieten').

4.4.4.3. Die Modernisierungen bel den Ubersetzungen der Verba werden wir vor allem in den drei umfangreichsten Hss. S, R, W suchen. Die nicht-terminologisierten Verba dieser Hss. stellen verschiedene Stufen der Modernisierung dar. Wăhrend die terminologisierten Verba in $S$ und $R$ sehr alt sind, findet man bei den Bezeichnungen für alltăgliche Handlungen die alten Ausdrücke nur in $S$, aber in $W$ und besonders in $R$ kommen schon neue zeitgemásse Verba vor - Mt 5,23: of-

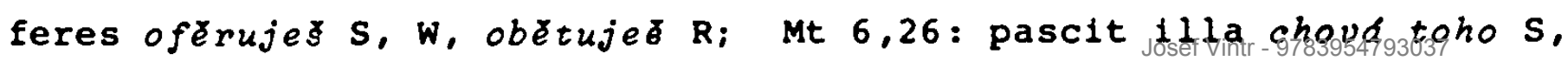


pastvi je W, pase je R; MC 8,8: sustulerunt podjeli s, podvizechu W, advihli R; L 18,9: aspernabantur ceteros pýchachu jinymi $S$, praviechu jinym R, prave $j i m w$ (in $R, W$ gemeinsamer Fehler aus dem Protograph $\mathrm{x}_{0^{\prime}}$ pychati schon im Protograph nicht verstanden?); $J 10$, 31: ut lapidarent eum aby nañ bili R, aby jej kamenovali $W$; $J$ 16,6: tristitia implevit cor vestrum sámutek srdce vaze najde $\mathrm{S}, \mathrm{smutek}$ važe srdce nadejde $\mathrm{W}, \mathrm{s}$ amutek vă naplnt srdce vałe $\mathrm{R}$. In der Hs. $\mathrm{R}$ findet man oft noch die alte mit der neuen Form nebeneinander, durch eine Abkürzung $t$. (= totiz 'nämlich') verbunden. Diese Stellen von $R$ deuten die Möglichkeit einer glossierten alttschechischen Vorlage $\left(x_{1}\right)$ für $R$ an, in der die neueren Ausdrücke in margine notiert wurden. Bel der Abschrift hatte dann der Kopist die Möglichkeit, entweder die alte Form oder die neuere oder beide zu übernehmen. Wir wollen diese Behauptung mit einigen Belegen dokumentieren - I 14,4: tacuerunt nerku i slova S, mleechu t. nerozumęchu R, mliichu W; J 7,49: maledicti sunt zloxedeni t. kleti jsu R, prokleti su w; loft atch bei den Nomina, z.B. L 19,45: speluncam latronum jeskyni t. pelesi lotroví $\mathrm{R}$, kotec lotrovy $\mathrm{S}$, pelež lotrovski W, u.a.).

\subsubsection{Die lexikalischen Besonderheiten}

Die Gruppe von lexikalischen Besonderheiten, die hier behandelt wird, umfasst einige Ungenauigkeiten und Fehlübersetzungen (4.4.5.1.) und weiter einige Belege mit sehr alten Ausdrücken (4.4.5.2.). Die Analyse dieser einzelnen Belege soll nicht nur das Gesamtbild des Wortschatzes unserer Denkmäler ergänzen, sondrn auch die schon erzielten Resultate über Alter und Entstehungsprozess dieser Texte durch neue Erkenntnisse prăzisieren und erweitern.

4.4.5.1. Es ist erstaunlich, wie wenige Ungenaulgkeiten bei der Reproduktion der lateinischen worte mit ihrer dem wissen des damaligen Gebildeten oft fernstehenden Semantik in diesen nicht gerade kleinen Evangeliarhandschriften erscheinen.

Falls die Bedeutung des lateinischen Wortes dem Ubersetzer nicht ganz klar war, ubersetzte er es mit einem allgemeineren Ausdruck (vgl, auch die Bezelchnungen der Krankheiten, 4.4.2.), z.B. Mt 13,45: margaritas kamenie ('steine') $w$ anstatt perly 'Perlen'; J 2,17: zelus domus tuae duch domu svẻho W, R ('Geist') anstatt horlivost 'Elfer'; $J$ 8,20: locutus est in gazofilacio docens in

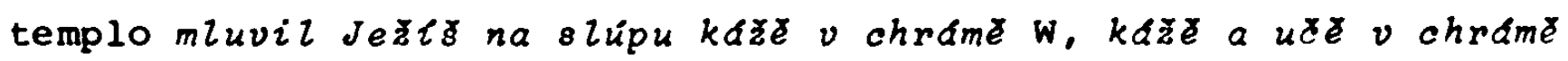


R, D (in der Kirche wurde von der an einer săule - na slupu - angebrachten Kanzel ausgepredigt, darum so $w$ anstatt des richtigen u pokladnice 'bel der Schatzkammer'; die unklare Wortverbindung wurde in $R, D$ einfach weggelassen). In einigen Fällen übersetzte er bel einem unklaren Wort durch Ubernahme seiner wortbildenden Motivation - Mt 1,11: in transmigratione Babylonis na prénesenie Babylona W: L 21,9: prodia et seditiones boje a sedanie W (sedanie = 'Ritterspiele'), u.a. Nur selten wurde das nicht verstandene Wort nicht übersetzt und einfach ubernommen - Mt 12,42: regina austri kralove austri $w$; Mt 2,16: occidit omnes pueros...a bimatu $z b i$

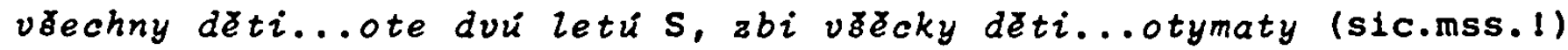
$D, R$ (in der Vorlage stand etwa *ot bymatu).

An einigen für den Ubersetzer schwierigeren stellen findet man eine ungefahre oder fehlerhafte Ubersetzung, nachdem das Wort schon anderswo richtig ubersetzt wurde - J 10,23: in templo in porticu Salomonis $v$ chrámè u vochode $/ v$ obchode $\mathrm{W} /$...Salomúnover $\mathrm{R}, \mathrm{W}$ (hier richtig 'im Rundgang'), und dagegen nur aus dem Kontext eine unge-' naue Ubersetzung in $J$ 5,2: piscina...quinque porticus habens rybnlk ...pét ostrovóv ('Insel') $v$ sober maje $\mathrm{R}, \mathrm{W} ; \mathrm{I}$ 14,5: in puteum $v$ duol S, R, $v$ studnici neb $v$ dö $\mathrm{W}$, aber fehlerhaft schon in $\mathrm{J}$ 4,11: puteus altus est okov vysoko jest $\mathrm{R}$, J 4,12: puteum okovy $\mathrm{R}$ (an beiden stellen in $R$ in der Bedeutung 'Kubel') - die Ubersetzung war wahrscheinlich schon in der Vorlage fehlerhaft - etwa *döl vysoko jest; diesen Fehler hat dann ein Glossator mit der Glosse okov nach seiner Meinung beseitigt - wenn der kubel hoch steht, muss der Brunnen tief sein; die Glosse okov wurde dann in die Abschrift ubernommen.

Durch eine Verwechslung zweier lateinischer Worte entstehen bei der Ubersetzung auch Fehler - Mc 6,21: dies oportunus bezděrný den $w$ - wurde mit importunus = bezdexny' 'unfreiwillig' (vgl. GEBAUER, slovn (k starołeský, s.v. bezdęný) verwechselt.

Durch mangelhafte Interpretation einer lateinischen Wortverbindung wird dann auch fehlerhaft ubersetzt - L 16,24: ut intinguat

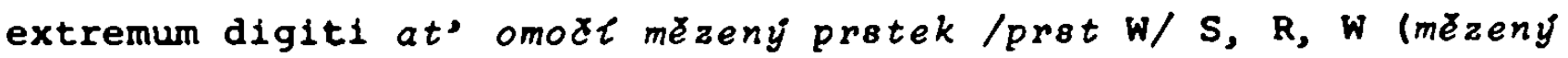
prstek ist eine Bezeichnung für einen Ringfinger, richtig wăre *konec protu' 'Spitze des Fingers').

Unklar ist folgende Stelle - L 1,7: esset Elisabeth sterilis bieze Elzbęta zákona $w$ - denn die Erklärung von VAŚICA als *zatkand (von aksl. zatbkati 'obturare') 60 stimmt unserer Meinung nach 
nicht. Es handelt sich un eine Fehlabschreibung des Wortes yaloua = jalova (so z.B. in der Handschrift S, L 1,36); ein y mit einem 3 , ein $l$ mit einem $k$ und ein $u(=v)$ mit einem $n$ waren leicht verwechselbar und auf diese Weise musste zakona (sic ms.) in der Handschrift $w$ zustandekommen.

Als Fehlinterpretationen der tschechischen Vorlagen sind einige Stellen zu bezelchnen, wo die Kopisten das alte oder fremde Wort nicht mehr verstanden, z.B. I 2,34 : in ruinam $v$ obidu S, D, u biedu (l) R; Mt 2,11: murram myrru S, R, mieru (l) W.

4.4.5.2. Die folgenden Belege stellen eine nur auf die meist sehr alten lexikalischen Besonderheiten aus unseren Handschriften begrenzte Auswahl dar:

p a $v 1$ a $k$ a, p a v l a ¿ n $Y$ - l 16,19: induebatur purpura et bysso obladieže sè u paviaky $S$, u paviadné rucho $R, v$ aksamit $i$ u postavee $W$ - es sind in $S$ und $R$ alte worter. Auf den ersten Blick könnte man meinen, dass es sich hier um einen palaoslovenismus handelt, denn das Wort pavlaka ist sogar in einem mit Bohmen verbundenen Denkmal - in der Vita palaeoslovenica s. Venceslai recentior seu Nikolskiana, vgl. Prager akademisches Altkirchenslavisches worterbuch s. v. - belegt. Es ist aber eher in VencNik ein Bohemismus, weil das wort bfters auch in den anderen jüngeren alttschechischen Denkmälern vorkommt (vgl. Klarets worterbücher u.a.).

p o d r a $h$ - Mt 23,5: phylacteria et...fimbrias podolky své a...podrahy $R, W$ (vgl. podragb im Prager Altkirchenslavischen worterbuch) - es ist ein klarer Palăoslovenismus. 61 Die Handschriften $R$, $W$ ubersetzen eigentlich nur fimbrias durch zwei synonymische Ausdrücke podolky, podrahy, wobei das zweite nicht mehr verstanden wurde. Das lateinische phylacteria blieb auf diese Weise unubersetzt. Diese stelle ist ein zeugnis dafür, dass die alteste alttschechische Evangellarübersetzung in irgendeinem - obwohl recht lockerem - Zusammenhang mit einer altkirchenslavischen Version der Evangelien- oder Evangeliarubersetzung gestanden sein muss; es wăre denkbar, dass mindestens bel schwierigeren stellen schon beim Entstehen des alttschechischen Archetyps ein kirchenslavi-

61 wie vom lexikalischen Archiv des Alttschechischen worterbuchs an Institut fur tschechische Sprache der CSAV in Prag bestatigt wird, ist das Vorkommen des Wortes podrah im Alttschechischen nur auf Evangeliare beschränkt - ausser in $R$ und $W$ kommt es an derselben Stelle noch in zwei Evangeliaren der zweiten Ubersetzungsredaktion, im Olmutzer- und Ctenie kneze Benesovy-Evangeliar vor. 
scher Text (des XII., XIII. Jhs.) 62 konsultiert wurde (vgl. uber Aufenthalt russischer Priester in Böhmen, 3.2.).

$\mathrm{p} \circ \mathrm{n}$ a $\succ i \mathrm{n}$ - Mt 9,12: non est opus nenie ponadin $\mathrm{w}$ (aber in $\mathrm{J} 2,25$ : opus non erat nebieße treba $W, R)$; $J$ 16,30: non opus est

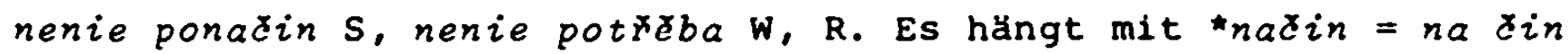
'auf richtige Weise.63 zusammen; nadin kommt bis heute in mährischen Dialekten vor und auch ponadin ist aller Wahrscheinlichkeit nach ein alter Moravismus.

$r \circ z p u t i e \quad c e s t n e ́$ - Mt 22,9: ad exitus viarum na rozputie cestné $S$, na rozpuð̇enie cest $R$, na cèsty $W$ - in $S$ vielleicht auch ein Paläoslovenismus ${ }^{64}$.

s tred - L 24,42: favum mellis stredi medu W, plasku medovú R. In der Hs. $W$ kommt stred noch in der alten konkreten Bedeutung 'die Honigwabe' vor, sonst im Alttschechischen nur als med 'Honig'.

z v $\circ \mathrm{n}$ - L 24,42: partem piscis zvon ryby W (wörtlich 'Fischglok$k e^{\prime)}$, castku ryby R. Diese stelle in $W$ muss sehr alt sein (ein alter Moravismus?). Das Wort ist sonst nur im Altpolnischen als dzwono ryby ,apolectum, segmentum piscis' belegt. ${ }^{65}$ Es geht um eine portion des Fischfleisches, die durch zwei von einem Wirbelknochen hinausgehenden Fischgrăten zusammengehalten wird - die Gräten mit dem wirbel bilden eigentlich eine Glocke.

\subsubsection{Zusammenfassung}

Die Analyse der Ubersetzungen der einzelnen lateinischen lexikalischen Einheiten, besonders der biblischen Termini, bestätigte unsere Erkenntnisse über das relative Alter der Handschriften (z.B. die Analyse der Ubersetzungen des Terminus hora - $x_{a s}$, hodina beweist das hohe Alter dieser Evangeliare, vgl. 4.4.2.) und brachte einige neue über die Art, wie die einzelnen Handschriften von den Vorlagen übernommen wurden. Was den wortschatz betrifft, sind die Hss. S, D (aie kleinen, eindeutig alten Bruchstücke $A$ und $C$ liefern $z u$ wenig Material für solche Untersuchungen und wurden hier nur selten be-

$62 \mathrm{Vgl}$. V. VONDRAK, Die Spuren...(s. Fn. 29), und besonders die Rezension von J. POLIVKA (s. Fn. 29), 468-469.

$63 \mathrm{Vgl.} \mathrm{V.} \mathrm{MACHEK,} \mathrm{Etymologickł́} \mathrm{slovnik} \mathrm{jazyka} \mathrm{Łeského,} \mathrm{Praha} 1963$, 2. Aufl., s. v. nadin.

$64 \mathrm{~J}$. VASICA, o.c. (s. Fn. 2), S. 16, Anm. 1.

65 slownik polsczyzny XVI wieku, Wroclaw-Warszawa-Kraków-Gdańsk 1973 , s. v. dzwono 2 . 
rücksichtigt) die konservativsten. Die Hss. $R$ und $W$ weise viele lexikalische Neuerungen auf, wobei einige schon in den Vorlagen dieser Handschriften vertreten waren. Auch die Analyse anderer terminologischer Einheiten, der Pronomina- und Verbaubbersetzungen bestätigte die chronologische Reihenfolge $(A, C)-D$ - S - W/R. Die Handschrift $W$ ist auf einigen Sachgebieten - dank den Korrekturen nach Vergleich der meisten Perikopen mit dem lateinischen Text moderner als $R$, vor allem bei den Bezeichnungen der Krankheiten und bei der Fischereiterminologie. Die interessante Frage des $\mathrm{zu}-$ sammenhanges der Lesungen von Proprium de Tempore und von Proprium Sanctorum in der Hs. W konnte nicht endgultig gelöst werden. Die meisten Perikopen des nur in $w$ vorhandenen Proprium Sanctorum sind jüngeren Datums als der ubrige W-Text, aber dazwischen kommen auch sehr alte Perikopenubersetzungen vor. Wir sind der Meinung, dass die Perikopen des proprium Sanctorum nicht erst für $W$, sondern schon in den Vorlagen stufenweise ubersetzt und zusanmengestellt wurden (vgl. 4.4.1. unter ecce und 4.5.1.). Einige Belege der Ubersetzungen der Verba (4.4.4.3.) zeigen, dass die Hs. $R$ aus einer mit moderneren Ausdrucken bereits glossierten vorlage (in einem skriptorium, wo mehreren Schreibern diktiert wurde?) abgeschrieben wurde. Die eindutigen lexikalischen Palăoslovenismen sind sehr vereinzelt (4.4. 5.2.). Ihre Anzahl, die schon im Archetyp nicht besonders hoch war, weil ein kircherslavischer Text wahrscheinlich nur bei schwierigeren Stellen konsultiert wurde, verkleinerte sich wăhrend der mehrfachen Abschreibungs- und Bearbeitungsvorgănge stăndig. Interessanterweise kommen nur wenige lexikalische Moravismen (4.4.5.2.) vor.

4.5. Die Ergebnisse der Ubersetzungscharakteristik

Die Analysie der Ubersetzungstechnik sollte uns durch Untersuchung der Textabweichungen vom Vulgatatext, der grammatikalischen Kategorien und les wortschatzes ermolglichen, genauere Schlússe über das lateinische original und die alttschechischen vorlagen (4.5.1.), uber die Qualitat der alttschechischen Ubersetzung (4.5.2.) und uber die Filiation der alttschechischen Evangeliare der ersten Ubersetzungsredaktion (4.5.3.) zu ziehen.

\subsubsection{Die Vorlagen}

Die kritische Uberprufung der bisherigen Literatur zum Gegenstand und ein Vergleich mit Ergebnissen unserer Analysersosibrt zum 
eindeutigen Schluss, dass die alttschechische Evangeliarübersetzung in keinem direkten Zusammenhang $z u$ einer altkirchenslavischen Evangelienübersetzung stand, die alttschechischen Evangeliare hatten also keine direkte altkirchenslavische Vorlage. Die seltenen Paläoslovenismen betrachten wir als Reste einer langen Periode der münlichen Uberlieferung der Evangelienperikopen, an deren Anfang eine tschechisch-kirchenslavische Ubersetzung stehen könnte, die in der Seelsorgenpraxis im Laufe der zeit ganz bohemisiert und erst dann - Ende des XIII. Jhs. - zum erstenmal (mit korrekturen und in einer neuen Bearbeitung nach dem lateinischen Text, ev. mit Hilfe einer russisch-kirchenslavischen Ubersetzung, vgl. 3.2.) aufgezeichnet wurde. Der Schreiber des Archetyps übersetzte aus einem lateinischen Original unter Berücksichtigung der gewohnten mündlichen Uberlieferung (bei schwierigeren stellen konsultierte er vielleicht auch eine russ.-kirchenslavische Ubersetzung). Zur Feststellung, dass aus einem lateinischen Original ubersetzt wurde, kam schon Dobrovský und wir brauchen dies nach unseren Erkenntnissen nur $z u$ bestätigen und als endgültig $z u$ betrachten.

Das lateinische Original wurde bisher noch nicht näher bestimmt. Es gelang uns auf Grund der Untersuchung der im alttschechischen Text vorkommenden Abweichungen vom Vulgatatext festzustellen, dass die alttschechische Ubersetzung aus einem Text erfolgte, der von einem Text der Alkuinbibel abstammt. Diese Feststellung ist sehr wichtig, weil sie einerseits unsere Handschriften als ein Ganzes - als eine Ubersetzungsredaktion - präsentiert (die zweite Redaktion der alttschechischen Evangeliarübersetzung wurde schon nach einem Text der Sorbonne-Bibel gemacht) und andererseits setzt sie den, terminus post quem non' fest - die Sorbonne-Bibel war in Böhmen erst in der 2 weiten Hälfte des XIV. Jhs. bekannt. Dadurch eröffnet sich leider auch ein sehr weiter zeitraum in der Richtung von der ersten Hälfte des XIV. Jhs. rückwärts; jedenfalls ist aber diese Erkenntnis ein wichtiges zeugnis für das hohe Alter der ersten alttschechischen Evangeliarübersetzung.

Alle unsere Handschriften, wie es die Abschreibefehler (4.2. 2.1.) bezeugen, sind Abschriften. Die alttschechischen Vorlagen der auf uns kommenden Texte waren noch in der alteren Variante der alttschechischen Digraphenorthographie geschrieben - ganz bestimmt die Vorlagen $x_{1}$ und $x_{2}$ für die Hss. $R, D$, sowie auch der Protograph $x_{0}$; die Hss. A und $S$ wurden direkt vom Archetyp $X$ abgeschrieben; die Hs. $w$ hatte schon eine in der neueren (in der zweiten Hälfte des XIV. 
Jhs. üblichen) Digraphenorthographie geschriebene unmittelbare Vorlage $x_{3}$. In der älteren Digraphenorthographie wurde um die Wende des XIII. und XIV. Jhs. und in den ersten Jahrzehnten des XIV. Jhs. geschrieben - also die Hyparchetypen $x_{0}, x_{1}, x_{2}$ waren ziemlich alt. wie es die gemeinsamen echten Ubersetzungsfehler (4.2.2.2.) bezeugen, stammen alle Handschriften und ihre Vorlagen von einem Archetyp. Die Hss. A, C, D und besonders $R$ und $W$ unterscheiden sich von der Hs. S durch die in $S$ nicht vorhandenen Lesungen der Ferialtage. Die Perikopen für Sonntage und Feiertage sind im allgemeinen älter als die Ubersetzungen der Ferialperikopen. Bei der Herstellung der Filiation hilft uns besonders die Perikope für Dominica $V$. in Quadragesima ( $J$ 8,46-59), die in allen Handschriften (ausser $A$ ) enthalten ist. Im alttschechischen Text dieser Perikope zeigt sich, dass die Hss. C, D, R sehr ähnlich sind, ein wenig weiter steht die Handschrift $S$ und ziemlich entfernt ist schon $W$. Einige Ferialperikopen in $R$ und mehrere in $W$ wurden aller Wahrscheinlichkeit nach erst um 1320 oder noch später übersetzt (z.B. Mt 21,33-46; J 5 , 17-29; J 7,14-31; ganz bestimnt die Perikope fur das erst 1316 eingefuhrte Fronleichnamsfest $J 6,56-59$ in $R)$. Es gibt aber auch oft grössere Ubersetzungsunterschiede der Ferialperikopen in $R$ und W. typisch dafür ist $z . B$. die Perikope $J 11,1-45$. Die Vorlage für die Hs. W $\left(x_{3}\right)$ war von den anderen durch einige schon vorhandene Perikopenübersetzungen des Proprium Sanctorum verschieden. Die Ubersetzungen der Perikopen des Proprium Sanctorum in $W$ sind nicht alle gleich alt, 2.B. die Perikope In Inventione S. Crucis J 3,1-15 hat mehrere alte lexikalische Einheiten (nemo - ijeden, amen amen - vërné jister, spirat - poělva, omnis - proknt), die typisch für die Hs. S sind und auf einen Hyparchetyp hinweisen. Die anderen alten Perikopen sind 2.B. Mt 5,1-12; Mt 12,46-50; Mt 16,13-19; Mt 19,27-29; L 1,5-17; L 10,1-9. Die meisten übrigen Perikopen des Proprium Sanctorum in $W$ sind jüngeren Datums und wurden erst für die Handschrift $W$ ubersetzt (ganz neu ist $2 . B$. die Perikope Mc 6,17-29 mit ihren zahlreichen Latinismen und Ubersetzungsfehlern). Die Vorlage für die Hs. $w\left(x_{3}\right)$ und vielleicht auch die Hs. $R$ selbst wurden dem Schreiber (oder gleich mehreren in einem Skriptorium) wahrscheinlich diktiert. Die Vorlage für die Hs. $R\left(x_{g}\right)$ wurde, wie es einige stellen mit synonymischen (in dieser Verdoppelung im Latein nicht vorhandenen) Ausdrücken belegen (4.4.4.3.), durch einen den Wortschatz modernisierenden Glossator bearbeitet. Wieviele 2 wischenglieder es vom Archetyp bis zu unseren Handschrif- 
ten gab, behandeln wir noch unten (siehe 4.5.3.).

4.5.2. Die Qualitat der Ubersetzung

Unsere Handschriften haben uns die älteste Ubersetzung der Evangelienperikopen ins Alttschechische in Abschriften bewahrt. Die eingehende Untersuchung der Abschreibefehler (4.2.2.1.) und der Ubersetzungsfehler (4.2.2.2.) ergab, dass diese Urübersetzung als Erstversuch und im Hinblick auf ihr Alter erstaunlich hohes Niveau aufweist. Die jüngeren Abschriften beinhalten zahlreiche Kopistenfehler (vor allem die Hs. R), da sie aus den für die Kopisten schwer lesbaren in einer nicht mehr benutzten Orthographie geschriebenen Manuskripten (meist auch ohne Kontrolle durch den lateinischen Text) abgeschrieben wurden. Die echten Ubersetzungsfehler, die oft noch vom Axchetyp stammen, kommen relativ selten vor; man muss aber damit rechnen, dass einige von ihnen in den Hyparchetypen, in der Hs. S und besonders in der Hs. W durch Vergleich mit dem lateinischen Text verbessert wurden. Die Hs. W bringt zahlreiche neue, von den anderen Evangeliarhandschriften abweichende eigene Ubersetzungen, die uns aber nicht immer besser als die freieren und der tschechischen Ausdrucksweise mehr entsprechenden alten erscheinen (s. 4.1.).

Die genaueren Schlüsse über die Technik und Qualitat der Ubersetzung ermöglichte uns die Analyse der wiedergabe lateinischer grammatikalischer Kategorien (4.3.) und des lateinischen Wortschatzes (4.4.). Es wurde festgestellt, dass nur wenige Latinismen vorkommen - sowohl im Wortschatz als auch beim Ersatz der lateinischen grammatikalischen Konstruktionen.

Es ist merwirdig, dass bisher keine ausfuhrlichere systematische Analyse der Art der Ubersetzung lateinischer grammatikalischer Kategorien ins Alttschechische (ausser der kurzen Aufzahlungen der Ubersetzungsungenauigkeiten in den Einleitungen der Editionen der alttschechischen übersetzten Denkmäler) gemacht wurde. Wir haben versucht, an Material der ältesten Evangeliare diese Lücke zu füllen. Die Ergebnisse dieser Analyse bezeugen, dass die meisten lateinischen Konstruktionen schon im Archetyp durch ausgeprăgt heimische Aquivalente ersetzt wurden (z.B. ,ablativus absolutus' meist durch eine alttschechische Partizipialkonstruktion Part.Präs./Prăt. +Akk.. vgl. 4.3.1.1.; die lateinischen attributiven Partizipien durch alttschechische Transgressivformen, vgl. 4.3.1.2., oder schon von den Kopisten durch die alttschechischen absolutiven Partizipien, 
vgl. 4.3.1.2.2.; die lateinischen zeiten der Vergangenheit durch die alttschechischen einfachen zeiten Aorist und Imperfekt und erst später von Kopisten durch die zusammengesetzten zeiten wie das alttschechische Perfekt, vgl. 4.3.2.1.; der lateinische Akk. + Inf. durch eine alttschechische Konstruktion Akk. + Part., vgl. 4.3.3.1.. usw.). Die Eingriffe der Kopisten zeigen sich auf diesem Gebiet sehr deutlich, so. z.B. die Einfuhrung der relativ jungen absolutiven Partizipien, des Perfekts, des einfachen negativen Imperativs (nur mit dem Präfix ne-anstatt des alteren nerod'+ Inf., vgl. 4.3.4.). Die meisten Neuerungen in dieser Hinsicht weist die Handschrift $W$ auf. Die Nechahmungen der lateinischen Konstruktionen sind vereinzelt und meist nur auf die jüngste Handschrift $w$ beschränkt (vgl.4.3.4.4.).

Bei der Analyse des Wortschatzes wurde vor allem die Art, wie die typisch biblischen Termini (Dominus, publicanus, discipulus u.a. vgl. 4.4.1.) wiedergegeben sind, untersucht. Im Gegensatz zur Wiedergabe der lateinischen grammatikalischen Kategorien wurden die lateinischen Termini nicht so einheitlich ubersetzt. Aus dem lexikalischen Material unserer Texte geht hervor, dass im Wortschatz von jedem schreiber relativ viele Neuerungen eingefunrt wurden. Einige neuere Ausdrücke zeigen sogar, dass man auch deutsche Evangelienübersetzungen für den liturgischen Gebrauch kannte und vielleicht auch benutzte - z.B. das wort mzadi $i$ für, discipulus' wurde aus dem deutschen 'Jünger' übernommen (vgl. 4.4.1. unter, discipulus'). Die lexikalisch progressivste Handschrift ist die Hs. $R$, vor allem bei den Ubersetzungen der Verba (vgl. 4.4.4.), bei einigen biblischen Termini (4.4.1.) und bei Ausdrucken aus dem Alltagsleben; aber auf einigen Sachgebieten (z.B. Bezeichnungen der Krankheiten) werden die alten Ausdrucke bewahrt. Die Handschrift w hat auch viele jüngere lexikalische Einheiten (z.B. bei den Bezeichnungen der Krankheiten, bei den biblischen Termini), die úbrigen Handschriften sind im Wortschatz eher konservativ. Die ältesten Ausdrücke (unter ihnen einige eindeutige Paläoslovenismen, 4.4. 5.2.), findet man vor allem in der Handschrift $S$.

Die Aufgabe, die der alttschechische Ubersetzer der Evangeliare bewältigen musste, war einmalig und sehr anspruchsvoll. Praktisch ohne Vorbilder (im Alttschechischen) sollte er eine sachlich und sprachlich möglichst genaue alttschechische Version eines kanonischen und darum verbindlichen sakralen lateinischen Textes herstellen. Die Mittel, die inm die Muttersprache anbot, waren zur zeit 
der ersten Aufzeichnung für solche zwecke $z u$ wenig erprobt. Es ist erstaunlich, wie reif und vollständig diese erste alttschechische Ubersetzung wirkt - sowohl im grammatikalischen als auch im lexikalischen Bereich. Für die Reife der ăltesten Evangeliarübersetzung spricht nicht nur die (relative, weil durch Kopisteneingriffe gestörte) Konsequenz, mit der die lateinischen grammatikalischen Konstruktionen übersetzt werden, sondern auch die Tatsache, dass man nicht fürchtete, bei diesem liturgischen "heiligen" Text die Ubersetzung freier und durch Ausnützen frischer alltăglicher Ausdrücke und Redewendungen lebendiger und für das zuhörerpublikum zugănglicher zu gestalten, ohne dabei durch zu naive und unbeholfene Ausdrucksweise die hohen künstlerischen und philosophischen Werte des Originals zu erniedrigen oder zu zerstören. Diese Feststellungen liefern ein überzeugendes und eindrucksvolles zeugnis von dem ausgeprägten Sprachgefühl und von den hohen geistigen Qualitäten des Ubersetzers des alttschechischen Evangeliars. Diese Tatsache wird indirekt auch durch die Handschrift $w$, die als jungere, durch engere Anknüpfung an ein lateinisches Original oft steif und ungeschickt wirkende Ubersetzungsvariante in dieser Hinsicht eher einen Schritt zurück bedeutet, bestätigt.

4.5.3. Filiationsschema der ersten Ubersetzungsredaktion

Die Fillation unserer Handschriften, die wir hier aufstellen, basiert auf den Ergebnissen der Analyse der Ubersetzungsmethode. Das endgultige Filiationsschema wird erst nach der Untersuchung der grammatischen struktur zusammengestelit (siehe 12.).

wie schon oben (4.5.1.) festgestellt wurde, handelt es sich bei allen unseren Handschriften nur um Abschriften. Die Zwischenglieder $\left(x_{n}\right)$ - die Vorlagen unserer Texte - stammen alle von einem Archetyp $(X)$. Wieviele es genau waren, kann man heute nur abschäzen. Keine von unseren Handschriften diente als unmittelbare vorlage einer anderen. Daraus kann man schliessen, dass wir noch mit ălteren Texten rechnen mulssen. Am ältesten (aus der ersten Hälfte des XIV. Jhs.) sind die Handschriften $A$ und $C$, die was den Text betrifft fast identisch sind und von einem Archetyp ( $X$ ) stammen. Die Handschrift $C$ wurde nicht direkt (wie die Handschrift A) vom Archetyp, sondern von einem Hyparchetyp $\left(x_{0}\right)$ abgeschrieben. Diesen Hyparchetyp $\left(x_{0}\right)$ kann man in die ersten zwel Jahrzehnte des $x I V$. Jhs. datieren. Die nächste drittalteste Handschrift (knapp nach 
1350) ist das Bruchstück $D$, das auch uber eine Abschrift $x_{2}$ vom Hyparchetyp $x_{0}$ stammt. Die Handschrift $s$ vom Ende des zweiten Drittels des XIV. Jhs. ist mit der vorangehenden Handschriftengruppe (A, C, D) auch eng verwandt, aber keine Kopistenfehler (4.2.1.) deuten auf die Existenz eines zwischengliedes hin - die Handschrift $S$ wurde direkt vom Archetyp $X$ abgeschrieben. Die jüngere Hs. R (um 1370) steht auch der Gruppe A, C, D ziemlich nahe (am nächsten der Hs. D), naher als die Hs. S, und wurde von einer um 1350 glossierten Abschrift $x_{1}$ abgeschrieben. Die jüngste Handschrift $w$ aus dem Ende des XIV. Jhs. stammt auch vom Hyparchetyp $x_{0}$, hatte als unmittelbare Vorlage eine Abschrift $x_{3}$ des Hyparchetyps $x_{0}$, von der die meisten perikopen des proprium Sanctorum, die in den anderen vorlagen $\left(x_{1}, x_{2}\right)$ noch nicht übersetzt waren, und der grösste Teil der Lesungen des Proprium de Tempore abgeschrieben wurden.

Aus dieser Uberlegung ergibt sich für die erste Redaktion der alttschechischen Evangeliarübersetzung folgendes Filiationsschema: 66

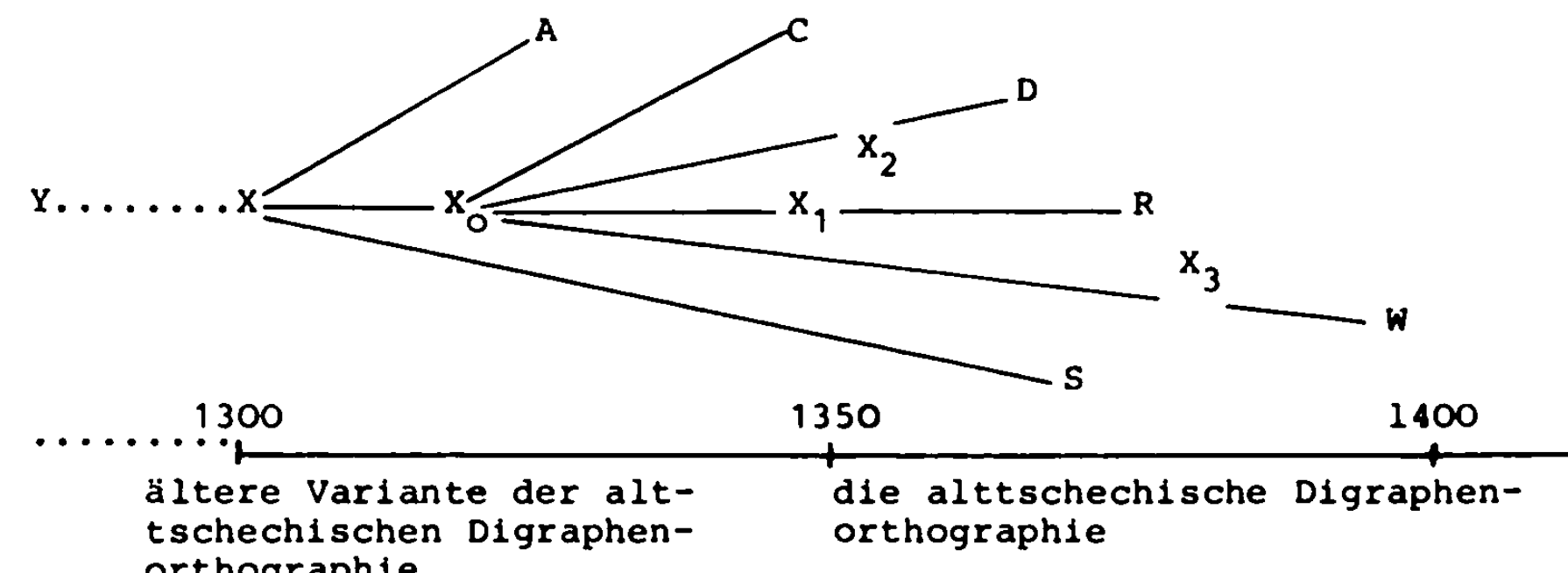

Anm. : Unter dem $Y$-Text verstehen wir den von Dobrovky (für das XI. Jh. ?!) vorausgesetzten Archetyp, bei dem es sich unserer Meinung nach nicht um eine vollständige Ubersetzung des Evangeliars (so Dobrovský), sondern entweder un eine tschechisch-kirchenslavische (was uns ausserst fragwirdig erscheint) oder eher um eine tschechisch glossierte lateinische Handschrift erst aus der zweiten Halfte des XIII. Jhs. handelte.

Uber den Ort der Entstehung der ersten Aufzeichnung kann man bis jetzt nichts genaueres als unter 3.2. sagen, es war wahrschein-

66 Zum Vergleich die Filiation von J. VASICA, 0.C. (Fn. 2), 102:

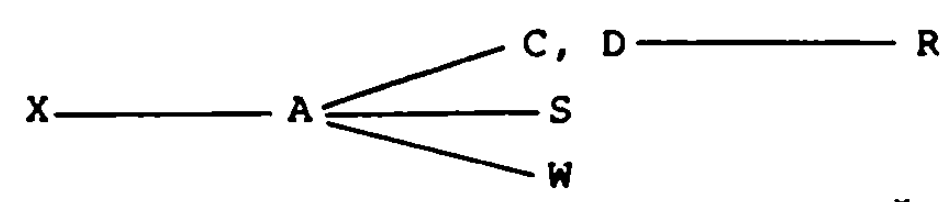

Unsere Handschrift $D$ bezeichnet Vasica $C$, unsere Handschrift $C$ als $D$ - wir haben im obigen Schema die Abkurzungen von Vasica durch unsere (heute allgeme in benutzte) ersetzt. 
lich das Benediktinerkloster Błeunov in Prag. Einige lexikalische Moravismen in einigen unserer Handschriften deuten darauf hin, dass auch in Mähren - uber das Kloster Rajhrad (eine Błevnov-Gründung) von diesem Archetyp kopiert wurde. Genauer können wir diese Frage hoffentlich erst nach der Analyse des grammatikalischen (vor allem des phonologischen) Systems unserer Handschriften beantworten (s.12.). Uber den zeitpunkt der Entstehung des Archetyps kann man schwer eine sichere Aussage machen. Die etwa zehn-bis zwanzigjahrigen Zeitabschnitte, die die einzelnen Glieder des Filiationsschemas trennen, deuten die Mglichkeit an, dass der Archetyp auch etwa zwanzig Jahre vor der Entstehung des ersten vorausgesetzten Hyparchetyps $x_{0}$, also um die Wende des XIII. und XIV. Jhs., entstand. Diese Hypothese schliesst die Existenz eines vielleicht nur stellenweise glossierten Evangeliars $(Y)$ und der müdlichen Uberlieferung nicht aus und kann ausserdem noch durch die bekannten Tatsachen uber die Entstehung der altesten kontinuierlichen (nicht glossierten) Texte der alttschechischen Literatur (Legenden, Psalter, die geistliche Lyrik) zum Ende des XIII. Jhs. nur gestützt werden. Bei einem so dringend nötigen und gebrauchten Text wie es ein Evangeliar im hohen Mittelalter war, muss man damit rechnen, dass wir hier nit einem der ersten umfangreicheren Denkmäler der alttschechischen Sprache und Ubersetzungskunst begegnen. 
ZWEITER TEIL

LINGUISTISCHE CHARAKTERISTIK DER TEXTSTRUKTUREN VON ALTTSCHECHISCHEN EVANGELIARHANDSCHRIFTEN

5. Eine genaue Charakteristik der Sprache eines Textgebildes erfordert neben der philologischen Darlegung einer Ubersetzungscharakteristik bei den in die untersuchte sprache transponierten Texten eine solche Methode der Analyse, durch welche optimal garantiert wird, dass das sprachliche Gebilde unter Berücksichtigung seiner Kompliziertheit und seiner strukturenhierarchie interpretiert wird. Für eine solche möglichst objektive Methode der Textuntersuchung bietet sich dem heutigen Forscher die Anwendung der Prinzipien des linguistischen Strukturalismus, vor allem in der Fassung der sog. Prager Schule an. Die Methodik wird nicht unkritisch übernommen; es wird versucht, sie schöperisch zu applizieren und durch eine synthese unserer Ergebnisse auch die Theorie des linguistischen Strukturalismus ein wenig $z u$ bereichern.

5.1. Zur Methodik der linguistischen Anaylse

Jede sprachliche Aussage, sowohl ein Satz als auch eine grössere Texteinheit, soll als eine Struktur nach ihren Elementen und ihren Bindungsrelationen analysiert werden. Unsere Textstrukturen, die altesten alttschechischen Evangeliarhandschriften, betrachten wir als konkrete Realisationen des alttschechischen Sprachsystems. Der Analyse der strukturelementen und ihrer Relationen muss eine Synthese der Ergebnisse folgen, die sich als $2 i e l$ die Entdeckung des systemaufbaues der untersuchten sprache steckt. Für die Gesamtcharakteristik eines Sprachsystems ist die Anzahl der von uns analysierten Texte $z u$ gering. Aber schon diese begrenzte Textauswahl wird es uns ermöglichen, $z u$ wichtigen Schlüsen uber die Teilsysteme (vor allem uber das phonologische system) des Alttschechischen zu gelangen. Die Moglichkeiten einer umfangreicheren Charakteristik der grammatischen - syntaktischen und morphologischen - Teilsysteme und des wortschatzes bleiben auf die in unseren Textstrukturen belegten systemerscheinungen beschränkt. Die vollkommene Darstellung des ganzen alttschechischen Systems - sowohl in einigen synchronen schnitten als auch in seiner Dynamik 
und Diachronie - kann nicht unser Endziel sein. Die folgende Studie wird sich auf zwei Forschungsbereiche konzentrieren: 1. durch das Generalisieren der Analyseergebnisse den Systemrohbau, d.h. die zentralen Systemelemente und -relationen festzulegen, die peripheren Erscheinungen der Textstrukturen festzustellen und dem Systemzentrum $^{67}$ entsprechend anzuordnen; 2. Durch Vergleich mehrerer synchroner Schnitte, wie sie sich aus dem verschiedenen Alter unserer Textstrukturen ergeben, die im Material belegten Systementwicklungsvorgänge, also die diachrone, vertikale, struktur klarzulegen. Diese Strukturanalyse und die daran anschliessende Synthese soll das alttschechische Sprachsystem anhand einer seiner Kommunikationsfunktionen und in seiner dynamischen Entwicklung (als eine dialektische Einheit der sich immer wechselseitig beeinflussnden Vorgänge - der konkreten subjektiven Sprachaufzeichnungen und der objektiven Bezeichnungsmöglichkeiten des Systems) darstellen. Unter einem Sprachsystem verstehen wir also einen Komplex von sprachlichen Fakten, dessen zahllose unsynchrone und spezifische Text- und Aussagestrukturen sich in der ständigen Konfrontation mit den aussersprachlichen Strukturen der Realität befinden.

\subsection{Zur Einteilung der Strukturanalyse}

Der Prager sprachwissenschaftliche strukturalismus gliedert das system einer sprache in mehrere Teilsysteme auf - in ein lexikalisches, ein grammatisches (syntaktisches und morphologisches) und ein phonologisches. Alle diese Teilsysteme und ihre Einheiten bilden ein hierarchisches Relationsnetz und beeinflussen einander.

Die linguistische Strukturanalyse der Evangeliartexte soll die bisherigen Kenntnise uber das alttschechische Sprachsystem erweitern und hervorheben, welche der Entwicklungstypen und -vorgänge für die gegebene Periode die bedeutendsten und progressiven und welche die rückläufigen sind. Bei der Analyse werden vor allem die Besonderheiten unserer Textstrukturen berucksichtigt, ins system als Trăger oder sogar Urheber der systemänderungen eingegliedert und

$67 \mathrm{Vgl}$. dazu vor allem F. DANES, Vztah centra a periférie jakožto jazykové universále, Jazykovědné aktuality 1965/II-III, 1-6; ausfuhrlicher d e r s.. The Relation of Centre and Periphery as a Language Universal, in: Travaux linquistiques de Prague 2 (1966) 9-21; die übrigen Beiträge in dieser Travauxnummer, die nur den Problemen des Zentrums und der Peripherie gewidmet ist, behandeln die zentralen und peripheren Erscheinungen in den lexikalischen, grammatikalischen und phonologischen systemen. 
mit allgemeinen Systementwicklungstendenzen in Einklang gebracht. Die Charakteristik der lexikalischen struktur (6.) soll auf einige anhand unseres Materials erkennbaren Entwicklungsvorgänge im alttschechischen wortschatz und auf ihren zusammenhang mit den anderen Systemänderungen aufmerksam machen. Die Analyse der Abweichungen und Besonderheiten im Rahmen der wichtigsten grammatikalischen Kategorien im syntaktischen (7.) und morphologischen (8.) Teilsystem soll besonders auf die ständigen Verschiebungen zwischen dem Systemzentrum und der Peripherie hinweisen. Die Analyse des Phonembestandes (9.) soll nicht nur eine Gesamtübersicht der Entwicklung des alttschechischen phonologischen systems im XIV. Jh., sondern auch eine Erklärung der Korrelationen- und Phonemumschichtungen darbieten. Eine kurze Beschreibung der graphematischen Strukturen (10.) wird die Strukturanalyse des alttschechischen Sprachsystems abschliessen. Die Zusammenfassung der linguistischen Durchforschung (11.) soll dann als Grundlage für die Gesamtwertung der Evangeliartexte als Sprachdenkmäler dienen.

\section{LEXIKALISCHE CHARAKTERISTIK}

In diesem Kapitel wird eine kurze strukturelle Charakteristik des Wortschatzes unserer Denkmäler geliefert; die ausführliche Beschreibung der wichtigsten Termini und Wortgruppen enthält schon das Kapitel mit der Analyse der Ubersetzungstechnik (4.4.), hier werden einige lexikalische Einheiten als zentral oder peripher einstufende Elemente des alttschechischen lexikalischen Teilsystems (6.1.) und als Träger der lexikalischen Entwicklungsvorgänge (6.2.) untersucht.

6.0.1. Zum Begriff, das lexikalische System'

Das lexikalische system besteht aus organisierten Gruppierungen sprachlicher zeichen; die durch grammatische, morphonologische und phonologische Mittel gebildeten Einheiten fungieren als sprachliche, die Semantik der aussersprachlichen Realität widerspiegelnde Bezeichnungen eines generalisierenden Benennungsvorganges. Diese Einheiten des lexikalischen Systems, die Lexeme, stehen in einer engen Beziehung sowohl zu anderen sprachlichen Teilsystemen als auch zu den "Systemen" der Realitat und werden in ihrer Funktion von diesen belden Hauptfaktoren stark beein- 
flusst. Die Erklärungen des Entstehens, des Unterganges und der Bedeutungsverschiebungen bei den Lexemen sind also nicht nur in der Innenstruktur des lexikalischen systems, sondern auch in den Anderungen innerhalb anderer Teilsysteme der Sprache und der Realität zu suchen.

6.0.2. Die bisherige Literatur zur alttschechischen Lexik

Der alttschechische Wortschatz $k a m$ in den sonst sehr zahlreichen Abhandlungen über das Alttschechische bisher zu kurz. Dieser Mangel ist nur teilweise dadurch erklärbar, dass es bis heute kein vollständiges alttschechisches worterbuch gibt. Das von GEBAU$E R$ herausgegebene worterbuch erschien in zwei Bănden, aber nur bis zum Wort netbanlivost. ${ }^{68}$ Das neue akademische alttschechische worterbuch, bearbeitet vom lexikographischen Kollektiv des Instituts für tschechische Sprache der CSAV in Prag unter der Leitung von B. HAVRANEK und I. NEMEC ${ }^{69}$, soll die moderne, nach strukturalistischen Gesichtspunkten zusammengestellte Fortsetzung des Worterbuches von Gebauer sein. Erst diese lexikographische Kollektivarbeit war Anlass dazu, sich auf Grund eines sehr umfangreichen lexikalischen Archivs nicht nur lexikographisch, sondern auch lexikologisch eingehender mit dem alttschechischen wortschatz zu beschäftigen. Es entstanden mehrere theoretische Aufsäze, in denen ihre Verfasser (vor allem I. Nëmec und E. Michálek) moderne methodologische Grundlagen für die wissenschaftliche Durchforschung des alttschechischen lexikalischen systems darlegten. In dieser Hinsicht sind zwei Arbeiten am bedeutendsten: fur die Analyse der alttschechischen Terminologie die Monographie uber die alttschechischen Rechtstermini von E. MICHALEK, 70 für die allgemeine strukturelle Beschreibung des alttschechischen lexikalischen systems in seiner Dynamik die umfangreiche Abhandlung von I. NËEC. 71 Die letztgenannte Arbeit als repräsentativste Darstellung der lexikologischen Theorie der Prager Schule beeinflusste methodisch massgebend die

68 J. GEBAUER, Sloun lk staročesky, I, II, Praha 1903, 1916.

69 Starocesky slovnik, Autorenkollektiv unter Leitung von B. HAVRÁNEK und I. NEMEC, Hefte 1-7, Praha CSAV, seit 1968. Das wörterbuch beginnt mit dem Buchstaben $n$; bis jetzt erschienen: Einführungsheft mit den Prinzipien und dem Quellenverzeichnis und 7 Hefte von na bis ob-.

70 E. MICHALEK, Cesky právn1 jazyk udobl předhusitskéno a doby Husovy, in der Serie: Rozpravy CSAV, Praha 1970, Heft 2, 74 S. Rezensiert von J. VINTR, Naž मैe 54 (1971) 308-310. 
folgende strukturelle Charakteristik des Wortschatzes unserer Evangeliarhandschriften.

6.1. Die zentralen und peripheren lexikalischen Erscheinungen

Das zahlenmässig und thematisch begrenzte lexikalische Material unserer Texte erlaubt uns nur bescheidene Urteile uber das System des alttschechischen Wortschatzes im XIV. Jh. Die Ubersicht der thematischen Wortgruppen in ihrer Varilerbarkeit wurde schon unter 4.4. dargeboten. Die Erklärung, warum einzelne Lexeme in demselben Kontext im Laufe der zeit durch andere ersetzt wurden, darf man nicht bloss in einer mehr oder weniger subjektiven Reproduktionsfahigkeit oder in einem besseren oder schlechteren Sprachgefuhl der Kopisten und Korrektoren suchen. Beim Vergleich unserer Textstrukturen muss man die lexikalischen Varianten als zeugen und Folgen der Änderungen im lexikalischen System betrachten, genauer gesagt, als Reflexionen des ständigen Austausches zwischen dem Systemzentrum und der systemperipherie.

Im lexikalischen system unserer Textstrukturen kann man die Verschibungen $z$ wischen dem Systemzentrum und der Peripherie am besten an den biblischen Termini erkennen ${ }^{72}$ : im lateinischen original gehören die Ausdrucke wie Dominus, daemonium, sacerdos, pontifex usw. zum Zentrum; in den altesten alttschechischen Evangeliaren findet man für diese Termini zweierlei Aquivalente - die alten noch aus dem Altkirchenslavischen stammenden (Hospodin, bers, pop) konkurrieren mit den neueren heimischen ( $P$ d́n, didbel, knéz, biskup). Die alteren Handschriften A, C, D, S haben meist noch die alteren Lexeme, in den jüngeren Hss. $R$ und $w$ werden diese durch heimische, in das ganze lexikalische und morphonologische system fester eingegliederte und darum zentrale lexikalische Einheiten ersetzt. Die bohemisierten lexikalischen Palăoslovenismen, die schon in der zweiten Hălfte des XIV. Jhs. als Historismen mit wenigen Bindungen an das zentrum des alttschechischen lexikalischen Systems wahrgenommen wurden, darf man als an die Peripherie verdrăngte Lexeme ansehen. Durch die Trennung vom Altkirchenslavischen

71 I. NÉMEC, VÝ̛vojové postupy Ceské slovní zásoby, CsAV-Verlag, Praha 1968, $194 \mathrm{~S}$.

$72 \mathrm{zu}$ den genauen Kriterien der zugehorigkeit von Lexemen $\mathrm{zum}$ zentrum oder zur Peripherie vgl. J. FILIPEC, Probleme des Sprachzentrums und der Sprachperipherie im System des Wortschatzes, in: Travaux linguist.de Prague 2 (1966) $264 \mathrm{ff}$. 
und durch die dem Alttschechischen fernstehenden oder durch eine mehr spezialisierte Semantik schon besetzten stammbildenden Morpheme verlieren diese Historismen die Fahigkeit, sich auf Grund eines semantisch produktiven Grundmorphems im Zentrum durch die Schaffung mehrerer eigener lexikalisch-grammatischer Relationen zu erhalten (z.B. auch die alteren Adjektivableitungen popovy, bersovy werden durch knezzsky, diabbelsky ersetzt). 73 solche auch heimische lexikalische Einheiten, die wegen der wenigen Verbindungen $z u$ den anderen Lexemen oder wegen eines unproduktiven Suffixes schon an der Peripherie stehen, werden aus dem lexikalischen System verdrängt: das Wort obida (L 2,34: ,ruina', S, D) wurde vom Kopisten der Handschrift $R$ nicht mehr verstanden und auf bieda 'Not' geăndert, die Evangeliare der zweiten Redaktion haben hier schon padenie, pad, spadenie; das alte kvałennin für discumbens, recumbens, cizozemenin fur alienigena mit unproduktivem suffix -ènin ${ }^{44}$ wird durch host, cizozemec ersetzt (Mc 6.22: kvasanöm W, Mc 6.26: pro hoste W: L 7,49: kvasené W; L 17,18: cizozemenin S, cizozemec $R$, W). Die angeführten Beispiele bezeugen, dass die lexikalischen Varianten nicht nur als subjektive Eingriffe eines Kopisten, sondern als systembedingte Reflexionen anzusehen sind.

6.2. Die Entwicklungsvorgänge im Wortschatz unserer Texte

Die Änderungen im alttschechischen lexikalischen System - Entstehung oder Untergang lexikalischer Einheiten oder Bedeutungen werden vor allem durch $z$ wel Typen von Faktoren verursacht: durch die sprachlichen (6.2.1.) und durch die aussersprachlichen (kulturhistorischen) Faktoren (6.2.2.). Es gibt noch eine dritte Gruppe, die der psychischen Faktoren, 75 durch die meist nur Ainderungen bei den Fremdwörtern verursacht werden. Da die Fremdwörter in unseren Texten vereinzelt vorkomen, und die Lehnubersetzungen schon behandelt wurden (4.4.), konzentrieren wir uns auf die sprachlichen und aussersprachlichen Faktoren der lexikalischen Entwicklungsvorgänge.

73 zur Entwicklung pop $\rightarrow k n e x z$ vgl. J. BAUER, Zur Auffassung des sprachlichen Zeichens, in: Zeichen und System der Sprache II, Berlin 1962, 11.

74 Vgl. I. NĚMEC, O.C. (Fn. 71) 166.

$75 \mathrm{Vgl}$. I. NEMEC, O.C. (Fn. 71) 40. 
6.2.1. Die sprachlichen Faktoren der Entwicklungsvorgănge

im lexikalischen System werden durch die Auswirkungen der Strukturănderungen im phonologischen, morphonologischen und grammatischen System reprăsentiert. Wir wollen dabei aber noch betonen, dass ein einziger Faktor fast nie die einzige ursache der Anderung ist - es handelt sich eher um ein zusammenspiel mehr oder weniger dominierender Faktoren. Für die Behandlung der phonologischen und morphonologischen Faktoren ist unser Material zu beschränkt, wir bleiben bei einigen Beispielen für die gramatikalischen Faktoren in der Entwicklung des Wortschatzes.

Die lexikalischen Folgerungen der Änderungen grammatikalischer Systemkategorien sind in unserem Material vor allem im Bereich des Nomens und des Verbums feststellbar. Bel den Nomina findet man in der Lexik noch Nachklänge des Umbaues der alten lexikalisch-gramatikalischen Kategorie des Stames zur gramatikalischen Kategorie des Genus. Die alten doppelgeschlechtigen Bezeichnungen werden für Maskulina und Feminina differenziert - L 15,9: amicas et vicinas protel a suised S, R, pritelkyne a susedy W (vgl. L 15,6: amicos et vicinos pratel a süsed $S$, pratel a súsedóv R, prately a suse$d y(w)$. Im Bereich des Verbums sind in unseren Texten immer noch Reste der zerfallenden Kategorie der Ingressivität/Durativităt ${ }^{76}$, die durch das sich immer noch im Ausbau befindende Tempus-Aspektsystem ersetzt wird, zu finden. So z.B. geht die speziell alttschechische ingressive Konstruktion vzieti 'nehmen' + Akk.Subst. unter - Mc 16,16: baptizatus fuerit krest vezme S, kr̉est prijme R, po$k$ kzden bude $w$; genauso schwinden die alten Ingressiva mit vorsilben $v a-$, po-, und werden durch unpräfigierte Verba mit anderen Aspektpräfixen oder durch Synonyma ersetzt - Mt 22,12: obmutuit pomlde S, pomldev R, mlde W; Mc 16,18: biberint vapijl S,, vypijl R; L 12,36: venerit et pulsaverit pride a potluce $W ; J 11$,

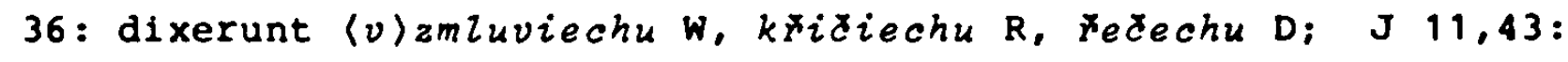
clamavit $\langle v\} z$ vola D, zavola R, kPid W: J 16,13: loquetur vamluvi S, W, praviti bude R; J 14,30: loquar pomluvi S, pomluvim R, mluvi W; J 16,27: exivi porel S, prizel R; L 10,30: plagis inpo-

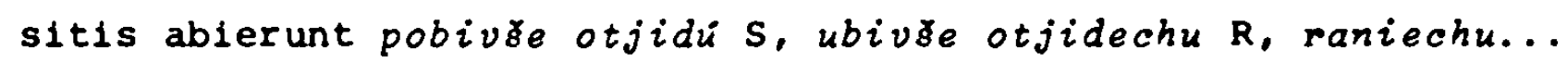
otejdi w, u.a.

Die universelien Vorgănge im lexikalischen System, z.B. die Tendenz zur Bildung symmetrischer lexikalischer Korrelationen und

76 Vgl. I. NËMEC, O.C. (Fn. 71) 52. 
die allgemeine Tendenz zur Systemsymmetrie 77 , kann man an unserem begrenzten Material nicht verfolgen.

\subsubsection{Die aussersprachlichen Faktoren}

Die aussersprachlichen Faktoren der lexikalischen Entwicklungen werden nicht nur durch Anderungen der Objekte und deren Relationen in der Realităt, sondern auch durch die Änderungen der Kenntnisse uber die Realităt repräsentiert. In den lexikalischen Einheiten unserer Textstrukturen spiege in sich vor allem die im Laufe der zeit geănderten und vervollkommneten Auffassungen der Wirklichkeit. Das alte Wort mit einer breiten Bedeutung wird auf Grund neuer Erkenntnisse durch ein oder mehrere neue Lexeme mit engeren, spezialisierteren oder fast terminologischen Bedeutungen ersetzt. Die besten Beispiele können wir aus der medizinischen Terminologie anfuhren - das alte undifferenzierte nuzný für leprosus in den Handschriften $S$ und $R$ wird in der jungen Handschrift $W$ durch genaues malomocny ersetzt; das alte ungenaue żivot fur lepra in $S, R$ wird in $W$ durch malomocenstvie ersetzt; die Ubersetzung vodné tele fur hydropicus in $S, R$ wird in $w$ durch eine mehrgliedrige, aber genaue Erklärung nemoc vodna mezi masem a közi ersetzt, u.a. (die zitation biblischer stellen siehe 4.4.2.). Ahnlich auch in der religiossen Terminologie - das alte pop für sacerdos, pontifex in $S, C$ wird in $W, R$ schon differenziert auf knéz für sacerdos und biskup für pontifex; das alte mistr für rabbi, praeceptor wird in jüngeren Evangeliarhandschriften auf mistr für rabbi und kazatel, prikazatel für praeceptor umbenannt (die zitationen s. unter 4.4.1.). Auch die abstrakten Ausdrücke spezialisieren sich im Laufe der zeit - für veritas neben dem hăufigsten pravda und schon seltenem alten viera erscheint unter dem Einfluss der alttschechischen Ubersetzungen für iustitia (meist pravda, einmal in $R$ odplata und in $S, W$ spravedlnost) in der Hs. $R$ fur veritas auch spravedlnost; spater stabilisiert sich für veritas der Aquivalent pravda und für iustitia das relativ junge spravedlnost. An solchen Stellen, wo die fremde wirklichkeit immer noch nicht erkannt wurde, hăufen sich in den jüngeren Evangeliarhandschriften Synonyma mit breiten Bedeutungen an - für synagoga kommt am häufigsten das alte modla vor, aber in $\mathrm{S}, \mathrm{R}, \mathrm{W}$ auch $\$ k o l a$, chrom

(die zitationen der biblischen stellen s. unter 4.4.1.).

77 Vgl. I. NÉMEC, O.C. (Fn. 71), 41; F. KOPECNY, K symetrii a asymetril $v$ jazyce, Naš tec 55 (1972) 68-72. 
6.3. Zusammenfassung zur lexikalischen Analyse: s. unter 11.1.

\section{SYNTAKTISCHE CHARAKTERISTIK}

Die Analyse der syntaktischen Strukturen unserer Texte wird dadurch erschwert, dass es sich un Ubersetzungen aus einem lateinischen Original handelt. Im Kapitel uber die Ubersetzungstechnik (4.) wurden schon die wichtigsten Ubersetzungsarten und die Einflüsse der lateinischen syntaktischen konstruktionen auf das Alttschechische unserer Denkmäler festgestellt (siehe 4.3.). Es zeigte sich, dass die lateinischen Partizip- und Infinitivkonstruktionen (4.3.1., 4.3.3.) durch heimische Mittel ausgedrückt werden und dass die Nachahmungen des Lateinischen recht selten sind. Der Einfluss dieser hochentwickelten Kultursprache bestand eher im Zwang, für die oft komplizierten Gedankenaufzeichnungen, die im Lateinischen durch vorhandene syntaktische Mittel leicht ausgedrückt wurden, auch im Alttschechischen entsprechende syntaktische Aquivalente zu finden. Der Jahrhunderte wahrende Kontakt mit dem Latein brachte die relativ rasche Entwicklung der Hypotaxe besonders im XIV. Jh. und die darauf folgende systemisierung der hypotaktischen Formalmittel mit sich. 78 Die schon dargebotene syntaktische Charakteristik (4.3.) betrachten wir für deskriptive zwecke als ausreichend; hier werden noch einige syntaktische Besonderheiten im Hinblick auf ihre Position im alttschechischen syntaktischen Teilsystem behandelt. Es wird uns vor allem die Beziehung zu zentrum und Peripherie des syntaktischen Teilsystems (7.1.) und ihre Klassifizierung als Reprasentanten der systementwicklungsvorgănge (7.2.) interessieren.

\subsubsection{Zum Begriff, syntaktisches System'}

Das syntaktische system in seiner komplizierten mehrfachen Verflechtung der Elemente und Relationen ist bis heute - vor allem in der Diachronie - nur wenig erforscht. Die syntaktischen Phänomene und ihre systemrelationen reagieren schneller als die anderen sprachlichen Teilsysteme auf die von aussen gestellten Anforderungen an die kommunikative Funktion der Sprache, sie sind am meisten den Einflüssen der strukturen anderer Sprachen aufgeschlossen (z.B. die

78 B. HAVRANEK, Vy̛voj spisouného jazyka Ceského, in: Ceskoslovenská vlastivèda, Reihe II Jazyk, Praha 1936, 29; - J. BAUER, Vy̆voj Ceského souvět 1, Praha 1960, $19 \mathrm{ff.}$ 
alttschechische Entwicklung der Hypotaxe unter lateinischem Einfluss, die Einführung des Modalverbs musiti 'müssen' aus dem Deutschen anstatt einer pronominalen Dativkonstruktion mit byti, usw.). Gerade diese Eigenschaft des syntaktischen Systems erschwert die Entdeckung der systemzusamenhänge und deren Entwicklungsfaktoren. Sehr wenig wurden wegen der Kompliziertheit des Fragenkomplexes die zentralen und peripheren Erscheinungen in der syntax behandelt, 79 überhaupt noch nicht im Bereich des Wortgefüges. Wir werden auf dem Forschungswege dieses unbekannten Gebiets nur einige vorsichtige Schritte wagen (7.1.). Eine umfangreichere syntaktische studie uber den Satzbau unserer Textstrukturen mit allgemein geltenden Schlussfolgerungen erlaubt uns das relativ beschränte Material und besonders sein vom lateinischen original vorgezeichneter Charakter (vgl. 4.3.) nicht. Wir werden darum unsere Untersuchungen auf einige besondere Falle der syntaktischen wortverbindungen und auf die funktionelle Erklärung ihrer Systemposition (7.1.) und ihrer Entwicklungsvorgänge (7.2.) im Sprachsystem des Alttschechischen beschränken.

7.0.2. Die bisherige Literatur zur alttschechischen Syntax

Die alttschechische Syntax wurde im umfangreichen Werk von $\mathrm{J}$. GEBAUER ${ }^{80}$ bisher am ausfuhrlichsten beschrieben. Neben der alttschechischen Satzlehre werden auch die syntaktischen Bedeutungen der wortarten und ihrer Formen behandelt. Verschiedenen syntaktischen Teilbereichen und Problemen wurde eine ganze Menge von Studien gewidmet - von den wichtigsten seien besonders die Arbeiten von B. HAVRANEK und F. TRAVN1CEK ${ }^{81}$ angeführt. F. Trávnlðek befasste sich nochmals mit alttschechischer syntax in dem Hochschullehrbuch der tschechischen historischen Grammatik, 82 allerdings nicht in ihrem ganzen Umfang, sondern nur mit den Differenzerscheinungen

79 Die Pionierarbeit auf diesem Gebiet leistete mit seiner Studie $J$. BAUER, Phénomènes centraux et périphériques dans l'évolution du système syntactique de la langue tchèque, in: Travaux linguistiques de Prague 2 (1966) 225-238.

$80 \mathrm{~J}$. GEBAUER, Historická mluvnice jazyka Łeského IV, Skladba, herausgegeben aus dem Nachlass von F. Trávnicek, Praha 1929, 764 S.

81 B. HAVRANEK, Genera verbi v slovanskych jazyclch, I, II, Praha 1928, 1937; - F. TRAVNICEK, Neslovesné věty v Łeštině, I, II, Brno 1930, 1931.

82 F. TRAVNICEK, Historická mluvnice ¿eská III, Skladba, Praha 1956 (Hochschullehrbuch). 
zum Neutschechischen. Eine moderne strukturelle Bearbeitung des alttschechischen Satzgefüges lieferte in seinen methodisch beispielhaften und materiell vorzüglich fundierten Arbeiten der Brünner Slavist J. BAUER. 83

7.1. Die syntaktischen zentralen und peripheren Erscheinungen

Die Frage der syntaktischen Kategorien und Typen ist bis heute immer noch nicht $\mathrm{klar}$ genug dargelegt worden. Es ist dann ziemlich schwierig, die Kriterien für zentrale oder periphere zugehorigkeit von syntaktischen Phänomenen zu finden, wenn die Verhältnisse auf der syntaktischen Ebene noch unklar bleiben und wenn man bei syntaktischen Erscheinungen mit ihren vielfaltigen Systembindungen sowohl die formalen als auch die syntaktisch-semantischen Relationen berücksichtigen muss. In der Satzlehre wurden einige alttschechische zentrale und periphere satztypen von J. BAUER ${ }^{84}$ ausgegliedert (z.B. werden die eingliedrigen Sätze von den zweigliedrigen an die Peripherie verdrängt). Bei den syntaktischen Wortgruppierungen stehen die Komponenten nur selten in binären Korrelationen, es handelt sich hier eher um eine Hierarchie mehrgliedriger Relationen, die dann für die Systemposition einer syntaktischen Einheit massgebend sein muss. Die Festlegung einer solchen Hierarchie ist aber relativ. Die Reihenfolge in der Hierarchie der syntaktischen systemrelationen kann sich durch verschiedene Einflüsse (anderer sprachen oder sich rasch verăndernden Wirklichkeit) schneller in Bewegung setzen, als dies in den ubrigen systemen einer sprache der Fall ist. In einer bestimmten Entwicklungsperiode kann aber das syntaktische System für eine syntaktisch-semantische Funktion noch keine Relationenhierarchie haben und sich mehrerer gleichwertiger formeller Mittel zur konkreten Ausdrucksweise bedienen. Im Verlauf etwa eines Jahrhunderts, das ungefahr in unserem Material belegt ist, kann man aus diesen Gründen nicht alle Erscheinungen im Bereich der syntaktischen Funktionen von Wortgefügen als zentral oder peripher einordnen, weil auch ihre Frequenz und ihre Varilerbarkeit in unseren einzelnen Textstrukturen nicht massgebend sein muss. Wir sind gezwungen die tschechische historische Gramatik, in unserem Fall die histori-

$83 \mathrm{~J}$. BAUER, Vývoj... (s.Fn. 78); vgl. auch seine anderen Studien, zusammengestelit im Sammelband Syntactica slavica, Brno 1972 (besonders die studie Staroceská věta a starođeské souvêt 1 na základé srovnávacim, 107-121).

$84 \mathrm{Vgl}$. J. BAUER, Phénomènes... (Fn. 79), 232-235. 
sche Syntax von Gebauer, zu Hilfe nehmen. In den Beschreibungen der Bedeutung von Wortarten und Wortgefügen von Gebauer stellt man fest, welche syntaktischen phănomene für die gegebene Periode des XIV. Jhs. von grosster Frequenz und wichtigkeit waren und welche progressiv oder schon veraltet erschienen. Dieser Vergleich unseres Materials mit dem von Gebauer gesammelten wird auch zeigen, welche syntaktischen Mittel durch recht zahlreiche Relationen an den Kern des systems eng gebunden sind und welche sich schon durch ihre Ausdrucksform in einem lockeren Verhăltnis zu den zentralen Kategorien und Funktionen befinden.

In unseren Texten kommen noch einige prăpositionslose adnominale Genitive vor. Sie stehen, formell-syntaktisch gesehen, in der Funktion eines Attributs, semantisch sind es ,genitivi partitivi'. Am interessantesten sind die schon seltenen Belege mit solchen Genitiven nach einem substantivierten Pronomen ijeden (nizddný) 'keiner'. jeden 'einer', $c \ell$ 'wessen' - L 14,24: nemo virorum illorum ijeden muz

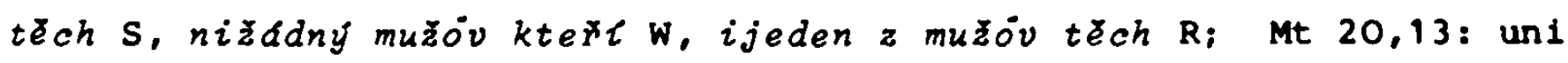
eorum jednomu jich $S$, jednomu $z$ nich $R$; L 14,5: cuius vestrum $t i$ vas $S, \ell \ell R, \tau \ell z$ vás W. Es handelt sich hier sicher nicht um einen Latinismus, diese Funktion des Genitivs nach Pronomina war im Altkirchenslavischen ziemlich haufig, 85 es könnte eher ein syntaktischer Palăoslovenismus sein (unter dem Einfluss des Griechischen?, vgl.z.B.

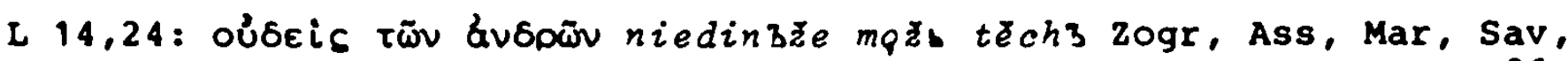
aber auch in den Gregors Homilien niktože muż onéchs Bes $272 \mathrm{aB8} 8)^{86}$ Die von Gebauer angeführten Beispiele ${ }^{87}$ zu dieser Erscheinung stammen alle aus der alteren schicht der alttschechischen Denkmaler (Psalter, Evangeliare, Alexandreis, Stitny) und bezeugen, dass dies schon im xIV. Jh. ein syntaktischer Archaismus war. Die attributive Funktion eines prăpositionslosen Genitivs wurde im Verlauf des XIV. Jhs. immer mehr auf die echte Partitivfunktion bei den Angaben eines Teiles aus dem Ganzen bei substantiven und Numeralien konzentriert. Diese Funktion befindet sich bei Substantiven und Numeralien im zentrum ihrer systemrelationen und wird durch parallele Funktionen des -genitivus possessivus, qualitatis' u.a. und durch ihre hohe Frequenz

85 J. KURZ, UCebnice jazyka staroslovênského, Praha 1969, 207.

86 Das zitat stammt aus dem altkirchenslavischen Denkmal tschechischer Provenienz - Besedy na evangelije papy Grigorija Velikago (Bes), vgl. Quellenverzeichnis im Slovnlk jazyka staroslovenskeho, Praha 1966, LXVII; zitiert nach einer Abschrift von Prof. Mares mit seiner freundlichen Erlaubnis.

87 J. GEBAUER, Skladba (siehe Fn. 80), 338-339. 
gestärkt. Bei den Pronomina war diese syntaktische Funktion isoliert, darum an die Peripherie gedrängt und letzten Endes ganz aus dem System ausgeschieden; in der zweiten Hălfte des XIV. Jhs. wurde sie durch einen präpositionalen Genitiv ersetzt (vgl. die Lesarten in den Handschriften $R, W$ bei obigen Beispielen).

Bei den Numeralia kommen keine Unregelmässigkeiten vor. Einen aufschlussreichen Fehler in $\mathrm{Z}$ ahlangaben hat aber die Handschrift $R$ an folgender Stelle - J 6,10: viri numero quasi quinque milia poret

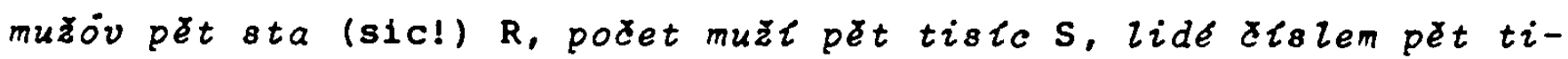
sicuov $W$. Die Zahlangaben wurden in der $\mathrm{R}$-Vorlage $\left(\mathrm{X}_{1}\right)$ mit aller Wahrscheinlichkeit abgekurzt. Da man nicht voraussetzen kann, dass ein mittelalterlicher Schreiber die ublichsten lateinischen Abkürzungen für Zahlangaben schlecht entziffern würde (hier VM für 5000), muss eine andere Erklärung gesucht werden. Diese Stelle ist nicht die einzige in $R$, wo man in den $Z$ ahlangaben Fehler findet - L 2,36: annis septem sedm let $S$, peet let $R$; $J 2,19$ : in tribus diebus ve trech dnech $w, v$ etylech dnech $\mathrm{R} ; \mathrm{J} 11,39$ : quadriduanus 8 tvrty den $W, t_{i} i \operatorname{dny} R, D ; I$ 15,7: nonaginta novem devietidedt devieti $S, W$, devadesat $R_{i} L$ 16,6: quinquaginta padesat $S, W, \xi e d e s a t ~ R$. Die Fehler kommen merkwürdigerweise gerade bei solchen $\mathrm{zahlwbrtern}$ vor, deren $\mathrm{Zahlenwerte}$ durch verschiedene glagolitische und kyrillische Buchstaben ausgedrückt wurden. Es wăre möglich, dass die Vorlage für Handschrift $R$ kyrillische Buchstaben als Zahlzeichen hatte, die die alteren glagolitischen unrichtig ersetzten und vom Kopisten der Hs. $R$ darum nicht richtig wiedergegeben werden konnten.

Der adnominale Dativ bei Deverbativen ist im XIV. Jh. im Alttschechischen schon eine periphere Erscheinung, obwohl er noch des öfteren auf die Rektion des Grundverbs gestutzt ist (z.B. otpugzenie hriechóm 'Vergebung der Sünden', otpużeti + Dat. 'vergeben'). Unser Beleg skrehot zuböm (stridor dentium Mt 8,12; Mt 13,50; Mt 22,13; kommt nur in $S, R$ vor) ist auch später noch ziemlich hăufig ${ }^{88}$, was aber durch den Ubergang $z u$ einer erstarrten Redewendung $z u$ erklaren wăre. Schon im XIV. Jh. wird dieser adnominale Dativ meist durch eine für diese syntaktische Funktion zentralen Genitiv ersetzt (vgl. in der jungen Handschrift w - Mt 22,13: skrehot zubóv).

Als periphere Erscheinung musste man auch die Supinumform in $\mathrm{J}$ 6,31: dedit eis manducare dal jim jest $\mathrm{R}$ bezeichnen. Das alttschechische supinum erscheint regelmässig nach, verba movendi' und nur

88 J. GEBAUER, Skladba (s. Fn. 80), 396. 
selten dann, wo sich die Bewegung nur aus dem Kontext ergibt. 89 Das Fehlen der formalen Bedingung (ddti ist kein , verbum movendi') verschiebt dann eine solche nur durch semantische Voraussetzung gehaltene - mit dem Geben muss eine Bewegung verbunden sein - syntaktische Erscheinung an die Peripherie.

Anm. : Die Form jest 'essen' könnte aber auch ein Moravismus sein (bis heute in den zentralmăhrischen Dialekten im Infinitiv nur jest). Diese măhrischen Infinitivformen ohne Quantităt und mit der Endung - $t$ (anstatt $-t i$ ) wilrden noch eine gründliche syntaktische Analyse verdienen, um herauszufinden, ob man hier nicht noch die Reste der alten nominalen Funktion des Infinitivs begegnet (diese kurzen Infinitivformen kommen nach Modalverben museti 'mussen', ume$t i$ 'konnen', miti 'haben' und 'sollen', und nach byti 'sein' vor).

\subsection{Die Entwicklungsvorgänge im syntaktischen Teilsystem}

Unser Material ist für 1rgendwelche verallgemeinernde Schlussfolgerungen im Bereich der alttschechischen Satzlehre was den belegten zeitraum betrifft nicht breit genug und ausserdem wurde das alttschechische Satzgefüge sehr gründlich von J. BAUER (vgl. Fn. 78) erforscht. Wir werden uns auf die Untersuchung einiger syntaktischer Funktionen der grammatikalischen Kategorien und ihrer Entwicklungstendenzen beschrănken. Einige Entwicklungsvorgănge, wie z.B. die sich im Laufe der zeit ändernde Rolle der alttschechischen Partizipia, wurde schon (4.3.1.) behandelt. Jetzt werden uns besonders die Anderungen im Kasussystem, in der Kategorie des Numerus, des Passivs und in der Form der Negation im Alttschechischen interessieren. Die Entwicklungstendenzen kann man durch einen Vergleich unserer Belege mit den Erkenntnissen der alttschechischen historischen syntax feststellen.

Im Kasussystem kommt neben der Peripherisierung einiger Kasusfunktionen (vgl. 7.1.) in unseren Textstrukturen besonders der formale Ausbau der Kategorie der Belebtheit und Unbelebtheit klar zum Ausdruck. Die ălteren Nom./Akk. Formen werden nicht nur bei Personennamen, sondern auch bei Tiernamen ( $2 \mathrm{u}$ denen damals auch bës, duch gehörte) durch die jüngeren Gen./Akk.-Formen ersetzt. Die ălteren Formen kommen in unseren älteren Handschriften $D$ und $S$ vor, in der Hs. $R$ und besonders in $W$ werden sie schon meist durch die Gen./Akk.Formen ersetzt. Die Nom./Akk. Formen findet man interessanterweise am häufigsten bei lexikalischen Archaismen (z.B. L 11,14: eicisset daemonium vyhna bĕs S, R, bësy W; ibid.: eicere daemonium vyhnati

89 J. GEBAUER, Skladba (s. Fn. 80), 585. 
bësa S, ..bès R, ...diabla W; aber auch bei anderen Wortern - Mt 3,16: vidit Spiritum Dei descendentem sicut columbam videl Duch Bo$z_{i}$ /Ducha svateho W/ schodiece jako holub/holubici R/ S, R, W, U.a. Die Kategorie des Duals unterliegt im XIV. Jh. im Alttschechischen starken Veränderungen. In unseren alteren Texten sind die Duale besonders in den nominalen Formen noch stark belegt (in jüngeren Texten oft schon durch die pluralformen ersetzt), auch dort, wo die Objekte nur aus dem Kontext als zwei Dinge zu verstehen sind, vgl. 2.B. Mc 7,33: misit digitos suos in auriculas pusti prsty sva $v u s i$ S, pusti prsty $v$ uei R, upusti prsty své $v$ usi w. Die verbalen Dualformen werden, wie es die Belege aus den jüngeren Handschriften $R$ und $W$ andeuten, früher als die nominalen durch Pluralformen ersetzt - Mt 20,21: ut sedeant hi duo filli mei aby sedeli/sedela R/ tato dva syny ma $W, R ;$ L 10,23: oculi qui vident ori ktexej vidita $\mathrm{S}$, odi jenz vidita $R$, odi jezto vidie W: L 24,17: quos confertis (sc. duo discipuli) ad invicem ambulantes et estis tristes jerto roamlüvata /rozjimate $\mathrm{R} /$ jdice a suce smutni /i sta smutna R/ W, R; $J$ 10, 30: ego et Pater unum sumus ja a otec jeden sve /sme R, D/W, R, D; Mt 15,14: ambo...cadunt oba...upadnú $W, o b a . . . u p a d n e t a$. Wie es die Konkordanzstellen unserer Handschriften bezeugen, beginnt die Tendenz zur Ersetzung des Duals durch den Plural in der Konjugation; in der Deklination können sich die Dualformen länger halten, weil sie sich auf die sehr frequenten und beständigen Formen der Numeralia dva, oba als eine besondere Numeralienrektion stützen (vielleicht also keine wahre Dualbedeutung, vgl. die Entwicklung im Russischen und Serbokroatischen). Die starke Tendenz zur Vereinheitlichung besonders der verbalen pluralformen, die auch in der heutigen tschechi schen Umgangssprache sehr ausgeprägt ist, zeigt sich auch in der sto rung der Kongruenz bel verbalen Pluralformen der Neutra - J 3,20: ut non arguantur opera eius aby netresktany byla/netresktali W/ diela jeho R, W.

Die periphrastischen Formen des Passivs konstituieren sich in den temporalen Funktionen unter dem Einfluss des Lateinischen. Die Feststellung HAVRANEKs, 90 dass das lateinische passivum sowohl durch das alttschechische periphrastische Passivum als auch durch aktive oder reflexive Verbalformen ubersetzt wird, bestatigen auch unsere Texte - Mt 22,10: impletae sunt nuptiae aby nazel duom svatebnt $\mathbf{S}, \mathbf{R}$ $a b y$ byla svatba naplnéna W: Mc 16,16: baptizatus fuerit krest vezme 90 B. HAVRANEK, Genera verbi II, Praha 1937, $101 \mathrm{ff}$. 


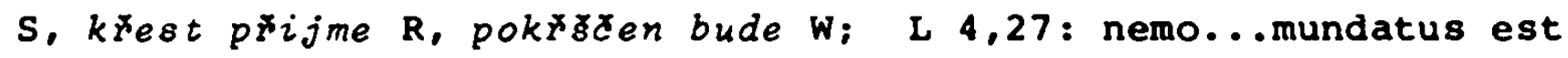
nikte...neby 2 uzdraven $W$, neby 2 ijeden zdráv R; L 13,13: erecta est sé aprostie $W$, zprostiena jest $R ; L$ L 16,22: sepultus est pohrben jest S, W, pohrebechu jej R. Die Belege aus unseren Texten bezeugen die Entwicklungstendenz zum periphrastischen Passivum - die alteren Handschriften haben oft noch aktive oder reflexive Verbalformen, dagegen bedient sich die jüngste Hs. W meist schon einer periphrastischen Passivform. Auf die noch lockere funktionelle Position der periphrastischen Passivformen weisen die Belege hin, wo im alttschechischen Text eine Passivform einer lateinischen Aktivform gegenübersteht - J 11,10: offendit uražen bỹva R, uražen bude D, urazl se W: J 11.34: ubl posuistis eum kde jest polozen $W, k d e$ ste jeho polozili R, D. Schon HAVRANEK ${ }^{91}$ stellte fest, dass die Passivformen im Alttschechischen auch für die resultative Bedeutung der Handlung, die später durch perfektive Verbalformen ausgedrückt wird, benútzt wurden. Die vielfachen semantisch-syntaktischen Funktionen der Passiv formen werden langsam vereinfacht und beschränkt, aber im Bereich der temporalen Funktionen stabilisieren sie sich viel spater - erst im Laufe des XVI. Jhs.

Die alttschechische satznegation wurde gründilch von GEBAUER 92 bearbeitet. Die von ihm entdeckte Entwicklungstendenz zur Ersetzung der einfachen Satznegation (die Verneinung bei einem Satzglied stellt den ganzen Satz in die Negation) durch eine doppelte Satznegation kommt auch in unseren Texten zum Ausdruck. Die alteren Texte haben noch die einfache Satznegation, z.B. L 16,21: nemo 1111 dadat nikte jemu dodadiese $\mathrm{S}$, nikto mu nedadieš W, R; L 16,31: neque si quis ex mortuis resurrexerit credent ani komu $z$ mrtvych votanuce

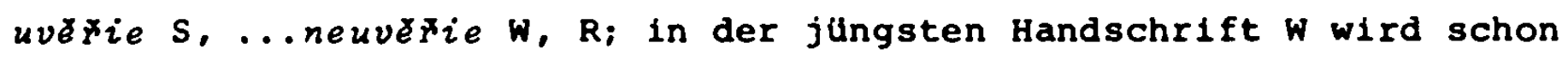
meist die doppelte Satznegation verwendet, z.B. J 7,4: nemo quippe in occulto quid facit nebo nizddny tajne nitse netini $w$, nebo ijeden tajne nic uxini $R, D ; J$ 7,13: nemo tamen palam loquebatur de 1110

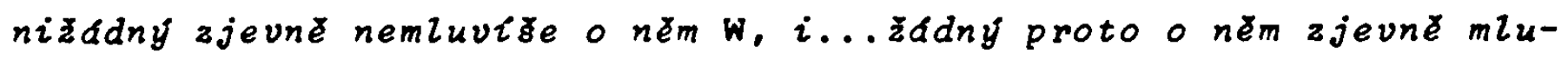
vięe R, u.a.

Die Wortfolge in den alteren Evangeliarhandschriften ist nicht streng an das lateinische original gebunden, obwohl das alteste Frag ment $A$ mehr als die übrigen Handschriften $S, D, C, e v$ auch $R$ dem la teinischen Vorbild in dieser Hinsicht unterliegt und daher anzunehme 1st, dass auch der Archetyp eine latinisierende Wortfolge hatte. Die

91 B. HAVRANEK, Genera verbI II, Praha 1937, 102.

92 J. GEBAUER, Skladba (s. Fn. 80), 638-673. 
Schreiber der Handschriften C, D, S, R übersetzten nicht mehr, sie verglichen nicht mehr (teilweise mit Ausnahme der Hs. S) den vorliegenden alttschechischen Text mit dem lateinischen, doch versuchten sie, die Vorlage nicht nur lexikalisch oder grammatikalisch, sondern auch, was die Wortfolge betrifft, auf den zeitgemăssen Stand zu bringen. Die zweite Welle der latinisierten Wortfolge kann man besonders in der Handschrift $w$ beobachten, die die alteren Vorlagen durch einen Vergleich mit dem lateinischen Text verbesserte, aber auch bei einigen neueren Perikopen der Hs. $R$, 2.B. Mt 6,16: cum autem leiunatis nolite fieri sicut hypocritae tristes kdyzto sé postite nerod'te býti jako pokrytci smutni demoliuntur enim facies suas ut pareant hominibus leiunantes nebo zamitie svü tvar aby znamenáni byli pred lidmi postnici amen dico vobis quia receperunt mercedem suam zavèrné pravi vám że jsú vaèIi mzdu svú R, usw. Die Welle der latinisierenden wortfolge dauert in den Ubersetzungen der Evangelien weiter an, z.B. hat das spätere Olmützer Evangeliar eine stark latinisierende Wortfolge ${ }^{93}$; erst die alttschechischen biblischen Texte des XV. Jhs. berúcksichtigen bei der Wortfolge wieder die abweichende syntaktische Struktur des Alttschechischen. Wir sind im Gegensatz zu VASICA 94 der Meinung, dass der Archetyp der alttschechischen Evangeliarubersetzung die lateinische Wortfolge in der altesten (interlinearen) Ubersetzung beibehalten hat. Die relative Freiheit der Wortfolge in den Handschriften $C, D, S$ ergab sich als Folge der Verbesserungen der Kopisten, die die altschechischen Texte nicht nach dem Lateinischen korrigierten.

7.3. Die Zusammenfassung der syntaktischen Charakteristik: s. 11.2.

\section{MORPHOLOGISCHE CHARAKTERISTIK}

Die Analyse der morphologischen Struktur unserer Texte bleibt auf die Untersuchung der Besonderheiten auf formal-funktioneller Ebene beschränkt; die Bedeutungen der grammatikalischen Kategorien (z.B. Numerus, Kasus) werden hier nicht berucksichtigt (vgl. dazu 7.1.). Die Einflüsse der lateinischen Formen auf die alttschechische Deklination wurden schon behandelt (4.3.4.4.); die Konju-

93 J. LEVY, Ceské teorie pł̌ekladu, Praha 1957 , 14-15.

94 J. VASICA, O.C. (s. Fn. 2), 54 . 
gationsformen unserer Textstrukturen wurden in dieser Hinsicht auch einer Analyse unterzogen $(4.3 .1 ., 4.3 .2,4$ 4.3.3.). Wir werden uns auf die Abweichungen in der Deklination (8.1.) und der Konjugation (8.2.) konzentrieren.

\subsubsection{Zum Begriff der diachronen Morphologie}

Das (formale) morphologische system des Alttschechischen ist traditionell hinlänglich gut beschrieben, genauso wie die Reihenfolge der Endungsänderungen. Die Problematik des funktionellen zusammenhanges und der Bedingungen, die im System zu den Veränderungen führten, ist bis heute nur wenig erforscht. Unser Material, das auf relativ wenige parallele Texte aus einer nicht zu langen zeitperiode (etwa 80 Jahre) beschränkt ist, erlaubt es uns nicht, in diesem Problemkreis neue umfassende Losungen $z u$ wagen. Die morphonologischen Untersuchungen der alttschechischen Formalmittel benötigen eine breitere Materialbasis als die unsere. Die diachrone strukturelle Morphologie ist eine noch zu junge Disziplin, die heute noch nicht im stande ist, ein vollstandiges Bild der Entwicklung des alttschechischen morphologischen systems darzubieten. Die Schwierigkeiten liegen vor allem bel der kleinen Anzahl der strukturalistischen Vorarbeiten für die einzelnen Teilsysteme. Unsere Analyse soll einige der vielen fehlenden Steine in das unvollständige Mosaikbild des alttschechischen morphologischen systems einfügen.

8.1. Die Deklination

Die Deklinationsformen unserer Textstrukturen entsprechen in einem erstaunlich hohen Mass dem alttschechischen Standard des XIV. Jhs. Die Abweichungen in der Deklination der Substantive sind so selten, dass wir nur wenig Raum brauchen werden, um sie zu beschreiben (8.1.2.). Mehr Besonderheiten findet man schon bei den Pronomina (8.1.3.). Die zeitgemăssen, keinesfalls archaisierten Formen der substantivischen Deklination zeigen, dass die Entwicklung in diesem Teilsystem fast abgeschlossen worden ist und dass die Anpassungsfăhigkeit dieses Teilsystems den Sprachgewohnheiten der Kopisten grösser als die des syntaktischen (vgl. 7.0.1.) war. Die Reste der älteren Kasusendungen bei den Substantiven wurden von den Kopisten fast restlos beseitigt und durch neuere lebende ersetzt, sodass wir 
die ausgehenden Entwicklungsvorgange der alttschechischen Deklination nur an einigen Beispielen feststellen kơnnen.

\subsubsection{Die bisherige Literatur}

Die alttschechische Deklination wurde bisher am ausfuhrlichsten von J. GEBAUER, ubersichtlicher von F. TRAVNICEK und unter Berücksichtigung der moderneren Erkenntnisse von V. VAŽNY95 beschrieben. Es gibt eine ganze Menge von Monographien zur Entwicklung der alttschechischen Deklination, von denen bis heute noch die Arbeiten von F. OBERPFALCER-JILEK, K. ROCHER-SKALA, und besonders die strukturalistischen, viele Anregungen enthaltenen Studien von $v$. SKALICKA und $k$. HAUSENBLAS 96 wertvoll sind.

\subsubsection{Die Substantive}

Be1 den in unseren Textstrukturen belegten Deklinationsformen der Substantive kommen äusserst selten Besonderheiten vor. Nur vereinzelte Schwankungen (Nom./Akk. anstatt eines damals schon hăufigen Gen./Akk. bei belebten Substantiven, u-Stämme-Endungen bei den o-stämmen, u.a.) bezeugen den fast vollgezogenen Umbau der alten Kategorie des Stammes zur Kategorie des Genus. Uber die Entwicklung der Kategorie des Numerus wurde schon gesprochen (siehe 7.2.). Die älteren Deklinationsendungen in unseren Texten passten sich wăhrend der Abschreibungen den zeitgemassen neueren an. Einen einzigen eindeutigen Archaismus (einen Paläoslovenismus?) findet man an folgender Stelle - L 14,24: nemo virorum illorum...gustabit cenam meam

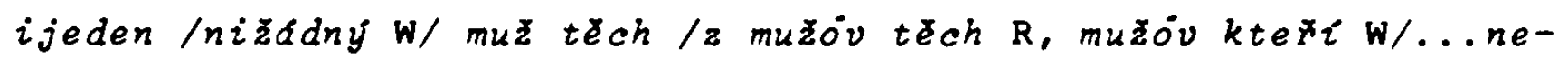
okusl vęer̉e mé $S, R, W$ (vgl. diese biblische stelle in Besedy Gregors des Grossen: niktože muž onéchz $272 \mathrm{aB8}$, siehe auch 7.1.). Sehr selten kommen morphologische Moravismen vor - J 4,28: dicit illis hominibus żena povede oným lidóm /onëm lidem R/ W, R; J 12,1: ante sex dies Paschae venit Bethaniam pred sesti dnech velikonoenni

95 J. GEBAUER, Historicka mluvnice jazyka Ceskêho III/1, Skloñován1, Prag-Wien 1896; - F. TRAVNfCEK, Historická mluvnice Ceskoslovenská, Praha 1935, 279-374; - V. VAŹNY, Historická mluvnice ceská II, Tvaroslovi i (Skloňovánf), Praha 1964.

96 F. OBERPFALCER-JfLEK, Rod jmen v testiné, Praha 1933; - K. ROCHER-SKALA, Gramaticky rod a vývoj Ceskych deklinacl jmennych, Praha 1934; - V. SKALICKA, Vyvoj Ceské deklinace, Praha 1941; - K. hausenblas, vývoj predmétového genitivu v Cestině, Praha 1958. 
prisei iežż do Betané R; sowohl der Dat.Plur. lidóm als auch der Gen.Plur. dnech (anstatt $d n o^{\circ}$, $d n i$ ) kommen nur in den altmährischen Texten vor. 97 Die Deklinationsformen der substantive helfen uns also nicht, das Alter und den Entstehungsort des Archetyps näher $\mathrm{zu}$ bestimmen (die Moravismen kann man den Kopisten zuschreiben).

\subsubsection{Die Pronomina}

In der Deklination der Pronomina kommen noch einige sehr alte Formen vor, besonders in der jüngsten (!) Handschrift $W$ (z.B. die alten Formen des Dat. Plur. - Mt 19, 27 und J 14,9: nobis nem W; $J$ 15,21: vobis vem $W$, und so an zahlreichen weiteren Stellen; die Handschriften $R$ und $S$ - in $S$ nur einmal vem $L 10,24$ - haben schon $n\left(\dot{m}, v\left(b^{\prime}\right)\right.$. Nur in $\mathrm{W}$ sind die alten pronominalen Formen des Gen./ Akk. von $8 \hat{b m}$ - samoho - belegt, die Handschriften $R$ und $D$ haben schon die Formen der zusammengesetzten (Adjektiv-)Deklination samého - J 17,3: te solum té samoho W, te sameho R, Di J 17,5: temet ipsum $u$ tebe samoho $W, v$ tobe $\mathrm{R}$, $u$ tebe $\mathrm{D}$; nur in der $\mathrm{Hs}$. $W$ belegt ist die erstarrte absolutiv verwendete Form $k e$ (Nom.Sg.N.) - Mt 12,48: quae est mater mea et qui sunt fratres mei ké/ktera S/

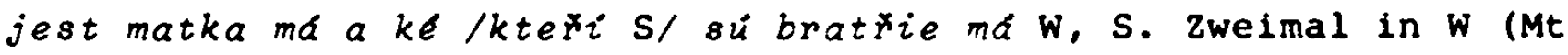
3,17 und $M t 21,38$ ) und nur einmal in $R, S$ (Mt 3,17 ) kommt für das lateinische Pron.Masc. hic die alte Form ted vor. Diese Form sollte richtig tet ${ }^{98}$ heissen (tet aus $t z t z$ ), das $-d$ anstatt eines - $t$ in der Neutralisationsposition am Ende des Wortes könnte leicht nach Diktat geschrieben worden sein. Noch einen Archaismus - vielleicht noch einen Paläoslovenismus - findet man in J 1,7: hic /Jo-

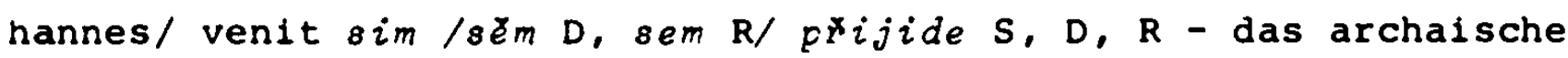
Demonstrativpronomen sen (oder ev. sier.) wurde von den Kopisten nicht mehr verstanden, fehlerhaft abgeschrieben und dann mit dem Adverb, hic' sem ('hierher') verwechselt. Die Handschrift $W$, besonders im Vergleich $z u$ ihrem relativ progressiven Wortschatz (vgl. unter 4.4.) ist bei der Auswahl der Personal-, Interrogativ- und Demonstrativpronomina ziemlich konservativ (vgl. aber 4.4.3., die Ubersetzungsweise von nemo, omnis, wo auch die Handschrift $W$ schon junge Ausdrulcke hat!). Kam der Schreiber der Hs. $W$ aus einer mundartlich archaisierenden (mähr.-slowakischen) Gegend?

97 Vgl. J. GEBAUER, Sklon̆ovánl (siehe Fn. 95), 93, 413.

$98 \mathrm{Vgl}$. J. GEBAUER, Skloňovánl (siehe Fa. 95), 442. 
Die Konjugationsformen unserer Textstrukturen entsprechen im allgemeinen dem Gebrauch im Alttschechischen des XIV. Jhs. Einige Entwicklungstendenzen, wie z.B. das zurulcktreten der einfachen Vergangenheitszeiten (Aorist und Imperfekt) zugunsten der zusamengesetzten Perfektformen, ist in unseren Handschriften noch nicht im grösseren Umfang feststellbar. Dagegen kann man ziemlich klar einige andere Entwicklungstendenzen bei Verbreitung neuer Konjugationsendungen beobachten, 2.B. die $-m$ Endung der 1.Person Sing. Ind.Prăs. anstatt des älteren $-u(>-i)$ bei den Verben der IV. und $V$. Konjugationsklasse (Typ prosim, dě $\zeta \mathrm{a}$ ) kommt in der Handschrift $W$ fast regelmässig, in der Hs. $R$ oft, dagegen in der Hs. S nur selten vor (J 5,31: perhibeo testimonium svedeðstvie dávám $\mathrm{W}, \ldots$ dávaji R; J 8,25: loquor mluvim W, mluvi R; L 2,49: opportet me esse musi byjti S, R, mosim býti w, usw.). Bis auf die Formen des Futurs, die noch näher untersucht werden (8.2.2.), kommen in unseren Texten keine Besonderheiten bei den Konjugationsformen vor.

\subsubsection{Die bisherige Literatur}

Obwohl die tschechische (und besonders die alttschechische) Konjugation bis heute im Ganzen noch nicht strukturell bearbeitet wurde, gibt es auch fur das alttschechische Verb genügend Vorarbeiten, die einmal mit Hilfe eines umfangreicheren Materials als das unsere ist, eine solche funktionelle Bearbeitung der alttschechischen Konjugation ermöglichen werden. Die beste Beschreibung des alttschechischen Verbs liefert immer noch die Historická mluvnice von J. GEBAUER. Die historische Grammatik von F. TRÁUNfCEk bietet eine gute Ubersicht, wichtiger ist aber seine studie zum Aspekt im Tschechischen. Die letzte Bearbeitung der alttschechischen Konjugation bringt das Hochschullehrbuch der tschechischen historischen Grammatik, Teil Konjugation, von A. DOSTAL ${ }^{99}$ mit kurzen, manchmal recht strittigen Versuchen der funktionellen Erklärungen zu den Entwicklungen des tschechischen verbalen Teilsystems.

$99 \mathrm{~J}$. GEBAUER, Historická mluvnice jazyka Ceského III/2, Casován1, Praha 1909; - F. TRAVNfCEK, 0.C. (siehe Fn. 95), 375-423; - F. TRÁVNCCEK, Studie o Ceském vidu slovesném, Praha 1923; - A. DOSTAL, Historická mluvnice Ceská II, Tvaroslovi 2 (CasovánI), Praha 1967. 
8.2.2. Die Problematik des alttschechischen Kond. Fut (des sog. 'futurum exactum') und die Funktionen der vier stämme des Hilfsverbs býti

vas altschechische Futur, wie schon angegeben (unter 4.3.2. 1.1.), wird in unseren Textstrukturen bei den Perfektiva durch synthetische (oft präigierte) Prăsensform, bei den Imperfektiva durch analytische Formen (budu + Inf.) ausgedrückt. Es kommen aber auch einige (4) Belege vor, die nach den bisherigen Erkenntnissen der tschechischen historischen Grammatik als ein ,futurum exactum' bezeichnet werden können - Mt 18,15: si te audierit lucratus es fratrem tuum bude $l i$ tè uslyzal /poslechne $l i$ tebe W/ zlskal s bratra svého R, W; J 3,3: nisi quis natus fuerit denuo non potest videre regnum Del jedno ktoż znova narodil se bude nemöz vidëti kralovstvie Bożieho W: $J$ 8,55: si dixero quia non scio eum ero similis vobis mendax $x_{k} u$ li neznal sem/jeho add. C, D, R, W/ budus vami $v$ roveñ /om. W, zarouno C, D, R/ selhal /nazván lhár C, D, R, W/ $S, C, D, R, W$; $12,24:$ nisi granum frumenti cadens in terram mortuum fuerit ipsum solum manet jedno at zrno upadna $v$ zemi umrelo /umrlo W/ bude jinak samo ostane $R$, $W$ (aber im folgenden Vers schon ein synthetisches Futur - J 12,25: si...mortuum fuerit pak $l_{i}$ umre /neumbre R/ W, R).

$J$. GEBAUER zitiert zwei unserer Belege $(J 8,55$ und $J 12,24)$ und ausserdem noch 15 andere und bezelchnet alle als ein, futurum exactum. 100 P. VYSKOCIL macht bei der Untersuchung dieser Formen im Altkirchenslavischen als erster die Andeutung, dass es sich hier nicht um ein , futurum exactum' sondern um einen Konditional des Futurs handelt. ${ }^{101}$ H. KRIZKOVA ${ }^{102}$ analysierte ausfuhrlich ausser den altkirchenslavischen und russischen auch die ebenfalls nicht zahlreichen alttschechischen Belege des sog. Futur II und glaubt behaupten zu können, dass diese Formen nur freie, zerlegbare syntaktische Verbindungen sind, bei denen die von Vyskoxil erwăhnte konditionale Funktion nur sekundăr ist. Kł̌lzkova meint weiter, dass die Formen budu + $\imath$-Part. nach der konstituierung der temporalen Funk-

100 J. Gebauer, Skladba (s. Fn. 80), 554-555; - d e r s., Casován 1 (s. Fn. 99), 426-427.

101 P. VYSKOCIL, Staroslovènské sztvorilz bpdo, slavia 25 (1956) 260-261.

102 H. KRIZKovA, Vývoj opisného futura $v$ jazycich slovanskych, zvlástè v rustinę, Praha 1960, 94-96, $156 \mathrm{ff.}$ 
tion des z-Partizips schwinden. Die Behauptung von Křlžková über die zeitliche Begrenzung der Existenz dieser Formen mag auch für das Alttschechische stimmen; was die Funktion dieser Form betrifft, bestätigen unsere Belege (und auch die von Gebauer angeführten) eher die Meinung von Vyskotil, dass es auch im Alttschechischen noch im XIV. Jh. einen Konditional des Futurs gab. Alle unsere vier Belege (und die meisten von Gebauer) kommen in Konditionalsätzen vor, wo eine reale Bedingung in der zukunft nicht bloss durch die Konjunktion ( $z_{i}$, jedno, jedno ar) ausgedrückt wird, sondern gleichzeitig und vor allem auch durch die zusammengesetzte verbale Form budu + $z$-Part., die für den Ausdruck dieser Modalităt relevanter als die nur signalisierende Konjunktion ist. In unseren sätzen tritt ein Aspekt der Modalität (einer bedingten Handlung) hervor, durch den die temporale Funktion dieser zusamengesetzten Form völlig überdeckt wird. Die Vollendung der Handlung in der zukunft wird als Modalitat aufgefasst, als Bedingung gestellt. Diese alten zusammengesetzten Formen stellen keine freie syntaktische Verbindungen sondern einen in das damalige Teilsystem der verbalen Formalmittel eingegliederten Ausdruck der Modalität in der zukunft dar, also ein Parallelmittel zu den Formen des Kond. Präs./Prät. bych + $\imath$-Part. Nach Ausbau des Tempus-Aspektsystems wurde der Kond.Fut. durch synthetische Aspektformen (wie es schon die Lesarten in den Hss. $R$ und $W$ zeigen) ersetzt; die Modalitat in der zukunft wird dann nur durch bereits ausgebaute hypotaktische Mittel, durch die Konjunktionen und die dadurch signalisierten schon eingefürten syntaktischen Strukturen - durch die Konditionalsätze - zum Ausdruck gebracht. Einer der Gründe für die Beseitigung des kond.Fut. (oder bei Kř́žková des Futurs II) lag sicher, wie Kł̌žcová feststellte, in der Stabilisierung der temporalen Funktion des 2 -Partizips; die Hauptursache liegt aber unserer Meinung nach in der Entwicklung der syntaktischen Funktionen des Hilfsverbs býti.

Die Formen des Hilfsverbs bÿti werden in den alteren Phasen des Alttschechischen von vier Stämmen gebildet: imperfektive Stämme $j e s-, b e-$ und perfektiv/imperfektive Stämme bud-, by-. ${ }^{103}$ Die Distri bution der Funktionen von býti in den alttschechischen zusammengesetzten Verbformen demonstriert die Ubersichtstafel an der folgenden Seite:

103 Für das Altkirchenslavische vgl. H. G. LUNT, Old Church Slavonic Grammar, S'Gravenhage 1955, 121. 


\begin{tabular}{|c|c|c|c|c|c|c|}
\hline Stamn Zeiten & $\begin{array}{l}\text { periphr. } \\
\text { Konjug. }\end{array}$ & $\begin{array}{l}\text { Perfekt } \\
\text { (Plpf.) }\end{array}$ & Futur & Kondiz. & Pass. & $\begin{array}{l}\text { wird } \\
\text { ausgedruckt }\end{array}$ \\
\hline$j e s-$ Prăs.jsem & nesa & nest & - & - & nesen & Temp., Genus \\
\hline$e-\{$ Impf.biech & nesa & nesl & - & - & nesen & ${ }^{+}$Temp. ${ }^{+}$Gen. \\
\hline Aor. bexch & - & - & - & - & tnesen & ${ }^{+}$Gen. \\
\hline$b u d\{$ Präs.budu & ${ }^{7}$ nesa & - & nesti & tnes 2 & nesen & Temp. ${ }^{+}$Mod. \\
\hline C Impi.budiech & $\overline{-}$ & - & - & - & $+\overline{n e s e n}$ & - -tGen. \\
\hline$b y-\overline{\text { Aor. bych }}$ & $n e s a$ & - & - & $n e s l$ & $+\overline{n e s e n}$ & Temp. Mod \\
\hline
\end{tabular}

Anm.: Durch das zeichen ${ }^{+}$wollen wir auf die peripheren Formen, die nur geringe Frequenz aufweisen und meist noch im XIV. Jh. ausgestorben sind, aufmerksam machen.

Alle mit ${ }^{+}$bezeichneten Formen, die meist noch Beziehungen zwischen zwei zeiten in der Vergangenheit oder zukunft ausdrücken konnten, werden nach der stabilisierung des Aspektsystems und nach dem Umbau des Tempussystems zuerst an die Peripherie verschoben und dann bald aus dem System der Verbformen beseitigt. Die verbliebenen Formen des Hilfsverbs byt $i$ bekommen neue Aufgaben - es wird nicht mehr die Relation zwischen den zeiten, sondern die relative grammatikalische zeit ausgedrückt (der jes-stamm bezeichnet die Gegenwart, der bud-Stamm die zukunft, der by-stamm die Vergangenhe1t, der bè-Stamm ist verschwunden).

Bei den Passivformen wurde das hilfsverb byti sowohl früher als auch nach dem Umbau des Tempussystems nur $z$ um Einordnen in eine grammatikalische zeit benüzt. Die alte Einteilung der Funktionen der stämme (jes-, bé-in temporaler Funktion, bud-, by- in modaler Funktion) wird durch die Entstehung des Aspektsystems und den damit verbundenen Umbau des Tempussystems zerstort. Die temporale Funktion geht auch auf den ursprünglich modalen stamm bud-über (die modale Funktion bei diesem stamm bleibt nur auf den Imperativ begrenzt) und iberdeckt die modale schattierung des von Ingressivum ${ }^{104}$ zum Perfektivum gewordenen budu. Durch diese Entwicklung wurde der Form budu + l-Part. die Grundlage entzogen, die Modalitat in der zukunft zu bezeichnen. Zum Ausdruck der modalen (bedingten) Handlung blieb dann nur eine einzige, vom system der alttschechischen Verbformen isolier te finite Form des Hilfsverbs byti - der später eher in die syntaktische Ebene eingegliederte Aorist bych.

Anm.: Es sind nur wenige Belege für die Imperfektformen vom

$104 \mathrm{Vgl}$. F. KOPECNY, Byti - verbum existentiae (VE), kopula (VC) a pomocné sloveso (VA), přecházejicl v morfém v ceétinè, slovenstiné, polstiné, Slavia 42 (1973) 147. 
Stamm bud- (budiech, usw.) im Alttschechischen bekannt, Gebauer führt nur drei an. Wir wollen von unseren Texten noch einige andere zitieren, die dadurch wichtig erscheinen, dass sie in den altesten Handschriften den lateinischen konjunktiv nach einem, cum historicum ersetzen. Auf diese Weise wird durch solche Imperfektformen nicht nu. die von GEBAUER 105 festgestellte Wiederholbarkeit der Handlung, sondern auch ihre Ublichkeit und Vertrautheit wiedergegeben. In dieser präzisen, eher stilistischen als grammatikalischen Funktion von budiech 'wurde' müssen wir die grossen Fahigkeiten der alten Ubersetze: schatzen, die von den kopisten nicht mehr verstanden und durch seman. tisch nicht so präzises bieše 'war' ersetzt wurde (die von Anfang an beginnende Vertrautheit der Handlung ist bei biese ausgeschaltet). Die budiech-Formen in den folgenden Belegen könnte man fast als einel alttschechischen ,modus narrativus' bezeichnen - Mt 1,18: cum esset ...desponsata Maria Ioseph Kdyz budiese /biełe R/ otdána...Maria Jozefu S, R; Mt 1,19: Ioseph autem vir elus cum esset iustus Jozef mu: jeji kdyi budiese /biese R/ pravy S, R; Mt 20,8: cum sero autem fac. tum esset $\dot{k} d y z$ vecer budiese /by R/ S, R; J 20,19: cum esset ergo sero die $1110 . .$. et fores essent clausae Gdyz veçer budieze/bieze R/ tono dne a duom budise /biese R, W/ zavíien S, R, W; J 5,4: qui prior descendisset in piscinam post motionem aquae sanus fiebat $k$ to proni vstupil $v$ rybnik po hnuti vody zdróv budize $\mathrm{W}, \mathrm{R}$.

8.3. Die zusammenfassung der morphologischen Charakteristik: siehe unter 11.3 .

\section{PHONOLOGISCHE CHARAKTERISTIK}

In diesem Kapitel werden zwei grössere Problemkreise behandelt - die phonologischen Systeme einzelner Handschriften (9.1.) und das alttschechische phonologische system des XIV. Jhs. allgemein, mit einigen Lösungsversuchen der Hierarchie der systemkomponenten und Korrelationen und ihrer Entwicklung (9.2.).

9. 1. Charakteristik der phonologischen Systeme der einzelnen Handschriften

9.1.1. Die Handschrift $A$

Das phonologische system des Fragments ist von unseren anderen Handschriften ziemlich abweichend. Der Lautwandel $a>k, a>i e$ ist durchgefüht und graphisch konsequent bezeichnet; die Änderungen $u>i, \dot{u}>i$ (in der Graphik durch-iu-) - pocoleniu, $k$ Jezu\$owi -, weiter $0>\varepsilon, \dot{0}>$ uo (ev. $0>\hat{o})$ - $\omega$ dom, duchow - sind noch nicht belegt. Dem zustand des vokalischen Systems nach kann man die Existenz der Mouillierungskorrelation im konsonantischen system voraussetzen,

105 J. Gebauer, Casováni (s. Fn. 99), 431, hat nur drei Belege. 
obwohl für sie keine direkten Belege aus der Graphik des Textes vorhanden sind (diese sind allerdings auch in anderen alten alttschechischen Denkmälern äusserst selten). Das phonologische System des Fragments entspricht dem alttschechischen Lautzustand im ersten Viertel des XIV. Jhs.

\subsubsection{Die Handschrift C}

Im vokalischen System findet man Anfänge der Anderungen, die für die Entwicklung des alttschechischen Vokalismus in dieser Periode typisch sind. Hăufiger kommt nur die Senkung der Jotierung vor (wecze J 7.33; rzecz J 7,36; obyczey J 19,40; cze\$ty = Eiesti'lesen' $J 19,23, u . a$.$) . Der Lautwandel u>i$, durch Labialisierung verursachte Diphthongierung $0^{\circ}, 0>40, \delta$, die Monophthongierung $i e>i$ sind nur vereinzelt $z u$ finden (prawy $=$ pravi $\mathrm{J} 8,46$; $\$$ ubu $\$$ tranu $\mathrm{J} 19,18)$, die ălteren Formen dominieren.

Anm.: Auf den übrigen Blättern (3-6) unseres Fragments sind noch zwei unvollkommene Texte (ein Teil der Legende uber den $h l$. Georg und ein Teil Des Gesprăchs der Jungfrau Maria mit Anselm über das Leiden Christi), die derselbe Schreiber geschrieben hat. Auch im vokalischen system dieser Texte sind die Belege fur die beginnenden Änderungen nur vereinzelt (przytel, buoh, wuoly, u.ä.).

Der zustand des vokalischen systems zeugt davon, dass auch das konsonantische system noch nicht stabilisiert war, dass die Beseitigung der konsonantischen Mouillierungskorrelation erst im Gange war. Unser Text weist keine dialektalen Merkmale auf und wegen seiner Kürze ist auch seine provenienz schwer feststellbar (eher aber in Böhmen geschrieben).

Das phonologische system entspricht dem alttschechischen phonologischen System, wie es um die Mitte des XIV. Jhs. bestand (wahrscheinlich in einem Gebiet, das weiter vom Sprachzentrum entfernt gewesen ist).

\subsubsection{Die Handschrift D}

Das vokalische System behălt die Jotierung ganz genau bei; die Belege ohne Jotierung sind sehr selten. Der Umlaut $u>i$ wurde durchgeführt (kazy L 2,10; \$uzy J 8,16), der wandel $0^{\circ}, 0>40$, $\delta$ nur in der silbe buo- (buon J 11,22; J 8,54; buozye J 11,52), vereinzelt ist noch die Monophthongierung ie $>:$ (wyerzycze J 7,39). Im konsonantischen system wurde die Mouillierungskorrelation beseitigt.

Das in der Hs. D vorhandene phonologische system, ein wenig (bei 
der Jotierung) vom Schreiber archaisiert, lässt voraussetzen, dass die Handschrift im zweiten Drittel des XIV. Jhs. entstanden ist.

Anm.: Dieses der Handschrift $\mathrm{R}$ sehr nahestehendes Fragment ist fast ganz frei von Schreibfehlern und es ist zu bedauern, dass es so beschädigt und unvollständig auf uns gekommen ist.

9.1.4. Die Handschrift $S$

Das vokalische system befindet sich noch im wandel. Relativ konstituiert ist schon das system der Kurzvokale, die einzige noch nicht stabilisierte stelle ist der Vokal $z$ - man findet schon, obwohl nicht zu häufig, Belege, wo die Jotierung beseitigt worden ist (potrzeju Mt 21,3; morze Gen., L 21,25; vecze J 6,12, u.a.), stellen. weise auch wörter mit einer hyperkorrekten Jotierung (przyblyzyeffye Sye Mt 21,1 u.a.). Diese Erscheinung - dass die Jotierung in diesem Text ins wanken geraten ist - stammt nicht vom Archetyp, man muss si, als Eingriffe der Kopisten beurteilen. Die Handschrift $S$ ist nur ein Abschrift einer älteren Vorlage. Der Archetyp entstand un 1300 (vgl. 4.5.3.) und damals wurde die Jotierung sehr genau bezeichnet, wie es die anderen aus dieser zeit stammenden alttschechischen Handschrifte: bezeugen. Auch die konsequente Durchführung des wandels $u>i$ (in der Vorlage bestimmt noch nicht vorhanden, weil dieser Lautwandel erst in der 2 weiten Hälfte des XIV. Jhs. vollendet wurde) ist dem Kopiste zuzuschreiben. Im Vergleich mit den kurzen befindet sich das system der Langvokale noch in Bewegung. Der Lautwandel $0^{\circ}>$ uo ist im Gange (in der Handschrift $S$ kommen beide Formen in fast gleicher Anzahl vor): die Monophthongierung $i e>l$ beginnt erst ( $k$ dywcze L 1,$27 ; t_{y}$ S\$e J 1,9; wycze Mt 6,26), die Diphthongierung $u>o u$, ev. die Monophthongierung $u c>$ is ist hier nicht belegt. Die noch laufende Diphthongierung $\dot{0}_{>}>$uo dokumentieren auch folgende bemerkenswerte Belege mit einem verlängerten anlautenden $0^{-}$nach einer Prăposition ( $k$ notczy J 14,18; J 16,16; J 16,17; J 16,28, aber auch einmal $k$ otczy $=k$ ötci $\mathrm{J} 16,10)$. Man findet aber auch -uo- anstatt des kurzen -onach den harten Konsonanten ( $\omega$ duomu L 19,5; s nuoczy J 4,52; sto kuorczuow p\$enycze $L 16,7$ ), was nach A. LAMPRECHT ${ }^{106}$ mit der Entfaltung und Ausgliederung der Lablalisierung $z u$ erklăren ist. Als einen Archaismus betrachten wir $-\imath-$ in myr (J 20,19 u.a.), denn die jünge-

106 A. LAMPRECHT, Vývoj fonologického systému Ceského jazyka, Brno 1966, 70; durch einen Systemzwang wird (bei der Ausgliederung der Labialisation nach den harten Konsonanten vor einem -0-) für kurze zeit auch $y_{0}$ anstatt $-c$ - ausgegliedert, geht aber bald verloren, weil auch das $e$ aus dem system beseitigt worden ist. 
re Handschrift $w$ hat schon auch die hyperkorrekte Form myer. Das vokalische System der Handschrift $S$ entspricht dem Vokalbestand des Alttschechischen im letzten Drittel des XIV. Jhs.

Das konsonantische system ist schon ziemlich stabilisiert. für die Mouillierungskorrelation bestehen keine Belege (vielleicht nur der einzige - \$umenye L 21,25 sollte nach den orthographischen Gewohnheiten dieser Handschrift eigentlich \$umyenye geschrieben werden und bedeutet darum mit grosser wahrscheinlichkeit šumenie). Die Anderungen im Vokalsystem (konsequent durchgeführter Umlaut $u>i, u_{\text {.a. }}$, siehe oben) zeugen davon, dass die konsonantische Mouillierungskorrelation beseitigt wurde, denn diese Änderungen wurden durch das Verschwinden der palatalisierten Konsonanten verursacht. Die Assibilierung $t^{\prime}>c\left(d^{\prime}>d z\right.$ ist hier nicht belegt), furr das Gebiet der mährischen Dialekte besonders typisch, wird nicht konsequent durchgeführt, komnt aber verhältnismässig oft vor (40 Belege). Ausser dem Schwanken zwischen den assibilierten und nicht assibilierten kommt haufig auch das Schwanken zwischen den assimilierten und nicht assimilierten vor lwzchod vs. w\$chod, \$bozye vs. zbozye, gdyz vs. kdys u.a.). Diese Erscheinungen und auch der Beleg gazdy ( $L$, $40=k a z d y$ 'jeder', durch reflexive Analogie nach dem gdyz) beweisen, dass die regressive Assimilation erst begann und noch im Gange war. Bemerkenswert erscheint auch das Eliminieren des - $h$ - in einer Endung nach einem vorangehenden Gutturalkonsonant - hlucheo Mc 7,32; druheo Mt 6,24. Der festgestellte Zustand des konsonantischen systems der Handschrift $S$ (mit der Beseitigung der Mouililerungskorrelation, mit einem Moravismus $t^{\prime}>c$ und mit hăufigen Belegen für die regressive Assimilation) entspricht einem vorausgesetzten system der alttschechischen Konsonanten im letzten Drittel des XIV. Jhs. wahrscheinlich in Mahren.

9.1.5. Die Handschrift $R$

Das phonologische System der Handschrift $R$ scheint ziemlich alt zu sein. Es war aber entweder nur eine Unvollkommenheit oder die Vorliebe des Kopisten für das Altere, denn dieser Schreiber beseitigte - ob schon bewusst oder unbewusst - nicht alle Bestandteile des phonologischen systems der Vorlage, die zu seiner zeit schon archaisch wirken mussten.

Im vokalischen Teilsystem der Kurzvokale wird die schwächste Stelle vom $e$ dargestellt. Quantitativ fast gleich ist die richtige, 
die verschwundene und die hyperkorrekte Jotierung vertreten (die hyperkorrekte in gleichen Positionen wie in der Handschrift $w, v g l$. 9.1.6). Bei einigen wortern fehlt die Jotierung in den silben de, te, ne, me, ve: entweder handelt es sich um Archaismen mit mouillier. ten Konsonanten ( $\omega$ medenyczy J 13,5; nezame§tnugye $\mathrm{L} 13,7$; poweztez Mt 21,3; ne\$wetle J 11,54; dyetecake Mt 2,20; nekterzy J 13,11), oder aber um Moravismen (in măhrischen Dialekten wird die Depalatalisation später als im zentralen sprachraum durchgeführt), oder sind es geworhnliche Schreibfehler, die in dieser Handschrift sonst recht haufig sind. Der Umfang der Jotierung zeugt davon, dass ihre Beseitigung schon zur Entstehungszeit der Abschrift im Gange war, also auch die Aufhebung der konsonantischen Mouillierungskorrelation beendet sein musste (die Folge dieser Aufhebung, der wandel $u>i$, wurde in $R$ konsequent durchgeführt). Bei den Langvokalen kommt ein anderer Archaismus vor, nämlich das durch den Schreiber aus der Vorlage beibehaltene nicht diphthongierte - $0^{-}$(diese Diphthongierung ist nur bei buoh J $6,27 \mathrm{u}$.a., belegt). Selten ist auch 0 - nur in od buoha...k buohu J 13,6 und mehrmals bei buozy J 9,31 u.a. Die Diphthongierung $\dot{o}^{-}$uo musste zur zeit des Abschreibens unseres Textes schon fast durchgefüht sein, weil es ziemlich viele Belege der Monophthongierung $i e>i$ gibt ( $w$ my\$to L 1,39; przytel J 11,11 u.a.). Diese Monophthongierung beginnt erst, wenn die Diphthongierung $0^{-}>0$ schon im Gange ist. Die Belege mit der gesenkten Jotierung (gmyegechu Mc 6,5; newyerzeczye L 8,12; czerkwe Mt 18,17 u.a.) zeigen, dass die Bedingung für diese Erscheinung - die Beseitigung der Mouillierungskorrelation bei den Konsonanten - schon vorhanden war. Auf die mittelmährische Herkunft des Textes weisen die Belege mit den Änderungen $y, \dot{y}>e$, $e$ hin (\$\$ye otewrzele oczy $\mathrm{J} 9,10$; na \$\$ame kray I 4,29 und andere).

Das konsonantische system ist stabil. Die Mouillierungskorrelation gibt es nicht mehr, die Assibilierung $t^{\prime}>c$ ist nicht belegt. Die regressive Assimilation funktioniert schon (droptov $\mathrm{L}$ 16,21; bly\$ko L 21,30; zbor zhromazdyeny Mc 9,24 u.a.), wie es auch die nicht der Regel entsprechende Assimilation besonders bei $z>s$ bezeugt - zmyechu $\oint_{y}=$ smiechu $8 E$ Mt 9,23: \$rno $=z$ rno J 12,24; obraye§awanye $\mathrm{J} 7,23 \mathrm{u} . \mathrm{a}$. (die Verwechslungen dieser beiden Konsonanten sind sonst in dieser Handschrift recht selten).

Der Bestand der Phoneme im Evangeliartext der Handschrift $R$ entspricht dem phonologischen system der mittelmahrischen Dialekte im letzten Viertel des XIV. Jhs. 
9.1.6. Die Handschrift $w$

Im vokalischen Teilsystem der Kurzvokale gibt es, genauso wie in der Handschrift $S$, nur eine nicht stabilisierte stelle - $e$. Die Senkung der Jotierung ist oft belegt (sogar auch nach Labialen wezy Mt 21,33; oder in langen silben - ge\$ty, \$e\$ty u.a.), aber sie wurde noch nicht vollendet, wie es die recht häufigen Belege einer hyperkorrekten Jotierung, vor allem im Auslaut in den Silben -ce,

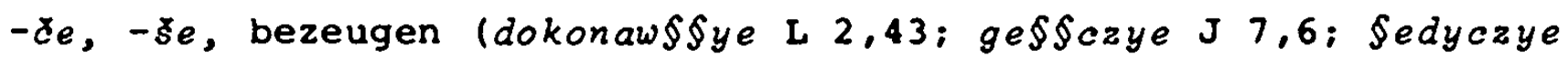

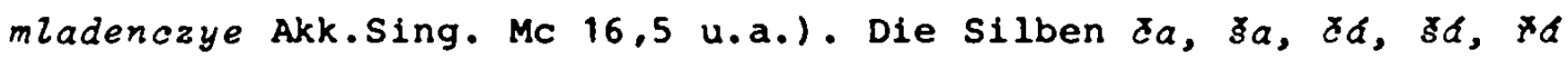
werden oft czya, $\$$ ya, rzya geschrieben. Diese Graphik bezeichnet aber kein altes' $a$, $a$ und keine dialektale ${ }^{2} a,{ }^{i} a$-Aussprache, sondern das zeichen $y$ dient nur als graphisches hyperkorrektes Weichheitszeichen bei palatalen $x, \delta, \not{r} .{ }^{107}$ Das $e$ anstatt a in $\$$ \&efarz L 12,42 kann auf die mittelmährische Herkunft ${ }^{108}$ des Kopisten hinweisen. Der Lautwandel $u>i$ wurde vollzogen (ausser drei Belege, die als aus der Vorlage stammende Archaismen zu bewerten sind - $w$ czuzolozईtwye $\mathrm{J} 8,3$ und 4; $w$ zemu $J 12,24)$. Das kurze $-u$ - in pude $\left(=p 0^{\circ}\right.$ jde) L 11,5 und $\mathrm{L} 16,30$ ist eine Form der damaligen Umgangssprache. Der von JIRECEK ${ }^{109}$ beschriebene Slowakismus som kommt in der Handschrift $w$ nicht vor. Es handelte sich um Lesefehler bei oft undeutlich geschriebenem - $e-$ (richtig: $8 \mathrm{em}$ 1.Pers.Ind.Prás. von byti). Die Diphthongierung $u>o u, \dot{y}>e j$ ist nicht belegt, was auch ein Grund für die mährische Herkunft dieser Handschrift sein könnte, denn in Mähren gab es diese Änderungen erst später oder gar nicht. Das system der Langvokale ist in Bewegung. Der Wandel $0^{-}>$uo ist im Gange (im Text findet man hăufiger noch $0^{\circ}$ ), genauso wie $0>\delta$ besonders in der silbe bo-lod buoha J 8,47; buozye $\mathrm{L} 11,28$ - insgesamt über 70 worter, dazwischen aber auch kuo\$\$uow $110 \mathrm{~J} 6,12)$. Relativ häufig sind schon die Belege der Monophthongierung uo> $\ddot{u}$ (muzem Mt 20,22; $w$ dul Mt 15,14; pugdu J 5,29; wul L 14,5 u.a.), also ein Zeugnis dafür, dass die Handschrift $W$ jünger als Handschrift $s$ ist oder aus einem Mundartgebiet stammt, wo diese Anderungen schon früher vor sich gegangen sind. Die Monophthongierung $i e>i$ wird durch

107 J. GEBAUER, Historická mluvnice jazyka ceského I, Hláskoslov1, Praha - Viden̆ 1894, 128.

$108 \mathrm{~J}$. GEBAUER, Hláskoslov1 (siehe Fn. 107), 122.

109 J. JIRECEK, O zvlastnostech Cestiny ve starych rukopisech moravskych, Praha $1887,77$.

$110 \mathrm{Vgl}$. Fn. 106 . 
viele Belege dokumentiert (po praytelech L 2,44; dytye Mt 8,6 U.a.), sogar durch solche, die mit einer hyperkorrekten -ie- Gruppe anstatt - $i$ - erscheinen (nazyewaty Mt 23,9; zakonnyekow J 7,48 u.a.). Die letzten Beispiele beweisen, dass es sich um eine noch laufende Ainde$r$ ung handelt. Die Handschrift $w$ hat schon die Form myer ( $L$ 10,5; in $S$ nur myrl, aber erst in den Lesungen des proprium sanctorum, in den alteren Sonntags- und Felertagsperikopen gibt es nur myr ( $J 20$, 19; J 14,27 u.a.). Das vokalische system der Handschrift $W$ entsprich1 dem zustand, der für das Alttschechische mit Spuren der mittelmährischen Mundart um das Jahr 1400 bekannt ist.

Das konsonantische system ist schon stabilisiert. Die Mouillierungskorrelation wurde schon beseitigt. Die Assibilierung $t^{\prime}>c$ kommt selten vor (wratyczy J 16,2; azcz L 13,8; fwyeczegyczye J 5 , 35), genauso wie die regressive Assimilation (nenale§\$ye L 24,23 ). Für westmăhrische Herkunft dieses Textes willde das prothetische $w$ zeugen (fehlt in ostmährischen Dialekten) - wo rzyeczy L 3,4. Als einen Dialektismus (auch in Böhmen möglich) betrachten wir das fehlende auslautende $-h$ (buo Mt 15,3; J 4,24 u.a., vgl. auch die heutigen Formen $P a m b u$ 'Herrgott'). Ebenso kann das fehlende anlautende $\dot{h}$ - auch böhmich sein ( $w$ robyech $=v$ hrobiech $J 5,28)$. Das grosse Alter der Vorlagen (oder noch des Archetyps?) beweisen auch Reste der alten Orthographie $h=c h$ (hczyete J 5,47; hczy L 14,19 u.a.) und das Schwanken, das durch Ersetzung dieser Schreibweise verursacht wurde (ruchanye = rihanie Mt 5,10). Sonst weist das konsonantische System keine anderen Dialektismen oder Besonderheiten auf und entspricht dem zustand der alttschechischen Konsonanten in Măhren um das Jahr 1400.

9.2. Neue Einblicke in das alttschechische phonologische System ${ }^{111}$

Schon die begrenzte Auswahl von Handschriften erlaubt uns, das phonologische System des Alttschechischen zu verschiedenen zeitpunkten des XIV. Jhs. zu rekonstruieren. Die grossen Systemerschüterungen (die Anderungen der Jerlaute, der Silbenstruktur, der Liquide, die Entstehung neuer Korrelationen), durch die sich das Tschechische im Rahmen der nordslavischen Sprachgruppe abgesondert hat, gehen in dieser zeit zu Ende. Im Laufe des XIV. Jhs. stabilisiert

$111 \mathrm{Vgl}$. J. VINTR, Die Symmetrie im phonologischen System des Alttschechischen, Wiener Slavistisches Jahrbuch 20 (1974) 152-163; - de r s.. Dynamisches Raummodell des alttschechischen phonologischen Systems, Wiener Slavistisches Jahrbuch 21 (1975) 290-9 
sich der Konsonantismus, im vokalischen system sind noch die letzten grösseren Verschiebungen im Gange. Die Ergebnisse dieser jahrhundertlangen Prozesse kann man am Sprachmaterial der Handschriften feststellen. Gilt das auch für die einzelnen Entwicklungsphasen und vor allem für die Ursachen der wandlungen?

\subsubsection{Die bisherige Literatur}

Die bisherigen Arbeiten über die Entwicklung der alttschechischen Laute geben auf diese Frage nicht immer eine klare Antwort. In den Standardwerken der historischen Lautlehre des Tschechischen findet man ausführliche Beschreibungen des Lautbestandes in verschiedenen Entwicklungsetappen. Als klassisches Werk auf diesem Gebiet ist auch heute noch die historische Lautlehre des Tschechischen von $J$. GEBAUER $^{112} \mathrm{zu}$ betrachten. Dieses Buch ist wegen der Fülle von Belegen, der Breite und Gründlichkeit der Beschreibung und des ersten geschlossenen Bildes der tschechischen Lautentwicklung für jeden Forscher eine ausgiebige und unentbehrliche Hilfe. Das Hochschullehrbuch der tschechischen historischen Lautlehre von M. KOMAREK 113 geht von Gebauer aus, beschreibt und untersucht die alttschechischen Laute schon als Bestandteile eines phonologischen Systems. Es ist ein nicht besonders umfangreiches, aber gutes, genaues Buch. In seiner historischen Grammatik befasst sich F. TRAVN fCEK ${ }^{14}$ auch mit dia. lektalen Erscheinungen, deren präzisierte strukturelle Bearbeitung man auch in der kompakten diachronischen Phonologie des Tschechische: von A. LAMPRECHT ${ }^{115}$ findet. Komárek und Lamprecht versuchen schon, für Ursachen der Lautentwicklungen systemgründe zu entdecken. Vieles bleibt noch ungeklärt, z.B. die Erforschung der zusammenhänge der einzelnen Lautentwicklungen. Wir werden hier versuchen, das bisherige wissen in dieser Hinsicht um einiges zu erweitern.

9.2.2. Zur hierarchischen Gliederung der Systemelemente; die Einteilung der Problematik

Das phonologische System einer Sprache erfordert meines Erach-

112 J. GEBAUER, Hláskoslovi (siehe Fn. 107).

113 M. KOMÁREK, Historická mluvnice Ceská I, Hláskoslovi, Praha (2. Aufl.) 1962 .

114 F. TRÁnfČKK, Historická mluvnice Ceskoslovenská, Praha 1935.

115 A. LAMPRECHT, O.C., (siehe Fn. 106). 
tens noch eingehendere Untersuchungen - vor allem eine Analyse der Anordnung der Elemente des Ganzen. Dabei sollte es sich nicht nur um die Feststellung der systemkomponenten (die Phoneme der Prager Schule und die distinctive features der Harvard-Schule) und ihrer Korrelationen handeln, sondern auch um die Entdeckung der inneren Struktur, der Hierarchie der Systemkomponenten und Korrelationen. Auf diesem Gebiet hat F. V. MARES ${ }^{116}$ mit seiner analytischen Phonologie eine Pionierarbeit geleistet. Seine Prinzipien (auch mit seiner Akzeptierung der Grundsätze der Prager Schule) werden im wesentlichen in den folgenden Ausfuhrungen ubernommen, besonders seine hierarchische Gliederung der Merkmale, die für die Struktur eines Phonems relevant sind.

Für weitere Erwăgungen gliedern wir die Problematik in folgende Problemkreise - Rekonstruktion der phonologischen Systeme unserer Handschriften (9.2.3.; dem Alter nach bilden die sechs Evangeliarhandschriften zwei Gruppen - Handschriften $A$ und $C$ aus der ersten Hălfte des XIV. Jhs., 9.2.3.1., und Handschriften D, S, R, W aus der zweiten Hălfte des XIV. Jhs., 9.2.3.2.); Zahlensymmetrie der systemelemente (9.2.4.); Raumsymmetrie der systemelemente (9.2.5.); parazentrische Bewegungen als Entwicklungsprinzip des phonologischen systems $(9.2 .6$.$) .$

9.2.3. Rekonstruktion der phonologischen Systeme der Handschriften $A, C, D, S, R, W$

Es werden zuerst die phonologischen systeme der Texte $A$ und $C$ aus der ersten Hälfe des XIV. Jhs. (9.2.3.1.), dann die Systeme der Handschriften $D, S, R, W$ aus der zweiten Hălfte des XIV. Jhs. $(9.2 .3 .2$.$) behandelt.$

Anm.: Die Unterteilung der Handschriften in zwei Gruppen ist auf Erkenntnissen der historischen Grammatik des Tschechischen über die Entwicklung des alttschechischen Lautbestandes während des XIV. Jhs. gegründet: am Anfang des XIV. Jhs. ist noch mit der konsonantischen Mouillierungskorrelation (oder mindestens noch mit ihren Resten), mit der konsequenten Jotierung, mit den Langvokalen $\dot{0}^{-} \dot{u}$ und mit dem Diphthong ie zu rechnen; in der zweiten Hälfe des XIV. Jhs. ist die konsonantische Mouillierungskorrelation verschwunden, das vokalische System befindet sich aber noch in Bewegung (Senkung der Jotierung, die Diphthonglerung $\dot{o}^{-}>u_{0}$, ev. die Monophthongierung $i e>i)$. Die Handschriften $A$ und $C$ sind also năher dem alttschechischen phonologischen system um 1300, die Handschriften $D, S, R, W$

116 F. V. MARES, Analytische Phonologie, The Slavic Word (1970), preprint, 1-33. 
dem System um 1400. Dem phonologischen System des nicht erhaltenen Archetyps würde das System der Handschrift $A$ am năchsten stehen.

9.2.3.1. Rekonstruktion des phonologischen Systems der Hss. A und C

Nach einer Materialanalyse und unter Berücksichtigung der bisherigen Erkenntnisse wurde der Phonembestand festgestellt. Das Schema (siehe Tafel I) wurde mit freundlichen Hilfe von F. V. Mares und nach den Prinzipien seiner analytischen Phonologie ${ }^{117}$ zusammengestellt.

Tafel I

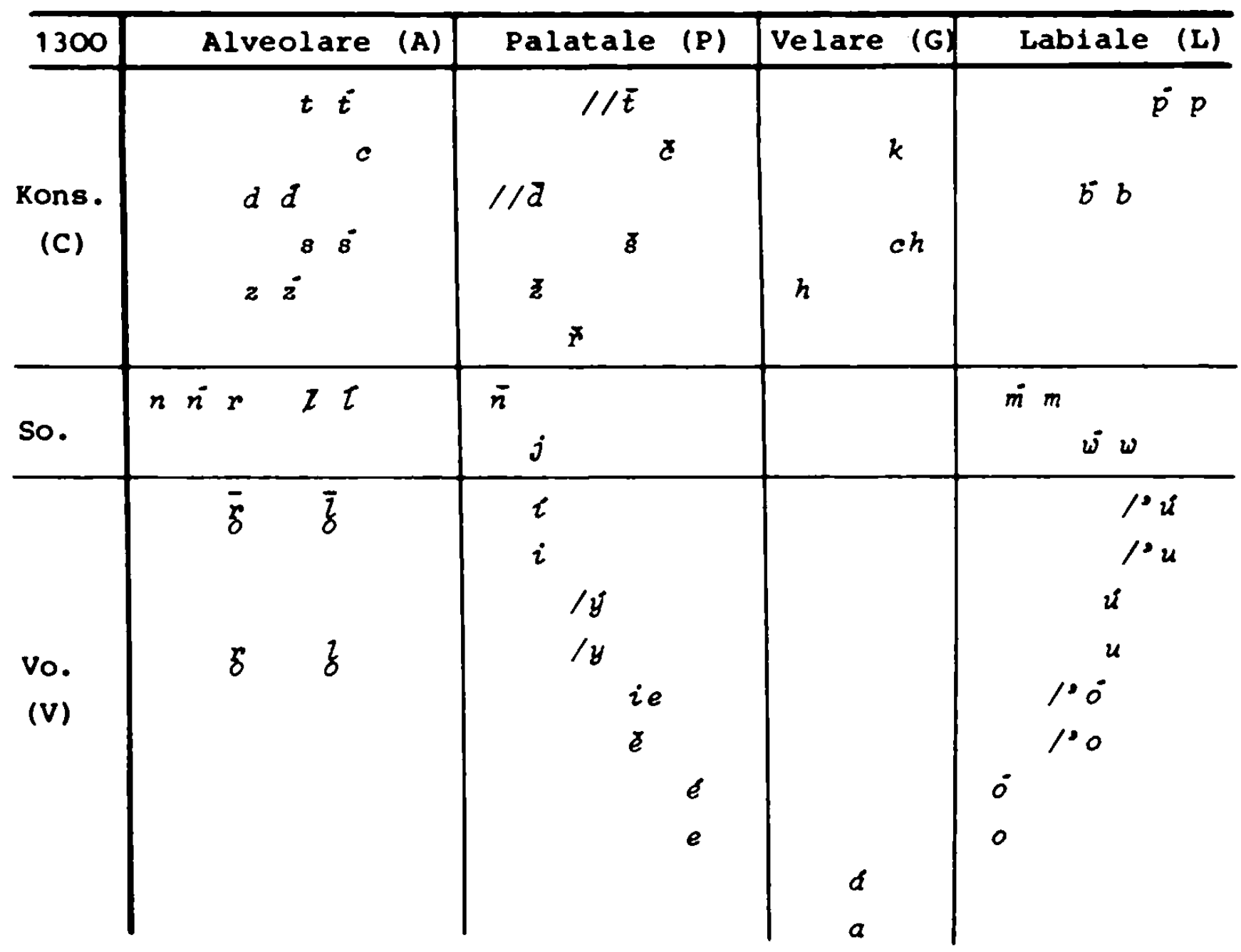

Erklärung der zeichen:

$e$ - traditionelle Bezeichnung für den Vokal'e $\left(\dot{=} i_{e}\right)$

/ - Bezeichnung für eine Variante

// - Bezeichnung für eine chronologische (im begrenzten zeitraum vorhandene) Variante

Anm.: Fur die Handschrift $C$ gilt die Tafel I nur teilweise, weil

117 F. V. MARES, Das Lautsystem im Licht der analytischen Phonologie, in: Phonologica 1972, München-Salzburg 1975, 267-281.

$118 \mathrm{Vgl}$. K. HORALEK, Zum Begriff der phonologischen Korrelation, in: Phonologie der Gegenwart, Wien 1967, 366. 
sie am Ubergang zwischen diesem und dem späteren System (siehe Tafel II) steht.

Das erste rekonstruierte system entspricht im wesentlichen dem alttschechischen phonologischen system um das Jahr 1300. Im Schema sind die Phoneme $/ f /, \mid g /$ nicht vertreten, die $z u$ dieser Zeit im System der heimischen Laute noch als fremde Elemente empfunden wurden. Die Varianten bei den Vokalen spielen noch eine grosse Rolle, wie unten (siehe Tafel III, IV und 9.2.4.5.1.,9.2. 4.5.8.) noch näher erklät wird. Die langen Vokale gehoren vollig ins phonologische system und können nicht als nur prosodische (suprasegmentale) Erscheinung betrachtet werden! 18

\subsection{Die Stellung der silbischen Sonanten}

Die kurzen und langen silbischen Sonanten $\gamma$, $z$ waren im Alttschechischen um 1300 noch selbständige Phoneme (so KOMAREK, 82; wir ubernehmen hier einige seiner Beispiele), die als Merkmal gegenuber dem $r$, $i$ die Fähigkeit einer silbenbildung hatten. Sie könnten in ăhnlicher Lautumgebung silbisch oder nicht silbisch vorkommen (pquvé vs. krve) und könnten auch die Wortbedeutung unterscheiden - držĕti (zweisilbig) 'zittern' und dzžeti (dreisilbig) 'halten, besitzen'. Man kann zwar kein anderes Beispiel finden; trotzdem glauben wir, dass die notwendige wiederholbarkeit für eine systemerscheinung (mindestens zwei Paare) durch das ganze Paradigma dieser zeitwörter gegeben ist.

waren aber $\bar{\delta}, \bar{z}$ auch Phoneme oder nur Varianten? Komárek und Lamprecht rechnen im Alttschechischen (auch nach 1400) mit den langen Phonemen $\bar{r}, \bar{z}$. Für ein $\bar{\gamma}$ findet man in den alttschechischen Handschriften Belege mit einem Längezeichen, z.B. in der Postilla von Johannes Hus: wriczy /chleb/płom 46b; on nas nakrimy 2 69b, u.a. Langes $\bar{z}$ muss man nach dem zustand in den măhrischen Dialekten oder im Slowakischen z.B. für wörter wie v $\bar{z} z \bar{e}$ 'ein junger Wolf'. $p \bar{z} n i t i$ 'fullen' voraussetzen. 119 Auch die alttschechische Schreibweise -rr-, $-2 \imath$ - in den altesten Handschriften, wo durch die Verdoppelung manchmal die Vokallăngen bezeichnet werden, könnte in einigen Belegen auch ein $\bar{\gamma}, \bar{z}$ bedeuten. Diese Schreibweise ist während des XIV. Jhs. verschwunden und die Belege mit $-r^{-}$- in der Postilla von Johannes Hus kann man beim konservativen hus als Ar-

$119 \mathrm{Vgl}$. J. GEBAUER, Hláskoslovi (siehe Fn. 107), 300; - M. KOMAREK, 0.c. (siehe Fn. 113), $99 \mathrm{ff.}$ 
chaismen oder als hyperkorrekte Formen betrachten. Wir nehmen an, dass die langen $\bar{\gamma}, \bar{z}$ um 1400 nur Varianten der Phoneme $r$, $z$ waren (vgl. Tafel II). Die Beseitigung einer nicht mehr relevanten sonantischen Lănge könnte in engem Zusammenhang mit den Bewegungen im alttschechischen System der Langvokale stehen. Die ganze Entwicklung der silbischen Sonanten sollte noch genauer untersucht werden.

9.2.3.2. Rekonstruktion des phonologischen Systems der Handschriften $S, R, W, D$

Das phonologische System der Handschriften S, R, W, D entspricht im wesentlichen dem alttschechischen System zum Ende des XIV. Jhs. Die Varianten bei den Vokalen spielen jetzt keine wichtige Rolle mehr (vgl. 9.2.4.5.9, Tafel III, IV). Die konsonantische Mouillierungskorrelation wurde beseitigt, die konsonantische Labialisierung war phonologisch nicht (oder noch nicht) relevant und nicht für das ganze system typisch - darum brauchen wir die labialisierten Varianten bei der Betrachtung des Systems als eines Ganzen nicht zu berúcksichtigen.

Tafel II

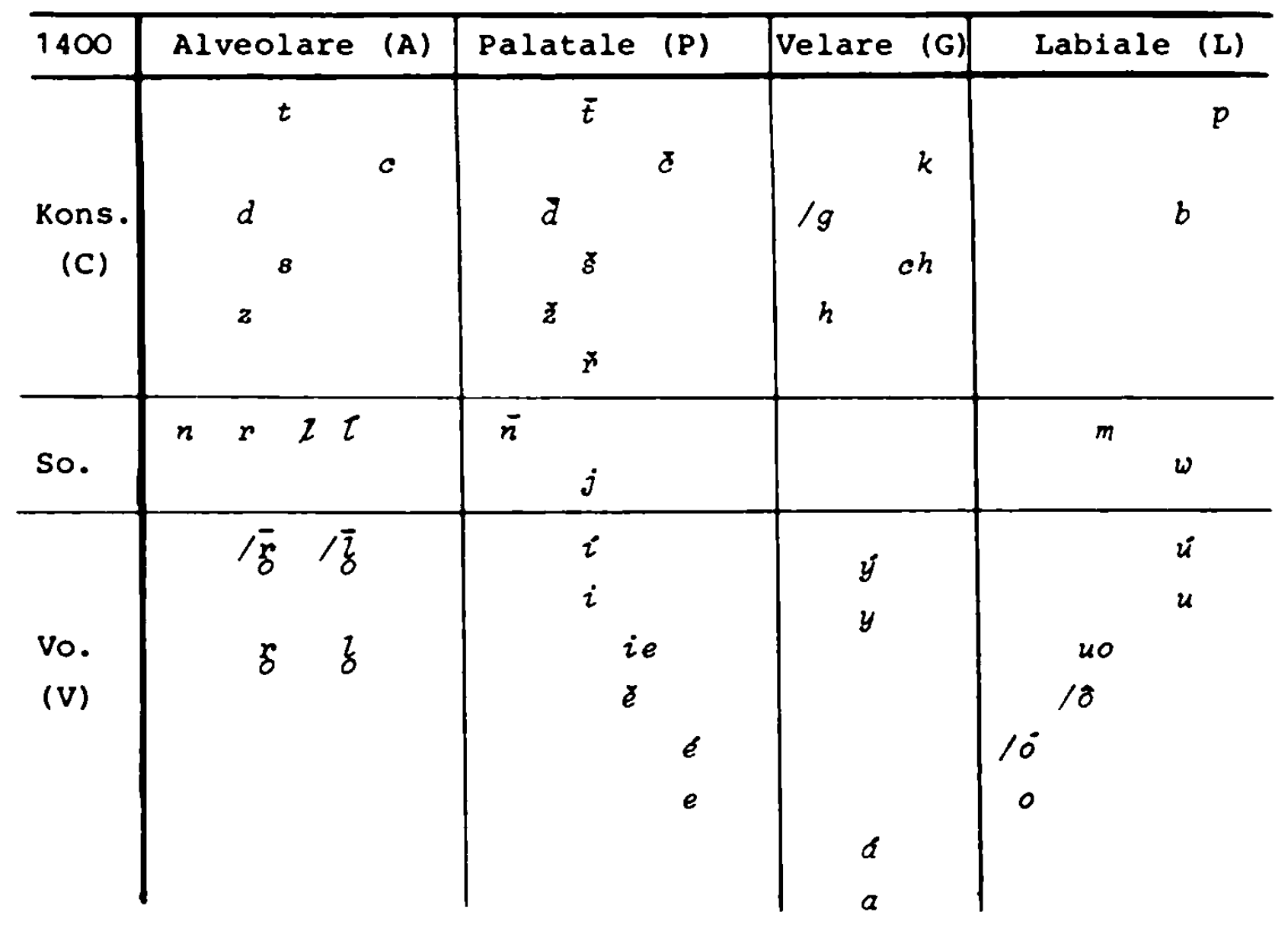

Erklärung der zeichen: wie bei Tafel I, neu nur

$\delta$ - Bezeichnung für den $0-$ Vokal mit zusätzlicher Labialisierung $=\aleph_{0}$ 
Auf einer zeitachse sind die phonologischen systeme unserer Handschriften folgendermassen verteilt:

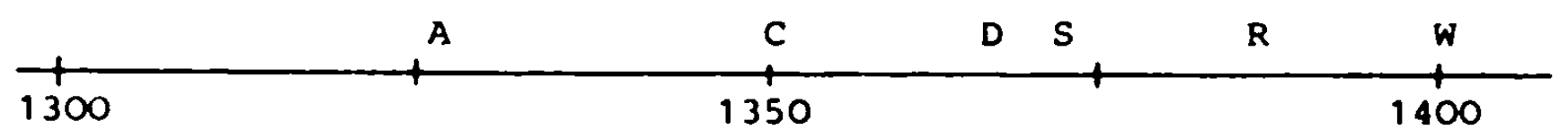

9.2.4. Zahlensymmetrie der systemelemente

9.2.4.1. Die bisherige Fachliteratur

Der Begründer der Phonologie N. S. TRUBETzKOY hat die Symmetrie für eine der Grundeigenschaften des systems gehalten. 120 Die Tendenz zur Erhaltung der Symmetrie auch während der Systementwicklung kann bewiesen werden, wie es für das tschechische phonologische system J. VACHEK ${ }^{121}$ in seiner hervorragender, viele Anregungen bietenden Arbeit getan hat. Es ist nicht besonders schwer, beim heutigen Stand unserer Kenntnisse z.B. bei den Vokalen auch in der Diachronie eine Symmetrie festzustellen. Wir werden versuchen, die Beweise dafür zu erbringen, dass die Symmetrie im phonologischen System (auch in den Wechselbeziehungen der Phonemgruppen - z.B. von Konsonanten, Sonanten, Vokalen) ein grundlegendes ordnungsprinzip darstellt. V. SKALICKA 122 formuliert das Symmetrieprinzip allgemeiner als inneres Modell einer sprache. Unter innerem Modell versteht er eine doppelseitige Ahnlichkeit sprachlicher Mikrostrukturen, die als solche erlebt wird.

\subsubsection{Zum Begriff eines Systemmodells}

Unserer Meinung nach gibt es nicht nur eine erlebte logische Symmetrie der Mikrostrukturen, sondern auch eine dem system inh $¥-$ rente Symmetrie der strukturen; nicht nux eine Symmetrie der Qualitat, sondern auch eine Symmetrie der Quantitat. Das ganze System wird einem, in seinen Grundrissen einfachen Modell nachgebildet, das man abstrahieren und durch einfache mathematische (aritmetische, geometrische) Formeln ausdrücken kann. Ändert sich etwas

120 N. S. TRUBETzKoY, Grundzüge der Phonologie, GSttingen (3.Aufl.) $1962,6 \mathrm{ff}$. , 67ff.

$121 \mathrm{~J}$. VACHEK, Dynamika fonologického systému soucasné Céstiny, Praha 1968.

$122 \mathrm{~V}$. SKALICKA, O tzv. vnitinlm modelu $v$ jazyce, slovo a slovesnost 34 (1973) 22-26. 
im System, wird eine Änderung am Modell folgen. Wird das ganze System umgebaut, ändert sich auch das ganze Modell. Zum Umbau des ganzen Systems führen mehrere Änderungen. Eine grössere Anzahl von Änderungen bringt das Modell ins Wanken, und das System ist gezwungen, einen solchen Weg zu suchen, welcher $z u$ einem stabileren Modell und $z u$ einer ausgewogeneren Symmetrie führt.

\subsubsection{Das arithmetische Systemmodell}

Das Modell eines Systems kann man sich entweder als eine Raumanordnung der Teilsysteme (ein geometrisches Modell) oder als Anordnung der Teilsysteme in einfache, im system wiederholbare Zahlenrelationen (ein arithmetisches Modell) vorstellen. Die Zahl der Elemente einzelner Teilsysteme (z.B. der Konsonanten, Vokale, Sonanten; der Alveolare, Palatale, usw.) bildet Relationen, die auf ganz einfache und wenige Grundrelationen reduziert werden können (z.B. $1: 1,2: 1,3: 2)$. Jedes Phonem (eventuell jede Phonemvariante) stellt eine Einheit dar und wird bei den zahlangaben in einem arithmetischen Modell durch die 2 ahl 1 repräsentiert. Die Relationen der Elemente sind in einem system nicht nur wiederholbar, sondern sie können dazu auch noch symmetrisch sein. Betrachten wir die Elemente eines Teilsystems als eine (mathematische) Menge: eine Relation $R$ ist in einer Menge $M$ dann symmetrisch, wenn fur alle Elemente $x, y \in M$ gilt: $x R y \Rightarrow y R x(x, y$ sind Elemente der Menge $M$ ). Eine symmetrische Relation ist z.B. die Grundrelation 1 : 1. Die Relation $2: 1: 2$ (die Mengen $A, B, C$ ) können wir auch als symmetrisch bezeichnen, denn die zahl der Elemente der Mengen $A, C$ ist symmetrisch im Hinblick auf die $\mathrm{Zahl}$ der Elemente der Menge $B$. Wenn wir $A$ und $C$ vertauschen, bleibt die Relation erhalten. Die Relation 3 : 2 ist nicht symmetrisch, wir werden sie hier als eine proportion bezeichnen (sie ist eigentlich nur eine Seite - die einfachere - einer Verhältnisgleichung $a: b=c: d$, wo in unserem Fall $a=3, b=2$ ). Die einfachen, reduzierten Grundrelationen, die bel der Herstellung eines arithmetischen Modells im System am häufigsten vorkommen, nennen wir das Grundordnungsprinzip eines systems.

9.2.4.4. Die Grundsatze der analytischen Phonologie als Kriterien

Bei der Suche nach Relationen und Ordnungsprinzipien im phonologischen system des Alt tschechischen gehen wir Jvorintderiagraßna- 
sätzen der analytischen Phonologie Mareł' aus. Mares gliedert die (Bau-)Elemente eines Systems auf: Grundelemente (V - der vokalische Charakter; C - der konsonantische Charakter; X - Farbe: L - labial, G - velar, P - palatal, A - alveolar; S - silbischer Wert) und akzessorische Elemente (n - Nasalität, $m$ - Mouililerung, $q$ - Quantität, v - Stimmbeteiligung). Wenn man nach diesen Kriterien das phonologische System des Alttschechischen gliedert (vgl. Tafel I, II), findet man im Schema weitgehende symmetrie.

9.2.4.5. Zahlenrelationen und Zahlensymmetrie im phonologischen System des Altschechischen und in seinen Teilsystemen un das Jahr 1300

9.2.4.5.1. C, V-(Konsonanten, Vokale) symmetrie

Die Symmetrie zwischen den Vokalen und den Konsonanten ist nicht eindeutig, vor allem wegen der grosseren Anzahl der vokalischen Varianten. Im phonologischen system des Alttschechischen um $1300 \mathrm{gab}$ es folgende Phoneme: 12 Vokale, 4 silbische Liquiden (die wegen ihres Silbenwertes zu den Vokalen gezählt werden), 11 Sonanten und 22 Konsonanten (vgl. Tafel I unter 9.2.3.1.). Problematisch ist die stellung der vokalischen Varianten. Wenn man nämlich mit ihnen beim Versuch der Herstellung eines einfachen arithmetischen Modells der Relation Ko : Vo als mit den "gleichberechtigten" (im Hinblick auf die Vo-Phoneme) Einheiten nicht rechnet, whe das Bild des Systems nicht vollständig, nicht der (damals) erlebten Funktion der Vo-Varianten entsprechend und nicht einmal auf ein einfaches Modell, eine einfache zahlenrelation zuruckzuführen (z. B. ohne die vokalischen Varianten $2 u$ zählen: 12 Vo +4 silbische So : 11 So : 22 Ko = $16: 11: 22$ ?)! Wenn wir aber die Vovar $z u$ den Vo und silbischen so zählen und die So und Ko als selbständige $\mathrm{Zahlenmengen}$ belassen, dann kommen wir bei der Aufzählung der Elemente in diesen Mengen zu einer symmetrischen Relation - 12 Vo + 6 VoVar + 4 silbische so : 11 So : $22 \mathrm{ko}=22: 11: 22=2: 1: 2$.

Daraus kann man den Schluss ziehen, dass die vokalischen Varianten - wenigstens in der zeit um 1300 - ins alttschechische phonologische system als die den vokalischen Phonemen funktionell vollig gleichgestellte Einheiten eingegliedert sind. (Sollte oder könnte man diese vokalischen Varianten, diese "fast-Phoneme" . nicht "Allophoneme" nennen?) 
$9 \cdot 2 \cdot 4 \cdot 5 \cdot 2.5-($ silbenwert-) symmetrie

Stellen wir die Silbenwerte (S) der Vo und der silbischen So den $\emptyset S-W e r t e n$ der Ko gegenüber: wenn wir (bei den Vo) nur die Phoneme nehmen, kommen wir zu keiner symmetrie - 12 vokalische S $4 \mathrm{~S}$ der silbischen So : 22 konsonantische $\varnothing S-W e r t e=16: 22$. Die übrigen So (als potenzielle Silbenwertträger) stehen zwischen den Vound Ko-Mengen als eine selbständige Menge. Wenn wir auch die s-Werte der vokalischen Varianten nehmen (und die so-Werte als eine selbständige Menge), dann bekommen wir folgende symmetrische Relation - 12 Vos + 6 VoVars + 4 silbische Sos : 11 So : 22 Koøs = $22: 11: 22=2: 1: 2$ - also dieselbe symmetrie wie bei $c, v$.

\subsubsection{3. $x$-(Farbe-) Symmetrie}

Das ganze phonologische system des Alttschechischen ist, was die Farbe betrifft, ziemlich symmetrisch, besonders bei den Alveolaren und Palatalen (vgl. Tafel I unter 9.2.3.1.) - 9 alveolare Ko vs. 9 alveolare So stehen in einer 1 : 1 Relation. Wenn man auch die Varianten der vorderen Vo in Relation der palatalen Reihe nimmt und die So zu den ko zählt - dann entsteht eine symmetrische zweigliedrige Relation $6 \mathrm{Ko}+2 \mathrm{So}: 6 \mathrm{Vo}+2$ VoVar $=8: 8=1: 1$. Die velare Reihe ist asymmetrisch - 3 velare ko : 2 mittlere Vo = $3: 2$. Die Relation der Labiale ist - ahnlich wie bei den Palatalen - in einer zweigliedrigen Form symmetrisch -4 Ko +4 So $: 4$ Vo + 4 VoVar $=8: 8=1: 1$.

Im Laufe der Beseitigung der konsonantischen Mouililerungskorrelation kam das ganze system in Bewegung, und auch die X-Symmetrie wurde gestort. Unserer Meinung nach schwinden in diesem Prozess zuerst die mouillierten Alveolare $\left(d, t, \dot{t}, \dot{s}, z^{-}\right)$und dadurch wird das Gleichgewicht nicht nur in diesem $A$ : $\AA$-Teilsystem, sondern die symmetrie des ganzen Systems gestort. Durch Anderungen, die dann sowohl bei ko als auch bel Vo folgen, wird das ganze system so lange ungebaut, bis wieder eine mehr oder weniger ausgewogene symmetrie hergestellt ist.

9.2.4.5.4. m-(Mouillierung-) symmetrie

Die Moullierungskorrelation hat bei den Ko und so 10 Paare - 6 alveolare und 4 labiale (vgl. Tafel I unter 9.2.3.1.). Diese 
sind iber die velare Reihe (vgl. Tafel I) in derselben Relation wie die Velaren (siehe 9.2.4.5.3.) $3: 2$ (=6:4) proportional. Diese Proportionalität entspricht auch der Relation zwischen den alveolaren und palatalen konsonanten $(9: 6=3: 2)$. Daraus sieht man, dass die proportionale Relation $3: 2$ im system um 1300 als ordnungsprinzip ofters vorkomut. Von einer symetrie kann in diesem Fall nicht gesprochen werden, wohl aber von einer proportionalität, die im System des Alttschechischen um 1300 fest verankert und wiederholbar ist.

\subsubsection{5. q-(Quantität-) Symmetrie}

Bei der Quantitäskorrelation stehen die an dieser Korrelation beteiligten Phoneme in einer symmetrischen Relation - 6 lange Vo +2 lange silb. So : 6 kurze Vo +2 kurze silb. So $=8: 8=1: 1$ (auch mit den dazugezăhlten Vovar bleibt diese Relation symmetrisch $-11: 11=1: 1)$.

Wenn man das Verhältnis zwischen den nicht beteiligten $(22$ Ko +11 So) und den beteiligten systemeinheiten $(12$ Vo + 6 Vovar + 4 silb. So) sucht, kommt man zu einer proportionalen und im phonologischen system um 1300 wiederholbaren Relation $33: 22=3: 2$.

9.2.4.5.6. n-(Nasalität-) Symmetrie

Die Verankerung der Nasallaute im sonst ziemlich symmetrischen alttschechischen phonologischen system ist problematisch und nicht ganz klar. Wo sollte man eine im arithmetischen Modell proportional oder symmetrisch feststellbare systemopposition für Nasallaute suschen oder nach welchem Prinzip sind diese ins system eingegliedert?

Die alten vier Nasalvokale (zwei lange, zwei kurze) gibt es im Alttschechischen um 1300 schon lange nicht mehr. Nur in der Sonanten-Gruppe befinden sich $z u$ dieser zeit 5 Nasalsonanten, die zu den ubrigen so in einer asymmetrischen und im system kaum wiederholbaren Relation 5: 6 stehen. Das Verhältnis der Nasale und der ubrigen nicht nasalen ko und so ergibt auch keine brauchbare Relation, nămlich $5: 28$.

Nach diesen eher negativen Feststellungen nehmen wir an, dass die Nasalität eine Erscheinung war, die in der Sprachentwicklungsetappe des Alttschechischen um 1300 nicht das ganze phonologische system, sondern nur einen Teil des konsonantischen Teilsystems 
betrifft und dass die eventuelle Symmetrie oder Proportionalitat nur im Rahmen dieses Teils zu suchen ist. Ein solches Teilsystem bilden die Nasale mit seinen nicht nasalen widerspiegelungen $d, d$, $d, b, b$, mit denen sie in einer symmetrischen Relation 1 : 1 stehen.

9.2.4.5.7. Zusammenfassung der Relationen

$\mathrm{C}$ und $\mathrm{V}-2: 1: 2 ; \mathrm{s}-2: 1: 2 ; \mathrm{x}-1: 1,1: 1,3: 2$, $1: 1 ; m-3: 2 ; q-1: 1(3: 2) ; n-1: 1$. Die hăufigste Relation im phonologischen System des Alttschechischen um das Jahr 1300 ist die symmetrische Relation $1: 1$.

9.2.4.5.8. Die Rolle der vokalischen Varianten als potenzieller Phoneme

Analysieren wir jetzt das alttschechische phonologische system um 1300 als ein Ganzes nur mit den Kriterien der Grundelemente $C, V$, $X,(S)$. Wenn man von dem Grundsatz ausgeht, dass das ganze System zu einer symmetrie tendiert, scheint die Rolle der Vovar um 1300 anders $2 u$ sein als in der traditionellen Phonologie des Alttschechischen behauptet wird. Vom standpunkt einer systemsymmetrie spielen die vokalischen Varianten zu dieser zeit dieselbe Rolle wie die vokalischen Phoneme (vgl.9.2.4.5.1.). Sind wir dann berechtigt (in einem synchronen schnitt und bei konkretem Material) noch von den Varianten $2 u$ sprechen?

9.2.4.5.9. Die Ergebnisse der Zahlensymmetrieanalyse

Die Ergebnisse dieser Analyse fasst die Tafel II zusammen. Hier sieht man auch, wie wichtig die Vovar für eine systemsymmetrie zu dieser zeit noch waren. Das ganze system ist namlich nur dann symmetrisch, wenn man die weichen und harten Vovar mitzăhlt.

Tafel III

\begin{tabular}{l|cccc|c|cccc|c}
\hline \multirow{2}{*}{1300} & \multicolumn{4}{|c|}{$\begin{array}{c}\text { a) } \\
\text { ohne VoVar }\end{array}$} & \multicolumn{5}{|c}{$\begin{array}{c}\text { b) } \\
\text { + VoVar }\end{array}$} \\
\cline { 2 - 10 } & A & P & G & L & alle & A & P & G & L & alle \\
\hline Ko & 9 & 6 & 3 & 4 & 22 & 9 & 6 & 3 & 4 & 22 \\
So & 5 & 2 & & 4 & 11 & 5 & 2 & & 4 & 11 \\
Vo & 4 & 6 & 2 & 4 & 16 & 4 & 8 & 2 & 8 & 22
\end{tabular}


Anm: Die als fremd empfundene Phoneme $/ f / g / g /$ stehen ausserhalb des Systems; die Phoneme $|r /,| \bar{g} /,|z /,| \frac{z}{\delta} /$ zählt man wegen
ihres silbischen Wertes zu den ${ }^{\prime}$ o.

In der Tafel IIIb) zeigt es sich, dass das ganze system nur dann symmetrisch ist $(22: 11: 22=2: 1: 2)$, wenn man die vokalischen Varianten als den Phonemen gleichberechtigte Einheiten dazurechnet. Interessant ist, dass es sich bei den gleichberechtigten Varianten gerade um solche handelt, die in einer späteren Entwicklungsphase Phoneme geworden sind und die man darum als potenzielle Phoneme (Allophoneme?) bezeichnen sollte.

9.2.4.6. Zahlensymmetrie im phonologischen System des Alttschechischen un das Jahr 1400

Die Ergebnisse der Analyse des phonologischen Systems des Alttschechischen um 1400 am Material unserer Handschriften $S, D, R, W$ und nach den Kriterien der Grundelemente (siehe 9.2.4.4. und 9.2. 4.5.6.) sind in der Tafel IV zusammengestellt (vgl. dazu auch die Tafel II, $s .119)$. Für $f, g, r, z$ siehe Anmerkung bei Tafel III. Tafel IV

\begin{tabular}{|c|c|c|c|c|c|c|c|c|c|c|}
\hline \multirow{2}{*}{1400} & \multicolumn{5}{|c|}{$\begin{array}{c}\text { a) Anzahl d. Phoneme } \\
\text { ohne VoVar }\end{array}$} & \multicolumn{5}{|c|}{$\begin{array}{c}\text { b) Anzahl d. Phoneme } \\
+ \text { VoVar }\end{array}$} \\
\hline & $A$ & P & G & L & alle & $A$ & $\mathbf{P}$ & G & L & alle \\
\hline Ko & 5 & 6 & 3 & 2 & 16 & 5 & 8 & 3 & 2 & 16 \\
\hline So & 4 & 2 & & 2 & 8 & 4 & 2 & & 2 & 8 \\
\hline Vo & 2 & 6 & 4 & 4 & 16 & 4 & 6 & 4 & 6 & 20 \\
\hline
\end{tabular}

Im jüngeren phonologischen system um 1400 ist die Symmetrie nur bei den Phonemeinheiten deutlich zu erkennen (siehe hier Tafel IVa) $-16: 8: 16=2: 1: 2$. Die Ausgewogenhe1t des Systems hängt nicht mehr von den Varianten, eventuell im Modell von ihrer Anzahl, ab (vgl. Taf.IIIb). Die Beseitigung der konsonantischen Mouillierungskorrelation hat auch die Rolle der weichen Varianten der hinteren Vokale abgebaut, und diese haben sich inzwischen in vordere Vokale verwandelt. Die Labialisierung hat sich bei den Konsonanten nicht durchgesetzt, und die vokalischen labialisierten Varianten stören jetzt die symmetrie (siehe Taf. IVb, vgl. auch Taf. II). Die Existenz dieser labialisierten Varianten muss zeitlich nur begrenzt lange dauern - und sie sind wirklich im Laufe des nächsten Jahrhunderts aus dem Alttschechischen verschwunden. 
Die Beseitigung der Mouillierungskorrelation und der Abbau der vokalischen Varianten vereinfachte und stabilisierte das damalige phonologische System des Alttschechischen.

\subsubsection{Raumsymnetrie der systemelemente}

9.2.5.1. Das geometrische Modell des phonologischen Systems

Die im alttschechischen phonologischen system vorhandene Zahlensymmetrie führt zum Schluss, dass die systemelemente auch im Raum ein Modell bilden. Die konstante Mitte bei den $\mathrm{Z}$ ahlenrelationen der Teilstrukturen $(1: 1: 1,2: 1: 2$; die Mitte = die Sonanten = 1) stellt eine Achse dar, um die das ganze phonologische System im Raum angeordnet werden kann. Wir werden versuchen, ein solches Raummodell $2 u$ finden, das dem alttschechischen System entspricht und das sich später auch auf andere systeme applizieren lässt. Die Darstellung des ganzen phonologischen Systems soll vereinfacht und auf.nur zwei Ebenen beschränkt werden (obwohl wir wissen, dass jedes Phonem nicht einen Punkt sondern einen gewissen Raum darstellt und dass er nicht zwei, sondern drei oder sogar vier Koordinaten hat, siehe auch 9.2.6.). Die Grundelemente (C, V, $x$, S) funktionieren als Koordinaten der zwei Grundebenen, die durch eine Achse der Sonanten hindurchgehen: die horizontale Ebene der Konsonanten (C-Ebene) und die vertikale Ebene der Vokale und silbenbildender Sonanten (VS-Ebene). Die konkreten Farben (A, P, G, L) gliedern die zwei Ebenen in je vier Teilebenen.

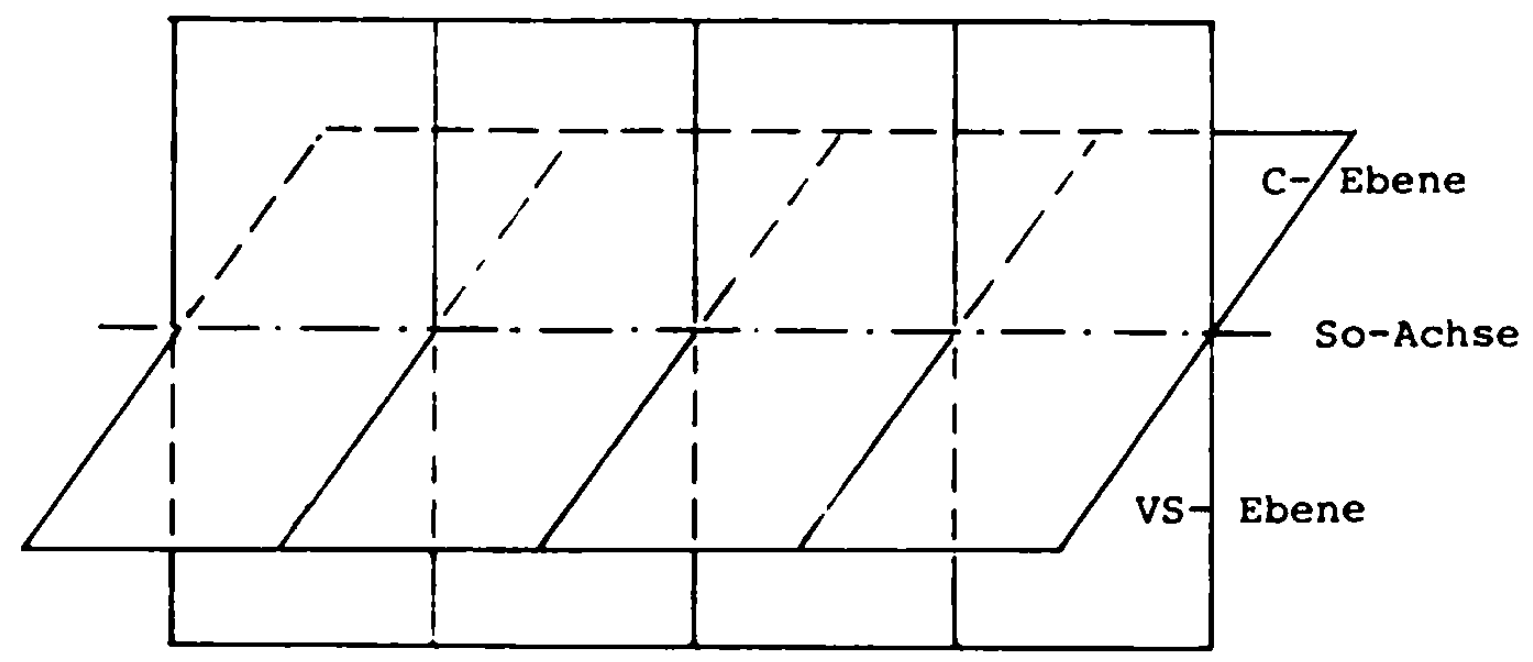

A-Teilebene P-Teilebene G-Teilebene L-Teilebene

9.2.5.2. Die Unterteilung der Teilebenen und Sektoren im Modell 
$q$ - Quantität, v - Stimmbeteiligung) sind mit den Grundelementen, was die Anzahl betrifft, symmetrisch. Die vier akzessorischen Elemente verursachen die weitere Unterteilung der Ebenen in folgende Sektoren: in mouiliferte (m), nasalisierte (n), stimmbafte oder stimmlose $(v, \phi v)$ Sektoren in der $c$-Ebene; lange und kurze (q, $\phi q)$ Sektoren in der vs-Ebene.

C-Ebene:
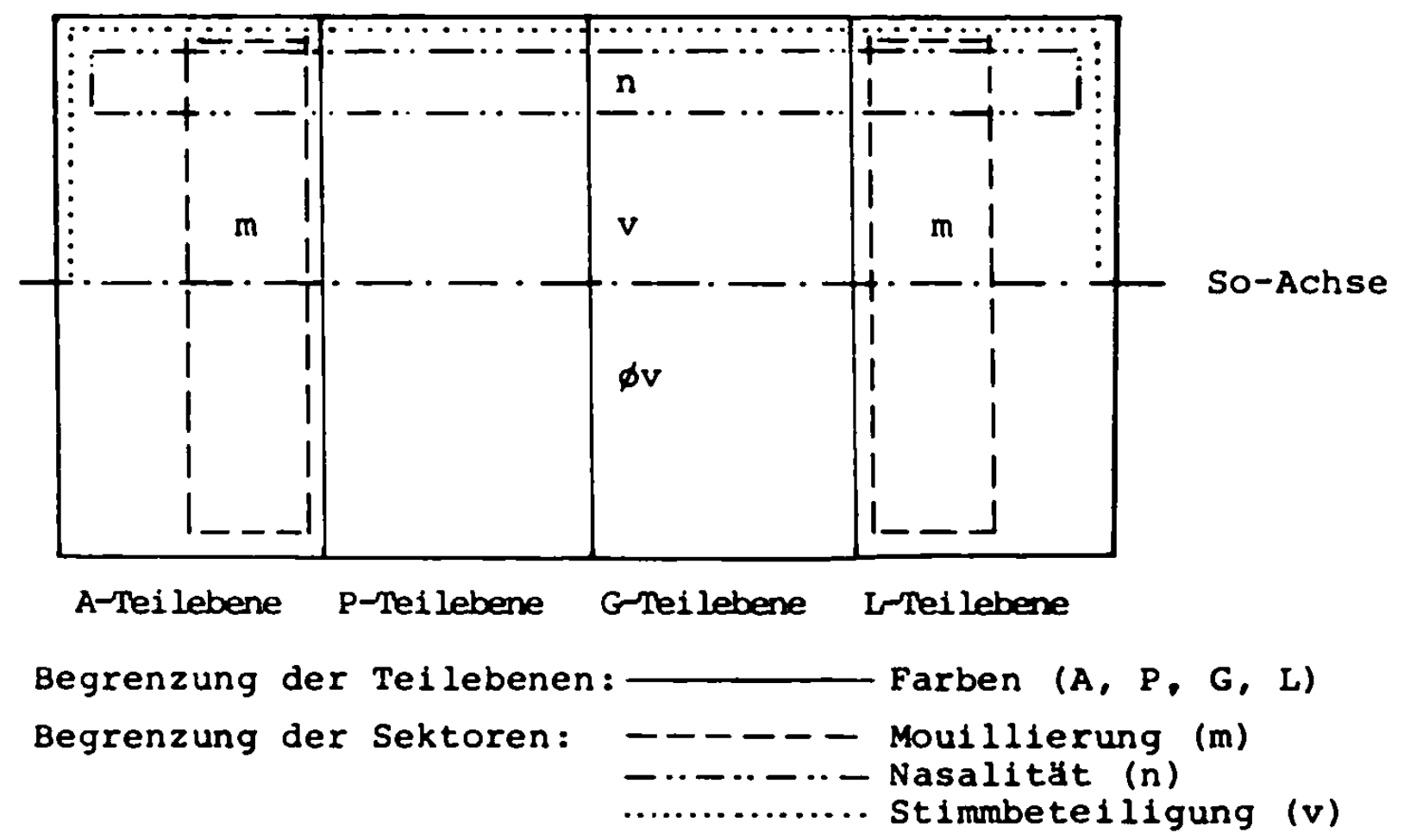

VS-Ebene:

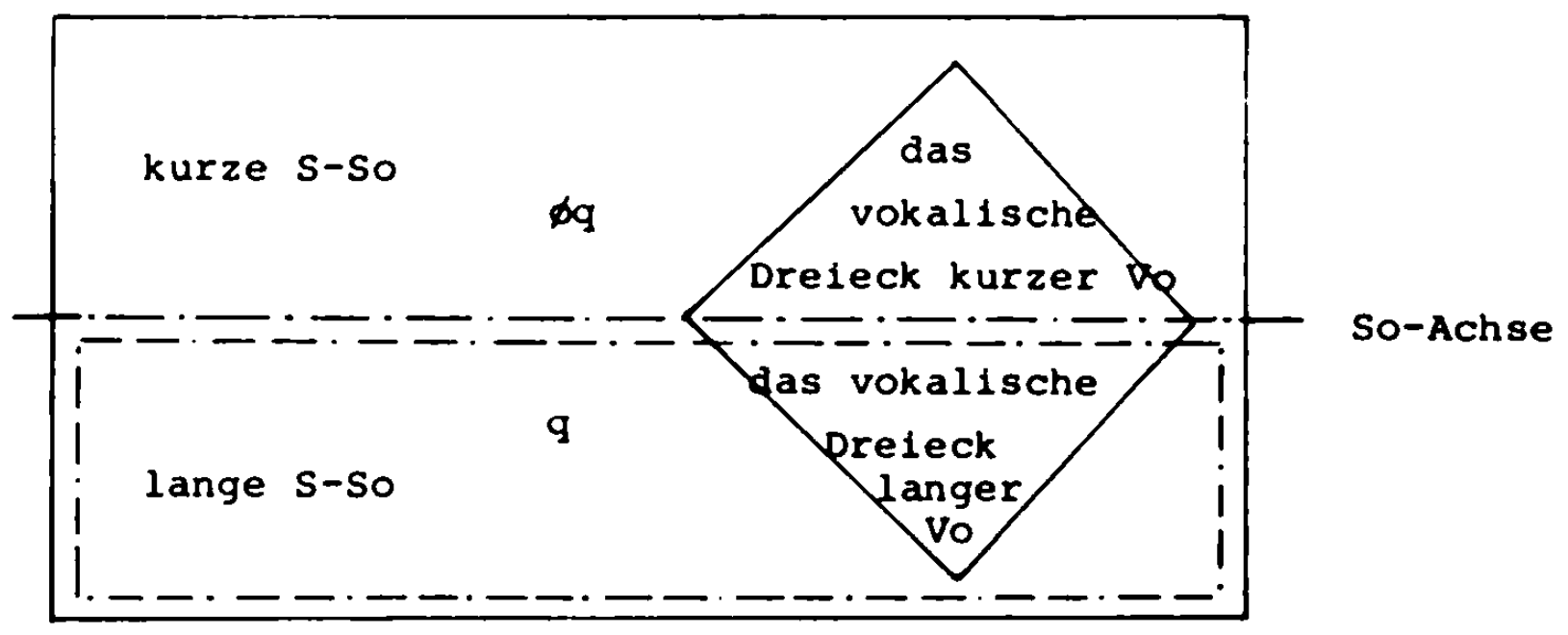

Begrenzung der Sektoren:-- - - - Quantitat (q)

9.2.5.3. Die Figuren im geometrischen Modell

Die Einheiten eines phonologischen Systems bilden dann in den Ebenen bzw. Teilebenen einfache Figuren - Dreiecke und vierecke (bei dem vokalischen Dreieck handelt es sich eigentlich um zwei 
Dreiecke, die miteinander über die Sonanten-Achse verbunden ein Viereck bilden). Die Form der Figuren ist nicht statisch. Die Teilsysteme varileren wăhrend der Entwicklung zwischen einem Dreieck und einem Viereck, zwischen einer ausgestreckten (breiteren) und einer zusammengezogener (schmaleren) Figur.

Das konsonantische Viereck in der C-Ebene
Das vokalische Dreieck in der VS-Ebene

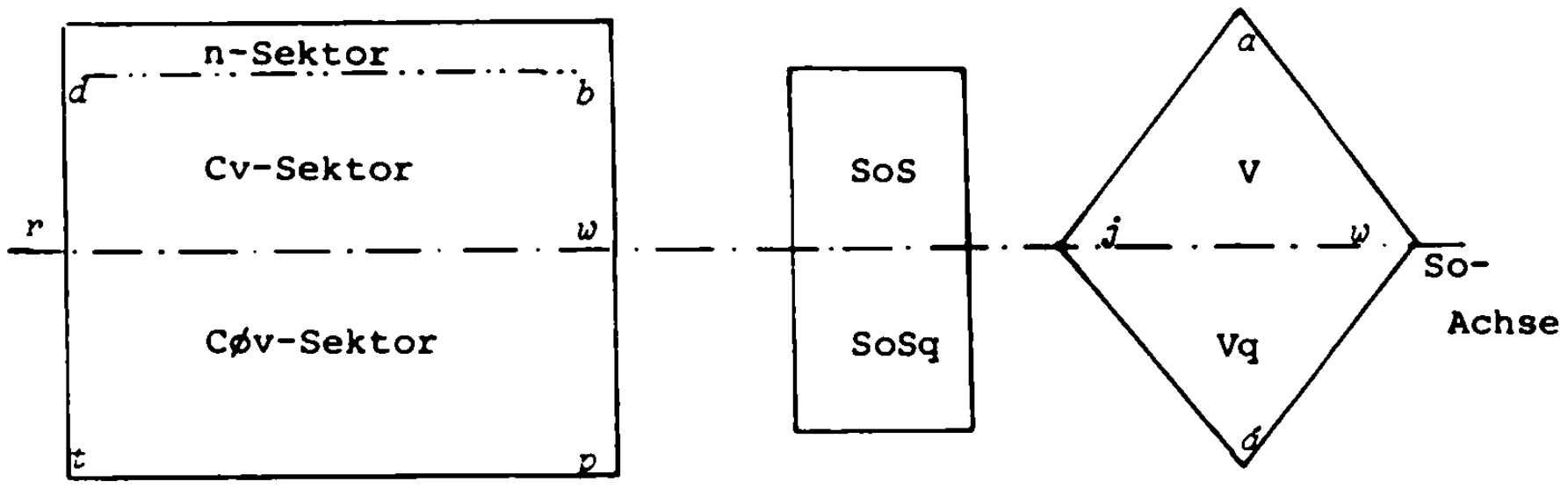

9.2.5.4. Ein Raummodell des alttschechischen phonologischen Systems un das Jahr 1300:

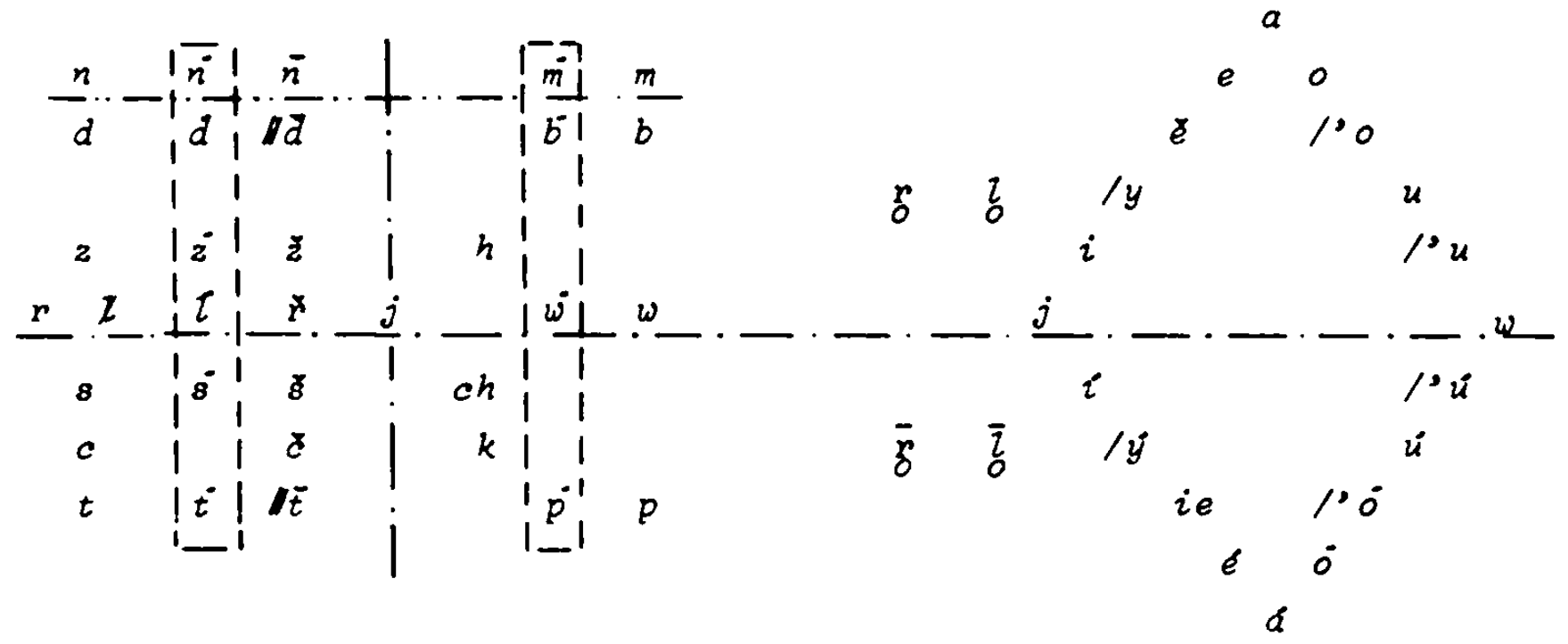

Konsonanten

silbische Sonanten, Vokale

Anm.: / vor den Buchstaben bezeichnet eine Variante // bezeichnet eine chronologische Variante

Die Ko und Vo + silbische So, hier der Ubersichtlichkeit wegen getrennt, sind durch die Sonanten-Achse verbunden zu einem Ganzen; man muss sich diese Laute im Raum vorstellen, placiert in den zwei oben Deschriebenen zueinander rechtwinkelig stehenden Ebenen (vgl. dazu die zeichnung unter 9.2.5.1.). 
9.2.5.5. Ein Raummodell des alttschechischen phonologischen Systems um das Jahr 1400:

Konsonanten

$\frac{n}{d} \cdot-\frac{\bar{n}}{d}-\cdots-\cdots-\cdots$

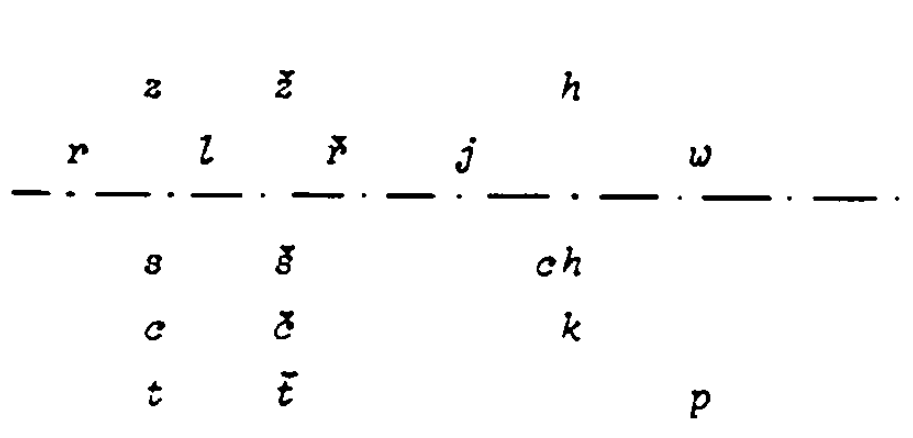

silbische Sonanten, Vokale

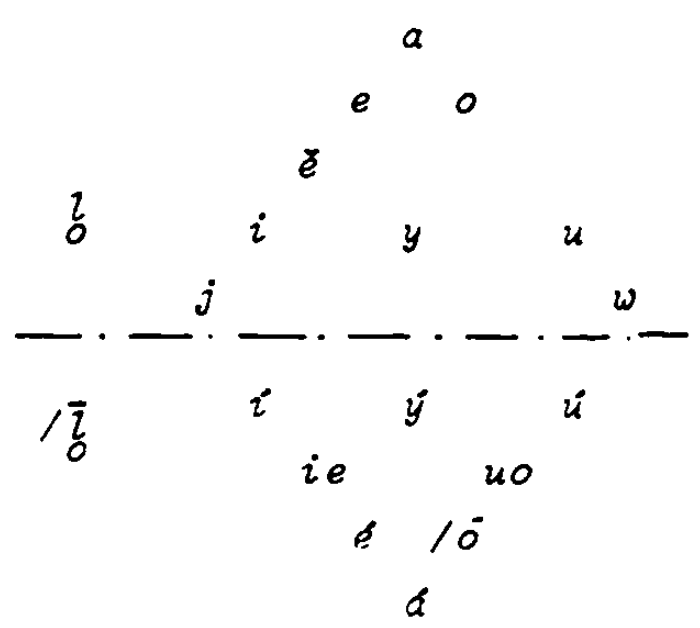

Anm.: $\mathrm{Zu}$ den Raummodellen vgl, auch die Tafel I, II unter $9.2 .3 .1 ., 9.2 .3 .2$.

9.2.5.6. Die Symmetrie in Raummodellen

Das konsonantische Teilsystem des Alttschechischen um 1300 war nicht nur horizontal (um die Sonanten-Achse), sondern vor allem auch vertikal (um die j-Achse, vgl.9.2.5.4.) symmetrisch.

Anm.: Unter $j$-Achse verstehen wir die Gerade, die durch den von $j$ auf der Sonanten-Achse besetzten Punkt in der C-Ebene vertikal zur So-Achse geht (vgl, das Schema unter 9.2.5.4.).

Die beiden um $j$ symmetrischen mouillierten Reihen (und auch die mouillierten Varianten im vokalischen Teilsystem) wurden im Verlauf des XIV. Jhs. beseitigt. Die heute schon bekannten Ergebnisse der Lautentwicklung des Tschechischen im XIV. Jh. zeigen, dass zwei Raumsymmetrien, die dazu noch in zwei verschiedene Richtungen gehen, in einem phonologischen system nicht auf längere zeit nebeneinander existieren können (horizontale m-symmetrie vs. vertikale v-symmetrie vgl. das Schema unter 9.2.5.4.). Die Teilsysteme $C$, V lassen offensichtlich nur eine - vertikale - Raumsymmetrie (eine Spiegelung)zus die Vorale die der Quantität ( $V$ v8. $V q$ ) und die Konsonanten die der Stimmbeteiligung ( $C$ vs. $C v$ ). Im System um 1400 wurde diese Tendenz schon realisiert. Die Figuren im Modell dieses Systems wurden dadurch in einer Raumdarstellung kleiner, das ganze Modell einfacher. Das konsonantische Viereck wurde schmäler, weil die beiden Sektoren der Mouiliferten aus dem System des Alttschechischen um das Jahr 1400 ausgeschieden sind. Dasselbe gilt für das vokalische Dreieck. 
9.2.5.7. Die Konkurrenz der Symmetrien

Die Raummodelle zeigen ebenso, dass ein system eine innere Symmetrie hat. In verschiedenen Entwicklungsetappen kơnnen mehrere symmetrische Anordnungen der Phoneme miteinander konkurrieren, wobe $i$ eine Anordnung zu bestimmter zeit redundant wird und infolgedessen dann aus dem system ausgeschieden oder durch eine andere, relevante, ersetzt wird. Aus den Verschiedenheiten in zwei oder mehreren Modellen für verschiedene zeitquerschnitte in der Diachronie eines phonologischen systems kann man feststellen, auf welche Art und Weise es zu einer systemänderung kommt.

9.2.6. Parazentrische Bewegungen der akzessorischen Elemente als Entwicklungsprinzip im phonologischen system

9.2.6.1. Gibt es ein dynamisches Systemmodell?

Bei einer statischen synchronen Beschreibung kann man ein phonologisches system an einem zahlen- oder an einem Raummodell darstellen. Ist für die systemänderungen, für die diachronische Lautenentwicklung auch ein Modell zu finden? Gibt es ein dynamisches Modell eines phonologischen systems?

9.2.6.2. Die Beweglichkeit der akzessorischen Elemente

Wenn wir von der Voraussetzung ausgehen, dass nicht nur die Systemeinheiten (Phoneme), sondern auch die systemelemente (die Farbe, die Mouillierung, usw.) im Systemmodell ihren Platz haben, dann kann etwas neues im systemmodell (neue Systemeinheiten) nur durch Bewegung entstehen, durch gegenseitiges Annähern einiger Einheiten, oder - genauer gesagt - durch die Annăherung einer systemeinheit und eines systemelements. Diese Bewegungen, wie alles andere in einem phonologischen system, sind nicht chaotisch, sondern geregelt und geordnet. 123 In einem Raummodell sind die Grundelemente $C, V, S, X$ fast konstant, bewegen sich nicht und behalten fast immer ihren Platz als Grundkoordinaten der Systemeinheiten. Die

123 Die Ursachen der Bewegungen im Modell eines phonologischen Systems behandelte J. HAMM, Die Verschiebungen der Velarkonsonanten, Wiener Slavistisches Jahrbuch 15 (1969) 38-58; vgl. die Schemata auf Seiten 51 und 50 . 
akzessorischen Elemente $(q, m, n, v)$ sind nicht so stabil, sie können sich im Raummodell des systems freier bewegen. Ein akzessorisches Element kann in einem Raummodell $\mathrm{zu}$ verschiedenen zeitpunkten der Sprachentwicklung verschiedene Positionen, verschieden grosse Tellebenen oder Sektoren einnehmen (vgl. das Schema unter 9.2.5.2.). Diese Bewegungsfähigkeit der akzessorischen Elemente kann als Hauptfaktor der systemönderungen bezeichnet werden.

9.2.6.3. Konkurrenz in der Hierarchie der akzessorischen Elemente

Die Hierarchie und die Relevanz einzelner akzessorischer Elemente ändert sich in der Sprachdiachronie. Ein Element kann in einer Entwicklungsperiode eine zentrale systemposition einnehmen (z.B. die Mouillierung im alttschechischen phonologischen system vor 1300), später dann an der systemperipherie vorkommen (die Mouillierung im alttschechischen phonologischen system um die Hälfte des XIV. Jhs.), oder aus dem System ausgeschieden werden (die Mouillierung im Alttschechischen nach 1400). Parallel zu diesem Prozess kann ein akzessorisches Element durch ein anderes ersetzt werden (die stimmbeteiligung - v - ersetzt im alttschechischen phonologischen system im Laufe des XIV. Jhs. die Mouillierung - $m$ ), wobei noch $z u$ einem Konkurrenzkampf um eine systemposition zwischen zwei Elementen kommen kann (z.B. die Labialisierung vs. Stimmbeteligung im Alttschechischen des XIV. Jhs.).

9.2.6.4. Die parazentrischen Bewegungen eines akzessorischen Elements

Die Bewegungen der akzessorischen Elemente stelien wir uns in einem Raummodell eines phonologischen systems als parazentrische Bewegungen vor - sie verlaufen vom systemzentrum loder vom Teilsystemzentrum) in der C- oder VS-Ebene in zwei einander entgegengesetzten Richtungen gleichmässig und symmetrisch hin und zurück (die Vektoren dieser Bewegungen sind gleich gross).

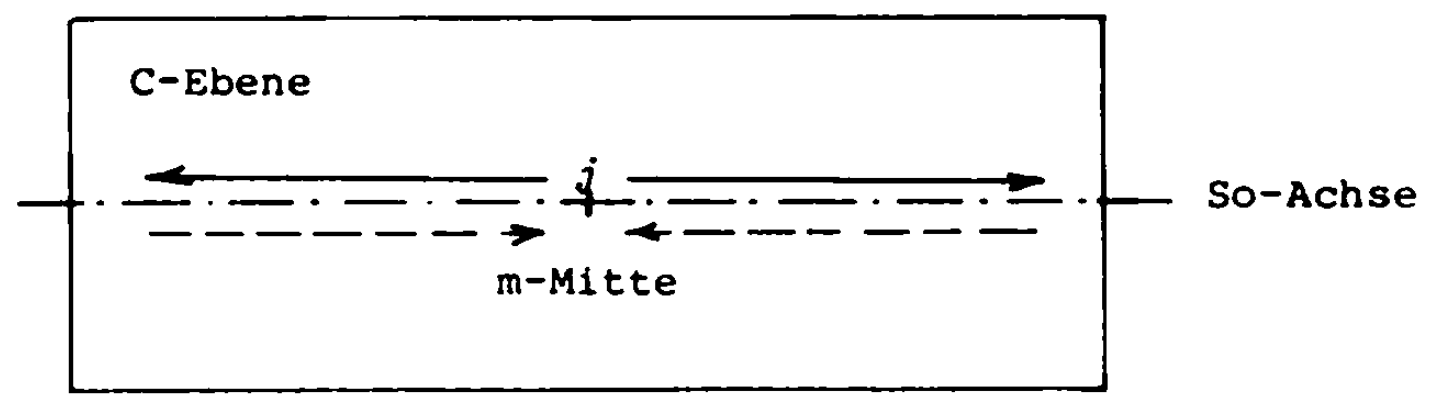


$\longrightarrow--\longrightarrow$ Vektoren der Bewegungen der akzessorischen Elemente

Man könnte dieses Prinzip auch folgendermassen formulieren: Ein durch starke Konzentration eines akzessorischen Elements aufgeladenes Zentrum verfügt über zwei Eigenschaften - Ausstrahlungskraft und Anziehungskraft - die im Stande sind, ganze Phonemreihen $z u$ beeinflussen und $z u$ ändern.

9.2.6.5. Die parazentrischen Bewegungen des m(Mouillierung)-Elements im alttschechischen phonologischen System - Entwicklung der alttschechischen Mouillierungskorrelation

Wir wollen jetzt diese Hypothese durch die Entwicklung der alttschechischen konsonantischen Mouillierungskorrelation beweisen. Der Ursprung der Mouillierungsvorgänge im Tschechischen ist unserer Ansicht nach noch in den Ainderungen der Jerlaute (um das Jahr 1000 nach Datierung von Mares) zu suchen. Die $m(j)$-Mitte (vgl. 9.2.6.4.) wurde durch den Schwund der weichen Jerlaute mit neuer kraft aufgeladen. Den Schwund der weichen Jerlaute können wir uns als eine positionell bedingte spaltung der reduzierten weichen Jerlaute einerseits auf volle $e$-Vokale, andererseits auf ein Mouillierungselement vorstellen. ${ }^{124}$ Das m-Element wandert zur m-Mitte, verstärkt sie und versucht sich auch in der C-Ebene als Spiegelung oder Widerhall des Vorganges der VS-Ebene zu realisieren.

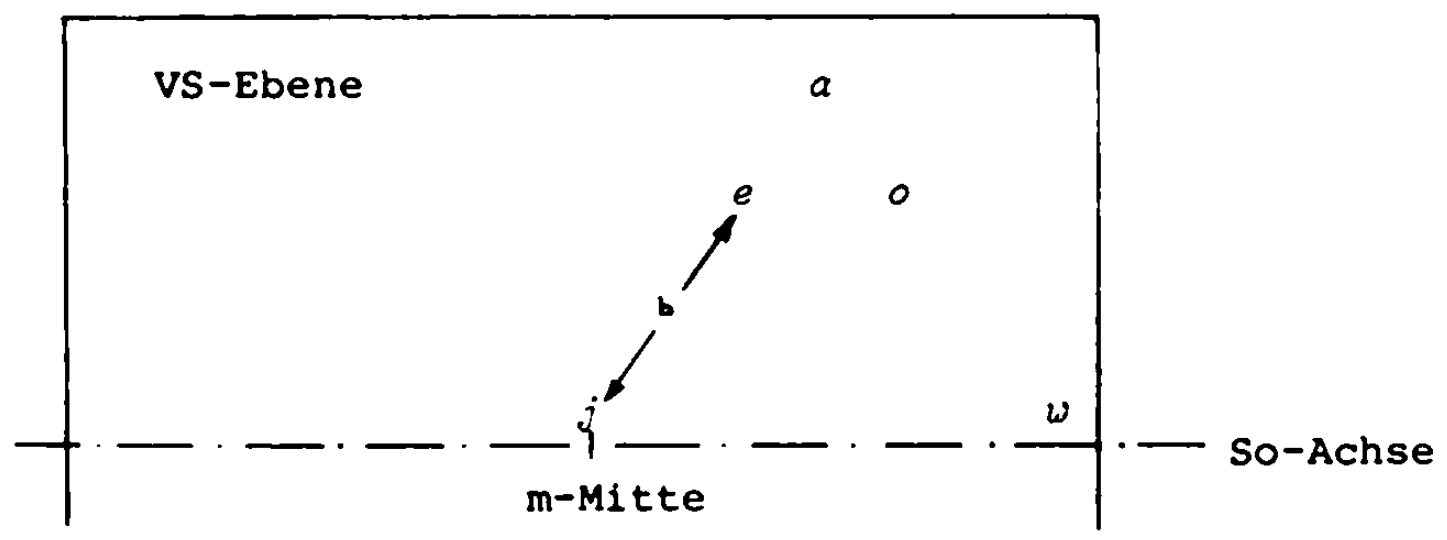

Von der mit dem m-Element aufgeladenen m-Mitte auf der SonantenAchse gehen in der C-Ebene starke Mouillierungsimpulse aus, zuerst nur entlang der Sonanten-Achse (es entsteht $\tau, \dot{r}$, ev. auch $w$ ) und dann von der So-Achse in der $A$ - und $L$-Reihe:

124 H. D. POHL, Ein Beitrag zur serbokroatischen Morphonologie: nepostojano a, Wiener Slavistisches Jahrbuch 21 (1975),S.222, setzt (für das Serbokroatische) voraus, dass im zusammenhang mit Verlust der Palatalität b, z $z u$ einem Schwa-Laut zusammengeflossen sind. 


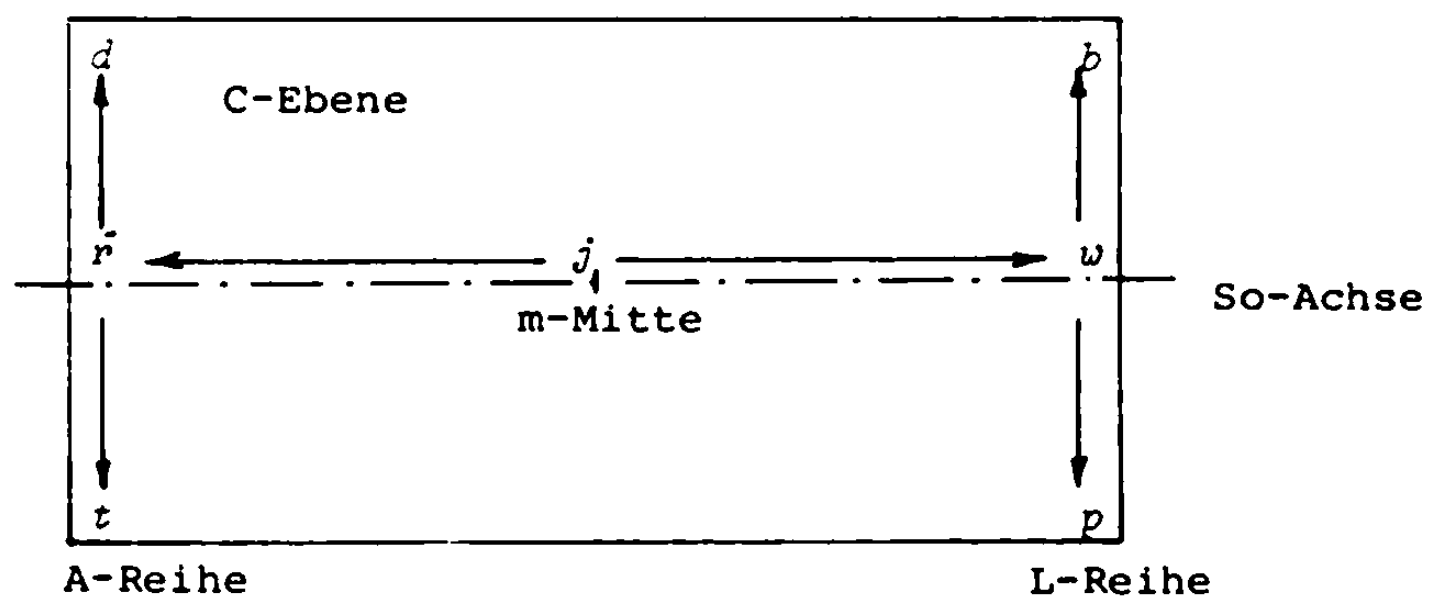

Die P- und G-Phonemreihen werden durch diese Impulse nicht beeinflusst, weil sie schon weich sind (die p-Reihe, zu der zeit noch ohne $\bar{t}, \vec{a}$, phonologisch; die G-Reihe morphonologisch: $k>c, r$; $\dot{n}>z, \tilde{z} ; c h>s, \xi-\operatorname{man} k a n n$ also die G-Reihe als morphonologisch weich betrachten). Nur die harten $A-$ und L-Reihen sind noch potentiell erweichbar und können die m-Impulse aufnehmen. Die m-Impulse sind so stark, dass es zu einer Spaltung dieser beiden Phonemreihen kommt, und als Produkte dieser spaltung entstehen im alttschechischen phonologischen System vor 1300 die zwei moulllierten $A-$ und $[-R e i h e n$. Das Phonem $/ c /$ wurde durch diese Entwicklung nicht berührt, weil es schon immer und ausschliesslich weich war. Die zwei neuen Reihen werden dann symmetrisch $z u$ der m-Mitte (in einem Raummodel1) zwischen den $A-$ und P-Reihen und zwischen den G- und L-Reihen placiert:

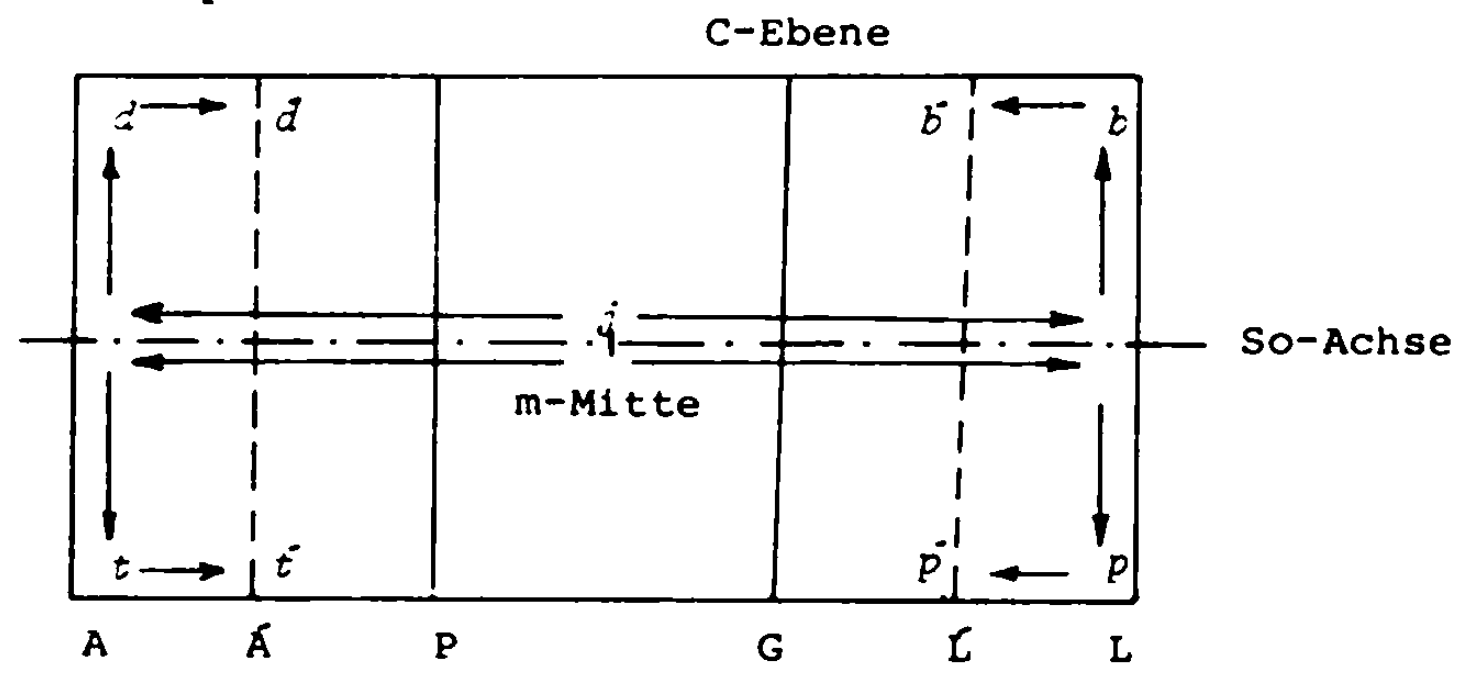

Man kann annehmen, dass die m-Impulse von der m-Mitte nach dem Schwund der Jerlaute auch zurück in die vs-Ebene ihre wirkung ausdehnen und dort, parallel zu den Moulllierungsänderungen in der C-Ebene, den Lautwandel $a>d$ verursachen: 


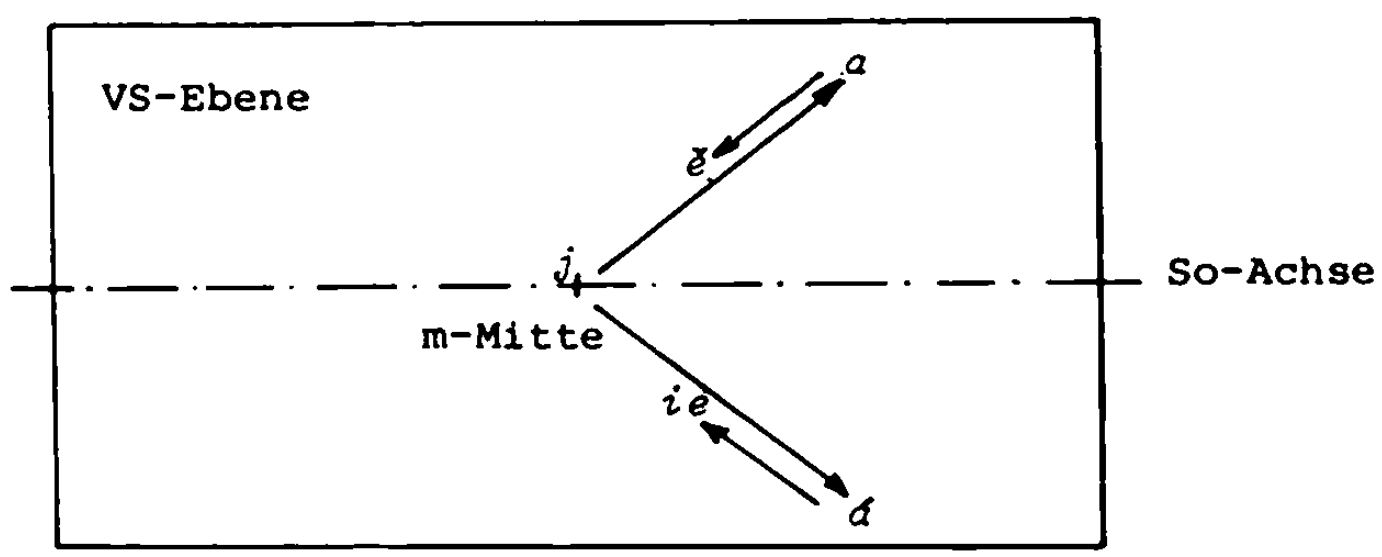

Die Phoneme $/ \ell /$, /ie/ sehen wir dann als Produkte der spaltung von $a, b$ an, die durch einen von der m-Mitte ausgehenden m-Impuls verursacht wurde. Die beiden neuen Vokale haben genauso wie die beiden neuen mouillierten konsonantischen Phonemreihen $\AA, L$ im keinen festen Platz, sind morphonologisch nur ganz schwach oder gar nicht verankert und dadurch auch in ihrer Existenz chronologisch begrenzt. Die beiden konsonantischen $\AA$ - und $\mathfrak{L}$-Reihen lobsen sich im Laufe des XIV. Jhs, auf und dann folgt derselbe Vorgang in der VS-Ebene auch bei $e$ und später bei $i e$. In der C-Ebene wurde das m-Element durch die geschilderten Bewegungen und damit verbundenen Phonemănderungen sehr geschwăcht und blieb noch eine gewisse zeit als rein periphere Erscheinung bei den Korrelationspaaren $z-\tau, w-w$ (svaty) auf der Sonanten-Achse, wo sich auch der Kreis der Bewegungen des akzessorischen $\mathrm{m}$-Elements in der C-Ebene schliesst und wo der m-Impuls in der C-Ebene endgültig erlischt. Die Konsonanten der $\AA-, C$-Reihen kehren $z u$ den Phonemen der $A-$ und L-Reihe zurück (die Frequenz der Alveolare und Labiale wird dadurch höher) - die Qualităt wandelt sich in die Quantität um.

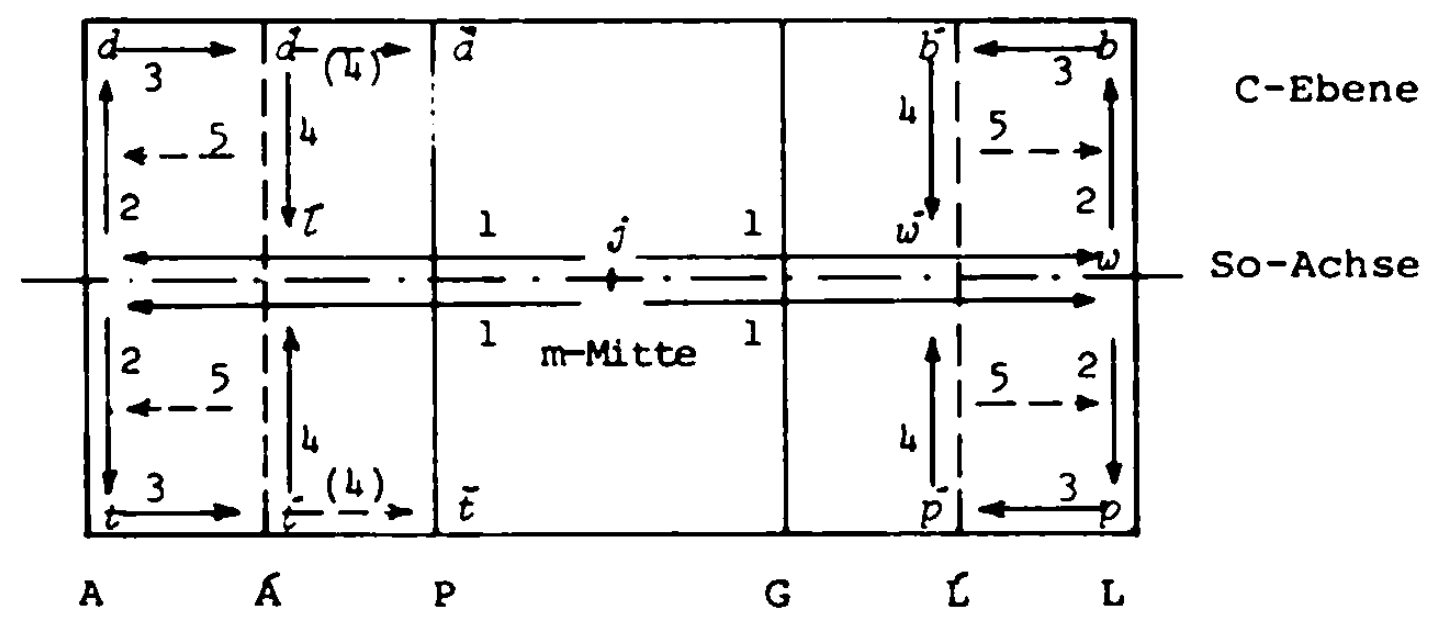

Anm.: Die Reihenfolge der Mouillierungsvorgănge wird durch die 2 iffern bei den Vektoren bezeichnet; der Vektor 5 bezeichnet den Rückkehr der Mouililerten in die $A-$ und $L-R e i h e n$. 
In der VS-Ebene ist dagegen das m-Element auch nach der Senkung der Jotierung bei $e$ noch aktiv: als letzten Vorgang der durch m-Bewegungen verursachten Ainderungen betrachten wir den Lautwandel ' $u>i$. Die Vollendung dieser Anderung in der zweiten Halfte des XIV. Jhs. hat auch in der VS-Ebene den Kreis der Bewegungen des m-Elements geschlossen. Im folgenden Schema werden die letzten Bewegungen des m-Elements in der VS-Ebene dargestellt: $\overline{\text { verliert }}$ das m-Element, andert sich $z u e, m-E l e m e n t$ wandert (über $a, e v .0$ ) $z u^{\prime} u$ und dann $z u$.

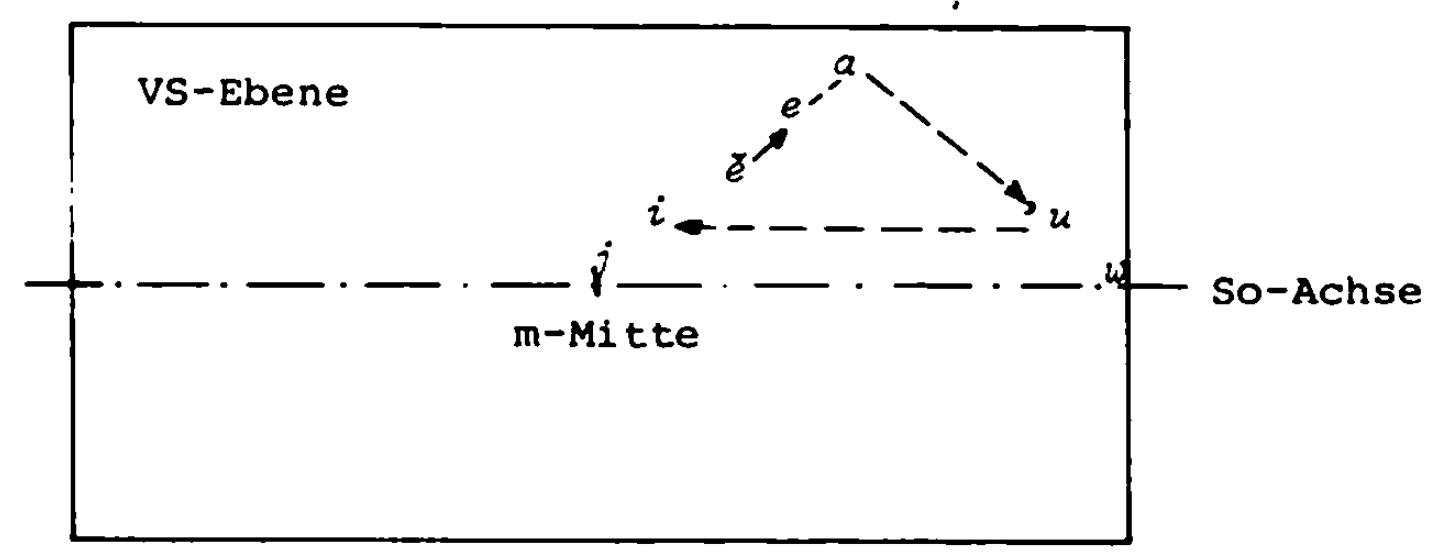

Wir haben in unseren Darstellungen nur die wichtigsten Bewegungen des m-Elements beschrieben. Ein ausführlicheres Schema könnte $2 . B$. auch den wandel $\dot{r}>\not x, b z w ., 0>\sum$ darstellen und behandeln; aber wie die schon beschriebenen, so entsprechen auch diese Änderungen den Möglichkeiten und Prinzipien des demonstrierten dynamischen Raummodells.

Die durch die Bewegungen des akzessorischen $m-E l e m e n t s$ neu entstandenen Qualitäten ( $\dot{E}, \hat{A}$ - und $\mathcal{L}$-Reihen, ev. auch' $u$ ) wurden durch neue Quantităten ersetzt (hohere Frequenz des $e$, der $A-$ und $L-R e i h e n$ und des $i$ ). Die Beseitigung des m-Elements, dessen Bewegungen das ganze System ins Wanken brachten, hat drei wichtige Folgen: 1. Die Phonemqualitäten werden durch Phonemquantitäten ersetzt. 2. Das ganze alttschechische phonologische system ist dadurch stabiler geworden. 3. Die höhere Frequenz der vorderen Vokale und die relative Ausgewogenheit des phonologischen Systems führen au Anderungen im morphologischen system 125 .

$125 \mathrm{Z} . \mathrm{B}$. grössere Änderungen in der alttschechischen nominalen Derivation (besonders bei Deminutiva) als Folge der hoheren Produktivitát der -i-Formanten - vgl. dazu I. NËMEC, Hláskos lovné predpoklady produktivity slovotvornych formantú, slovo a slovesnost 32 (1971) 217-224. 
9.2.6.6. Die parazentrischen Bewegungen als Entwicklungsprinzip eines phonologischen systems

Die parazentrischen Bewegungen eines akzessorischen Elements (die meist um ein system- oder Teilsystemzentrum verlaufen) fuhren stufenweise von der Verminderung uber das Erschöpfen bis zum Erlöschen seiner Potenz; das Element wird an die systemperipherie gedrängt oder gar aus dem system eliminiert. Inzwischen wird aber im System ein anderes Element aktiv, das dann weiter für die notige Bewegung und Dynamik sorgt.

9.3. Die Zusammenfassung der phonologischen Charakteristik: siehe unter 11.4 .

\section{CHARAKTERISTIK DER ORTHOGRAPHIE}

10.1. Die Schreiber allex Evangeliare unserer Handschriftengruppe bedienen sich der sogenannten Digraphenorthographie, wie es den schreiberischen Gewohnheiten des XIV. Jhs. entspricht. Man findet fast keine Abweichungen von der damaligen - nicht ganz festen orthographischen Norm. 126

10.2. Die Orthographie von unseren Evangeliarhandschriften im Vergleich (Buchstabe in klammern kommt nur vereinzelt vor)

$\begin{array}{lllllll}\text { Transkription } & \text { A } & \text { C } & \text { D } & \text { S } & \text { R } & \text { W } \\ \text { a } & a & a & a & a & a & a \\ \text { a } & a & a & a & a & a & a \\ \text { b } & b & b & b & b & b & b \\ \text { C } & c z & c z & c z & c z & c z, / c / & c z, / c / \\ \text { c } & c S & c z & c z & c z & c z, / c / & c z \\ \text { d } & d & d & d & d & d & d\end{array}$

126 Leider gibt es bis heute keine umfassende moderne Beschreibung der tschechischen Orthographie in ihrer Entwicklung. Zur Orientierung dienen am besten die Anmerkungen zur alttschechischen Orthographie in den Werken von J. GEBAUER, Hlaskoslovi (s. Fn. 107), 11-16 und bei einzelnen Lauten, und in vývoj... (s. Fn. 78) von B. HAVRANEK. Die Monographie von J. GEBAUER, Pŕ Ispěvky k historii Ceského pravopisu, Praha 1871, ist heute in mancher Hinsicht schon veraltet. Moderne Blickpunkte auch auf die alteste tschechische Orthographie bringt J. SCHROPFER, Hussens Traktat orthographia Bohemica, Wiesbaden (Harrassowitz-Verlag) 1968. 


\begin{tabular}{|c|c|c|c|c|c|c|}
\hline Transkription & A & C & D & $\mathbf{S}$ & $\mathbf{R}$ & $\mathbf{w}$ \\
\hline$d^{\prime}$ & $d$ & $d$ & $d$ & $d$ & $d$ & $d$ \\
\hline e & $e$ & $e$ & $e$ & $e$ & $e$ & $e$ \\
\hline é & $e$ & $e$ & $e$ & $e$ & $e$ & $e$, leel \\
\hline é & ie & $y e, i e$ & ye & $y e, i e, / e /$ & ye & ye,/el \\
\hline f & - & - & $p h$ & $f, p h$ & ph & $f, p h$ \\
\hline$g$ & - & - & $g$ & $g$ & $g$ & $g$ \\
\hline$h$ & $h$ & $h$ & $h$ & $h$ & $h$ & $h$ \\
\hline ch & $c h$ & $c h$ & ch & ch & $c h$ & $c h, / h /$ \\
\hline$i$ & $i, / y /$ & $y$ & $y, i$ & $i, y,|\dot{y}|$ & $y,|i|$ & $y, i$ \\
\hline 1 & $i$ & $y$ & $y$ & $i, y$ & $y$ & $y$ \\
\hline $1 e$ & ie & ye & ye & ie, ye & ye & ye \\
\hline$g, y$ & $y, i, y g$ & $g, y, y g$ & $g, y, y g$ & $g, y, y g$ & $y, g$ & $g, y, y g, / g i$ \\
\hline k & $k, c$ & $k$ & $k$ & $k$ & $k, / c \mid$ & $k$ \\
\hline 1 & $\imath$ & 2 & 2 & 2 & 2 & $\tau$ \\
\hline$m$ & $m$ & $m$ & $m$ & $m$ & $m$ & $m$ \\
\hline$n$ & $n$ & $n$ & $n$ & $n$ & $n$ & $n$ \\
\hline$\check{n}$ & $n$ & - & $n$ & $n$ & $n$ & $n, n y$ \\
\hline 0 & 0 & 0 & 0 & 0 & 0 & 0 \\
\hline $0^{-}$ & - & 0 & 0 & 0 & 0 & 0 \\
\hline $\mathbf{p}$ & $p$ & $p$ & $p$ & $p$ & $p$ & $p$ \\
\hline$r$ & $r$ & $r$ & $r$ & $r$ & $r$ & $r$ \\
\hline$\check{\mathbf{r}}$ & $r z$ & $r z$ & $r z$ & $r z, / r /$ & $r z, / r /$ & $r z$ \\
\hline $\mathbf{s}$ & $\$, \$ \$, 8$ & $\$, \$ \$$ & $\$, \$ \$, 3$ & $\$, \$ \$, 8$ & $\$, \$ \$, 8$ & $\$ \$, \$, s$ \\
\hline$\zeta$ & $\$ \$, \$, 8$ & $\$ \$, \$, s$ & $\$ \$, \$, 8$ & $\$ \wp, \wp, / z /$ & $\$ \$, \S$ & $\$ \$, \S$ \\
\hline$t$ & $t$ & $t,|t h|$ & $t,|t h|$ & $t$ & $t, \mid t h /$ & $t,|t h|$ \\
\hline$t^{\prime}$ & th & $t$ & $t$ & $t$ & $t$ & $t$ \\
\hline $\mathrm{u}$ & $u, v$ & $u, v$ & $u, v$ & $u, v$ & $u, v, w$ & $u, v$ \\
\hline u & $u$ & $u$ & $u$ & $u, v$ & $u$ & $u, v, / u u /$ \\
\hline$v$ & $w$ & $w$ & $w$ & $w, v, u$ & $w, v, u$ & $w, / u /$ \\
\hline$y$ & $i$ & $y, i$ & $y, i$ & $y$ & $y$ & $y, i$ \\
\hline$y$ & $i$ & $y$ & $y$ & $y$ & $y$ & $y$ \\
\hline $\mathbf{z}$ & $z$ & $z$ & $z$ & $2,|\$|$ & $z, / \$, \$ \$ /$ & $z$ \\
\hline$z$ & $\mathbf{z}$ & $z, / 2 z /$ & $\mathbf{z}$ & $2,|\$|$ & $z, / 2 z, 8 /$ & $z, / \$ \$, z z$ \\
\hline
\end{tabular}

10.3. Die Handschrift A

Dieses Bruchstuck ist das alteste und auch seine Orthographie weist die Merkmale der altesten Variante der Digraphenorthographie auf: $c$ für $k$, seltenes Vorkommen von $y$, fast regelmăssig $\$$ fur $s$ 
und $\$ \oint$ für $\delta, z$ regelmäsig für $z, z$. Diese Orthographie unterscheidet sich am meisten von der Orthographie der Handschrift $S$ - bei den Vokalen kommt der Buchstabe $y$ nur selten vor, sonst 1 mmer ein $i$. Bei den Konsonanten wird $c \oint$ regelmässig für $t$, für $k$ bfters auch $c$, für $s$ fast 1 mer nur $\S$, für $\&$ fast 1 mmer nur $\S \S$ und für $t$ ' 1 mmer nur th geschrieben.

10.4. Die Handschrift C

Fast dieselbe Orthographie wie bei der Handschrift $S$, mt wenigen Abweichungen: th erscheint dreimal statt $t$ (\$wathy, \$watheho, mathye - ist es vereinzelte Bezeichnung der vokalischen Quantităt?). $z z$ einmal fưr $z(y a k z z)$.

10.5. Die Handschrift D

Dieselbe Orthographie wie bei der Handschrift $S$ (siehe 10.6.) mit nur einem Unterschied: th wird selten fur $t$ geschrieben.

10.6. Die Handschrift $S$

Die Vokale werden durch die lateinischen Buchstaben $a, e, i$, $o, u, y$, der Vokal $z$ und der Diphthong ie durch den Digraphen ye (selten durch $e$ für $\varepsilon$ - meist nach einem $n$ ), ie wiedergegeben. Die Quantitat wird nicht ausgedruckt, die langen Vokale werden als kurze geschrieben.

Die Konsonanten werden auch mit den einfachen oder verdoppelten lateinischen Buchstaben bezeichnet. Es gibt folgende Digraphen: cz für $c, z_{j} y g$ für $j$ meist am wortanfang nach einem vokalisch auslautenden wort, selten auch im wortinneren nach einem Vokal; $r z$ für $\dot{r}$ (vereinzelt auch noch r, z.B. dczery Dat.Sing. Mt 21,5; rkucze Mt $21,9)$; $\$ \S$ für $8, \xi$ praktisch ohne Unterschied, $\xi$ aber oft auch nur $\$$ geschrieben. Menclk (Vorwort, $S$. VII) fuhrt auch $z$ für 8 , $\delta$ an es handelt sich nur um zwei Belege - zez = ze $s \mathrm{~L} 16,25$ und wydyz $=v i d i \xi$ L 6,41, die eher $1 \mathrm{~m}$ ersten Fall als ein Schreibfehler, $1 \mathrm{~m}$ zweiten Fall als assimiliertes $-Z=[\xi]$ zu interpretieren sind. Das Graphem $z$ funktioniert für $z, z$, vereinzelt wird für diese $z$ wei Laute auch $\S$ verwendet - hwie§dy Mt 2,7; pra\$nyecze Mt 20,6; przyka\$al Mt 4,6; ye§u§ie Mt 1,18; nemuo\$te J 16,12; die letzten zwei Belege könnte man als einen Rest der primtiven Rechtschreibung betrachten 
$(\xi=\check{z})$, aber eindeutig sind auch diese nicht.

Man muss also feststellen, dass Menclks Behauptung über die Reste der älteren Orthographie (Vorwort, VII) nicht beweisbar ist: bis auf die zwei obgenannten selege ist alles als Erscheinungen der damaligen Digraphenorthographie erklärbar (oder eventuell auch als Schreibfehler).

Besonders zu Beginn des Textes erscheinen auf einigen Stellen Punkte über $\dot{y}$ (einmal auch über $\dot{z}$ ), die aber keine diakritische Funktion haben, nicht regelmässig vorkomen und wurden mit aller wahrscheinlichkeit erst von einer späteren Hand bei gefügt.

10.7. Die Handschrift $R$

Fast dieselbe Digraphenorthographie wie bei der Handschrift $S$. Unterschiede bei den Vokalen: $i$ - nur als y geschrieben (sehr selten und nur in Fremdwörtern wie Maria u.ä. durch ein i). Konsonanten: vereinzelt anstatt $c z, k$ für $c, c, k$ wird $c$ geschrieben (ce\$tu, rzkucy, cynte, oklycy, cleopha\$\$l; für ein $x$ ofters nur ein $r$ (hrye§\$na, \$hrye\$\$y, uzryechu, dczery Dat.Sing., u.a.); anstatt $t$, $t$, manchmal th (pyeth, sobothny u.a.); $\$, \$$, s wird vereinzelt auch für $z$, ż geschrieben (\$rno, \$\$radu, gens).

Der Schreiber dieser Handschrift hat sehr viele Schreibfehler ge macht. Die tschechische schrift war inm wahrscheinlich nicht so gelăufig wie die lateinische - daraus könnte man auch die Unregelmässigkeiten bei $c, c, k$ erklären.

10.8. Die Handschrift $w$

Fast dieselbe Digraphenorthographie wie bei der Handschrift $S$. Besonderheiten bei den Vokalen: Vereinzelt wird auch die Länge bezeichnet $-e e=e(z$ lee Mt 12,39; mee J 9,11; tee L 10,2; w\$\$yelykee Mt 7,17), uu = $\dot{u}($ zemuu Mt 5,4 - in der handschrift radiert und auf ein $-\ddot{y}$ verbessert). In dieser Erscheinung kann man einen Rest der alten einfachen orthographie sehen.

Besonderheiten bel den Konsonanten: $h$ - selten auch für $c h$ (hozyete J 5,47; hczy L 14,19); ny - für $\tilde{n}$, aber nicht immer; th selten für $t ; \$ \$, z z$ - vereinzelt für $z$ (Ge\$\$y\$ J 8,42; gezz L 11,8$)$. 
10.9. Zusammenfassung

Die meisten Schwankungen gibt es bei der 8ezeichnung von $z$, $z$ und $s, \xi$. Die erweichten Konsonanten ( $d^{\prime}, t^{\prime}, \bar{n}, \bar{z}, \xi, \varepsilon$, $\bar{x}$ ) haben keine besondere und konsequente Buchstabenbezeichnung (Ausnahme bildet $f$ mit $r z$ - daraus ersieht man, dass dieser Laut nicht als weiche Opposition $2 u r$ betrachtet worden ist). Die Handschrift $C$, vielleicht noch unter dem Einfluss der einfachen Orthographie, versucht fast konsequent $c$ von $\delta(c z$ vs. $c \$), s$ von $\delta(\$$ vs. $\$ \$)$ und $t$ von $t^{\prime}(t$ vs. $t h$ ) $2 u$ unterscheiden. Wie bel der Handschrift $S$ ist es auch bei anderen Handschriften schwer, über die Reste der alten sog. einfachen oder primitiven Orthographie, in der der Archetyp aller dieser Abschriften verfasst war, zu sprechen, weil die vorausgesetzten $B e-$ weise äusserst selten sind (vgl. auch 4.2.2.1.).

\section{DIE ERGEBNISSE DER LINGUISTISCHEN CHARAKTERISTIK}

Die strukturelle linguistische Charakteristik der ältesten tschechischen Evangeliartexte hat sich als ziel gesteckt, mit Hilfe der schöpferisch applizierten prinzipien des prager linguistischen Strukturalismus die bisherigen Kenntnisse des alttschechischen Sprachsystems 2 u erweitern, weiters hervorzuheben, welche der systementwicklungsvorgänge für das Alttschechische im XIV. Jh. die zentralen und welche die peripheren sind und letzten Endes auch Anregungen für die diachronische Strukturanalyse der alten Sprachdenkmäler zu liefern. Unsere Paralleltexte aus dem ersten bis letzten Viertel des XIV. Jhs. stellen geeignete Grundlagen fur mehrere synchrone schnitte durch das alttschechische system dar; die durch Vergleich dieser horizontalen Strukturen entdeckten Entwicklungstendenzen - die durch qualitative und quantitative Anderungen der Systemrelationen und systemfunktionen verursachten ständigen Bewegungen zwischen dem systementrum und der systemperipherie - betrachten wir als die vertikale struktur eines Sprachsystems in der Diachronie. Die wichtigsten Ergebnisse der lexikologischen (11.1.). der syntaktischen (11.2.), der morphologischen (11.3.), der phonologischen (11.4.) und der graphematischen (11.5.) Analyse unserer Textstrukturen fassen wir anschliessend zusammen:

11. 1. Die lexikologische Analyse

befasste sich besonders mit den Lesarten unserer Texte, die Josef Vintr - 9783954793037 
wir nicht als subjektive Eingriffe der Kopisten, sondern als objektive Reflexionen der Entwicklungsvorgănge im alttschechischen lexikalischen System bewerten. Die ständigen Verschiebungen zwischen dem Systemzentrum und Systemperipherie (siehe 6.1.) aussern sich z.B. im Verdrängen der älteren, nur uber vereinzelte systembindungen verfügenden archalschen Lexeme altkirchenslavischen Ursprungs wie Hospodin, bers, pop durch die jüngeren, in die anderen Teilsysteme des Alttschechischen vielfaltiger eingegliederten lexikalischen Einheiten $P a ́ n, d i a b e l, k n e z$. Die Entwicklungsvorgănge in der Lexik werden durch sprachliche und aussersprachliche Faktoren verursacht (6.2.) - im Wortschatz der Evangeliare sind die Folgen der sprachlichen Entwicklung der alten Kategorien $z u$ jüngeren grammatikalischen Kategorien feststellbar (z.B. der Zerfall der nominalen Kategorie des Stammes oder der verbalen Kategorie der Ingressivitat/Durativität, vgl.6.2.1.), ebenso wie die Folgen der anwachsenden Kenntnisse der aussersprachlichen Realitat (die Lexeme mit breiter Bedeutung werden im terminologischen Bereich abgebaut, z.B. für leprosus in alteren Texten nuzny, nemocny, spăter nur malomocny, usw., vgl.6.2.2.). Diese Ergebnisse bestätigen unsere These, dass eine objektive Charakteristik des Wortschatzes einer Textstruktur nicht mit blosser philologischer Beschreibung auskommen kann.

\subsection{Die syntaktische Analyse}

konzentrierte sich auf die Erklärung der zentralen, resp. peripheren Systemposition einiger syntaktischer Wortverbindungen (7.1.) und auf die Feststellung einiger Entwicklungsvorgänge im syntaktischen Teilsystem (7.2.). Die meisten syntaktischen Funktionen der Kasus kann man als zentral oder peripher einstufen, $2 . B$. der alte prăpositionslose adpronominale Genitiv bei den Pronomina jeden, ijeden, $\tau_{i}$ (jednomu jich, ijeden muzojv, $\iota_{i} v a s$ ) wird im XIV. Jh. peripher und durch einen präpositionalen Ausdruck ersetzt (jednomuz nich, ijeden $z$ muzóv, $\tau \imath z v a s)$; der alte ebenso schon periphere adnominale Dativ (skrsehot $z u b 0^{\circ}$ ) wird durch ein zentrales Formalmitt - durch einen adnominalen attributiven Genitiv (skłehot zuböv) ersetzt. Von den Entwicklungsvorgängen im Bereich der Kasusfunktionen kommt in unseren Textstrukturen besonders der formale Ausbau der Kategorie der Belebtheit/Unbelebtheit bei den Maskulina klar zum Ausdruck - die ălteren Nom./Akk. werden durch die jüngeren Gen./Akk. 
Formen ersetzt. Die Dualformen werden zuerst in der Konjugation, später in der Deklination durch den Plural verdrängt. Neben dem Vordringen der periphrastischen Passivformen lasst sich in der jüngsten Handschrift $W$ noch eine verstärkte Tendenz zur doppelten (anstatt der alten einfachen) Satznegation und zur latinisierenden (anstatt der älteren vom Lateinischen weniger abhängigen) Wortfolge feststellen.

11.3. Die Analyse des morphologischen Teilsystems

bestätigte die Ergebnisse der Obersetzungscharakteristik, dass nämlich die Einflusse des Lateinischen (vgl.4.3.1.-4.3.4.) auf die alttschechische Deklination auf ein Minimum beschrănkt blieben, denn der formale Ausbau der alttschechischen nominalen Flexion war $z u$ dieser Zeit praktisch abgeschlossen. Die ganz seltenen Archaismen (Reste der alten Kategorie des Stammes) und Dialektismen bei den Substabtiven (vgl. 8.1.1.), und die etwas zahlreicheren bei den Pronomina (2.B. alte pronominale Formen bei sam, vgl. 8.1.3.) bezeugen die Stabilisierung dieses Teilsystems. Relativ stabil ist auch das System der Verbalformen; die grösste Anderung - der Abbau des Aorists und des Imperfekts - ist nur in ihren Anfängen in der jüngsten Handschrift $w$ feststellbar. $Z u$ den archaischen Konjugations. formen gehören einige Belege des sog. futurum exactum (budu $+-\imath$ -Part.) und des Imperfekts budiech (vgl. 8.2.2.). Diese Reste der alten verbalen Kategorie der IngressivitătDurativităt, die wir statt futurum exactum eher als einen Konditional des Futurs bezeichnen, verlieren durch den vorangehenden Umbau des alttschechischen Tempussystems und durch die Anderungen der Funktionen der vier Stämme beim Hilfsverb byti in zusammengesetzten Verbalformen ihre Existenzbasis $(j e s-/ b e x-$ früher primar in temporaler, by-/budprimar in modaler Funktion; nach dem Umbau wird die Funktion der vier Stămme von býti geändert - die absolutiv zuordnende Stammverteilung der aspekt-temporalen Funktion - jes-unmarkiert Prăs., bud-markiert Fut., by-markiert Prăt. - macht den durativen Stamm $b \ddot{e}$ - redundant, die Stämme bud-/by-werden nicht mehr primăr $z$ um Ausdruck der Modalităt benützt. Die Formen des Kond.Prăs./Prăt. (bych + 2-Part.) sind durch Beibehaltung der funktionell isolierten Aoristformen des Hilfsverbs byti (bych usw.) vom alttschechischen Tempus- und Aspektsystem getrennt, gehen in die syntaktische Ebene uber und werden allmăhich zu Formalmitteln (Entstehung und 
Entwicklung der hypotaktischen Konjunktionen kdyby, kdybys..., aby, $a b y 8 \ldots)$.

11.4. Die phonologische Analyse

brachte die wichtigsten, allgemein geltenden und applizierbaren Ergebnisse. Nach der Rekonstruktion der phonologischen Systeme einzelner Evangeliarhandschriften kann man unsere Texte chronologisch fest einordnen: Handschrift A - erstes Viertel, Handschrift C - Mitte, Handschriften D, S - zweites Drittel, Handschrift R drittes Viertel, Handschrift $W$ - gegen Ende des XIV. Jhs. Die mit Hilfe der Prinzipien der analytischen Phonologie rekonstruierten phonologischen Systeme kann man als reprasentativ für das Alttschechische am Anfang und zum Ende des XIV. Jhs. betrachten. Es zeigte sich, dass das alttschechische phonologische System eine starke immanente Tendenz zur symmetrie aufweist, die man sowohl an einem arithmetischen (9.2.4.5.) als auch an einem geometrischen Modell (9.2.5.) darstellen kann. Im alttschechischen phonologischen System um das Jahr 1300 spielen die vokalischen Varianten eine wichtige Rolle: falls man sie als den Phonemen gleiberechtigte Einheiten nicht mitzahlt, ist das Bild des Systems nicht symmetrisch. Wir bezeichnen darum diese vokalischen Varianten als potentielle Phoneme ("Allophoneme"); wahrend des XIV. Jhs. werden die vokalischen Varianten als potentielle Phoneme abgebaut und um 1400 ist das Systel auch ohne diese Einheiten symmetrisch. Die Raumnodelle des alttschechischen phonologischen Systems (siehe 9.2.5.) zeigen ebenso, dass diesem System eine innere Symmetrie eigen ist. Die mehrfachen symmetrischen Anordnungen der Phoneme konkurrieren in verschiedenen Entwicklungsetappen untereinander, wobei eine Anordnung $z u$ bestimmter Zeit redundant und durch eine relevante ersetzt wird. Der Vergleich von zwei oder mehreren Modellen fur verschiedene Zeitquerschnitte kann zur Entdeckung und Erklärung der Hauptfaktoren der Anderungen führen. So wird z.B. durch die Konkurrenz zweier verschiedener Symmetrien im Konsonantensystem un 1300 (die horizontale Mouillierungssymmetrie vs. die vertikale Symmetrie der Stimbeteiligung, vgl. 9.2.5.4.), denen im Vokalsystem nur eine (vertikale) Symmetrie der Quantitat gegenubersteht, die Zahl der Synmetien auf nur je eine (vertikale) Symmetrie sowohl im Konsonanten-als auch im Vokalsystem reduziert. Diese Entwicklung wird durch das Bild des alttschechischen phonologischen Systems um 1400 bestatigt 
(siehe 9.2.5.5.), wo die horizontale Symmetrie der mouillierten Phoneme beseitigt wurde. Diesen Aus führungen sei aber noch hinzugefügt, dass wir die Systemerscheinungen nur für eine dynamische Tendenz halten, die in einem synchronen Systemschnitt nie hundertprozentig vorhanden sein kann; als zentrale Erscheinung in einem phonologischen System kommt immer nur eine Korrelation vor; in der Diachronie können die Korrelationen ihre zentralen oder peripheren Positionen wechseln. Bei der Suche nach den Hauptfaktoren, ev. Ursachen der Systemănderungen wurde festgestel1t, dass die Grundelemente (C, V, S, X, vgl.9.2.4.4.) relativ stabil bleiben und die akzessorischen Elemente $(m, q, n, v)$ dagegen uber eine Beweglichkeit (im Rahmen eines Raummodells) verfügen; parazentrische Bewegungen eines akzessorischen Elements (die im Raummodell eines phonologischen Systems immer parallel zur Systemmitte verlaufen) halten wir für den Hauptfaktor der Systemänderungen. Diese These kann man an der Entwicklung der alttschechischen Mouillierungskorrelation durch Untersuchung der Bewegungen des m-Elements in chronologisch verschiedenen Raummodellen des alttschechischen phonologischen Systems (vgl. 9.2.6.5.) demonstrieren. Die Bewegungen eines akzessorischen Elements führen zum Erlöschen seiner Potenz, infolgedessen $z u$ seiner Eliminierung aus dem System und zur Aktivierung eines anderen akzessorischen Elements, das dann für die nötige Dynamik im System sorgt.

11.5. Die kurze graphematische Analyse

unserer Textstrukturen führt zur Feststellung, dass alle von uns untersuchten Evangeliarhandschriften in der für das XIV. Jh. in den böhmischen Lăndern ublichen Digraphenorthographie niedergeschrieben wurden: die Handschriften $A$ und $C$ in einer älteren, die ubrigen Handschriften in einer in der zweiten Hălfte des XIV. Jhs. normal verwendeten Variante des Digraphensystems (mit einigen Schwan. kungen und Inkonsequenzen bei den Bezeichnungen für $z, z, \varepsilon, \delta, c, \varepsilon$, x, vgl. 10.1.-10.9.). Die Reste der altesten tschechischen sog. einfachen Orthographie, in der auch der Archetyp aufgezeichnet wurde, sind in unseren Handschriften nur bei Analyse der Kopistenfehler und nur vereinzelt feststellbar (vgl.4.2.2.1.). 


\section{DRITTER TEIL}

\section{ZUSAMMENFASSENDE KONFRONTATION DER TEXTOLOGISCH-PHILOLOGISCHEN} UND LINGUISTISCHEN ANALYSE

Am Anfang der Abhandlung über die Sprachstrukturen der altesten tschechischen Evangeliare haben wir uns zun Ziel gesteckt, mittels einer textologisch-philologischen und einer linguistischen Analyse diese Texte möglichst objektiv $2 u$ charakterisieren und in ihrem Sprachmaterial die wichtigsten Entwicklungsvorgănge im Sprachsystem des Altschechischen aufzudecken.

Die textologisch-philologische Analyse lieferte die äussere und innere Textcharakteristik und zeigte, dass diese alttschechischen Evangeliartexte aus einem lateinischen Original (aus einem Text, der der Alkuin-Bibel sehr nahe stand) ubersetzt wurden. Ein direkter Zusammenhang mit der altkirchenslavischen Evangelienübersetzung ist nicht nachweisbar. Die alttschechische Evangeliarubersetzung mit ihren recht seltenen Paläoslovenismen berucksichtigte aber die mündliche Textüberlieferung (die vielleicht sogar ins $X I$. Jh. zurückreichen kann) und konsultierte mit aller Wahrscheinlichkeit stellenweise einen von russischen Priestern am Ende des XIII. Jhs. nach Böhmen mitgebrachten russisch-kirchenslavischen Evangelientext (vgl. 3.2.). Die erste alttschechische niedergeschriebene Evange liarübersetzung entstand nicht für $Z$ wecke der Seelsorge, sondern für den Bedarf der tschechischen adeligen Nonnen (Benediktinerinnen im Kloster Sv. Jiłr in Prag?); sie stammt von einem unbekannten Benediktiner, der offensichtlich im Prager Kloster Brevnov, vielleicht mit Hilfe eines bereits tschechisch glossierten Textes die Obersetzung unternahm.

Alle Handschriften der ersten Obersetzungsredaktion der alttschechischen Evangeliare sind Abschriften. Die gemeinsamen Obersetzungsfehler bezeugen, dass der Archetyp an der Wende des XIII. und XIV. Jhs. entstand. Die Obersetzung ist stufenweise angewachsen - vom Zyklus der Perikopen für die Fastenzeit (Handschrift A) uber die vollkommene Obersetzung der Lesungen des Temporale (Handschrift S) bis zur Ergänzung durch die Perikopen des Proprium und Commune Sanctorum (Handschrift W, vgl. dazu 3.5. und 5.1.).

Die Analyse der Obersetzungstechnik (siehe 4.) konzentrierte sich auf die bisher für kein altschechisches ubersetztes Denkmal 
durchgefuhrte Untersuchung der Wiedergabe der lateinischen grammatikalischen Kategorien durch Mittel des alttschechischen Systems. Es ist erstaunlich, wie hohe Qualităten diese Obersetzung aufweist, wie selten die Latinismen sowohl im Wortschatz als auch im syntaktischen und morphologischen Teilsystem der Textstrukturen vorkommen und wie konsequent die lateinischen Konstruktionen durch heimische syntaktische Mittel ersetzt werden (z.B., ablativus absolutus' durch ein Part.Prăs./Prăt. + Akk., vgl.4.3.1.1., die lateinischen attributiven Partizipien durch alttschechische Transgressivformen oder später durch absolutive Partizipien, vgl. 4.3.1.2., usw.). Die Analyse des Wortschatzes (4.4.) bestätigt die Feststellung von Vasica, dass die orale Diktion der ăltesten tschechischen Evangeliare ( $A, C$, $D, S, R$, weniger schon $W$ ) durch eine Jahrhunderte wăhrende mündliche Oberlieferung beeinflusst wurde.

Die beiden Analysen - die textologische und philologische ermöglichen es uns, folgendes Filiationsschema der Evangeliarhandschriften der ersten obersetzungsredaktion aufzustellen (vgl. 5.3.):

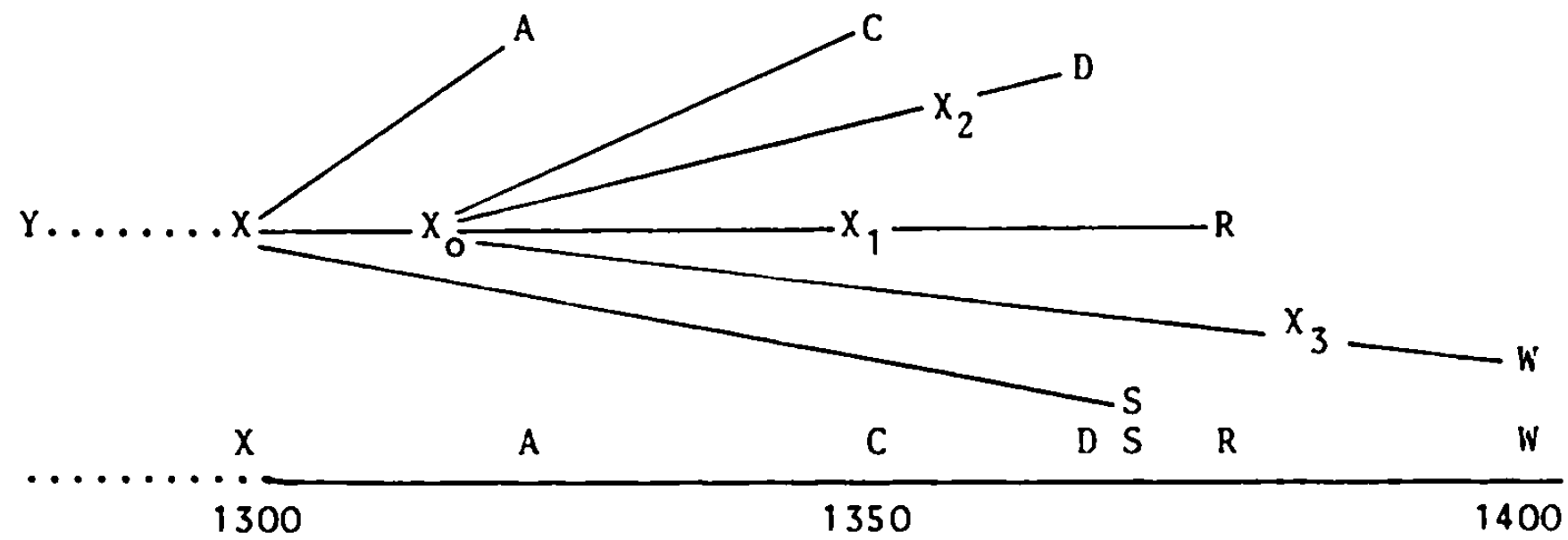

Die unter dem Filiationsschema aufgezeichnete Zeitachse mit den nach den Ergebnissen der linguistischen (vor allem der phonologischen und graphematischen) Analyse datierten Handschriften stimmt, was die relative Chronologie der Texte betrifft, mit dem Filiationsbaum überein, wobei die Position der Handschriften auf der Zeitachse mindestens bei den Seitenstettener und Rajhrader Evangeliaren durch die Datierung der Papierwasserzeichen (vgl. 3.3.4. und 3.3.5.) doppelt bestatigt wird.

Die funktionelle linguistische Charakteristik der Evangeliartextstrukturen befasste sich vor allem mit zentralen und peripheren Systemerscheinungen und versuchte weiter, durch vergleich der Lesarten und Textabweichungen die Entwicklungsvorgănge im Sprachsystem des Altschechischen im XIV. Jh. festzustellen und auf die- 
ser Basis zur Aufstellung einer möglichst kontinuierlichen diachronen Systemvertikale zu gelangen.

Sowohl im lexikalischen als auch im syntaktischen und morphologischen Teilsystem wurden die Folgen der Entwicklung von den alteren grammatikalischen Kategorien ( $z$. B. der nominalen Kategorie des Stammes, der verbalen Kategorie der Ingressivitat/Durativităt, u.a.) zu den neuen (des Genus, des Aspekts) festgestellt. Im phonologischen System des Alttschechischen wurde eine starke Tendenz zur Symmetrie gufunden, die man an arithmetischen und geometrischen Modellen demonstrieren kann. Durch den Vergleich der Raummodelle des phonologischen Systems kamen wir zum Schluss, dass die Systemänderungen durch parazentrische Bewegungen der akzessorischen Elemente erklärbar sind. Die in horizontalen (synchronen) Schnitten festgestellten Folgen der Systementwicklungsvorgäge - die gleichermassen in der Synchronie und der Diachronie des Alttschechischen als Systemerscheinungen eingegliedert sind - halten wir fur die vertikale (diachrone) Struktur eines Sprachsystems.

Die wichtigsten Ergebnisse der textologisch-philologischen und der linguistischen Analyse stimmen uberein; in Einzelheiten bei der Beurteilung der Archaismen (Paläoslovenismen?) und Latinismen können beide Analysen von einander abweichen, aber beim Wesentlichen - sowohl bei der Datierung der Evangeliarhandschriften als auch bei der Anordnung der zentralen sprachlichen Erscheinungen dieser Textstrukturen in der Diachronie des alttschechischen sprachsystems - stimmon sie überein. 


\section{SCHLUSSWORT}

Am Anfang jeder europäischen nationalen Literatur steht die Bibelübersetzung. Auch die tschechische Literatur bildet mit den frühen Psalter- und Evangeliarübersetzungen keine Ausnahme und sie ist keineswegs eine der letzten, die sich solcher Zeugnisse hoher heimischer Sprachkunst rühmen kann.

Die Analyse der altesten tschechischen Evangeliarübersetzung zeigte ihre hohen sprachlichen Qualitaten. Die Einflüse des lateinischen Originals blieben auf ein Minimum beschränkt, denn die Mittel des tschechischen Sprachsystems befriedigten fast vollkommen den Bedarf an Ausdrucksmoglichkeiten des Obersetzers. So ist auch diese Evangeliarübersetzung ein Zeugnis dafür, dass im Entstehungsprozess einer Schriftsprache die fremdsprachigen Impulse nicht mechanisch, sondern nach den Mrglichkeiten und Bedürfnissen des heimischen Sprachsystems ubernommen und angepasst werden. Die Sprachstrukturen unserer Evangeliare wurden eher durch den Kontakt mit dem alltäglichen Tschechischen massgebend beeinflusst. Umgekehrt nach der Verbreitung unter dem Volk im XV. Jh. besonders in der hussitischen Zeit - übte die Evangelienubersetzung einen bedeutsamen Einfluss bei der Stabilisierung und Standardisierung der tschechischen Schriftsprache aus und diese Rolle der Bibelubersetzungen blieb dann durch die Kralicka bible weitere Jahrhunderte bestehen. In dieser Hinsicht ist die alteste tschechische Evangeliarübersetzung auch für das heutige Tschechische eines der wichtigsten Denkmäler seiner Sprachgeschichte. 


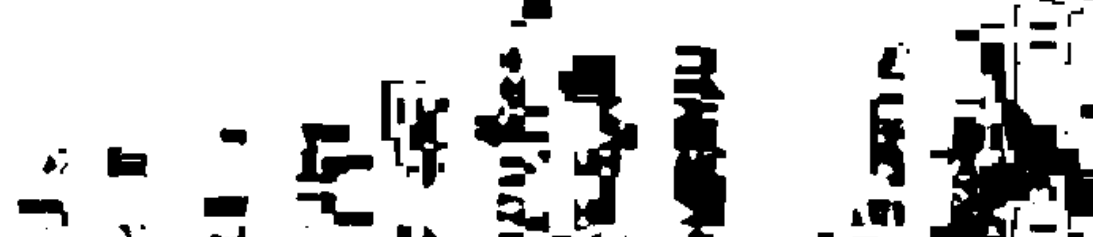

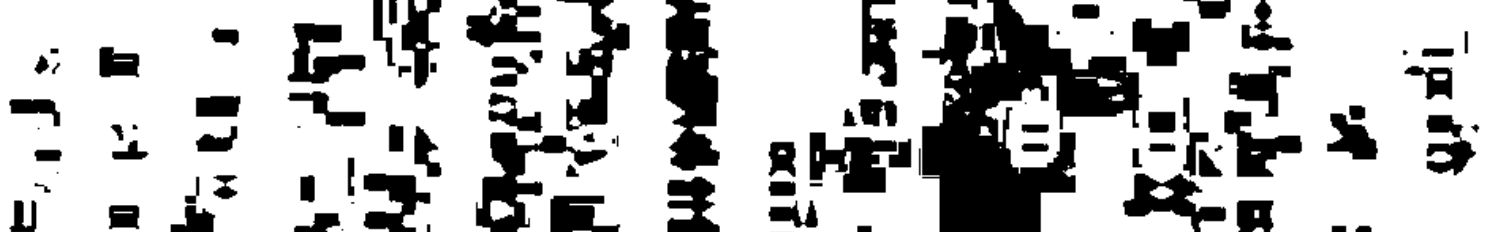

m

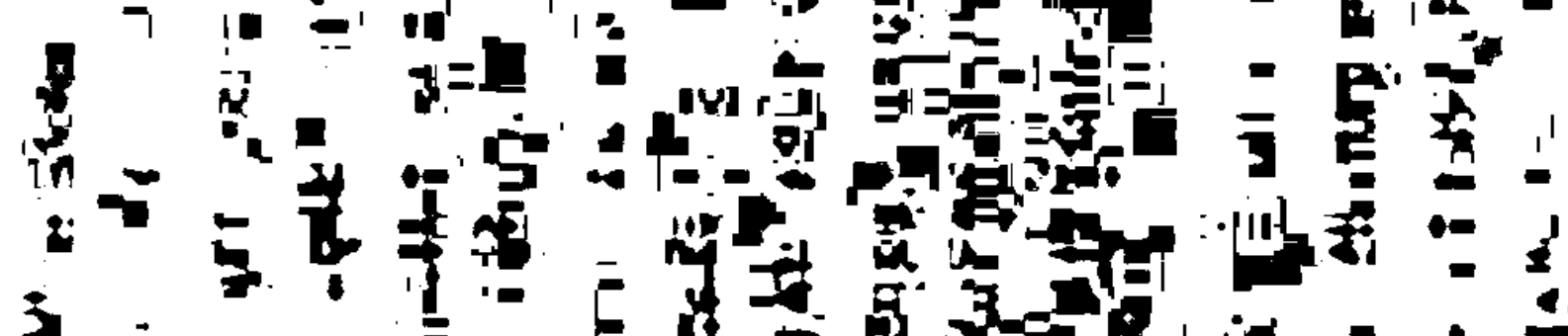

7 :

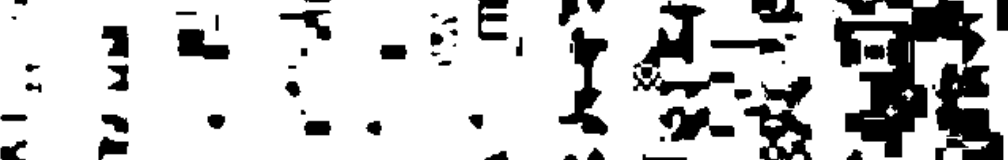

- $\bar{\alpha}$

$+\frac{1}{i}$

it

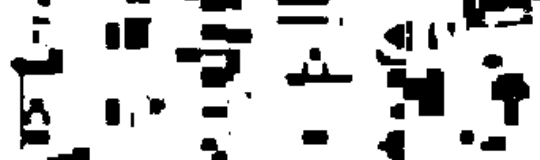

1. $\begin{gathered}40 \\ 3\end{gathered}$

$\Leftrightarrow r$ a

i if

$=$

I I

EI

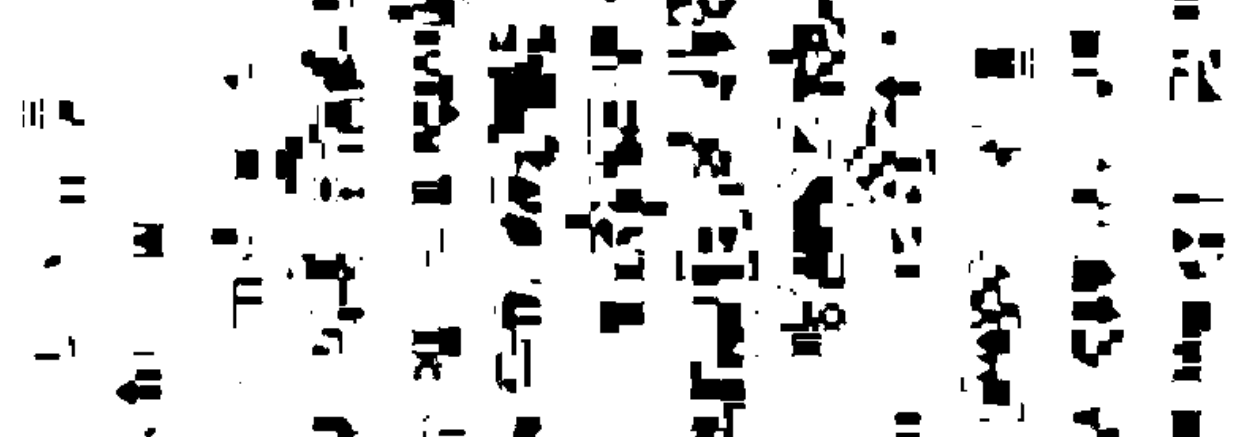

$2=$

$\overline{2}$

$\square$

-

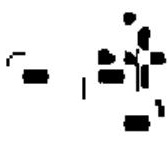




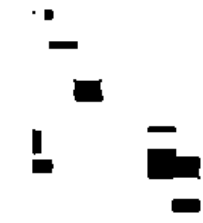

$=$

iH
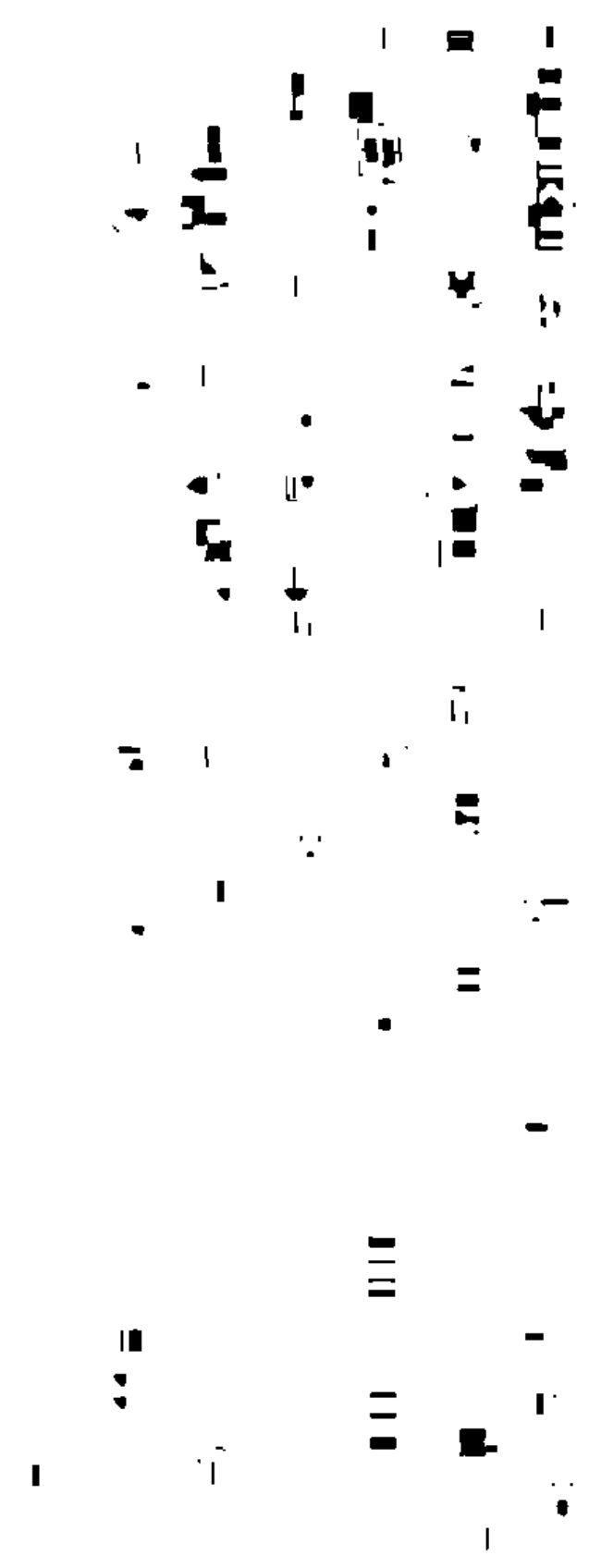

2

$$
1
$$

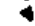

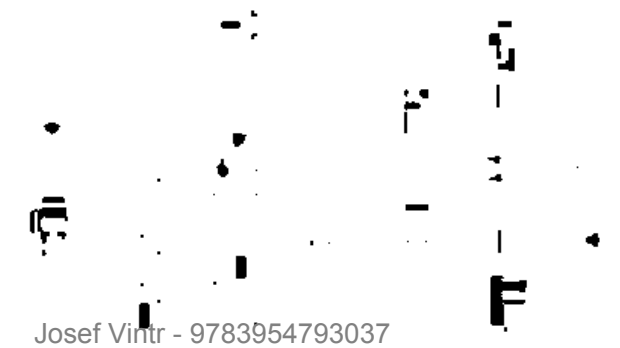




\section{VIERTER TEIL}

\section{EDITION}

\section{Editorische Anmerkung}

Die wissenschaftliche Edition (mit kritischem und parakritischem Apparat) gibt in transkribierter Form die Texte der ersten Obersetzungsredaktion der alttschechischen Evangeliare aus dem $X I V$. Jh. wieder - die Fragmente A, C, D und die Handschriften $S$, $R$, W (Seitenstettener, Rajhrader und Wiener Evangeliar); die Beschreibung der Handschriften siehe unter 3.3., die bibliographischen Anmerkungen zu den einzelnen Texten siehe unter 13.1. Für die Edition nahmen wir als kanonischen Text das SeitenstettenerEvangeliar, das unter den drei umfangreicheren Handschriften der ersten Redaktion ( $S, R, W)$ den altesten und fast fehlerfreien Text darstellt. Die Perikopen, die in dieser Handschrift $S$ nicht vorhanden sind, wurden in erster Linie nach der Handschrift $w$ ediert, weil sie, was die Fehler betrifft, unvergleichlich besser als die Handschrift $R$ ist. Nur wenn die Perikope sowohl in $S$ als auch in iv nicht aufgezeichnet ist, nehmen wir sie aus der mit zahlreichen Kopistenfehlern durchsetzten Handschrift $R$ oder aus einem Fragment. Die vollkommene Obersicht über die aus einzelnen Handschriften edierten Perikopen bietet die Synopsis der Handschriften (14.1.) in der Reihenfolge der Feste des Kirchenjahres dar. Aus dieser Synopsis kann man auch den Umfang einzelner Handschriften he rauslesen. Die zweite Synopsis, in der Reihenfolge der Evangelisten und Evangelienkapitel zusammengestellt (14.2.), soll dem Benützer die Suche der betreffenden Evangelienstellen in der Edition und ihrer alttschechischen Lesarten im kritischen Apparat erleichtern.

13.1. Bibliographische Anmerkungen $z u$ einzelnen Handschriften (die kodikologische Beschreibung siehe unter 3.3.)

A Handschrift (Vasica: A, vgl. 3.3.):

Natinalmuseum Prag, Sign. 1 Ac 47; zwei Pergamentabschnitte; Edi- 
tion - A. PATERA, Zbytk̄̄ evangelis ze XIV. stoleti, Ceské museum filologicke 1 (1895) 46-48; als Textprobe V. FLAJSHANS, Nejstar $\mathbf{1}$ pamatky jazyka a pisemnictvi Ceskeho, Praha 1903, 144, die Stellen Mt 12,38-39, 42-47,50; die Beschreibung des Fragments von Patera ergänzte und verbesserte, vor allem was die unrichtig bezeichneten Evangelienabschnitte betrifft, J. VASICA, Starołeske evangelišre, Praha, 1931 , S. 2 .

C Handschrift (Vaßica: D):

Nationalmuseum Prag, Sign. 1 AC 67; ein Pergamentdoppelblatt; Edition - A. PATERA, Nove nalezene zbytky staroceskeho evangeliałe, Anselma a UmuCenl sv. Jił ze XIV. stolet1, Casopis Ceskêho musea 74 (1900) 504-507; neuere Beschreibung siehe J. VASICA, o. c.,11-12.

D Handschrift (Vasıca: C):

Staatsarchiv Brünn, Sign. G 1, Kart. 86 (im Katalog der Bocek-Sammlung Numner 12307); drei Papierbläter; Edition - bisher keine, kurze paläographische Textprobe veroffentlichte J.VASICA, o. c., 10-11 ( $\mathrm{J} \mathrm{7,32-39);} \mathrm{eine} \mathrm{kurze} \mathrm{Beschreibung} \mathrm{bietet} \mathrm{F.} \mathrm{CERNY,} \mathrm{Frag-}$ menta Bockova, Casopis Ceského musea 73 (1899) 505-506, eine umfangreichere J. VASICA, o. C., 9-11.

\section{S Handschrift (Vasica: S):}

Bibliothek des Benediktinerstiftes Seitenstetten (Niederösterreich) Sign. CCLXXII, f. 144a-153a (alte, noch in der Edition von Mentik angeführte Foliation 139a-148a); eine Papierhandschrift; Edition F. MENCfK, Dva evangelisţ̌re, Praha 1893 (Rozmanitosti III), 1-41; eine Textprobe ( $8,4-16)$ veroffentlicht in Výbor z Ceské literatury husitské doby II, Praha 1964,449-450; die Edition von Menclk rezensierte $z$ inlich kritisch F. CERNY, Listy filologicke 21 (1894) 477. Dieses Evangeliar wurde zum erstenmal in der Usterreichischen Zeitschrift für Geschichts- und Staatskunde im J. 1836, S. 404, erwähnt (nach dem handgeschriebenen Katalog der Stiftsbibliothek in Seitenstetten). Eine kurze Beschreibung der Handschrift (ausser dem Vorwort zur Edition von MENCfK) liefert J. VASICA, o. c., 2-3. Die Studien, die sich mit der Problematik der altkirchenslavischen Nachwirkungen im S-Evangeliar auseinandersetzen, wurden in den Fussnoten unter 4.1 .1 . ange führt. 
Auf dem letzten, auf die hintere Deckelinnenseite aufgeklebten Papierblatt ist ein alttschechisches, von derselben Hand wie das Evangeliar geschriebenes Mariengebet zu finden:

Zdrava pani Maria, zemé zlata, chróme Bož, lože Ducha Svatého, zdráva pani Maria, studnice zahradnie, smývadio hriechóv, tistoto

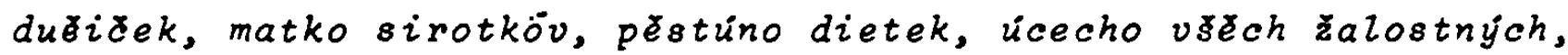
zdrava mila dievko, stojici pred obliðejem Bozim. Ej, rad spomenici na naż hriechy, na naßz zámutky, na naß̌ nedostatky. Ty dobrociva, ty milosciva, ty milosrdna, daj nam s pravú vierú zeleci smrci a nevinné krve prolicie tvého syna, nałeho milého Boha. Bychom ser mohli s tobü radovaci tu, kdež sbožné duše prebyivaji $v$ nebeském kralovstvi ve̊ky veköm Amen amen.

Eine im letzten Satz nur wenig erweiterte Version dieses Gebets findet sich in der Handschrift I E 25 aus der zweiten Hălfte des XIV. Jhs. der Prager Universitătsbibliothek am fol. 137a, veroffentlicht von I. HANUS, Malý výbor ze starožské literatury, Praha $1863,65-66$.

\section{R Handschrift (Vasica: R) :}

Universitatsbibliothek Brunn, Sign. $R 364$ (fruher in der Bibliothek des Benediktinerklosters Rajhrad) fol. 106a-124a; eine Papierhandschrift; Edi^tion - bisher keine. Die erste Beschreibung der Handschrift lieferte J. VASICA, O. c., 7-9, eine ausfühlichere V. DOKOUPIL, Soupis rukopisú knihovny benediktinu v Rajhradé, Praha 1966, 144-145. Erstmals wurde dieses Evangeliar von J. DOBROVSKY in der Korrespondenz mit F. DURYCH (die Korrespondenz ediert von A. PATERA, Bd. 1, Praha 1895, 382) im Brief vom 26. XI. 1797 erwähnt, seitdem blieb der Text vergessen, bis sich J. Vasica damit beschäftigte, der auch eine Edition vorbereiten wollte.

W Handschrift (Vasica: V):

Osterreichische Nationalbibliothek in Wien, Sign. 4733, f, 1a-49b; eine Papierhandschrift; Edition - F. MENCfK, Dva evangelistáre, Praha 1893, 42-136; eine Textprobe (Mc 6,17-29) veroffentlicht in Výbor $z$ Xeské literatury husitské doby II, Praha 1964, 448. Die neueste textologische Beschreibung der Handschrift (nach Mencrk im Vorwort zur Edition und nach J. VASICA, o. c., 3-7) in der Arbeit von $K$. SCHWARZENBERG, Katalog der kroatischen, polnischen und tschechischen Handschriften der osterreichischen Nationalbibliothek, Wien (Museion-Verlag) 1972, 242-246, dort auch die weiteren biblio- 
graphischen Angaben $z u$ der Handschrift. Die Literatur $z u$ den angeblichen Palăoslovenismen siehe unter 4.1.1.

\subsection{Zur Gestaltung der Texte in der Edition}

Die überschriebenen Buchstaben, Marginalien und Glossen (in der lateinischen Sprache), Rubriken und Initialen, Abschreibefehler und Durchstreichungen in den edierten Handschriften wurdem im Hinblick auf die Obersichtlichkeit des Apparats nur in den für die Verstädlichkeit des Textes wichtigen Fällen in Anmerkungen be rücksichtigt (sonst kann man sie in der paläographischen Edition von Mencfk finden). Es war unsere Absicht, die phototypischen Reproduktionen aller edierten Texte der Edition beizufügen, aber aus verlagstechnischen Gründen war es leider nicht möglich und so blieb es nur bei je einer Reproduktion aus jeder edierten Handschrift, an der wenigstens das Schriftbild jeder Evangeliarhandschrift demonstriert werden kann. Unser kritischer Apparat wurde aber so zusammengestellt, dass er - gemeinsam mit dem transkribierten Editionstext - dem Leser und auch einem Sprachforscher die möglichst objektive Darstellung eines handgeschriebenen alttschechischen Originals bietet.

Die Titel der Perikopen über das liturgische Jahr wurden nicht nach den oft unrichtigen handschriftlichen Rubriken, sondern nach Bezeichnungen im Missale Romanum (vor der neuesten Liturgiereform) angegeben.

Die Evangelienverse der Perikopen im edierten Text wurden nach der neuesten Edition der Vulgata (R. WEBER, Biblia sacra iuxta Vulgatam versionem, Stuttgart 1969) eingeteilt und, wie auch in der Weber-Edition, absichtlich ohne Interpunktion, die in den alttschechischen Handschriften inkonsequent und sehr oft auch irreführend ist, wiedergegeben.

Bei der Transkription (die alphabetische Obersicht siehe 10.2 . halten wir uns an die Transkriptionsgrundsatze des neuen Prager Alttschechischen worterbuchs (Staroceský slovnlk: Uvodn1 stati, soupis pramenu a zkratek, Praha 1968, 44-49), das heisst z.B.: die hyperkorrekte Jotierung (besonders in der 3.Pers.Sing.Ind.Prăs., in Lok. Sing.N. auf -ie, beim Part.Prăs. -ce, u.a.) wird meist ohne Anmerkung weggelassen, genauso wie die überflüssige Labialisierung beim kurzen -o- (kommt nur in den Casus obliqui von Böh - buoha... und im Adj. Bož - buozy vor); die grossen Buchstaben werden nach dem 
Zustand in der Handschrift wiedergegeben, nur bei handschriftlich oft kleingeschriebenen Namen in der Edition auf Grossschreibung korrigiert; die handschriftlichen Wortabkürzungen (Obersichtstabelle unter 13.5.) lösen wir ohne Anmerkung auf; die Abkürzung $i \bar{h} s, i \hbar \bar{u} s$ wird im edierten Text der Handschrifte $C$ und $S$ als Jezuz (da hier häufiger auch ausgeschrieben, und 2 war mit $-\ddot{u}-$, auch in den Casus obliqui - Ježļovi, usw.), bei den anderen Handschriften ( $R, W)$ wird diese Abkürzung immer als Ježz aufgelöst. Die Konjekturen werden in Spitzklammern ( ) angefüht; das Sternchen * verweist auf einen korrigierten, im Apparat erklärten Fehler.

\subsection{Der kritische Apparat}

ist zweiteilig. Der erste Teil bringt Angaben uber das Vorkommen und den Umfang der betreffenden Perikope in einzelnen Handschriften, der zweite Teil bringt die Lesarten (Varianten), Korrekturen und Erklärungen aus den Parallelstellen der Handschriften, wo die Perikope belegt ist. Von den Lesarten werden nicht die phonetischen (auch z.B. já vs. jaz, je vs. jest, kde vs. kdeż, u.å.), wohl aber die morphologischen (z.B. pros $t m$ vs. prozi, unterschiedliche Kasus, Tempora, usw.) berücksichtigt. Die geănderte Wortfolge in einer Parallelhandschrift wird im Apparat durch arabische $Z$ iffern bezeichnet. Die Abkürzungen für die edierten Handschriften ( $A, C$, $D, S, R, W, v g 1$. oben und unter 3.3.) werden in Anmerkungen nach einer eckigen Klammer ] angefuhrt, jedoch nur bei einer Variante oder Erklärung; falls die im Apparat angefühte Stelle in einer Parallelhandschrift (in welcher, ersieht man aus dem ersten Teil des Apparats zur betreffenden Perikope) mit dem edierten Text identisch ist, entfăllt nach der eckigen Klammer die Handschriftabkürzung (z.B. im ersten Teil des Apparats: $S, R, D$ ) deest $A, C, D$; im zweiten Teil zur betreffenden Perikope z.B. $z l i]$ \$laly $R$; das bedeutet: Ediert ist der Text $S$, Handschrift $R$ hat eine lexikalische Variante und die Handschrift $D$ ist an dieser Stelle identisch mit dem edierten Text $S$, also auch $z l i$, usw.).

13.4. Die im kritischen Apparat benützen Abkürzungen

add. addidit, additum

adscr. adscripsit

cf.

confer 


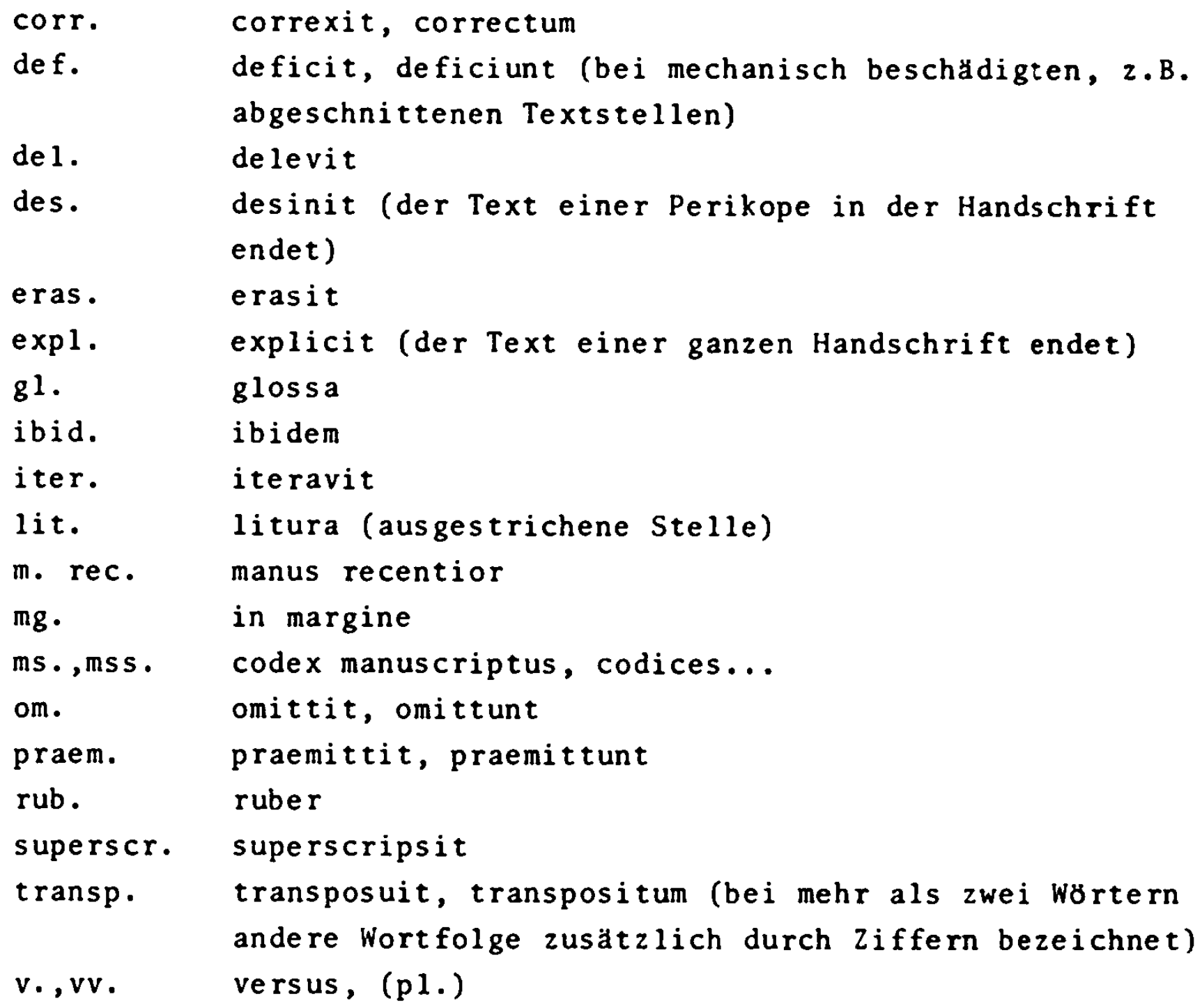

Abkürzungen der edierten Evangeliarhandschriften: (vgl.3.3.,13.1.)
A
Fragment des Prager Museums
C
Fragment des Prager Museums
D
Fragment des Staatsarchivs Brünn
S
Seitenstettener Text
R
Text von Rajhrad
W
Text der Nationalbibliothek Wien 
13.5. Verzeichnis der handschriftlichen Abkürzungen

Anm.: Alle Abkürzungen wurden im edierten Text ohne Anmerkung aufgelöst.

+ Abkürzung kommt in der Handschrift vor

- Abkürzung kommt in der Handschrift nicht vor

Abkürzungen

$-\bar{a}$

$-\bar{a}$

$-\bar{a}$

$-\bar{e}$

$-\bar{e}-$

$-\mathrm{X}$

-em-

$-\bar{i}-$

$i^{c}$

ins

ihüs

Ihu

$x^{c}$

$x \bar{p} c, x \bar{p} s$

xpūs

$\operatorname{mag}^{\mathrm{n} a}$

$-\overrightarrow{0}$

$-\overline{0}$

$-\overline{0}-$

$\tilde{\mathrm{w}}-$

5-

$-t^{2} e$

$-t^{2}$

$-\bar{u}$

$-\bar{u}$ o

$-?$

$-\bar{y}$
Transkription

- ám

$-a n$

-an

-em, -ém

-en-, -em-

-emu

-erem-

-ri-

Jez1క

Ježrs (in C,S Ježus )

Jeẑ́

Jesu

Kristus

Kristus

Kristus

Magdalena

-om. -óm

-on

-on-

pra-

pro-

-teré

-tra

-um

-rio

-us

$-1 \mathrm{~m},-\underline{y} \mathrm{~m}$

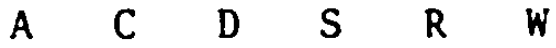

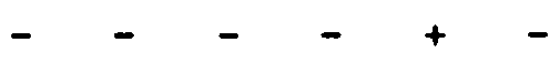

$\begin{array}{rrrrr}+ & - & - & - & - \\ - & - & - & - & +\end{array}$

$-\quad-+-+$

$-\quad-+-$

$-\quad-+-$

$-\quad-+$ + -

$-\quad-+-$

$++$

$-+++$

- - - - - +

$-\quad-+-$

$-\quad-++$

$-\quad-\quad+\quad+$

$-\quad-+-$

$-\quad-++$

$-\quad-+-$

$-\quad--\infty+$

$-+-+-+$

$-\quad-+-+$

$-\quad-+-$

- $-\quad+-$

- - - - - +

$-\quad-+-$

$\begin{array}{llllll}- & - & - & + & + & - \\ - & + & - & + & + & +\end{array}$ 
EVANGELI ARIUM

I. Dominica $I$. in adventu - Mt 21,1-9

$S 139 a_{1}$ 1. Gdyž pŕiblužlese sĕ Ježús k Jerusalemu

$\left(144 \mathrm{a}_{1}\right)$ a płidiese $k$ Betfaje hoł̌ olivet 1

tehdy posla dva uČenlky 2. pravě jima

Jdète na hrádek jenž proti váma jest

a inhed naleznete osličku pł́lvázanu a diecé s ni zpros $\left(t^{\prime}\right\rangle$ te a prived'te mner

3. Pak 11 kto vám co die

povězta že Hospodin potł̌ebu má

a inhed *puscr je

4. ale to jest uxiňeno

aby naplnĕno bylo jenž pověděno jest prorokem praviece

5. Povězte dcełi Sion

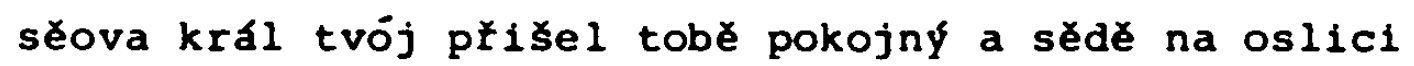

a dieté syna podlé sebe

6. Tehdy jidu uXenfci uxinichu jakože kázal jim Ježus

7. I płivedli oslici a oslátko $s \mathrm{n} 1$

1 polozichu na nè rúcha svá

A jemu na to vsiesci kázachu

3. Ale věcšl sbor stlachu rúcho své po cestě

A jini sěkáchu ratolestí s dł̉ievie stláchu na céscè

9. Tehdy lid płèdni 1 potomń voláchu łkúce

chvála synu Davidovu

BlaženÝ jenž pł̌łsel ve jmě Hospodina

I. $S, R]$ deest $A, C, D, W$

1. pildiese] przy§§ed $R_{i}$ olivet1] olywet $\{k e \mathrm{R}-2$. naleznete] nalezneta $R_{i}$ zpros $\left(t^{\prime}\right)$ te $]$ odwyeztez $R-3$. povězta] poweztez $R_{;}$potřebu má] potrzyeby gma gych R: "puscl (pu§czie ms.) - 4. ale] om.

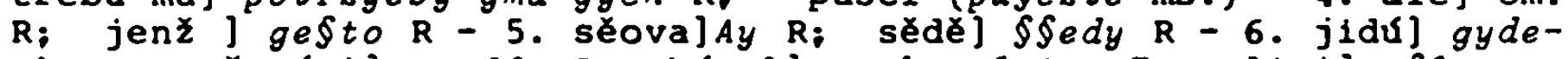
chu $R_{i}$ uxen[ci] $y$ add. $R ;$ kázal] rozkazal $R-7$. oslici] o\$lycz$k u R_{i}$ oslátko] dyetye $R_{i}$ na ne rucha svánna ny rucho fwe $R_{;}$a... kázachu) om. (unam lineam) $R-8$. A] Ale $R ;$ dłlievie] y add. $R-$ 9. potomn 1 ] zadny $R_{i}$ chvála synu Davidovu Blažený] transp.4123 R. 
II. Dominica II. in adventu - L 21,25-33

25. Pověděl Ježús ư̌en Ikơm svým

Budú zázraci na slunci i na měsieci i na hvězdách

a na zemi dávenie pohanské

ot slévanie sumenie mołe a vlny

26. starost lidem pro strach při Cakánf jenž pŕlde vక̌emu suětu

nebo moci nebeské hnu sè

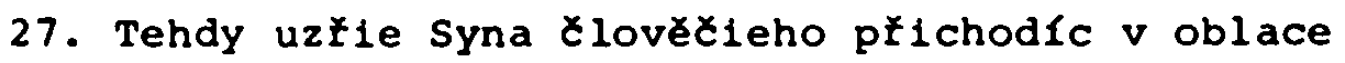
s mocl veliku a u Bostvi

28. Tehdy tomu býti pocinajice

hledajte 1 pozdvihajte vase hlavy

nebo blizi se vykúpenie /

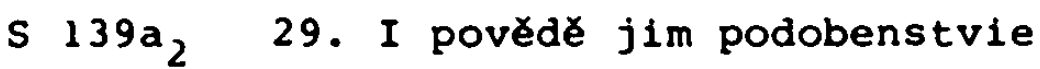

$\left(144 \mathrm{a}_{2}\right)$ vizte fík 1 vseho dł́levie

30. kdyz dávajl z sebe ovoce viete zet' sé blizi léto

31. Takoz 1 vy kdyz uslysite to buduce vězte žt' jest bliz královstvo Božie

32. Jiscè pravi vám nemine pokolenie toto dřieve všecko bude

33. Nebe a zemé préjứ ale slova má nepominu

II.: $S, R]$ deest $A, C, D, W$

25. na slunci i na měsieci i na hvézdách] transp̣. 12678345 R: a]y $R$ vlny] wln (wtn ms.) $\mathrm{R}-26$. starost] bude add. $\mathrm{R} ;$ moci] $\$ \$ y[y, \mathrm{R}-$ 27. płichodlc] praygduczye $R_{i}$ mocl] $\$$ add. $R$; a u Bostvi] a boz$\$ k u R-28$. vase hlavy] transp. $R ;$ blizi sej] $k$ wam add. $R-29$. $f\{k]$ wynycze $R$ - 30. vietel om. $R$; se blizi] ge\$t gyz bly\$ko $R$ - 31. i] om. R; uslyšlte] uzrzyte $R$; vězte zet'] om. R; jest bliz královstvo Bozie] to ge§t kralow\$twye nebe§ke $R$ - 32. pravi] prawym $R$ 33. nepominu] nemynu $R$.

III. Dominica III. in adventu - Mt 11,2-10

2. Kdyz uslyš Jan $v$ okoviech skutky Bozie posla dva uxeniky suá 3 . vece jemu

Ty 11 s jemuž płijlti ci jiného cakáme

4. Tehdy odpovẽdé Jezús jim

sedకe odpovězte Janovi jez viderste a slyšste 
5. Slepr vidie

hlust slysie

chroms chodie

nuznl cisti

mrtvi vstávajl

chudi kází

5. A blažený jest jenž nebude zrádce muoj

7. Onych $o\langle t\rangle \operatorname{sed}(s) e$

poce Ježú pravici $k$ lidem o Janovi

Co $z$ těchto na pưsti vidèste

trest větrem hyblce

8. Ale co z tèchto vidite

cl〈o〉věka u měkém oděn 1

Seova kto měkké oděnie majl v králových domiech jsú

9. Ale z téchto vidlte proroka

Také pravi vám viece nez proroka

10. Tu to je ten o nèmžto psáno jest

Seova sli anjela mého jen uxinl cestu pred tobu

III.: S, R] deest $A, C, D, W$

2. uslyక̌] [waty add. R; okoviech skutky] okowach g\$\$a czyny R: Božie] Tehdy add. $R ;$ uðen $\{k y] k$ gezy\$\$owy add. $R-3$. vece] $y$ praem. R; jemu Ty $1 i$ s] Ay ty $l_{y} g \$ \$ y R_{i}$ jemuz] gejt add. $R$ 4. Ježús jim] transp. $R$; viděste] wydyte $R ;$ slysèste] $\$ \$ 2 y \$ \$ y t e R$

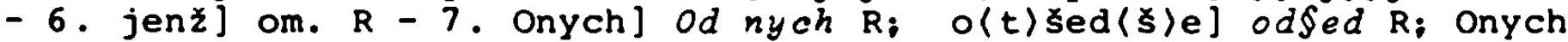

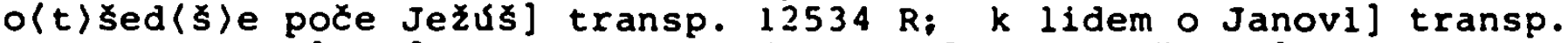
$3412 \mathrm{R}$; lidem] za\$tupowy R; vidéste... 8...2 těchto] om. R; Seova] Ay $\mathrm{R}$ - 9. Take...proroka] om. (unam lineam) $\mathrm{R}$ - 10. Seova] Ay $\mathrm{R}$

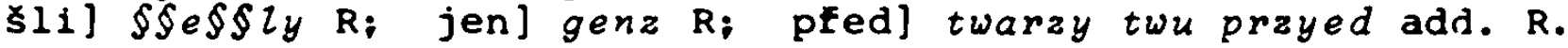

IV. Feria IV. in IV temporibus - L 1,26-38

26. Poslán jest anjel Gabriel ot Boha do města jemuž jmex Nazaret

27. $k$ ॠlvce otdanéj muži jemuž jmè Jozef z domu Davidova a dievce jmě Maria

26. I vstupi $k$ niej anjel vece zdráa milosti plna Hospodín s tobu blažená ty mezi ženami

29. Kdyz to uslyše smutila sĕ u pověsci anjela smýslese kake by to bylo zvěstovánie

30. I vece anjel jie Neboj sè Maria // 
S $139 b_{1}$

nalezla si milost u Hospodina

$\left(144 b_{1}\right)$

31. Seova potne $v$ Zivoce 1 porodis syna

1 dás jemu jmě Ježus

32. Ten bude veliký a Syn Vrchovaného nazván bude

I dá jemu Hospodin Buoh jeho otce Davida stolici

33. I kralovati bude $\mathrm{v}$ domu Jakubovu věrnè

a královstvu jeho nebude konec

34. 1 vece také Maria anjelu

Kako to bude neb já muž neznaji

35. I odpovědĕ anděl 1 vece $j 1$

Duch Svatý navstievi tebe

a moc Vrchnieho obklici ce

A proto co sè narodi s tebe svaté nazváno bude Syn Boż

36. A tedé jest Alžběta rodicka tvá a ona połala syna $v$ starosti svej

a ted' měsiec jest sestý tej jez slóve jalová

37. Nebo nebude nepodobno u Boha všliké slovo

38. 1 vece Maria

Seova robotnice Bożie bud' mi podlé slova tvého

IV.: $S, R$ ] deest $A, C, D, W$

27. "divce (dwywcze ms.) - 28. niej] ny R; anjel] y add. $R_{;}$ty]

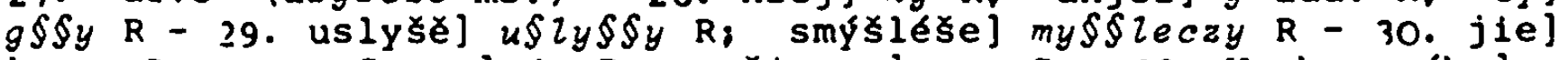
$k$ nye $\mathrm{R}$ - 31. Seova] $A y \mathrm{R} ; \mathrm{v}$ ivoce] om. $\mathrm{R}$ - 32. Vrchovaného]

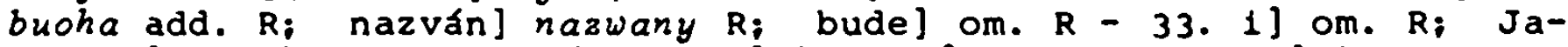
kubovu] yakubowye $\mathrm{R}$; královstvu] kralow\$twye $\mathrm{R}$; konec] konczye $\mathrm{R}$ - 34. i] om. $R_{i}$ muže neznaji] transp. $R$ - 35. I] om. $R$; 1$]$ om. $R$;

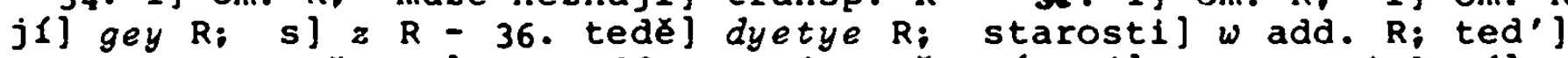
tento ge $R_{i}$ mésiec] ten add. $R_{i}$ jest Sesty tej] om. $R ;$ jalová] om. $R$ - 37. nepodobno] podobno $R ;$ Boha] buoh $R:$ vङeliké w\$\$ye[ykake $\mathrm{R}-38.1] \mathrm{om}$. $\mathrm{R}$; vece] take add. $\mathrm{R}$; Seova] $A y \mathrm{R}$.

V. Feria VI. in IV temporibus - L 1,39-47

R 106b, 39. Vstausi Marie jde mezi hory s rychlosti u *mèsto Juda 40. 1 vnide $v$ dóm Zachařóv 1 navstieví Alzběty

41. 1 sta sè kdy uslyše radovánie Alzběta

vzveseli sè dietè $v$ żivotè ješe

Tehdy naplnèna jest Ducha svatého Alžbéta

42. 1 zavola hlasem mocným a ŕkúci

Blažena si ty mezi zenami ...

43. I blaze to ze jest płišla matka Hospodina ke mnĕ

44. Aj nebo jakoz uslyšán jest hlas u mú uś tvého navstie ven 1 
radova sè splod u mém żivotè

45. Blažena jsi že uvěrilla

nebo naplněno bude to jenż jest povědéno o tobè ot Hospodina

46. i vece Maria

Chval duše má Hospodina

47. I raduj sè duch mój u Bozè spasiteli mému

V.: R] deest $A, C, D, S, W$

39. *mésto (my\$to ms.) - 42. ms. om. unam lineam (et benedictus fructus ventris tui vulgata).

VI. Sabbato IV temporum adventus - L 3, 1-6

W $37 \mathrm{~b}$ 1. $V$ (1e)to patnásté Ístvie Tiberinské tisaře vladarstuie Ponského Pilata Zidovstvem tetrarchy galilejského Erodese

a Filipa bratra jeho tetrarchy iturejského a trakonicského královstvie

a Lysanie abilinského popravcé

2. pod vejvodami kněžskými Annú a Kaifá̧e(m)

W 38a Stalo se jest slovo // Hospodinovo na Janu synu ZachaYovu na pústi

3. i priłsel jest do suého kraje jordánského káze křest pokánie $v$ odpuše〈n 1$\rangle$

4. jakoz psáno jest $v$ kniehách vo řx̌i Izaiảe proroka hlas volajici na pušxi hotujte cêstu Hospodinu tieté ciňte stezky jeho

5. każý duol naplnèn bude a každá hora i pohrobek pon 1žen bude

a budú kíivá u pílemá a nerouná v césty trété

6. 1 užr kazdé télo spasitele Boha svého

VI.: W (inter lectiones Proprii sanctorum)] deest A, C, D, S, R

VII. Dominica IV. in adventu - J1,19-28

S 139b, 19. Poslali żidové z Jeruzalema knežl a jáhny $k$ Janovi

$\left(144 b_{1}\right)$ aby otazali jeho Ty kto jsi

20. poznaj se nezapri

Pozna sè že nejsem jă Kristus 
21. A druhé otázachu jeho

Co tehdy Eliás si ty

Vece nejsem

Prorok si

povědě nejsem

22. 1 řetechu toho dle jemu

Co jsi abychme odpověděli těm ješto sú poslali ny

Co pravis sám o sobe

23. povědě já hlas volajicieho na pứxi

zprostierajte cestu Hospodinu zpravite

jakož pravi Isaiás prorok

24. A jenž posly biechu zákony nosiechu

25. Otázachu $i$ vecechu jemu

Proc tehdy křtis kdys ty nejsi Kristus ni Eliás ani prorok

26. Odpovẽ jim Jan jka

já křest vodú rini

s $139 b_{2}$ Ale prostřed vás stojl jehož vy / neviete

$\left(144 b_{2}\right)$ 27. Ten jest jenž po mně přıšel

přede mnu stvořen jest

jehož nejsem dóstojen řemene na obuvi rozvázati jeho

20. To sé stalo je u Betani ob onu stranu Jordána kdesto Jan křest činieše

VII.: $S, R$ ] deest $A, C, D, W$

19. żidové] zyde R; kněžl a jáhny] om.R; jsi] Kry§tus add. R - 20. poznaj] om. $R$ - 2l. ty] om. $R ;$ Prorok] $l_{y}$ add. $R ;$ povědé] om. $R$ - 22. abychme] abychom $R_{i}$ poslali ny] transp. $R$ - 23. povědé] gym add. $R ; j\{] \oint \oint e m_{i}$ add. $R ;$ volajlciehol wolagyczy $R ;$ zprostierajte] proftyerayte $\mathrm{R}$; zpravitel a prawyeczye $\mathrm{R}-24$. posly] lyczomyernyczy add. $\mathrm{R} ;$ zákony nosiechu] om. $\mathrm{R}-25$. Otázachul geho add. $\mathrm{R}$; ni] ani $R-26$. Cini] czynym $R-27$. Ten jest] om. $R$; stvořen] narozen $\mathrm{R}$.

VIII. Nativitatis Domini, missa in primo galli cantu L $2,1-14$

1. Vynide přikázanie od ciesaře Augusta aby popsán byl vsitek suêt

2. To psánie prvé stalo sè od sudce Cyrina

3. i diechu věichni aby sẻ pokázali u město jeho

4. Jide také Josef od Galilee z mèsta Nazareta do Judea města Davidova jemuž jmě Betlém 
protože z domu 1 z Celedi Davidovy

5. aby sè pokázal i Marii zenu sobè otdanu těskú

6. Sta sto kdys biechu tu ...

7. I porodi syna svého jednorodilého

a $v$ ruchy jeho obinu

1 polož $v$ jeslech nebo nebiese jemu miesta mezi vsěmi

8. A pastýli té noci biechu nad svými stády chovajice

9. Tehdy anjel Bozl pristúpi vedlé jich

a suétlost Bozie obkliti je

1 báchu sè strachem velikým

10. 1 vece jim anjel

Nejmèjte strachu

Nebo vám ukâzi radost jenż bude vక̌emu lidu

11. Nebo narodil sĕ dnes spasitel svêta jez jest Kristus Hospodin u mèstè Davidovè

12. a to vám znamenie

naleznete diece u pleny obinuto a polozeno $v$ jeslech

13. A $v$ tu dobu pojide hlas s anjelem chváléce Boha a $s$ nim sila nebeského rytiełstua

chváléce a zpievajice

14. Chvála u výsostech Bohu

a na zemi mir lidem dobré vóle

VIII: $S, R, D]$ deest $A, C, W$

1. Vynide] wanyde $R ;$ aby] om. $R ;$ viltek] w\$\$eczken $R$ - 2. psánie] py§§anye $R ;$ sẻ] ge§t add. $R$ - 3. diechu vडichni] gydechu w\$\$czkny R; město] mye§tye R - 4. od] do R; protoze] by\$\$ye add. R; $i z$ ] om. $R$ - 5. sé pokázal $i$ Marii zenu] $\oint_{y} l$ on z marygy $\S$ zenu $R$ - 6. (impleti sunt dies ut pareret vulgata)] om. S, R - 7. jednorodilého a] gedyneho odyeleho $R$; polozi] geho add. $R$; jeslech] nyeईlech $\mathrm{R}$; nebo] incipit $\mathrm{D}-8$. biechu] bdyechu $\mathrm{R}-9$. vedlé (wedl $\mathrm{ms}$.

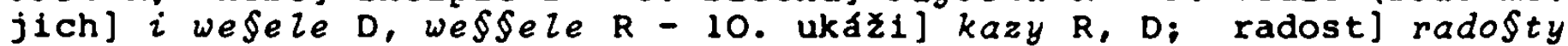
$R ;$ jenz] gez $D_{i}$ lidu] Swyetu $R$ - ll. dnes spasitel] transp. $R, D$, w̧yeho add. R; jeż] genz $R, D ;$ mésté] $w$ add. $R-12$. u pleny obinuto a polozeno $v$ jeslech] $w$ plenky obynute a polozene $w$ nye\$\$lech $\mathrm{R}$ - 13. pojide] przygyde R, przygde D - 14. u výsostech] na nebe\$fyech R, D; m[r] pokoy R, D; vóle] woly $D$.

IX. In vigilia Nativitatis Domini - Mt 1,18-21

S 140a, 18. Kdyz budieše otdána matka Jezúš // Maria Jozefu $\left(145 a_{1}\right)$ dł́éve nez sè sendu nalezena jest jmajlci ot svatého Ducha

19. Jozef muz jejie kdyz budiese pravý nechtè jie pronésti 
i chtiese tajemnè pustiti ji

20. To jeho mysléce

$v$ tu dobu anjel Božr ze sna zjevi sĕ jemu pravě

Josef synu Davidóv nerod' se lekati pł̌ijmi Marii żenu svu

jenż sè $v$ niej pocalo ot svatého Ducha jest

21. a porod1t' syna i nazoves jeho Jezr sem

Nebo on usdravi lid svój ot jich hriechóv

IX.: $S, R($ in $R$ ante $[2,1-14)$ ] deest $A, C, D, W$ -

18. budiese] bye§\$ye R; Jozefu] yozephowy R; sendu] §nydu R; ot] om. $\mathrm{R}$ - 19. budiese] bye§\$e R; pravy] om. $\mathrm{R}$; pronésti i] prowe§ty $\mathrm{R}$ - 20. *mysléce (my§le§e ms.)] my§§leczye R; pravěl a rzka R; príjmi Marii] wayety marige $R_{i}$ jenz] ge $\$ \$ R_{i}$ niej] ny $R_{i}$ pocalo] ge§t add. R; ot Svaténo Ducha\} \$watym duchem $R-21$. a] om. $R$.

x. Nativitatis Domini, missa secunda in aurora - L 2,15-20

15. Pastuchy mluviechu $k$ sobè

pojdèmy do Betléma

i vizme to slovo

jenż nám hospodín ukázal

16. I píldú chvátajlce

i naleznu Marii a Jozefa

a dieté položeno $v$ jeslech

17. Tehdy vidúce jeho porozuméchu o slově jenż bylo pověděno o dietěti o tom

18. A vłichni jesto diviechu sè slyక̌iec

- tom jeż pověděno od pastuch $k$ nim

19. Ale Maria pamatováse vłěchna slova ta kladúci v svém srdci

20. I vratichu sè pastuchy chvaléce 1 slaviece Boha ve vsem jez slysĕli i viděli sú

jakož pověderno $k$ nim

X.: S, R, D] deest $A, C, W$

15. K] W R; Pojdémy] podmy $R$, podme $D$; to slovo] toho \$lowa $R$ 16. prildu] poydu $R ;$ jeslech] nye\$\$lech $R-17$. porozuméchu] prorozumnychu $R, D ;$ o] tom add. $R, D ;$ tom] om. $R, D$ - 18 . jesto]

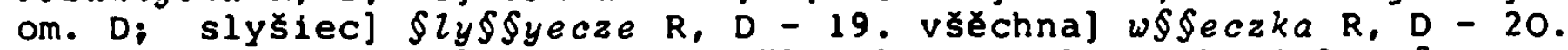
jez] genz R, D; suj om. R; jakoz] yako D, yak $R$; $k \mathrm{nim}$ ] ge§t gym R. D. 
XI. Nativitatis Domini, missa tertia in die - J 1,1-14

1. Na poxátce bylo slovo

A Slovo biese u Boha

a Buoh blse slovo

2. To biese na poćatce u Boha

3. vక̌echno jim učiněno jest

a bez ňeho stalo sè nice

Co stalo se 4. jlm zivot biese

A zivot bieše suětlost lidcká

5. A suêtlost ve tmè sviet 1

a tmy jie neobjechu

6. Byl clověk poslán ot Boha jemužto jmě biese Jan

7. sim prijide na svědečstuie

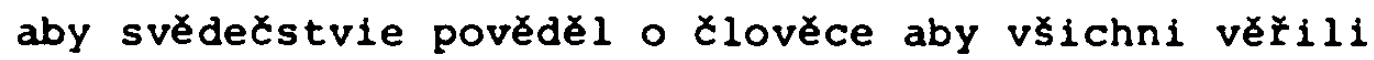

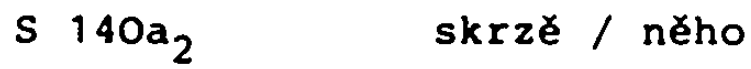

$\left(145 a_{2}\right)$ 8. Nebiese on suetlost

ale aby svědextstule povĕděl o svĕtlosci

9. BIక̌e světlost pravá jenž osvěcuje všelikého clověka príduce na tento svět

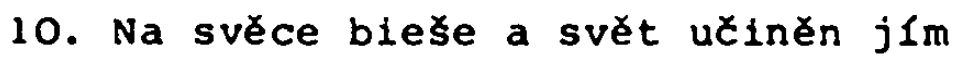

a svět jeho nepozna

11. Mezi vlastnie vnide a svoji jeho nepijijechu

12. Ktozto prijechu jeho dal jim moc syny Bozimi býci Tym jez věrile ve jme jeho

13. Ce ne z krve

ani z vóle téla

ani z vóle muzké

Ale $z$ Boha rozeni su

14. A Slovo tẻlo stvờeno jest i prébýlati bude $v$ nás

I vidĕli sme chvalu jeho

chvâlu jako jednorozeného otce plného milosti i pravdy

$X I .: S, R, D]$ deest $A, C, W$

1. U Boha] w bohu R, w bozye D - 2. U Boha] w bozye D, R - 3. vsechno] w\$eczkno $R, D$; stalo sé nice] vczynyeno ge\$t nycz $R, D$; stalo sé] transp. D - 5. A] om. $D$; ve tmé] $w$ temnye $R-6$. jemuzto] gemuz D: jmél gmeno R - 7. sim] Sem R, Syem D; pł́ijide] praygde D, pray-

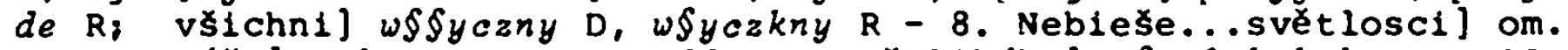
$R$ - 9. Blకe] neb praem., on add. $R ;$ vłelikého] w\$yelykakeho $R-10$.

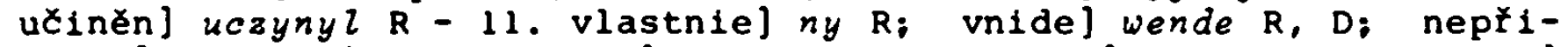
jechu] praygechu $R$ - 12. tol om. $R$; dal...jehol om. $R, D-13$. Ce]

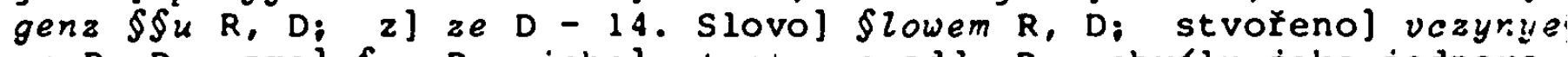
no R, D; sme] §my D; jeho] ot otczye add. D; chvalu jako jednoro- 
zeného Otce] transp. $1423 \mathrm{R}$; Otce] om. D; pravdy] rado\$ty $\mathrm{R}$.

XII. In die S. Stephani - Mt 23,34-39

34. Pravieše Ježús zboru židovskému a kn zatám popovým Seova já šli k vám proroky i múdré zákonníky

a $z$ těch zabiete 1 ukřizujete

zbičujete u modlách vasich

I hledati budete *od města do města

35. aby přišla na vy všliká krev pravá

jez jest prolita na zemi

od krve Abel pravého až do krve zacharie syna Barachie jehož ste zabili mezi chrámem a oltárem

36. Jisce pravi vám přlde to na národ tento

37. Jerusalem Jeruzalem jesto zbfjies proroky

$i$ kamenuješ jè jesto sú posláni $k$ tobe

kolikrát *chtêl sem sebrati syny tvé

jakožto slepice sbierá kuřence své pod křidla 1 nechtělo jsi

38. Seova ostane vám duom vás pustý

39. Nebo pravi vám

ze mne neuzŕlte viec jeliz diete

Blažený jenž jest přišel ve jmex Hospodina

XII.: $S, R, D]$ deest $A, C, W$

34. Seova] Ay D, aby R; ja] om. R, D; sli] §laly R; $z$ téch] ty $R, D ; \quad z a b i e t e]$ zabygyete $D_{i} 1$ ukřizujete] a $z$ tyech $R$, Om. $D ;$ zbicujete] zbyczygyte D; od (ob ms.)] od R, D; města) az add. R 35. vłélika] w\$yeczka R, D; krev pravá] transp. D; Abel] abe lowy $R, D ;$ Zacharie] zacharzowy $R, D ;$ jez] genz $R, D ;$ ste zabili] ge $\$ t$ $z a b y$ [ R, D; oltárem] zady add. D - 36. Jisce] wyernye D, zagy§te wyernye $R ;$ vám] om. $R$; to na narod tento] to w\$\$e na rod tento $D$, tento w\$eczken narod na wy $R-37$. Jerusalem Jeruzalem] Jeru§aleme Jeru§aleme $R, D ;$ jesto] genz $R$; zbIjies] zabyge\$\$ $R, D ; i\}$ a $R$, $D_{i}$ jesto] genz R; *chtél (chtyem ms.)] chtyel $R_{1} D_{i}$ sbierá) om. $R$, $D$; nechtělo] nechtyel $R, D-38$. Seova] Nebo ay $R$, Nebo zagy§te

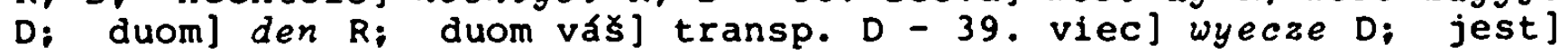
om. R, D.

XIII. In die S. Johannis - J21,19-24

19. Viděl Ježús petra 1 pověděl jemu Jdi po mnex

s 140b, 20. Obráciv sè // petr vidè toho ucenfka jehosto milo$\left(145 b_{1}\right)$ vase Ježú jứce po sobè 
jenz odpotival na jeho prsech 1 vece Hospodin kto zradr ce

21. kdyz toho uzłe Petr vece Ježrsovi

Hospodine A kak tento

22. Povědě jemu Ježús

Tak jeho chci ostaviti až sě vráci co ti jím

Ty jdi po mnè

23. príde slovo to mezi bratł́ ze ten uXennik neumre

Ale nepovèdẻ Ježus neumłe

ale tak jeho chci nechaci a co tobe

24. To jest uðennik ten jenż suědečstvie povie $\circ$ tom

$i$ psal to

A viem Že pravé je suẽdę̌stuie jeho

XIII.: $S, R, D]$ deest $A, C, W$

19. Vià̃l] Wedl $R_{i}$ jemu] om. $\left.R, D ; J d i\right]$ poydy $R, D-20$. Obráciv] y obraty $R, D ;$ Ježus] $y$ add. $R ;$ i] om. $R, D-21$. toho uzłe] to wydye R, $D_{i}$ Petr...tento] om. $R, D-22$. Povèdé ] weczye $R, D ;$ Tak ] tako R; jeho] gey $\mathrm{D}_{\text {; }}$ ti] tobye $\mathrm{R}, \mathrm{D} ;$ jdi] poydy $\mathrm{R}, \mathrm{D}-23$. pílde] przygyde $R_{i}$ slovo tol transp. $D_{i}$ bratfi] bratry $R_{i}$ Ale...ale] om. $\mathrm{R} ; \mathrm{CO}$ ] czoz D - 24. viem] wyeme $\mathrm{D}$.

XIV. In die Innocentium - Mt 2,13-18

13. Andẻl Bož́ pokázal sè ze sna Josefu pravě vstañ a vezmi dieté a matku jeho

a běz do Ejipta

1 budeš tu až já tober pověde

Nebo to pŕlde až Herodes vshledá dietěte na zahubenie jeho

14. Jenż vstana vze diete 1 matku jeho $v$ noci 1 jide do Ejipta

15. 1 by tu až do smrci Herodis

Aby se naplnilo jenž jest pověderno ot Hospodina prorokem Ikuce

2 Ejipta pozval sem syna mého

16. Tehdy Herodes viděv ze je oblưzen od králóv hněviv by velmex

A poslav zbi vsechny děti jenż biechu u Betléme 1 jeho ve vsech krajlch

ote duv letú aź doluov jakož biese na králfch vztázal

17. Tehdy sě naplnilo jenž je prorokem pověděno Jeremiałen a Íkuce 
18. hlas u vísosti slysán jest plaçce a huhlice Ráchel plakăe synóv svỵch a nerodiese utex̧iti nebo jich nenie

XIV.: S, R, D] deest $A, C, W$

13. pokázal] pokaza R, D; ze] om. R; Josefu pravěl yozephowy a rzka

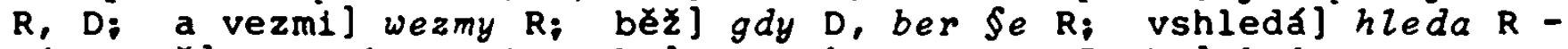
14. Jenż] Yozeph $R$; 1 matku] a matku $R, D-15$. by ] by $2 R, D$; He-

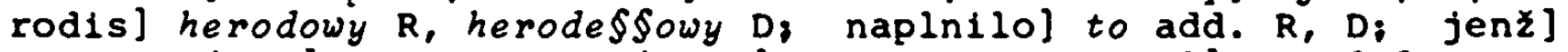
gez D; jest] om. R, D; Ejipta] egyptu R; pozval] powolal D, po\$lal $R$ - 16. vidèv] to add. $R, D ;$ obluzen] oluzen $R ;$ velme] wel-

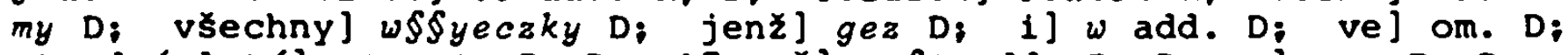
ote dvu letu] otymaty $R, D-17$. sé] ge $\$ t$ add. $R, D ;$ a] om. $R, D-$ 18. u visosti slysán] w chramye v\$ly\$\$an $R, D ;$ huhlice] kwyelycze R; nerodiese] $\$ \$ y e$ add. $R ; j i c h]$ om. $R$.

XV. Dominica infra octavam Nativitatis Domini - L 2,33-40

33. Biełe Josep a mátè Ježúsova Maria diviece sĕ jež o nèm praviechu

34. I blahoslaviełe jim simeon

1 povědĕ $k$ matce jeho

S $140 \mathrm{~b}_{2}$ $\left(145 b_{2}\right)$

Seova / polozen jest tuto $v$ obidu a na vskísenie mohych $v$ zidovstvi

35. Aby pronesena byla ze mnohych srdec myslenie

a tứ sám dusi projde mex

36. I biese Anna prorocnice dci Samuelova ta sĕ méla $z$ pokolenie Asser

Ta bydlése ve mnoze dnech

i biese s mužem svým sedm let ot svého děvojstra

37. a také vdovs osmdesát a tetyri let

jež neotchodiese ot chrámu

postem a modlitbu sluzéci ve dne $i \mathrm{v}$ noci

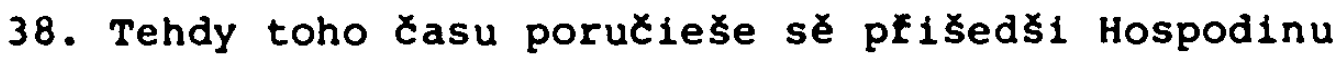

1 mluvieše vక̌̉(m) o nĕm jesto cakáchu vykúpenie Jeruzalema

39. A kdy̌ naplni sě vక̌e podlé zákona Mojziešova vrátili se do Galilee města Nazareta

40. Ale dietě rosciese a mužiełe plno múdrosti a milosti Božie s nIm biese

$X V .: S, R, D]$ deest $A, C, W$

33. máte Jezusova Maria] transp. $312 \mathrm{D}$, maria matka yezy\$\$owa R; di-

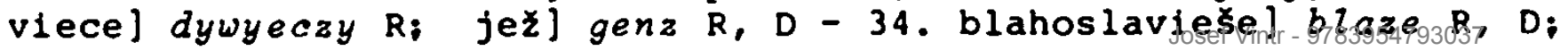


1 povědé] wecze R, D; k] om. R; Seova] $A y$ R, D; obidu] byedu R; $v$ żidovstv1... 35....ze mnohych] om. $R, D ;$ a] $t u$ add. $R, D ; s a m$ ] om. R, D; mex] geho add. R, D - 36. proročnice] prorokynye R; sé] gie add. D; svym] zywa pyet let a add. R; devojstva] dyewecz\$twye $\mathrm{R}$ - 37. take] bye\$\$e add. R; vdovi] bye\$\$e add. D; a ‘tyłi let] transp. $312 \mathrm{R}, \mathrm{D}$ : jez] genz $\mathrm{R}$, $\mathrm{D}$; modlitbu] modiytwamy y zado\$ty

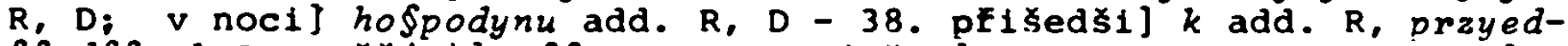

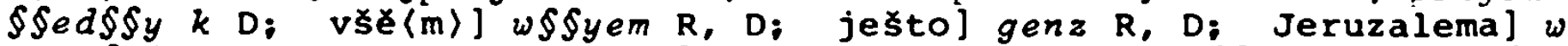
Jeru§alemye $R$ - 39. naplni sě] transp. $R, D ; v$ i ] w\$\$yeczko $D, w \$ e-$ czkno R - 40. a mužiese] a mudrzye\$\$e D, om. R; biese] om. R.

XVI. In vigilia Epiphaniae - Mt 2,19-23

19. Po smrti Erodesove

Seova anjel Bož zjevil sẽ ve sně Jozefu $v$ Ejlptě

20. pravě

vstañ a vezmi dietè a matef jeho

$i$ jal do zemé zidovské

Nebo sú zmrli jenź hledáchu dusé dietécé

21. A on vstana vzè dietè 1 matku jeho 1 jide do zemé

zidovské

22. A uslysav jez Archelaus kraluje v Zidovstvĕ za Eroda

otce svêho báse se proñ jiti

Ale napomenut ve snach otjide 1 dojide do vlasti Galilee

23. I pł̆išed bydlése u mésce jemužto jmĕ Nazaret aby naplnĕno bylo jez jest prorokem povĕdĕno Nebo Nazarenus bude jmenován

XVI.: S, D, R, W] deest $A, C$

19. Po] $W$ onom cza\$\$y praem. W; Seova] $A y$ D, R, Ez W; Boź zjevil] holpodynow zgewy $R, D$ : Jozefu] Jozephowy $W$, Yozeffowy prawye R, D - 20. prave] a rzka R, D, a rzka add. W: jeho i] om. R, D, a W: jdi] dy W, gdyz D; su] gyz add. W, R, D; zmrli jenz] zemrzyely gye to W, R, D: dietěcél dytyeczye W, D, dyeteczke R - 21. A] Tehdy W, $\mathrm{R}, \mathrm{D}$; vstana] $w \$ t a w \mathrm{~W}, \mathrm{R}, \mathrm{D}$; 1 matku] a matku $\mathrm{W}, \mathrm{R}, \mathrm{D}-22$. A usly

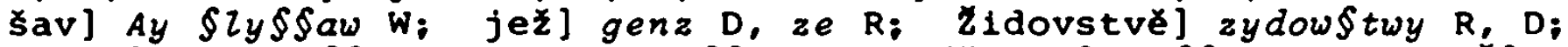
Eroda] herode $\$ \$ a W$, $R$, herode\$\$ye $D ;$ base se] ne\$\$mye $R$; proñ] pro

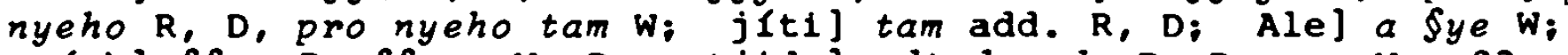
snách] \$\$nu R, \$\$nye W, D; otjide\} odtud gyde R, D, om. W - 23. DI sed] przygyde W: jemuzto ]gemus D, W: aby] to add. R: jez] genz R, D, czo W: jest prorokem pověděno] powyedyno ge $\$ t$ \$kraye proroky W: Nazarenus] Nazaret\$\$ky. 
XVII. In Epiphania Domini - Mt 2,1-12

1. Gdys sě narodil biese Ježus u Betlêmě těch dnI Eroda krále

S $141 a_{1}$ $\left(146 a_{1}\right)$

Tehdy múr̆́ králové ze vschoda slunce // přišli do Jeruzalema 2. praviece

kde jest jenž sè narodil král zidovský

Viděli sme hvězdu jeho na vschod slunce

i přisli sme následovaci Hospodina

3. Uslyšav Herodes král smúti sĕ 1 vše Jeruzalemstvo s nim

4. i sebra vక̌ kniežata $z$ popóv a pisaře lidské

Tázáse jich kde by se kristus narodil

5. Tehdy oni pověděchu u Betlémě v Żidovstve

Tako jest psáno prorokem

6. A ty Betléme zemé židovská nikoli menšie jsi mezi kniezaty zidovskými

Nebo $z$ tebe vynde vévoda jenż bude vlásti lidem israhelitkým

7. Tehdy Herodes tajnĕ zavola králuoh snažně poče zpytati casu hvězdy jež se jim pokázala

8. I poslav je do Betléma vece Jděte abyste tázali snažnè na dietě

A kdyz naleznete vakažtež mně at' já př́la chválu vzdám jemu

9. Tehdy uslyševse králé otjidu

A seova hvězda již biechu videlli ote vschoda jdieše př̀d nimi

dotad až tu kdež bieše dietě

10. A viděvše huězdu radovachu se radosci velikú

11. A všedše $v$ duom nalezli diete $s$ mateř́ Maril jeho I přistúpiece porữĕchu sè jemu

A otvơ̆ivše zbožie obetovachu jemu zlato kadidlo a myrru

12. A *vzemše odpovědĕnie ze sna aby nevrátili se k Erodesov jinú cestú vrátili sé do královstvie suéno

XVII.: S, D (des. v. 4), R, W] deest A, C

1. Gdyక ] $V$ onom cza\$\$y praem. W; u J om. R; Betléme] zydow\$kem add.

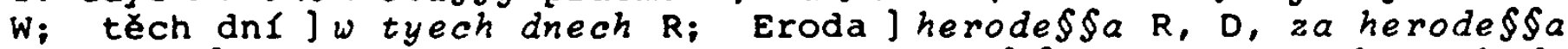
$W ;$ mudrol magy trzye $R$, hwyezdarzy $W$; ze J $\mathrm{Se}_{\mathrm{W}} \mathrm{W}$ vschoda] wychoda

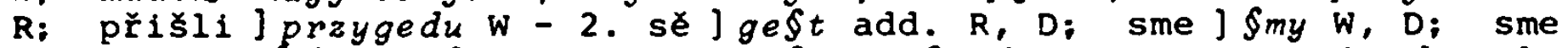
následovaci f $\$ m y$ na\$ledowat $W, R$, Sme na\$ledowat $D$; Hospodina] geho W - 3. Uslysav J y praem. D, to add. W, $R$; Herodes král ] transp. D, 
R, W: 1] a W: Jeruzalemstvo] Yeruzalem\$twye W - 4. vSX] w\$yeczka $R, D, w \$ \$ y e c z k n a W ;$ kniezata] des. $D ; z]$ y $R$, om. W; popóv a] popow y R, popowa y $\mathrm{W}$; lidské] I add. W; kde] om. R; sé] by $l$ add. W; Kristus] buoh $W, R-5$. Zidovstve] zydow\$twy R; Tako] Tak W, $R$ - 6. nikoli] nykde $R$; vynde] wyde $R$; israhelitkym] mym zydow\$kym $W$, mym $w$ zydow\$twy $R$ - 7. tajné] om. $R$, ruczye add. $W, R ;$ snaznè połe zpytati ¿asu huězdy jez] py Inye navczy $\$ y e$ od nych caya\$\$u hwyezdy genz $W$, mylo\$tywye \$ye nauczy od nych cza\$\$y hwyezdye genz R; jim] om. $R-8$. I] $A R$; poslav] po\$la R, po\$\$lal w: vece] a rzka $W, R ;$ abyste tázali snazne na dieté] aby\$\$te myle tazaly na dyetye

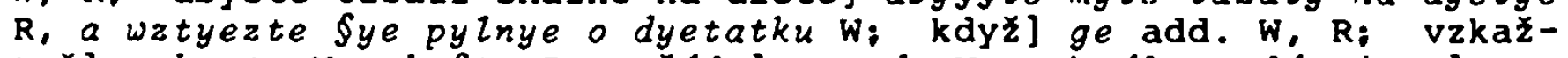
tez] wakazte W, vka\$te R; pÍlda] przydu W; chvalu vzdám jemu] na-

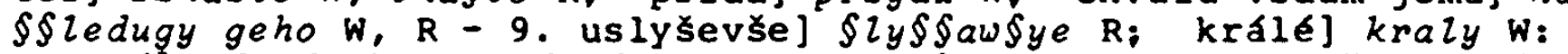
otjidu\} odgydechu $W$, odgedu R; A seova] Ay R, Ez W: hvezda jiz biechu] hwyezdu genz $W, R$; ote vschoda] od wychoda fluncze $R ;$ jdiese] dyechu $\mathrm{R}$; dotad] dotud $W$ - 11. vडedకe] w\$edcze R; nalezli] nagydechu W: s mateł 1 Maril] § marygy matku W, a marygy matku R: I płistípiece porucechu] A poklonyw\$\$ye \$ye pomodiychu $w$, przy\$tupyw\$\$e poruczychu R; otvořivłe] odkryw\$ye R: zbozie] poklady \$we W: obětovachu jemu] dawachu $R$; jemu] dary add. $W$; myrrul myeru $W-12$. *vzemse (w\$en§e ms.)] wzem\$\$ye $W, \mathrm{R}$; odpovědurnie] odpowyed $\mathrm{W}$, odpu§tyenye R; ze sna] \$krzye \$en W: nevratili se] transp. W: $k$ ] om. R: kralovstvie] kralow\$twa W.

XVIII. In octava Epiphaniae - Mt 3,13-17

13. Pł́išel Ježús z Galilea do Jordána k Janovi aby kłtěn ot nèho byl

14. Ale Jan bránieše jemu pravě Jáz od tebe mám pł́ijieti kłest

a ty des ke mner

15. Odpovědĕ Ježus jemu

Nech toho

tak nynie slušie nám naplniti vałicku pravdu

Tehdy otpusti jeho

S $141 \mathrm{a}_{2}$ 16. Tehdy křtên Jezus inhed vystúpi / z vody

$\left(146 a_{2}\right) \quad a v$ tu dobu otvořena su jemu nebesa

I videl Duch Boź schodiece jako holub

jdúce nad sè

17. A seova hlas $s$ nebes prave

Ted jest syn mój milý jenž sem vzvolil

XVIII.: $S, R, W]$ deest $A, C, D$

13. Płisel] $U$ onom czaf̧y praem. W, Przy\$\$ed R; Galilea] Galylee W; kłtěn] krzye\$t $W$; byl] przygal W-14. brániese] $\$ y e$ add. R, pra-

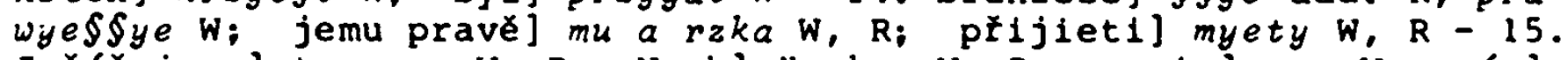
Jezús jemu] transp. $W, R ;$ Nech] Nechay $w, R ;$ nynie] om. $W ;$ nám]

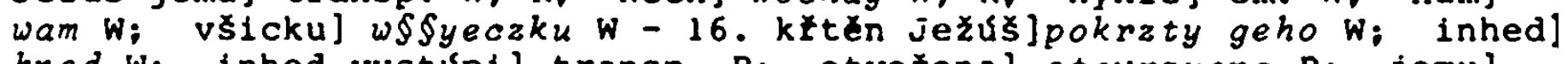
hned $W$; inhed vystupi] transp. $R_{;}$otvołena] oteurzyena $R_{\text {; jemu] }}$ 
om. W; Duch Bożl] ducha Swateho W; schodiece jako holub] yako holubyczy wachodyecze R; jduce] bye§§ye W, om. R; sè] nym W- 17. A] $y$ W, om. $R$; seova] $A y R$, tot $W ; s] z R$, om. $W$; nebes] om. W, $a$ add. W, R; pravĕ] rzka R; jenż] gehoz R; vzvolil] zwoly $[W, R$, Sobye add. W, R.

XIX. Dominica I. post Epiphaniam - L 2,42-52

42. Gdyz biese Jezús na dvanáct let jidú do Jeruzalema podlé obyceje hodu

43. dokonav̧e dny kdy sě vrátichu osta Jezús v Jeruzalemé

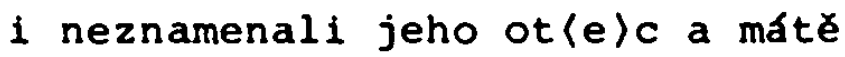

44. domniece sè by byl na cèstě 2 družinu př Idu jednoho dne

i hledáchu jeho po přietelech a u známých

45. nenaleznúc vrátichu se do Jeruzalema hledat

46. I sta se to tretr den

naleznú jeho $v$ chrámé mezi mistry sediece poslúchaje jich i tázáse jich

47. diviechu sè všicni jesto jeho slyšiechu pro mudrost 1 otázanie jeho

48. (i vidice a divichu sé)

$i$ vece matè jeho $k$ nèmu

synu co si nám ucinil

Seova otec tvój a jáz hledachme teb

49. i pověde jim

co je to az ste mne hledali

Nevěděli ste že co *otcovo jest musi býti v těmže

50. I neurozumęchu slovóm jez $k$ nim povědĕ

51. I jide s nimi i pijidu do Nazareta

a bře poddaný jich

a matka jeho znamenáváse vłěch sluov kladúci v své srdce

52. A Ježús prospieváse u múdrosti i věkem i milosti u Boha i u lidr

XIX.: $S, R, W$ ] deest $A, C, D$; in $W$ ante lectionem $M t 3,13-17$

42. Gdyż $W$ onom cza\$\$y praem. W; biese] budy§§ye $W, R$; dvanáct let] dwanad\$te leto $R ;$ jidu\} pogydechu $W$, dyechu $\$$ nym $R ;$ Dodle obyðeje] yakoz obyczey W, R; hodu] hodny W, R - 43. dny] dny o\$m W, Swe dny R; kdy] kdyz W, R; vrátichul za\$\$ye add. R; neznamenali] 
neznamenal $R$, toho add. $W, R ;$ ot $(e) c]$ przyatele $W ; a]$ any $R$, om. $W$; máté ] om. W- 44. domniece] domnyewagycze $W, R ;$ by] on add. $R$;

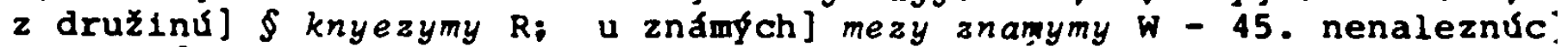
nenalez§ye $\mathrm{R}, A$ nenalezechu geho $\mathrm{W} ;$ Jeruzalema] geho add. $W-46$. to] om. W: naleznu] nalezly W, nalezechu $R ;$ posluchaje] po\$lucha§§ye W, R; i] a W, R; tázáse] tazye W; jich] om. R - 47. diviechu] leczyechu W, leczechu R; vङicni] w\$\$yczkny W, R: pro] prawye praem. R; otázanie] otazachu $W, R-48$. i vidĺce a divichu sé W] om. S unam lineam, y dywyechu \$ye gemu R; máté jeho] transp. R; Seova] $A y \mathrm{R}, E z \mathrm{~W}$; hledachme] hledamy $\mathrm{R}$, zelegyczye hledachom W 49. jim] gyma $R_{;}$Co] $C z O z W, R_{i}$ je to] transp. $R ;$ to] om. W; az] gez $W, z e \mathrm{R}$; ste] om. $\mathrm{R}$; hledali Nevédeli ste] hledate Newyete $\mathrm{R}$; co] czoz W, $R_{i}$ totcovo (otczowa ms.)] otczowo $W, R_{i}$ musi] mo\$\$ym $W_{i}$ $v$ témže] om. W, R - 50. I] Tomuz praem. R; neurozuméchu] nerozumyechu W, nerozumychu $R_{i}$ slovóm] §lowu $W_{1}$ tyem]add. $R_{;}$jez] genz $R_{\text {, }}$ czo W: pověde] powyedyel R, mluwy $2 W-51$. i pijjidu] om. W; poddany jich] poddan gym $W ;$ a] om. W; znamenáałe] znamena\$\$ye $W, R ;$ vకech sluov] w\$\$yechna ta \$lowa W; sluov] a add. W, R; své srdce]

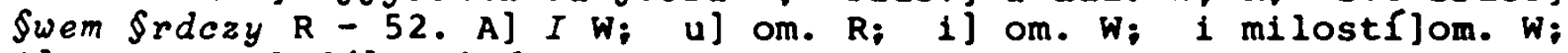
i] a W: u lidi] $w$ lydu R.

XX. Dominica II. post Epiphaniam - J 2,1-11

1. Svatba stala se jest v ulici galilejské

a bieše máti Ježšova tu

2. Pozván bieše Jezušs a ucenníci jeho na svatbu

2. nedosta ș vina vece máti $k$ nĕmu

vina nejmaj 1

4. povědě jiej Ježus

co tobe a mnè jest zeno

Ješe Łas nepřǐel mój

5. vece matka Jež́sova sluhám

co koli káze vám učiňte //

S 141b, 6. Tehdy bieše tu sest stłezóv kamenných postaveno

$\left(146 b_{1}\right) \quad$ podle obyčeje zidovskěho

każy jich ve tri miery a ve dvè

7. 〈Povede jim Ježß

Naplñte š̉zy vodú

A naplnili je aż dovrchul

8. povědě jim Ježus

Načete jiz a neste starému svatu

i nesu

9. A kdyz okusi stary svat vodu vínem uxiněnú povĕdĕ ženichovi

ale nevědieše odkat to jest

ale sluhy vèdiechu jenz biechu vodu leli 10. i vece svat 
každý člověk pruně víno postaví dobré až sé zpojie tehdy to co horsieho jest

Ale ty si schoval víno dobré do toho casu

11. To poxátek znamen 1 uxinil Ježus v ulici v Galilei

a z jevil chválu sur

i uvěrichu veň uCennlci jeho

$X X .: S, R, W]$ deest $A, C, D ;$ in $W$ ante lectionem Mt $8, i-17$

1. Svatba] $W$ onom cza\$\$y praem. W; stala së] transp. W; jest] om. W, R; galilejské] Galylee $W, \omega$ kalylee $R ;$ a] $y$ R; biěe máti Je¿łsova tu] transp. $1423 \mathrm{~W}-2$. Pozván] tu add. W, praem. $R-3$. nedosta] nedo\$tawa\$e $R$, ne§tawa\$\$ye $W ;$ sej om. W; vina] $y$ add. $R$; máti] matye geho $R ; k$ němu] Gezy\$§owy $W$, om. $R-4$. jiej] gy $W$; Co] $A$ czoz W: Čas nepřisel mój] transp. $321 \mathrm{~W}, 132 \mathrm{R}-5$. vece] $y$ praem. R; Jezišova] geho W; sluhám] \$wym add. $R ;$ co] czoz W, $R ;$ káze] kazy W; vám] to add. W, $R$; ux̌iňte] czynte $W-6$. bieše tu] transp. $\mathrm{R}_{i} \mathrm{tu}$ ] tud $\mathrm{R}$; strezóv] Gbelu mg. m. rec. W; postaveno] om. R; podlé obyčje zidovskěho] yakoz obyczey zydow\$\$ky $\mathrm{W}, \mathrm{R}$; každs] kazda W: tr̆i miery a ve dvĕ] dwa \$trychy neb we trzy $W$, trzy §trychy $R$ - 7. Povědě...dovrchu $W$ ] om. $S, R-8$. povědě] $y$ praem. W: Načete jiz] natriety gyz wody $R$, Pyte a dayte $W$; nesu] ne§§yechu w - 9. kdyz] yak w: uxiněnu] obraczyenu $w$; povèdẻ om. $W$; zenichovi] zenych $R$, om. $W ;$ ale nevědiełe] a newyedye $Z W$; odkat] dobrzye odkud R; to jest] \$ye wzalo W; ale] a R; léli] lyly $R$ - 10. i] powola zenych \$tareho \$watu praem. W: svat] gemu $W$, om. $R$; každý] Stary add. R; prvné] nayprwyczy $W$; vino postavi dobré] transp. $312 \mathrm{~W}, 132 \mathrm{R}$; postavi] da $\mathrm{W}_{\text {; }}$ az] $k d y z \mathrm{~W}_{\text {; }}$ zpojie] zpygy $\mathrm{W}, \mathrm{R} ;$ tehdy] to add. $\mathrm{R}$; horsiehol hor\$ye $\mathrm{R} ;$ schoval] choval W: vino dobré] transp. W; tohol tohoto $R$ - 11. ulici] chana W: $v$ Galilei] Galylee $W, R ;$ a] $y$ W: svu] y wazynyl add. R; uvěrichu] wyerzychu W.

XXI. Dominica III. post Epiphaniam - Mt 8,1-13

1. Kayz pojdieše Ježus s hory jdiechu po něm zástupi velici

2. Tehdy nuzny pilda prosi jeho łka Hospodine chces 11 muožes mě uzdravici

3. Pozdvihna Jezus ruky dotce jeho Íka Chci uzdraviti

Inhed by tist zivot jeho

4. I vece jemu Jezús

diz neprav nikomu

i jdi pokaz sè knězi

a ofěruj jemu dar jakoš kázal Mojzies na svědecstvie

5. A kdyz płíde do Kafarna pristúpi k němu centurio prosè jeho

6. Hospodine diece mé ležl v domu trudno a zle sĕ jmá 
7. Odpovědĕ jemu

jáz pł́du a uzdravím je

8. odpovědè tako łka centurio

Hospodine nejsem duostojen aby všel pod mu stłechu

Ale o jediném slově pověz budet' zdrávo dietè mé

9. Nebo sem já clověk ustaven pod moc1

maje pod sebú rytieřstvo

kku li tomuto uxiñ to uxinl

druhému pojdi a pójde

A jinému jal a jde

10. Slyše to Jezús divieše se velmě

i povĕdè těm jenž za ním jdiechu

s $141 \mathrm{~b}_{2}$ zavêrné pravi / vám nenalezl sem také viery $v$ Israheli

$\left(146 b_{2}\right) 11$. Jistè pravi vám

že mozl z vzchoda 1 z západa płr 1 du

i budu odpođłvati s Abrahem Isákem a Jakubem v nebeském kralovstvi

12. Ale synové tohoto králevstva vyvrženi budu do tmy věxné Tu bude plác a skřehet zubóm

13. I povědě Ježus centurionovi

I jai jako si vĕril tako ti bud'

$i$ uzdraveno by diete $v$ tu hodinu

XXI.: S, R, W] deest $A, C, D$; in $W$ om. vv. 7-13

1. Kdyż] $V$ onom cza\$\$y praem. $W$; pojdieš] pogyde $\left.R_{i} s\right] z R_{i} j d i e$. chu] y gydechu $W, R ;$ zástupi] załtupowe $R-2$. nuzný] malomoczny $W ;$. prida] praygyde $y \mathrm{R} ;$ jeho] $a$ add. $W, R_{i}$ Hospodine] acz add. $W: 11$ : om. W: mé] mne $W-3$. Pozdvihna] po\$dwyh R; Jezús] om. $W$; ruky]

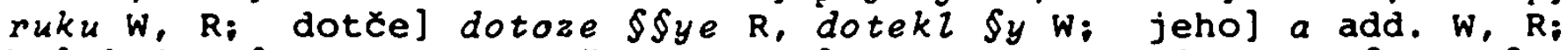
by] by $l$ ge\$t $W$, om. $R$; zivot jeho] transp. $R$, malomoczen\$twye \$weho $W-4$. I] $A$ R; Jezus] om. $R ;$ diz] Wyz W; nikomu] nykomemu $W$, $R_{i}$ oféruj jemu] obyetugte gym $R$; jakos] yako W: Mojzies] om. $R$, gym add. W - 5. płlde] praygyde R; Kafarna] Kapharnaum W: prosé] Pro\$\$y $W$ - 6. Hospodine] a rzka praem $W, R ;$ diece mé lezi $v$ domu trudno a zle sẻ jmal dytye me ale fye ma nemoczno $w$ domu $W$, dyetye me zle §\$ye ma lezy $w$ domye trudnye $\mathrm{R}-7$. Odpovědĕ] Powyedye $\mathrm{W}$, hic des. W: jemu] $i \hbar \bar{u} s$ add. $R ;$ jẹ] gey $R-8$. odpovèdé] a add. R; vsel] Se [ R; jediném] gednem $R$ - 9. ustaven pod mocl] transp. 231 $R$; rytierstvo] rytyerzow $\$$ to $A \mathrm{R}$; tol om. $\mathrm{R}_{\text {; }}$ pojdi al pod an $\mathrm{R}$; A jinému jdi a jde] om. $R$ - 10. za nIm jdiechu] znamy byechu R: zavěrne pravi] zagi§te prawym R: nenalezl] nenad\$el $R$ - 11 . Jistě pravi] Ge§tye wyecze R; $z$ vzchoda $I z]$ od wychoda az do R; Abra-

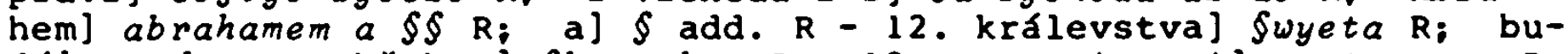
duj poydu R: skrehet] \$krzyehot $R-13$. centurionovi] centuryowy $R$; I] om. $R$; verill tako] vwyerzy 2 takzt $R$; ti] om. $R$; bud'] bude $R$; by] ge§t R. 
XXII. Dominica IV. post Epiphaniam - Mt 8,23-27

23. Vstúpajlce Ježř̌ $v$ lodici diechu po nĕm množstvie lidu uXennici jeho

24. Tehdy veliký vietr vsta moł́ský

jakož sé lodicka přikrýváse vlnami

Ale on spáse

25. ani přistúpivse ubudichu jej rkúce

Hospodine usdrav ny hynemet'

26. Povẽdęt' jim

Co sex strasivite malé viery

Tehdy vstana káza vêtrovi

*i by tichost veliká

27. Tehdy lidie diviechu sè řkuce

kto je ten zde jenže větróm káze a moži 1 poslưchajl jeho

XXII.: S, R] deest $A, C, D, W$

23. Vstupajlce] W\$tupugycze $\mathrm{R}$; lodici diechu] lodiczku dye§\$e $\mathrm{R}$ 24. veliký vietr vsta mořský] om. $R_{i}$ spáse] $w$ tu dobu add. $R-25$. ani] Ale ony $R_{i}$ ubudichu] zbudychu $R_{i}$ jej] $a$ add. $R_{i}$ hynemet'] a nezhynem $R-26$. Povědět') Tehdy praem. R; sè strašivite] $\$$ te

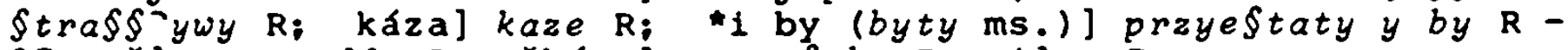
27. sé] tomu add. R; ‘kuce] mezy §ebv R; i) a R.

XXIII. Dominica V. post Epiphaniam? - Mc 3,1-5

1. Vnide Ježus v skolu

a bieše tu muž jmějieše suchú ruku

2. I chováse jeho zda by $v$ sobotu létil

3. I povẽde tomu jesto jmá suchú ruku vstañ a stój mezi námi

4. I pověde $j i m$

Jestli lze $v$ sobotu dobłe ciniti

¿i nenie lépe li dusi schovati ti ztraciti

Oni "pocichu

5. 1 obež̆ev je hněvivĕ

zamúti sè na jich slepotu

Povědè elověku tomu

pokaž ruku

On pokáza Tehdy bieše celá ruka jeho

XXIII.: $S, R, W$ (in $W$ inter lectiones Proprii sanctorum)] deest $A, C$, 
1. Vnide] $V$ onom czya\$\$y praem. $W ; a] y, W, R ; t u]$ om. $v ;$ muz] $y$ add. R, nemoczny $y, W-4$. jim] Gezy\$\$ add. W, R: lze] om. $R ;$

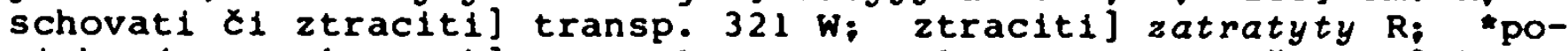
cichu (poczechu ms.)] poczechu R, potychu $W$ - 5. obezłev je] bez hrzyechu gey R: sè na jich] om. R; ¿loveku tomu] transp. W, R: On] an R: celá z za R.

XXIV. Dominica in Septuagesima - Mt 20,1-16

1. Pověděl Ježuš učenníkóm svým tuto pověst a pravĕ Rouna sè kralovstuo nebeské clověku otci Celedinnému jenž vynde $z$ jitra ráno uvésti dẹlnfky u vinnici svú

2. .....

3. I vyšel $v$ hodinu tret 1 vide jine stojiece na trhu (prazdne)

4. 1 vece $j i m$ Jděte i vy li virnici mu

S $142 a_{1}$ A co právo bude dám // vám

$\left(147 a_{1}\right)$ 5. Tehdy jidu druhé vynide $v$ sestú a $v$ devatu hodinu $i$ ucini takéz

6. a $v$ jednunadctu hodinu vynide $i$ naleze jiné stojiece 1 vece $j i m$ co tu stojite cely den prániece

7. Odpověděchu oni Nebo nás ijeden neuvede povède jim Déte $i$ vy u vinnici mu a což právo bude dám vám

8. A kdyz vecer budiese pravi pán starostè vinnice suému pozov délnikuov daj jim mzdu pocna na poslednich aż do prunich

9. A kda płldú jesto jednunadste hodinu vešli vzechu téz penieze posledni

10. viděvse najał̆euni to domnĕchu sè aby viece vzeli Pobrachu $i$ oni téz penieze

11. a poberúce reptáchu protiv otci domovitému 12. a Ikúa Ti posledni čas dělali

a rovny si nám uxinill jenż sme nesli bł̆iemé anem $v$ horkost 1

13. 1 on odpověder jednomu jich łka prieteli necinit' kłivdy Vedĕ $z$ penieze jsi najat ke mnĕ 
14. vezmi co tvé jest a jdi

Nebti chci tomu posledniemu dáci jako tobe

15. Ci nelze mi cinici co chci

A nenie oko tvé zlé nebo jáz dobrý sem

16. Tako budu posledni pruni a prunl posledni

Nebo mnozi tu jsu pozvani a łiedci zajisté vybranl

XXIV.: $S, R]$ deest $A, C, D, W$

1. tuto pověst a] om. R; pravĕ] raka R; královstvo] kralow\$twye $\mathrm{R}$; nebeské] $k$ add. $\mathrm{R}$; otci] om. $\mathrm{R}$; Celedinnému] ce [ednyemu $\mathrm{R}$; vynde] wyde $R ; \quad z$ jitra] zytra $R ;$ ráno] om. $R ;$ uvésti]chty we§ty $R-2$. om. $S, R-3$. vysel] wy $\{[a[R ;$ tyetl] y add. $R$; trhu] prazdne add. $\mathrm{R} ;$ (prázdné) $\mathrm{R}$ ] om. $\mathrm{S}-4$. u] na $\mathrm{R} ;$ vinnici muj transp. $\mathrm{R}$; právo bude] bude prawo to $R ;$ dám vám] transp. $R$ - 5. Tehdy] ony add. $R ;$ jidu druhé] gydechu druhy $R$ - 6. jednunadctu] gedenadcztu $R_{i}$ vynide] opyet add. $R$; prániece] prazdny $R$ - 7. neuvede] newywede $R ; j i m]$ om. $R ;$ vinnici mu] transp. $R ;$ a což právo bude dám vám] om. $R-8$. když] by add. $R ;$ budieše] om. $R$; pravi] wecze $R$; vinnice] om. $R$; svemu] gdy na wynyczy add. R; daj] aby R; na poslednich az do prvnich] od prnyeho az do poßlednyeho $R$ - 9. A kda] kdyz R; jednunadste] w gedenaztu $R$; vesli] wy\$ly $R$; vzechu] dachu gym R: penieze] mzdu R; poslednl] yako prnym $R$ - 10 . viděvłe najdřevni to] $y$ wydye§§e to nayprny $R$; domnĕchu] domnyewa§§e $R$; aby] zda by $\mathrm{R}$; vzeli] vczyny ly $\mathrm{R}_{i}$ i] om. $\mathrm{R}$ - 11 . poteruce] pobraw\$ye $\mathrm{R}-12$. posledni] geden add. $\mathrm{R}$; si] ge add. $\mathrm{R}$; błieme] brzyemena $R ; \quad v$ ] y $R-13$. jich] z nych a $R$; nexinit'] neczynymt $R$; $z$ penieze] ze na penyezy $R$ - 14. tvé] om. $R$ : tomu] tomiuto $R-15$. cinici] $z$ meho add. R; chci] nebo czo my libo add. $R$; dobry sem] transp. R - 16. budu] bude R; prvnil prvy R; tu] om. $R ;$ zajisté] om. R.

XXV. Dominica in Sexagesima - L 8,4-15

4. Tehdyze sbor veliky

$z$ měst k Jež́sovi bližiechu sè

povèdè rovenstuie

5. vyšel jenž seje siemẽ své

A kdyz vsievá

jedno padlo podlé cesty

a ptaci s nebe snechu to

6. A jiné pade na skalu

vzejda i shoře nebo neméjieše vláhy

7. A jiné pade mezi trnie

spolu rosta trnie zahubi to

8. LA jiné padlo na semi dobrú

a rosta udini plodu stokrat vicel

To povèdév voláse 
Jenż má usi slyšeti slys

s $142 \mathrm{a}_{2}$ 9. Tázáchu jeho uxenníci kaká by to pověst / byla

$\left(147 a_{2}\right)$ 10. Jimžto on otpovědě

vám jest dáno poznati věst královstuie Božieho

Ale jiny̆m u pověstech

aby vidúc neviděli

a slyšiece nerozumèli

11. A jest ta pověst

sémè jest slovo Božie

12. Jesto vedlé cesty to sú ci jeź poslúchaj1

a diábel beł́e slova $z$ jich srdce

aby nebyli spaseni věriece

13. A jez na skále

jesto slysiece u veseli płijeli slovo

a $t i$ kořenie nejmajl nebo na cas vĕłie

a $v$ Casu pokúseném otejde

14. A jesto $v$ trnie upadlo

ti sú jez slysie

a u *myšlen

ti nenesu plodu

15. Ale jesto na dobru zemi

Ti sú jež srdcem dobrým a šlechetným slovo Božie obdržil

a plod nesu u pokoji

XXV.: S, R, A] deest $C, D, W ;$ in $A$ desunt vv. 9.-11

4. Tehdyže] Kdyz R; Tehdyž...mĕst] om. A; k Jež́šovi blıžiechu

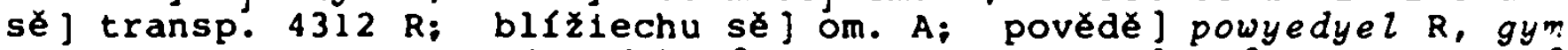
add. $R, A$; rovenstuie] podoben\$twye $R$ - 5. vysel] ge\$t add. A, ge\$t czlowyek add. $R ; k$ kyzj ge add. $R, A$; cesty y pot laczeno ge\$t add. $R_{i} s$ nebe] $z$ nebes $A$, om. $R$ - 6. pade] padlo $R$; skálu] \$kaly $R$; vzejda] y zahyne add. $R$; shoře] Shorzy $R ;$ nemejiese] negmye\$̧e $R$ 7. mezi) $w R-8$. (A gyne padlo na zemy dobru a roßta vczyny plodu §tokrat wycze) $R$ ] om. S, A; Jenž] genze A; má ušil magy w\$ychny $R$; slys] om. $R$ - 9. vv. 9.-11. desunt in $A ;$ kakal yaka $R$ - 10. Jimžto]

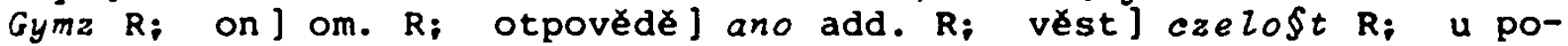
věstech ] powyelty dano wyedyety $R$; nerozuméli] nezrozumnyely $R$ 11. ta] om. $R$ - 12. vedle] podle $R$; jez] genz $R$; srdce] ferdecz $R$; nebyli spaseni věriece] incipit deruo ms. A, newyerzeczye zdrawy by $l_{1}$

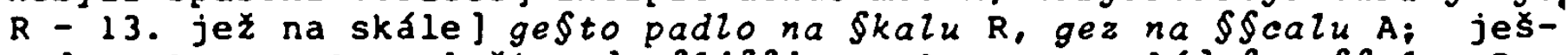

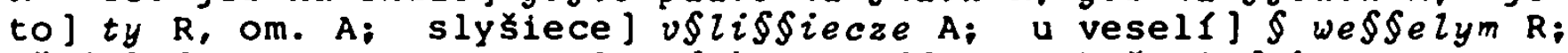
płijeli] przygymagy $R_{i}$ slovo] bozye add. $R$; koł̌enie ] korzene $R_{;}$

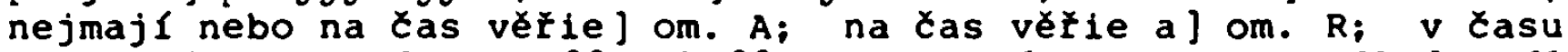
pokušeném otejde] $w$ ca $a \$ \S$ poku§§yenye oteydu $R$ - 14 . upadlo] padio $R, A ;$ upadlo] to add. $R ;$ ti suj transp. $R, A_{i}$ jez] genz $R_{i}$ *myslens (myleny ms.)] my§lenye $R, A ;$ "sbožie (\$lozye ms.)] zbozie $R$, $A_{i} 1 \mathrm{v}$ ] om. $R, A ;$ plodu] ploda $R$ - 15. jestol padlo add. $R ;$ dobru ] (pa)dnu add. A; zemi] dyedynu R, om. A; zemi ] to add. R, A; 
Ti sú transp. $R, A_{i}$ jež] genz $R_{i}$ slovo Božie obdržie] transp. $312 \mathrm{R}$, obdirzie slowo \$obie $A$; a plod nesu u pokoji] om. A.

XXVI. Dominica in Quinquagesima - L 13,31-43

31. Pojem Ježuš dvanádcte uxennikuov svých povědĕ jim Seova jdemy do Jeruzalema

i skonţ sě vకe jež je psáno proroky o synu Božiem

32. Prorazen bude lidem na posmievanie na bicovánie i na plvánie

33. a po bicováni zahubie jeho

a třet 1 den vstane

34. Oni tomu nerozumerchu

a bieše slovo to schováno před nimi

〈neurozumichu co praviese〉

35. I sta sě to až pojdieše $k$ Jeruzalemu

slepý jeden sedieše u cesty žebře

36. (A kdy uslyze lidi jdúce

otdza co by to by 20 )

37. Pověděchu jemu že Ježuśs Nazarenus jde

38. I zavola rka

Ježři synu Davidóv smiluj se nade mnú

39. A jesto mimo něho diechu lajiechu jemu aby mlexal

Ale viece voláse

Synu Daviduov smiluj sè nade mnú

40. Sta Ježús i káza jej vésti před se

a kdyz bliz bieše otáza jeho

41. Co chces at' uxini

On poverde

Hospodine bych viderl

42. Ježus jemu vece

prozŕi viera ta té uzdravila

43. Inhed prozr̃e $i$ jide za ním chvále Buoh

A všitek sbor jenž vidieše da chválu Bohu

XXVI.: $S, R, A]$ deest $C, D, W ;$ in $A$ desunt vv. $31 .-39$.

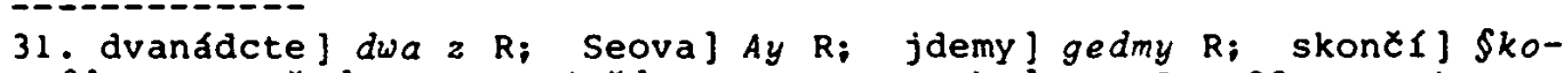
nałfye $R_{i}$ vङe] om. $R_{i}$ jez] $c z 0 R_{i}$ prorokyj om. $R$ - 32 . posmievanie] a add. $R ;$ na] om. $R-33$. den] $z$ mrtwych add. $R-34$. nerozuměchu) nevrozumyechu $R_{i}$ (nevrozumychu czo prawye§̧e) $R$ ] om. $S$ - 35. to] om. $R$; ǎ̌ pojdieše $k$ Jeruzalemul kdyz pogyde do Jeru§alema a $R$ 36. (A kdyz $v \S l y \S \S y e$ lydy gducze ottaza czo by to bylo) R] om. S 37. Ze] om. $R ;$ jde] gede $R$ - 38. zavola] zwola a $R-39 . A]_{\text {t }} y_{7}$ add.

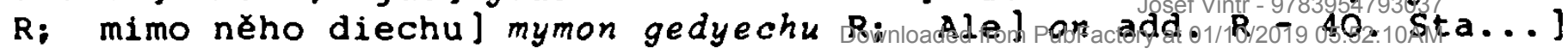


incipit ms. A - 4l. uxini] vczynym $R$; povědĕ] odpowyedye $R, A$; bych] chczy abych R, A - 42. viera (ța add. ms.)] twa add.R - 43 . Inhed pro...] des. A; prozfe] prozrä $R$; i] a $R$; Buoh] boha $R$; visitek] we§jken $\mathrm{R}$; da] wzda R.

XXVII. Peria IV. cinerum - Mt 6,16-2?

$R_{109 a_{2}}$ 16. 〈K〉dyzto sè postfte nerod'te býti jako pokrytci smutni Nebo zamútie sứ tvá Aby znamenáni byli pł̌ed lidmi postn1ci

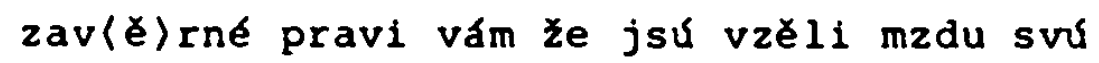

17. Ale ty kdyż póst más umaź hlavu svis i umyj oblič̉j svój

18. aby nebyl lidem poznán postnlkem Ale otci tvému jenz $v$ tajnè jest

A Otec tvój jenž vidr tè $v$ tajnè odplatí tobè

19. Nechovajte sobe zbożle $v$ zemi jesto zhynuje a molové ztocie

a zlodejie vykopajice 1 ukradnu

20. klad'te poklady $v$ nebesiech

kdezto rez ani molové ztocie

Ani zlodejie ukradnu ani vykopaj 1

21. Nebo kde jest poklad tvój tu jest srdce tvé

XXVII.: R, A] deest C, D, S, W; in A desunt vv, 16.-17.

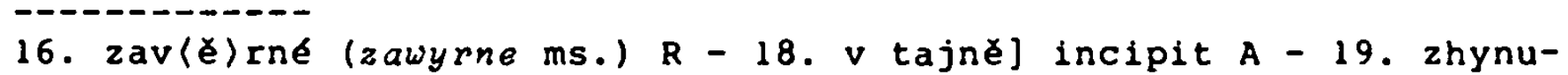
je] rzie A; zlodejle] zlodiegi A; vykopajlcel wykopaiu A - 20. klad'te] wasfe add. A; rez] rzie A; ztotiel zkazie A; zlodéjie ukradnu ani vykopajl] zlodieygi wikopaiu ani vkradne A - 21. tvój tu jest srdce tvé] om. A.

XXVIII. Feria VI. post Quinquagesimam - Mt 5,43-48, 6, 1-4

43. (P) ověděl Jež́s uxedlníkóm svým

slyšli ste Ze jest pověděno starým

Milovati budeś bližnieho svêho a nenávidèti budes nepítele suého

44. Ale já pravím

milujte sué neprátely

a dobł̌ ciňte jesto vás nenávidẹti budu

A proste za protivniky a na hanbu ciniece vám

45. *abyste byli synové otcè vałeho jenz $v$ nebesiech jest jenź slunci svému kấe svietiti na dobré i na zlé... 
46. AC milujete ty jesto vás miluji kterú odplatu máte ano $i$ zevnici cinie

47. Pakli zdravie váááte bratý svéj tolikż A což jiného *cinfte

ano to $i$ zevnici cinie

48. Budete toho dle ustavicni jako otec vás jenż jest ustaviten i na nebi

1. Rozuméjte abyste nexinili odplaty své přè lidmi aby vidéni byli od nich

Jinak odplaty nebudete mieti od otcé svého jenż $v$ nebesiech jest

2. Toho dle když cinf́s almužnu hlasitè necin̆

jako i pokrytci cinie $v$ chrámiech aby *ðěst ot lidi jmè 11

zavěrné pravi vám vzěli sứ mzàu

R $109 b_{1}$

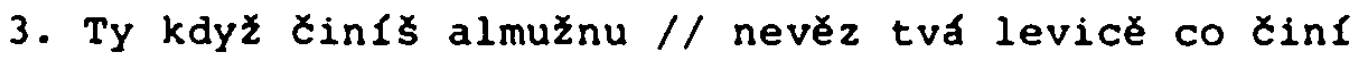
tvá pravicè

4. a bud' almužna tvá $v$ tajnè

A otec tvooj jenž vidi tajnè vrátí tobè

XXVIII.: R] deest $A, C, D, S, W$

45. *abyste (aby\$te aby§te ms.): *dobre (drobre ms.); (et pluit super iustos et iniustos vulgata) deest ms. - 47. *Čninfe (anytyte ms.) - 2. *ð̌st (czy\$t ms.).

XXIX. Sabbato post Quinquagesimam - Mc 6, 47-56

47. $(K\rangle$ dyz biese pozdn 1 vecer biese lodf posty̌d moře a Jež́s stúpi na zemi

48. i vidiese je těžcĕ plovice

nebo vietr biese jim

a ve $c_{t}\langle v\rangle$ rtej ciesti $k \mathrm{nim}$ da po *voder

a chtiese minuti ...

49. Ale mněchu by byl přèlud

1 zvolachu

50. vł̌ickni jenż jej viděchu i smutek jméjechu

a ihned mluvi s nimi a ł́ka

verte nerod'te sè báti ját' jsem

51. I vstúpi $k$ nim $v$ lodf ihned pitsta vietr

a mnohem $v$ sobe viec strachu jmějéchu 
52. ješce neurozuměchu o chlebě nebo biese jejich srce jestè oslepeno

53. A kdyz vynde ploví do zemé Genezareth i pristúpichu

54. A kdyz płistúpichu vyndú $z$ lode inned poznachu jeho

55. A *běhajlce po tom království pocechu nemocn $k$ lodi *mietiti kdyz slyslechu jeho

56. A kdy̌ vejdiese nebo ve vsi nebo u mèstè *kladiechu nemocné na uliciech

1 prosichu jeho Aby toliko rúcha jeho a podolka dotkl

A ktoz jeho dotknieše zdráv bieše

XXIX.: R] deest $A, C, D, S, W$

48. *vode (wyedye ms.) - 49. (at $i l l i$ ut viderunt eum ambulantem super mare vulgata) deest ms.- 55. „běhajlce (byehogycze ms.); *mieŕiti (myczety ms.) - 56. *kladiechu (kradychu ms.).

Xxx. Dominica I. in Quadragesima - Mt 4,1-11

S 142b, 1. Veden jest Ježús u pušti / aby pokứen od diábla byl

$\left(147 b_{1}\right)$ 2. A kdy posti sex ctyrydceti dn 1 a ctyrydceti nocl potor prolačne

3. A pristúpiv diábel vece jemu

Jsi li Syn Bož́ uxiñ aby kamenové tito chlebem byli

4. Jenž odpovědĕ a vece

psáno jest

ne $v$ jednom chlebě ziv jest clověk ale vక̂́m slovem Bozim jesto jde ot ust Božlch

5. Tehdy poje jeho diábel do svatého mésta postavi jej na kostelniem hřebeni 6 . i povědĕ jemu Jsi li syn Božl pust' sè za sè

Nebo psáno jest

Anjelóm svým płikázal jest o tobé aby ce $v$ ruce uchycili aby neurazil nohy o kámen své

7. Odpovědě jemu Ježús

druhé Psáno jest

nepokusił Hospodina Boha tvého

8. Opět pojal jej diábel na vysoku horu velmé

i poká(za) jemu vše královstvie světa

9. i vece jemu

To vకecko tobě dám ał padna "poklonis sě mně

10. Tehdy povědě jemu Ježus 
diáble di

psánoti jest

Hospodina Boha tvého následovaci budes a tomu samému slúziti budes

11. Tehdy osta jeho diábel

A anjeli přistúpiece slúziechu jemu

$X X X .: S, R]$ deest $A, C, D, W$

- - - - - - - - - -

1. u pušti] na pu§§t R; od diábla byl] transp. $312 R-2$. posti sę] transp. $R$; a ttyrydceti] a tolyko\$\$ $R$ - 3. płistúpiv] $k$ nyemu add. $R ;$ jemu] om. $R ;$ kamenové tito] kamenye toto $R ;$ byli] by $R_{0} R-4$. Jenž odpovèdé] y powyedye ihuss $R ; v$ jednom chlebě] gednyem chlebem $R-5$. mésta] y add. $R-6$. pust'] zpu\$ty\$ $\$$; $v$ ruce uchycili] od vraza vchytly $R$; nohy o kámen] transp. $321 \mathrm{R}$; své] twe $\mathrm{R}-7$. nepokusis ]nepoku§§ $R$ : Hospodina Boha] transp. $R$ - 8. Opét] $A$ praem. $\mathrm{R}$; pokáza) (poka ms.)] pokaza R; vš] w\$eczkno R; kralovstvie] toho add. $R$ - 9. *poklonIS(poklo\$ys ms.)] poklony\$\$ $R$ - 10. diáble di] transp. $R$; psánoti jest] om. $R$; Boha] om. $R$ - 11 . anjeli płistúpiece] angele przy§§tupyw\$§ye R.

XXXI. Feria II. post dominicam I. in Quadragesima Mt 25, 31-46

w $3 a$

42. ...

lacen sem byl a vy ste nenakrmili mne

Piti sem chtel nenapojili ste mne

43. Hostem sem byl neschovali ste mne

Nah sem byl nepriodeli ste mne

Nemocen $i v$ zalári neprisli ste ke mnex

44. Tehdy oni vecechu

Hospodine kde smy tè viděli lačného pitie žádajlc

hostem nahym

nebo nemocným $v$ zalałi

neposlužili smy tobe

45. Tehdy odpovie jim a rka

zavěrné pravi vám

Co ste jednomu neucinili $z$ mých mensiech mnè ste neucinili

46. i pójdú ti $v$ oheñ vex̌ny

Ale spravedlni v zivot věxny

XXXI.: $W$ (desunt VV. 31.-41.) ] deest $A, C, D, S, R$ 
XXXII. Feria III. post dominicam I. in Quadragesima Mt $21,10-17$

10. $V$ onom rasi

Kdyż vnide Ježrs do Jeruzalema smúti se vse město

A İkúc

kto jest zde

11. lidé praviechu

zde jest Ježı́ prorok 2 Nazareta Galilee

12. i vnide Jež́s v chrám Božl

1 vymeta vక̌eckno kupujlcé a prodávajlcie $z$ chrámu

a také stoly a lavice kupeie i stolice prodajnie holuby vyvráci

13. i vecé jim

Psáno jest dóm mój dóm modlitevni nazván

vy ste jej ucinili peles lotrovn

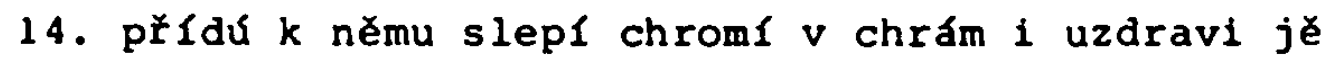

15. Vidiece to kniezata popova i pisari divy jenž ukáa

i déti volajlcie v chrámu i łkúcie

Chvala synu Davidovu

Rozhněvachu se 16. i vecĕchu jemu

slysı že tito zpievaj1

Ježrs odpověde jim

w 3b Ovక̌em nikdy ste nextli že z ust dětiných / a (s)suciech z jednal s chvalu

17. 1 ostavi jĕ vynide ven 2 města do Betanĕ tu uçıe je o královstǔ̌ Božiem

XXXII.: W] deest $A, C, D, S, R: 16$ *zjednal s (zgedlnal\$S ms.)

XXXIII. Feria IV. post dominicam I. in Quadragesima Mt $12,38-50$

38. $V$ onom Cas1

Płistúpili k Ježlłovi plsałi a zákonnlci łkúce Mistre chcemy od tebe znamenie videxti

39. Jenž odpovĕdĕ rka jim

Pokolenie zlé uxinilo zie znamenie hledá

a znamenie nebude mu dáno jedno znamenie Jonásovo proroka

40. Jakoz byl Jonás u briser ryby tłi dni a tłi noci 
Takéz bude Syn clovexi $v$ zemie tri dni a tri noci

41. Muzie Ninivite vstanu $k$ sudu s tiemto pokolenim

i zahubie je

nebo sú pokáni děli na kázanie Jone

i *viece nez Jona tuto

42. králová austri vstane s tiemto rodem

i zahubr jej

Nebo jest pł́sla z krajě zemé slyseti mudrost Salomunovu

i tot' viece nez Salomúnovu tuto

43. kdyz zlý duch vynidiese od clověka

chodl po mieste suchém hledaje pokojer a nenalezne

44. Tehdy die vrátim se $v$ dóm mój odkud sem vyšl

1 płrde nalezne prázden

umeten a krásen

45. Tehdy jde $i$ pojme $z$ sebu sedm duchóv horłlech sebe

i vejduce bydlé tu

1 bude poslednieho ¿lovéka toho skonðénie horł1 pociátka

Takez bude pokolen 1 tomu skaredému

46. Ješe mluviese tehdy $k$ lidu

tot' máti jeho a bratł́le hledáchu jeho mluviti //

w $4 a$ 〈chtiece) $k$ nèmu

47. Pověděl jemu ktos 1

Tot' matka a bratie tva vnè stoji hledajic tebe chtiece mluviti s tobu

48. 1 on odpovědè témuz $i$ vecè která jest máti má a ktełl sú bratie moji

49. I ztáhna ruku na učenniky své 1 vecĕ tot' máti má a bratíie moji

50. Ktếl kolvěk uxinie völi otcè mého jenž jest v nebesiech

ten mój bratr i sestra i máti jest

XXXIII.: $W, A]$ deest $C, D, S, R ;$ in $A$ desunt vv. 40.-41,.48,-49.

38. $V$ onom ¿asi] om. $A$; rkuce] prawiecze $A$; chcemy] chczem A 39. Ika jim] a prawie A; uxinilo zle] i czuzolozne A; hleda] pta $A ;$ jedno znamenie] gedno zna def. A - 40. zemie (zenye ms.) $W$ 41. "viece (wecaye ms.) $W-42$. slyset1) hoc loco incipit denuo ms. A; i tot'] owa A; Salominovu] Salomun A - 44. vratim] wraczu $A$; odkud sem vysell otkedz winid $A$; prázden] prazen $A$; krásen] ukra\$\$len A - 45. sebe i] Sebe a A; bude posledniehol \$u po\$lednie A; 
horsi pociatka] hor\$\$e pocફietye A; Takéz] tak A - 46. k lidu tot'] om. $A_{i}$ (chtiece)] chtyecze $A_{i}$ mluviti (chtiece) $k$ nèmu] chtyecze miuwity gemu A - 47. Pověděl] Tehdi praem. A; jemu ktosi... 48. ... 49. ... 50. ... v nebesiech ten] om. $A$; mój bratr i] ge\$t moy bratr A; máti] matye A.

XXXIV. Feria V. post dominicam I. in Quadragesima $J 8,31-47$

31. $V$ onom Casi

Mluvise Ježš k tym jesto věriechu veñ $k$ těm Zìóm Budete li prébývati u mém kázani věrnè budete uxennici moji

32. a poznate pravdu

a pravda vykupr vy

33. Odpověděchu jemu

Sêmé Abrahamovo smy

nizadnému smy slúzili

a kako ty pravis budete svobodni

34. Odpovĕdè jim Jež́s

Jisté pravi vám

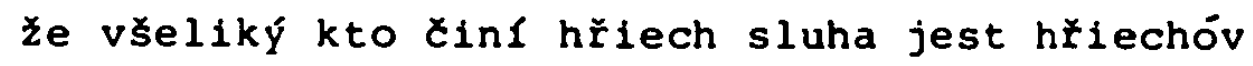

35. Ale služebn $1 k$ nebydlı $v$ domu věxnè

syn býva

36. ał vy Syn vykúpl zavěrné vykúpeni budete

37. vědě że jste synové Abrahamovi

Ale hledate mé zabiti

nebo kázanie mé nejme vás

38. Proto co sem vidél u otcé mého mluvím

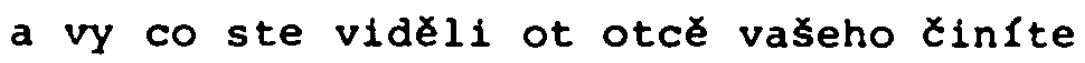

39. Odpovĕděchu i vecĕchu jemu

otec nás Abraham jest

odpovèdè jim Jež́s

Byste synové Abrahamovi byli jeho byste skutky cinili

$w 4 b$ 40. Nyn(1e) / proto hledate mé zabiti

clověka jenž pravdu povèdẻl sem vám nebo slyšel sem od Boha

toho Abraham neucinil

41. vy Cinfte diela otcé suého

Proto pověděchu jemu

My 〈z〉 smilstule nejsmy posli

jednoho otcě mámy Boha 
42. Povědě jim Jež́s

by Buoh otec vấs byl milovali byste mé

Já jsem od Boha přı̌el 1 pošel

ani sem sám od sebe pŭišel Ale on mé poslal

43. proc ł̌ci mej nepoznate

nebo nemózete sly.seti slova mého

44. Vy od otcé diábla ste

a zádost otcè vałeho chcete điniti

Ten je vražedinfk od pocatka by 1

a u pravdě nestál

Nebo pravda nebyla $v$ něm

Kdyż mluviese lez sám od sebe mluviše

Nebo lez jest 1 otec jeho

45. nebo já (kdyz) pravdu mluvím nevě́lte mi

46. Kto $z$ vás bude mé tresktat 1 hriechuov

ac pravdu mluvím Proc vy nevěrite mnè

47. Který jest od Boha slovo Bozie slyšle

XXXIV.: $W, R, A]$ deest $C, D, S$; in $A$ desunt vv. 35.-47.

$31 . \mathrm{V}$ onom Casi] om. $\mathrm{R}, \mathrm{A} ; \mathrm{k}$ tym] $k$ tyem $\mathrm{R}$, om. $A_{i} k$ texm] om. $\mathrm{R}$; přébývati] bydlity $A$, wy bydlyty $\mathrm{R}$; budete] wy add. $\mathrm{R}, \mathrm{A}-32$. pravdu a pravda] wyeru a wyera $\mathrm{R}, \mathrm{A}$; vykupl] o\$wobodi $\mathrm{A}$, o\$oby $\mathrm{R}$ - 33. jemu] mu zydowe $\mathrm{R}$; smy] §me $\mathrm{R}$; niżádnému smy služili] a $a a d-$ nemu $\S l u z y l y \oint m y n y k d y R$, om. A - 34. Otpo] def. A; jim] om. R; vłeliký] kazdy $R$; hłliechóv] hrzyefny $R$ - 35. býva] bydly wyeoznye $R$ - 36. ac] Proto praem. R; vy] om. R; vykupl] wypro\$y $[$ wy $R ; 2 a-$ věrnę] om. $R$; vykúpeni budete] pro\$ty $\$ t e R-37$. jste synove Abrahamovi] transp. $231 \mathrm{R}$; Abrahamovi] abrahama R; nejsme] negme $\$ \$ y e$ $R$ - 38. U] ot $R$ - 39. Odpověděchu] $m u$ add. $R ; i$ vecěchu jemu] $r z k u-$ cze R; Byste] Ste $l_{y} \mathrm{R} ;$ byli] om. R; byste] om. R; Cinilij czyn-

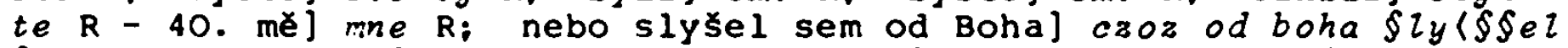
(em) $R_{i}$ neutinil] neczyny $2 \mathrm{R}-41$. jemu] zydowe add. $\mathrm{R}_{i}\langle z\rangle$ smilstvie nejsmy] transp. $312 \mathrm{R} ;$ (z) smilstvie] od Smy [\$twa $R_{i}$ mámy] om. $R-42$. ani sem sám od sebe prisel] om. $R-43$. proć] protoz $R$; ¡̌̉̇i méj] transp. $R_{i}$ méj] me $R_{i}$ nemózete] nemozte $R-44$. zádost] zadoßty $R ;$ vaseho chcete ciniti] Sweta czynyte $R ;$ lez sám od sebe mluvise] Se lzy mluwy $\mathrm{R}_{i}$ i] om. $\mathrm{R}-45$. jaj $k d y z$ add. $\left.\mathrm{R} ; \mathrm{mi}\right] \mathrm{mnye}$ $R-46$. om. $R-47$. Který] Ktoz $R$; slovo Bozie] transp. $R$; slovo] Slowa R.

XXXV. Feria VI. post dominicam I. in Q̇uadragesima $J \quad 5,1-15$

1. $V$ onom casi.

Biese den slauný zidovský

1 jide Jezís do Jeruzalema

2. Nebo jest $v$ Jeruzaleme $z k u s e n i e ~ r y b n f k$ 
jenž menuj 1 Zidové Betsaida

pět ostrovóv v sobè maje

3. u něhozto ležleše mnohost nemocných

slepých chromých

Cekajice hnutie vody

4. Anděl Božl podlé casi vstúplse $v$ rybnlk hnieše vodu

A kto prunl vstupil $v$ rybnlk po hnut 1 vody

W $5 a$ zdráv budı́se kterú // kolvěk nemoci byl svázán

5. bieše tu jeden clověk jenž osm a tłidset let maje $v$ nemoci svéj

6. toho kdyz vidé Ježrs ležie〈c)

pozna jež dlứý cas mèl pověde jemu

chces zdráv býti

7. Odpovědě jemu nemocný

Hospodine člověka nejmám

Kdyz se voda zamutl aby mé pustil $v$ rybnlk

A kdy přldu Ale jiný dřieve vejde

8. vecě jemu Ježŕs

Vstañ a vzdvihni lože své a chod'

9. Inhed $z$ dráv by clověk

Podvih lože své pojide

a bieše den nedělský

10. Povědiechu żidové tomu uzdravenému

sobotat' jest nelzet' tobe zdvihnuti lože

11. Odpověde jim

Jenž mé uzdravil

ten mè přikázal zdvihni lože suê a chod'

12. ...

13. ten uzdravený nevědieše kto jej uzdravil

Jež́s vzdáli sě od lidu ostaviv jej na miesté

14. Potom naleze jej Ježiš v chrámè $i$ vecě jemu tot' jsi jiz zdráv

jiz nerod' hřěiti at' se potem tobě hư̌ nestane

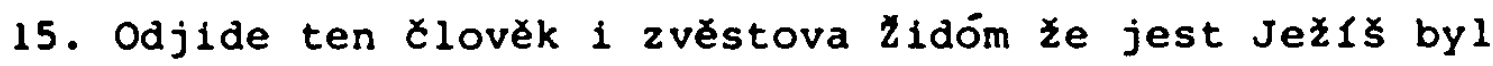
jenz jej uzdravil

$\mathrm{XXXV},:$ W, R] deest $A, C, D, S$

1. $\mathrm{V}$ onom časi] om. $\mathrm{R}-2$. Nebo] $A \mathrm{R}$; zkúsenie (piscina ieruzalem mg.)] waku§\$owany $R_{i}$ jenż] gey add. $R$ - 3. něhożto] tyech $R ;$ mnohost] mno\$twy lydy $R$; nemocných slepych chromých] transp. $231 \mathrm{R}-$ 4. Andé1] Ale praem. $R ;$ Božl] Sedye\$\$e w rybnycze add. R; vstu- 
piłe $v$ rybnik] om. $R ;$ hniese vodu] hny§§e §ye woda R; prvnl] prayedny $R ;$ Kteru] kakuz $R ;$ byl sváán] yat by $[R$ - 5. biese] Tehdy praem. $\left.R_{i} t u\right]$ om. $R_{i}$ jenz] om. $R_{i}$ osm a tridset let maje $v$ nemoci svej] traydczety a o\$\$m let nemoczen bye\$\$e $R-6$. lezie(c) (Lezyez ms.)] lezyecze a R; jez dluhy tas mél] ze geft diuho lezel $R$ - 7. nejmám] $a b y$ add. $R ;$ se] om. $R$; zamutij hne $R_{i}$ aby] om. $R ;$ me pustil] transp. $R ; k d y] k d y z R ; k d y]$ ya add. $R-3$. a vzdvihni] wezmy $R$; své] twe $R$ - 9. Podvih] wzem $R$; své] y add. $R$; biese] $w$ add. $R ;$ nedélsky] om. $R$ - 10. Povédiechu Zidove] proto weczechu $z y d e$ $R ;$ tobě zdvihnuti]ge§t pozdwyhnuty $R ;$ lož̉] tweho add. $R$ - $11 . j i m$ ] nemoczny add. $R_{i}$ mé] ge§t add. $R_{i}$ mé] my ge§t $R_{i}$ zdvihni lože své a chod'] wezma poßtely $w_{w u} d y \S$ pokogem $R-12$. om. W, $R-13$. ten] Ale praem. R; uzdraveny (vzdrawenye ms.)] wzdraweny $R ;$ jej uzdravil] by to ten by 2 Tehdy $R ;$ vzdali] wadalyw R; lidu] [yda R; na] temz add. $R-14$. jej] geho $R ;$ chrame] $\$ \$ k o l e R_{i}$ tot' jsi jiz] $A y$ gyz g\$y R; jiz nerod' hłéliti] nehrzye§\$ wycze R; potem tobe] om. $R$ - 15. Clověk] muz $R$; zvéstova] wzkaza $R_{i}$ jest] to add. $R_{i}$ jenż jej] ge§to geho R.

XXXVI. Sabbato post dominicam I. in Quadragesima Mt $17,1-9$

1. V onom Casi

Pojal Ježs Petra a Jakuba a Jana bratra svého $i$ vede je na horu vysoku velmi

2. i pokry sè prè̃ nimi

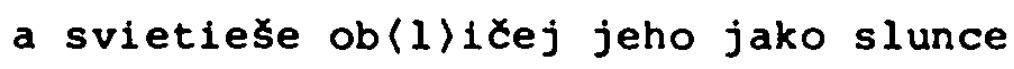

Rucho jeho bllo jako sníh

3. I tot' zjevi se jim Mojzies i Eliás s nim mluvíce

4. 1 povědĕ petr $k$ Ježr కovi

W $5 b$ Hospodine dobro nám zde býti / Chces 11 uxiñmy sobè tri stany tobe jeden a Mojziesovi jeden a Eliásovi jeden

5. a tak s nfm mluviece

Tot' svêtly oblak obstúpi jè

$i$ tot' hlas z oblaku a łka

Tot' jest syn mój mily jehoz mnè dobł̌e uhovell toho posluchajte

6. A slyక̌̌v̌̌e učenníci báchu sĕ velmi padechu na suú tvă

7. 1 płistúpi Ježł doťe se jich $i$ povědĕ jim vstañte nerod'te sè báti

8. Podvižechu oxi své nižáného neviděchu jedno Boha

9. A słedse s hory Vece jim Ježs a łka

Nizáanému nepravte vidénie tohoto jeliz syn clovexi $z$ mrtvych vstane 
1. $V$ onom Casi] om. $R$; Pojal] Poge $R$; vysoku velmi] we $I_{m y}$ we ${ }^{y k u}$ $\mathrm{R}$ - 2. pł̌d nimi] gych $\mathrm{R}$; svietiese] o\$wyetye $\$ \oint_{e} \mathrm{R}-3$. i tot'] $A y$ $R ;$ i] a $R-5$. $S \mathrm{nim}$ (m. rec. in rasura et iterum mg.)) gedno $R_{\text {; }}$ tot'] Ay $R_{;}$i tot'] wecze $R_{\text {; }}$ oblaku] oblaka $R_{i}$ a] om. $R_{;}$syn mój] transp. R; mnè dobł̌ uhověl] \$§em zwoly §obye $R_{i}$ tohol geho $R$ - 6. velmi padechu na svi tvał] a padnu w\$\$yczkny $R$ - 7. nerod'te se bati] neboyte \$ye $\mathrm{R}-8$. Podvižechu] pozdwyh\$ye $\mathrm{R}$; své] om. $\mathrm{R}$; nižadného] y $\mathrm{R}$; neviděchu] gednoho add. R; Boha]gezy\$ye R - 9 . š̌edŠe] Schodyecze R; Vecě] przykaza R; Nizadnému nepravte] neprawte nykomemu $\mathrm{R}$; tohoto] toho $\mathrm{R} ; \mathrm{z}$ mrtvích] om. R.

XXXVII. Dominica II. in Quadragesima - Mt 15,21-28

S 142b, 21. Vyšed Ježuš 1 pł́lde do vlasti Tyri a sidona

$\left(147 b_{1}\right)$ 22. a $v$ tu dobu Zena $z$ Kanenea voláse $z$ těch "vlast క̌edకł ł łúci

Smiluj sè nade mnu Hospodine synu Daviduov dci má běsem zle *zajata jest

23. Jenž neotpovède 1 slova

A płistúpiece ucennici prosiechu za ni źkuce zprost' $j 1$ nebot' volá po nás

24. Ale on otpověde jim

Nejsem poslán jedno $k$ ovcem jenž zhynuly sư domu

Israhelova

25. Tehdy ona pŕijide následova jeho ŕkúci

Hospodine zpomoz mi

26. Jenže otpovědð /

S $142 b_{2}$ $\left(147 b_{2}\right)$

Nenie dobro vzieti chléb synuov 1 dáti psuom

27. Ale on vece

〈jiste Hospodine〉

Anebo 1 šeñátka uźrvajl drobetkóv jež letie se stolóv pánóv jich

28. Tehdy otpovědě Ježús jéj

$\delta$ Żeno veliká jest viera tvá bud' tobě jakož chces

i uzdravena jest dci jejie toho casu

XXXVII.: $S, R, W]$ deest $A, C, D$

21. Vy§ed ] $V$ onom cza\$\$y praem. W; vlast1] mye\$ta R; a Sidona ] \$ydonys $W-22$; $v$ tu dobu] tehdy $W ; z$ J om. $W ;$ voláse $z$ těch *vlastI (w\$a\$ty ms.) vyకedకi ] transp. 23451 W, R; vysedకi Íkuci] wy\$§edczy a rzkuczy gemu R; Hospodine J om. W; dcil om. R; zle ] om. W; *zajata (gayata ms.) ] yata R, obklyczena W; jest J om. W - 23. neotpovêdę ] gey add. R; i] zadneho W; uXennicil geho add. W; prosiechu ] geho add. W; za ni J om. W, a add. R, W; zprost'] zpu\$t W 24. jim ] om. W, a rzka add. W, $R$; ovcem jenz zhynuly l ouczyem kte-

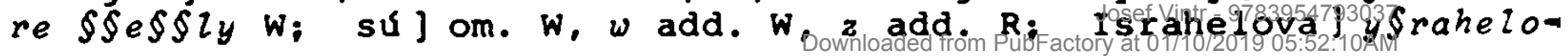


$w u w-25$. ona] om. $W_{i}$ płijide] y add. $R ;$ následova] na\$\$ledowat Wi jeho] a add. W, $R$; Ikuci] rakucz $R$ - 26. Jenž] Genz W, $R$; otpovede] a rzka add. W; dobro] dobre W; synuov] synow $\$ k y R, \$ y-$ nom W; 1] a R; psuom] gy\$ty add. W - 27. Ale] Tehdy $W_{;}$vece] powyedye $\mathrm{W}$; (GyStie ho\$podyne) $\mathrm{W}$ ] om. $\mathrm{S}, \mathrm{R}$; Anebo] nebo $\mathrm{W}, \mathrm{R}_{\mathrm{j}}$ i] om. W; uzivaji] gedye W, zadagy (zadaty ms.) $R_{k}$ drobetkóv jez letie] drobtow genz padagy $R$, \$trzyedu ktere padagy $W_{;}$se] om. W; stolóv] Stola W; pánóv jich] transp. W-28. jéj] gye $R$, gye a rzka W; Jezus jej] transp. R; bud'] \$tan $\$ y e W_{i}$ jejie] od add. W.

XXXVIII. Feria II. post dominicam II. in Quadragesima J $8,21-29$

w $6 \mathrm{a}$

21. V onom Casi

Pověděl Jež́s učenníkóm a sboróm žldovským

Já chozi a vy hledáte mne

zemřete u vasiech hriesich

Kam já jdu vy nemózete jlti

22. Povědiechu jemu Zidé

zda sě sám zabie

nebo praví kam já jdu vy nemóžete płijlti

23. $i$ pověde jim

jste zdolu ale já sem shóry

vy ste $s$ tohoto suéta

já nejsem s tohoto suěta

24. Proto sem povẽdēl vám nebo zemfete u vašiech hřiešiech ješe nevěrite že já jsem umřete $v$ hr̈lechu vasem

25. Tehdy vecěchu jemu

Kto jsi ty

več jim Ježrs

Pođátek jenž mluvím vám

26. Mnoho vám mám o vás mluviti a súditi

Ale kto mé jest poslal spravedlný jest

i já co sem slysal od něho to mluvím na suétu

27. i nepoznachu ze jim Otcě Y̌ekl Boha

28. 1 pověde jim Ježrs

Kdyz povýsite syna clověrieho

tehdy poznáte że sem já

od sebe sám ničse netinim

Ale jakoz me otec nauril tak mluvim

29. a jenz mé poslal se mnu jest

a neostavil mè saméno 
XXXVIII.: $W, R]$ deest $A, C, D, S$

21. V onom Casi] om. $R_{;}$mne] y add. $R_{i} j a ́$ ] om. $R_{i} j$ du] a add. $R_{i}$ nemóžte] nemozte $R$ - 22. jemu] k nyemu y $k$ Sobye $R ;$ íidé] om. $R$; nebo] ze R; nemóžete] nemozte $\mathrm{R}-23$. jim] wy add. $\mathrm{R} ;$ svétal ale add. $R-24$. sem povědĕl] powyedyech $R ;$ nebol om. $R_{i}$ ješce nevěIfte] acz \$te newyerzyly $R_{;} j a$ jsem] transp. $R_{i}$ umřete $v$ hriechu vašem] om. $R-25$. vecéchu] rzeczechu $R$; Kto jsi ty] transp. 312 $R_{i}$ vecé] powyedye $R_{i}$ Jež́ş] om. $R_{i}$ mluvím] $m[u w y R-26$. vám] om. $R_{;}$o] om. $R_{;}$mluviti] wymluwyty $R_{;}$a] $y R_{i}$ spravediný] prawy $\left.R_{i} y\right]$ om. $R_{i}$ na] om. $R-27$. i] $A R$; rekl] prawye§\$ye $R-28$. sem játransp. $R ;$ sám] om. $R$; nið̌se nexinlm] neczynyl nycz $R_{i}$ jakož] yakz $R_{i}$ mé Otec nautill transp. $231 \mathrm{R}-29$. neostavil mě] neo\$tawy mne R; *libo (bylo ms.)] iybo R; cinfm vezdy] czyny wady R.

XXXIX. Feria III. post dominicam II. in Quadragesima Mt 23,1-12

1. V onom casi

w 6b Mluvil Ježis k zástupóm / a k uCennikóm sv̛̛́m 2, a łka na stolici Mojžlsover seděli jsú pisaři a zákonnici

3. Všecko což kolvěk kázi vám chovajte a đ̌iñte Ale podlé jejich skutkóv nerod'te ciniti Nebo pravie a nečinie

4. Vzdvihaji bř̀mena neskrouná i kladú na ramena lidská Ale prstem suým nerodie dotknuti jich

5. vš̌ckna svá diela ěinie aby viděni byli zdvihaj1 podolky své

a zprostierajl podrahy

6. miluj1 prvnie miesta na večeřiech a prunie stolicè u modlách

7. i navšcievanie mé $v$ trhu

i nazván od lidí Mistie

8. Ale vy nerod'te nazievati mistie nebot' jest jedinký mistr vás

Ale *useckni ste bratie

9. a otce nerod'te sobé nazievati na zemi Jeden jest otec vás jenž $v$ nebesiech jest

10. ani se nazývajte mistri nebo mistr vás jediný jest kristus

11. jenž $z$ vás vêtక̣̌ jest bude služebnik vás

12. nebo kto se povýs bude ponizen

A kto sè poniż bude povýsen 
XXXIX.: W, R] deest $A, C, D, S$

1. $V$ onom Casi] om. $R$ - 2. p[sar̂i] py \$arzye $R$ - 3. Vక̌ecko] proto praem. R; kolvěk] om. R; kazl] powyedye R; podlé jejich skutkóv] po gych $R$; pravie a neuxinie] powyedye a nevczenye $R$ - 4 . Vzdvihaj1 břmena] wazugy brzyemye R; i] a R; prstem svým] transp.

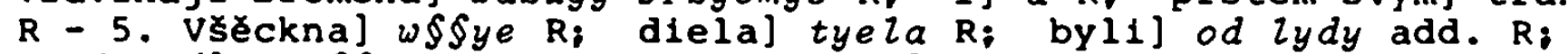
zdvihajl] Roz\$\$yrzugy R; podolky sve] transp. R; zprostierajl] proßtyeragy $R$ - 6. prunie] prone $R ;$ na veðerilech... 7. ...Mistre] om. $R-8$. nazievati mistie] nazwany byty my\$trzy $R$; nebot'] om. $R$; jest jedinky] transp. $R_{i}$ mistr] ge\$t add. R; Ale] om. R; "vङéckni (w\$yeczny ms.) ste bratłie] wifyczkny zagy\$te wy bratrzye Ste R - 9. sobę]wam R; na zemi] om. R; Jeden jest] gedynky zagy $\$-$ te ge\$t $R$; nebesiech] neby $R$ - 10. se nazyvajte] transp. $R ;$ nebo] nebot $R ;$ jediny] geden $R$ - 11. jenz $z$ vás vétsijom. $R:$ jest] kto

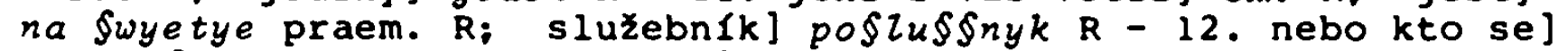
Pakly $\$ e k t o R ;$ bude ponfzen] transp. $R ;$ bude povýsen] transp. $R$.

XL. Feria IV. post dominicam II. in Quadragesima Mt 20,17-28

17. V onom Casi

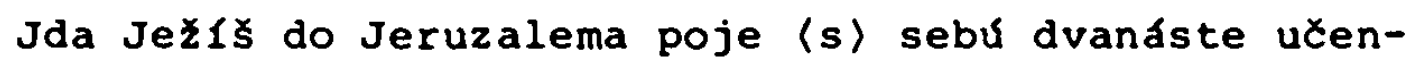
nIkóv svych $v$ tajemstvie 1 povědĕ jim

18. Tot' jdem do Jeruzalema

a Syn Łlověx 1 zrazen bude kniezatóm popovým 1 starostám 1 prsaróm

1 odsudi jej na smrt

19. 1 zradie jej lidu na posmievanie na bicovánie 1 na uk izovánie

a tret 1 den vstane

20. Tehdy pristúpi // k nèmu matka synóv zebedei s syny svymi

nazievajlci a prosieci nextso u ñeho

21. 1 on vece $j 1$

Co chces

povědě jemu

rci aby sedẽli tato dva syny má jeden na pravici a druhý na levici v králoustuí tvém

22. Odpovědé jim Jeził a łka

Neviete co prosite

Móżete 11 piti kalich jenź já sem pil

Pověděchu jemu mužem

23. 1 povědĕ jim 
Kalich mój budete piti

Ale seděti na pravici a na levici mej

nenie mé dáti vám

Ale jimžto připraveno od otcě mého

24. Uslyšrvèe to deset nenávidẹchu $\langle n\rangle a$ dví bratru

25. Ježrs zavolav jich $k$ sobe $I$ vecé $j i m$

vite li ze kniežata lidská panují nad nimi

a jesto najmocnějšl jsu vejvodie nad nimi

26. Ne tak bude mezi vámi

Ale kto kolvěk mezi vámi věcšl *chce býti

bud' vás sluha

27. A kto koli chce mezi vámi přědni býti bude sluha vás

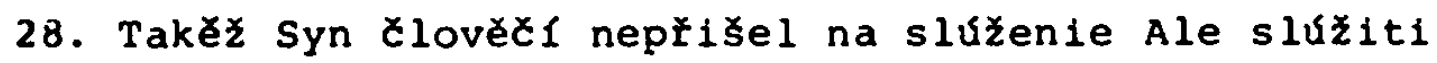
a dáti duši svú za vykúpenie mnohé

XL.: $W, R]$ deest $A, C, D, S$

17. $\mathrm{V}$ onom Casi] om. $\mathrm{R} ;\langle\mathrm{s}\rangle] z \mathrm{R} ; \mathrm{V}$ tajemstvie] om. $\mathrm{R}-18$. Tot' jdem] Ay dyemy $R_{i} i$ starostám] om. $\left.R_{i} i\right]$ a $R_{i} i$ odsudil a potupye R - 19. zradiel dadyet R; posmievanie] obyedu R; ukizovánie] krzyzowanye $\mathrm{R}$; den] $z$ mrtwych add. $\mathrm{R}-20$. Tehdy] $W$ tu dobu $\mathrm{R}$; matka] matye R; Zebedei s syny svými nazievajlcil zebedowych a $\$$ Synoma §wyma zadagyczy $R$; $u$ neho] na nyem $R-21$. on] om. $R$; jemu rci] ona kaz $R_{i}$ sedéli] Sedyela $R_{i}$ dva] om. $R ;$ královstul tvém] transp. $\mathrm{R}-22$. Odpovědě] Ale praem. $\mathrm{R} ;$ Móžete] Nemozete $\mathrm{R}$; piti] tyz add. R; sem pil] budu pyty R; Povĕděchu... 23. ...piti] om. $R_{i}$ a] any $R_{i}$ méj] om. $R_{i}$ jimžto pripraveno od otcé mého] gemzto vczynyeno ge§t otczem mym $R-24 .(n) a]$ om. $R-25$. Ježls] Ale praem. R; zavolav] zawola $\mathrm{R}$; vece] kaze $\mathrm{R}$; VIte li ze] $A$ wedly gye R; najmocnéjకl jsu] mocznye\$\$y $R-26$. ktol om. $R ;$ ko1i] kolywyek R; mezi vámi] bude chtyety R; «chce (a chcze m. rec. mg. rub.l) om. $R ;$ bud'] bude $R_{i}$ vás sluhal transp. $R$, pano\$§ye add. $R-28$. 2a] na $R$; mnohé] mnohym $R$.

XLI. Feria V. post dominicam II. in Quadragesima $J 5,30-47$

30. $V$ onom Casi

Pověděl Jež́s uCennfkơm svým A sboróm židovským Nemohu já sám od sebe ničse Ciniti

ale jakěz sly̌́lm sudim

Ale súd mój pravý jest

nebo nehledaji vóle méj

Ale vóle jeho jenž mĕ poslal

31. AC jă suẹdečstuie dávám sám od sebe 
suědečstuie mé nenie pravé

32. Jiný / jest jenž suědečstvie dává ode mne

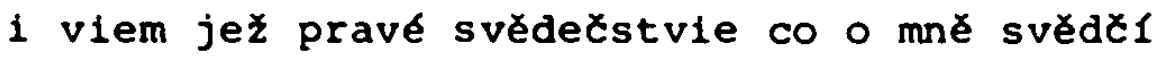

33. vy ste poslali $k$ Janovi

1 pověděl jest suědeð̌stuie pravé

34. Ale já neberu suědečstvie od Jana clověka

Ale já to pravi abyste vy spaseni byli

35. On biese světlost hořiecie a sviecějlcie

Nebo vy ste chtéli ste se radovati na cas $v$ jeho světlosti

36. Ale já mám věxie Jana

Nebo skutek jenž $m i$ dal otec abych skonal to

ta diela jenž já đ̌inı́m svědečstvie povědie o mnĕ

37. Nebo mé Otec poslal otec on suědečstvie dává o mnè

Nebo ste hlasu jeho nikdy neslyseli

Ani oblicéje jeho viděli

38. A slova jeho nejmáte $v$ sobé bydléce

nebo jehoz on poslal tomu vy neverite

39. zvězte pismo

v nèmžto vy mńte zivot věxný jmieti

a ti su jenż svědečstvie dadie o mně

40. Avsak nechcete přijlti ke mnĕ abyste méli zilvot vě̉ný

41. Oslavenie od lidu nevezmu

42. Ale poznal sem vy nebo milosti Božiej nejmáte $v$ sobé

43. já płíłel ve jmè otcě mého a nepłijali ste mne Ac jiný pł́lde $v$ jeho jme toho píljmete

44. kako mózete věriti nebo chválu narữno bérete i chvála jenż od samého Boha jest nehledáte

45. Nerod'te věriti bych já omluvil vy u otcé mého jest kto vy omluvi

Mojžies $v$ něho vy úfáte

46. AC byste věili Mojžlsovi snad byste 1 mnĕ věrili //

w $8 a$ Nebo on o mnè psal

47. Pakli plsmu nevělte jeho

kako hcete mým slovóm věriti

XLI.: W, R] deest $A, C, D, S$

30. $V$ onom Casi] om. $R_{i}$ sboróm židovským] §boru zydow§kemu $R ;$ sám od sebe nið̌se] transp. $4123 \mathrm{R}$; jakéz slyş́m sudím Ale] yakoz $\$ \$ e m$

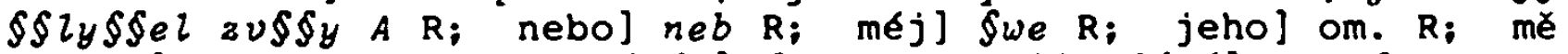
poslal] transp. $R$ - 31. dávám] dawagy $R-32$. dává] wywede $R ;$ ode 
mne 1 viem] om. $R ;$ jež] genz $R ;$ pravé] ge§t add. $R ;$ o mnĕ svèd¿l] transp. $312 \mathrm{R}-33$. pravé] prawdy $\mathrm{R}-34$. od] $v \mathrm{R}$; ‘lověka] om. $R ; j a]$ om. $R ; \quad v y$ ] om. $R$ - 35. světlost] Zucerna $R ;$ a sviecěj[cie] na §wyetye $R ;$ Nebo vy ste] om. $R, a$ add. $R ;$ se radovati na Cas] transp. $3421 \mathrm{R} ; \mathrm{v}$ jeho] $k$ gemu $\mathrm{R}-36$. věðie] §wyedecztwye wyecz\$\$e R; skutek] $\{k u t k y \mathrm{R}$; $\mathrm{mi}]$ ge§t add. R; skonal to] czyny $2 \mathrm{R}$; svèdexstvie povĕdie o mnè] \$wyedcze za mnye $\mathrm{R}-37$. Nebo mé... dává o mné] om. R; obliðejje jehol oblyczege $R$ - 38. nebo] To$m u \quad R_{i}$ tomu vy] om. $R-39$. zvezzte plsmo $v$ némžto vy mnlte] w \$wate płanye nebo mozte $w$ nych $\mathrm{R} ;$ jenz] za mye add. $\mathrm{R}$; dadie o mnej czynye $R$ - 40. nechcete] om. $R ;$ abyste] aby $R$ - 41 . lidu nevezmu] $l_{y}-$ dy neberu $R$ - 42. poznal sem] pozywagy $R-43$. já] \$\$em add. R: mého] Sweho $R$ - 44. kako] Jako wy $R$; narúznol narozeneho $R_{;} i$ chvála... nehledáte] om. $R$ - 45. věriti] mnyety $R_{;}$mého] om. $R_{;}$jest] ge§to $\mathrm{R}$; vy] om. $\mathrm{R}$; něho] nyeho\$\$to $\mathrm{R}-46$. AĆ byste] aby\$te $\mathrm{R}$; mnè věrili] mne newyerzyly $R$; Nebol om. $R ;$ on] ge§t add. $R-47$. kako] kakzz R; slovóm] Slowam R.

XLII. Feria VI. post dominicam II. in Quadragesima Mt $21,33-46$

W 38a 33. V onom Casi

Pověděl Ježí uČennikōm svým a zâstupóm židovským Clověk jeden bieše hospodắem

jenž udělal vinnicè

a týnem ohradil ji

a ucinil v niej lisice

a udělal prostř̀d nie *vězi

i usadil v niej dělniky

a sám po púti šl jest

34. Tehdy kdyz cas ovoce pí ijide

posla sluhy své $k$ * dělníkóm aby vzali ovocè jeho

35. Tehdy délnici popadse sluhy jeho

jedny zbichu

a druhé zabichu

a nékteré ukamenovachu

36. Tehdy opèt jiné sluhy posla viece prunich ani jim téz uéinichu

37. Tehdy najposledy posla $k$ nim syna suého a ŕka stydéti se budú syna mého

38. Tehdy dělníci *vidúce syna vecěchu mezi sebú Ted jest dietě pod'te zablmy jej budem mieti dědicstvo jeho

39. Tehdy popadxe jej vyvržechu přxd vinnici i zabichu 40. Nuž když prijide pán téj vinnicè 
co uxin 1 dělnikóm tĕm

W $38 \mathrm{~b}$

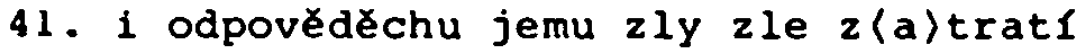

a vinnici / svu dá jiným jenž mu vráti ovocĕ $v$ času svém

42. 1 odpověde jim Ježrs

$\chi_{i}$ nectli jste u pismé

kámen jenž sư zavrhli ten ư̌inèn jest $v$ hlavu uhla

Od Hospodina stalo se to a jest dimo $v$ oti nasi

43. Proto pravím vám

protože odjato bude královstvie Božie

a bude dáno lidu jinému plodit svému ovocé jeho

44. a ktož na ten kámen spadne zety̌n bude

A na kohoz on spadne zetye jeho

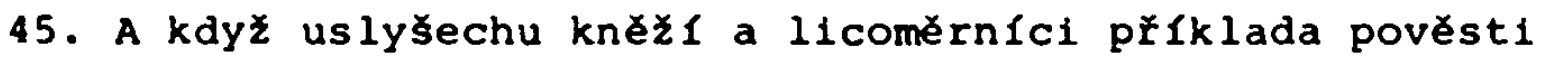
jeho

srozuméchu že to od nich pravi

46. Tehdy hledachu popadnúti jeho 1 báchu se jeho zástupóv nebo jako proroka jmějlchu jeho

XLII.: W (inter lectiones Propril sanctorum)] deest A, C, D, S, R 33. "véż (wezy ms.) - 34. * đělnlkóm (dyelnyekom ms.) - 38. "vidúce (wywedicaye $\mathrm{ms}$. )

XLIII. Dominica III. in Quadragesima - L 11,14-28

S $142 b_{2}$ 14. Bieše Ježus chtieše vyhnati běsa a ten bieš nĕmý

$\left(147 b_{2}\right) \quad$ A kdy vyhna bès mluviese nĕmic

1 diviese sè sbor

15. Nětê̌ mezi nimi dĕchu

Moc1 Beelzebub kniežte běsového vyhon 1 běsy

16. 〈Ani vakušujłce jeho znamenie z nebe hledáchu od nĕho)

17. Ale on kdyz pozna jich myslenie pověde jim

každé královstvie $v$ sobè zdělené opustr

A duom na duom spadne

18. Pakli jest Satanas sám $v$ sobě rozdělen jest

kakos stane kralovstule jeho

Ze pravite mè diáblovu mocl diábly vyhoniti

19. Pakli ja toho moci vyhoňuj1

A synové vası $v$ cl budu moc vypuzet 1

Toho dle ont sudce budu vase

20. Proto ą já Bož 1 ruku vyháněji běsy 
s ziskem príde u vy královstvo Božie

21. Tehdy že silný oděnec střeže předsieni sur u pokoji jest to coz má v domu

22. Pakli silnejsł jeho pride i svitezr jej pobére oděnie jeho a kơ̌ist v'̌eho domu pobére

23. kto nenie se mnu protiv mnĕ jest

A jenže nesbierá se mứ dělı

24. A kdy̌ nexistý duch vynde od clověka chodl po miestech

hledaje pokoje a nenalezna i povie

Navráci sè $v$ svój duom otkavad sem vyšel

25. A kdyz sè vráti naleze umeten i ukráslen

26. i jde tehdy i pojme s sebú sedm duchuov sebe horsfch

S $143 a_{1}$

$\left(148 a_{1}\right)$

A vejduce // i chodie tu

i bývajl skoncenie toho đlověka horšie pođetie

27. Stalo sè jest kdy̌ to povĕdĕ

vysokým hlasem Jedna Žena łekla k Ježłovi

Blažený żivot jenž tè nosil a prsy jenż tè krmily

28. Tehdy on pověder

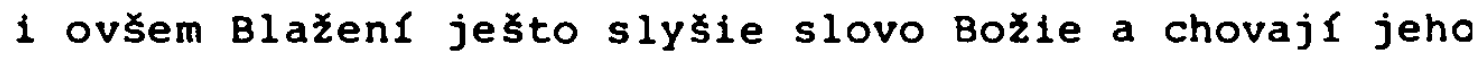

XLIII.: S, R, W] deest A, C, D

14. Bieše] $U$ onom czya\$\$y praem. W; Ježús] a add. R; vyhnati běsa] dyabla wypudyty $W$; běsa] bye $\$ \$ R ; A]$ om. R; kdy] kdyz W, R;

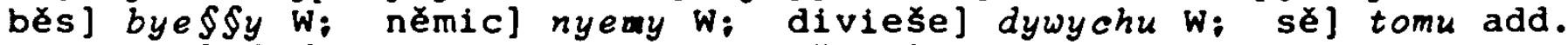
$R ; 2$ bor] Zyde $W-15$. mezi nimi děchu] mezy nymy prawyechu $R, z$ nych weczyechu W; Beelzebub kniezete] transp. W; Beelzebub] belzebubowu R, be [zebubowa W: běsového] dyabe [\$\$keho W: vyhonI] wyhanye $R_{i}$ bésy] dyably $\mathrm{w}-16$. (Any wzkugfugycze geho znamenye $z$ nebe hledachu od nyeho) R] om. S, Tehdy ony czyekachu znamenye z nebe\$ Otazachu geho W - 17. jim] gemu R; kazdě] W\$\$yelyke W; zdělené] dye lene W, rozdyeleno $\mathrm{R}$; spadne] padne $\mathrm{W}, \mathrm{R}-18$. jest Satanas] transp. W, Sathana\$\$ R; jest] om. W: kakos] yako tehdy $R ;$ ze] nebo wy $W:$ mé diáblova moci] be lzebubem knyzatem $W:$ diably] bye$\$ \$ y$ R; vyhoniti] wyhonym $W$, wyhonycze $R$ - 19. Pakli ja toho moci vyhoňuji A] om. W: toho mocl vyhonuji] moczy dyablowu bye\$\$y wyhonym R; $v$ ¿l budu moc vypuzeti] w czyem wywrhu $\mathrm{W}$, czy moczy budu wyhonyety $\mathrm{R}$; Toho dle] y pro tu $\mathrm{W}$; sudce budu vaš] transp. $312 \mathrm{R}$,

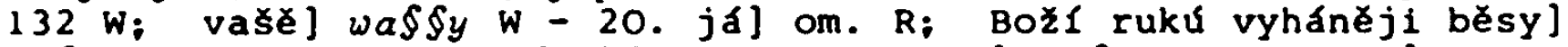
pr\$tem bozym wyhanym dyably $W_{;}$s ziskem] ge§tye $R ;$ u vy] na wy $W$, na wa\$§ R; královstvo] kraloußtwye $R, W-21$. Tehdy] $A R$, om. W: ze] kdyzW, R: stłeže predsieni svu u pokoji] §trzyzye \$tatku Sweho $\$$ pokogem $W_{;}$jest] $w \$ \$ y c z k 0$ add. $W_{i}$ tol om. $R_{i} v$ domu] om. $w-$ 22. i svitězl] przyemoz $W$; jej] nad nym $R$; pobełe] w\$\$yeczkno W: odénie jeho] transp. W; a kơ̌ist vక̌eho domu pobéłe] y czoz ma rozdye ly $\mathrm{W}-23$. jenže] genz $\mathrm{W}, k t o z \mathrm{R}-24$. A] om. W; miestech] rozlycznye add. W: pokoje a nenaleznal odpoczywanye y nenalezne $W$; 
i] om. W; povie] gde R; Navráci] nawraty R, Nawratym W; svōj] moy W; svój duom] transp. W; otkavad] odkowad W, odkad R; sem] by [ R

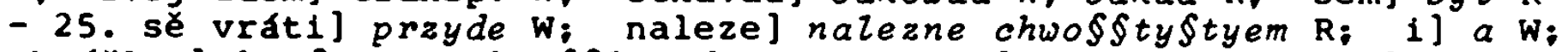

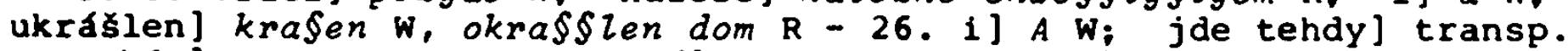
$W$; tehdy] om. R; pojme s sebu] praygme $W$; sedm] gynych add. $W ;$ sebe horšfch] transp. W; sebe] z\$ebu R; 1] om. W; bývaj1] bywa W, R; potetie] poczyatka $W, R-27$. jest] jenz $W$, om. $R$; Jedna] ktera $g \$ \$_{y}$

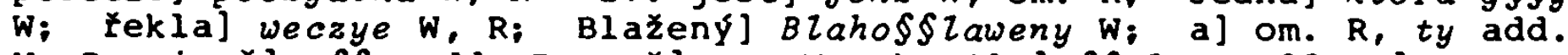

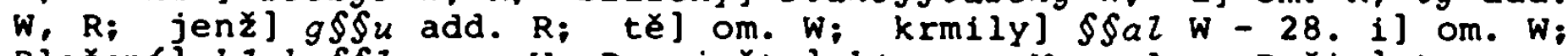
Blažen 1 ] blaho§̧laweny $W, R_{;}$jesto] kterzye $W_{;}$slovo Božle] transD. W; chovajl] chlow)aly R.

XLIV. Feria II. post dominicam III. in Quadragesima $L 4,23-30$

w $8 b$ 23. V onom Casi

pověděli zákonnf́ci k Jež́sovi

Co smy slyšeli div v Kafarnaum ueiñ tež i zde〈u〉 vlasti v svéj

24. Povědě jim

zavěrné pravi vám

že ijeden prorok vzácen nenie $v$ zemi svéj

25. za pravdu pravi vám

Mnohé vdovy byly za dni Eliásových v Izraheli

kdyz bylo zavièlo nebe Tri léta a sest Mésícóv

kdyz biese hlad veliký $v$ zemi vకelikéj

26. 1 do nižádnéj jinéj zemè poslán jest Heliaš

jedno do Sarepty Sidona $k$ zenè vdova

27. A mnozl malomocn 1 byli $v$ Izraheli pod Helizeem prorokem a nikte $z$ nich nebyl uzdraven jedno Naaman Syrus

28. I biechu naplnéni hněvu u modle jich to slyšiece

29. I vstachu vypudichu jej $z$ města

$i$ vedechu jeho až na samy vrch hory

na němžto mèsto jejich bieše ustaveno

aby stř̌hli jeho

30. ale on mezi nimi uprostzed chodiese //

XLIV.: $W, R]$ deest $A, C, D, S$

23. $V$ onom Casi] om. $R_{i}$ div] dywa $R_{i}$ tež 1 zde] zde tez $R_{i}\langle u\rangle$ vlasti (wla\$ty ms.) v svej] $w$ \$wey wla\$ty $R-24$. jim] ihüs add. R; zavěrné] czele R; zemi svéj] transp. R - 25. Mnohé vdovy byly za dni Eliásových (dnych add. ms.) v Izraheli] mnoho vdov bye\$\$ye za elya\$\$ye $R_{i}$ bylo] \$ye $R_{i}$ nebe] nebo $R_{i}$ když $A R_{i}$ vSelikéj] w\$\$elyke $R-26$. $i$ do nižádnéj jinéj zemé posián jest] Aw\$\$ak k nyeterez $\$$ nych neby 2 poßzan $R_{i}$ Sidona $k$ ] \$ydony $k e R_{i}$ zené] Om. $R-27:$ mozl malomocn $[$ byli] mnoho nuznych by lo $R$; pod Helizeem prorokem a] 
om. R: nikte $z$ nich nebyl uzdraven] $z$ nych ze nebyl ygeden zdraw $R$ - 28. naplněni hněvu u modle jich] w\$ychny w modle nap lnyeny nyemu R - 29. vstachu] y add. $R$; vypudichu jej] wywedu geho wen $R ;$ vedechu jeho] wedu gey $R_{i}$ samý vrch] \$\$ame kray $R_{i}$ nèmżo] nyezto $R_{i}$ jejich] om. $R_{i}$ biese ustaveno] transp. $R-30$. uprostięd] proStrayed R.

XLV. Feria III. post dominicam III. in Quadragesima Mt $18,15-22$

W 9a 15. V onom Casi

Hledě Jež́s na své uxenniky

Pověde Simoniovi Petrovi

AC provini protiv tobè bratr tvój

di a treskci jej mezi sebu a jim

poslechne $1 i$ tebe $z$ lskal s bratra tuého

16. Pakli tebe neposlechne pojmi k sobé jednoho nebo dva aby mezi duěma nebo tŕmi stálo všecko slovo

17. Pakli neslyş jich pověz kostelu

pakli kostela neposlechne bud' tobé jako zjevný hìieš$n \in k$

18. Zavěrné pravím vám

Co koli sviežete na zemi bude svázáno $v$ nebi

(A což rozviežete na zemi bude rozvázáno i na nebì)

19. Opět pravi vám

AC $z$ vás dua povolé na zemi

ze vł̌elikéj věci co kolvěk budú prositi stane sĕ jim ot otcè mého jenż jest $v$ nebesiech

20. Nebo kdež dua Nebo trie sberú sè u mé jmè

tu sem já mezi nimi

21. Tehdy přistúpi petr $k$ němu i vecè

Hospodine kolikrát shřexí ve mnè bratr mój i odpustím jemu

az sedmkrát

22. Odpovědě jemu Jež́s

Neřku tobè Petře sedmkrát ale sedmdesátkrát

XLV.: $W, R]$ deest $A, C, D, S$

15. V onom Casi] om. R; Petrovi AC] om. R; provini protiv] prowyny $\{\langle y\rangle$ $\$ y e k R ;$ jej mezi] geho $\$ a m$ przyed R; poslechne li tebe] Bude ly tye v\$ly\$\$al R: tvého] \$weho $R$ - 16. tebe neposlechne] nev\$ly $\$ \$ y$ tebe $\mathrm{R}_{i}$ mezi dverma] we dwu $\mathrm{R}_{i}$ trmi] we trayech $\mathrm{R}$, tyech add.

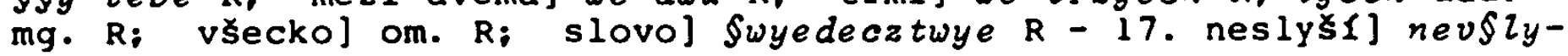


\$\$ R; kostelu pakli kostela neposlechne] czyerkwy paklyt nev\$ly $\$ y$ czerkwe R - 18. zavěrné pravím] zagyjte prawy R; Co koli] czoz kolywyek $R_{i} v$ ] i na $R_{i}$ (A CzOz rozwyezete na zemy bude rozwazano $y$ na neby) R] om. W-19. ač $z$ vás dva] $A$ czoz pakly dwa mezy wamy $R$; povolé na zemil om. R; všlikej] chczeta w\$\$yelykake R; co kolvěk] y $R_{i}$ budu prositi] transp. $R_{i}$ stane sé] bude $R_{i}$ mého] dano add. $R_{;}$ v] na $R-20$. kdež] $k d y z R-21$. Petr $k$ nému] transp. $231 \mathrm{R}$; ve] $k e$ R; $\mathbf{i}$ odpustim] odpu§ty $R-22$. tobe Petře] om. R.

XLVI. Feria IV. post dominicam III. in Quadragesima Mt 15, 1-20

1. $V$ onom Casi

Přistúpili k Ježŕovi z Jeruzalema pisaři a zákonnici

a řkúce

2. Prođ tvoji uěennici př〈ě stupujf zákon starých Neb neumývajl rukú když chléb jedie

3. on však Odpověde jim Proč vy př̌stupujete kázanie Bozie pravého práva svú $z$ radu

4. Nebo jest Buo povědęl

Cti otce $i$ mate

který zlaje otci nebo mateři umře věčnu / smrtí

5. Nebo vy dite

kto zle die otci neb mateři což koli jest ode mne tobe probude

6. nectlte otcé suého a matky suéj roztrhali ste kázanie Božie pro zradu vaši

7. licomèrnfici dobř prorokoval 1 o vás Izaiás prorok a ŕka

8. Lid mój ústy mé chvall ale srdce jich daleko jest ode mne

9. Nebo bez viny následuji mne učiece *ucenie a kázanie lidské

10. A príivolav $k$ sobě lidi pověde jim posluchajte a rozumejte

11. ne to jenz $v$ usta jde dusi tup 1 Ale jenz $z$ ust jde to dusi tupi

12. Tehdy přistúplce $k$ nĕmu učennlci jeho vecĕchu jemu Vies ze zákonnlci slyšiece to slovo zrazeni su

13. On odpovědě jim a łka

Každé šxěpovánie jenž neక̌tiepil otec mój nebeský Vyvrát1 sĕ 
14. nechajte jich slepr su vódce slepých

slepec at slepému próvod dá oba $v$ dúl upadnu

15. Odpovědě Petr vecĕ jemu

vypověz nám tuto pověst

16. Tehdy vecé jim Jež́s

Ješe vy bez smysla jste

17. Nerozumiete Nebo vłeckno jenž vende $v$ usta u błicho jde 1 z něho vynde

18. Ale co 2 úst a 2 srdcè vychodr

to dusi tup 1

19. z srdcé vychodf myšlenie zlé

vražda cizoložstvie

smilstvie krádeż

falešné suědexstuie posmievanie

20. to jsu jenż cloveka tup

Ale neumýajlc rukú jlsti chléb netupl clověka

XLVI.: $W, R]$ deest $A, C, D, S$

1. V onom Casi] om. R; Přistúpili] Przy§tupychu R; $z$ Jeruzalema

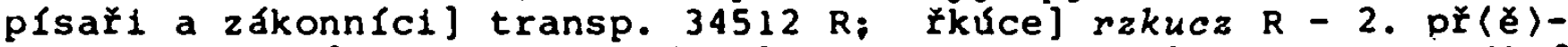
stupuji (przy\$tupugy ms.) zákon] transp. $R_{i}$ neb] om. $R_{i}$ rukú $\$ w u$ add. $R$ - 3. on ] Tehdy praem. $R ;$ vsak] om. $R ;$ jim] $A$ add. $R ;$ kázanie Bozile] transp. R; pravého práva sví zradú] pro wa\$\$y zradu $R$ - 4. Ct1] $w$ cze\$t myety $\mathrm{R}_{i}$ mateŕ] matku R; který zlaje... 5. ... ditel om. $R$; ktol $A$ praem. $R$; coz koli] dar kterykoly $R$ - 6. nect $1-$ te] a praem. $R ;$ svêho] om. $R ;$ a] y $R ;$ svéj] Swe y $R-7$. 1icoměrnici] poknyrzeny $R ;$ i] om. $R ;$ prorok] om. $R$ - 8. mój] wzdy add. R; usty mé] tr_ansp. $R ;$ chvalli] czty $R ;$ daleko jest ode mne] transp. $3412 \mathrm{R}$ - 9. následujl mne] transp. $\mathrm{R}$; mne] mye R: *učenie (vczynye ms.)] vczenye $R ;$ a kázanie] om. $R$ - 10. pŕivolav $k$ sobě lidi] pozwaw §boru $k$ Sobye $R$ - 11. jde] om. R; Ale...tupl] om. R - 12. pristuplce k nèmu] przy§tupyw\$ye R; jeho vecěchu] rzeczechu $R$; slysiece] $\{$ ly\$ew\$§ye R; zrazeni su] zradu gmagy $\mathrm{R}-13$. On] I praem. R; a łka] om. $R$; Kazdé] w\$§ye $R ;$ nebeský Vyvrát sé] $z$ nebe $\$ \$$ wymetano bude $R-14$. jich] tak add. R; vódcé slepých Slepec at slepému próvod dáwoczy gych Pakly \$lepi \$lepeho wede a R: upadnu] vpadneta $R$ - 15. Odpovědě] y wecze $R$; vecé jemu] om. $R$; vypověz] powyez R; tuto] tu R - 16. Tehdy] om. R; jim] om. R; Ješe vy] om. $R$; smysla] rozuma $R$ - 17. Nebo v̌eckno] om. $R ;$ jenż] zze czoz $R$; vende $v$ usta] transp. $231 \mathrm{R} ; 12$ něho vynde] a na odchod potom gde $\mathrm{R}-18$. col czoz R: $z$ ust a 2 ] gde $\mathrm{R}-19.2$ srdcé vychod1 myslenie zlé] nebo §rdcze wychody zle my\$§lenye R: cizoložstvie smilstvie kradez falesné] czyzoloz§two \$myl\$two zlodyey\$two krzywe $\mathrm{R}$; posmievanie] om. $\mathrm{R}-20$. jsu] ty add. $\mathrm{R}$; jenž clovéka] ge\$to du§§y R; Ale neumývajic ruku jisti chléb netupl clovéka] $A$ le chleb ge $\$ t y$ nevmytyma rukama nenye du\$\$y zatupa any zatraczenye $R$. 
XLVII. Feria V. post dominicam III. in Quadragesima J $6,27-35$

27. $V$ onom rasi

R $111 b_{2}$ Povědĕl Ježř zboru ži / dovskému dělajte krmi jesto nehyne

Ale jesto bude zivot věñy jesto Syn člověx 1 dá vám Toho jesto Buoh Otec znamenal

28. proto jemu pověděchu

Co riniece 1 děláme dielo Božle

29. Odpovědě Ježrš jim

To jest dielo Božle aby vểill veñ jehoz on to plo)$s\langle 1\rangle a\}$

30. proto ł̌ěechu jemu

A ktere ty znamenie $\boldsymbol{c}_{i n} \leq s$ Abychom my ty znamenie $\boldsymbol{c}_{1-}$

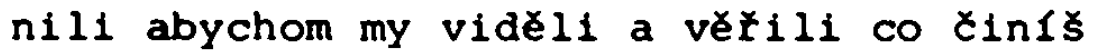

31. otcě naše na pústi manu jedli a zemřeli jsú pisáno jest

chléb $z$ nebe dal jim jest

32. proto jim Ježrs povědě

Jistè pravi vám

Ne Moyses dal vám chléb s nebes

Ale mój Otec dává vám chléb $z$ nebes věrný

33. nebo chléb stúpil jest $s$ nebes 1 dává světu život

34. . .

35. . .

A kto ke mně pr̆lde nebude laren

A kto u mé věr l nevzechcet' plti nikdy

XLVII.: W (solum v. 27.), R] deest $A, C, D, S$

27. $V$ onom Casi] om. $R_{i}$ zboru zi] des. $W-29 . p\langle 0\rangle s\langle 1\rangle a l$ (p\$al ms.) $\mathrm{R}$ - 34. om. R - 35. (Dixit autem eis Iesus ego sum panis vitas vulgata) ]or. R.

XLVIII. Feria VI. post dominicam III. in Quadragesima $J 4,5-42$

5. (P) Yłišl Ježš do mésta Samar̀ie jesto slóve sychen podlé zbożle jesto dal Jakub Synu svému Jozefovi

6. a bieše tu studnice Jakubova

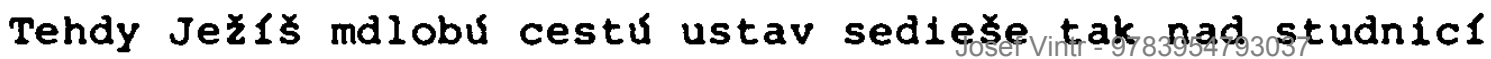


A biě̌ jiz šestá hodina

7. Pijide Žena od Samarie $c h(t) i e c i$ vodu bráti vece jéj Ježrs žno daj mi *piti

8. Ale ucedlníci biechu $5 l i$ do města ztravy kupovat

9. Tehdy jemu vece Zena samaritánska

vědĕ že neobcují $Z(1) d i$ s (Sa)maritánsvem

10. odpovědě jéj Jež́s

by vidèla dar Božl

A kto jest jenz pravi tobe daj mi piti

Snad by prosila jeho a dal by żivé vody

11. vece jemu

Hospodine a hyn móžes natřlti a okov vysoko jest odkudz jmás natýti zivú vodu

12. A zda $s$ ty mocn〈 jenż nám *okovy dal

$R 112 a_{1}$ on jest $z$ něho pil $1 \mathrm{sy} / /$ nové jeho

13. Jezis odpovè jie jie každý kto bude pitı tuto vodu...

14. jižto já dám jemu vodu $v$ nèm studnice tekứcie $\langle u\rangle$ vě̀ný zivot

15. vece jemu žena

Hospodine daj $\mathrm{mi}$ tuto vodu at' viece nevzechci plti Ani po nI sem pójdu

16. Pověd〈̌̌ jéj Ježř

jdi kaž sem mużi svému z sebú

17. Odpověd(é) Žena

nemám muže

Povědě jie Jež́s

Dobře pravís nemám muže

18. Pět mužóv měla s ty

A nenie jehožto más nenie tvój muź

To s pravě řekla

19. vece jemu žena

Hospodine vizi prorok jsi

20. Otci nasi na této hơ̌ následovali

A vy pravite $v$ Jeruzalemé miesto jest kdez nusie následovati

21. vece jéj Jezí 
zeno *věr *mně že přlde ten tas

Ze ani na té hơ̌ Ani $v$ Jeruzalemé budú otci následovati 22. vy následujete ze vidite/

w loa My následujemy jenž viemy

Nebo spasenie od Zidovstva jest

23. Ale přisla hodina i nynie jest

Kdyz věrni modlitevnlci následovati budu otcě v duchu

1 u pravde

Nebo otec kaky hledá jesto následovati jej budu

24. Duch jest Buo

1 ti jenž následuji $v$ duchu jeho a u pravdè musi následovati

25. Povědě jemu žena

vèdě ze *Mesiás prišel jenż slóve Kristus

proto když príle ten nám zvěstuje vకecko

26. Vecě jiej Jezís

Ja jsem jenz *mluvim s tobu

27. a $v$ tu dobu prijidechu ucennlci jeho

1 divichu sè že s zenu mluvise

vłak nikte nełekl co hledás nebo co mluvís s ní

28. Tehdy ostavi tu vědro své Žena i jide do města povědě onym lidóm

29. pod'te a vizte toho clověka jenž mi pověděl všeckno co koli sem ucinila

zda on jest Kristus

30. I vynidechu 2 města 1 diechu $k$ nĕmu

31. Zatiem prosiechu jeho učennici İkuce Mistře *jez

32. $i$ on odpověder jim

ja mám krmi jiesti jéjz vy nevite

33. Tehdy řeðechu uðennlci $k$ sobě

Zda mu kto płinesl jiesti

34. Povedě jim Jež́s

Má krmè jest abych cinil vili jeho jenż mè poslal

a dokonal dielo jeho

35. A zda vy diete Ze ješce cty̆̌ie měslci jsư až žeñ bude Tot' pravi vám

Podvihnete oči vaš a uzílte královstvie kak bielé 1 jiz ke zni

36. A kto zne odplatu vezme 1 sbierá plod $v$ zivot věny 
Nebo kto seje raduje se 1 kdy / žne

37. Nebo $v$ tom jest slovo pravé

Nebo jiný jest jesto seje a jiny jest jenż żne

38. já sem vy nechal «žleti jesto ste nedélali

Jinf su usilovali

$A$ vy ste $v$ jich úsilé vstúpili

39. Tehdy $z$ toho mésta mnoho vĕrichu veñ Samaritánóv pro slovo téj ženy suědeðstuie že jest fekla

Pověděl mi jest vక̌ecko což sem koli učinila

40. A když pr̆ijidechu $k$ nĕmu Samaritáni

prosiechu jeho aby tu ostal

1 ostal tu dva dni

41. a mnohem viece věrichu ven̆ pro kázeñ jeho

42. I praviechu żenè

Již ne pro tvi ł̌è věrimy

sami jsmy slyšli z jeho ust i viemy nebo tot' jest zajisté spasitel suěta

XLVIII.: $R, W$ (in $W$ vv. 5-21. def.) ) deest $A, C, D, S$

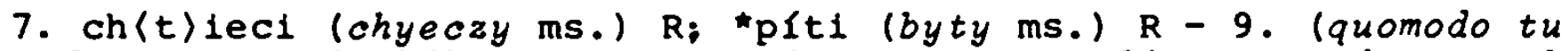
Indaeus cum sis bibere a me poscis quae sum mulier samaritana vulgata)] om. $R_{i} \quad Z\langle i\rangle d i$ (zdy ms.) $R_{i} s$ (Sa)maritánsvem (\$marytan\$wem

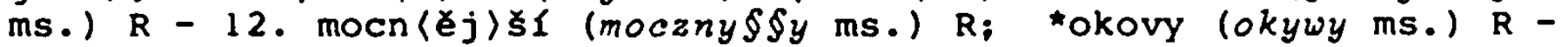
13. (sitiet iterum qui autem biberit ex aqua quam ego dabo ei non sitiet in aeternum vulgata)] om. $R$ - 14. (u) věnny (wyeczny ms.) $R$ - 16. Pověd〈é) (Powyedy ms.) R - 17. Odpověd(é) (Odpowyedy ms.) $R$ 21. *věr *mnè (wyernye ms.) $R-22$. My následujemy (1ncipit w)] $A y$

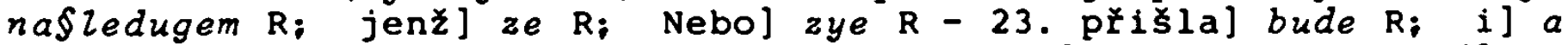

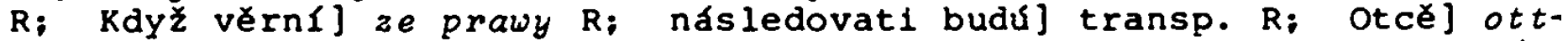
czy $R_{i}$ i] om. $R_{i}$ Otec kaky] transp. $R_{;}$kaky] takych $R_{i}$ jesto nasledovati jej budu] gez by gemu $\$ l u z y l y R-24$. i] a $\mathrm{R}$; jenz] ge§to

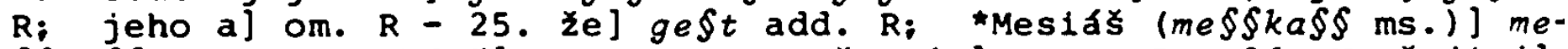
§ya§§ R; proto kdyż $A z$ ten R; zvěstuje] powye $R-26$. Vecé jiej] om. R; *mluvim (mZuwyem ms.) - 27. plijidechu] przydu R; divichu] dywyechu $\mathrm{R}_{\text {; }} \mathrm{s}$ ženu] $k$ zenye $\mathrm{R}$; nikte neřekl] newecze yzadny $\mathrm{R}$;

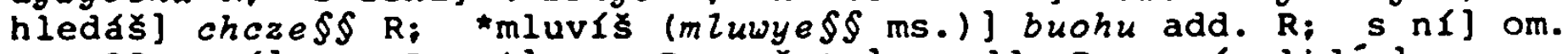
$R$ - 28. sve] om. $R ; 1]$ om. $R ;$ mésta] $y$ add. $R ;$ oným lidóm] onyem Zydem $\mathrm{R}$ - 29. mi pověděl vకeckno co koli] my ge§t prawy 2 czo $R$; on jest] transp. $R$ - 30. i vynidechu] wygdu $R ;$ diechu] du R - 31. prosiechu] pro§ychu R; Ikuce Mistre „jez (gey ms.)] geho aby gedl R 32. 1] Ale $R ;$ odpověde] powyedye $R_{i}$ jéjz] genz $R-33$. uXennici] Samy add. $\mathrm{R} ; \mathrm{Zda}] Z_{y}$ add. $\left.\mathrm{R} ; \mathrm{mu}\right] \mathrm{ge} \$ t$ add. $\mathrm{R} ;$ prinesl] dal $\mathrm{R}-$ 34. jeho] otczye meho $\mathrm{R} ;$ mé ge\$t add. $\mathrm{R} ; \mathrm{a}$ ] abych $\mathrm{R}-35$. A zda]

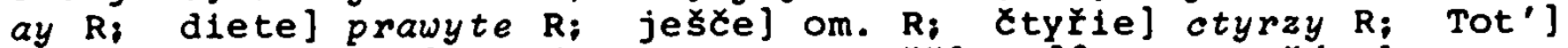
Ay R; Podvihnete] Pozdwyhnete $\mathrm{R}$; vaße] wa\$§y $\mathrm{R}$; uzŕfte] wyzte $\mathrm{R}$; kak bielé i] kako byelegy $R$ - 36. vezme 1 sbiera plod] wezme wyecznu a §klada vzytek R; zivot věnyj transp. R; Nebo kto seje raduje se (\$e altera $m$. rub. superscr.) i kdy] aby y ten myel rado\$t genz Syege y ge\$to $R-37$. Nebo] Neb R; Nebol zze R; jiny jest] transp. $\mathrm{R}$; jenžj ge§to $\mathrm{R}-38$. vy nechal *zieti (atey ms.) jesto ste neder- 
lali] jpu\$ty $z$ we mzdu ge\$\$tye nezdyelaly R - 39. toho mésta mnoho věrichu] transp. $2143 \mathrm{R}$; věrichu] wyerzyechu $R_{i}$ veñ] om. $R_{i}$ téj] te $R$; vకecko] om. $R$; koli] kolywyek $R$ - 40. prijjidechu] przygdu $R_{i}$ ostal] bydly $R_{i}$ ostal] by $R-41$. kázeñ] kazanye $R-42$. nebo tot' jest zajisté] zae ge§t to prawy $R$.

XIIX. Sabbato post dominicam III. in Quadragesima J 8, 1-11

1. $V$ onom casi

Sel Jež́s na horu Olivetsku

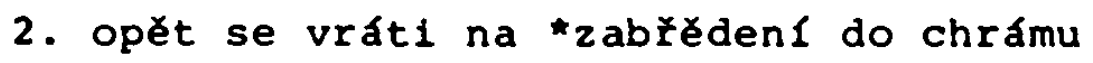

a v̌̌eliký lid přisel $k$ nèmu

a on sedé uxiese je

3. přivedechu plsaři a zákonnlci ženu jatú v cuzoložstvè $i$ postavichu ji u prostredku

4. i vecéchu *jemu Mistře tato žna nyni v cuzoložstuě jata jest

5. v zákonè Mojzés přikázal nám pro takú věc ukamenovati Co ty tomu dies

6. To mluvichu zkusujice jeho aby jej mohli omluviti Jezís pochýli se na stranu prstem psáse na zemi

7. Kdyz pristúpáchu mluviece skloni se Ježł $i$ vece jim Ktoz jest bez hřiecha $z$ vás ten pruý kámen na ni pust'

W lla 8. i opět sĕ // nakloně psăse na zemi

9. Slysiece to jeden po druhém vynidechu 1 stari 1 mladi

A Jež́s osta sám A žena stáse u prostřęce

10. Tehdy nadvihna se Jezís Vecé ji Zeno kde sú jesto na tè żalovachu zádný tè nepotupil

11. ona vecé nizadný Hospodine Pověde ji Ježs ani já tè zahubim jdi viece nerod' hrésiti

XLIX.: W] deest A, C, D, S, R

2. *zabł̌den 1 (zahrzyedenym ms.) - 4. *jemu (gy ms.). 
L. Dominica IV. in Quadragesima - J6,1-14

S 143a, 1. Šl Jezús za moře Galilee jenž sióve Tiberiad:s

$\left(148 a_{1}\right)$ 2. a jaleక̌e po nĕm sila velika

nebo vidiechu divy Łiniece na těch jež nemocn: biechu

3. Tehdy jide na horu Ježús

(tu sedieše s učenntky suými

4. biěse bliz velikonoc den hodný židovský

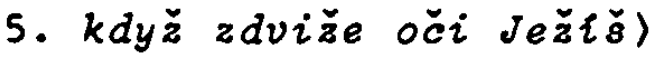

i uzłe słlu veliku $k$ sobè jdúce

pověděl Filipovi

odkad kuplme chleba aby tito jedli

6. a to xiniese skusuje jeho

on vědiese co riniti

7. odpovědě jemu Filip

duěstè peněz nic chleba nestať̉ie 〈jim

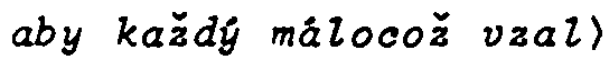

8. Povědĕ jeden $z$ ǔennikuov ondł̌j bratr Simonóv Petróv

9. Jest jedno dietě zde jež má pět chlebuov jex̌ných a duĕ ryber

Ale coz jest to mezi toliko

10. Tehdy povědě Ježús

Kazte lidu siesti

a biese mnoho sena tu

tehdy sède u pocet mužr pèt tisic

11. i vze Jezús chléb

i vzda chvalu i rozdĕli tèm jenžto sediechu

Takoz ryby co chtiechu

12. A kdyz syti biechu vece uxennikóm svým

Sberte ostatky drobty at' nehynu

13. i sebrachu a nakladú dvanác kosóv ostatkuov

2 péti chlebuov jexných a ze dur rybu

jez ostalo tèm jesto jedli

14. Tehdy oni lidé viděvse že ǔinil pověděli zajisté zde jest prorok jemuz na svět płijfti

L.: $S, R, W]$ deest $A, C, D$

1. Sel] $V$ onom czya\$\$y praem. W; za] przye $\$ W ;$ moře] do add. $R$; jenz] ge\$\$to $\mathrm{R}-2$. a] y R; sila veliká transp. $R, l_{y} d u$ add. R; vidiechu] $\left\{l_{y} \$\right.$ yechu od nyeho welyke $\mathrm{W} ;$ jez\} gye§to $\mathrm{W}, \mathrm{R}-\mathrm{j}$. ji-

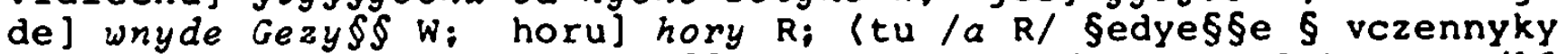
(wymy) W] R, om. S - 4. (bye§§ye /A praem. R/ blyz welykonocz /blyz- 


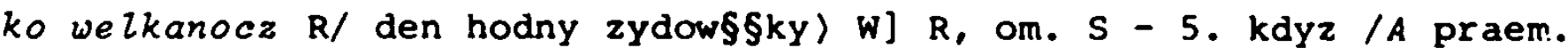

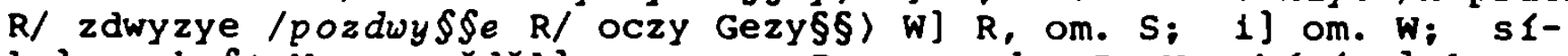
lu] mnoho§t $W$; povęěl] y praem. $R$, powyedye $R, W ; k u p i m e] k u p y-$ my $W-6$. a to tiniese skuSuje] on to weczye zku§\$ye $W$, om. R; jeho] $A$ le add. W, om. $R$; vĕdiese co ¿initi] wydye\$̧ye czo ma vczynyty W; ciniti] vczynyty R - 7. dvěsté] za praem. R; nic] om. W, R; (gym aby kazdy maloczoz wzal) $W$ ] aby kazdy malo wzal $R$, om. $S$ - 8 . Pověde] powyedyel W; ucennikuov] geho add. W - 9. jeż genz R; jecnych] geczmennych $W$; Ale] $A$ W, $R$; toliko] lyda add. $R$, tolyk

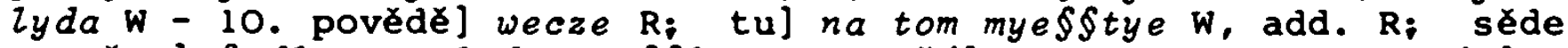
$\mathrm{u}$ počet] §edly ony lyde czy§§lem $w$; muźl] muzow $R$, om. $W$; tisic] ty\$\$czuow $W$, \$ta $R-11$. I vze] Wzaw $W$, vzrzyelu $R ; ~ i$ vzda chvá-

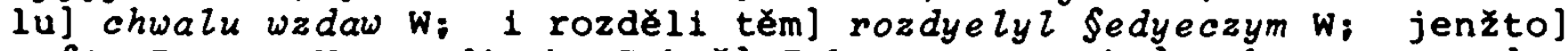
ge§to $R$, om. W; sediechu Takoz] Takez $y$ W; ryby] ryb W, $R$; co] czoz W - 12. A Jom. $R$; drobty] drobtow $R$, om. W; nehynu] nezhynu W. nezahynu $R$ - 13. i] om. W; a nakladu dvanác] y nakladechu dwanad\$te $\mathrm{R}$, nap Inyechu dwanadczyet $\mathrm{W}$; ostatkuov] dobczye W; jexnych] geczmennych W; jez] genz W, ge§to R; ostalo] po nych add. W - 14.

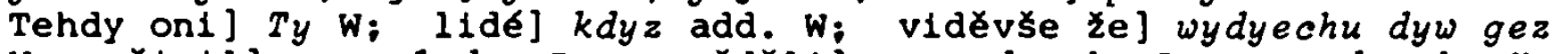
W: uxinil] czyny 2 dyw R: povedelil] powyedyechu R, powyedyechu $\mathrm{Ne}-$ bo $W_{i}$ zajisté] zawyerne $R$, zawyernye $W ;$ zajisté zde jest] transp. $231 \mathrm{~W} ;$ jemuz] genz $\mathrm{W}$, ge $\$ t$ add. $R$; na suet pijifti] transp. $312 \mathrm{R}$, przy§@el ge§t na \$wyet $W$.

LI. Feria II. post dominicam IV. in Quadragesima $J 2,13-25$

W 11b 13. V onom Casi

Blizko biese velika noc zidovská

1 Jide Ježs do Jeruzalema

14. i najide $v$ chráme prodajné ovce 1 voly $i$ holuby

a obrazniky sediecie

15. A kdyz učinı́se bičk z provázkóv vłèckny vyhna z chrámu

ovce a voly

a obraznikovi vyli méd'

a stoly př̀ráti

16. A tym jesto holuby prodávachu vecè odneste toto odtad

a nerod'te ciniti domu otce mého domu kupcového

17. Rozpomenuchu sĕ zavĕrné ǔennici jeho nebo psáno jest Duch domu suêho jie mé

18. odpověděchu żidové 1 vecěchu jemu Které znamenie ukazujes nám že to cinßs

19. Odpovĕdĕ Ježı̌ i vecĕ jim Obołte chrám tento a já ve trech dnech ustavím jej opèt

20. Odpověděchu Zidé

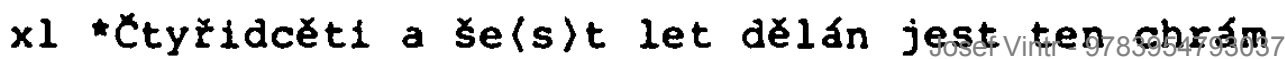


w 12a 21. Ale on miniše chrám// zivota suého

22. Kdyz bieše vstal $z$ mrtvých tret 1 den rozpomanuchu se UČennici že to praviše věrichu pismu 1 řěi jesto mluviese Ježrs

23. A když byl $v$ Jeruzaleme na veliku noc $v$ den hodny mnozi 〈vérichu〉 veñ a $v$ jeho jmé viduce divy jesto cinfse

24. Ale on sám Ježís nevĕriese jim proto že znăse vక̌̌ckny

25. i nebiese trǔba jemu aby suědečstvie povědęl o clověcer Ale on vêdieše co by bylo $v$ člověcer

LI.: $W, R]$ deest $A, C, D, S$

13. $V$ onom Casi] om. $R$; velika noc] we lkanocz $R$ - 14. najide] naleze $\mathrm{R}$; prodajné] prodanye $\mathrm{R}$; 1 voly i] a woly a $\mathrm{R}$; sediecie] $\mathrm{Se}-$ dyeaze $\mathrm{R}-15$. uxinfSe] vczyny $\mathrm{R}_{i} \mathrm{z}$ provázkóv] $z$ prowazow $\mathrm{R}_{\text {; }}$ obrazn\{kovi vyli méd' a stoly\} obraczy wyby yhned aby \$taly $R-16$. tym] tyem $R_{;}$odneste] prycz add. $R_{i}$ odtad] om. $R_{i}$ nerod'te] rodte $\mathrm{R}_{i}$ Otce] ottczy $\mathrm{R}-17$. zavěrné] om. $\mathrm{R}_{i}$ jeho] om. $\mathrm{R}_{i}$ nebo] zze $R_{i}$ psáno jest] transp. R; svého jle mè] tweho gey my $R$ - 18. ukazujes] pokaze\$\$ $R-19$. I vecé jim] om. $R ;$ Oboťte] Oborzye R; a já! Om. $R$; ve třech] w cztyrzech $R-20$. Odpovědęchu Zidé] Tehdy wecze-

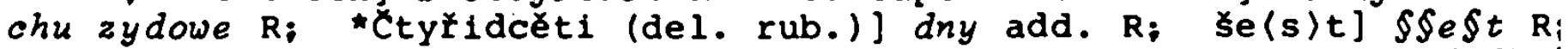
ten] tento $R_{i}$ jej za tri dny ustaviti] transp. $23451 \mathrm{R}-21$. mInISe: tyem add. $R_{i}$ chrám] chramem $R-22$. Kdyz] yako\$§ $R_{i}$ vstal $z$ mrtvíd třet1 den] transp. $45123 \mathrm{R}$; rozpomanuchu] rozpomnyechu $R_{i}$ praviše] $y$ add. $R-23$. byl] by $R ; ~ v$ den hodny] om. $R ;$ mozi] wyerzychu add. $R ; \quad v]$ om. $R ;$ viduce] wyeduczye $R-24$. vseckny] w\$\$ye $R-25.1$ ne.

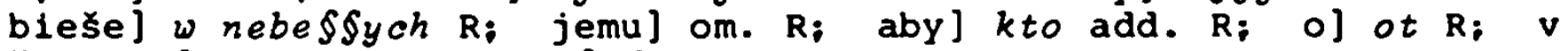
¿́lověcĕ] w czlowyeczyem frdczy R.

LII. Feria III. post dominicam IV. in Quadragesima J $7,14-31$

14. V onom Casi

Jiz dnè hodnieho prichodiece

jide Ježı̌ $v$ chrám a sedĕ uç̌̉e je

15. I divichu sě Żidově velmi ł́kúce

kak ten pismo um 1 kdyz se jest neuril

16. Odpovědě jim Ježrs 1 vecĕ

Mé uxenie nenie mé ale toho jenž mé poslal

17. Ale kto bude vóli jeho tiniti

pozná ư̌en mé jest li od Boha ट̌i li já sám od sebe mluvim

18. Kto sám od sebe mluvie chvály svéjoshliêta 
Ale kto hledá chvály jenż jej poslal

tu prav jest a kłivdy $v$ ném nenie

19. Vědě Mojžés dal vám zákon

a nikte mezi vámi nechová zákona

20. Co mé hledáte zablti

Odpovědé jemu sbor

Diábla más

kto tebe hledá zablti

21 . Odpovědĕ Ježrs $i$ vecé $j$ im

jedno dielo ucinil sem 1 všickni divite se

W $12 \mathrm{~b}$

22. Proto Mojzéš dal vám / obłězánie

aby nebylo od Mojzieš Ale od otcóv

a $v$ sobotu obřězujete clověka

23. Ac obř̌zánie vzal člověk $v$ sobotu Mojžlešovu

ke mně hněv nesete neb všeho člověka uzdravil sem v sobotu

24. Nesud'te podlé obličje

Ale pravý sud sud'te

25. Praviechu něteřl 2 Jeruzalema

zda jest ten jehož hledajl żidove zahubiti

26. Tot' zjevné mluví a nic jemu nedĕji

zda su vêru poznala kniežata ze jest kristus

27. Ale jej viemy odkad jest

Nebo Kristus kdyz pride zádný nevi odkad jest

28. Volẳe ư̌ Ježr $v$ v chrámě a řka

u mè viete odkad sem

vězte az sem od sebe nepřišel

ale jest pravý jenž mé poslal

jehoz vy neviete

29. Ale já vêdě jej

pakli řku nevěder jeho budu s'vámi nazván lhár

Ale viem jej neb od něho sem pošel a on mě poslal

30. Tehdy jeho hledáchu chtlce jej jiti

Ale nikte nañ nepod $\langle v\rangle i\langle z\rangle$ e ruky

Nebo neptisla bieše jeho hodina

31. ale $z$ toho sboru mnozl věrichu veñ

LII.: $W, R]$ deest $A, C, D, S$

14. $\mathrm{V}$ onom ¿asi] om. $\mathrm{R}$; Jiz dne hodniehol Kdyz dne rodynneho R; sedě ux̌še je] \$\$yede vcze\$\$ye $R-15$. kak ten] kako $R ;$ jest] ge $R$ 16. $i$ vecé] om. $R ;$ mé] ode mne $R ;$ poslall om. $R-17$. Ale kto] $A$ 
ktoz R; uXeni me] wyecznye mye $\mathrm{R}$; wy $\mathrm{R}$, chwaly wla\$tnye hleda czyny $y$ mluwy add. $\mathrm{R}-18$. Kto] ktoz R; svéj] wlaßtne $R ;$ chvally] toho add. $R ;$ jej] mye $R ;$ tu prav] ten prawy $\mathrm{R}-19$. Vědé] $z e$ add. $\mathrm{R}$; dal vám] transp. $\mathrm{R} ;$ nikte] zadny $\mathrm{R}$; zákona] zakonu $\mathrm{R}$ - 20. mé] mne $\mathrm{R}$; sbor] zydow\$ky add. $\mathrm{R}$; Diábla] Bye $\$ a R$ - 21 . Odpovědę] gym add. $R ; j i m]$ om. $R ;$ vక̌ickni] om. $\mathrm{R} ;$ divite] dywy $\mathrm{R}-22$. obřxzánie] ne add. $\mathrm{R}$; nebylo] by Zo $\mathrm{R}$; nebylo od Mojziese] transp. $231 \mathrm{R}$; od otcóv] otczowo $R$ - 23. obřzanie vzal] obrzye\$awanye $\mathrm{R}$; sobotu] aby ne\$tal zakon moyzye\$ow add. $\mathrm{R}$; Mojziešvu\} om. $\mathrm{R}$; ke] om. $\mathrm{R}$; hněv] om. $\mathrm{R}$; nesete] ne§tote $\mathrm{R}$; neb] nebo $R$ - 24. obliceje] obyczyege $R$; Ale pravý sud sud'te] om. $\mathrm{R}$ - 25. něteŕl] gedny $\mathrm{R}$; zda] Ay ted $\mathrm{R}$; zahubiti] zabyty $\mathrm{R}-26$. Tot'] $A y \mathrm{R}$; nedĕj 1 ] nedyete $y \mathrm{R}$; vĕru] czele $\mathrm{R}$; poznala kniežata] transp. $R-27$. jej viemy] toho wyeme $R ;$ Nebo] om. $R ;$ kdyz] aczR; zádný nevi] nebudem wyedyety $R-28$. Jezis] Kry\$tus $R ;$ a Yka] om. $\mathrm{R}$; me] mne $\mathrm{R}_{\text {; }}$ vězte az sem] wyete a \$\$am $\mathrm{R}$; neprisel] \$em add. $\mathrm{R}$; jest] ottecz add. $R ;$ mé poslal] transp. $R-29$. jej] om. $R ;$ rku] dyem $R_{;}$nevèdé jeho] newyem $R_{i} s$ vámi nazván lhálj zarowno \$elhal $\S$ nymy y $\$$ wamy $R_{\text {; }}$ pakli... lhály cf. J 8,55!; viem jej neb] wyedye zze R; sem posel] transp. R; posel] przy\$\$e $R$ - 30. nikte nan̆ nepod $\langle v\rangle i\langle z\rangle e]$ yzadna nany neztaze $R-31$. veñ] w nyeho $R$.

LIII. Feria IV. post dominicam IV. in Quadragesima $J 9,1-38$

1. V onom Casi

Jda Jež́s vidẻl clověka slepého od narozenie jeho

2. 1 otázachu jeho uCennici

Mistre kto shréril

tento $\iota_{1} l i$ rodici jeho že se slep narodil

3. Odpovědě Jezis

Ani tento hrex̌il ani rodici jeho

w $13 a$

Ale aby Bożie diela // na něm zjevena byla

4. já mosi dẻlati diela jeho jenź mě poslal doñaž den jest príle noc kdyz nikte nemúz dělati

5. Dokud sem na suětè světlost sem suěta

6. to povexder plinu na zemi

1 ueini z prsti blato

1 omaza oxi jeho 7. 1 vecé jemu

Di omyj na plaviši do siloe jenžto poslán jide

odsed promyv oci i prisel vidé

8. I takéz súsedi 1 ti jesto jej vidêli Nebo drieve žebrák biěe vecechu

Ne zda ten to jest jenž sedieše žbł̌

JinI praviechu ten jest který sedieše a zebrăe

Jin1 vecechu Nebo ten jest 
9. Jinf opět nikakéz Ale podobny $k$ němu jest Ale on praviese já sem

10. vecexchu jemu kako otvořeny tobe oxi

11. Odpovèdé

ten clověk jenž slóve Jež́s

bláto uxinil 1 zmazal oci mé 1 fekl mi

Di na plavisce siloe

a vyডel sem unyv 1 vizi

12. 1 řěechu jemu kde jest ten

odpovêdè nevèdé

13. privedú toho přxd zákonnlky jenž slep byl

14. a biese $v$ sobotu kdyz blato uxinil Jezis jesto otvoril oci jeho

15. Opět otázachu jeho zákonnlci Kak jest *prozł̌l on jim odpovèderl

blato polozil na moji oxi 1 umyl sem 1 *vizi

16. Praviechu jeden zákonniekuov

nenie ten ‘lověk od Boha jenž soboty nechová

Jin1 vecéchu

Kak móz hř 1 ñny clověk ty divy ciniti

1 biese svár mezi nimi

17. Tehdy Iexechu slepci opet

W $13 b$

ty co o nĕm pravís jenž tober / oxi otvołıll

Ale on vece

nebo prorok jest

18. nejęchu jemu viery Židové o ňem by slep byl 1 videxl

az povolachu rodiny jeho jenz su vidéli

19. 1 otázachu jich a ŕkúce

To jest syn vás jehoz praviete by se slep narodil

Kakoz tehdy nynie vidie

20. Odpověděchu rodina jeho a řkúce

I viemy zet' tot' jest syn nás

neb slep narodil sè

21. Kako nynie vidie toho neviemy

Nebo kto otevĭel jeho oxi my neviemy

*otiezte jeho

lêta má on sám za sè sám mluví

22. nepovędéchu rodina jeho băchu se ziduov

Jiz se biechu smluvili zidé 
ac by kto nazieval jej Bohem musil ven $z$ modly

23. Proto rodina jeho vecé leta má jeho otažte

24. $z\langle a\rangle$ volachu opět clověka který slep biełe vecĕchu jemu Daj chválu Bohu

My viemy že ten clověk hřiešný jest

25. On odpověder

Jest $1 i$ hřiešný toho nevědĕ

jedno viem že sem slep byl Ale nynie vidlm

26. Tehdy vecěchu jemu

cot' ucinil

kakt' oxi otvoŕil

27. Odpovědě jim

Již sem pravil vám a slyšxli ste

Co opèt chcete slyšti

zda vy chcete ucennici jeho býti

28. Lajiechu jemu rkúce

ty jeho uxennik bud'

Ale my Mojžiešovi uCennici smy

29. My vímy そ̌e Mojžlesovi Buoh mluvil

Ale toho neviemy odkad jest

30. ...

divne Nebo vy neviete odkud jest

a otvořil moje oxi

31. Ale viemy že Buo hřiešných neslyšr

W $14 a$

Ale ac kto děln $1 k$ Božr // jest a vóli jeho cin toho uslysi

32. Na suẹtè nenie slýcháno

by kto otvoŕil oxi slepci narozenému

33. jedno by byl tuto od Boha sice nemohl by nic uxiniti

34. Odpověděchu i ł̇eðechu jemu

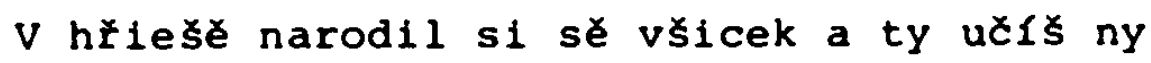

i vyhnachu jej ven

35. uslyšav Ježļ že jest ven vyhnán

A když naleze jeho povědĕ jemu

Ty věriš v syna Božieho

36. Odpovědě ón a řka jemu

Kto jest pane abych veríil veñ

37. i povědě jemu Ježŕs

1 vidêl si jej a jenž mluvi s tobu ten jest

38. tehdy on povědě 
LIII.: W, R] deest A, C, D, S

1. $V$ onom Casi] om. $R$; jeho] om. $R$ - 2. tento] $2 y$ add. $R ;$ rodici] rodcze $R$ - 3. zjevena] prone\$§ena $R$ - 4. mosi] mu\$\$y $R$; diela jeho] transp. $R$; doñaz] dokaz $R$; nikte] zadny $R ;$ nemúz dělati] transp. $\mathrm{R}$ - 5. Dokud] Dokad R; světa] tohoto add. R - 6. to] A praem. R; $z$ prsti] om. $R$; blato] blatcze $R$ ( $R$ add. ex errore XII lineas, incipit any oblyczege...neprzygely \$te mne expl.. rub. del.); omaza] pomaza $\mathrm{R}-7$. vecé] powyedye $\mathrm{R}$; omyj na] umyg $w \mathrm{R}$; jenzto] §lowe add. $\mathrm{R}$; Odsed promyv oxi 1 pł́isel vidé] y vmy y prayde wyda $\mathrm{R}-8$. 1 ta-

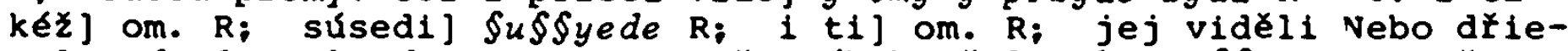
ve] wydyely geho drzewe zze R; zebrák biełe] zebraye\$\$e R; vecè-

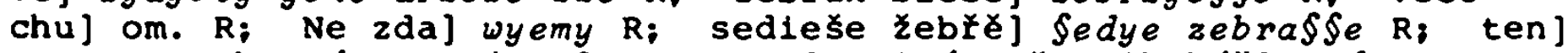
tento R: ktery...tenjest] om. $R$ - 9. Jinf opét nikakéz] $A$ druzy prawyechu nenye $R$ - 10. vecěchu] y praem. $R ;$ kako otvořeny tobé oði] kako \$\$ta \$ye ottewrzele oczy twogy $R$ - 11 . zmazal oxi mé polozyl na mogy oczy y wyzy R; mi] ge\$t add. R; plavisce] do add. R; Si-

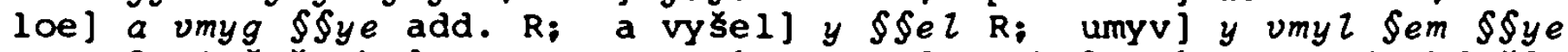
$\mathrm{R}$ - 12. i IeXechu] Proto weczechu R - 13. toho] geho R - 14. kdyz] to add. $R_{i}$ blatto uxinil] transp. R; jesto otvołil oxi jeho] y ottewrzye 2 geho oczy $\mathrm{R}-15$. Kak jest *prożel (prorayek $\mathrm{ms}$.)] kterak by wydye [ R: odpovědĕl] powyedye [ R: *vizi (wyerzy ms.)] wyzy $R$ - 16. Praviechu] Prawye\$Se $R_{i}$ jeden] $z$ add. $R ;$ nechova] $A$ add. $\mathrm{R}$; Kak] gakz R - l7. Yexechu slepci opét] weczechu opyet \$lepemu R; o ném pravis] prawy\$ o tom R; tobé oxi otvołil] otewrzye[ oczy twogy $R$; nebo] om. $R$ - 18. nejechu jemu viery] newyerzychu gemu $R ;$ o nem by slep byl] o tom by byl slep $R$; $i$ videl] potom powyedyel $R$; povolachu rodiny jeho] pozwachu geho $k$ \$obye rodyny $R$; jenz su vidéli] om. R - 19. jest] om. R; jehoz] wy add. $R_{i}$ by se slep narodil Kakoz tehdy nynie vidie] byw\$\$e \$lepa vrozena a yako\$\$ ted nenye hledy $\mathrm{R}$ - 20. Odpovédéchu] gym add. R; Ikúce] rzkucs R; I viemy zet' tot' jest syn nă neb slep narodil sé] wyeme zey $\$ y n$ na\$\$ \$lep vrody 2 \$ye $\mathrm{R}-21$. Kako] Ale yako R: toho neviemy] transp.

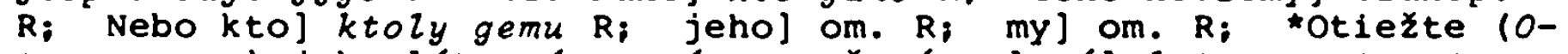
tyezye ms.) jeho léta má on sám za sè sám mluvil letat ma tyezte geho Samt za Sye mluwy $\mathrm{R}-22$. nepovédéchu] to powyedye $\mathrm{R}$; jeho] nebo add. R: Jiz] Nebo R: se biechu] transp. R: Zidé zydowe R: aC by kto nazieval jej Bohem musil ven $z$ modly] kto by wyerzy $w$ buoh mu\$\$y ly by $z$ modly byty $R$ - 23. léta] letat $R$; otazte] tyezte $R$ 24. $z$ (a)volachu opét] opyet zawolachu \$lepeho $R$ : ktery slep biese] genz by $\{$ §lep y $R$; viemy] wyeme $R$; hłiesny] hraye\$\$nyk $R-25$. On

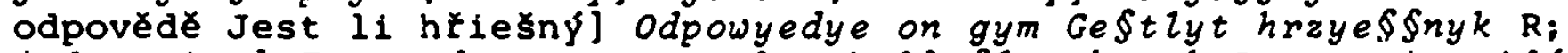
jedno viem] To wyedye $R_{i}$ sem slep byl] \$lep byech $R_{i}$ nynie vidim]

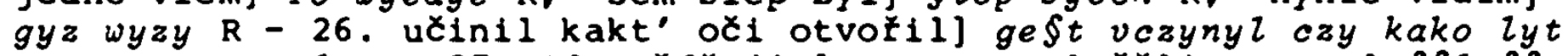
oczy otewrzyel R - 27. Odpoveder jim] om. R; slyseli ste co] $\$ \$ l y \$ \$ y-$ te coz tolyko tyezete Czoz R: uXennlci jeho] transp. $R-28$. Lajiechu] Tehdy praem. R; jeho uCennIk] transp. $R-29$. mluvil] ge\$t add. $\mathrm{R}$ : toho] tohoto $\mathrm{R}$; odkad] adkud $\mathrm{R}-30$. divne] odpowyedye ten czlowyek $y$ weczye gym tot ge\$t dywne praem. $\mathrm{R}$; Nebo vy] ze $\mathrm{R}$; a otvoIil moje oxi] an otewrayel oczy mogy $R$ - 31. Ale aX] Pakly R; délnik Boźl] buozy \$luha R; a völ1 jeho cinl (-ye ms.)] om. R; uslysi] $\$ l y \$ \$ y \quad R-32$. otvolil oxi slepci narozenému] otewrzyel \$lepczye vrozeneho $R$ - 33. jedno] acz add. R: byl tuto od Boha sice nemohl by] od boha ten by 2 nemoh $R-34$. jemu] om. $R ;$ hiliese narodil si sé visicek a] hraye\$\$yech $\$ \$ y$ vrozen $y \mathrm{R}$; ty uCI\$] transp. $R$ - 35 . jest ver 
vyhnán A kdyż] geho vyhnachu wen $R_{;}$jeho povèdẻ gey y wecze $R$ 36. jemu] om. $R_{i}$ jest pane] $g \$ \$ y$ ho\$podyne $R_{i}$ věłil veñ] transp. $R-37$. 1 povědé] wecze $R$; ten] tent $R-38$. povědě věłi Hospodine] odpowyedye wyerzym R.

LIV. Feria V. post dominicam IV. in Quadragesima $J 5,17-29$

17. $v$ onom Zasi Povědél Jež́s sboróm židovským Otec mój ted' dêlá a já dexlaji

18. Proto viece hledáchu jeho zidé zablti nebo netoliko tupise sobotu

1 Otcĕ svého nazváse Bohem roven se ciniese Bohu Odpovědĕ Ježrs 1 vecĕ jim

19. zavěrné zajisté pravím vám Nemóz syn od sebe nic uriniti jedno což uż́l otcè tiniec Cokolvěk on uxině téz 1 Syn uxini

20. Nebo miluje Syna

a vక̌e pokáze jemu což sám « đin

i večie toho ukáze jemu diela Abyste sé divili

21. jakož Otec *zkřies 1 mrtvého 1 oživi

takéz i syn které chce zivi

22. ani Otec koho sudi

Ale všicek súd dal Synovi

23. aby vsickni ctili syna jako ctie otcer

W $14 \mathrm{~b}$ kto nect1 / syna nect 1 otcé jenż jeho poslal

24. Zavêrné zajisté pravi vám

Nebo ktož mé slovo slyšl a vĕł jemu jenž mé poslal ten má vě̉ný żivot

$i \mathrm{v}$ sud nebude ale jde $z$ smrti $v$ zivot

25. zavêrné zajisté pravi vám

Nebo pride cas 1 nynie jest

Kdyz umrlf uslysi hlas Syna Bozieho

A kteřl uslysie oživu

26. jakož otec má żivot sám v sober takéz i synovi dal zivot mieti sám $v$ sobe

27. I moc dal jemu súd tiniti nebo syn clověx jest 
28. Nerod'te diviti se tomu

nebo přlde cas $v$ nĕmžto vł̌ickni jesto $v$ robiech jsu uslysie hlas Syna Božieho

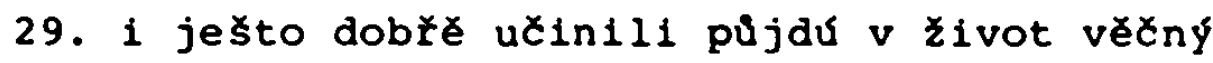

kteřr zle uxinili $v$ oheñ věxný

LIV.: $W, R]$ deest $A, C, D, S$

17. V onom ‘asi] om. $\mathrm{R}$; sboróm zidovskym] §boru zydow§kemu a raka

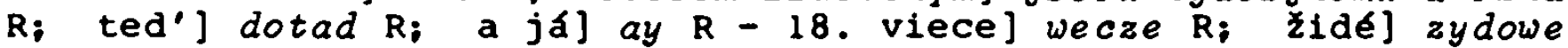
$\mathrm{R} ;$ sobotu] $A$ le add. $\mathrm{R}$; nazváse] prawye\$Se $\mathrm{R}$; roven sè ¿iniełe] rowna ge vcayny $\mathrm{R}_{i}$ Odpovědè] gym add. $\mathrm{R}_{i} i$ vecé $j \mathrm{jm}$ ] a tak rzka $\mathrm{R}$ - 19. zavěrné] a add. R; pravím] prawy $R ;$ syn] \$am add. $R ;$ nic uCiniti] nycze R; Ciniec Cokolvěk] czynyecze czozkolywyek R; uXinę] vezyny $2 \mathrm{R} ;$ i] om. $\mathrm{R} ; \mathrm{Syn}$ ] rowno add. $\mathrm{R}-20$. Nebol otecz add. $\mathrm{R} ;$

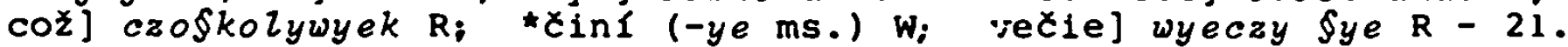

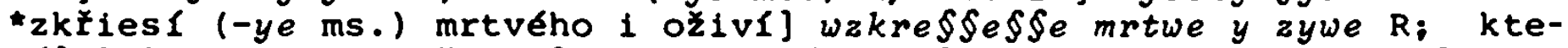
ré] kohoz $R$ - 22. víicek] om. $R$; sud dal] transp. $R-23$. jako] yakoz $R_{i}$ Syna] ten add. $R_{i}$ jeho poslal] transp. $R-24$. Zavêrné za-

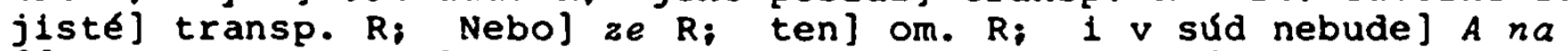
§̧ud nepoyde $R ; z]$ od $R$ - 25. zavérné zajistél Gy\$te $R ;$ i nynie] a gyz R; jest] ze add. R; kteł l uslysie] kto budu $\$ z y \$ \$ y e t y ~ R-$ 26. jakoz] Nebo praem. $R_{i}$ má żivot] transp. $R_{i}$ takéz...v sobé] om. $R-27$. i] $A R-28$. Nerod'te] Proto praem. $R ;$ diviti se] transp. $R_{i}$ tomu] om. $R_{i}$ nebo] ze $R_{i}$ nemzto] nyezto $R$; jesto] genz $R-29$.

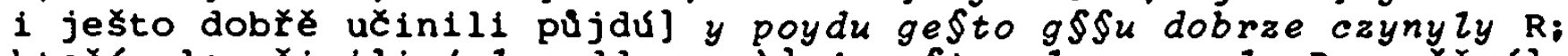
ktế1 zle uxinili (zle add. ms.)] $A$ ge\$to zle caynyly R; věny] Nebo wakrzye§§enye §udowe bude add. R.

LV. Feria VI. post dominicam IV. in Quadragesima $J 11,1-45$

1. V onom Casi

Biese některý stonavý Lazar̆ od Betanĕ hráku Marie a Marty bratr jich

2. Ale Maria biese jesto zmazala biese mast 1 a utř̉la nohy jeho vlasy svými jejlzto bratr Lazał nemáhăe

3. tehdy poslachu sestry $k$ Jezísovi a rkuce Pane viz ten jehoz milujes nemáhá

4. uslyšrv to Jež́s vece jim Nemoc ta nenie $k$ smrti nez pro chválu Bozie aby syn Bozi byl ji pochvalen

5. nez milováse Jež́s Martu a sestru jeji Mariji a Lazał̌

6. a jakz slyš ze Lazał nemáháse $v$ tom miestè osta za dva dny

7. Tehdy potom vecé uxennikóm svým // 
Pod'my opét do Zidovstvie

8. Povědie jemu mlaď 1

Mistre vnove chtiechu té tam Zidé kamenovati a opět tam navracije〈̧) se

9. Odpovie Ježrs

vsak dvanást jest hodin za den

Ktož ve dne chodl "neurazl sè nebo suětlost má tohto sueta

10. Ale chodè $v$ noci urazl se Nebo $v$ nie svĕtlost nenie

11. to povèdèv

potom svým mladerm

Lază̌ př́tel nás spí

Ale jdu abych ze sna ubudil jej

12. Povĕdie jemu mlaď́ 1

Pane kdyz spi zdráv bude

13. To Ježř povědě mienĕ smrt jeho

nez oni mienichu by o snu mluvil

14. Tehdy die jim zjevně

Lazar̆ umřl j jest

15. I raduji se pro vás abyste věrili neb sem nebyl tam Ale pod'my $k$ nèmu

16. Tehdy Tomás povie $k$ mlade $1 m$ pod'myz i my a umřem s nIm

17. I přlde Ježls i najde jej štyř dny v hrobě ležiece

18. Biese Bethania u Jeruzalema jako za *patnáste honóv

19. mnozl Židóv pŕijidechu k Mařie a k Marté aby je utěsili

20. Marta jakž slyš že Ježı́ přisel vyběže protiv němu nez Maria doma sediese

21. 1 povie Marta k Ježŕsovi

Pane by $z$ de by 1 mój bratr nebyl by umžel

22. Ale i nynie viem že což kolvěk budeš žádati na Bozě Dá tober Buoh

23. die jie Ježı̌

Vstane bratr tvój

24. die jemu Marta

vědě že vstane na vzk řlešenie u poslednı den

25. Povie jI Ježis

já sem vzkílesenie a zivot

ktož u mè věr 1 ač by umǐèl ožive 
W 15b 26. A vక̌liký / živ jsa věłil u mě neumre na věky vèris tomu

27. Die jemu

zajisté Pane

jă sem věłila že s ty Kristus syn Boha żivého jenž s na tento suèt prisel

28. Ieknuci to

jde 1 povie Marii sestž suéj tajnè łkúci

Mistr přisel a vola té

29. ta slyక̌rułi vstanúci brzo i jae $k$ nĕmu

30. jesce Ježł nebiese płisel v hrádek

nez jesce tu biese jesto Marta protiv němu biese vyšla

31. tehdy Zidé jesto s nI $v$ domu biechu texic ji

kdy̌ viděchu Ze Maria vstavłı vskoře 1 *vynide

jdiechu za nI a rkuce

jdet' $k$ hrobu aby plakala tam

32. Maria pł̇isedðı kdezto Jež́s biese

padకi $k$ nohám jeho 1 vecé jemu

pane by byl zde bratr mój nebyl by umłærl

33. Jezis jakz ji uzłe placice

a Zidy jesto s ni kvielichu

steskliv sobě $v$ duše smúti se $v$ sobe 34 . I vecé

kde jest položen

łečchu $k$ nému

Pane pod' a viz

35. i pocé slzeti

36. Zidé zmluviechu

viz kakot' jej miloval

37. nětế mezi zidy povêděchu

nemohl ten jesto oxi slepému urozenému otvoŕli zpósobi-

$t 1$ aby tento neumièl

38. Ježs opět smuten $v$ sobě $k$ hrobu pristúpi tudiez biese hrob kamenem surchu płiloženy

39. I die Ježs

zdvihněte kámen

Odpovie Marta sestra jeho umrlého

Pane Jizt' smrdi

sturty den jiz lezr

40. 1 die jI Jezis

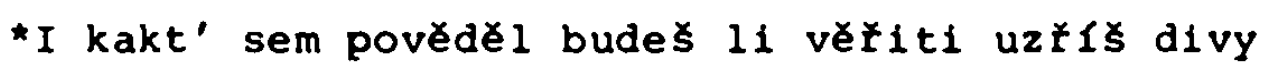


41 .

พ $16 a$

Tehdy Ježs vzdvih oxi vzhóru 1 die

42. nebo sem vĕděl ze s mĕ vždy slyšal

to sem mluvil *pro lid jesto tuto stojie

nebo $s$ ty me poslal

43. Rekl to velikým hlasem křicex

Lazaře vyndi ven

44. a inhed vynide jenż umf̌l

biese nohy a rucě i tvał

v̧̌e by zavázáno

Pověde jim Ježs

Rozvězte a nechajte ho odjiti

45. Tehdy mnozl z Zidóv jenż s Marijl biechu pł̇ł̇li viděv-

Se ten div

věrichu veñ

LV.: W, R, D (in D om. vv. 1.-5.) ] deest A, C, S

- - - - -

1. $\mathrm{V}$ onom Casi] om. $\mathrm{R} ;$ některý stonavý] geden nemoczny gmenem $\mathrm{R}$; hradku] z hradku nebo z ka\$tela R; bratr jich] \$e\$try geho R 2. Ale Maria] $A$ R; zmazala biese] ho\$podyna maza\$§ye $R ;$ uť̌la] vtyera§§e $R_{;}$nohy jeho vlasy] transp. $321 \mathrm{R}$; svimi] om. $R_{;}$jejizto] genz $R-3$. tehdy] Proto $R ;$ poslachu sestry] transp. $R$; sestry] geho add. R; JezlSovi] hoßpodynu $R_{i}$ viz ten] ay $R_{i}$ nemáhá] nemoha $R$ - 4. uslysèv] Tehdy praem. $R ;$ to] om. $R ;$ ta] tato $R ; \quad k$ smrti nez pro] na \$mrt $A$ i e za R; Syn Bož 1 byl ji pochválen] chwalen byl \$yn buozy R - 5. nez] Nebo R; jejl] gmyem add. R; a]

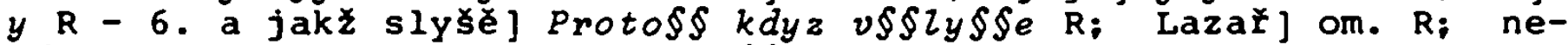
máháse] nemaha $R$, Tehdy gedno o\$\$tal add. $R ; \quad v]$ na $R ;$ miestě] incipit D; osta za] om. R, D - 7. Tehdy potom] Potom $k d y z$ by $R$, def. $D$, po tyech dnech add. R, D; vecé] powyedye R, D; Pod'my opet do Zidovstvie] Gdyemy R, Gdyeme D, do zydow\$twa opyet R, D - 8. Povědie] $Y$ powyedyechu $D$, Odpowyedyechu R: mladCI] vczedlnyczy geho rakucze R, D, opyet add. R; vnovè chtiechu] nenye wecza\$\$ $\mathrm{R}, n y-$ nye $i$ weczas $\mathrm{D}$; tè tam Zidé kamenovati] hledachu tye zydowe zabyty $\mathrm{R}$, hledachu tye zydowe hubyty $\mathrm{Di}$ a] om. $\mathrm{R}_{i}$ tam navracije(S) sè] gde $\$ k$ nym R, D - 9. Odpovie] Odpowyedye R, D; Jezis] a rzka add. $\mathrm{D}$; v'sak] wyem ze add. $\mathrm{R}, \mathrm{D}$; dvanast jest hodin $z a$ den] transp. $31452 \mathrm{R}, \mathrm{D}$; Ktoz ve dne chodl *neurazl (in rasura mg. nawraty ms.) sẻ Nebo acz kto za dne chodyty bude (bude om. D) vrazen nebywa R, D: má tohto sueta] tohoto \$wyeta wydy R, D - 10. Ale chode $v$ noci urazl se] Pakly bude w noczy chodyty vrazen bywa $R$, Pakly bude chodyty w noczy vrazen bude $\mathrm{D} ; \mathrm{v}$ nie] om. $\mathrm{R}, \mathrm{D}$; nenie] $w$ nyem add. R, D - 11. svým mladxim] wecze gym a rzka $R$, D; pŕltel nás] wa\$ prayte $2 \mathrm{R}$; jdu abych ze sna ubudil jej] poydem a zbudymy (-me D) geho ze Sna R, D - 12. Povèdie jemu mladé Pane když J odpowyedyechu mu proto (proto gemu D) vczedlnyczy geho ho\$podyne acz R, D -

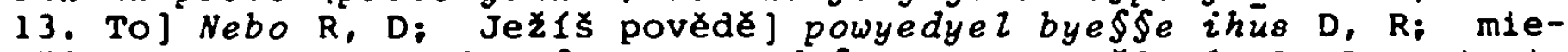
nè] om. R, D; smrt] o §mrty $D$, od \$mrty $R$; nez] Ale R, D; mienichu by o snu mluvil] domnyewachu \$ye o Spany \$nowem mluwy $R, D$ -

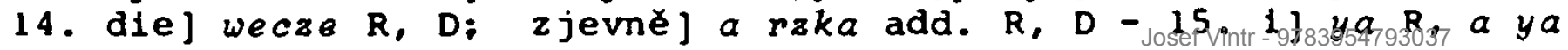


D; vás ] wy R, D, proto add. R; neb sem nebyl tam] Nebo ya neby 2 Sem tu R, D: pod'my] poydem R, poydme D - 16. Tehdy] proto R, D:

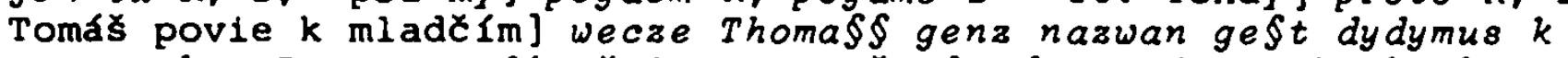
vczennykom R, D: pod'myz i my a umrem] gdyemy (-me D) abychom umrayely R, D - 17. i] Protoz R, D; pílde] praygyde D: najde jej] naleze geho $\mathrm{D}$, nalezne ho a $\mathrm{R}$; $\mathrm{V}$ hrobé leziece] transp. $312 \mathrm{D}, \mathrm{R}$; leziece] lezye $\$$ e $R-18$. Bieš] nebo praem. $R, D ; \quad u$ ] podle $R, D$; za *patnáste (pa\$tne ms.) honóv] v patnaczty honech $\mathrm{R}$, w patnadczyet honech D - 19. mnoz 1] Protoz praem. R, D, mnoho R, $z$ add. D; přijidechul byechu pray\$\$Zy R, D; $k$ Maŕie a $k$ Martej $k$ martye a $k$ ma-

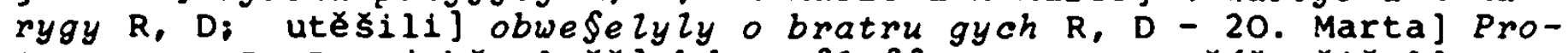
to praem. R, D; jakz slyš j kdyz v\$ly\$\$ye R, D; Ježs płisel] transp. R, D; vyběze protiv němu] praybyeze geho R, przyedbyeze geho $D_{i}$ neż] ale $R, D-21$. i] Tehdy $R, D ;$ povie Marta] martha wecae R, D: Pane] ho\$podyne R, D; zde byl] transp. R, D; mój bratr] transp. R, D - 22. i nynie] gyz to $R, D$; budes zadati na Boze] transp. $3421 \mathrm{R}, 2341$ D - 23. die jle Ježs Vstane] Powyedye gey (gye D) buoh (ihuss D) wakrye§Sen bude R, D - 24. die] y wecze R, we-

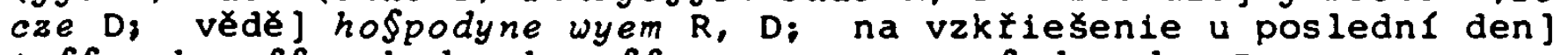
to\$\$ wakrye§\$en bude zkrye§\$enye $w$ zywe w \$udny den $R$, toczyz w\$krzye§en bude D - 25. Povie jI] Powyedye gym R, def. D: sem] om.

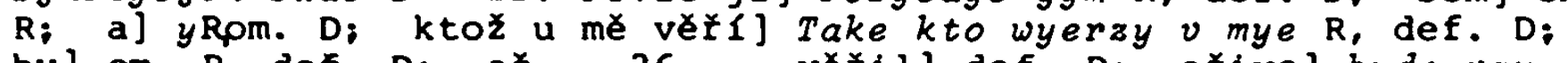
by] om. $R$, def. $D$; ac...26...vě̉ill def. $D$; ožive] bude vaywen $R$ - 26. vక̌eliky] tak kazdy R; ziv jsa] om. $R$; vĕrill u mé] $v$ mye wyerzy $R_{i}$ veŕls] $l_{y}$ add. $R$, def. $D$; tomu] $w$ to $R$, def. $D$ 27. Die] wecze $R$, def. $D ; z a j i s t e ́$ Pane] ow\$\$em ho\$podyne $R, D$; Kristus] om. $R$, def. $D$; jenž s] genz $\$ \$ y R$, def. $D$; na tento svét] def. D - 28. Ýeknuci to jde $i$ povie Marii sestře svéj] $A k d y z$ to powyedye odeyde y zawola maryge \$e\$try $R$, def. $D ;$ Ikuci] y wecze $R$, $\mathrm{D}$ : Mistr priłel] def. $\mathrm{D}$, ge§t add. $\mathrm{R}, \mathrm{D}-29$. ta] Ale ona R, $\mathrm{D}$;

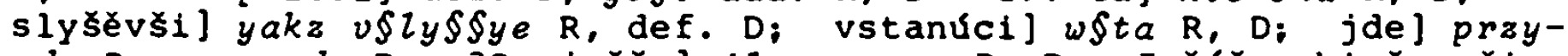
gde $\mathrm{R}$, przygyde $\mathrm{D}$ - 30. jesce] Ale praem. $\mathrm{R}, \mathrm{D}$; Jež́s nebiese priSel] transp. $231 \mathrm{R}, \mathrm{D} ; \mathrm{v}$ hrádek neż] do ka\$tela do hradku $A l e \mathrm{R}$, do Ca\$stelium do hradka Ale $\mathrm{D}$; tu] om. $\mathrm{R}, \mathrm{D}$; biese] w tom mye\$tye add. $R, D ;$ jestol przyede\$la gey add. $R, D_{i}$ protiv němu biese vysla] om. R, D - 31. tehdy Zidé jesto] Proto zydowe genz $R, D ; \quad s$ n1 $v$ domu biechu] transp. $51234 \mathrm{R}, \mathrm{D}$; téslc] y vtye\$\$owachu $\mathrm{R}, y$ v tyeSSowaly $D_{i}$ ze Maria vstavsi vskofe $i$ vynide (wynyede ms.) jdiechu za ní a] marygy ze w\$tala a chodyla na\$\$ledowachu gye $\mathrm{R}, \mathrm{D} ;$ jdet'] Nebo gde\$\$ R, Nebo gdye\$\$e D - 32. Maria] Proto praem. R, D; pri-

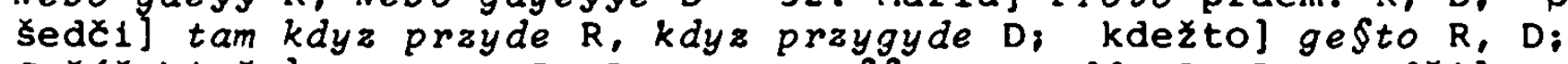
JežY biese] transp. R, D, vzrzyew\$\$y gey add. R, D; padsi] pade $\mathrm{R}, \mathrm{D}$; Pane] ho\$podyne $\mathrm{R}, \mathrm{D}-33$. Jezis] $A$ kdyz praem. $\mathrm{R}, \mathrm{D}$; jakz] om. R: ji uzíj] transp. R, Di Zidy jesto s ni kvielichu steskliv sobe $\mathrm{v}$ duse] zyde genz $\$$ ny byechu przy\$\$ly placzycze $\mathrm{D}$; se $\mathrm{v}$ sobè] duch y zamuty \$ye \$ameho R, D - 34. jest položen] \$te geho polozyly R, D: řeðechu $\mathrm{k}$ nèmu Pane] weczechu gemu R, weczyechu gemu ho\$podyne $\mathrm{D}$ - 35. i poxe slzeti] Tehdy plakal ge§t ihus $\mathrm{R}_{1} \mathrm{D}-36$. Zidé] Proto praem. R, D; Zidé zmluviechu] krzyczyechu zyde R, raeczechu zyde D; viz kakot' jej miloval] Ay kako mylowa\$se geho R, D - 37. neteŕl mezi Zidy povedechul Ale nyekterzy z nych miuwyechu $R$, D: nemohl ten jesto oxi slepému urozenému otvoril zpósobiti aby tento neumiel] zdaly nemohl vczynyty aby by $l$ nevmrzel genz by 2 otworay oczy §lepemu R, D - 38. Jezis] Proto praem. R, D; opert smuten $v$ sobe $k$ hrobu pristupi tudiez] druhe zamuty §ye §am $w$ fobye y przyde $k$ hrobu $A l e$ R, D; hrob kamenem svrchu prilozeny]_kamen na nyem polozen R, D - 39. i die] wecze R, D; kámen] Ale ihüs pozdwyh druhe oczy wecze add. R; Odpovie] odpowyedye gemu $R, D$ : sestra jeho] transp. D, toho \$e§tra R; umrleho Pane Jizt'] genz umrzyel bye\$\$e hofpodyne gyz R, D; sturtý den jiz lezi] nebo tray dny lezal ge\$t 
$R, D, w$ zemy add. $R-40$. i die] wecze R, $D_{i}$ jI] gyey $D_{;}$*I ( $V$ ms.) kakt'] $w \$ \$ a k$ R, $D ;$ sem pověděl budes Ii věriti] def. $D$, Sem powyedyel tobye ze acz $g \$ \$ y$ wyerzy $2 a \mathrm{R}$; divy] chwalu buozy $\mathrm{R}, \mathrm{D}-\mathrm{41}$. Tehdy] Protoz wzdwyzechu kamen $A$ le $\mathrm{R}, \mathrm{D} ; \mathrm{vzdvih]}$ po$z$ dvih druhe $R, D_{\text {; }}$ vahóru] om. $R, D$; $i$ die] wecze $R, D$; tobé Nebo $s$ mé vždy sl(yS)al] toho ze\$ v\$zy\$al mye R, tobie ze v\$ly$\$ a l \$ y$ mye $\mathrm{D}-42$. nebo] ya $\mathrm{R}, \mathrm{D} ; \mathrm{ze} \mathrm{s}]$ ze $\mathrm{R}, \mathrm{D}$; mé vǐdy] transp. $D ;$ slysal] $\$ \$ l y \$ \$ y \$ R, D$; to sem mluvil *pro lid (prolyz ms.) jesto tuto stojie] $A$ le pro tento lyd ge§to okolo na\$\$ \$togye rzyekl \$em aby wyerzyly R, D; nebo s] ze $\$ \$ y R, D-43$. Rekl to] $K d y z$ to powyedye tehdy $\mathrm{R}, \mathrm{D}$; kłice] zawola $\mathrm{R}$, zwola $\mathrm{D}$; vyndi] poyd $R, D-44$. a] Tehdy $R, D$; inhed] w\$ta $y$ add. $R, D$; vynide] pogy-

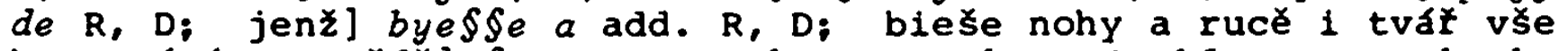
by zavázáno Povèdẻ] Swazanymy nohamy y rukamy A oblyczyey geho bye\$le pro\$tyeradiem (transp. D) zawa\$\$an wecze R, D; Rozvezte a nechajte ho] Odwyzte gey a kazte gemu R, D - 45. Tehdy] Protoz R, D; s) $k$ R; s Mariji biechu prisli] transp. 3412 R, D; s Marijl] $a$ martye add. $\mathrm{R}, a k$ martye add. $\mathrm{D}$; viděvše ten div vĕłichu veñ] wydye $l_{y}$ ge $\$$ to vcayny $z$ wyerzy $l_{y} w$ ney (nen ms.) $R, y$ wydyely ge\$to vcayny $z$ wyerzychu $w$ neho $\mathrm{D}$; veñ] Ale \$wyedecztwye twe nenye prawe add. $R$ ( $C E$. J $8,13 !)$.

LVI. Sabbato post dominicam IV. in Quadragesima $J 8,12-20$

12. $\mathrm{V}$ onom Casi

Pověđěl Jeż́ sboróm żidovským

já sem suětlost suěta

kto následuje po mnè nechodr $v$ temnosti

Ale bude mieti svétlost zivota

13. Tehdy recechu jemu zákonnici

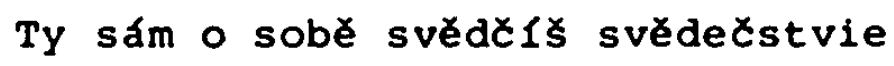

Svèdečstuie tué nenie pravé

14. Odpovědĕ Jež́s i vecĕ jim

AC já suẹè̃stuie sám o sobě nesu

svědečstuie mé pravé jest

nebo vĕdĕ odkad sem płisel a kam jau

15. vy tèlestnè sudite

já nesúdim ijednoho

16. i ac já sudim sưd mój pravý jest

nebo nejsem sám

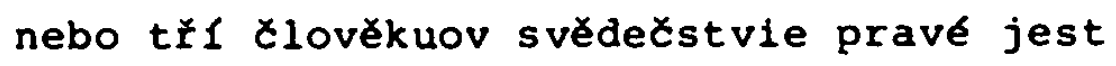

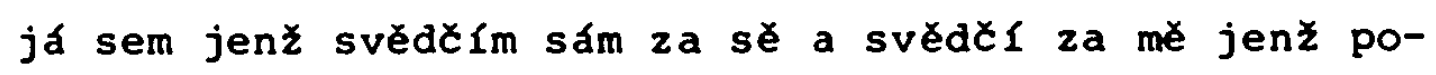
slal mè otec

17. a (u) vasem zákonu psáno jest

Nebo dur clověkuov suẽdecstvie pravé jest

18. já sem jenż suědečstvie dávám o sober 
-.. jenż mè poslal otec

19. Povědiechu jemu Zidé

W $16 \mathrm{~b}$

kde / jest otec tvój

Odpovědě Ježı

ani mne vite ani otce mého

ac mè viete snad byste 1 otcè mého věděli

20. Ta slova mluvil jest Jež́s na slúpu kâze v chrámex

a nikte nesáhnieše rukú nan̆ nebo nebyl pł̆išl cas jeho

LVI.: W, R, D] deest A, C, S

12. V onom Casi] om. R, D; Povedęl] Prawye R, Prawye§fe D; sboróm ¿idovskym] zboru zydow§kemu R, $\mathrm{D}$; svetlost] tohoto add. $\mathrm{R}, \mathrm{D}$; $k$ to následuje] $K t o z$ gde $R, D ; v$ temnosti] we tmye $D$, wyecznye $R$ 13. łečechu jemu] weczechu mu $R$; zákonnici] zydowe $R, D$; sám] $z a$

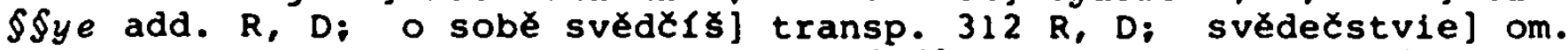
$D$, twe nenye prawe add. $R$ - 14. Odpovede] gym add. $R, D$; svêdexstuie sám o sobé] transp. $2341 \mathrm{R}, 2134 \mathrm{D}$; odkad] adkud $\mathrm{R}$; płisel] om. R, D; jdu] Ale wy newyete odkad fem a kam gdu add. R, D - 15.

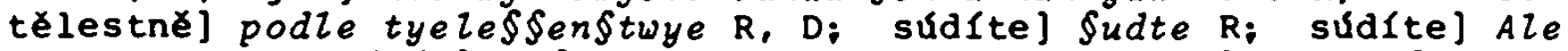
add. $R, D_{i}$ nesudim] ne§uzy $R, D-16.1$ ad ja sudim] pakly $\$ u z y$ ya

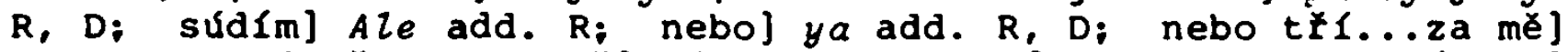
om. R, D: jenz poslal mé] Ale genz mye poßlal R, D - 17. zákonu] zakonye $R, D_{\text {; }}$ Nebo...prave jest] om. $R$; Nebo dvil ze dwu nebo tray D - 18. svědečstuie] §wyedczy R, §wyedczym $D_{i}$ dávám] om. $R$,

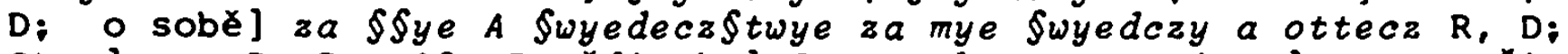
otec] om. R, D - 19. Povẻdiechu] Rzeczechu $R, D ;$ jemu] mu $R ;$ Zidé] proto zydowe $R, D_{;}$méhol wyete add. $R, D_{i}$ ac mé viete] Pakly by§te mne wyedye $l_{y} \mathrm{R}$; mé viete...méhol def. $\mathrm{D}$ - 20. na slupu] om.

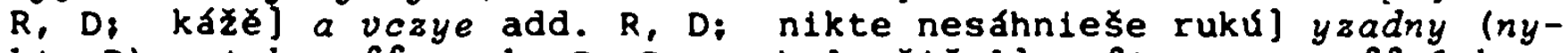

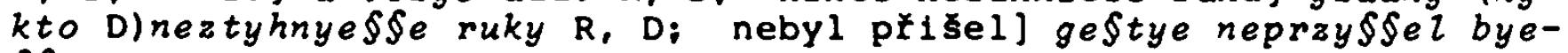
$\$ \$ e$ R, D.

LVII. Dominica V. in Quadragesima - J 8,46-59

S 143a, 46. Pověděl Jezús sboru zidovskěmu a kniežatóm popovým

$\left(148 a_{1}\right) \quad k t o$ mezi vámi bude mé tresktati pro hłiech

AC pravdu pravi proc mi nevěrite

47. kto jest od Boha slova Bozie slysi

proto vy neslyslte nebo ot Boha nejste

48. Odpovê chu jemu そidové łkúce

S $143 a_{2}$

$\left(148 a_{2}\right)$

Jistę do / błe pravime samaritánus ty si a běs jmás

49. odpovědě Jezús

jáz běsu nejmám

ale ctim otce mého ale mne ste vy nepoctili

50. Jáz nehledaji sué chvály

ale jest kto hledá 1 sudi 
51. Cele jisté pravi vám

Bude 11 kto mé kázanie chovati smrti věcné nepokus 1

52. i łeđechu jemu zidové

Již záme že bès jmă

Abraham a proroci jsu zemłeli

a ty pravís kto mé kázanie chová nepokusi smrti

53. zda s ty věcšl našeho otce Abrahama jenž umřel jest

1 proroci

kým ty sè xinßs

54. Otpovèdě Ježứ

AC jáz chváli sè sám nice nenie chvála má

jest otec muoj chvâl mè

jehoz vy pravite Buoh nás jest

55. I nepoznali ste jeho

ale jaz sem znal jeho

A łku li neznal sem budu $s$ vámi $v$ roveñ selhal

Ale jấ vĕdĕ jej

i kázanie chovaji jeho

56. Abraham otec vás radoval sè aby vidĕl den muoj videl a vesel byl

57. Kechu k němu Zidové

pextidcát let jestè nejmás a viděl si Abrahama

58. vece jim Ježús

Jiste pravi vám

dřéve nez Abraham byl jáz sem

59. vzechu $\mathbf{z}$ idové kamenie aby nañ metali

ale Jezús skry sè 1 vynide z chrámu

LVII.: S, C, D, R, W] deest $A$

46. Povědēl] Mluwye§\$e R, C, D, U onom czya\$\$y praem. W; Ježus] $k$ add. $\mathrm{R}, \mathrm{C}$ : popovym] $A$ tak $r z k a$ add. $\mathrm{R}, \mathrm{D}$, tak rzka add. C: mezi vámi] z wa\$§W; bude] om. D; pro hriech] z hrzyechu W: pravi] wam add. W, C, D, R; mi neverite] newyerzyte mnye $W-47$. Boha] ten add. C, D: slova] \$lowo C; Bozie] bozyeho W; slysi] po\$lu-

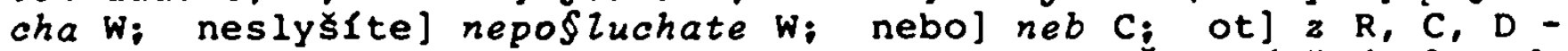
48. Odpověchu] Odpowyedyechu W, R, C, D: jemu Zidové łkuce] zydowe a rzkucze gemu $\mathrm{R}, \mathrm{C}, \mathrm{D}$, zyde y weczyechu $\mathrm{W}$ : Jiste] $2 d a l y \mathrm{R}, \mathrm{C}$, D, Ge§\$czye W: dobře] my add. R, C, D: pravlme] prawymy W, D, nebo add. W: Samaritánus ty si] transp. 231 R, C, D, W, y pohan add. C, nebo pohan add. R, D: běs] bye§\$a R, C, D, dyab [a W: jmás] $w$ Sobye add. D, R - 49. běsu] bye\$\$a R, C, D, dyabla W: mne ste vy] transp. $321 \mathrm{R}, \mathrm{C}, \mathrm{D}, \mathrm{W}$ - 50. své] me $\mathrm{R}, \mathrm{D}, \mathrm{mey}_{\mathrm{W}}$; ale] om. W; i] a $W$ - 51. Cele] Zawyerne W, C, D, zawyerno R, $y$ add. $C, a$ add. D; jisté] zagy§te $W, R, C, D ;$ Bude li kto mé kázanie chovati] Acz kto 
me \$lowo bude chowaty $W$; věné] om. W: nepokus 1] nevarzy na wyeky W, y nepoku\$\$i na wyeky C, nevarzy y nepoku\$y na wyeky R, D 52. i] Proto R, D, praem. C, om. W; retechu] weczechu R, C, D; známe] znamy W, D; běs] bye\$\$a R, C, D, dyab Za W; Abraham] vmrzye gie§t add. W, R, C, D; a] y W; jsu zemřeli] om. R, W, C, D; pravił kto mé kázanie] dye§\$ Acz kto kazanye me W: chovaj bude chowaty R, C, D; nepokus $\{$ smrti] \$mrty neoku\$\$y na wyeky $R, C, D, n e-$ vzrzy \$mrty na wyeky $W-53$. zda $s]$ zdaly\$ R, zdaly \$y C, $D_{;}$věcSI naseho otce Abrahama] wyeczyey nez na\$\$ otecz Abraham $w$; i] $a$ W: proroci] zemrzely g\$\$u add. R, C, D, umrzyely g\$\$u add. W; kým ty sĕ] Czym §ye ty R, D, Czym ty \$ye C, Czo z \$ebe W - 54. chvalil] chwalym W, R, C, D; sê sám] transp. $R ;$ transp. $3412 \mathrm{~W}$; má $A Z$ e add. $R, C, D$; muoj] genz add. $W, C, D$, gez add. $R$; Buoh nás jest] by bil wa\$\$ buoh $W$, ze buoh wa\$\$ ge\$t $R, D$, by boh wa\$\$ by $Z C-55.1]$ a $W$, aw\$\$ak $R, C, D$; nepoznali ste] neznate $\mathrm{R}, \mathrm{C}, \mathrm{D}$; A rku li] Pakly rzku R, C, D; sem] geho add. $W, R, C, D$; $v$ roveñ] zarowno $W, R, C, D$; selhal] nazwan Lharz R, C, D, Lharz W; jaz] om. W, R, C, D: jej] geho R, C, D

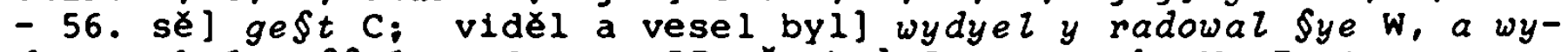
dyew y by $z$ we\$\$el R, C, D - 57. Rechu] Rayeczyechu W, Proto rzeczechu $R, C, D ; k$ nèmu] mu R, gemu $D, k$ nym C; Pětidcát] Pade\$\$at W, $R, C, D$; videll si Abrahama] wydye $2 \$ \$$ Abraham $W-58$. vece] Powyedye $W, R, D$; vece...pravi] def. $C$; Jisté zagy\$te $R, D$, zawyerne zagy§te $W$; byl] om. $R_{i}$ sem] by $Z$ add. W - 59. vzechu] Tehdy proty nyemu R, C, D, podwyhachu W; Zidove] zydye C, zyde W, zdwyzechu add. R, D, wzdwizechu add. C; aby nañ metali] aby nan luczyely $W$, y luczely nan R, C, D; ale] om. W.

LVIII. Feria II. post dominicam V. in Quadragesima $J 7,32-39$

W 17a 32. V onom Casi

Poslali kniežata a zákonníci a licomérníci služebniky aby Ježše jeli

33. Rekl jim proto Ježrs Ješce malý cas s vámi sem a pójdu $k$ tomu jenž mé poslal

34. hleda(te) mne a nenaleznete a kdež já sem vy nemóžete přijiti

35. Povĕděchu żidovê sami k sobè kam chce tento jiti at ho nenalezn's zda mezi pohany chce jlti uxiti jich

36. která jest to rex jenž rekl hledate mne a nenaleznete a kam já jdu vy nemóžete prijiti

37. Na posledni den veliky hodný stăe Ježı̌ i volałe a řka kto chce piti pŕlda ke mné i pi

38. ktož věri u mé jakoz pismo pravi 
potoci z jeho bricha potek's żivé vody 39. Ale to pověder z Duchu jenž vzlti méjlchu vểice veñ

LVIII.: $W, R, C, D]$ deest $A, S$

32. V onom ‘asi] om. $R, C, D ;$ a licomérńlci] om. $R, C, D$; služeb$n[k y]$ Swe add. $R, C, D$; aby Ježiłe jelil om. $R$ - 33. Kekl jim proto] proto wecze gym $\mathrm{R}, \mathrm{C}, \mathrm{D}$; malý] nemaly $\mathrm{R}$, namaly $\mathrm{C}, \mathrm{D}$; mé] ge add. $C$ - 34. hledá(te)] hledate $\mathrm{R}, \mathrm{C}, \mathrm{D} ; \mathrm{a}$ ] ale $\mathrm{C}$; nemóžete] nemozte $\mathrm{R}$ - 35. Pověděchu] Proto weczechu R, C, D; Zidové sami $k$ sobé] me-

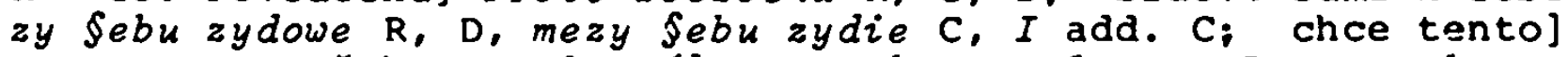

transp. $\mathrm{R}_{i}$ ac ho nenalezn'S] acz geho nenaleznem $\mathrm{D}$, ze geho nenaleznem $C$, gehoz nenalezemy $R, A$ add. $R, D ; j[t i]$ a add. $R, C, D$; jich] ge R, C, D - 36. ktera] kaka R, C, D; jest to] transp. R, C, D; jenž rekl] ge§to mluwye§\$e a rzka $R, C, D_{i}$-date mne a nenaleznete] def. C; a] om. $R_{i}$ a kam] a kamo C, D, a kaz R; nemóžete] nemozte $\mathrm{R}-37$. Na] $A$ na $\mathrm{C}, \mathrm{D}, A \mathrm{R}$; hodný] hod $\mathrm{R} ;$ i] a $\mathrm{R}, \mathrm{C}, \mathrm{D} ; \mathrm{a}$ rka] $A C z$ add. $\mathrm{R}, \mathrm{C}, \mathrm{D}$; i] ten $\mathrm{R}$, om. $\mathrm{C}, \mathrm{Di}$ pi] pyze C - 38. oismo pravi] prawy y \$\$wyedczy py\$mo R, C, D; bricha] braycha y zywota R, D, zywota y z brzycha C - 39. z Duchul \$wateho add. R, C, D; jenž] genze C, chtyechu add. $R, C, D$; méj[chu] om. C, D; vzlti] wyerzyty $R$; věrlce veñ] transp. $R, C, D$.

LIX. Feria III. post dominicam V. in Quadragesima $J 7,1-13$

1. V onom Casi

Chodiese Jež́s do Galilea /

W $17 \mathrm{~b}$ a nechtieš jIti do Zidovstva

nebo hledachu jeho Zidovstvo zabiti

2. nebo biese den hodný židovský bliz

3. vecéchu jemu bratie jeho Odejdi odtad a di do Zidovstva

aby ucennlci tvoji videxli tvá diela jesto ty cinis

4. Nebo nizadny tajnè nicse *nečin 1

Ale on hledá zjevné býti

ac to ‘inı́s zjevies se sám suẹtu

5. ani bratrie jeho věrichu veñ

6. Proto vecé jim Jež́s

Cas mój jeß̌e nepřisel

Ale cas vás vezdy jest hotov

7. Nemóż suět nenáviděti vás

Ale mè nenávidie

Nebo já suědečstuie o tom dávám Nebo diela jeho zlá ș

8. vy jĕte $k$ tomuto hodu

ja nepójdu $k$ tomuto dni hodu

Nebo nepriłel ješe cas mój 
9. To kdyz on pověder sám osta v Galilee

10. A kdyz bratřie jeho $k$ tomu hodu jidechu

Tehdy on jide

ne světle ale tajemne

11. Tehdy zidové hledáchu jeho na tom suátku a řkíce kde jest ten

12. a bieše veliké šeptánie o ňem $v$ lidu

Tu nèteřl diechu že jest dobrý

a jinf diechu nenie

Ale svodr lid

13. nižáný zjevně nemluviše o nĕm pro strach żidovský

LIX.: W, R, D, C (v. 3. des. C) ] deest A, S

1. V onom Casi] om. R, C, D; Galileal galylee R, D; a] nebo R, C, $\mathrm{Di}$ nechtieš] nechtyechu $\mathrm{R}$; nebol zze $\mathrm{R}, \mathrm{C}, \mathrm{D}$; Zidovstvo] zydowe $\mathrm{R}, \mathrm{D}$, zyde $\mathrm{C}-2$. nebo] $A$ tehdy $\mathrm{R}, \mathrm{C}, \mathrm{D}$; bliz] \$cenopheya tak rzeczeny add. $\mathrm{R}, \mathrm{C}, \mathrm{D}-3$. vecéchu] Tehdy oraem. $\mathrm{R}, \mathrm{C}, \mathrm{D}, \mathrm{rzecze-}$ chu $\mathrm{D}_{i}$ Odejdi] odfed R; odtad] odtud $\mathrm{R}, \mathrm{C} ; \mathrm{a}$ di] om. $\mathrm{C}_{;}$tvá] twoge $R_{i}$ ¿in[S] des. C - 4. nižsdný] ygeden R, $D_{i}$ nitse *nexin 1 (-ye ms.) Ale on] nycz vozyny $I \mathrm{R}$, nycze czyny I $\mathrm{D}$; hled\}] fam

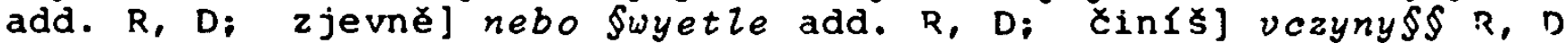
- 5. ani] A nycz $R_{i}$ věrichu veň] wen ge§czye wyerzychu $R, D-6$. vecĕ] powyedye $D_{i}$ vecĕ jim Ježls] transp. $312 \mathrm{R}, \mathrm{n}, a$ rzka add.

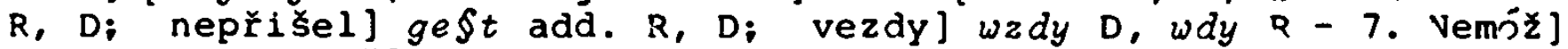
Vemoze $R, D ;$ mé] mne $R, D ;$ já svèdecstvie ... 3. ... hodu] om. R,

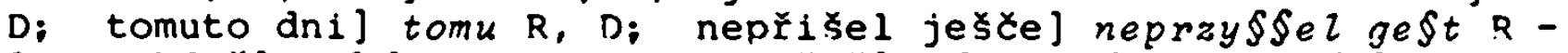
9. To kdyz] $A k d y z$ to $\mathrm{R}, \mathrm{D}$; povede] odpowyedye $\mathrm{R}$; $\mathrm{s}$ ám] on add. $R, D ;$ Galilee]galizey $D$ (a hoc loco in D media columna abscissa) - 10. A kdyz] def. D,tam gydechu add. R; bratfie] bratrzy R; hodu] Iydu R, def. D; jidechu] om. R, D; Tehdy or.]def. $D ;$ jide]

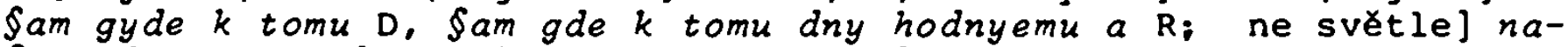
Swyet le D; ale] a yako R, D; tajemne] taynye R, def. D - 11. Tehdy] def. $D ;$ Zidové] proto add. $D ;$ hledáchu] proto add. $R ;$-dáchu jeho na tom] def. $D$; kde jest ten] def. $D$ - 1?. a] y $R$; a bie-] def. $D$; Septánie o ňem $v$ ] def. $D$; Šptánie] reptanye $R ; ~ v$ lidu] mezy \$borem R, \$borem D; Tu nèteŕl diechu] Nyekterzy prawychu R; - ŕ diechu ze] def. $D$; diechu ne-] def. $D$; diechu] prawyechu $R$ : neniel tak add. $R, D ;$ Ale] $z e$ add. $R, D$; svodi lid] def. $D ;$ lid] lydy R - 13. nizádný zjevně nemluviše o něm] y \$bor zadny proto 0 nyem zgewnye mluwye§§e R, Nykte proto o nyem D; zjevné nemlu-] def. D; strach] lyd R, D.

LX. Feria IV. post dominicam V. in Quadragesima J $10,22-38$

22. V onom ¿asi Staly sě hody $v$ Jeruzalemé a zima biese

23. A chodieše Jež́s $v$ chráme i $v$ obchode Salomúnově 
24. ostúpichu jej Zidové Y̌ecechu jemu

i dokovad duši nasłi bétes

Jsi li ty Kristus pověz // nám zjevně

25. Odpovědě jim Ježs

Mluviem vám nevěrite

Diela která já cinim ve jmè otcĕ mého

ta suědecstuie povědie o mne

26. Ale vy nevĕlte nebo nejste $z$ ovec mých

27. Ovcè mé hlas mój slyšle

1 já je znám

1 chodie po mne

28. a já věčny żivot dávám jim

a věčñ nezahynu

ani jich kto vynme $z$ mych ruku

29. Otec mój jenż mi dal věçı jest vకěch

a nikte nemóz vynieti z rukú otcé mého

30. já a otec jeden sue

31. podvižechu kamenie Zidové aby jej kamenovali

32. Odpovẽde jim Jezis

Mnoho dobrého diela ukázal sem vám od otcē mého Pro nézto dielo chcete mè kamenovati

33. Odpověděchu jemu Żidové

$z$ dobrého diela nekamenujem tebe Ale $z$ mluvenie anebo ty clověk jsa tinfక sè Bohem

34. Odpovědĕ jim Ježr

Ne zda psáno jest $v$ zákonè vałem

Nebo já sem Ǐekl bozi jste

35. AC sem Y̌kl bohy $k$ nimžto slovo Božie uxinéno jest a nemóz písmo dosvědeiti

36. jehozto Otec osvětil i poslal na suět vy pravite ze mluvim lżi Nebo łekl sem Syn Boź sem

37. AC nexin Im skutkuov otcĕ mého nerod'te mně věfiti

38. pakli ‘ini

v̧ak mi nechcete věiti

skutkóm věrte

abyste poznali a věrili nebo ve muè jest otec a já $\checkmark$ otci

LX.: $W, R, D]$ deest $A, C, S$

22. $V$ onom Casi] om. $R, D ;$ hody $v$ Jeruza-] def. $D ;$-ma biese] 
def. D - 23. A] Tehdy R, def. D; chrámě...Salomunovę] def. D; $i$ u obchodel $w$ vochodye $y$ w\$ecany chodye $w \mathrm{R}-24$. ostupichu] $y$

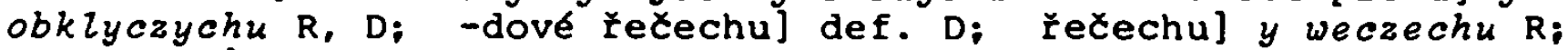
$i$ dokovad] y odkavad $R$, podkowad $D_{;}$duši nasi béres] def. $D ;$ nám zjevně] nam \$wyet le $R$, def. $D-25$. Ježls] om. $R, D, a$ rzka add. $R ;$ vám] a add. $R$, $D$; nevěrlte Diela] def. $D$; Diela] dye 2o $R ;$ která já] ge§to R, D; Cinfm] czyny D; otcé mého] def. D; ta svèdexstuie povědie o mą] ta a mye \$wyedczy $R, D-26$. Ale vy nevě-l def. $D ; z$ ovec mých] def. D - 27. hlas mój] transp. R; slysie 1 ja] def. $D_{i} i$ já] Ay ho\$podyn $R_{i}$ je znám] znagy ge $D$, zna ge $R_{;}$ $i$ chodie] y gdu R, def. $D ;$ po mne] def. $D-28$. a já] def. $D ;$ věcný zivot] transp. R, D; -vám jim] def. $D_{i}$ a] proto add. R; a vextnè] def. $D ;$ věnnè nezahynu] nezhyne $\mathrm{D}$, nezahyne z nych gedna wyecznye $\mathrm{R}$; vynme] wygme $\mathrm{D}$, wytrhne $\mathrm{R} ;$ vynme $z$ mych ruku] transo. 2341 $R, D-29$. mój...věčri] def. D; dal] ge§t add. R; všech a nikte

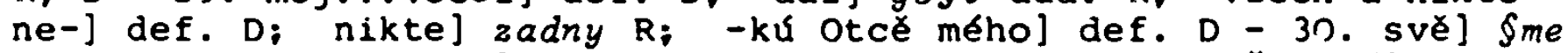
$\mathrm{R}, \mathrm{D}-31$. podvižechu] Pozdwyhnu $\mathrm{R}$, def. $\mathrm{D}$; kamenie Zidové] kamene zyweho $R ;$ aby jej kamenovali] aby nan by $z_{y} R$, def. D - 32. Jdpovédẻ] Powyedye R, D: Mnoho dobré-] def. D; ukázal] pokazal R, D: sem vám od Otcé] def. $D_{i}$ od Otcé] ottczy $R ;$ dielo chcete mé] def. $D$ - 33. -dpověděchu] def. $D$; jemu] $m u$ R; -brého diela] def. $D ;$ nekamenujem tebe] transp. $R_{i}$ tebe] def. $D_{i} z$ mluvenie] ze zleho prohoworzenye $R$, -worzenye $D$; ty Xlovék] ty czlowyekem $R$, def. D;

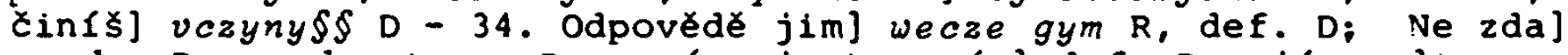
wyedye $\mathrm{D}$, wyedye to ze $\mathrm{R} ;$ psáno jest $\mathrm{v} z a-j$ def. $\mathrm{D} ;$ já sem]transp. $R$ : Nebo já sem rekl] def. $D ;$ bozi] bohowe $R, D$ - 35. sem Yekl] ty add. $R$, def. $D ; k$ nimžto] $w$ nyemzto $R_{i}$ slovo Božie] transp. $R ;$ Božie...nemóz $\left.p{ }^{-}\right]$def. $D ;$ dosvéď́iti] dowe§ty $R, D$ - 36. jehožto]

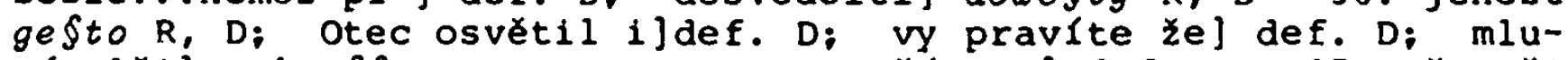
vím lzij] pohor\$§ugy $R, D$; sem Syn Božl sem] def. D - 37. AC neti-

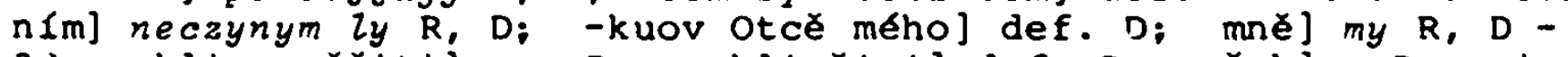
33. pakli...věritij om. $R$; pakli Łini] def. $D ;$ vsakj a $D ;$ mi nechcete] transp. $D_{i}$ věriti] def. $D, A Z e$ add. $R ;$-byste poznali] def. $D_{i}$ a] $y R$, def. $D ;$ mne jest Otec a] def. $\left.D_{i} j a\right\}$ ] $\$$ em add. $R, D ; v$ Otci] $w$ mem otcay $R, w$ nyem $D$.

LXI. Feria V. post dominicam V. in Quadragesima $J 7,40-53$

40. V onom Casi

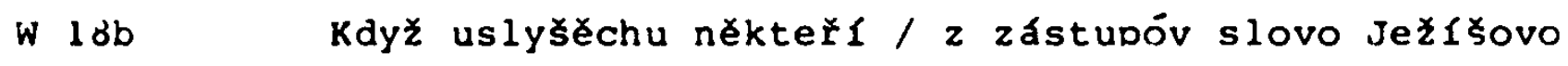
povědęchu

toto jest jiste prorok

41. jinl vecěchu

To jest Kristus

někteř 1 diechu

zda jest z Galilea Kristus prišel

42. Ano plsmo pravi

že z Davidova semene a z Betléma $z$ hrádku kde byl David odtud Kristus prisel

43. hněv sě sta mezi sborem proñ

44. Někteł̆ $z$ nich chtiechu jej jiti 
Ale nižádný pustil nañ ruky

45. Tehdy přijidechu panose ku biskupóm a k zákonnடkóm řęechu oni jim

prod ste jeho nepřivedli

46. odpovèděchu jemu sluhy

Nikdy tak nemluvil clověk jako tento Łlověk

47. Odpověděchu jim zákonníci

A zda ste vy svedeni

48. A zda kto z kniežat věrí veñ Nebo *zákonnIkóv

49. Ale $z$ toho sboru jesto neznali zákona prokleti su

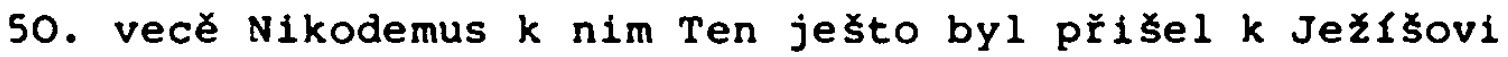
$v$ noci jenz biese jeden 2 nich

51. Ne zda nás zákon sứl clovèka

jedno uslyšl od nèho a pozná co Łinl

52. i odpovĕděchu i vecéchu jemu

Ne zda ty z Galilea jsi

ztázati plsma $i$ viz Nebo prorok z Galilea nevstane

53. i vrátichu sè každý v dóm svój

LXI.: W, R, D] deest A, C, S

40. V onom ¿asi] om. $R, D ; k d y z$ usly-l def. $D_{i}$ uslysechu] v\$2y-

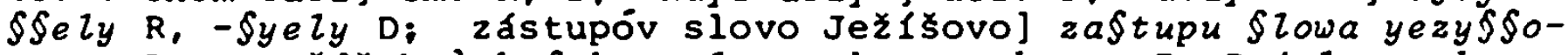
wa R, D; povědéchu) $k$ \$obye mluwyechu a rzkucze R, D (mluwyechu def. D); toto jest] def. D; toto jest jiste] A gy\$tye toto ge $\$ t$ $R$; prorok] def. D - 4l. jinl] A praem. $R, D ;$ vecechu] prawyechu $R, D ;$ To jest Kristus] def. D, $A$ add. $R, A l e$ add. $D ;$ diechu] prawyechu R; zda jest] def. D, zcaly ge\$t R; Kristus] def. D; Kristus přisel] transp. $R-42$. Ano $p$ [s-] def. $D_{i}$-vidova seme-] def. $D_{;}$semene] bye $\$ \S e$ add. $R ; z$ hrádku kde] a $z$ rodu genz $R$, def. $D$; byl] bye $\$ S e R, D ;$ odtud] odtad R, D; Kristus pfisel] def. D, przy-

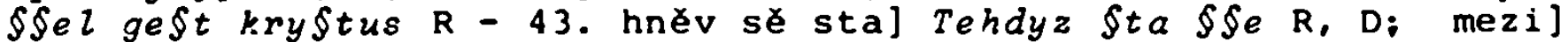
def. D, pro nye praem. $R ;$ sborem proñ] \$borem knyez\$kym D, \$borem zydow\$kym y knyez $\$$ kym $R-44$. Něktefl z nich] def. $D_{i}$ jej jiti] transp. D, gyety geho R; Ale] def. D, Aw\$\$ak R; nizádny] ygeden $\mathrm{R}, \mathrm{D} ;$ pustil] nehnnu $\mathrm{D}$, om. $\mathrm{R}$; rukyl ruku $\mathrm{R}, \mathrm{D}-45$. Tehdy plijidechu] def. D, Protoz przydu R; Danose ku] $\$ l u h y k R, D ;$-póm a zákon-] def. $\mathrm{Di}$ zákonn[kóm] y add. $\mathrm{R}, \mathrm{D}$; řecechu] weczechu $\mathrm{R}$; oni jim proč] def. $D-46$. odpověděchu] def. $D ;$ jemu sluhy] pano$\$ \$ y e \mathrm{R}, \mathrm{Di}$ tak nemluvil] nemluwy ge§t $\mathrm{D}_{\text {; }}$ clovek] def. $\mathrm{Di}$ tento clověk] def. $D, m\{u w y$ add. $D, R-47$. -děchu jim zá-] def. $D ; A]$ om. $R_{i} D ;$ ste] $y$ add. $R ;$ vy svedeni] def. $D-48$. A] def. $D ;$ vĕŕl veñ] def. $D ;$ *ákonn[kóv (-nye-ms.)] z zakonow $R, D-49$. 2 to-

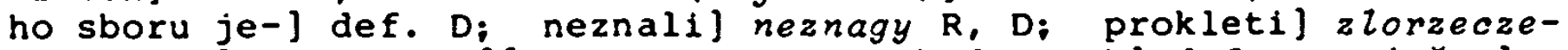
ny $\mathrm{R} ; \mathrm{suj}$ y klety $g \$ \$ u$ add. $\mathrm{R}$ - 50. Nikodemus $\mathrm{k}$ ] def. $\mathrm{D}$; jesto] ge§t $R, D ;$ pfišll) def. $D_{i} k$ Jež́švil ten add. $D ; k$ Jež́sovi $v$ noci] transp. $3412 \mathrm{R}$; $v$ noci jenz biesel def. $D-51$. Ne] om. $R$,

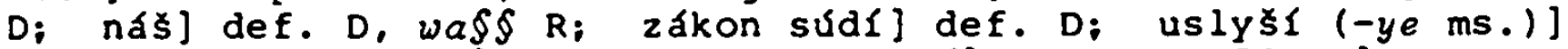
$R$, def. $D ;$ od něhol om. $R, D ;$ a poznal def. $D-52$. i] om. $R, D ;$ -věderchu $i$ ve-] def. $D_{i} i$ vecéchu] om. $R_{i}$ jemu] mu $R ;$ Ne] $A R_{\text {, }}$ D; ty...jsi] def. $D_{i}$ Galilea] galylee $R_{i} z$ tázati plsma] Srozu- 
myey py $\$ m u R$, vrozumyey py\$- D; 1 viz Nebo] def. D, a wyezzze R; nevstane] new\$tawa $R$, ne- D - 53. i vrá-] def. $D$; $v$ dóm svój\} def. D.

LXII. Feria VI. post dominicam V. in Quadragesima J $11,47-54$

47. V onom Xasi

Sebrali sê biskupi a zákonnfci v radu i pověděchu Co uxinfmy že tento clověk veliké divy cinl

48. AC jej pustımy tak vక̌̌ckni veñ uvěrie

w 19a

a pridú kímané i zdvihnú nase miesto // i lid

49. Jeden $z$ nich Kaiphas jménem Kdyz biese biskupem toho léta vecé jim

vy neviete nitce

50. ani pomyslite nebo hodr sè vám aby jeden tlověk umře l za lid aby ne vsecken lid zahynul

51. Toho sam od sebe nepovědél

Ale kdyz biese biskupem toho léta prorokoval

aby Jež́s umřel za lid

52. A netolik za lid

Ale aby synové Boż jenż biechu rozdél(e)ni ve vకè královstvie sebrali se na hromadu

53. Od toho dne poxechu mysliti zablti jej

54. Ježš jiz nezevnè chodiese u ziduov

Ale jide do vlasti podlé pušxe do mèsta jemuž jmè Effrem

A tu bydlése s uxenniky svými

LXII.: W, R, D] deest $A, C, S$

------------

47. V onom Casi] om. $R, D$; Sebrali] def. D; se] om. $R, D$; v raduj Sfnem $R, D$ (in $D$ hoc loco columna abscissa finivit); ucinlmy) vczynyme $D:$ velike divy] welyka znamenye $R, D-48$. jej pustimy pu§tymy geho $R, D$; vłécknil w\$\$yczkny $R, D ;$ veñ uvěriel transp.

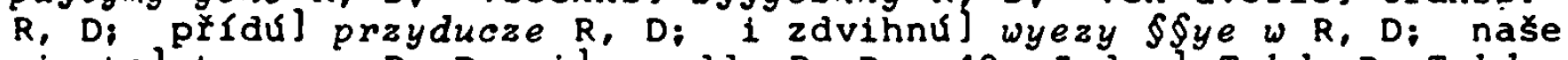
miestol transp. R, $\mathrm{D} ; \mathrm{i}]$ w add. $\mathrm{R}, \mathrm{D}-49$. Jeden] Tehdy $\mathrm{R}, \mathrm{Tehdy}$ praem. $D ;$ vecé $j i m$ ] om. $R$ - 50. pomyslite] rozumyete $R$, $D$; ne vłecken] we§ken $R, D ; z a h y n u l]$ nezahynul $R, D$ - 51. prorokoval]

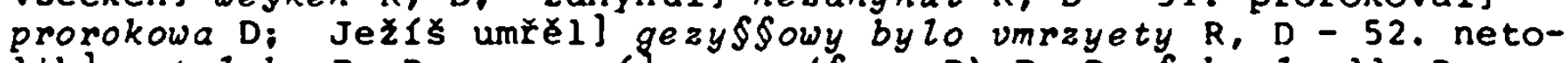
lik] netolyko R, D: synové) syny (\$amy R) R, D, Sebral add. D; Bozi] Sebral add. R; rozděl(e)nil rozdyeleny $R$, $D ;$ královstvie] kralow\$two R, D: sebrali se] \$ezwaw ge R, D - 53. Od] gedno praem. $R_{1} D_{i}$ dne] proto add. $R$, $D_{i}$ mysliti\} miuwyty $R ;$ zabiti jej\} aby

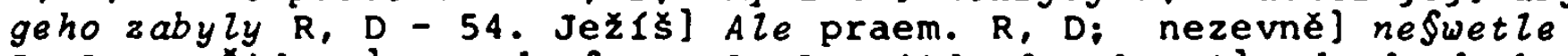
$\mathrm{R}, \mathrm{D} ; \mathrm{u} \mathrm{Z}_{\text {iduov] } w}$ zydow\$twye R, $\mathrm{D}$; jide do vlastilintodgude do kra- 
Low\$twye R, D; do mésta] $w$ mye§to $R, D ;$ jemuž gemuzto $R ; A$ tu bydlése] $A$ by tu R, y by tu D.

LXIII. Sabbato post dominicam V. in Quadragesima J 17,1-11

1. V onom Casi

Podvihl Jež́s oxi $k$ nebi povědĕ

oťe płišl cas oxisti syna svého

aby syn tvój ocistil tě

2. jakoz jemu dal v'̌eho tělesenstvie aby vłeho jenž si dal jim život věčny

3. a to jest život vě̌ný aby poznali tè samoho pravého Boha a jehoz si poslal Jež́se Krista

4. já té oxistil na zemi

dielo dokonal jenz si mi dal abych uxinil

5. A nynie *oxisti mé ty otce u tebe samého ¿istot(u) mú jez mél u tebe samoho dřieve než suét byl

6. zjevil sem jméno tvé lidu které s mi dal na světè Tvoji byli a mně s jĕ dal a kázanie tvé chovali

7. jiz poznali nebo vłè krome tebe sú které $s$ mi dal

W 19b 8. nebo slova / ktera s mi dal dal sem jim ani sư vzali i poznali věrně jez sem od tebe poł̌l a věrili sú jez si mé poslal

9. jă za nĕ prosím ne za suèt prosím ale za ty jez si dal nebo tvoji su

10. a tvé vše mé jest a mé tvé jest oðišen sem $v$ nich

11. a již nejsem na svĕtĕ Ale oni na světě sú a já $k$ tobè jdu

LXIII.: W, R, D (in v. 8. expl. ms. D)] deest $A, C, S$

1. V onom Casi] om. R, D; Podvihl] Pozdwyh D, wzdwyh R; Ježs oxi] transp. $R, D ; k$ nebi pověde] $w$ nebe y wecze $R, D ;$ oxisti] o§law $R, D ;$ svého] tweho $R, D ;$ oxistil] o\$lawy $2 R, D-2$. jakoz jemu dal vక̌ehol yakoz $\$$ my dal mocz z \$weho $R$, D; vకeho] w\$\$ye R, D: dal] my dal add. D - 3. samoho] \$ameho R, D; pravého Boha] transp. $R, D-4$. jal] §em add. $R, D ;$ oxistil] oł[awy $D, R-5$. nynie toxisti (-ye ms.)] gyz o\$law $R$, $D ; ~ u$ tebe samého] om. $R, D$; ristot(u) mu jez mel u tebe samohol \$lawenym ge§to fem myel w tobye ( $v$ tebe D) $R, D-6$. jméno tvé lidu] twe gmye lydem $R, D$; které s] kterez $\$ y R, D ;$ na] $w R, D ; s] \S \S y, D ; \quad k a ́ z a n i e ~ t v e ́]$ 
take g\$\$u twe kazanye czynyly y R, D - 7. poznali] $\$ \$ u$ add. R, D; kromé tebe su které s mi dal\} genz $g \$ y$ my dal od tebe g\$u D, R -

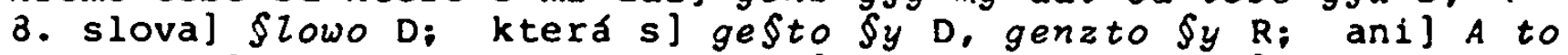
$\mathrm{R}$, $\mathrm{D}$, expl. $\mathrm{D}$, ony add. $\mathrm{R}$; vzali] vczynyly $\mathrm{R}$; jez] ze $\mathrm{R}$; od tebe] om. $R ;$ a věłili sú jež] om. $R$ - 9. ale za ty jež si dal] om.

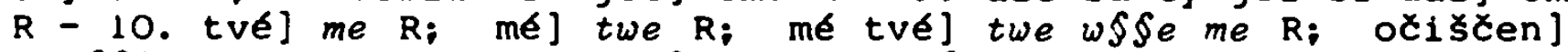
$y$ o\$ईlawen $R$ - 11 . na suété] z tohoto \$wyeta $R$.

LXIV. Dominica in Palmis - J17,11-26

R 115b, 11. (0)tと̌e svatý schovaj *jè $v$ jmé tvé jenž mi dal aby byli jeden jako i my

12. když biech s nimi já chovach *jè v tvô jmè jenż si mi dal choval sem

A ižáný $z$ nich nezhynul jedno syn ztrátce

a to aby se pismo naplnilo

13. Ale jiz $k$ tobé prijidu

A to mluvím na světé aby oni jměli radost mu i naplnili sami $v$ sobè

14. Já sem dal kázanie tvé

a suět *je nenávidĕl

Neb sư nenáviděli světa jakož já nejsem z suéta

15. Neprosi aby jè pojal z suéta ale choval jé od zlého

16. 〈z〉 suěta nejs's jakož já nejsem $z$ světa

17. A suět' jè u pravdě

Nebo kázanie tué pravda jest

18. kak s ty mé poslal na suèt...

19. a za nè prosím já i tosvěcuji mè samého aby *osvéceni byli oni u pravdè

20. Ale neprosim za ty toliko

ale za ty prosím jesto věrlcí sú skrzé slovo jich u mè

21. Aby v̌̌ickni byli «jeden jakož ty otðe si ve mnĕ a já $\checkmark$ tobé

Aby tak oni byli $v$ nás jeden

aby suět tomu vĕril že si ty mè poslal

22. A i slávu jenžto si mi dal jim sem dal

Aby byli jeden jako i my jeden smy

23. já $v$ nich a ty ve mnex

aby byli dokonáni $v$ jeden

aby poznal suět že ty si m〈ě) poslal

i miloval si jé Jakož si mě miloval

24. Otłe které si mi dal chci tomu aby kde já sem aby oni 
by li se mnu

R $115 b_{2}$ A také aby vidéli slávu mu jenž si al / dal

Nebo miloval si mĕ pł̌̀d stvořením suěta

25. Otð̌e právě tebe suět nepoznal

Ale ja sem tè poznal

a ti jistl tĕ poznali Nebo si ty mě *poslal

26. A oznámil sem jim tvé jmè $i$ ještè oznamuji

Aby milost jǐ si mé miloval $v$ nich byla a já $v$ nich

LXIV.: R] deest $A, C, D, S, W$

11. *je (gey ms.) - 12. *jĕ (gey ms.) - 14. *je (ge§t ms.) - 18. (et ego misi eos in mundum vulgata) om. ms. - 19. *osvěcuji (o\$wyedczu-

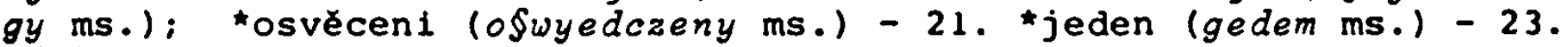
m(é) (my ms.) - 25. *poslal (poznal ms.).

LXV. Feria II. post dominicam in Palmis - J 12,1-36

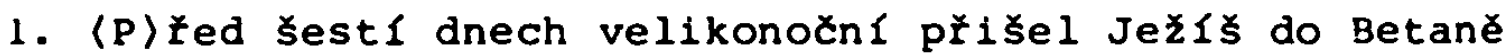
jesto Lazar bieše umřll jehožto vskřiesil bieše Ježrs

2. Tehdy učinichu mu tu veceri

a Marta slữiese

Ale Lază jeden $z$ nich bieše jenz sediechu $s$ ním

3. Ale Maria vzè pusku masti vónè drahé

a mažése Ježš̌vi nohy

a utieráse svými vlasy jeho nohy

i naplnèn jest dóm vóně $z$ té masti

4. Tehdy proto vece jeden $z$ uxedlnikóv jeho Judás Skariotis s toho miesta tak rečeného jenż biełe jeho zradil a rka

5. proc je této masti neprodal dobře za tři sta peněz aby dána byla chudým

6. Ale to mluvieše proto ze nepřlslusiełe $k$ chudým ale proto že zlodej biese a měsec mĕjése a to coł Bohu posláno bylo kradieše

7. Proto vece Jezís nechaj jie at' ji schová do dne pohřebenie mého

8. nebo vdy chudé máte sebú Ale mne ne vždy jmiti budete

9. Protož pozna sbor veliký ze tam biese 1 přldu netoliko pro Ježlsex ale aby vidĕli Lazaře s ním... 
10. ... zablti

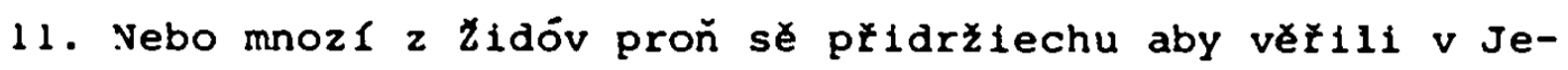
ż̌è

12. Tehdy nazajtřé sbor veliký jenź biechu píisli $k$ dni hodnému

když uslysechu že přisel Jež́s do Jerusalema

13. vzĕchu ratolesti s palmy i vyjư proti němu na cestu

i voláchu

Blahoslavený chvála *tomu jenž přišel ve jmě Božl král

R $115 a_{1}$ israhe // lský a židovský

14. Tehdy naleze Jež̧́ oslika i vsède nan̆ jakoz psáno jest

15. Nerod' sè bati Rci dceři sion

Aj král tvój přišl pokojný sedě na oslıku

16. Ale jesto nepoznachu ucednici prvé

Ale kdyz oslaven jest Ježs

Tehdy rozpomanuchu sě Nebo to bieše psáno o něm

a to uxinichu mu

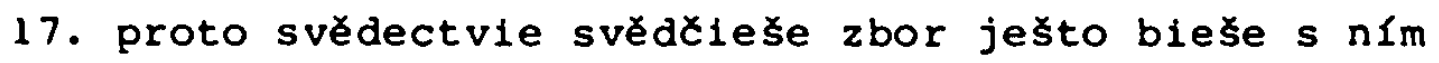
kdyžto Lazaře volăe z rovu a vzkřiesil jeho z mrtvých

18. protoz zbor pr̆ijide jemu na cêstu

Nebo slysechu divy jeho riniece znamenie

19. Proto zákonnici vecechu sami $k$ sobe ...

Aj suět vešken jae po nĕm

20. Ale biechu pohané $z$ nich jedni jenz pravichu aby modli$1 i$ se $v$ den hodny

21. Proto tito pristúpichu k Filipovi ten jenž biełe Bethsaida Galilee

i prosiechu jeho a $̌ k u ́ c e$

Pane chcem Jež́se videxti

22. pr̆ijide Filip i vece Ondř̉jovi

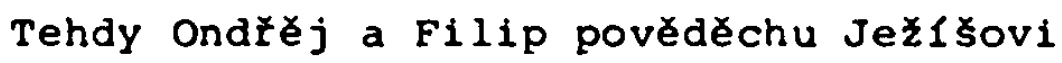

23. Odpovědě Ježr jim a íka

Pŕisla je hodina aby oslaven byl syn clověr

24. Zajisté a zapravé pravi vám

Jedno ac zrno upadna $v$ zemi umřelo bude 25. jinak

samo ostane

Pakli neumře veliký užitek přinese

ktoz miluje dusi sví strati ji

Ale kto nenávidi duse své na tomto suétè 
na věxny żivot schová $j i$

26. A ktož muè slữ po mnè jde

A kdez sem já tudiež i služebnik mój bude

Bude li kto mnĕ slữiti poctl jeho otec mój jenž na nebi jest

27. nenie duš smútila se jest

a co々 diem

Otec uzdrav mĕ tuto hodinu

Avకak proto přisel sem $v$ tuto hodinu

28. Otce oslav jmě tvé

proto přišel hlas $z$ nebe

i oslavil sem a druhé oslavim

29. proto zbor jenž stáse a slyšéce pravieše by hrom

R $116 a_{2}$

Ale druzı praviechu by anděl / byl jemu mluvĕ

30. Povědě Jež $1 \zeta$

Ne pro mé hlas tento přisel jest Ale pro vy

31. Nynie jest sud tohoto světa

*A nynie knieže tohoto světa vyvrženo jest ven

32. Já budu li povýšen od zemĕ všecko pưitáhnu sám k sobě

33. Ale to pravieše znamenávaje kteru smrt 1 umřel by byl

34. Povědě zbor jemu

my smy slyšeli že Buoh věčnè jest a $v$ zákonè nebo že kristus bydlı na věky

a kako ty pravis musie povýsiti syna clověieho kto jest syn clověr

35. Tehdy jim povědĕ Ježrs

* Jester málo jest suétla $\langle u\rangle$ vás

Protoz chod'te dokaz světlo jmáte at' vás "tma nesvieže kto chod 1 ve *tmè nevie kam jde

36. dokudz suětlo jmáte věrte $v$ světlo abyste *světlosti synové byli

To povědĕ Ježrs jide schova sĕ přĕd nimi

LXV.: R] deest $A, C, D, S, W$

9. (quem suscitavit a mortuis vulgata) om. ms. - 10. (cogitaverunt autem principes sacerdotum ut et Lazarum vulgatal om. ms. - 13. *tomu (momu ms.) - 19. (videtis quia nihil profitimus vulgata) on. ms. - 26. jenz na nebi jest (deest in vulgata) - 31. *A nynie (nynye $A$ ms.) - 35. *Jestè (Ge\$ty ms.): *tma (ona ms.); *tmě (tnye ms.) 36. "světlosti (w\$乡yetlo\$ty ms.). 
LXVI. Feria V. in Coena Domini - J13,1-15

1. (P) Yede dnem hodným velikonoxnIm

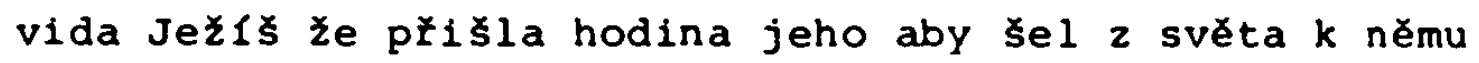
k Otci

kdy̌ milováse sué jełto biese na suêtĕ do skoncenie miloval je

2. kdyz vełeł̌ dospè tehdy diábel jiz poslal v srce aby zradil jeho Judás Simonóv Skariotis

3. věda že vłecko dal jemu otec v ruce anebo od Boha vyšel a $k$ Bohu jde

4. vstav od vecere i polozi *rúcho své Tehdy kdyz uzře prosterradlo opása sĕ

5. a potom uli vody $v$ měděnici

i poxè mýti nohy uxedlníkóm svým

a utierati prostěradlem jlmž bieše opásán

6. při $\zeta \zeta$ ed k Simonovi Petrovi

Tehdy vece jemu Petr

Hospodine ty mé myjes nohy

7. Odpovĕdĕ Jež́s $i$ vece $k$ nimu

To co já ciním ty nevies Ale zvies potom

8. vece jemu Petr

Nebudes mi mýti mých noh na věky

Odpovédé jemu Jež́s

R 116t 1 AC nebudu mýti / tobé tvých noh nebudes mieti césti se mnu

9. vece jemu Simon Petr Hospodine netoliko nohy mé Ale ruci i hlavu

10. Povĕdĕ jemu Jež́s

Ten jenž mluvil jest jiného nepotzebuje jedno aby nohy umy 1

nebo jest ¿ist vesken

Ano $z$ vás nekteł 1 Xisti ste ale ne vsickni

11. nebo jiz viděl kto jeho $2 \operatorname{rad} 1$ Protoz to mluvil ne vsickni jste tisti

12. kdyz jiz umy nohy jich tehdy vzé rúcho své tèm jenżo sediechu Druhé vece jim viete li co jsem uxinil vám

13. vy ste nazvali mé mistře i pána

A to dobře diete nebo jsem

14. Protoz ac já mistr a Pán umýval sem nohy vase 
takos 1 vy ciñte jeden druhému *umývajte nohy

15. Nebo pŕfklad dal sem vám

proto aby jakoz sem já vám ¿inil takés 1 vy ciñte

LXVI.: R] deest $A, C, D, S, W$

4. "rúcho (rucze ms.) - 14. *umývajte (vmywante ms.).

LXVII. Feria VI. in Parasceve - J19,15-37, 38-42

C $2 a_{1}$ 15. Ale oni volachu

Vezmi a ukřizuj jeho

Vece jim Pilát

Krále vašeho ukřizuji

otpovẽdêchu popové

Nemáme krále jedno ciesaře

16. *Tehdy on dá jim jeho aby jej ukřizovali

Prijerchu oni Ježusé i vyvedechu

17. A on vzemsi na sé křlz vynide na to miesto jenz slóve miesto popravy

ale zidovsky Golgota 18. tu kdez jeho ukfizovachu

A s ním jiná dua s vobu stranú

ale Jezúš u prostrèd

19. I tehdy napisa Pilat znamenie i postavi nad kłrem

A tot' bieše pisáno Ježús Nazarenus král židovský

20. To jisté pisánie mooz $\mathfrak{Z}$ idové citechu

neb bliz u mésta biese to miesto na nĕmž biese Jezús ukřizován

A biełe pisáno Zidovsky łecky a latine

21. *Tehdy vecechu Pilátovi *popové zidovsté

Nerod' psati kral zidovský

ale žet' jest łekl krâl sem zidovský

C $2 \mathrm{a}_{2}$ 22. Odpovedé / Pilat

Co ... pisáno

23. *Tehdy rytierové kdyz jeho ukřižovachu

vzemse rúcho jeho uxinichu ttyri césti

každému rytieři cést a sukni

Biese ta sukně neš̉itá surchu *ušckna tkaná

24. I vecechu $k$ spolu

Nerozdělujem jie

Ale losujmy o ni cie bude 
By sè plsmo naplnilo jenż praví

Rozdélili sú rúcho mé sobé a na "mé rúcho sjednali su losy

ani kteri rytieri su to uxinili

25. *Tehdy stojiechu za kł̌xem Ježưovým matě jeho a sestra matky jeho Maria Cleophe a Maria Magdalena

26. *Tehdy už̌̀ Ježús matku a uxennika jehož milováse vece matcè sué

ženo aj syn tvój

27. Opět vecě uxenniku

aj matka tvá

$z$ té jisté hodiny vzé ju uXennik za svú

28. Potom věda Ježứ že sě juž vక̌ecko skonalo

C $2 b_{1}$ By sĕ naplnilo písmo / Vecĕ żiezniv sem

29. Sud postaven tu biese octa pln

*Tehdy oni hubu plnu octa okladse yzopem obětovachu ustóm jeho

30. Kdỹ pìijě Ježús ocet vecè

skonáno jest

A nakloniv hlavu vzda dusi

31. *Tehdy Żidově že pátek bieše

by neostala téla na kł̌zu $v$ sobotu

Neb biese veliky den té soboty

1 prosichu Pilata aby zlámali v nich kosti a snêli jê

32. *Tehdy płijidechu rytieři

a prvniemu zlámachu jeho kosti 1 druhému jenž s nim ukizován biese

33. A kdyz k Jezúšovi płijidechu

jakz už̌chu jeho juz mrtva nelámachu jeho kost 1

34. Ale jeden 2 rytiełóv koplm bok jeho otevłe

$A$ inhed pojide krev a voda

35. A ktoz videxl suédectuie toho dal

a spravedlné jest svĕdectvie jeho

A on vie žet' pravdu pravi abyste vy také věrili

36. Stalo sè jest to by sè plsmo naplnilo

C $2 \mathrm{~b}_{2}$

ust / neposkvinite ot nèho

37. A opét jine plsmo die

uzłiet' $v$ něhožt' zakláli

Ctenie po pašl suatý Jan evangelista

38. Potom prosi Pilata Josef ot Arimathia 
proto ze biese uxenn1k Ježusóv

tajemný pro hrózu zidovsku

aby mohl vzieti tèlo Ježusovo

1 płépusti jemu pilát

*Tehdy přijide i vzè tělo Ježúsovo

39. Pŕłjide také i Nikodemus jenž biese přisel v noci najprvé

nesa smiesev myrru a aloes jako liber sto

40. "Tehdy vzěchu tĕlo Ježúovo 1 svázachu je s prostĕradly s mastmi aromatskými

jakoz obyčj jest żidovského pohřbuu

41. Bieše na tom jistém miestè na nèmž ukłižován jest zahrada

a $v$ zahradĕ hrob nový $v$ němž ještĕ nižádný nebieše položen

42. *Tehdy tu pro pátek żidovský jenż bliz biese hrob jesto položichu Ježuš

LXVII.: C] deest $A, D, S, R, W$

16. *Tehdy (Thedy ms., ibid. vv. 19, 21, 23, 25, 26,22331,32, 38, 40, 42) - 21. "popové (popone ms.) - 22. (scripsi vulgata) om. ms. - 23. *vక̌ckna (w\$§ieczkrrna ms.) - 24. *mé (nye ms.).

LXVIII. In vigilia Paschae - Mt 28, 1-7

S $143 \mathrm{a}_{2}$ 1. U vecer také sobotnl jez svietiese prunie soboty

$\left(148 a_{2}\right) \quad$ Prisla Marla Magdalena a jiná Maria vidéti hrob

2. A $v$ tu dobu zemé hnucle veliké sta sě nebo andel 1 (stúpi〉 s nebe

A pristupe otvali kámen 1 sěde na nĕm

3. a bieše tvăr jeho jako blesk

a rucho jeho jako snieh

4. Pro strach jeho lexechu sè stražn1 i biechu jako zem̌̌el1

5. Tehdy otpovĕdĕ anjel 1 vece zenám

Nebojte sè

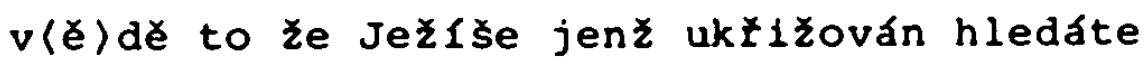

6. neniet' jeho

vstal je cele jakoźt' povédél

S 143b, Pod'te a ohlédajte miesto / kde bieše položen Hospodin

$(148 b$,$) 7. A rychle కedకe povězte uðennlkuom jenz je vstal$ 
A pod'te napred do Galilea

tu jeho uzŕlte

jako pravil vám

LXVIII.: S, R, W] deest A, C, D

1. sobotn[] $w$ \$obotu W: svietlese prvnie soboty] Swyety $v$ prwnyey Sobotye W: Maria Magdalena] magdalena $R-2$. zeme hnucie veliké] transp. $321 \mathrm{R}$; veliké sta sè] transp. $231 \mathrm{~W} ;$ [stupi〉] om. S, buo-

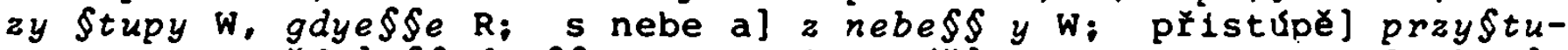

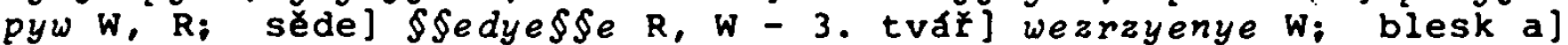
bly§kota $R_{i}$ jeho] byele add. W, bye ly add. R - 4 . Prol Tak praem. N: zemřeli] zmrly W-5. Tehdy otpověde] powyedye take W: Nebojte sé] Nerodte §ye baty $\mathrm{W}$; $\mathrm{v}(\grave{e}) \mathrm{de}$ (wydye ms.)] nebo wyedye $\mathrm{W}$, wydy $\mathrm{R}$;

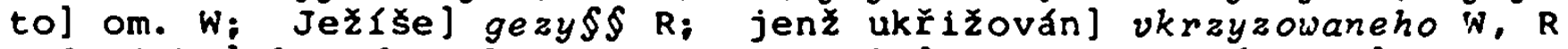
- 6. jeho] ho zde nebo gyz $W$; je cele] om. $W$; ohledajte] wyzte $W$,

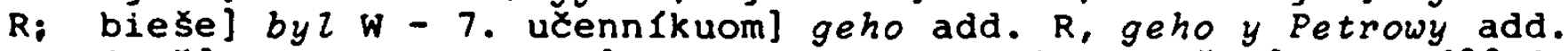

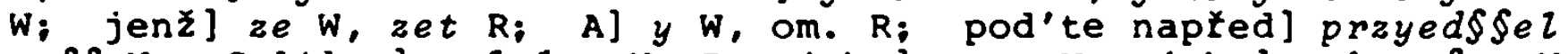
wa\$\$ W: Galilea] galylee W, R: jeho] gyey W; jako] yakoz \$em W: pravil] mluwy $l k R$.

LXIX. In festo Paschae - Mc 16,1-7

1. Maria Magdalena a druha Maria Jakubova i také salomee kúpily masti aby prúduce mazaly Ježı̌

2. A velmé ráno jedné soboty pridu $k$ hrobu na vschodu slunci

3. i mluviechu $k$ sobè kto otvall *nám kámen ot vrat hrobu

4. A pohleděvše viděly otložen kámen a biese veliky velme

5. A vejduce $v$ hrob vidély jinocha sediece na pravici płikryta stolu bielu

i lexechu sĕ

6. jenz vece

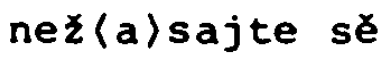
Ježš hledáte $z$ Nazarena křlzovaného vstal je nenie jeho zde

Seova jest kdez položen byl miesto

7. Ale jděte povězte uð̌enníkuom jeho a Petrovi

že płedejde vy do Galilea

tu jeho uzílte jakosto povèdél vám 
1. Maria] $V$ onom czya\$\$y praem. $W$; druha] om. W; Maria] om. $R$;

i] om. $R$ - 2. A] Tehdy $R ;$ velmé ] we Imy $W ;$ jedné soboty] gednu Sobotu R: na vschodu slunci] na wychod flunczye $W, R-3$. otval1] odlozy R: *nám (nan ms.) kámen] transp. R - 4. A pohleděvse viděly] Tehdy wezrzyew\$ye vzrychu $\mathrm{R} ; \mathrm{a}$ ) $y \mathrm{R}$; biełe] zagi\$te add. $\mathrm{R}$; veliky velmé] we lmy we lyky $W-5$. vejduce] w\$\$edcze $R ;$ vidély] varychu R: jinocha] mladenczye W; prikryta] praykryteho W, pokryta R; Stolu bielu] by $\{u$ ruchu $W-6$. jenz] on $W$, Gymz on $R$; vece] gym

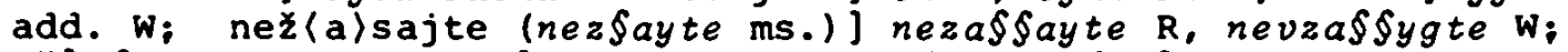
sè] Sebe W: Nazarena] nazaretha W: kílzovaneho] vkrzyzowaneho $W$, $\mathrm{R}$; jeho] ho $\mathrm{W}$ : Seova jest] Tot ge\$t mye\$to W, A tedye mye\$to R; položen byl miesto] bye§\$e polozen R, polozyly gey $W-7$. a] $y$ W; Ze] nebo W: predejde] przyegde R; Galilea] galylee R: tu] tam W: jeho] gey $W, R ;$ jakosto] yakoz W, R; pověděl] pravy 2 W.

LXX. Feria II. Paschae - L 24,13-35

W $20 \mathrm{a}$

13. $\mathrm{V}$ onom Xasi

vyłedక̌e dva $z$ učennikóv Ježrsových diesta toho dne do

kastela

jež biese sestdesăt mil od Jeruzalema

jménem Emaus

14. A ona mluvíta o tom o vłem co se stalo těch dn 1

15. Stalo sè kdyz mezi sebú mluviechu tasto

přibliživ sè Jež́s jide s nimi

16. oxi jejich biechu *posly že jeho nemožechu poznati

17. $i$ vece $j(i)$ ma

které su to rexí jesto rozmlúvata jaúce

a suce smutni

18. Odpovědě jeden jemuż jmè kleofás a fka

Ty sám jsa pútník z Jeruzalema

1 neviés co sè stalo tam texch dnI

19. On jim vecè $i$ co

i pověděch $(u)$

od Jezıłě $z$ Nazareta jenż biełe muz a prorok mocny

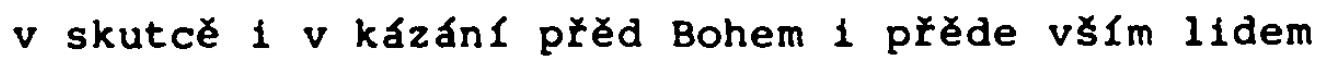

20. A tak sú zradili jej *vrchnie knězie a kniezata naš

sami na zahubenie smrti

1 uktižovali jeho

W 20b 21. a my se nadiechmy by on byl vykúpenie / lidské

a nynie nadto nade vłecko Třet 1 den dnes jest ar sě to

stalo

22. Ale *některé ženy $z$ našch smút1ly nás

jenž sư př̀d suétlem byly u hrobu 
23. a nenaleše têla jeho pŕisly praviece by viděly anděla jenż pravi *oziv sé

24. I šli někteř $z$ našiech $k$ hrobu

a takéz nalezli jakož zeny povèdely

〈jeho zajisté (ne)nalezechu)

25. $i$ on vece $j i m$

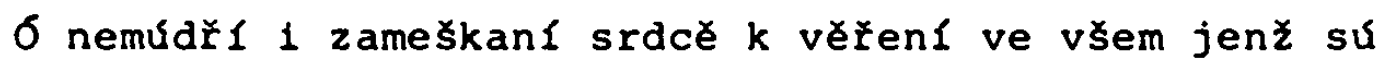
mluvili proroci

26. Ne zda mosil trpéti Kristus

a tak vstúpiti v královstvie své

27. I pocěv od Mojžiese a ode vsich prorokóv vykladáse jim ve vłem o nèmž psáno biese

28. A kdy̌̃ sẻ bližichu k hrádku kamže jidechu

$i$ on se pocite dále j1ti

29. Nutiechu jeho a łkuce

Ostañ s námi jižto jest večier chýlit' sĕ $k$ noci

1 vnide $s$ nimi

30. 1 sta sĕ kdy̌̃ *sedè s nimi

vze chlěb požehna $i$ rozlomi i poda jim

31. tehdy sex otvořista oxi jejich i poznachu jej

1 on ujide $z$ oxt jich

32. I vecěsta $k$ sobè

Ne zda nałe srdce thơ̌ $v$ nás kdy̌̉ mluviese na cěstĕ $a \star z j e v i$ nám pismo

33. i vstavłe $v$ tu chvili vrátichu se do Jeruzalema

i nalezechu sebraných jedenást

a ty jesto s nimi biechu 34. Praviechu

Ze jest Hospodin vstal jistě $i$ zjevil se Simonovi

35. a oni praviechu co sè stalo na cèstè

i kako sú poznali jeho na rozlomé chleba

LXX.: $W, R]$ deest $A, C, D, S$

13. $\mathrm{V}$ onom ‘asi] om. $\mathrm{R}$; vysedకe] Gdyechu $\mathrm{R}$; $\mathrm{z}$ ucenn[kóv] wczednyky R; Ježisových] gezy\$\$owa R; diesta] om. R; kastela jeż] hradku genz R; mil (del.', m. rec. hon)] honow $\mathrm{R} ;$ jménem] A tomu gmye $R$ - 14. o tom o vsem] Spolu o tom R; téch dnI] w tyech dnech $R$ 15. mluviechu? bye\$ta we\$la w rzecz R; Casto (\$ebe_add. ms. , rub. del.)] Tehdy R; pr̈ibliživ sě Ježí jide s nimij ihüs prayblyzy $\$ \$ e$ $k$ nyma $R$ - 16. "posly (del., m. rec. mg. zaderzeny); oxi... 17. ... $j\langle i\rangle \mathrm{ma}$ ] om. $\mathrm{R}_{i}$ to] ty $\mathrm{R}_{i}$ rozmlúváta] rozgymate $\mathrm{R}_{i}$ a suce smutni] y Sta §mutna R - 18. Kleofás] wecze gemu add. R; sĕl ge§t add. R: tam téch dnI] w tyech dnech $R$ - 19. On] Tehdy praem. R; vecer i] od-

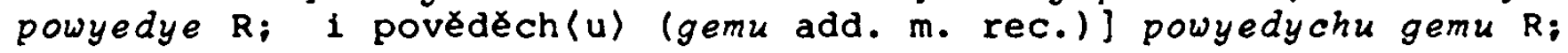


jenz biese muz a prorok] transp. $34512 \mathrm{R}$; mocny] om. $R$; $V$ kázanf]

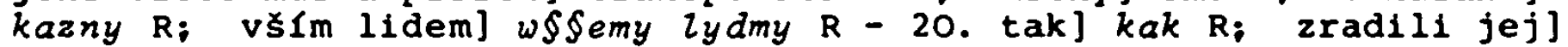
gey proradyly R; *vrchnie (rub. del., m. rec. mg. Naywi\$\$ij)] naywy\$\$ R; sami] om. R; zahubenie] potupenye R; ukfizovali] $g \$ \$ u$

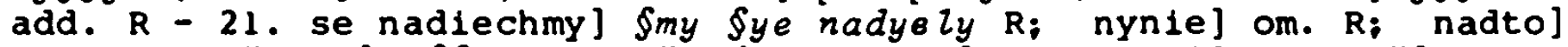
nato R; vsecko] w\$\$ye $R_{i}$ Tret 1 den dnes] transp. $321 \mathrm{R}$; az] $z z e$ $R_{i}$ to stalo] ge Stalo to $R$ - 22. *nékteré (nykte ms.)] nyektere $R_{i}$ jenż (del., m. rec. kterez); smutily...23. ...oživ sě] om. R; *oZiv sé (del., m. rec. gym ze zyw ge\$t mg.) - 24. I] om. R; sli]

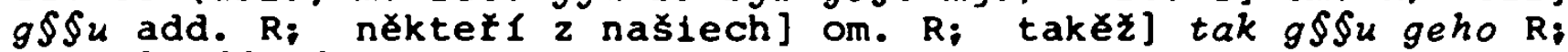
jakoz] $g \$ \$ u$ \$ate add. R; povédelly] odpowyedyely R; jeho zajisté (ne) nalezechu R] Ale ony newyedyely del. W - 25. i] Tehdy $R$ : vecer jim (m. rec. adscripsit ihs) ] transp. $R ; ~ \sigma$ nemudý (rub. del.); $i$ zameskanl] om. $R ;$ srdcé] Srdczem $R_{i}$ jenz] ony ont $R-26$. Ne zda mosil] wyedye ze tak mu\$\$yl R; trpéti Kristus] transp. R; vstu-

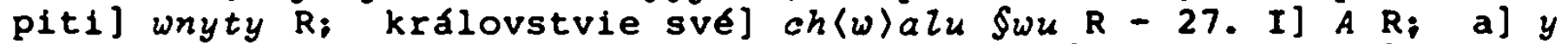

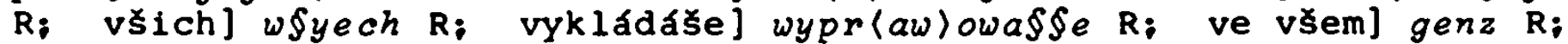
némz] nyem $R_{i}$ jest (rub. del.)] om. $R-28$. bl [zichu] przyblyzychu $\mathrm{R}$; hradku] blyz add. R; kamže jidechu (del.. m. rec. ku kteremuz \$iy)] yamzto gdyechu $R_{i} i$ on (del.. m. rec. ihs)] on $R ;$ se] om. R; pocite] pooze chtyety $\mathrm{R}-29$. Nutiechu (-echu del., m. rec. per $-l_{y}$ correxit)] Tehdy ony praem. $R ; s$ námi] pane add. $R ;$ jizto (del., m. rec. nebt)] nebot $R_{i}$ jest] gyz add. $R_{i}$ vecier] a add. $R_{i}$ vnide] gyde $\mathrm{R}-30.1]$ om. $\mathrm{R} ;{ }^{*}$ sedé $(-2 \mathrm{~m}$. rec; adscripsit); vze] wecze ihuse $R_{i}$ chléb] y add. $R$ - 31. otvołista] otewrzechu $\left.R_{i} j e j i c h\right]$ gyoh R; $i$ on ujide] Tehdy on \$kry \$ye R; $z$ ] od $R-32$. I] a ona $R$;

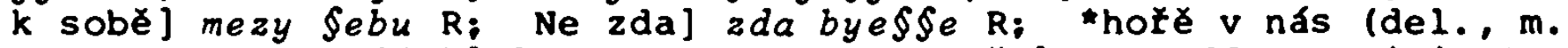
rec. nam neprawizol] horzyczye $R_{i}$ mluviese] nam add. $R_{i}$ zjevi (zgewye ms., m. rec. corr. in zgewy 2$)$ ] zewgye $R ;$ nám] nama $R-33$. i] $A$ R; chvili] dobu R; i] om. $R$; sebranych] gych $R$; jedenást] na Spolcze add. $R$ - 34. vstal] $z$ mrtwych add. R; jiste (del.. $\mathrm{m}$. rec. zagi\$te mg.)] zagy\$te $R_{i}$ sè] ge\$t add. $R$ - 35. praviechu co sè] hledachu genz \$ye geft $\mathrm{R} ; \mathrm{i}]$ a $\mathrm{R}$; rozlomé] rozlomeny $\mathrm{R}$.

LXXI. Feria III. Paschae - L 24,36-47

W $21 \mathrm{a}$ 36. V onom Casi

stă̌e Jež́s mezi ucennlky suými i łekl jim

pokoj vám já sem nerod'te se báti

37. zamúcen1 1 *otrápen 1

mniech $\langle u\rangle$ by viděli duch obluzen 1

38. 1 vece $j i m$

Co ste sè smútili a myšlenie vzchodie $u$ u vaš srdcĕ

39. vizte moji ruce $i$ noze zet' já sem ten

* Dotkněte a vizte nebo duch těla a kostr nemá jakoz mé vidite majice

40. A kdyz to vece Ukáza jim rucé a noze

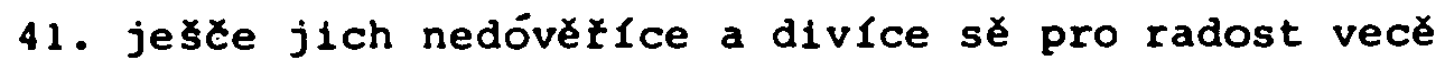
Mate 11 tuto pojésti co

42. Tehdy oni jemu dachu zvon ryby pexenej a stredi medu

43. A kdyz pojeda płéd nimi vzav ostatek poda jim 
44. i vecè $k \mathrm{nim}$

To sú slova jesto sem mluvil k vám kdy biech ješ̌e s vámi

nebo poť̆éba jest aby bylo naplněno jenż psáno jest $v$ zákonu Mojżiešovu i prorokóv i v žalmiech o mnè

45. Tehdy zjevil jim smysl aby rozumeli pismo

46. i łekl jim

Nebo tak jest psáno

a tak musil kristus trpèt

a vstav 2 mrtuých tyeti den

47. A kázati v jeho jmè pokánie $i$ odpušcenie hřiechuov v'semu lidu

LXXI.: W, R] deest A, C, D, S

36. $\mathrm{V}$ onom Casi] om. $\mathrm{R} ; \mathrm{jim]}$ ge§t $\mathrm{R}$; nerod'te se bati] neboyte Sye $\mathrm{R}-37$. *zamucen $\mathrm{i}$ otrápen 1 (zamuczyenye y otrapenye ms.)] zamuczeny ge§tye byechu R: mniech(u) by vidẻli duch obluzeni (odluzeny ms.) ] mnyechu \$\$ye obluzenye duch wyducze duch wydyety $R$

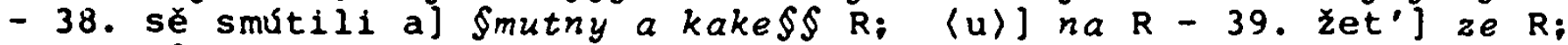
sem ten] transp. $\mathrm{R}_{\text {; }}$ \#otknéte (Dotknete ms.)] Pomakayte $\mathrm{R}_{i}$ nebo]

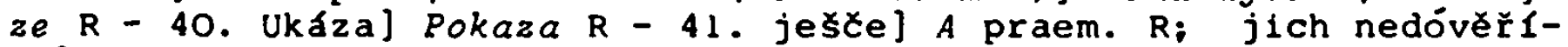
ce] gemu nedowyerzyechu $R$; vecé] gym add. $R ;$ pojéstí co] transp. $R$ - 42. jemu dachu] podachu gemu $R_{i}$ zvon] cza\$tku $R_{i}$ stredi medu] pla\$ku medowu $\mathrm{R}-43$. pojeda] poge $\mathrm{R}$; vzav] om. $\mathrm{R}$; ostatek poda jim] poda gym o\$tatka R - 44. k nim] gym R; jesto] genz R; Kdy] kdyzto $R$; nebo] Ale $R$; aby bylo naplnéno] na w\$em do \$konczenye py§mo R: psáno jest] py\$ma g\$\$u R: zákonu Mojziesovu i prorokóv $i \mathrm{v}$ zalmiech] zakonye $w$ moyzy\$\$owye a w proroczyech ge§to py\$\$ano $R$ - 45. zjevil jim] gym dal R; smysl] rozum R; rozuméli p[smo] vro-

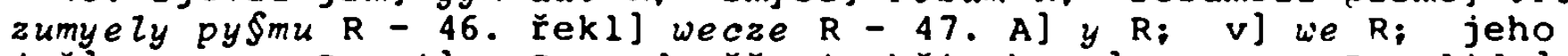
jmé] transp. $R ;$ i] a $R$; odpuscenie hriechuov] transp. $R ;$ lidu] genz zadagy toho add. R.

LXXII. Feria IV. Paschae - J21,1-14

1. V onom Casi

zjevil se Jež́s svým uxennikóm u moř Tiberiadis tak sè zjevil

2. A biechu tu spolu Simon Petr

a Tomás Druhynost

a Natanael je(n)Z biełe 2 Chana Galilee synové zebedei

a jinl 2 uxennikóv jeho dva

W $21 \mathrm{~b}$

3. Vece jim Simon Petr

Jdu ryb! *lovit

Povẽděchu jemu 
*Pójdem 1 my s tebu

$i$ vynidechu $i$ vstúpichu $v$ lodr

téj noci nic nejěchu

4. A když bieše ráno sta Ježrs na břěze

avšak nepoznachu učenníci jež bieše Ježrs

5. Proto vecé jim Ježrs

Dietky ne zda pokrmu nemáte

Odpověděchu jemu nemámy

6. Vecé jim

Puste na pravici lodi *sieté i najdete

upustiechu siet 1 a již nemožechu táhnúti pro mnohost ryb

7. Tehdy pověde ten ucenník jehož milováše Ježís nad Petra Hospodin jest

Simon Petr uslyšerv to že jest Ježš

Opása se sukni

nebo nah bieše

upusti sè u moře

8. Ale jinf uxennlci plaváchu přèd $n 1 m$

a nebiechu daleko od zemé

Ale jako loket dvě stè táhnúce sieti plnu ryb

9. A kdyz vstupi na zemi

vidèchu uhlé ležiec a rybu na uhli i chiéb

10. i vece jim Jež́s

Píineste ryb jesto ste nynie jeli

11. vstupi Simon Petr

vytaže siet plnu ryb velikých sto a padesát bez tŭ 1

Kdyz tolik bylo neprodřla se siet

12. Povědě jim Ježŕs

Pod'te obědujte

a nizádný nesmél z nich jeho otázati

ty kto jsi

$i$ věděvše že hospodin jest

13. 1 prísed Ježrs vzem chléb $i$ poda jim rybu takéz

14. To již třetı zjevil sè uxennı́kóm svým jakož z mrtvých vstal

LXXII.: $W, R$ ] deest $A, C, D, S$

1. $\mathrm{V}$ onom Casil om. $\mathrm{R}$; Tiberiadis ] tak rzeczeneho a add. $\mathrm{R}-2$. Druhynost ] om. $\mathrm{R}_{i} \mathrm{z}$ Chana] muz od $\mathrm{R}_{\text {; }}$ Galilee] a add. $\mathrm{R}_{\text {; }}$ zebedeil zebedowy $R_{i}$ jeho] om. $R-3$. Vecé ] Tehdy praem. $R_{i}$ ryb] om. R; *10vit (lowyet ms.) ] lowyt $R_{i}$ Povědechu) weczechu $R_{;}$*Pójdem (Podem 
ms., y rub. superscr.)] poydem $R_{i}$ vynidechu] wyndu $R_{i}$ téj] te $R$ - 4. sta] \$ta\$\$ye R; nepoznachu] gyeho add. $R_{i}$ jez biese\} by by 2 $\mathrm{R}$ - 5. Proto vece] powyedye $\mathrm{R}$; ne zda pokrmu nemáte] a $z$ da mata pogedenycze $\mathrm{R}$ : nemámy] nycze add. $\mathrm{R}-6$. `sieté (a \$yetye ms.)] Syet $R_{i} \quad i$ najdete] a naleznete $R_{i}$ upustiechu siet 1 a jiz] Tehdy ony pu§tyohu y naleznu y R; táhnúti] wytahnuty R: mnohost] mnoz-

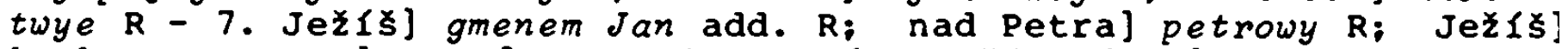
buoh R: upusti] y pu\$ty $R$ - 8. plaváchu př̉̆d nim a] plowucze przy-

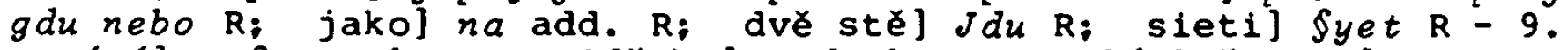
vstúp1] wy§tupychu R; viděchu] wydychu R; uhlé leziec a] om. $R ;$ rybu na uhll $i$ chléb] chleb a rybu naleznu na nye $R$ - 10. i] om. $R$; ste] $\S_{m y} R_{i}$ nynie jeli] transp. R - ll. vstupi] w\$tupyw $R_{i}$ vytaže. vzrze R; siet plnuj transp. $R_{i}$ ryb velikych] transp. $R_{i}$ bez *tr 1 (trzye ms.)] beze trzy A R; tolik bylo] tolyko bye\$\$e loweno R; neprodřla se] tehdy protrhla $\$ y e$ ge\$t $R$ - 12. obědujte] obyednyczy $\mathrm{R}_{i}$ a nižadný nesměl 2 nich] Ale ne\$mye gye§ty ygeden $\mathrm{R}$; ty kto

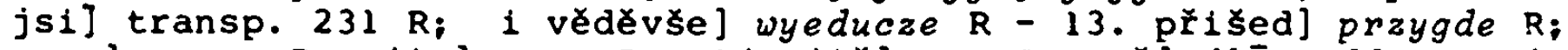
vzem] a wze R; jim] gyma R - 14.již] om. R; sé] ihuss add. R; ja. koz] y yakz ge§t R.

LXXIII. Feria V. Paschae - J20,11-18

11. V onom Casi

Maria stáse u hrobu vně placici

W $22 \mathrm{a}$

A kdyz plakałe nakloni se vezré // v hrob

12. i vidéla dva anjely $v$ ŕzzách sedice

jednoho $v$ hlavách a druhého $v$ nohách kdeź bieše položeno tèlo Ježrsovo

13. vecěchu jej on 1

zeno co pląes

Vecé jim

nebo zdvihli hospodina mého a nevĕdĕ kde sis jeho polo Zili

14. Kdyz to vece obráti se za se

i vidè Ježře stojlce

a nevidiese by Ježrs byl

15. Vecě jiej Ježrs

Zeno co plaðes koho hledás

Ona mnej 1 ci by zahradnik byl vecé jemu

Pane zda s ty zdvihl jej Pověz mi kde z jej položil a já jej zdvihnu

16. vecé jie Jež́s Maria

obráti se ona vecĕ jemu

Rabi jesto slóve mistr

17. Povědĕ jiej 
Nerod' mne dotýkati

ješe sem nepřisel $k$ mému Otci

Jdi k méj bratrie a rci jim

jdu k Otci mému 1 k Otci vašemu

$k$ Bohu mému i $k$ Bohu vasemu

18. př̉ Łedకi Maria Magdalena zvěstujlci ucenn la sem Hospodina a to řekl mnè

LXXIII.: W, R] deest A, C, D, S

11. V onom Casi] om. R; vné om. R; A kdyz plakáse] Tehdy zaZoßtyecay R; se] $y$ add. $R$ - 13. jéj onil gye andyele $R$; co] czemu $R$; Vecé] Odpowyedye R; zdvihli Hospodina mého] g\$\$u odge ly meho pana $R:$ jeho položili] transp. $R$ - 14. Kdyz] A praem. R; vecé] prawye-

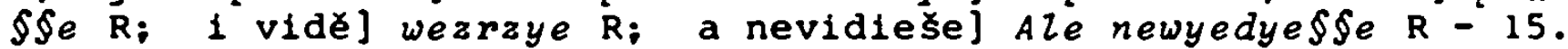
jiej] gye R; mnéj\{ci\} mnye§§e R; zahradnik byl] transp. R; vecè jemu] proto powyedye $k$ nyemu R; zda s ty zdvihl jej] acz \$y przygal geho R; kde z] kde $\$$ y ty R; jej polozil] polozyl geho R; ac] $a b y c h R_{i}$ jej zdvihnu] geho wzala $R-16$. se] za\$\$e add. R; vece jemu] powyedye $k$ nyemu $R-17$. Povědé] Wecze R: jiej] gey ihüs $R:$ nepriłel] new\$tupy [ $R ;$ Jdi] $A l e g d u$ ya $R ;$ a] om. $R: j i m] z e$ add. $\mathrm{R}_{i} \mathrm{k}$ Otc1] $k$ memu a $k$ twemu otczy $\mathrm{R}$; mému 1 ...Bohu vašmu] om. $\mathrm{R}$

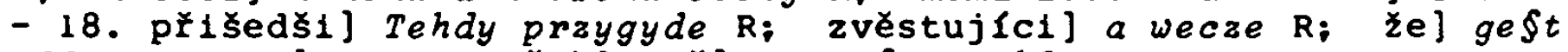
add. $\mathrm{R}$; sem] om. $\mathrm{R}$; Yekl mnè] my ge\$t rzek $2 \mathrm{R}$.

LXXIV. Feria VI. Paschae - Mt 28,16-20

16. $V$ onom Casi

Jedennádcět uCennikóv jidechu do Galilea na horu kdez jim ukázal Ježr

17. a vidúce následováchu jeho

a někteł 1 blúdichu

18. a płistúpiv Jež́ mluvı̌̉e jim a řka Dána mi jest vłickna moc na nebi 1 na zemi

19. chodiece proto uðlec v̌echen lid krtiece jej ve jmè otcé 1 Syna 1 svatého Ducha

20. Uxiece je chovati což koli sem vám kázal a já s vámi sem ve vక̌̌ch dnech až do skoncenie světa /

LXXIV.: $W, R]$ deest $A, C, D, S$

16. V onom Casi] om. $R$; Jedennadcét] Gedenaczte $R$; jidechu] gdu R; kdeż] kde§to $R-17$. viduce] varew\$§ye $R_{i}$ někteř́l] mezy nymy add. $R_{i}$ bludichu] newyedyechu $R$ - 18. a] Tehdy $R$; moc] $y$ add. $R-19$. chodiece] Protoz praem. R; protol om. R; uxiec vłechen lid] vcatez w\$§yeczkny lydy R; jej] ge $R$ - 20. koli] kolywyek R; kázal] miuwy $\left.R_{i} j a\right]$ om. $R_{i} s$ vámi sem] transp. $312 \mathrm{R}$; ve vsech dnech] po w\$Se dny R; skoncenie] koncze R. 
LXXV. Sabbato post Pascha - J20,1-9

1. $V$ onom Casi

Jednéj soboty Maria Magdalena prisla ráno kdy ješe

tma biese $k$ hrobu

i vidé kámen odjat od hrobu

2. «běze $k$ Simoniovi Petrovi a $k$ jinému ucennikovi jehoz milovăse Jež́s

$i$ vecè jim

Podvihli Hospodina mého $z$ hrobu a nevěde kde sú polozi11 jeho

3. Tehdy vynide Petr a jiny ucennik jidechu k hrobu

4. Tehdy bežrsta dva spolu

a ten ucennik predběze petra

i płisel prvé $k$ hrobu

5. A kdy̌ sè nakloni *vidé prostrieradla polozena avsak nevnide

6. Tehdy prijide Petr po nĕm vnide do hrobu

*a viděl prostěradla položena

7. a Cechel jez biese na jeho hlavě ne 〈s〉 prostěradly položen

ale rúzno leziechu

8. Tehdy vnide ten uXennik jenž splše předběhl petra k hrobu

1 viděl i uvěril

9. nebo ješe nezvẻdiechu pisma nebo mosil on z mrtvých vstáti

LXXV.: $W, R$ ] deest $A, C, D, S$

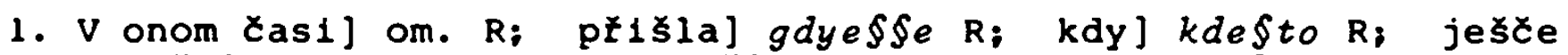
tma biese] transp. $312 \mathrm{R}$; vidé] varzye $R$; odjat od] odlozen $z R$ - 2. běze (bye\$\$ye ms.)] proto wecze y praygyde R; Simoniovi] om. $R_{i}$ jinému] druhemu $R_{i}$ jehoz] kterehozto $R_{i}$ Podvihli] wynyely $g \$ \$ u$ R; mého] om. $R ;$ nevědé j newyemy $R$ - 3. vynide] ugyde $R ; a$ jiny uCennik jidechu] proto y gyny vozednyczy I przy\$ly $R-4$. bézista] byechu R; dva] vczedlnyky add. R; priłel] praygyde R - 5 . *vide (wyedye ms.)] varaye R: prostieradla] prostyeradia R: nevnide] tam add. $R$ - 6. prijide] praygde Symon R; něm] y add. R; *a viděl (wydyela ms.)] I varzy R - 7. jez] genz R; ne 〈s〉 prostěradly položen] a na gezy\$\$owye $\$ \$$ proßtyeradiamy $R$; leziechu] lezecze y obynuto $w$ gedno mye $\$$ to $R-8$. vnide] wynde y $R$; spise

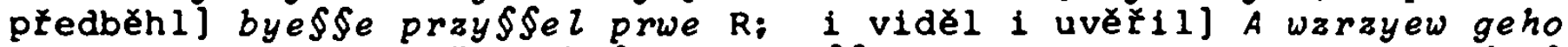
$y$ wecze $R$ - 9. nezvêdiechu]neznagye§\$e $R$; nebo mosil on $z$ mrtvych] zye opyet $z$ mrtwych mu\$\$y ihas R. 
LXXVI. Dominica in octava Paechae - J 20,19-31

S 143b, 19. Gdyz vecer budiese toho dne

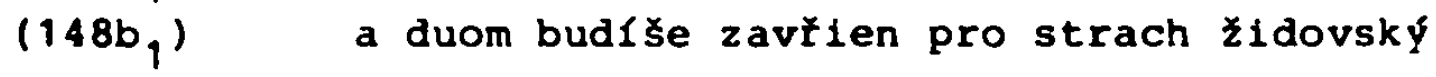

přised Ježús stana mezi nimi vece jim

mir vám

20. A kdyz to povédé pokáza jim ruce a bok

i radovachu sè uxennici vidúce Hospodina

21. Tehdy jim povědex po druhé

pokoj a mir vám

Jakoz poslal mé otec A já sell vy

22. A kdyz to povèdé pójdu $i$ vece jim

vezmète Ducha Svatého

23. jimžto hriechy odpustite odpustény sú jim /

w $23 a$

a komu zadrzite budu zadrzeny

24. Tomás jeden $z$ dvanásti jenz nazván Didymus nebyl s nimi kdyzto prisel Ježs

25. Povẽděchu jemu jinı uxennici vidêli smy Hospodina

Ale on vecé jim

Až uż́lm v jeho ruku *proklánie hł̌̉blkové

a upustım prst mój u miesto hřéblkové

- $i$ aź pustím ruku mú u bok jeho nevér Im

26. a po osmi dnech opet biechu uxennici jeho tudiez

a Tomas s nimi

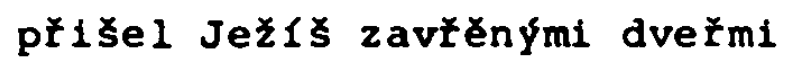

1 sta mezi nimi 1 vece

mir a pokoj vám

27. Tehdy vecé Tómex

Upust' prst svój sem a viz rucé mé

a vezmi ruku svi a upust' ji u bok mój

a nerod' błt 1 nevěren ale věren

28. Odpove̊dě Tóma 1 vecé jemu

Hospodin mój 1 Buoh mój

29. vecé jemu Ježı

Nebo jsi viděl mẹ Tóma i věril si

Blahoslaveni jsu jesto neviděvse 1 věłie

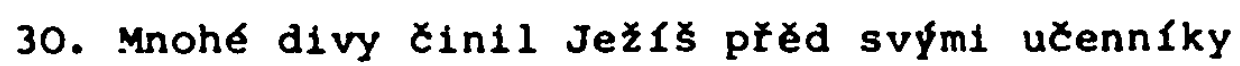

〈j)esto nenie psáno $v$ téchto kněhách

31. Ale psano jest abyste věrili ze Jezus Kristus syn Boź 
abyste věr̆lce そ̌ivot měli věxny̆ v jeho jmè

LXXVI.: S (om. vv. 24.-31.), N, R] deest A, C, D

19. Gdyz] $W$ onom czya\$\$y praem. $W$, bye $\$$ e add. $R$; budieకe] om. $R$; dne] $w$ \$ \$obotu add. $R, g e d n e y$ \$oboty add. $W$; budise] bye\$\$ye $N, R$; zavíien] kdyzto byohu \$ye vczadlnyczy \$ebraly add. R; zidovský] Tehdy add. R; PriSed] Przy\$S $[\mathrm{W} ;$ stana] \$ta W, y \$ta R; nimi] $y$ add. $W$ - 20. pokaza] vkaza W; a] y $R ; 1]$ Tehdy tyem $R$; viduce] varzyew\$\$v $W-21$. Tehdy] Opyet $R ; j i m]$ om. $W ;$ pol om. $W, R ; d r u-$ he] opyet W, a rzka add. $R$; pokoj a mir vám] transp. 3421 R; po-

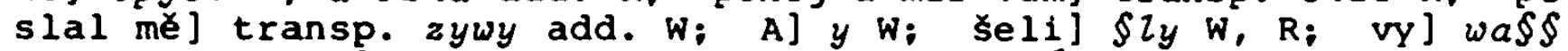
$R$ - 22. povědę] weczye W, propowyedye $R ;$ pójdú i] om. $R ;$ vece] rzyek $2 \mathrm{~W}$; vezmetel przygmyete $\mathrm{R}-23$. jimztol komu $\mathrm{W}$, komuz $\mathrm{R}$; odpuštèny su jim] des. S, budu gym odpu\$§czyeny $w$; a komu zadrzite budú zadrženy] om. $\mathrm{R}-24$. Tomás] tehdy praem. R; z] nych ze add.

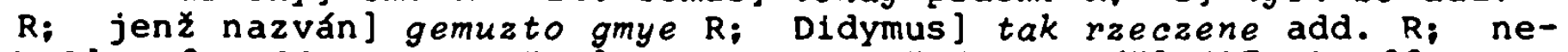

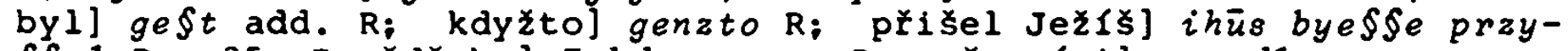
$\$ \$ e l \mathrm{R}-25$. Pověděchu] Tehdy praem. $\mathrm{R} ;$ uCennlci] vozedlnycze a rzkucze R; Ale] om. $R$; vecé jim] gym odpowyedye $R_{i}$ Aż gedno $R_{;}$ jeho ruku] rukach geho $\mathrm{R}_{\text {; }}$ "proklánie (rany rub. superscr.): upus-

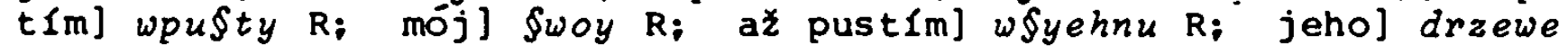
add. $\mathrm{R}-26$. a] $k d y z$ by add. $\mathrm{R}$; tudiež] wnytrz $\mathrm{R}$; Dřišl] przyde $R_{i} z$ avřénými dveřmi] zawrzew \$we rany $R_{i}$ sta mezi nimi] \$tal $w$ proßtrzyedcze $\mathrm{R}$; vecé] gym add. $\mathrm{R} ;$ a pokoj] om. $\mathrm{R}-27$. Tehdy] Potom R: Tómé Upust' prst svój] thoma\$\$owy \$yehny pr\$tem \$wym R; viz ruce me] patrzy\$§ ruku mu R; vezmi] \$yehny R; svu] twu R; a upust' ji] om. $R_{;}$nevěren] newyerzyczy $R_{;}$ale věren] om. $R-28$. ndpovédé] gemu add. $R_{i}$ Tóma il thoma\$\$ a $R_{i}$ jemu] om. $R_{i}$ Hospodin] pan $R_{i}$ mój] ho\$podyn add. R; 1 Buoh mój] om. $R-29$. jsi vidél mé Tóma i] wydyew\$y my R; jsu] ty w\$ycakny R; jeకto neviděv̌e 1 věrie] genz $g \$ \$ u$ newydyely a wyerzyly $R$ - 30. Jezis] om. R; svymi uXenniky\} oblyczege gych to\$ई vczedinykow \$wych $\mathrm{R}$; nenie psano] ge§tye nebylo py\$\$no $\mathrm{R}$ - 31. Ale] to add. $\mathrm{R} ;$ Ze] Nebo R; Kristus] ge\$t add. R; abyste] aby wy $R ; \quad$ ] om. $R ;$ jmé] om. $R$.

LXXVII. Dominica II. post Pascha-J10,11-16

S $143 \mathrm{~b}, 11$. Já sem pastý dobrý

$\left(148 b_{1}\right)$ dobrý pastýl dusi sur dáva za své ovce

12. Ale otrok jest jenz nenie pastý

jehoz nejsu ovce vlastnie

vida vlka bllžiece sè $i$ běźl pusté ovce

a vlk lapl a rozžene ovce

13. 〈Ale otrok běż nebo otrok jest nebo〉 Neslusejjl k nëmu ovce

14. Já sem pastỹ dobrý

S $143 b_{2}$

A poznávajl / më mé

$\left(148 b_{2}\right)$ 15. jakoz znal mé otec takož já znaji otce

a duši mú kladu za mé ovce

16. A jiné ovce jmám jenž nejsú $z$ tohoto ov̌ince 
i mosi jiné privésti a hlas mój uslysie

$i$ bude jeden ovtinec a jeden pasty

LXXVII.: S, R, W] deest $A, C, D$

11. Já] $V$ onom czya\$\$y praem. W, Powyedye 2 ihūs vezedinykom \$wym a rzka praem. R; dobry pastýy transp. W, da add. R; dává] da W, om. $R ;$ svu] om. $R-12$. jest] a ten $R$, om. $W$; nenie] prawy add. $R ;$ jehozj] a gehozto R; ovce vlastnie] transp. R; bliziece sé] byezyeczye W, przyduczyho R; bězl pustè ovce] pu§ty owczye y pobyehne W, necha owecz y gde przycz od nych $\mathrm{R}$; a vik...ovce] om. $\mathrm{R}-13$. Ale otrok byezy nebo otrok geft nebo W] om. S, Namznyk zagy\$te gde przycz nebo namznyk R: Neslusejji k nému] $k$ nyemuzto neprzy\$\$lu\$\$ye $R-14$. Já] Protoz dye ho\$podyn praem. $R ;$ A poznávaj1] y poznagy $W$; mé] owcze add. $R$ - 15. jakoz znal mé otec] om. $R$; takoz] $A$ R; znaj1] znam $W$, poznawam $R ;$ Otce a mu dusi kladul me owcze a tye lo me dam $R$ - 16. jenz] ge§to $R ;$ i] a ty $W_{\text {, }} R_{i}$ mosi] gy\$tye mu\$\$ym $R ;$ jine] om. W. R; a] aby R: uslysie] voly\$\$aly R; pastýl] owczynecz $R$.

LXXVIII. Dominica III. post Pascha-J16,16-22

16. Pověděl Jezús uxennikuom svým vamále aź neuzŕlte mne

A opět namále a užr te mě Nebo jau $k$ *otci

17. Tehdy pověděchu mlajłł jeho $k$ sobé

Co je to ze pravi nám

Namále a neuzíte mne

a namále a uzílte mé

a jáz jdu $k$ *otci

18. Tehdy řxchu

Kak je to že nám praví namále

nevieme co mluvi

19. Pozna Ježús že chtiechu jeho otázati

$i$ vece jim

o Łem jmáte řę mezi sobư že vám pravi namále až mĕ neuzílte opét namále az mé uzílte

20. věrně jistě pravi vám

Ze plakati a želeci budete vy

Ale svět bude vesel

ale vy zamúceni

Ale smutek vás obrát sè $v$ radost

21. Zena kdyz jest na porozen 1 jmá smutek

A kdyz porodl jiz nepomnl bolest 1

nebo sè clověk na svět narodil

22. jako $i$ vy nynie jmate smutek

Ale opét uż́ vy i radovati sĕ bude vaše srdce 
A vaseho veselé nikte neotejme vám

LXXVIII.: $S, R, W]$ deest $A, C, D$

16. Pověděl] $W$ onom ozya\$\$y praem. W; svym] a rzka add. $R ;$ Namále]

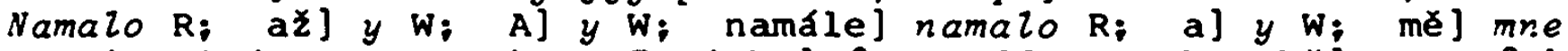
W: *otci (uotozy ms.) - 17. jeho] \$amy add. W; $k$ sobẻ] mezy $\$ o b u$ dywyw\$ye a rzkucze $\mathrm{R}$; ze] genzto $\mathrm{R} ; \mathrm{nam}$ ] om. $\mathrm{R} ; \mathrm{a}] \mathrm{y}, \mathrm{Wz} \mathrm{R}$; a]

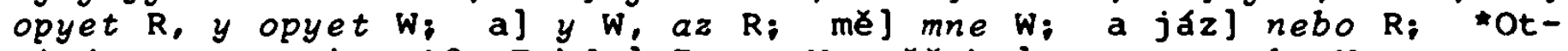
ci (uotczy ms.) - 18. Tehdy] Proto W: Y̌echu] rzyeczyechu W, weczechu R; Kak] Czo W: nevieme] newyemy $\mathrm{W}$ - 19. Pozna] Proto praem. R;

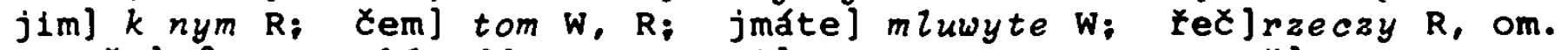
$\left.W_{i} z e\right]$ Sem rzyekl add. $W:$ pravi] prawym $R$, om. $W_{i}$ az] $z z e R, y$;

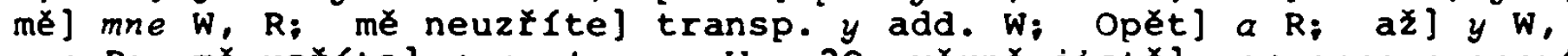

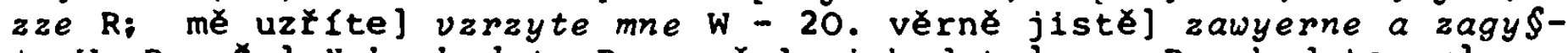
te W, R; Ze] Nebo budete R; a zeleci budete] om. R; budete vy] transp. $W ;$ vesel] $\$ e$ radowaty $W ;$ ale vy] om. $R ;$ Ale] w\$\$yak $W$; smutek vás] zamuczenye wa\$§e R; obrát sé] obraczyen bude W - 21 . jest na porozen I] porozyge W: jmá welyky add. R: smutek] nebo przy\$la ge\$t gegye hodyna add. $\mathrm{R} ; \mathrm{A}] \mathrm{Ale} \mathrm{R} ;$ porodi] dyetye add. R: bolesti] pro rado\$t add. W, procz pro welyku rado\$t add. $R$ : nebo] neb $W, g e \oint t$ add. R; sè clovék na suét narodil] \$ye narody 2 cz lowyek ge $\$ t$ na \$wyet $W$, transp. $25134 \mathrm{R}-22$. jako] Tako\$\$ $\mathrm{R}$, om. $\mathrm{W} ; \mathrm{i}$ ] om.

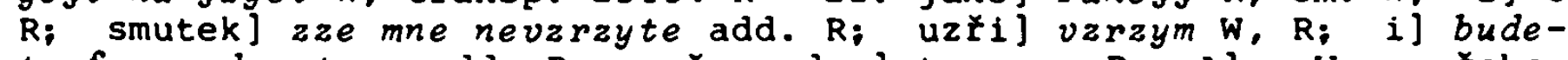
te Sye radowaty a add. $R ;$ vase srdce] transp. $R ; A]$ y $W$ vaseho veselé] wa\$\$ye rado\$ty $R$, rado\$ty wa\$\$ye $W ;$ nikte] ygeden $R$.

LXXIX. Dominica IV. post Pascha-J16,5-14

5. Pověděl Ježús mlazśm svým jdu $k$ tomu jenž mé poslal

A nikte $z$ vás netieže mne kam jdu

6. Ale sem to $k$ vám mluvil zámutek vase srdce najde

7. Ale já vám pravdu oravi hodno jest abych sel já

Pakli já nepójdu utěsitel neołride $k$ vám

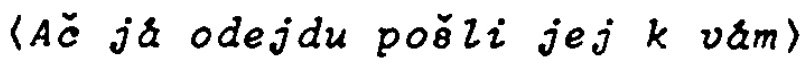

8. A kdyz príle ten budete tresktati suět pro hřlech a $z$ pravdy a $z$ sisda

9. 2 hr̆iecha nebo nevěrie u mè

10. 2 pravdy nebo jdu $k$ Otci a jiz neuzílte mne //

s 144a, 11. z súda nebot' knieze tohoto světa silzen jest

$\left(149 \mathrm{a}_{1}\right)$ 12. Jestě mnoho mám vám praviti ale *nemuozte ponésti nynie

13. Ale kdyz pŕ Ide ten Duch pravdy nauç vy v̌sie pravié nebo nebude mluviti sám o sobé ale co uslyș vamluví

a jemuž býti vzvèstovati bude vám 
14. ten mè oslavi nebo u mne vezme 1 zvěstuje vám

LXXIX.: $S, R, W]$ deest $A, C, D$

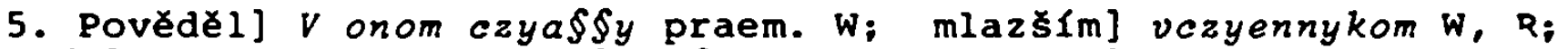
svým] a rzka add. $R ;$ mé] ge§t add. $R$; nikte] zadny $R ;$ netiež] neotyeze R; mne] om. $W ; \mathrm{kam}$; ya add. $\mathrm{R} ; \mathrm{jdu}]$ de\$\$ $\mathrm{W}-6$. Ale] ya add. $W, z z e$ add. $R ;$ zámutek] \$mutek $W$, wa\$§ nap Iny add. $R ;$ vaSe srdce] transp. $R ;$ najde] nadeyde $W$, om. $R$ - 7. pravil] prawym $\mathrm{R}$; Pakli] $A C z W ; A c z$ ya odeydu po§§ly gyey $k$ wam $W]$ om. $S, P a k l y$ poydu po\$\$ly geho $k$ wam R - 8. pride ten] transp. $k$ wam add. R; budete] bude $W$, ten gy§te bude R; svět]or.. W, pro troy vczynek add. R; 2 pravdy] pro prawdu R; a 2 s'Sda] y $z \$ u d u$ W -9.2 híiecha] procz add. $\mathrm{R}$; nevérie] newyerzyte $\mathrm{R}$ - in. 2 pravdy] procz add. $\mathrm{R}$; jdu $k$ otci] transp. $231 \mathrm{~N}$; neuzrite mne] newyerzyte mnye $R$ - ll. $z$ sisda] procz add. $R$; nebot'] nebo W; tohoto] tohto W; knieže tohoto světa] transp. $231 \mathrm{R}$; suzen] od\$uzeno $W-12$. *nemuožte (nemuo§te ms.)] nemozete $\mathrm{W}, \mathrm{R} ;$ Donésti] vne§ty $\mathrm{R}$, §ne§ty $\mathrm{W}$ - 13. pravdy] prawy $W$, on $R ;$ nauci vy] transp. $R ;$ nebo] om. $W ;$ o sobej od \$ebe W, R; col czozkolwyek W, czozkolywyek R; vamluvi] zm Luwy $W$, prawyty bude $\mathrm{R}_{i}$ jemuz] gemuzto $\mathrm{R}$, genz ma W; být1] orzygyty W; vzvěstovati bude] zwye§tuge $W, R-14$. ten] gy§tye add. R; mé oslavi] transp. R; oslavi] oczy\$ty $W_{;} u$ ] ote $R$.

LXXX. Dominica V. post Pascha-J16,23-30

23. Pověděl Jezứ mlazš́m svým vêrnè jistè pravi vám AC co prositi budete otcè u mé jmè dá vám

24. dotad ste nice neprosili u mé jmè Proste a vezmete aby vase radost plna byla

25. (To u pr̆́slovi vám mluvil sem) přisel Cas a jiže ne u ớlkladiech mluvi vám Ale zjevnè otce mého pověder vám

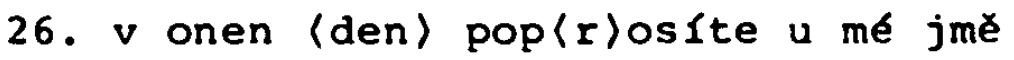
Nepravi vám já budu za vy orositi otce ot vás

27. on sám otec miluje vy nebo ste vy mĕ milovali

a věrili že sem ot Boha pošel

28. vyšl ot Boha prišel na suět opět ostavi suět a jdu $k$ *otci

29. Kechu jemu mlazł́ jeho Seova jiz na prosto mluvís a oł́lklada ijednoho nedies

30. Jiz viemy že rozumies v'̌emu

1 nenie ponatin aby kto tebe potazoval

$v$ tom věrime ze $s$ ot Boha posel

LXXX.: S, R, W] deest $A, C, D$ 
23. Povĕdĕl] $V$ onom czya\$\$y praem. W; mlazకlm] vczyennykom W; věrnè jistę] zawyerne zagy§te $R$; prositi budete] transp. W, R; Otcé] meho add. W, $\mathrm{R}$; jme ] gmeno $\mathrm{W}-24$. dotad] dokad $\mathrm{W}$, dokawad $\mathrm{R} ; \mathrm{ni}-$ ce] nynye $W ;$ neprosili] nytczye add. $W ; ~ U]$ we $R ;$ mé jme ] transo. gyz add. $R$; vaš radost] transp. $R ;$ olna byla] by la nap lnyena ' -

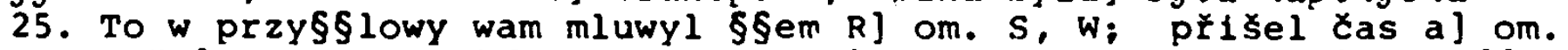

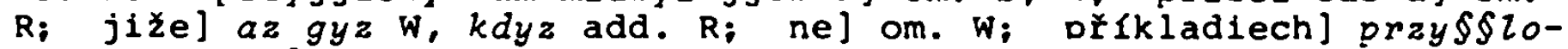
wy $R_{;}$mluvi] mluwym W, prawy $R_{;}$vám] nebo ya budu add. $R_{i}$ otce mého] o otczy mem $W$; povèdẹ] nezwye§tugy $\mathrm{R}-26 . \mathrm{V}$ onen (den)] $W$ onen den $\mathrm{W}$, Toho dne $\mathrm{R}$; pop(r)osite u mé jmé $v$ me gmye proßjyte y $W$, otcze meho proß§te $R$; Nepravi] Ale nynye zagy\$te prawy $R:$ vam] nebo add. $W, R ;$ budu $z a$ vy] transp. $231 \mathrm{R} ; 2 \mathrm{a} v y$ prositi otce] transp. $4312 \mathrm{~W}$; ot vás] om. $N-27$; on] nebo praem. W; vy] wa\$\$ R;

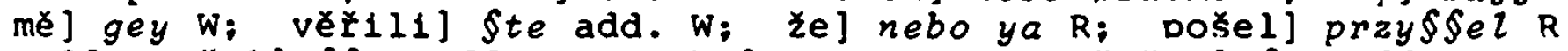

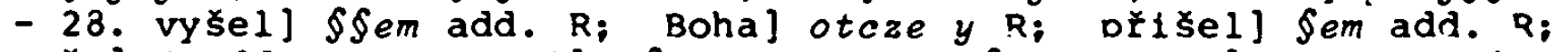
svět] $A$ add. R; ostavi] o\$tawugy W, opu§tym R; a] y $W, R ;$ otci (uotczy ms.)] memu add. $\mathrm{R}$ - 29. Rechu] Rzyeczyechu W, weczechu R; jemu] mu R; mlazsi] vczyennyczy $\mathrm{W}_{\text {; }}$ Seova] Ay R, Tot $\mathrm{N}$; na prosto] zewnye W: pílklada ijednoho] przykladu gednoho $w$ - 30. Jiz] to add.

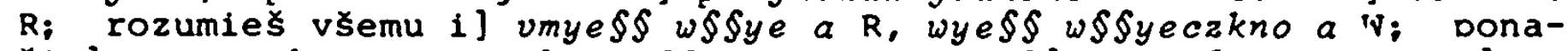
cin] potrzyeba W, R, tobye add. W; potazoval] otazal W, R; tom] to $W_{;}$s] g\$\$y W, R; poSel] przy\$\$el po\$\$el R.

LXXXI. In diebus rogationum - L 11,5-13

5. Pravil Jež́s mlazślm suým

Kto vás jmieti bude pŕletele

$i$ pójde $k$ nèmu $u$ puolnoci

i die jemu

prieteli požic $\mathrm{mi}$ trého chleba

6. Nebo príletel muoj płiłel s cesty ke mnè

i nemám co prédeñ položiti

7. $i$ on ze vnityka povèdé

Nezalost' mne

jizti duom zavien a déti na Dokoji se mnil sú nemohut' vstati dati tober

8. A on stane tluka

Pravi vám

nedá li jemu vstana pro prietelstvo

avšak pro lenost vstane 1 dá jemu co jmá potýebu

9. Ale já vám pravi

proste a dadie vám /

$S 144 a_{2}$ hledajte a naleznete

$\left(149 a_{2}\right)$ tlucte a otevrú vám

10. vక̌eliký co kto prosl vezme
A kto hledá nalezne
a tlukúciemu otevřeno bude 
11. kto $z$ vás otce prosi chleba

zda 1 i mu dá kamenie

Nebo ryby

zda mu poda za rybu hada

12. Nebo prosi vajce

vsak nedá jemu stıra

13. At vy ste zll znajte dobré dary dajte synóm vasim A ¿Im viece Otec vás nebesky dá duch dobrý prosicim sebe

LXXXI.: S, R, W] deest $A, C, D$

5. Pravil] $V$ onom czya\$\$y praem. $W$, Powyedye $Z W, R$; mlazßlm] vczyennykom $W$; svým] a rzka add. R; Kto] $z$ add. W, R; jmieti budejtranso

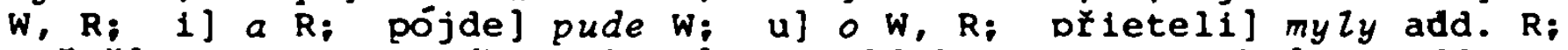
polic] poycz $R$; trého chlebajtrzy chlebow $w-6$. Nebo] my add. R;

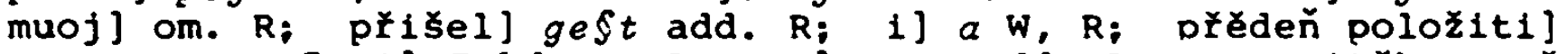
transp. W - 7. i] Tehdy W, R; on] gemu add. R; ze vnitłka pověde] ] odpowyedye wnytrz a raka R, w domu weczye W; Nezalost'] Nerod Sye hnyewaty $\mathrm{W}$; mne] toho $\mathrm{R}$, om. W; jizti] gyz W, mnye ge\$t add. $\mathrm{R}$; duom zavíien] dwerzy zawrzyeny $W$, moy add. $R ;$ a děti na pokoji] om. $R$, a dyety mogy $\left.W_{;} s u\right] g$ sum na lozy $R_{i}$ vstáti] a add. $R-8$. $A$ on stane] $A z$ ten dokona $\mathrm{R}$; vám] a add. $\mathrm{R}$; nedá li jemu] mg. ge\$tly ze neda gemu W, \$taty add. R; vstana] w\$taw superscr. W, pro przyetele $y$ add. R; pro prietelstvo avsak pro lenost] proto gezz (geho mq.) prayete $Z$ ge\$t ne pro dobrotu geho $W_{\text {: }}$ vstane] w\$tana W: jmá $\$$ add. $\mathrm{W}, \mathrm{R}$ - 9. Ale] $y \mathrm{~W}$; vám] to add. $\mathrm{R}$; proste] a dayte add. $\mathrm{R} ;$ dadie] dye W: otevrú vám] transp. R - 10. A kto...bude] om. R; tlukuciemu otevíeno bude] tzuczenemu otewru $W$ - ll. otce prosl] transp. $R$; prosi] om. W; chleba] ne add. $\mathrm{W} ; \mathrm{mu}$ ] gemu $\mathrm{W}, \mathrm{R}$; kamenie] kamen W, R; ryby] rybu ne W; mu] gemu R; podá za rybu] za rybu da W: hada] had $W$ - 12. Nebo] $n e b W, A n e b o ~ R:$ prosi] $2 y$ add. $W, R ;$ nedá jemu] nezda gemu da W; jemu] om. W: కtira] ge§tyera R, §kerzupynu $W$ - 13. AC] Proto praem. $W$; vy ste] transp. W; vy] $k d y$ add. $R ;$ znajte] bozye add. W; dobré dary] om. W; dajtel daty W, om. R; A] om. W; $[1 \mathrm{~m}]$ tyem W, R; nebesky] z nebe\$\$ W; prosicim] pro\$syeczye $W$.

LXXXII. In Ascensione Domini - Mc 16,14-20

14. Jědúcim jedennácte ư̌ennfkuom 2 jevil se jim Jezứ i znétil neviery jich a turdosti srdectné

Nebo $t 1$ jenz vidẻli jeho vstav̧e 2 mrtvých nevěriechu

15. I povědé jim

jdúce po vక̌em suětu kažte Božie slovo vక̌emu stvoł̌en

16. kto uveríl a kł̌est vezme zaráv bude

Ale kto neuver 1 potupen bude

17. A znamenajte je kto verilec toto prijmu

u mé jmè běsy vypudie

jazyky vsmluvie novymi 
18. hady vezmu

pakli co smrtedlného vzpijl neuvadr jim

Na nemocné ruku položie a zdrávi budú

19. A také Hospodin Ježus kdyz mluvil jim

vzat na nebe $i$ sedr na pravici Bożie

20. Tehdy oni rozsedకe sé kázali v̌̌ady

s pomocr Boźl slova to potvrzujlce 1 divy ciniece

LXXXII.: S, R, W] deest A, C, D

14. Jědúcim] $V$ onom czya\$\$y odpoczywagycz $W ;$ jedennácte] gedena-

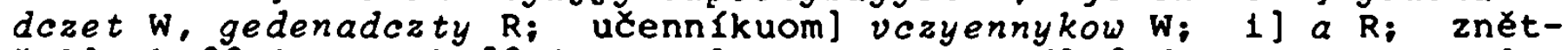

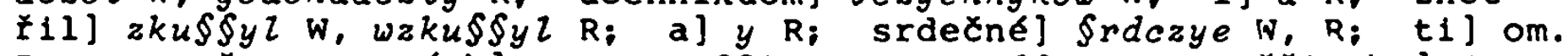
$\mathrm{R}_{\text {; }}$ vstavse $z$ mrtvých] transp. $231 \mathrm{~W}$, tomu add. R; neveriechu] $A$ gyzt newyerzychu W-15. I] Tehdy R; jim] ihūs add. R: světu] Swyetye $R$; Bozie] om. W; Bozie slovo] transp. $R$; slovol cztenye $W$ - 16. kto] $A$ praem R; a kłest vezme] a krze§t praygme $R, y$ pokrz§§czyen bude $W$; Ale] $A$, om. W; nevěrl] nevwyerzy $W$ - 17. A] om. $R$; znamenajte] znamenay $W$; ktol kterzy $W, R$; věriec] wyerzye $R$, vwyerzye $W$; totol tohot $W$; prijmu $u]$ przymucze we $R$; mé jmé] transp. R; běsy] dyably W, R; vypudie] wyhonyty budu R; jazyky vsmluvie novými] transp. $312 \mathrm{~W}, \mathrm{R}-18$. vezmu] podwyhnu $\mathrm{W}$; co smrtediného] transp. $W, R$; vzpijl] zpygy $W$, wypygy $R$; neuvadi] newa-

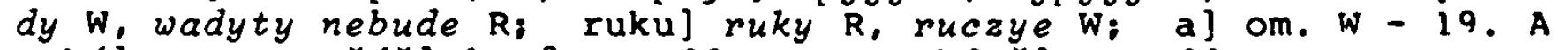
take] y $W_{;}$Jezus] kry\$tus add. $W, R ;$ kdyz] to add. $R ;$ vzat na nebe] zdwyzen do nebe\$\$ (ge\$t mg.) iv pravici] moczy add. R - ?n.

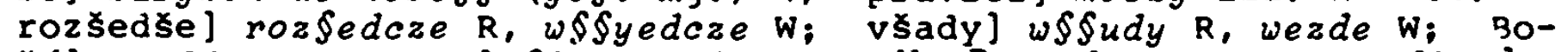
zi] $y$ add. $W$; slova] \$Low $R$; to] om. W, $R$; i] a R, om.W; divy] anamenye $W$.

LXXXIII. Dominica post Ascensionem Domini - i 15,26-27, $16,1-4$

26. Kdysto př́le ucesitel

jehoz já pošli vám ot otce Ducha spravedlivého ten suexdexstuie povie o mnè

27. A vy suědecstvie poviete nebo ot pocatika jste se mnis

1. To sem mluvil vám abyste nezbluzovali

2. bez modly ostavie vy

Ale prisla hodina aby vseliky kto zahubr vy ukladal obét' sobe vráciti Bohu

3. A to vám uxinie nebo neznali sú otce ani mne

S 144b,

$\left(149 b_{1}\right)$
4. Ale / to mluvil sem vám

Jakoz pride jich Cas smilujete se nebo sem já pravil vám

LXXXIII.: S, R, W] deest $A, C, D$

26. Kdysto] Kdyz R, $V$ onom czya\$\$y praem. $W$; jehoz] kterehoz R; 
já] om. W: posli vám] transp. W; spravedlivého] Sprawedlneho genz od otczye po\$\$ye $2 \mathrm{~W}$, Sprawedinyweho kteryz od otcze wynde $\mathrm{R}$; ten] gy\$te add. $\mathrm{R}-27$. poviete] date o mnye $\mathrm{R}$; jste se mnu] transp. $231 \mathrm{R}$; jste] gie§t $\mathrm{W}-1$. abyste] $\mathrm{m}$. rec. Se $\mathrm{W}$; nezbluzovali] $n e-$ wabuSowaly R, nezrazowaly $w$ - 2. bez] kdyz budu luczyty vas z obcze

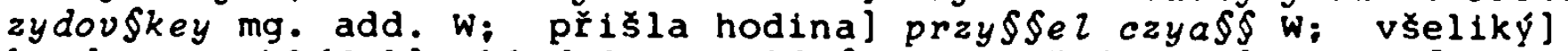
kazdy R; ukladal] vkladaly W, vkla\$t R; obet' sobél opyet §ebe W, vklad opyet $R$; vraciti] wraty $R$ - 3. vám ucinie] transo. $W, R_{i}$ sil] om. W; Otce] meho add. $R-4$. Jakoż] zze kdyz $R ;$ jich cas] transD. $R$; smilujete] Smluwyte $W$, rozpomyente $R$; já pravill powyedyel $R$.

LXXXIV. Sabbato in vigilia Pentecostes - J14,15-21

W $38 b$

15. V onom Casi

Pravil Jež́s uČennikóm svým

AC kto miluji mé Rázanie mé chovajte

16. a já budu prositi otcè a jiného utěsitele dá vám aby bydlil s vámi věčnè //

w $39 a$

17. Ducha jehož svět nemóž přijiti

nebo nevèdie ho ani vidie ho

Ale vy poznate jej nebo u vás bydliti bude a u vás bude

13. Veostavi vás sirotkóv pŕldu k vám

19. Jistè u mále aź suèt mne neuzŕr

ale vy mè vidèti budete

nebo sem já ziv a vy żivi budete

20. $v$ onen den poznáte że sem jáz v otci u mém a vy ve mnè a ja u vás

21. Kto má mé kázanie a chová je ten jest jenż miluje mé

A ktoz miluje mè milován bude od ntcě mého

a já budu jej milovati i zjevi se jemu sám

LXXXIV.: W (inter lectiones Proprii Sanctorum), R] deest A, C, D, S

15. V onom Casi] om. R; Pravil] Powyedye Z R; učennikóm svým \} S sym mlaz§ym R: AC] A czoz R; milujl] myluge $R ;$ mél a add. $R_{i} K\{z a-$ nie mél transp. $R ;$ chovajte] chowa $R-16$. a jábudul $A y$ jude $R$; a jiného] meho $R$; bydlil\} bydlyly $R$ - 17. Ducha] Sprawedineho add. $R_{i} p r i j\{t i\}$ wayety $R_{i}$ nevéde hol newye $R_{i}$ hol geho $R_{i}$ pornate jej] nepoznate gyeho R: bydliti bude] bydly R; u vás] ?ydlyty $R$ - 18. Veostavi] Veo\$tawym R - 19. Jistej ge\$tye R; mne] ayz add. R; vy mé ] transp. $R_{i}$ vidéti budetej wydyte $\mathrm{R}-20$. onen] $e^{2} \mathrm{R}_{i}$ den]

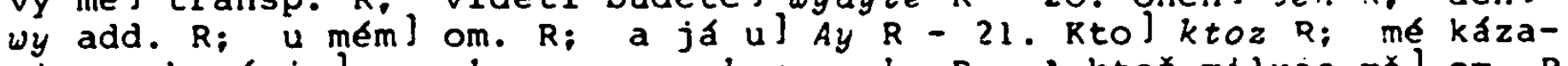
nie a chova je] przykazanye nechowa geho R; A ktoz miluje mél om. R budu jej] transp: R: zjevi] zgewym 
LXXXV. Dominica Pentecostes - J14,23-31

S $144 \mathrm{~b}$,

$\left(149 b_{1}\right)$

\section{Pravil Ježús mlazśm svým} kto miluje mé kázanie mé schová

A Otec muoj milovati bude jeho

a $k$ nèmu pł́ldemy a bydlo u něho uloźmy

24. Jenz nemiluje mne slova mého nechova a prikázanie jenž mi dal otec jez ste slyseli nenie mé Ale toho jenz mé poslal otcovo

25. To sem mluvil vám u vás bydle

26. ale ucesitel Duch svatý jehoz dosle otec u mé jmé ten vy naux̦ vłemu

a *podá vám všeho cokoli ł́ku vám

27. Mir vám ostavi Mir muoj dávaji vám ne jako suět zde dává já dávám vám Nemut' sè srdce vaše ani lekaj

28. vłak ste slyšeli že sem ł̌ekl vám jă otejdu a přliu k vár.

Byste milovali mĕ radovali byste sè všeliky že jdu

\section{$k$ *otci}

nebo Otec mne větక̆ jest

29. A již pravi vám dł́éve nez sé stane

a kdy̌̌ sĕ stane vĕťte

30. Již nemnoho pomluvi s vámi pł̇ılo knieže suětské a na mnĕ nejmá nice

31. Ale aby suět poznal že miluji otcè a jakoz mi kázanie otec dal tako cini

\footnotetext{
LXXXV.: S, R, W] deest A, C, D
}

23. Pravil] Powyedyel R, $V$ onom czya\$\$y praem. W; miaz\$lm] vczyennykom $W_{;}$svým] $A C z$ add. $W, R_{i}$ schova] chowa $W, R_{i}$ milovati bude] my luge $R$; milovati bude jeho] bude gey my lowaty $W$; oŕldemy] przydem $W, R ;$ bydlo] przybytek $W$, odpoczynutye $R ;$ u něho ulozímy] vczunymy $v$ nyeho $R$, $v$ nyeho vczynymy $W-24$. Jenż $K$ to $W, A k t o z R ;$ slova] kazanye $W$; mého nechova] transo. $R ;$ pł́ikazanie jenz] \$\$ lowo ge§\$to W; mi dal otec jez] om. W, $\mathrm{R}$; tohol geho $\mathrm{R}$, otczye add. W; Otcovol om. W - 25. Tol ge\$tye add. R; sem mluvil] transo. R; $u$ vás] $\$$ wamy $W$; bydle] prayebywage $N, R$ - 26. ale] om. $W$; posle] po\$\$lal R; vy] wa\$\$ W; poda (podda ms.)] poda 'v, powye R; vłeho] w\$eczko R; cokolil czoz kolywyek R, czoz kolwyek w: łku] powye $R$ - 27. Mir vám ostavi Mir muoj dávaji vám] Myr dawam wam myr a pokog o\$tawugy wam W, A myr moy dawam wam myr moy o\$tawgy wam $\mathrm{R}$; zde] om. W: dává] wam add. W: já] om. R; dávám] dawagy W, R; Vemut'] Ne\$mutyg W-28. vకak] om. W: ste slyseli] transo. 'v: já otejdu] $g d u$

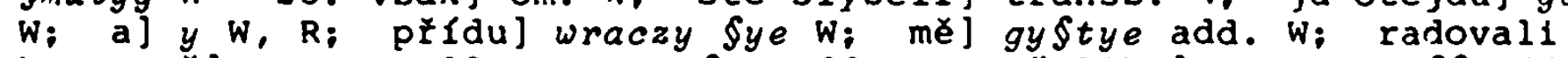
byste sĕ] transp. 231 W, zagy\$te add. $R$; vङeliky] om. $W$, wa\$§ add.R: 
Že] nebo W, R: otci (uotczy ms.); mne věţ́l] transo. W- 29. jiz pravi] nynye \$em prawy $W$ : věrte] vwyerzyte $W$ - 30. Domluvil pomluwym R, mluwy W; s vámi] Nebo add. W; oł́illo] pray\$\$el R; svétskbi] tohoto \$wyeta R, tohto Siyeta $W$; na] we $W$ - 31. suẹt poznal] transo. W. R; ze] ya add. W; kázanie] przykazanye R; tako tini] tak czynym $W, R$.

LXXXVI. Feria II. post Pentecosten - J 3,16-21

25b 16. $V$ onom Zasi

Pověděl Ježis učenn Ikóm svým

Tak Buoh miloval suét aby syna svého jedinkého dal aby vłeliký kto věr veñ nezahynul

ale aby mèl zivot vě̀ný

W 26a 17. Nebo neposlal Buo Syna svého // na tento svět aby súdil suẹt

Ale aby spasen byl suet skrzĕ ñen

18. kto vĕłi veñ nesuzen jest

Ale kto neverł jiz jest suzen

Nebo nevěr 1 ve jmě jednoho syna Bož fho

19. Ale to jest sud

nebo suétlost prisla na tento svět

a milovali sú lidé vice temnost než suétlost

biechu zlá jich diela

20. Nebo každy kto zle cini nenávidí suétla

a nepŕlde na suětlo aby netresktali diela jeho

21. ale kto Ciñ pravě jde na suétlo

aby otevína byla jeho diela nebo od Boha su posla

LXXXVI.: $W, R]$ deest $A, C, D, S$

16. V onom Xasi] om. $R$; uX̌ennfkóm] mlaz§ym $R$; milloval svět] transo. $\mathrm{R}$; $a b y] z z e \mathrm{R}$; jedinkéhol gedyneho $\mathrm{R}$; v̧eliky kto věr $[$ veñ] kaz$d y$; nyem $R$; aby\} om. $R$ - 17. neposlal] ne proto ge\$t po\$\$lal $R$; tentol om. R; svět] czlouyeka R; spasen byll zachowaly $R_{i}$ skrzé nen? gym $R-18$. kto] ktoz $R$; nesuzen jest] ten nebude fuzen $R$; $k t o] k t o z R ; j i z]$ ten add. $R$; jest suzen] transD. $R$; ve jmé jednohol $v$ mye $v$ gedyneho $R-19$. nebo] zze ge§t $R ;$ suétlost prisla] transp. $R_{i}$ a] y R: suj om. R; svétlost] Nebo add. R; zla jlch] transp. $R-20$. Nebo] zze $R$; kto] ktoz $R$; suétla a nepŕlde na suétlo] Swyet lo\$ty Any przyde na \$wyetlo§t R; netresktali] netrejktany by $2 a \mathrm{R}$; diela jehol transp. $\mathrm{R}-21$. kto] ktoz R; prave] prawdu ten $R$; otevienal zgewena $R$; posla] poßrana $R$. 
LXXXVII. Feria III. post Pentecosten - J10,1-10

1. $V$ onom casi

Pověděl Jež́s uXennikóm svým

zaverrné a zajisté pravi vám

který nevende dvermi do ovxince ovec Ale vende jinudy ten jest zlodej a lotr

2. Ale kto vchodr dvermi pastucha jest ovcr

3. Tomu vrátný otvoŕ a ovcé uslyšie jeho hlas a své ovcé volá jménem 1 vyvede je

4. a kdyz vlastnie ovcè vypust 1 před nimi jde a ovcè jeho následuji nebo v(è)dr hlas jeho

5. Ale po neznámém nejdú ale bězie od ňeho nebo nepoznaly hlasu neznámého

6. To slovo povẽ jim Jezŕs ale oni nerozumĕchu co mluvise jim

7. vecé jim Jezis opert zavěrné zajisté pravi vám nebo já sem dveri ovci

8. vకexckni kto koli su płisli zlodéjé a lotri sú ale neslysely sú jich ovce

9. já sem dueri

W 26b Kto vende skrze / mé uzdraven bude a vende $i$ vynde a pastuchy najde

10. zlodej nechodi jedno aby ukradl 1 zabil a zatratil

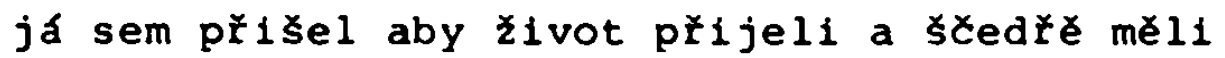

LXXXVII.: $W, R]$ deest $A, C, D, S$

1. $V$ onom časi] om. $R$; Zavĕrné a zajisté] transo. $321 \mathrm{R}$; dvermi do ovtincé ovec] $w$ owczynecz owczy dwerzmy $R$; a] y R - ?. kto vchodi] ktoz weyde $\mathrm{R}$; dvermi] ten add. $\mathrm{R}-3$. Tomu] gy\$temu add. $\mathrm{R}$; otvoli] otewrze R; uslysie jeho hlas] hia\$\$ geho $\$[y \$ \$ y e \mathrm{R} ;$ a své ovcé vola] y powola owecz wlaStnych $R-4$. orèd nimi jde] poyde przed nymy $\mathrm{R}_{i}$ a] ty add. $\mathrm{R}$; jeho následuj[] transp. $\mathrm{R}$; $v\langle\check{e}\rangle d 1$ (wydy ms.)] $\$ l_{y} \$ \$ y e ~ R-5$. neznámém] nezwanem $R ;$ ale] $\$ p y-$ $\$ \$ e$ add. R; nepoznaly] $g \$ \$ u$ geho add. R - 6. slovo dovědé] przy\$lowye powyedye [ $R$ - 7. vecé] Tehdy praem. $R ;$ vece jim] transp. $R$; opét] druhe R; zavěrné] y add. $\mathrm{R}_{i}$ nebo] zze R; dvełi ovcl] wratny owczyn\$ky $R-8$. vडeckni kto koli suj w\$ycakny kteryz kolywyek $\mathrm{R}$; a lotłi su] $\$ u$ a lotrzye $R$ - 9. dvefi] dwerze R; Kto] Mnu ktoz $R_{i}$ skrzé] om. $R_{i}$ mé] om. $R_{i}$ vende] tam add. $R_{;}$vynde] wyde $R_{;}$ pastuchy najde] pa\$twu nalezne $R$ - 10. zlodéj] pro gyne add. $R$; i] a R: Šedre] w rozko\$\$y \$ye R. 
LXXXVIII. Feria IV. post Pentecosten - J 6,44-52

44. V onom Casi

Pověděl Ježs sboróm zidovským

Nizáany nemóz ke mnè pijijlti

jedno otec jenz mĕ poslal płritrhne 11 jeho

a ja jej zkłisim $v$ sudny den

45. Jest psáno u prorociech

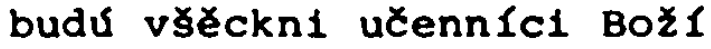

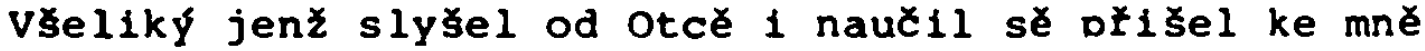

46. ne proto by kto otcer videl

jedno ten kto jest od něho ten vid1 otcĕ

47. věrnè jistè pravi vám

kto vèł u mè má żivot vè̃ny

48. já sem chléb zivota

49. Otci vaši jedli su mannu na pưxxi 1 zemřli sú

50. Tot' jest chléb *jenž s nebes stupil

ac kto jeho jésti bude neumřx věčñ

51. já sem chléb zivý jenz sem $z$ nebe stúdil

52. AC kto bude ten chléb jlsti ziv bude na vĕky a chléb jenż já dám tẻlo mé jest za lidský żivot

LXXXVIII.: $W, R]$ deest $A, C, D, S$

44. V onom ¿asi] om. R; sboróm Zidovským] \$wym mlaz\$ym a rzka R; $\mathrm{N}$ izadny] Igeden $\mathrm{R}$; nemóz ke mně] transo. $231 \mathrm{R}$; jedno] kromye

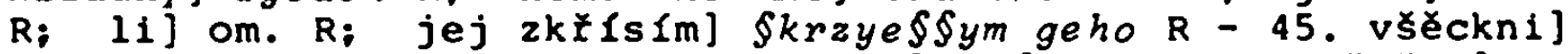
w\$ychny R; Vłeliký] kazdy R; jenż ge\$t add. R; pŕišl] przy-

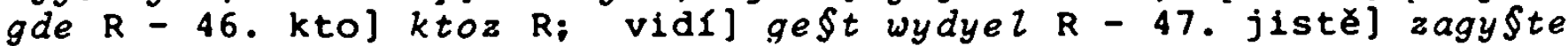
$\mathrm{R}$; ktol ktoz wen $\mathrm{R}$; $\mathrm{u}$ me] om. $\mathrm{R}$ - 49. Otci] Ottczowe $\mathrm{R}$; jedli sú] pozywaly $\mathrm{R}$ - 50. Tot'] Tento R; "jenz (genez ms.)] om. $\mathrm{R}_{i}$

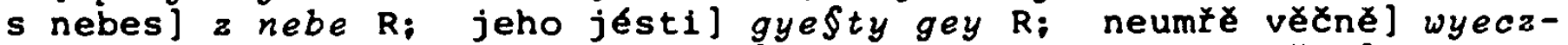
nye zyw bude $R-51$. ja...stúpil] om. $R-52$. AC...na věky] om. $R ;$ a) ya add. $R ;$ jenz já] gemu R; dám] tobye add. R; têlo mé jest] transp. 231 A to add. $R ;$ lidský] \$wyet $\$ k y R$.

LXXXIX. Feria V. post Pentecosten - L 9,1-6

1. V onom Casi

Pozval Ježs dvanáste ucennikóv

dal jim moc pode vక̌emi diábly

aby nemocné uzdravovali

2. 1 poslal je kázati královstuie Božie a uzdraviti nemocné

3. i vecè jim 
nitcè neneste po cèstè

w $27 a$

ani holi ani mosny ani chleba ani peněz //

ani dvi sukni mievajte

4. a v ktery koll dóm vejdete tu bydlte a odtud nevychod'te

5. A kto kolvěk vás nepł̇ijme vyndúce $z$ mexsta toho

tehdy nohami vašimi prorazte na suědečstuie na nĕ

6. Tehdy vysedకe chodiechu po hradech káziece a uzdravujlce všudy

LXXXIX.: $W, R]$ deest $A, C, D, S$

1. V onom Casi] om. $R$; uCennfkóv] \$wych $y$ add. $R$; moc] $y$ czno\$t add. $R_{i}$ pode] nade $R ;$ diably] bye $\$ \$ y$ y take $R$ - ?. kázati] y miuwyty add. $R_{i}$ uzdraviti] vzdrawowaty $R$ - 3. neneste] nene\$ty $R$; mosny] tobolky R; penez] zbozye R - 4. kterýkoli] kteryz kolywyek w R - 5. kto kolvěk] ktoz koly R; města toho] transp. R; tehdy] tak prach $R_{i}$ prorazte] pra\$te $R_{i}$ né] ty gy\$te $R-6$. chodiechu po hradech kazíece a uzdravujice vडudy] kazachu odchodyecze po kragych po hradyech $y$ vadrawowachu wezde $\mathrm{R}$.

XC. Feria VI. post Pentecosten - L 5,17-26

17. $V$ onom Casi

sta sex jednoho dne Ježř sediese ưe

a biechu zákonnici a mistíi zákonni sediece

jesto biechu pł̇łli z vłelikého hrádku z Galilee a 2

Zidovstvie a $z$ Jerusalema

a moc Bozie biese jim na uzdravenie

18. A tu mužé nesiechu $v$ loži clověka jenż biełe nemocnỵ hledáchu jeho vnésti i poloziti płéd nim

19. a nenalezechu kterú by stranu jej nesli oro sbor vstúpichu na střrchu

a po dskách spustichu jej s ložem mezi sebil ořę Jezr

20. Jichžto vieru jakz uzì vece

clovexe Odpusceni tobe tvoji hriesi

21. i poxěchu mysliti pisałi i zákonnici łxuce

kto jest ten jenz mluvi blániver

kto muz hílchy odpustiti jedno sám Buoh

22. Poznav Jezís myšlenie jich vecer $k$ nim

Co myslite u vasich sraciech

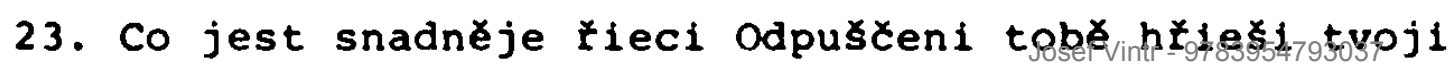


Ci li řieci vstañ a chod'

24. Ale abyste věděli že syn člověç moc má na zemi odpustiti hřiechy

vecè nemocnému

พ $27 b$

tobè pravím vstan̆ zdvihni / lože své i jdi v dóm svój

25. I náhle vstav p̧̌̀̃ nimi zduih lože své v nêmžto ležel jide do domu svého chvále Boha

26. a strach nadjide vకłickny $i$ chvalichu Boha

i naplnèni sư věchñ strachu řkúce

jiz smy divy vidéli dnes

XC.: $W, R]$ deest $A, C, D, S$

17. V onom ¿asi] om. $R$; dne] a add. $R$; uð̌] vczedlnyky add. $R$; a mistři zákonn1 sediece] transp. $4123 \mathrm{R}$; jestol genz $\mathrm{Q}$; biechu płisli] transp. $R ; z$ vडelikého hradku] ze w\$eho hradu $z R ; a z$ Zidovstvie] om. $R ; j i m\}$ om. $R ;$ uzdravenie] gych add. $R-13$. A tu] Ay $\mathrm{R}$; muźe] om. $\mathrm{R}$; $\mathrm{v}$ ] na $\mathrm{R}$; nemocný] nuznym y $\mathrm{R}-19$. a] $I$ $R$; nenalezechu] $w$ add. $R$; jej nesli] geho wne\$\$ly a to $R$; oro] welyky add. R; vstupichu] Wy\$tupychu R; střechu\} \$wrchu add. R; spustichu jej] pu§tychu geho R; mezi sebu] vproßtrzed $R$ - 20. uzrè] wydye $R_{i}$ vece] $k$ nyemu add. $\mathrm{R}$; Odpusteni] $\$ \$ u$ add. $R-21$. jest] $z$ de add. $R_{i}$ hřlchy odpustiti] transp. $R-22$. Poznav Ježs myšlenie jich vecé] Jakz pozna Buoh vmy§lenye gych odpowyedye a rzka $R$ - 23. snadněje] lehczegye R; Odpušenil g\$\$u add. R; tvoji] om. $\mathrm{R}$ - 24. ¿lověx 1$]$ magye add. $\mathrm{R} ; \mathrm{h}[\mathrm{lchy}] \mathrm{Tehdy}$ add. $\mathrm{R} ;$ nemocnému] pracznemu R; pravim] prawy R; zdvihni] $A$ wezmy $R$; své twe R; svój] twoy $R$ - 25. i] $A$ w tu dobu $R$; zdvih] a wzem $R ;$ v němzto] na nyemz $R_{i}$ ležel] y add. $R ;$ do domu svého] $w$ dom \$woy $R-25$. vडsickny i chválichu] w\$eczky y chwalechu $R ;$ vsechnij om. $R ;$ jiz] Nebo R: divy vidèli] transp. R.

XCI. Dominica I. post Pentecosten - L 16,19-31

S 144b, 19. Povědēl Ježus uxennikuom svým pověst tuto

$\left(149 b_{1}\right) \quad$ Clověk jeden bieše bohatý

i oblaxiese sè u pavlaky

1 hodováse prokn 1 den $v$ suétlosti

20. i bieše jeden chudý jménem Lazał jenż ležiese u dveřl jeho nežituov pln

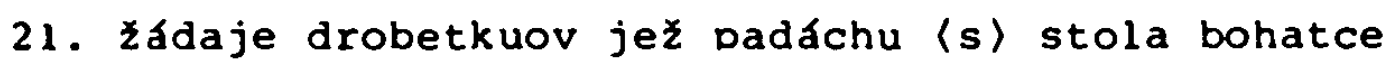
a nikte jemu dodadiese

Ale psi pŕdúce lizáchu nezity jeho

22. Stalo se jest az umre bohatý $i$ pohy̌eben jest u pekle A kdyz skonce chudý donesen je anděly do lóna Abrahamova 
23. Tehdy podvih oxi bohatec

vidèl Lazałe vysoko v lónè Abrahamové /

S $144 b_{2}$ 24. 1 zavola

$\left(149 \mathrm{~b}_{2}\right) \quad$ Otče Abraham smiluj sè

a pošli Lazałe at' omoci mézeny prstek u vodé

at' rozvlaž jazyk muoj nebot' mám muku $v$ tomto ohni

25. Pověde jemu Abraham

Synu rozpominaj se ze s płijal dobré $v$ svuoj zivot

a Lazar protiv tomu zlé

Nynie zde utěchu jmá ale ty mukú lkajes

26. A mezi tiem vక̌lem mezi námi a vámi duol veliký učiněn jest

jakž ti jesto chtie ot nás $k$ vám nemohú

ani ot vás sem prijíti

27. 1 vece

Prosi tebe tehdy otče aby jej poslal $v$ duom otcè méno

28. ješe mám pět bratruov aby jim pověděl aby oni nevesli $v$ toto miesto mucenie

29. I povèdé jemu Abraham

Jmajl Mojzise a proroky slyste ty

30. Tehdy on vece

Ne otce Abraham

ale kto by $s$ mrtvych $k$ nim sel pokánie oŕ(i)jmú

31. Vece jemu

AC Mojžlse a prorokuov neposlischaj 1

ani komu 2 mrtuých vstanúce uvềie

XCI.: S, R, W] deest $A, C, D$

19. Povědell] $W$ Onom czya\$\$y praem. $W$; tuto] a rzka add. $R$; jeden biese] transp. $\mathrm{R}$; i] a $\mathrm{R} ;$ u pavlaky] v pawlaczne rucho $\mathrm{R}$, $w$ ak\$amyt y v po\$tawcaye $W$; hodovałe prokni den] kocha\$\$ye \$ye wezdy $W$, chodye\$\$e y gmyege\$\$e \$ye na kazdy den $\mathrm{R}-20$. jeden] gyz den $\mathrm{R}$; Lazał] lazarus $W_{;}$dvełl] podwoge $R_{;}$jeho] a add. $R_{i}$ nezituov oln] wrzyedow plny $W-21$. zadaje] na\$ytyty add. W; drobetkuov jez] droptow genzto R, \$trayedy genz W; padáchu] pada\$\$ye $W ;\langle s\rangle] \S R$; stola] Stolu $\mathrm{W}$, toho add. R; bohatce] bohateho W; a nikte] Ale zadny $\mathrm{R}$; jemu ] $m u \mathrm{~W}$; dodadieš] nedadye\$\$e $\mathrm{W}, \mathrm{R}$; nezity] wrzedy $\mathrm{W}-2$ ?.

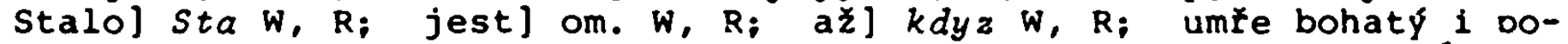
hłeben jest $u$ pekle $A$ kdyz skonce chudý donesen je anděly do lóna Abrahamova] vmraye chudy $y$ ne $\$$ en by $l$ od ange low $w$ lono Abrahamowo Vmrzye y bohatecz y pohrzyeben $v$ pekle $\mathrm{w}$, vmrze chudy ne\$\$en ge od angelow $w$ Lono abrahamowo $A$ kdyz vmrze bohaty Tehdy pohrzebechu gey $v$ pekle $R$ - 23. Tehdy] om. $w$; podvih] zdwyh $w, R$; oci] \$woge add. W; bohatec] bohaty $R, k d y$ bye $\$ \$ y e v$ mukach wydye Abrahama zdaleka a add. W, kdez to bye $\$ y e v$ mukach vzrzye Abrahama zdaleka a add. $R ;$ viděl] om. W, R; Lazał̌e] lazara W; vysoko] om. W, R; Abrahamově] 
geho W, R - 24. i] Tehdy R, on add. W; zavolal zwola a rzka W, R: Abraham] abrahame $\mathrm{R} ; \mathrm{se}]$ nade mnu adr. 'v, $\mathrm{R} ; \mathrm{a}$ ] $y$ 'v; omoti] $v-$ pu§ty $W$; mézený] mezny $R ;$ prstek] pr\$tel $R$, pr\$t \$woy $W$; vorie] wodu W, R: mám] horzym W: muku] muky do\$ty $\mathrm{R}$, om. W; tomto] tento W - 25. Povède] Odpowyedye R, y wecze W; Abraham] y wecze add.

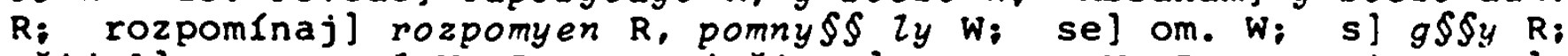
prijal] przygymal $W, R ;$ svuoj zivot] transp. $W, R ;$ orotiv tomu] om. $W ; z l e]$ ale add. $W, R ;$ zde utechu jmá] tuto vtye§\$en $W ;$ ale] a R; lkajes] $2 k a \$ \$ R$, om. $W-26$. mezi nami] om. $R ;$ a] $y$, om. $R ;$ vámi] om. $R$; duol veliký uxinèn jest] nebo dalekoft welyka vczynyena R; jaki] aby $R, y$ w; ot nás] tam gyty $W ; k$ vam] gyty add. $\mathrm{R}$; ot vas] odonud $\mathrm{W}$; sem] $k$ nam $\mathrm{R}$; płij[ti] gyty $W$, przygdu $\mathrm{R}-$ 27. I] mehdydruhe bohatecz $R$; Prosi] pro\$\$ym $W$, $R$; tehdy] om. ' $N$, $\mathrm{R}$; ot‘e] abrahame proto add. $\mathrm{R}$; aby] my add. W - 28. jeste] nebo $W$, nebo praem. R; aby jim povědel] acz \$wyedczy gym $W ;$ nevesli $v$

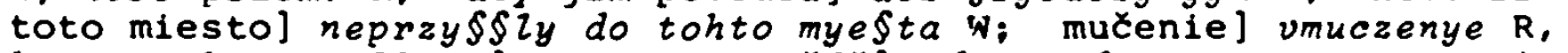
horuczyeho $W-29$. I] om. R; povède] Odpowyedye R, weczye W: jemu Abraham transp. a rzka add. R; a] $y$ W; ty] gych $W-30$. Tehdy] $y$ W; Ne] tak add. W, R; Abraham] abrahame $R ;$ ale] acz add.

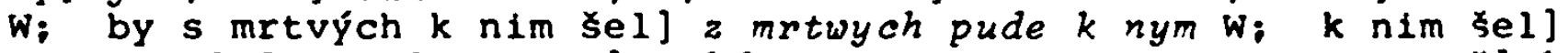
transp. $312 \mathrm{R}-31$. Vece] Tehdy praem. R, y on Draem. W: Axj kdyz $W: a]$ any $R$; neposluchajl] nevpo\$zuchagy $R$, ne\$\$Zy\$\$ye $W$; komu ] acz kto W, acz by kto R; vstanuce] by w\$tal W, w\$tal R; uvěrie] nevwyerzye $\mathrm{W}, \mathrm{R}$.

XCII. In festo S. Corporis Christi-J6,56-59

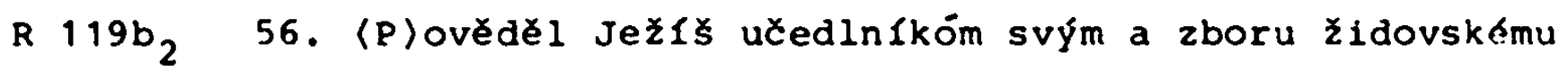
a $\check{r k a}$

Tèlo mé zajisté jest pokrm

a krev má zavěrné jest pitie

57. ktož kolivěk požlva mého tẻla a mis krev die Ten ve mnè přebývá a já v ném

58. Jakoz to mé jest poslal pracévati otec a ja pracuji za Otcè

A ktoz mne poziva ten ziv bude ve mnè

59. To jest chléb jenž jest żel z nebe

ne jako otci vasi pojedli manny i zemreli jsú

Ale kto poźrati *bude tohoto chleba ten ziv bude na věky

XCII.: R] deest $A, C, D, S, W$

59. "bude (budu ms.)

XCIII. Dominica II. post Pentecosten - L 14,16-24

s $144 \mathrm{~b}_{2}$ 16. Povĕděl Ježus uxennikuom svým pověst tuto

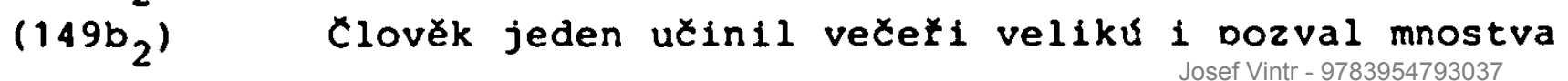


17. I poslal posla svého $v$ Cas večełi łéci zvaným aby płisli

nebo jiz hotovo jest vకechno

18. I poxechu sex vłichni omlúvati

i vece jemu prvy

ves sem kúpil i jmám potfebu ohlédati ji

prosi tebe méj mé omluvena

19. Druhý vece

patera jha volova sem kúpil proto nemohu býti

prosi tebe omluv i me

20. Thet1 vece

ženu sem pojal proto nemohu přjilti

21. Co učini panoše vráti sè i povědé pánu svému

Tehdy hněvi(v) pán povědè panosi svému

vyjdi rychle $v$ ulice méscké

S 145a, a chudé i nemocné slepé // i chromé ved' sem

$\left(150 a_{1}\right) 22$. 1 povědě panoser

pane stalo sè jakż si kázal

a ješe miesto jest

23. i povědě pán panosi

vyjdi na cesty a mezi ploty płipud' uniti aby naplněn

by 1 duom muoj

24. To vám pravi

jeż ijeden muž tĕch neokus 1 vecere mé

XCIII.: $S, W, R$ ] deest $A, C, D$

-

16. Pověděl] $V$ onom czya\$\$y praem. W: povést tuto] podoben\$twye toto a rzka R; Cloverk jeden] transp. $R_{\text {; }}$ veliku] om. $R$; mnostva] mnoz§twye W, mnohych $R$ - 17. posla] §luhu R, \$luzebnyka W; Cas] hodynu $R$; vexełi łéci] weczerzye powyedyety $W, R ;$ zvanym] pozwanym W: hotovol do\$pyeno R; vSechno] w\$\$yeczkno W - 18. sé visich-

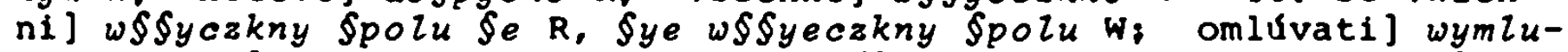
waty $\left.R_{i} i\right]$ om. $R$, $W$; vece jemu prvy] om. $W$, prwy wecze $\left.R_{i} i\right] a$ $R$; potfebu] wygyty a add. $W$, wynyty a add. $R$; ohledati] wydyety $W ;$ prosi] proß̧ym $W, R ;$ měj mé omluvena] omluv mye $W, R-19$. Druhý] y praem. W: patera jha volova sem kupil] patero gho wolow wecze kupy $l$ Sem chczy gych waku\$\$yty $R$, patero y ga \$em wolow kupy $l$ a hozy ty zku\$\$yty $W_{\text {; }}$ proto nemohu byti] om. W, R; Drosi] pro\$\$ym $\mathrm{R}$; omluv 1 mé] omluw mye $W$, myeg mye om $\{u w\langle e\rangle n a \mathrm{R}-20$. vece] ge$m u$ add. W; pojal] a add. $R-21$. Co uxini] om. w; panose ] \$[uha

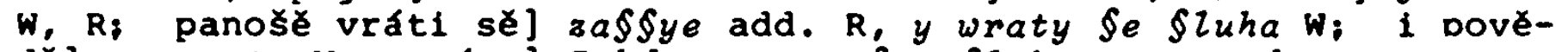
dé] powye to $\mathrm{W}$; svému] Tehdy wratyw Sye \$luha y powyedye to panu Swemu add. R: hnèvi(v) pán povèdé panosij rozhnyewal \$ye otecz cayeledynny Weczye Sluze $W$, rozhnyewam Sye ottecz czeledny y dye

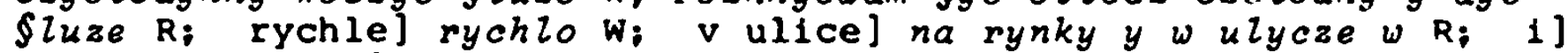
om. W: nemocné] $y$ add. $R$; i] om. W-2?. panose ] \$luha W, R; 
pane stalo sẻ] transp. $231 \mathrm{R}$; jakz] yakoz W-23. 1] Tehdy R; Dověde] weczye $W$; panosi] §wemu add. $R$; a] $y$ w; ploty] $y$ add. $W$, $a$ add. $R_{i}$ aby naplněn byl duom muoj] transp. $13542 \mathrm{R}$; naplnén byl] transp. $W-24$. Tol $A l e W ;$ vám pravil transp. W, R; jez] ze W, R; ljeden] nyzadny $W:$ muz] muzow $W, z$ muzow R; těch] kterzy \$u pozwa$n y$ add. W: vełełe] genzto $\$ \$ u$ zawolany $k$ weczerzy $R$; mé] mey $W$.

XCIV. Dominica III. post Pentecosten - L 15,1-10

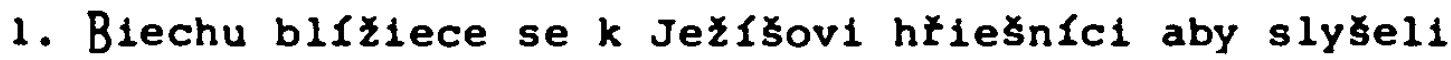
jeho

2. I reptáchu zákonnlci a plsałł łkúce proc tento hílesnlky płijlmá a jie s nimi

3. I povède $k$ nim poverst tuto

4. kto mezi vámi clovèk jenż jmá sto ovec pakli ztrat 1 jednu $z$ nich veder ostavi jich devaddesát a devět na pústi 1 jde $k$ té jež $z$ tracena hledá don̆avadže nenalezne

5. a kdyz nalezne pójde poloź na rameni radosten

6. A pł́lda domuov pozove płátel a súsěd pravě jim Radujte sè mnè že sem nalezl ovci potracenu

7. Pravi vám že taká bude radost anjelóm Boźm na jednom hřiešném pokánie cinfce

nez nad devietidcat devieti pravych jimzto netreba pokánie

8. Nebo která žena majlci peněz deset a potrati li peniez jediný ponét' płěvráti duom zažhúci suětlo

i hledá laskavě doñadź nenalezne

9. a kdyz nalezne pozove płátel a susexd pravieci poradujte sè mnè ze sem nalezla peniez ten jenzto ztratila biech

10. Takoz vám pravi radost bude płed anjely Božmi nad jednı́m hł̌iešným pokánie ciniece

XCIV.: $S, R, W]$ deest $A, C, D$

1. Biechu] $V$ onom czya\$\$y praem. W: Jezisovi] a add. $R$, zgewnye $y$ add. W; hłlesnlci] hrzye§§ny $W$, zewny add. $R-2$. reptáchu] $\$ \$ e p-$

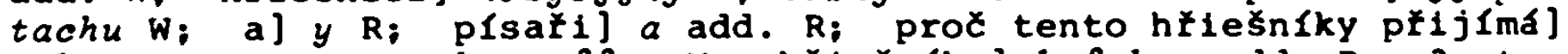
nebo tuto praygyma hrzye\$\$ne W: hiliesniky] $k$ Sobye add. R - 3. tuto] tu a rzka R, a rzka add. W- 4. kto] ktery W, ge\$t add. R; me-

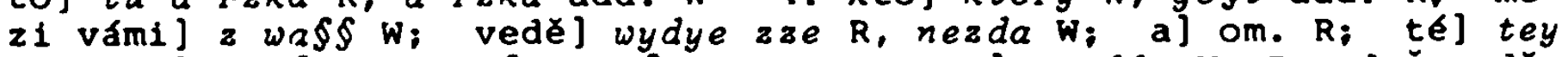

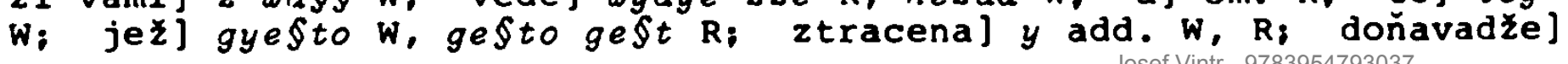


donydz $\mathrm{R}$, az gy $y \mathrm{~W}$; nenalezne] nayde $\mathrm{W}$, gye add. $\mathrm{R}-$ 5. nalezne] gy nayde W, gy add. R; pójde J om. $W$; položll wlozy W, gy add. R; rameni] Swe add. $W$, ramye $W_{e} \mathrm{R}_{i}$ radosten] rado\$tnye $\mathrm{R}-6 . \mathrm{A}$ ] $y$ R: pozove přatel] \$wola przyately $N$; susěd] \$u\$edy $W$, \$\$u\$edow a $\mathrm{R}_{i} \mathrm{jim}$ ] a raka add. $\mathrm{R}_{i} \mathrm{ze}$ ] nebo $\mathrm{W}, \mathrm{R}$; ovci] $m u$ add. $\mathrm{W}, \mathrm{R} ;$ potracenu] genz \$em ztraty $[\mathrm{W}$, genz bye\$\$e potraczena $\mathrm{R}-7$. taká] tak W, take R: Bozlm] w nebe\$\$yech add. R; na jednom] nad gednym

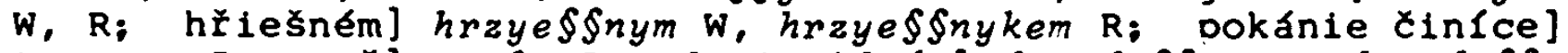
transp. $R$; nez] nezly $R_{i}$ devietidcat] dewade\$\$at $R$, dewade\$\$aty W; devietil om. R; pravých jimzto netłeba] \$prawedinywych ge\$\$to nepotrzebugy $R$ - 8. Nebo] om. $W$; a] acz $R$; Dotrat1] atraty $W$; 11) om. $\mathrm{R}_{i}$ peniez jediný] geden penyez $\mathrm{W}, \mathrm{R}$; ponét'] zda $\mathrm{R}$, ne$z d a W ;$ prévráti duom] om. R; zažhuci] rozhuczy $W$, nerozeyze $R ;$ světlo] Zucernu $R ;$ laskavě don̆adż] Snaznye donyz $W$, Snaznye dokudz $\mathrm{R}$ - 9. nalezne] tehdy add. R; pozove oł́atel a súséd] \$wych add. R, \$wola praytelkynye a \$u\$edy W: pravieci] rakuczy gym W: poradujte] radugte $W, R$; ten] om. $W, R$; jenzto] ge\$to $R$, genz Sem $W$; ztratila biech] transp. $R ;$ biech] om. W - 10. Takoz] takez W, R; vám pravi] transp. $W, R ;$ pravi] prawym $R$; hriesným] hrzye\$\$nkem R.

XCV. Dominica IV. post Pentecosten - L 6,36-42

36. Pověděl Ježus uxennikuom svým Bud'te proto milosrdni jako otec vas milosrden jest

37. Nerod'te suditi aby nebyli suzeni Nerod'te hubiti aby nebyli zahubeni

S $145 a_{2}$ Odpuste a odpustie / vám

38. dajte a dadie vám mieru dobrú a narovnanu 1 navrchovanu dadie $v$ lóno vaše

Také toliku mieru jižto namer ŕte otmérie vám

39. i povĕdĕ jim podobenstvie

a zda muoze slepý slepého vésti

snad $v$ duol ona upadneta

40. Nenie učennik nad mistrem

Mistrem bude gaždy jenz jest jako mistr jeho

41. AC vidis suk $v$ oce bratrove

a klády $v$ svém neznamenás

42. nebo kako muožes pověděti bratru tuému Bratr vyñmi suk 2 oka tvého

a v suém oce klády nevida

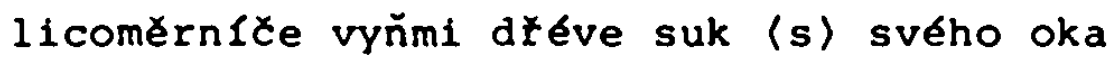

a potom prozł́s i vynmes kládu z oka bratra tvého

XCV.: $S, R, W]$ deest $A, C, D$ 
36. Pověděl] $V$ Onom czya\$\$y praem. W; uðennlkuom] m[ad\$\$ym R; svým] a rzka gym add. R; protol om. $W_{;}$jakol yakoz W; vás] nebe\$\$ky add. W, $\mathrm{R}-37$. aby nebyli] aby\$te neby $l_{y} \mathrm{R}$, a nebudete W: suzeni] Nerodte potupowaty aby\$\$te nebyly potupeny add. $R$; Nerod'te hubiti] nerodte zahubyty W, Nezahubuyte R; aby nebyli] $a b y \$ \$ t e$ neby $l y$ R, a nebudete $W_{i}$ a odoustie] $y$ odpu§§czyeno bude $W$, at bude odpu\$tyeno $R-38$. a] $y$, om. $W$; navrchovanis dadie] wrchowatu dayte $\mathrm{R}$ : Take tolikuj tuz zagy§te $\mathrm{W}$, Nebo yakuz koly $\mathrm{R}$; naměrlte otměrie] odmyerzyte odmyerzye $\mathrm{W}$, odmyerzyte gym tez odmyerzeno bude $\mathrm{R}-39$. i] $A l e \mathrm{~W}$, ?ehdy R; A] $N e \mathrm{~W} ;$ snad] a zda $\mathrm{W}$ : $\mathrm{v}$ duol oba] transp. $312 \mathrm{~W}, \mathrm{R}$; upadneta] neupadneta $\mathrm{W}-40$. mistrem] my§tra W; Mistrem] my§trnyegye R, Ale doßpyely W; bude gaždý] transp. W: jenz jest] acz bude W, om. R; mistr] yako iv - 41. AC] ACz czo W, czo\$ई tehdy R; bratrové] bratrowem R, bratra Sweho W: a] $A$ ie R; klady] kiadu W: $\mathrm{v}$ svém neznamenás] neznamena\$\$ ocze twem $\mathrm{R}$, genz ge\$t w oczye twem neznamena\$\$ $\mathrm{W}$ 42. nebo...tvému] om. R; povèdéti] rayeczy $W_{i}$ tvému] \$wemu $w_{;}$ Bratr vyñmi] Bratrzye §toy at wynmu $W, R$; oka] nohy $R$; nevida] newydy W: licomernite] lyczomyernyku W, Pokrytcze R; suk] kla-

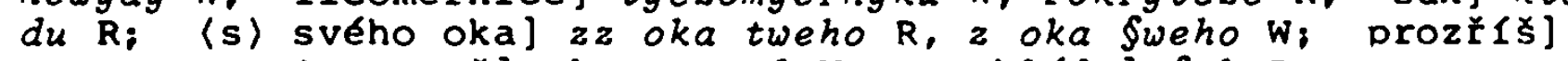
wyzrzy $R ; i$ vynmes] aby wynyal W, R: kladu] $\{u k R$.

XCVI. Dominica V. post Pentecosten - L 5, 1-11

1. Kayz zborové poběhu $k$ Jež́sovi aby slyకeli jeho A on stáse podlé césty jez slóve Genezareth

2. viděl due lodi stojiece tudieže ale rybitvi biechu $i$ práchu vystúpivse sieti

3. A vstúpiv Ježus $v$ lodr jenž bieše simonova prosiese jeho aby pristúdil málo k zemi

A sedě uxiese zbor

4. A kdyz présta mluvenie vece Simonovi vzved' vzhóru oslabtez sieti vaš na lov

5. i Simon pověder

Mistře po v̌̌echnu noc sme usilovali a nice nejeli ale v tué slovo upusti siet

6. A kdyz to uxinichu zatržechu silu ryb veliku Tehdy rozedre se siet jich

7. pokynuchu tovařišóm jez biechu $v$ jiné lodi i dristupichu $i$ pomohu jim

I naplnichu obe lodici Tak jakoz bez mála *toniesta

8. kdyz to $i$ uvidie Simon petr pade $k$ nohám Božlm íka vystup ode mne nebot' sem clověk hřiesny Hospodine

9. Nebo strach ostúpil jej veliký I vesechny jenż s ním blechu na lovu rybném

10. Takéz i Jakuba i Jana syna zebedeova jenz tovařiši 
S 145b, Simonovi / biechu

$\left(150 b_{1}\right)$ i povědĕ k Simonovi Ježus

Neboj sè

potom budes lidi jmati

11. A přivedక̌e sieti ku břehu $v$ lodiech ostav̌e vకeho jidu za nim

XCVI.: S, R, W] deest $A, C, D$

1. Kdyz] $W$ onom czya\$\$y praem. W: poběhu] pobyezechu W, po\$pye§§ychu R; jeho] Slowa buozye add. R; césty] gezera W, R; jež slóve Genezareth] om. W - 2. viděl...tudieže] om. W; tudieže] podle gezera R: ale] a R; rybitvi]rybarzy $\mathrm{R}$, rybarzye W; biechu] chodyechu R, ode $\$ Z_{y}$ add. W; i prachu vystupivङe] brachu $W, a$ promywachu R; sieti] Syetye W- 3. A] Ale W, Tehdy R; vstúpiv]

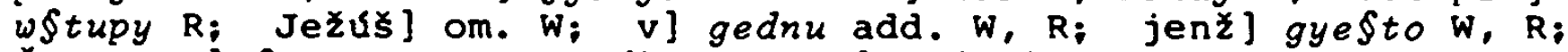
Simonova] \$ymonyova $W$; málo $k$ zemi] malo $k$ nyemu $W, k$ nyemu malo $\mathrm{R}$; sedĕ učiese] $\$ \oint e d y e \oint \$ e$ vcze $\mathrm{R}-4$. vzhórul y add. $\mathrm{R}$, $a$ add. $W$; oslabtez sieti] pu\$te \$ytye $W$; vase na lov] \$we $R-5$. i] Tehdy $\mathrm{R}$; Simon povede] odpowyedye symon $\mathrm{W}, \mathrm{R}$, weczye gemu add. W, $y$ wecze gemu add. R; Mistre] przykazately W; po vsechnu] Przyef\$e w\$\$yeczku W, prze\$ celu R; sme usilovali] \$my dyelaly W: nice] \$my add. R, $W$; upusti] vpu\$tymy $W$, o\$lawymy R; siet] \$yety $R$ 6. uXinichu zatržechu] weczye wztazechu (super wz-rub. y superscr.) W; silu] mnoztwye R, mnoho\$t w; velikuj om. $w$; siet jich] transo. $W$ - 7. pokynuchu] a praem. R; tovałisóm] towarzy\$\$ym \$wym $\left.W_{;} j e z\right]$ genz $W, R_{i}$ jine] gyney $W$; i] aby $R$; Díistúpichu i pomohu] przygydechu y pomozechu $W$, po\$pye\$\$yly pomohly R: jim I] przy\$\$ed\$乡e y W, A kdyz przygydechu R; obe] dwye R; lodici] lody $\mathrm{W} ;$ jakoz bezmála] yakz nemale W: toniesta (domye§ta ms.)] tonyechu $W$, nepohrzyzy\$\$e R - 8. kdyż A praem. W, R; to il om. W, R: uvidie] wydye\$\$ye W, $R$; nohám] nohama $W$; Bozim] gezy\$owym a $\mathrm{R}$, gezy\$\$wy a $W:$ vystupl wyndy $W$, wygdy $\mathrm{R}$; mne] ho\$podyne add. $W ;$ nebot'] Nebo W; Hospodine] om. W- -9 . ostupil] ob\$tupy $2 W, R$; ostupil jej veliky] transp. 312 bye\$\$e add. $R$; veliky\} om. $W ;$ vłechny jenž] w\$yeczkny ge\$to W; rybném] rybyem ge\$to Lowyechu w, ge\$to byechu popadiy add. R - 10. i] om. W, R; Jakuba] yakub R; i] om. W, R; Jana] yan $\mathrm{R}$; syna Zebedeova] \$yny zebedeowy $\mathrm{W}$, \$\$n zebedeow $\mathrm{R}$; jenz] byechu add. W, bye\$\$ta add. $R$; tovarisi Simonovi] towarzy\$l \$ymonowa $\mathrm{R}$; biechu] om. $\mathrm{W}, \mathrm{R}$; 1] Tehdy R; Dovèd] weczye $\mathrm{W}$; k] om. R: Neboj se potom budes] Nerod baty $\$$ e $z$ tohoto bude§\$ potom $W ;$ jmati] lowyty $W, R$ - 11. płivedse] przywed $W$, przywyezte $\mathrm{R}$; sieti] lody $\mathrm{W} ; \mathrm{ku}] k \mathrm{~W}$, om. R; brehu] om. R; $\mathrm{v}$ lodiech] om. $\mathrm{W}, \mathrm{R}_{i}$ ostavకe vక̌eho] o\$tawyw\$\$ye w\$\$yeczkno $\mathrm{W}$; jidu] y gydechu $\mathrm{R}$, a na\$§ledowachu W: za nim] gey W.

XCVII. Dominica VI. post Pentecosten - Mt 5,20-24

20. Pověděl Ježus učennikuom svým a sboróm żidovským Jisté pravi vám Jedno bude li pravda vaše surchovananejsie nežli plsałóv a zákonnlkuov nevejdete $v$ královstuie nebeské

21. Sly̧̌li ste そ̌e praveno jest starým Nezabljej 
nebo kto zabie virien bude suda

22. Ale já vám pravi

ze prokni kto jmá hněv $k$ bratru bez viny vinen bude suzenie

Jenže die bratru svému vilo vinen jest muky ohñové

23. Pakli ofěrujes dar tvój płed oltałem

a tu rozpomenes sě že bratr tvój má $k$ tobě nico

24. Ostavě tu svój dar

jdi dî́ve pokoł sè bratru svému

A tehdyz pł́des i polož́s potom svój dar

XCVII.: S, R, W] deest A, C, D

20. Povědęl] W Onom czya\$\$y praem. W; sboróm zidovskym] raka R; Jiste] zagy§te W, zagy§te a zawyerne R; bude] nebude W; svrchovananejsie] Swrchowanyey\$§ye $W, R ;$ nezli] nez $W$, wyecze nez $R ;$ zákonn\{kuov] $m$. rec. del.., a my\$tru mg., rub. del. $\mathbf{W}-21$. vinen bude] transp. $R ;$ suda] \$udem $W$ - 22. vám pravi] transp. W; prokn1] $w \$ \$ y e l y k y$ w, kazdy ten R; jmá hněv $k$ bratru] \$ye hnyewa \$bratrem Swym $W$; hněv $k$ bratru] transp. $231 \mathrm{R}$; bez viny] om. $W$; vinen bude] transp. $R$; Jenže] $k$ to $W, N e b o k t o z R ;$ die bratru svému] transp. $231 \mathrm{~W} ;$ bratru svému] transp. $R_{i}$ vilo] zle $W$, bude hoden Suzenye $A$ ktoz dye blazne add. R; jest] bude W, R; muky] muku W; ohñové] ohnyewu W, peke lne R - 23. Pakli] Proto acz W, zze add. R; ofěrujes] obyetuge $\$ \mathrm{R}$; rozoomenes sĕ] transp. R; $k$ tobé] om. $W$; nico] nyetczo protyw tobye $W$, nyeczo hnyewu proty tobye $R-24$. tu] om. W: svój dar] transp. R, przyed oltarzyem add. W; jdi] dyz R, y dyz W: pokoł] pokaz R; A] om. R; tehdyz] $y$ add. W; potom] om. W, R.

XCVIII. Dominica VII. post Pentecosten - Mc 8,1-9

1. Gdyz sila bieše z Ježłem ani jmĕjiechu co jlesti pozvav Jezús uðennlkuov svých vece jim

2. Slituji sè nad lidmi ze jiz trmi dny hovie ani má co jiesti

3. A pustíme 11 je lačny ustanú na cestè

A něktefl sư z nich zdaleka płišli

4. Otpovĕděchu jemu mlazš jeho odkad tyto kto moci bude nasytiti chleba

5. i taza jich

koliko jmáte chleba

odpověděchu sedm

6. I káza lidu siesti na zemi

A vezma sedmero chleba chvalu vzda i zláma

1 poda uxennikuom svym aby polozili lidu 
i položili su lidu

7. a jmejjiechu rybic maleðko

i těch požehna i káza položiti

3. i jedli su vǐichni i nasyceni su

i podjeli su jenž ostalo drobtuov sedm kosóv

9. a biechu jesto jediechu jako Ctyłi tisici

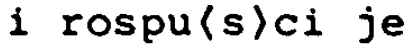

XCVIII.: $S, R, W]$ deest $A, C, D$

1. Gdyz] $V$ Onom czya\$\$y praem. W, mnoha add. R; sila] ray\$\$ue mnoha W; ani jméjiechu] a nemyechu W, nemyegechu R; Dozvav Ježís ucennikuov svych] y add. R, Swolaw vczyennyky \$we $y w-2$. Slituji] Slytwg R, \$mylug W; lidmi] Zydem W, R; ze] neb R, nebo W; trmi] trzy W, trzyety $R ;$ dny] den $R ;$ hovie ani ma] czekagy a nemagy $R_{\text {, }}$ trpye any magy $W ;$ jiesti] by gedly $R$ - 3. pustime] pu\$tym $W, R$; lacny] laczne $W$, domow add. $R$; ustanu] oßtanu $R$, \$endu $W ; A] n e-$ bo $R$, om. W; suj om. W: su z nich zdaleka] transp. 2341 R; priSI1] y add. W, R - 4. Otpověděchu] Odpowyedye R; jeho] a rzkucze add. $R ;$ odkad] moz add. $W$; tyto] to $R ;$ moci bude] om. $W ;$ chleba] chlebem na pu\$\$czy W - 5. táza] otazachu W; koliko] kolyk w; i tára...chleba] om. R; jmáte chleba] chlebow mate $W$; odpovědéchu] Ony powyedyechu gemu W, a rakucze add. R - 6. I] Tehdy R; kaza] przykaza W; siesti] Sedyety R; A vezma sedmero chleba] $y$ wa aw Sedm chlebow $W_{;} i$ ] om. $W ; i$ položili su lidu] om. R, $W-7$. rybic]

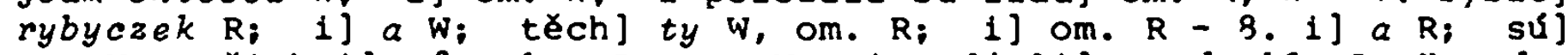
om. W: visichni] w\$yczkny R, om. W; i podjeli] a zdwyhly R, $y$ podwyzechu W; su] om. W; jenz ge\$to W, R; ostalo] zo\$talo W, $R-$ 9. a] om. W; biechu] bychu R; jediechu] gedychu R; tisici] ty\$ycz W, ty\$ycze lyda R; rospu〈s)ci] rozpu§ty W, R.

XCIX. Dominica VIII. post Pentecosten - Mt 7, 15-21

15. Pověděl Ježus uðennfkuom svým

Poslúchajte ot křivých prorokuov jesto prichodie

k vám v rựę ověiem

a vnity su vlkové lakom 1

S 145b/2 16. Po jich / užitku poznáte je

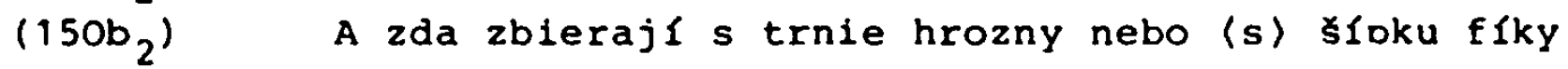

17. Tako vłeliké dł̌evo dobré cinf pozitek dobrý

〈Ale zlé dr̆ěvo zlé ovoce nese〉

18. nemuože drevo dobré ovoce zlého nésti

Ani dřevo zlé ovoce dobrého nésti

19. vłeliké dł̌evo jenž nenese dobrého ovoce vył̌ž́ je a v oheñ položie i shơ̌

20. Toho dle po jich olodu poznáte jé

21. Ne každý ‘lověk jenž pravi mi Hospodine Hospodine 
vejde $v$ královstvo nebeské

Ale kto Xinl vóli otcé mého

ten vejde $v$ královstuie nebeské

XCIX.: S, R, W] deest $A, C, D$

15. Povědēl] $V$ Onom czya\$\$y praem. W: svym] a rzka zagi\$te a zawyerne prawy wam gedne bude $l_{y}$ prawda add. R; Posluchajte ot kilvych] Chowayte \$ye od ffale§\$nych W: vlkove] wiczye R; lakomi] lapagyczy $\mathrm{R}$, dranye $\mathrm{W}$ - 16. uzitku] plodu $\mathrm{m}$. rec. del.. mq. owoczy W: poznate je] transp. R; A] Ne W; zbierajl z trnie] transo.

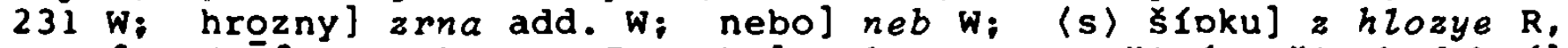
$z$ roßtu (zo\$tu ms.) W- 17. Tako] Takez W, R; cinI Dozitek dobry] cayny owoczye dobre $W$, nemoz nełty owocze zleho $R$; Ale zle drzyewo zle owoczye ne§̧e $W]$ om. $S, A l e z l e$ drzewo ne\$̧e zle owocze $R$ 18. nemuože] $A$ praem. $R ;$ ovoce zlého] transD. $R ;$ dł̌evo] dobre add. $\mathrm{R}$ - 19. vłelikej $A$ praem. $\mathrm{R}$; dłevo] zle add. W; jenž] gye\$\$to $W, R ;$ nenese] neczynye $W ;$ dobrého ovoce] transp. $W$, $R$; vyłezi] Wyrzyez $\mathrm{W}$; $\mathrm{v}$ ] na $\mathrm{W}$; polozle] at add. $\mathrm{W}$, gye add. $\mathrm{R}$ - 20. Toho dle] Proto W: plodu] vzytkow R - 21. Clověk] om. W; jenz] kto W; ora-

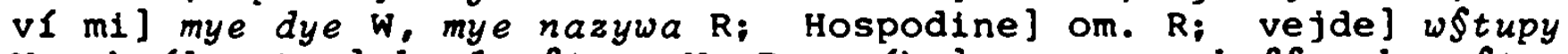
W: kralovstvo] kralow\$twye $W, R$; méhol gens w nebe§§yech ge§t add. W.

C. Dominica IX. post Pentecosten - L 16,1-9

1. Pověděl Ježús ucenníkuom svým pověst tuto Clověk jeden biě̌e jenž jmějiese vladał̌e

a ten biese omluven aby utratil vłe sbozie jeho

2. Pozvav jeho 1 povede jemu

co o tobe slysi

vrat' połet suého vládnucie

(Nebo jǐ̌ nebuders viasti)

3. Tehdy pomysli vladar

Co učini ze pán muoj vezme ote mne vladanie

Kopati nemohu

a žebrati sè styzi

4. vědě co ǔini

Jakoz budu zbaven vládanie ale oł́ijmu mé v svê domy

5. Tehdy sezva vł̌ dlužníky pána svého

diese pruniemu

Co si 〈dlužen〉 pánu mômu

6. jenz povèdé

sto vazen oleje

Tehdy jemu vece

sed' rychlo pis paddesat 
7. a druhému vece

a co ty

jenz povědè

sto kuorcuov płenice

vece jemu

vezmi listy své a napis osmdesat

8. 1 pochvali pán vladaře zleho že múdře uxinil

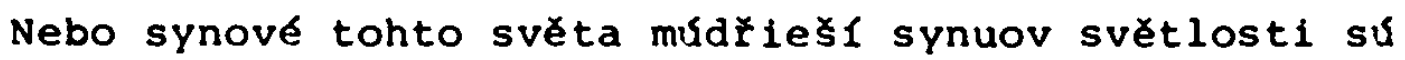
$\checkmark$ svém pokolen 1

9. Ale jáz vám pravi

cinte sobè prately ze zbożie kletého

A kdyz sejdete pojmu vy u věxné sué priebytky

C.: $S, R, W]$ deest $A, C, D$

1. Povĕď̃l] $V$ Onom czyaફ\$y praem. W; tuto] a raka add. Q; biese] bohaty add. W; vladaře] neb vrzadnyka m. rec. mq. rub. del. add. $W$; omluven] przyed nym add. $W, k$ tomu gy $\$$ temu add. R; aby] by R, yakoby W: utratil] wraty 2 : vSe] om. W, R - 2. Pozvav] Powolaw $\mathrm{W}$, om. $\mathrm{R}$; jeho i] om. $\mathrm{R}$; povede] weczye $\mathrm{W}$, Pan wecze $\mathrm{R}$; sly $\$ \$ l_{y} \$ y_{e} \mathrm{~W}, \$ l_{y} \$ \$ y m \mathrm{R}$; vrat'] my add. $\mathrm{R}$; vládnucie] wiadanye $W$,

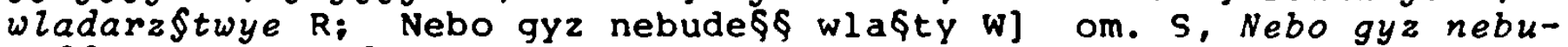
de $\$$ wyecze wla\$ty $\mathrm{R}$ - 3. Tehdy Domysli] wecze v; vladar] \$am $k$ Sobye (wecze $\mathrm{m}$. rec. $\mathrm{mg}$.) add. $\mathrm{W}, y$ wecze $\$ a m k$ \$obye add. R; Co] gye add. $\mathrm{R}_{\text {; }} \mathrm{uXini]} \mathrm{vczynym} \mathrm{W}$, vezynyty $\mathrm{R}_{i}$ vládanie] wladarz\$twye $W, R$ (poczet $\mathrm{m}$. rec. $\mathrm{mg}$. $W$ ) : nemohu] nehodym $\$ \$ y e \mathrm{R}$; a] om. $\mathrm{W} ;$

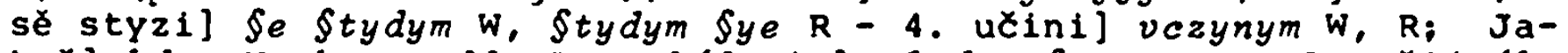
koz] $k d y z$ ', brzo add. $\mathrm{R}_{\text {; }}$ vladanie] wladarz§twye $\mathrm{R}$; ale prijmu] wezmu W - 5. Tehdy] om. W; sezva] Swola W, wladarz Sezwaw \$we R; pána svéhol transp. $R$; diese] weczye $W, R$; dluzen $W, R$ ] om. $S$ 6. jenz povèdX] On odpowyedye $W$, On gemu odpowyedye $R$; vázen 1$]$ wah $R$, ffontow $W$; Tehdy] $y$ w; jemu] on $R$; jemu vece] transo. ' $\mathrm{;}$ sed'] wezmy gy\$to\$t twu R; rychlo] om. W, a add. R; Daddesat] $\$ e-$ de§\$at $\mathrm{R}-7$. a] Tehdy $\mathrm{R}$; druhému] $k$ nyemu $\mathrm{W}$; druhému vece] transp. $R ;$ a] om. $W, R ;$ ty] $\$ \$ y$ dzuzen $R ;$ jenz pověde] On odpowyedye $\mathrm{W}, \mathrm{R}$; kuorcuov] $t$. myer add. $\mathrm{R}$; listy svej $l_{y} \$ t \$ w o y \mathrm{~W} ;$

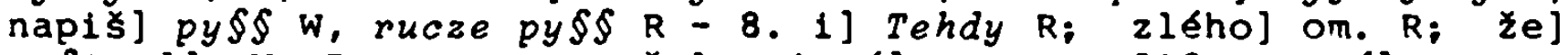
ge $\$ t$ add. W, $R_{i}$ synuov světlosti su] transo. 31? $R_{i}$ sú om. W; pokolen[] pokogy $R$, $\$ u$ add. $W-9$. Ale] $y w ; 2 e]$ om. $R$; kletsho] zleho W, t. zleho add. R; pojmú przygmu 'v; své] om. 'v.

CI. Dominica $X$. post Pentecosten - L 19,41-47

41. Kdyz jdiese Jezús k Jeruzalemu vida mésto zaplaka nad ním rka

42. Nebo by poznalo a ty

A jesto den tento jenž ku ookoji tobé

S $146 a_{1}$

a nynie skryto // jest pred oxima tv(ým)a

$\left(151 a_{1}\right)$ 43. Nebo oŕldu dni tobe 
a obklicie té vsady neołietelé tvoji mocr

i suzie té

44. I na zemi položie tè

i syny tué jenž $v$ tobè jus

a neostavie $v$ tobe kamene na kameni

proto že nevies casu pł

45. A vejda $v$ chrám

poče vymietati prodávajície a kupujicie $v$ něm 46 . Dravi jim

psáno jest že duom muoj duom modlitebn 1 jest

a vy ste uxinili jej kotec lotrový

47. A byl každý den uče $v$ chrámé

CI.: $S, R, W]$ deest $A, C, D$

41. Kdyz] $V$ onom czya\$\$y praem. W: jdiese] przyblyzy $\$ \$ y e$ R, przy-

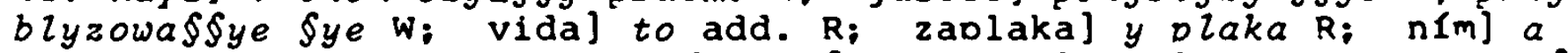
add. W, by by 2 poznal tento dar ge\$to tobye ku pokany vazynyen ge\$t a nenye tobye ge§t przyed oczyma twyma wyedye ze by \$mutyl \$ye a add. $R-42$. by] by 20 add. $R$; Doznalol poznal $w ;$ a] $y$ W, om. R;

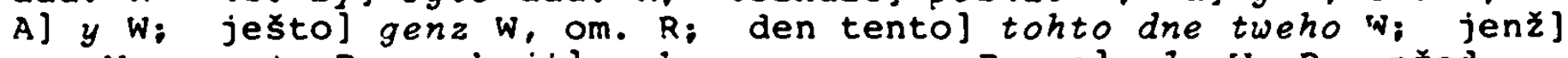
gez $\mathrm{W}$, genzto $\mathrm{R}$; pokoji] pokany vezynyen $\mathrm{R} ;$ a] ale $\mathrm{W}, \mathrm{R}$; Dred oxima tv(ým)a] otwych oczy $w$ - 43. dni] dnowe R; tobé] na tye $N$; a] $y w, R_{i}$ vSady] om. $W ;$ mocl] noczy $R ;$ suzie] zru\$\$ye $R, o \$ t u-$

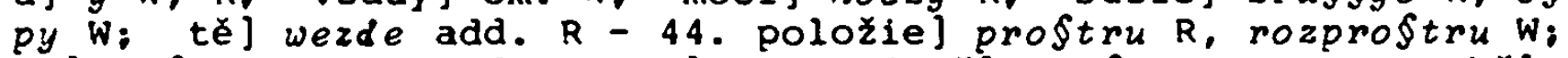
tè] a §mutye tye add. R; i] a W; jenz] qye§to $W, R_{i} v$ tobẻ om. $\mathrm{R}$; ze nevies] ze nepoznal\$\$ $\mathrm{W}, z z e \$ \$$ nepoznalo $\mathrm{R}$; płistie] om. W, $R-45$. A JTehdy R; vejda] w\$\$ed W; Doce] om. R; vymietati] jymeta $R ;$ a kupuj[cie] om. $R: v$ ném] om. $W$ - 46. pravíjim] $a$ rzka gym iv, om. R: psáno] $A$ tak prawe py§mo $R_{i}$ jest] nazwan $W_{\text {, }}$

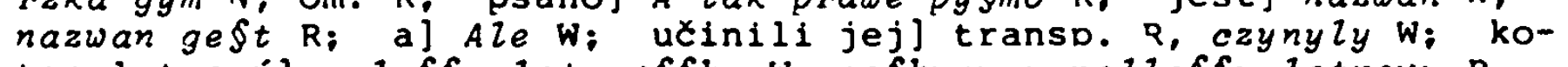
tec lotrový] pele $\$ y$ lotrow $\$ k u W$, ge $\$ k y n y$ y pelle $\$$ y lotrowu $R$ -

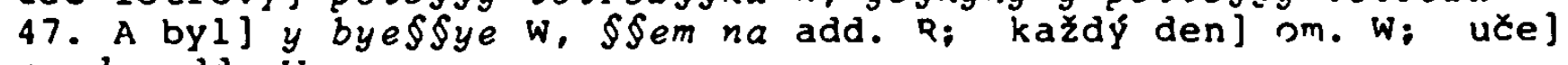
wezdy add. iv.

CII. Dominica XI. post Pentecosten - L 18,9-14

9. Pověděl Ježús k jednym jesto ufachu i vĕłiechu v sè

jako by byli spravedini

i pýcháchu jinými tuto povèst

10. Dva Clověky jidesta do kostela abysta sè modlila jeden zákonnik a druhý hžiešnik

11. zákonnik stoje to $v$ sober mluviese

Bože děkuji tobě že nejsem jako někteł́ lidé

dráxi a nevěrni a cizoložnici

jako tento tuto také htiešnik

12. Postím sè dua dny $z$ nedĕle 
desátky dávaji všeho jenż jmám

13. A tehdy hílesnik stoje

nerodieše oči $k$ nebi vzvésti

ale tlučiě̀e prsy své a łka

Hospodine smiluj sè nade mư hruešným

14. Pravi vám

stúpil jest zpraven $v$ duom ot onoho

Neb prokn 1 kto se povyšuje ponizen bude

A kto sê riszi povýsen bude

CII.: $S, R, W]$ deest $A, C, D$

9. Povědél] $V$ onom czya\$\$y praem. $W$, Powyedye $R ; k$ jednym] $k$ nyekterym $W$, gednyem $R$; jesto] $w \$ S e$ add. $W, R ;$ i] take $R$, om. W; verłiechu $v$ sej om. $W, R$; by byli] om. $W$; byli spravedini] prawy

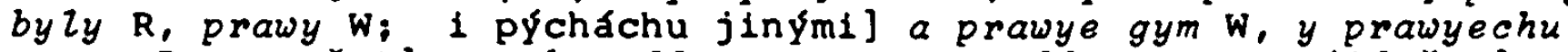
gynym $\mathrm{R}_{i}$ pověst] a rzka add. W, y wecze add. R - 10. jidesta] dye§ta R, wnyde\$ta W; kostela] chramu W, t. do chramu add. R; abysta sé modilia] om. W: zákonnik] [yczomyernyk R; druhy] zgewny add. W, R - 11. zákonnik] Zyczomyernyk $R ;$ tobé] z toho R; néktełl] gyny $W$; drąi a nevěrni] wyboynyczy na\$\$ylnyczy $R$, wyboynyczy naprawye $\mathrm{W} ; \mathrm{a}$ ] om. $\mathrm{W}, \mathrm{R}$; tuto] om. $\mathrm{W}, \mathrm{R}$; take] zgewny $\mathrm{W}$, take zewny $R-12$. sě] om. $W_{i} 2$ ] $w W$, om. $R ;$ neděle desátky] tyden de§\$atek $W_{;}$dávaji] dawam $\mathrm{W}$, dawam ze $\mathrm{R}$; jenż czoz $\mathrm{W}, \mathrm{R}-$ 13. A] om. $W$; tehdy] om. $R, z g e w n y$ add. $W ;$ stoje] zdaleka add. $W$, za dwerzmy add. R; nerodiese] nerodye $W ;$ vavésti] wane§ty $W$; tluciese] $w$ add. $W, \$ \$ y e w$ add. R; prsy své] transp. $W ;$ smiluj se nade mnu] bud my mylo\$tyw w; hriesnym] hrzye§nykem R, hrzye\$\$nemu W-14. Pravi] Zagy\$te praem. W, R: stupil jest zpraven] wy\$tupy $l$ \$prawedlny tuto $W$, w\$tupy 2 ge\$t ade vtye\$\$ute $[\mathrm{R}$; duom] Swoy add. $W, R$; onoho] neho $W, R ;$ Neb] nebo $W$; prokn $R$ ] kazdy $R$, w\$Syelyky $W$; ponfzen bude] transp. $W, R ;$ povýsen bude] transD.W,R.

CIII. Dominica XII. post Pentecosten - Mc 7,31-37

31. Vyšl Jezušs z kraje Tyri

płiłel skrze sidon $k$ mołi Galilee mezi vlasti jesto slóve Kapoleos

32. Pŕivedú jemu němého a hluchéo

aby na nè polożil ruku

33. A pojem jej ot hluku za sè pusti prsty svá v usi jeho

a slina dotče jazyka jeho

34. A vzezřev $k$ nebi vdese $i$ vece jemu

Effeta jenz slóve otevienie

35. a inhed sê otvolíta uși jeho

a rozprostre sé jazyk jeho 
i mluvieše pravě

36. i płikáza jim ijednomu nepraviti

Ale co jim pł́ikazovăe tiem viece kázachu

S $146 a_{2}$

$\left(151 a_{2}\right)$

37. a proto viece diviechu sé Ikúce /

dobłe vక̌e učinil hluchým kázal slyšeti a nĕmým mluviti

CIII.: $S, W, R]$ deest $A, C, D$

31. Vyłe1] $U$ Onom czya\$\$y praem. W, wy\$\$ed W, R; Tyri] rzeczeneho $y$ add. $R_{i}$ priłel] $\$ \$ e l \mathrm{R} ;$ skrze] $\$ k r z e$ mye\$to mg. m. rec.: rub. del. W; mezi] pol add. $W$; Kapoleos] dekapoleos $W-32$. Privedu] y przywedechu $W$, Tehdy praem. R; jemu] $k$ nyemu R; němého a hluchéo] hlucheho y nyemeho W, a proß\$yechu geho add. W, y pro\$\$yechu geho add. $R ;$ na nè] nan $W, R ;$ polożil] $\$ w u R-33$. A] Tehdy ihüs

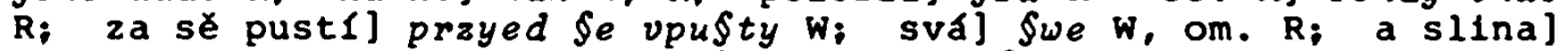
a plyna R, y naplynu W; dotCe] dotkne W, Sye add. $R$ - 34. vzezłev $k$ nebi] wezrzyew w nebe $W$; vdese] wzde\$\$ye W, $R-35$. sé $\$ u W ;$ otvolista] otewrze§ta R, otewrzyenye $W ;$ usi] v\$\$ta $R ;$ a] take add. R: rozprostre sé jazyk] rozwazany g\$\$u okowy yazyka $W-36$. jim] onym W, om. $R$; ijednomu] aby zadnemu W, aby yzadnemu R; nepraviti] neprawyly $\mathrm{W}$; Ale co] Ale tym wyecze (weczye ms.) $\mathrm{W}$, on add. R; pł́ikazováse] a ony add. R; kázachu] mluwychu $R$ - 37 . a] $y \mathrm{~W}$; proto] tyem add. $\mathrm{R}$; viece] Sye gyny add. $\mathrm{R}_{i}$ sé] $a \mathrm{R}$; Ikuce] Proto add. W: vše] w\$\$yeczkno W, R: káall daZ $R$.

CIV. Dominica XIII. post Pentecosten - L 10,23-37

23. Pověděl Ježús ǔennikuom svým Blaženy oci kteřéj vidita jenž vy vidite

24. Nebo pravi vem jenž mnoho králuov a prorokuov chtèlo vidèti jenż

vy vidfte a nevidéli sú

a slyšrti jenž vy slysite a neslyšli sư

25. A seova jeden misterny zákonnik pokús jeho vstúpiv

1 vece

Mistře co đinè život věčný prijimu

26. Tehdy odpovědě $k$ němu

$v$ zákonè co psáno jest

kako ctes ty

27. Onen jemu otpověde

Miluj Boha svého se všeho srdce tvého

a se vłsie duš

a se všeho zivota tvého

a bliźnieho jako ce samého

23. 1 vece jemu 
To ¿in̆ a budes ziv

29. Tehdy on chtex se oxistiti sám řekl k Bohu

a kto jest mój bližn 1

30. Tehdy vezre Jezús 1 vece

Jeden Clověk jdiese ot Jeruzalema do Jericho 1 vnide mezi lotry

jenz oblúpichu jeho

a pobivše otjidú za umrlého

31. prihodr sé až pojide pop jeden tứz cestú vida jeho 1 minu

32. Takéz i jáhen kdyz biese podlé cesty minu jeho

33. Ale Samaritánus jeden jada céstú

vidè jeho smilova sè

34. pristúpi uváza rány jeho naliv oleje a vína

1 vložr jeho ...v v stáji $i$ jmĕ starost o něm

35. A druhý den dá dua penieze stráznému i vece jmej nan̆ pexi

a co koli poprosí dám tobe

36. kto ti se vidr bližni mezi nimi

37. On povè dè

jenz se smiloval jest

pověde Ježus

jdiz uxiniz ty takéz

CIV.: $S, R, W]$ deest $A, C, D$

23. Povĕdx̄l] $V$ Onom czya\$\$y praem. W; svým] a rzka add. R; Blaže-

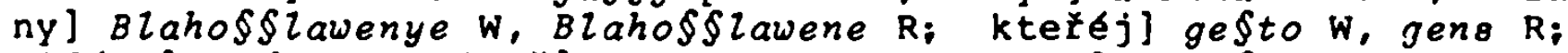
vidita] wydye $\mathrm{W} ;$ jenz] $c z 0 z \mathrm{~W}, \mathrm{R}-24$. Nebo] zagy\$te add. $\mathrm{R} ;$ vem jenz mnoho králuov a prorokuov chtělol wam ze mnozy kralowe y proroczy chtyely W, R, g\$\$u add. R: králuov a prorokuov] proroczy y kralowe $R ;$ jenz] czo W, czoz R; suj om. W; a slyseti...neslyselil su] om. $R_{i}$ suj om. $W-25$. A] $y W_{i}$ seova] $t u W$, gakoz $R_{;}$jeden] $k t e-$

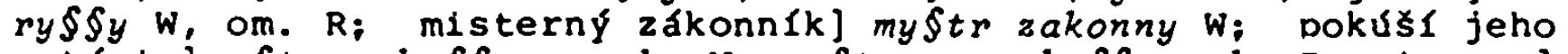
vstupiv] w\$ta poku§\$yge geho $\mathrm{W}$, wy\$tupyw poku\$\$y geho $\mathrm{R}$; 1 vece] a raka W; prijmu] obdrzym W-26. Tehdy] on add. W, R; otpovědé]

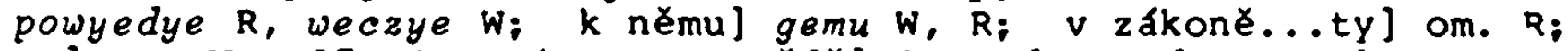
ty] om. W - 27. Onen jemu otpovêde] Ten odpowyedye a raka W, om. R; Boha svého] ho\$podyna buoha \$weho $W$, boha pana tweho R; tvého] Swe-

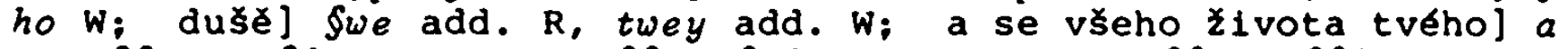
ze w\$\$ye my\$ly twe a ze w\$\$ye \$yly twe R, y ze w\$\$y my\$\$ly twey $y$

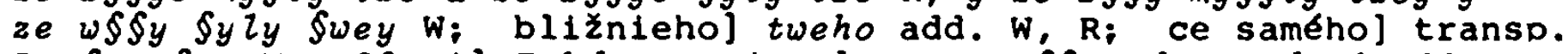
$R$, Sam $\S y e W-28$. i] Tehdy R; jemu] prawye $\$ \$ y$ odpowyedyel add. $R$, dobrzye $\$ \S$ odpowyedye $[$ add. W; budes] diuho add. $R-29$. chtě] chtye§\$ye W; se ocistiti sám] transp. $231 \mathrm{~W}, \mathrm{R}$; Yekl $k$ Bohu] weczye $k$ gezy\$lowy $W$, ho\$podynu y wecze $R$ - 30. vnide] wende $R ;$ jenz] ge§to take R: a pobivse otjidu za umrlého] y vbyw\$\$ye odgydechu geho za mrtweho W, y ranychu wrazyw\$e geho oteydu geho za mrtweho $\mathrm{R}$ - 
31. pr̆ihodr sĕ] Ale praem. W, Sta \$\$ye przyhoda R; aż] gez W; pojide pop jeden] ktery\$y knyez gyde $W_{;}$pop] knyez $R_{;}$tuz] tu $R_{;}$ cestu la ten add. $R_{i}$ jeho $i$ minul ho mynu gey $\mathrm{W}-32$. cesty] a wyda gey add. W, a wydyel geho add. R; minu] y mynul R; jeho] ho W, om. $R-33$. Ale] $A R$; Samaritánus] pohan add. W, te $\$ \$$ pohan add. $\mathrm{R}$; jeden] ktery\$\$ $\mathrm{W}$, tu $\mathrm{R}$; jda cěstu] transp. R; vidè jeho] $y$ $R$, wyda gey pray§§ed blyz k nyemu W: smilova sè] \$myzowal \$ye ge§t W - 34. přistúpi] a prayblyzyw \$ye y W, $k$ nyemu $y$ add. R; rány jeho] transp. $R_{i}$ naliv] wlyw $R_{i} v$ staji] $w$ Stawy \$we y wede ho do ho\$pody W- 35. da dva] dawa R: dva penieze stráżému] wratnemu dwa penyze $W_{;}$i] a gemu $R_{i}$ nañ péti] o nyem peczy $W$, o nyem praczy $\mathrm{R} ; \mathrm{a}$ ] om. $\mathrm{R}$; popros[క] kaze\$\$ R; tobe] kdyz $\$ y e$ wraty add. $w-36$. $t i$ sě vidl bližnl mezi nimil tyech tray blyzny tobye Sye zda W, ty \$ye wydy blyzny gemu Tomu genz bye\$\$e w\$\$ye $w$ lotry R 37. povědĕ] odpowyedye $R$; jest] y add. $R$, nad nym $y$ w; pověde] ] weczye W, gemu add. W, R; jdiz] gdy W, $y$ add. $R ;$ uciniz ty] ty wozyn $R$, vezyn to $W$.

CV. Dominica XIV. post Pentecosten - L 17,11-19

11. Kdyż dieše Ježús do Jeruzalema skrze Samarii a Galileu

12. kdyz vnide na jeden hrádek potkachu jeho deset muž nuzných

13. a zavolachu hlasy zdaleka a řkúce Ježçi kazateli smiluj sè nad námi /

S $146 b_{1}$ $\left(151 b_{1}\right)$

14. kdyz je vidě vece jim jděte pokažte sĕ popuom i sta sě kdyš jidu biechu zdrávi

15. Tehdy jeden mezi nimi kdyz vidieše sĕ zdráva navráti sè s velikým hlasem chvále Boha

16. i pade $k$ nohám jeho dieku vzdávaje

a ten biese Samaritánus

17. Tehdy Ježus pověde vědĕ deset jich uzdraveno

a devèt kte jich jest

18. Nenalezen jest kto by dal chvalu Bohu jedno tento cizozemenín

19. A vece jemu Ježús vstan̆ jdi nebo tvá viera zdráva ce ucinila jest

CV.: $S, R, W]$ deest $A, C, D$

11. Kdyz JU onom czya\$\$y praem. W: Jeruzalema] gdye\$\$ye add. W, R; Samarii a Galileu ] pol Samarye a galylee W- 12 . kdyż A praem. W, $\mathrm{R}$; na jeden hrádek] do gednoho hradku W: mužl] muzyew W, muzow $\mathrm{R}$; nuzných] malomocznych genz Stachu zdaleka W-13. a] y W, Tehdy 


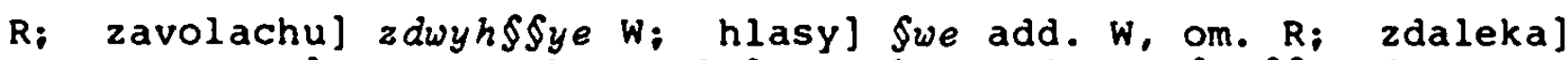
om. $W, R_{i}$ a] om. W; kazateli] przykazately $W$, Spa\$\$ytely $R-14$. je] gyey $\mathrm{R}$; vidě] vzrzye $\mathrm{W}, \mathrm{R}$; pokazte] vkazte $\mathrm{R}$; popuom] knyezyem W, $R ;$ sè] to add. W, R; jidu] gydechu W, R; biechu zdrávi] vzdraweny byechu $R$ - 15. Tehdy] $A$ le $W:$ jeden mezi nimi] transp. $231 \mathrm{R} ;$ mezi nimi kdyż z nych kdy $W_{;}$sě zdráva] ze zdraw by $W$, zze vzdrawen ge§t $R ;$ navráti] wraty $W ;$ sě $]$ za\$§ye add. $R ;$ hlasem] wolagye add. $R$ - 15. pade] przed oblyczey geho add. R, w twarz przyed add. W; k] om. W; nohám jeho] geho nohy W; dieku] chwalu W, gemu add. $R$; vzdávaje a] tak rzka add. $R$; ten] ty $R$, to $W$; biese] $\$ \$ y$ $\mathrm{R}$; Samaritánus] pohan $\mathrm{W}$, pohan add. $\mathrm{R}-17$. Tehdy] Odpowyedye $\mathrm{W} ;$

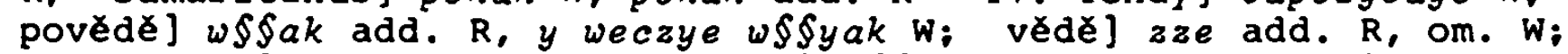
deset jich] transp. $R ; j i c h$ jest] $g \$ \$ u W-18$. Nenalezen] nalezen $R ;$ Bohu] om. W; cizozemen[n] czyzozemecz W, R- 19. A] y $W, T e h d y$ $R ;$ Ježus] om. W; zdráva ce uxinila] tye vzdrawyla W; jest] om. $R$.

CVI. Dominica XV. post Pentecosten - Mt 6,24-33

24. Ježus pravil svým mlazšm

Nemuoz nikte duěma pánoma slữiti

Nebo jednoho nenáld1 a druhéo milovati bude

Nebo jednoho poslusen bude a druhéo potupl

Nemózete Bohu sluziti a zboź

25. Protoz pravi vám

nestýskajte svý dusi co jiesti nebo plti budete

ani tělu vasemu $v$ Cem byste chodili

nebot' duše viece platı nez jiestojłka

a celo více nez rícho

26. Hlédajte ptákuov pod oblaky

zet' ni seji ani znu ani do stodol kladú

vsak otec nebeský chova toho

vedè vy ste drazsi 1 lepsi onéch

27. Nebo kto mezi vámi mysle móž přicinití k svému vzróstu loket jeden

28. proto co jmate péci za rúcho

znamenajte lilium polského kakot' roste

ani dẻlaji ani pradú ani vázús

29. Pravi vám

Nebot' ani Salomon ve vక̌iej svêj chvăle sě odẻl jest

jako jedno mezi cemito

30. Pakli jako seno polské jenz dnes jest a zajtra u pec pustěno bude takož Buoh odievá

a tím viece vy malé viery

31. Nerod'te proto truchli byti a rkuce co spiemy nebo sniemy nebo se odejemy 
32. vězte zet' toho vకeho lidé dobývaj1

nebot' otec vás vie ze toho vłeho potłebu jmáte /

S $146 b_{2}$

33. Proto hledajte náprvé královstvie nebeského a spravedlnosti jeho

a to vłechno pribude vám

CVI.: $S, R, W$ ] deest $A, C, D$

24. Jezus] $U$ Onom czya\$\$y praem. W: Jezús pravil] Powyedyel Gezy\$\$ W, R; svým mlazSIm] vezyennykom \$wym $W, R, a$ rzka add. $R_{i}$ Nemuoz nikte] transp. W, $R$; nikte] zadny $R$; nenávidl] nenawydyety bude $R$; milovati bude] my 2 ugye $W_{i}$ jednoho....a druhéo] om. $R ;$ poslušen bude] po\$§lechne $\mathrm{W}$; a] y $\mathrm{W}$ - 25. nestyskajte] \$obye add. $\mathrm{W}$; svy

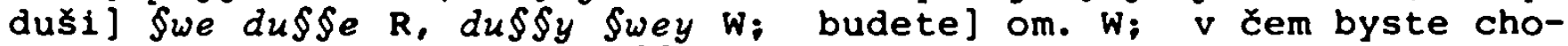
dili] cro obleczy $W$, wecz $\$$ ye odyegete $R$; nebot'\} zdaly $R$; viece plat $\}$ wyecz\$\$ye nenye $R$, wyeczye ge§t $\mathrm{W}$; jiestojska] gedenye $\mathrm{R}$, pokrm y W: vice] wyez $\$ y e \mathrm{R}-26$. ptátkuov] ptaczwa R, ptacz\$twye $W$; oblaky] nebem $W ; n i]$ any $W$, ty $R ;$ sej1] ne\$\$yegy $R$; do stodol] $w$ \$todoly $W ;$ vSak] y $W ;$ Otec] wa\$\$ add. W; nebesky] \$wa-

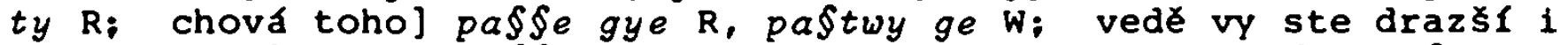
leps1 onech] zdaly wa\$§ wyecze nenye nezly gych $\mathrm{R}$, nezda ney\$te gych wyetczy $W-27$. Nebo] om. $R_{i} k t o l$ zagy\$te add. $R_{i}$ mezi vámi $z$ wa\$\$ W, wa\$ geden $R$; mysle\} pomy $\left\{l e R_{i}\right.$ přicinitil przyczynaty $R$;

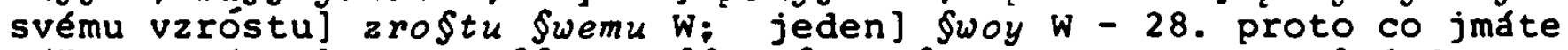
péti za rúcho] y o ru\$\$ye ge\$\$to \$taro\$t mate w; lilium] ly $w_{y u}$ (abbreviatura super $-u \mathrm{~m}$. rec. superscr.) $\mathrm{W}$; polského] pol\$ke $\mathrm{R}$, pol\$ku W: ani vázu] om. R, ny wazy $\mathrm{W}$ - 29. Pravi] Ale praem. W;

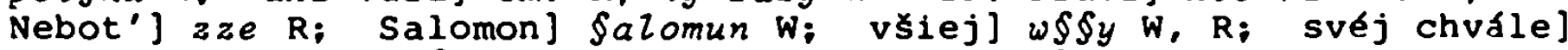
transp. W; svéj] \$we $R ;$ sẻ] om. W: sé odẻl] transp. $R ;$ mezi cemito] $z$ tyechto $W$ - 30. Pakli jako] Nebo acz W; dnes] dobre W: pustěno] wlozeno $W, R ;$ malé] maley $W-31$. truchli býti] my $\$ l y t y$ W: spiemy nebo sniemy] \$nyemy a \$pyemy R, \$nymy nebo czo \$pyemy $W$; nebol czym add. $W, R-32$. vězte zet'] om. W: lide] pohanny $W$; nebot'] nebo $R$; potrebu jmáte] potrzyebugete $W, R-33$. hledajte náprvé] transp. $R ;$ náprvé] nayprwe $W:$ nebeského] buozyeho $R ; a]$ om. $R_{i}$ spravedlnosti jeho] transp. W, om. $R$; vకechno] w\$yeczko $R$, $w \$ \$ y e c z k n o$ W.

CVII. Dominica XVI. post Pentecosten - L 7,11-16

11. Jaiese Ježus do mésta Naim

jdiechu s nIm učennici jeho a mnostvo lidu

12. A kdyz jdieše $k$ vratóm mésckým

Seova umrlého nesiechu syna jednoho matky své

a to biese vdova

a s nI zbor z města veliký

13. kdy̌̉ ji videx Hospodin smilova sé nad ni $i$ vece $j\{$ Nerod' plakati

14. i pristúpi doť̌e nosidl

A ti jesto nesiechu stáchu 


\section{I pověder}

jinochu tobe pravi aby vstal

15. I okř jenż biese umřel poce mluviti

Tehdy jej da mateŕ jeho

16. Tehdy podstúpi vłechny strach

I chváléchu Boha ł̌kúce

že prorok veliký jest mezi námi

anebo jest Buoh navštievil lidu svého

CVII.: S, R, W] deest A, C, D

- - - - - - - -

11. Jdiese] $U$ Onom czya\$\$y Gyde $W ;$ mesta] tak menowane add. $W ;$ Naim] $y$ add. $R ;$ a] $y W, k$ tomu add. R; mnostvo] mnoz§twye $W, R ;$ lidu] lyda $W, R-12$. jdiese $k$ vratóm] $k$ add. $R$, \$e przyblyzowa$\$ \$ y e$ ku branye W: mésckým] mye§t\$§key W: Seova] a R, Tehdy W: umrleho nesiechu syna jednoho] ne\$\$en by (by rub. adscr.) vmrly \$yn gedyny $W$, vmrczy ne\$yechu proty nyemu \$yna gedynkeho R; sve a to) Swey a ta W, Swata R; biese vdova] transp. W: s nI zbor z města veliký] lyd mye§t\$ky mnohy $\$$ ny $\mathrm{W}$, gdye§\$e add. $\mathrm{R}-13$. kdyz] $A$ praem. W, Tehdy praem. R; videj varze R; smilova] \$mylowal W; nI i] nym a $R_{i} j[\}$ gyey Noli flere $W$, zeno add. $R-14$. i] $A R$;

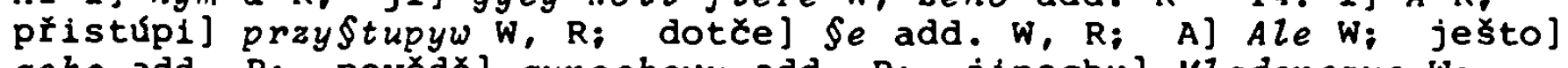
geho add. R; povědě] gynochowy add. $R_{i}$ jinochu] MLadenczye W; tobe pravi] transp. R; pravi aby vstal] rzku w\$tan W- 15. I] Tehdy on R, w\$taw W; okł̌] Sede W: jenż] genzto R; umrell a add. R; Tehdy] $y$ w; jej da] transp. $W, R ;$ materi jeho] transp. $R$ - 16 . Tehdy podstupi vsechny strach] zatyem po\$tupychu w\$yczkny \$trachem R: vłechny] w\$\$yeczkny W: Boha] a add. R; łkuce] om. W; jest] $w \$ t a l$ W: anebo] Ano R: lidu] $l_{y d} \mathrm{~W}, l_{y d a} \mathrm{R}$; svého] \$woy $\mathrm{W}$, om. $\mathrm{R}$.

R $122 b_{1}$ 16. Odpovědĕ jeden zákonn $1 k k$ sboru $i$ vece $k$ Ježlsovi a ‘ka

Mistře přivedl sem syna mého $k$ tobè majlc zlého ducha němého $t$. diábla

17. Tehdy pojé jeho

1 plvắe 1 skṛ̌hrăse zuby

Tehdy pověděchu uxedlnikóm tvým aby vyhnali jeho $z$ něho Ale nemohli jsu

18. on odpovĕde 1 vece $j i m$ a trka

Rode nevěr Icl

kako dlưho mezi vámi budu /

$\mathrm{R} 122 \mathrm{~b}_{2}$ A kako dlúno trpéti budu

prínestez toho př̀ mè

19. Tehdy prínesú jeho 
$A$ *kdyz už̀e jej *inhed duch *smuti jeho

až prostł̌ev sĕ na zemi ležieše slini

20. I otáza otec jeho

kako dlưhy Čas jest jakž sĕ jest pł̆ihodilo

Tehdy on vece

2 mladost 1

21. Tehdy ústaune jeho $v$ oheñ a $u$ vodu pustil aby jeho ztratil

AC co móžeš a smiluj sĕ nad námi

22. Ježš odpovědě jemu

AC móžes věłiti všeckno jenž býti móže jiz věriti

23. A inhed otec jeho dietexte zavola I se slzami plakałe a Yka

Vělim Pane Hospodine Spomož mi z nevěrnosti ré

24. A *kdyz uzłè Ježls zbor zhromazdèny

Tehdy vece duchu necistému A tak łka jemu

hluchý 1 němý duse

Já tobè pł̣łkazuji vyndi $z$ něho a viec nevchoc' ven̆

25. Tehdy volav a mnoho muexiv jeho i vynde 2 něho

1 učini jeho jako by umrexl

26. Tehdy Ježrš drže ruku jeho pozdvihl jeho 1 vstal

27. A kdyz vnide $v$ dóm

Tehdy ưedlnici jeho tajnè otázachu

proc smy nemohli vypuditi

28. A vece jim

ten rod nemóz zádného vjlti jedno modlitvami a postem

CVIII.: R] deest $A, C, D, S, W$

19. *kdyz (kyz ms.); *inhed (ihnde ms.); *smuti (\$nuty ms.) - 24 . ${ }^{\star} k d y z$ (kyz ms.).

CIX. Feria VI. Quatuor temporum septembris - L 7,36-50

W $42 \mathrm{~b}$

36. $V$ onom Xasi

Prosieše Ježı̌̌ jeden zákonnik aby $s$ nIm jedl

i vnide $\mathrm{v}$ dóm zákonníkóv 1 sede

37. Ež Žena jenž biese u mêstè hł̌iesná

Když pozna že sedi u zákonnfka $v$ domu

płinese pusku masti

38. a stanuci nazad podlé noh Bozlch 
slzami poce mýti nohy jeho

a vlasy trieti

a libałe nohy jeho a mast 1 mazáse

39. Tehdy vida zákonnłk jenž pozval ho pomysli sám $k$ sobe a İka

by toto byl prorok vêděl by odkud nebo kaká jest zena ze dotýká jeho a jsúci hr̉iešnicè

40. Tehdy vecé jemu Jež́s

simon jmám tobè nétco praviti

vecé jemu Simon

Mistze prav

Tehdy Jezis povęar

41. Dva dlužniky biesta jednomu kupci dlužna

Jeden bieše dlužen pẹt set peněz a druhý paddesát

42. A kdyz nejmejjiesta Łím platiti otpusti oběma kterýz ho proto viece miluje

43. Simon povède

zdá mi se jemuzto viece otpusteno

Povědě Ježř

*Praver $s$ *sudil

w $43 a$

44. obrátè sẻ $k$ ženè // Ježr vecè Simonovi

vidrs tuto zenu

v̧̌l sem $v$ tvój dóm

vody $s$ nepodal nohám mým

Tato zajisté žena slzami sulazovala nohy mé a vlasy třla

45. Políbeni s mi nedal

tato jakoz sem věel nepřstala libati mých noh

46. Olejem hlavy méj neumazal si

tato mast 1 zmazala mé nohy

47. "pro nèzto rku

odpušeny sú jéj hřlechy mnohé nebo milovala mnoho jemužto méně otpustie méně miluje

48. vece $k$ niej Hospodin

otpuscenit' su hriesi

49. I pocechu jedni kvašné mezi sobu mluviti Kto jest ten jesto hřiechy odpušxije

50. "pověả Ježs k žené

viera tvá zdrávu tě učinila jest 1 jdi s pokojem 
CIX.: W, R] deest A, C, D, S

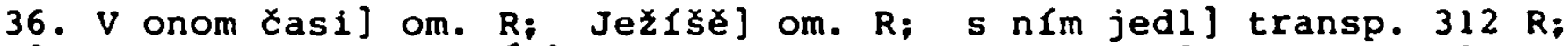
i] Tehdy R; zakonn[kóv] zakonnyka toho R - 37. Ež] a R; Rdyz] yakz nahle R; sedí u zákonníka $\mathrm{v}$ domu] ihūs odpoczywa $w$ domu zakonnykowye R; pusku] alaba\$trowu $\$$ add. $R$ - 38. stanuci nazad] \$togecz zadu R; Božlch] geho R; trieti] \$wymy \$ hanby vtyeraty R - 39. ho] geho bye $\$ e$ R; pomysli] y wecze add. $R$; toto byl] transp. $R ;$ by] zagy§te add. R; odkud] odkawad $\mathrm{R} ; \mathrm{ze]}$ genz $\mathrm{R} ;$ dotyká $\$ y e$ add. $\mathrm{R} ;$

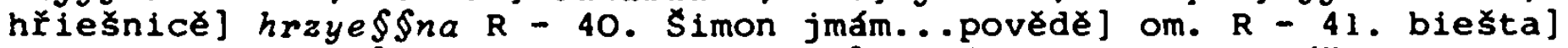
byechu R; peněz] om. R-42. platiti] zaplatyty R; kterýz ho proto] Protoz ktery geho $\mathrm{R}$ - 43. povéde] odpowyedye a rzka $\mathrm{R}$; $\mathrm{zda} \mathrm{mi}$ se] ya mnym ze ten R; otpušenol ge§t odpu§ty $2 \mathrm{R}$; Povědě Ježlక] Tehdy on wecze R; Pravé (Prawy ms.. e rub. superscr.) s *súdil (rzek $2 \mathrm{mg}$. m. rec.)] Prawye $\$ \S u d y Z \mathrm{R}-44$. obráté] Tehdy praem. R; $k$ Ženě Ježrక] transp. 312, y add. $R ; s$ nepodal] om. $R ;$ mým] Neda[\$ my $A$ le R; zajisté] om. R; svlažovala] vmyla R; vlasy] \$wymy add. $R ; \quad t$ íla] vtyerala $R$ - 45. nedal] $A l e$ add. $R ;$ jakoż $k d y z R ; n e-$ přestala libati] lybanye neprzye§tala $R ;$ mých noh] transp. $R-46$.

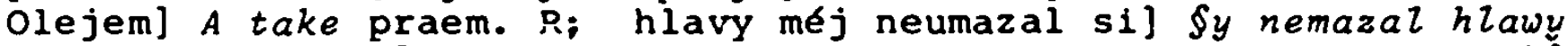
me ale $\mathrm{R}$; mast 1 ] drahu add. $\mathrm{R}$; zmazala (z- in rasuram adscr.)) mazala R; mé nohy] transp. $R$ - 47. pro nězto ŕku (m. rec. del. pro nezto et protoz superscr.)] Proto prawy tobye R; mnohé nebolgegye neb $\mathrm{R}$; milovala] ge§t add. $\mathrm{R}$; jemuzto] kteremuz $\mathrm{R}-48$. vecé] Tehdy praem. R; niej Hospodin] nye zeno $\mathrm{R}$; sul tobye twogy add. $\mathrm{R}-$ 49. I) Tehdy R; počchu jedni *kvaš̌né (del.. m. rec. nïekterzi superscr.)] ty genz fpolu §edyechu poczechu R; mezi sobu mluviti] prawyty mezy §ebu R; Kto] a to $\mathrm{R}$; ten] zde add. $\mathrm{R}$; jesto] genz $\mathrm{R}-$

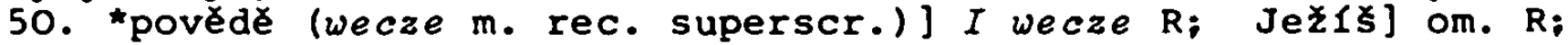
zdravu tĕ ucinila jest i] ta tye wadrawyla $R_{i} s$ pokojem (tyt tye Spałenu vczynyla gdy $v$ pokogy add. W, rub. del.).

CX. Sabbato Quattuor temporum septembris - L 13,6-17

w $33 b$

6. $\mathrm{V}$ onom Casi

pravı́se Ježı lidu podobenstvie toto

Dǐ̉vo frkové mĕjı̌̉e jeden vsazené $v$ ohradĕ svéj

přijide hledaje na ňem ovoce $i$ nenaleze

7. Tehdy vecé $k$ dẻln $1 k u$ vinnicer

a jiz týi léta jsú jakž hledám ovoce a nic nenajdu

Podetni ji pro to ovoce

jedno zemi zamiest 1

8. Tehdy odpovède $v\langle i\rangle n n i c i z$

Pane odlož ji tohto léta ažc ji okopám a hnojem pokladu

9. nebude 11 ploditi

Ale na léto srublmy $j i$

10. i biese u modle jich uxe je $v$ sobotu

11. Tu biě̌e žena jedna mějక̌̌e duch nemocny osmnást let a skloněna od vsěch let a nikdy nemóže ožlieti se za sé ani vzhóru 
12. kdyz ji vider Ježrs zvola ji $k$ sobé $i$ vecè jiej zeno zbavena jsi nemoci tvéj

13. vlozi na ni ruku inhed sè zprostre chváléci Hospodina

14. Odpovède starosta téj modly hněvaje se ze $v$ sobotu lécil i vecĕ lidu Sest dnI jest $v$ nichžto slusie dělati (Proto $v$ tèch budete uzdraveni)

Ale ne $v$ sobotu

15. $i$ vecĕ $k$ nèmu Hospodin

i pokryti každý vás neodviže volu ani osla $v$ sobotu i nenapoj 1

16. Ale tuto dcer̆ Abrahamovu jizto uvázal sám Sathanas aj ż̀i osmádcet let

1 nebylo jie zprostiti $v$ sobotu

17. A kdyz to povédé

w $34 a$ stydiechu se // v̌sickni protivnĺci jeho

a vక̌itek lid radováse sě všxm že dóstojnè vidiechu Einiece jeho

CX.: $W, R]$ deest $A, C, D, S$

6. $\mathrm{V}$ onom Casi] om. $\mathrm{R}$; pravı̌̌] Powyedye $2 \mathrm{R}$; lidu] $k$ ફboru zydow§kemu R; toto] a rzka add. R; vsazené $v$ ohradé svejj] \$tyepowaty

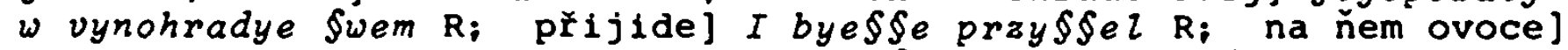
transp. $312 \mathrm{R} ;$ nenaleze] nenalez $[$ ge $\$ t ~ R-7$. déln[ku vinnicẻ] Strogyczy toho wynohradu a rzka R; a] $A y$ R; tíl léta] transp. R; jsu] om. R; jakz hledám] gena praychodym S\$em hledagye R; ovoce] na tomto drayewye add. $R$; nic nenajdu] a nenaleanu $R ;$ Podetni ji] protoz porub gye $R_{i}$ pro to ovoce] om. $R_{i}$ jedno zemi zamiest 1$]$ at darmo mye§ta nezame§tnugye $R-8$. odpovede $v(1) n n i c 1$ ] on powyedye gemu a raka R: Pane odloz ji tohto léta azc ji] neohay geho pane ge $\$ t y e$ tohoto leta at ya gye R: hnojem pokladu] napu\$tye okolo nyeho lagen $\mathrm{R}$ - 9. ploditi Ale na leto srublmy ji] nefty owocae dobrze Pakly nebude potom gye Setny $R$ - 10. i] Tehdy $R ;$ u modle jich] om. $\mathrm{R}_{i}$ je] zakonnyky $\mathrm{R}-11$. Tu] om. $\mathrm{R}$; biese] $A \mathrm{R}$; zena jedna] trans genz add. $\mathrm{R}$; nemocny osmnast let] nyemy let de\$\$yet a o\$\$m $\mathrm{R} ; \mathrm{skl0}$ nèna od vě̌ch let a nikdy nemóze ozłleti se za sé ani vzhóru] $k$ tomu bye\$\$e naklonyena zze ow\$\$em nemozye\$\$e nahoru hledyety $R$ - 12 . kdyz $A$ praem. $R$; vidé] varzye $R_{i}$ zvola ji? zawola gye $R_{i} k$ sobé $i$ vecé jiej] om. $R$; Zeno] wecze add. $R$; zbavenal vzdrawena $R ;$ jsil od add. R; tvéj] twe $R$ - 13. vlozi na ni ruku] Tehdy polozyw ruku \$wu na ny $\mathrm{R}_{i}$ sé zprostre chvaléci Hospodina] aproßtyena ge§t y chwale\$Se buoha R - 14. Odpovědé] Tehdy praem. R: starosta téj modly hnèvaje se ze] geden my\$trny zakonnyk nedowyerze tomu by $R_{i}$ lecil i]

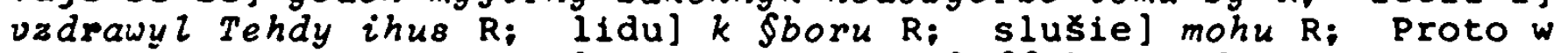
tyech budete vzdraweny $R$ ] om. W: sobotu] S\$obotny den $R-15$. $i$ vecé $k$ nèmu Hospodin] om. R; pokrytl] pokrytczy R; kazdý] $z$ add. R; neodvize volu ani] nezaplaty wol \$woy anebo $R$; $v$ sobotu] om. $R$; $i$ nenapoji] ode $\{l y$ a wede gyey napogyty $R$ - 16. Abrahamovu jizto 
uvázal sám Sathanas] abrahe genz przy\$wal §atan R; zíl] om. R; osmádcet let 1 nebylo jie zprostiti] de\$et leth a o\$\$m nemohl wyplatyty $z$ okow tohoto dne R - 17. to] om. R; vsickni] w\$\$ychny R;

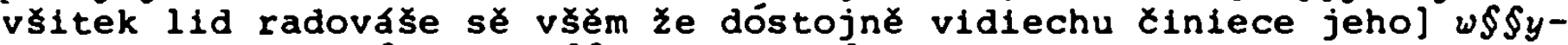
czkny radowachu \$ye we w\$yech genz \$lawny byly od nyeho R.

CXI. Dominica XVII. post Pentecosten - L 14,1-11

S $146 \mathrm{~b}_{2}$ $\left(151 b_{2}\right)$
1. Gdyžto vnide Ježus v duom jednoho kniežete zákonn1kuov $v$ sobotu chléb jiesti

1 on 1 jeho schováchu

2. A seova muž jeden jenž mĕjieše $v$ sobě vodné tele bieše pł̌ed nIm

3. I vece Ježuš chytrým zákonnlkuom jestli lze $v$ sobotu uzdraviti

4. Tehdy on 1 neřku 1 slova Ale on pojem jeho uzdravi 1 pusti

5. C1 vás vece Jezús vuol neb osel upadne $v$ duol a nevytáhne jeho $v$ den sobotni

6. I nemohu $k$ tomu i slova otpoverdèti

7. Tehdy povědě $k$ têm zvaným chte kak by prunie miesta volili povést tuto a łka

8. kdyz to pozván budeš na hody sěd' na posledniem miestè

a nesědaj na pruniem

Nebo snad płide tebe leps 1

9. a ten jenż té 1 onoho pozval povie tobě Posed' tomuto $s$ miesta

tehdy sè vstydls sede na konci

10. Ale budes 11 pozván sediż na konci

a ten jenž tè zval die tobě

Prieteli posed' nahoru

S $147 a_{1}$

1 bude tobe // chvalla pred hostmi

$\left(152 a_{1}\right)$ 11. Nebo prokn1 kto sè výsie ponizie jeho a $k\langle t\rangle$ o sè ponizuje povýsie jeho

CXI.: $S, R, W]$ deest $A, C, D$

$-----------$

1. Gdyzto] $K d y z R, W$ Onom czya\$\$y praem. W: kniezete] knyezyeczyeho $W$, a add. R; zákonnikuov] zakonnyka $R ;$ i] Tehdy $R-2$. A] $y$ W; seova] tot $W$, om. $R ;$ muz jeden] geden czlowyek $W$; jenz] genzto $R$; $v$ sobe] gednu nemocz gmenem add. $R_{i}$ vodne tele] to add. $R$, nemocz wodnu mezy ma\$\$em a mezy kozy W: płed n[m] przy nyem R - 3. I] Teh$d y \mathrm{R} ;$ Jež́s] $k$ add. $R$; chytrým zákonn[kuom] zakonnym my§trom $W$, 
a prawye gym zagy§te add. $\mathrm{R} ; \mathrm{lze}] \operatorname{moz} l y \mathrm{R}, z l_{e} \mathrm{~W} ;$ jestli] om. $\mathrm{R}$ - 4. nełku i slova] mlczychu W, mlczechu t. nerozumyechu R; pojem] popad W; jeho uzdravi] transp. W; uzdravi] vzdrawyw gey $\mathrm{R}_{\text {; }}$ i] $a$ W, om. R; pusti] zpu\$ty R, ho add. W - 5. CI] A odpowyedyew gemu praem. $R, Y$ odpowyedye gym praem. W; $C_{1}$ vás vece Jezus] y weczye Czy z wa\$\$ $\mathrm{W}, y$ wecze Czy $\mathrm{R}$; vuol nebo osel upadne] o\$\$el neb wuz $w$ Studnyczy neb $w$ dol vpadne $W$; neb] nebo $R ;$ a anhed $W ;$ nevytáhne] newytrhne $R$; jeho] rychle add. $R$; sobotnI] Sobot\$ky $R-6$. I] om. $R$; nemohu] nemozechu $W$, om. $R$; $k$ tomu ] om. $R ;$ i] any $R$, om. W; slova] nevmychu add. R; otpovědéti] rzyeczy W-7. tém] om. $R$;

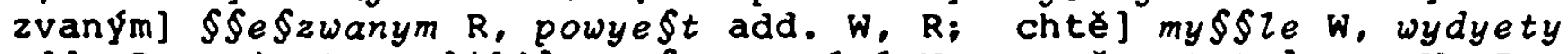
add. R: miesta volili] mye\$to zwoly $\left[\mathrm{W} ;\right.$ povést tuto] om. $W, R_{\text {; }}$ a $ł k a] k n y m$ add. W, y wecze $k n y m$ praem. $R-8$. to] om. W, R; pozván budes] transp. $R ;$ na hody] om. $R ;$ sěd' na posledniem mieste] om. W, R; nesedaj] nerod \$ye§ty $\mathrm{R}$; na prvniem] mye§tye add. $\mathrm{W}, \mathrm{R}$; snad pílde tebe] transp. $231 \mathrm{R}$; pride] om. W; tebe lepsi] canyey\$\$y tebe od neho pozwan $W-9$. a] przyda add. $W$; te 1$]$ om. $R$; onoho] geho $\mathrm{R}$; pozval] ge§t add. $\mathrm{R}$; povie] dye $\mathrm{W}, \mathrm{R} ; \mathrm{se}$ ] om. $\mathrm{W}, t y e m$ add. $R_{i}$ vstydí] om. W: seder na konci] Sede\$\$ $\$$ hanbu na po\$\$lednye mye§to $\mathrm{W}$ - 10. Ale] $k d y$ add. $\mathrm{W}, k d y z$ add. $\mathrm{R} ;$ il] om. $\mathrm{W}, \mathrm{R}$; pozván] na hody add. W; sediz] Sednyz R, Sed W; na konci] na dolnyem mye\$tye W, Stola add. R; ten] om. W, kdyz przyde add. $W, R ;$ jenz] ktery W: tě] ge\$t add. $R$; zval] pozwal W, R; PYieteli] om. $R$;

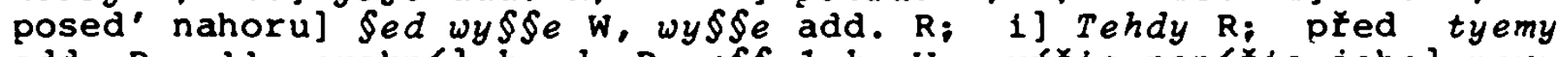
add. $R$ - 11 . proknI] kazdy $R$, w\$\$elyky W: výsie ponizie jeho] powy\$\$yge bude ponyzen $W ; \quad k\langle t\rangle 0]$ koz $R ;$ ponizuje] nyzy $R$, bude add. $W ;$ povýie] powyફjen $W, R$; jeho] bude $R$, om. $W$.

CXII. Dominica XVIII. post Pentecosten - Mt 22,34-46

34. Sešli sè zákonici na hromadu

35. 1 otáza jeho jeden mistr zákonny dokúseje jeho

36. Mistye které jest kázanie veliké $v$ zákoné

37. vece jemu Jezús

Milovati budes Boha se vseho srdce tvého a se vł́le duse tvé a se všie mysli tvé

38. To jest veliké píikázanie

39. druhé jest rouné $k$ tomu

Miluj svého bliźnieho jako sè sám

40. Na tom dvojím zákon pni i proroci

41. Tehdy sebrav Jezús zákonniky otáza jich 4?. a oravě které sè vám vidí o Kristu

ci by syn byl

Pravie jemu Daviduov

43. Pravi jim

kakoz tehdy David zove $v$ duchu Hospodinem a łka

44. Pravil Hospodín Bohu mému sed' na pravici méj donĕ-

vadz nepolożi neprátel tvých podnoź nohám tvým

45. Protoz ze jeho zove hospodinem kakoz syn jeho jest 
46. I nemohú jemu ijednoho slova otpověděti

ani kto smél jeho viec jednoho slova otazovati od toho Casu

CXII.: S, R, W] deest $A, C, D$

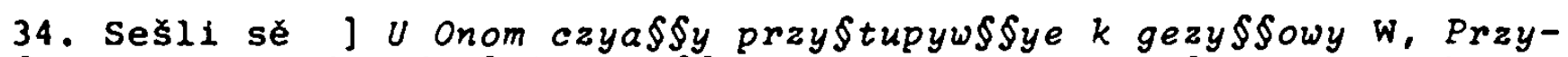

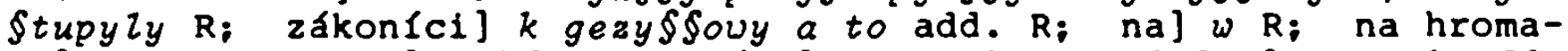
du] om. $W-35$. i] Tehdy R; otaza] otazachu $W ;$ jeden] $z$ nych add. W; zákonny] om. R; pokuséje] poku§§uge $R_{i}$ jeho\} a rzka add. R 36. kázanie] przykazanye $W, R$ - 37. vece] Powyedye R; Jezú] a tak rzka add. $R_{;}$Milovati budes] Mylug $w, R_{i}$ Boha] \$weho add. W; tvé] twey $W_{i}$ mysli] $\$ \$ y l y R ;$ tvé] twey $W-33$. To] tot $R$; veliké] $a$

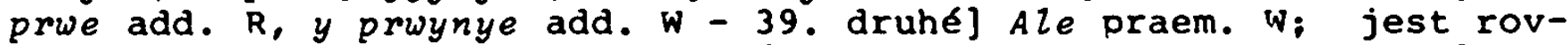
né] a podobne add. R, podobne ge\$t W; k tomu] temuz W; Miluj] MyZowaty bude $\$ \mathrm{R}$; svého bližnieho] transp. W; sĕ sám] transp. W, $\mathrm{R}$ - 40. tom dvoj $[\mathrm{m}]$ tem dwem kazanye w\$\$yechen $\mathrm{w}$, przyka\$\$any we\$\$ken add. $R$; pnI] om. $R-41$. zákonn $[k y] w \$ e\langle c z\rangle k n y$ add. $R-42$. a] tak add. R; pravé] rzka W, R; které] Czo W, R; vid1] $z d a W ; ~ b y]$ ge R, om. W: byl] ge§t W; Pravie] odpowyedyechu R, Powyedyechu $W_{\text {: }}$ jemu] mu R, rzkucze add. $\mathrm{R}$ - 43. Pravi] Tehdy wecze $\mathrm{R}$, Wecze W;

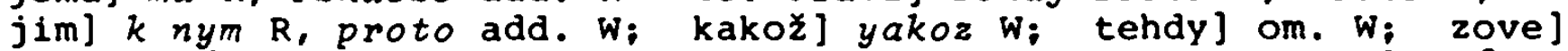
wola W, \$lowe $\mathrm{R}$; zove $\mathrm{v}$ duchu] transp. $231 \mathrm{~W}$; Hosdodinem] ho\$podyna $W$ - 44. Pravil] Powyedye $Z$ W, mluwy $l$ a praem. R; sed'] Sedye $\mathrm{R}_{\text {; }}$ méj] na me $\mathrm{R}_{\text {; }}$ doněvadż] donyez $\mathrm{W}$, donadz $\mathrm{R}_{\text {; }}$ nepolożi] nepolozym W, R; tvych] po add. R; podnožl] Podnoz W, R - 45. Protoz] Procz R; ze] acz W, R, dauid add. R; jeho] ho $W$, dawyd add. W; zove] wola W, nazywa R; kakoz] takoz tehdy R - 46. i] yzadny add. W: nemohu] nemoh $[\mathrm{W}$; ijednohol om. W; otpovĕdéti] rayeczy od toho czya\$\$u W; ani] potom add. $R$; kto] om. W; směl jehol transo.

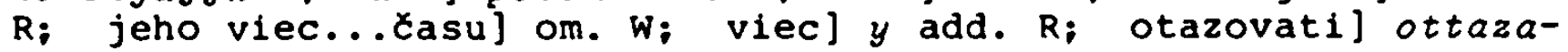
ty R.

CXIII. Dominica XIX. post Pentecosten - Mt $9,1-8$

1. Vstúpaje Ježus v lodici přejel přes moře i dĭišel do města svého Kafarnaum

2. Tehdy nesiechu jemu jednoho nemocného a ten ležieše v loži svém a jmějieše nemoc ješto slóve dna Tehdy vidẻ Jezús vieru těch lidi ľekl nemocnému uvèr synu otpuštěni sư tobĕ hrieši tvoji

3. Tehdy nèkteł́l zákonnlkuov a $z$ olsaróv vecechu mezi sobu Tento nás posmievá

4. a kdyz už̀e Ježus myšlenie jich vece

$i$ co myslite zlého na vasich srdciech

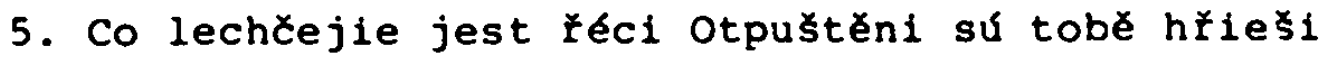
nebo Íéci vstañ a chod'

s $147 a_{2}$ 6. Aby vêdéli zajisté / že syn clověcl jmá moc na zemi $\left(152 a_{2}\right) \quad$ otpustěti hřiechy 


\section{1 vece nemocnému}

vstañ vzdvihni lože své a jdi v duom svój

7. 1 vstav $i$ jide $v$ duom svój

8. vidĕv̌̌e to zástupové báchu sĕ

a chválechu Boha jenż dal moc takú lidem

CXIII.: $S, R$ ] deest $A, C, D, W$

1. Vstupaje] W\$§edl R; lodici přejel] lodyczku y przewezl $\$ \$ y e ~ R ;$ Kafarnaum] nazareta $R$ - 2. Tehdy nesiechu] przyne fechu $R$; a ten] om. R; ležiese v] lezyecze na R; svém...dna] om. R; Tehdy vidé] A kdyz varze $R ;$ těch lidl lekl] gych wecze R; nemocnému] zagy\$te

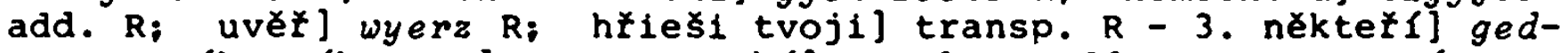
ny $R_{i}$ zákonnikuov a] om. $R_{i}$ sobu] a rzkucz add. $R ;$ Tento nás dosmieva] Tot pohor§ugye $R$ - 4. vece] gym add. $R$; $i$ col $A$ czoz tolyko $R_{i}$ na] $w R_{i}$ vasich srdciech] transp. $R$ - 5. lechrejie jest] transp. $R ;$ suj om. $R_{i}$ tobè hłiesi] transp. $R_{i}$ nebo] $C z y$ ly $R-$ 6. Aby vědéli zajisté] aby§te to prawye wyedyely $R$ : ¿lověcl] y marye add. R; otpustęti] odpu\$tyty $R_{i}$ i] potom $R_{i}$ vstañ] wahoru $A$ add. $R_{i}$ sve] twe $R_{i}$ svoj] twoy $R-7$. i vstav] Tehdy w\$ta nemocz-

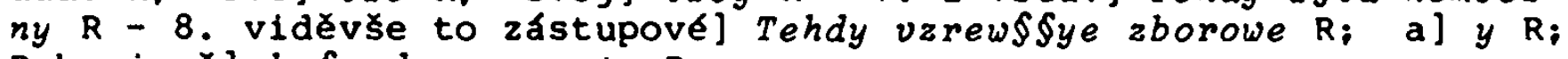
Boha jenz] ho Spodyna genzto $R$.

CXIV. Dominica XX. post Pentecosten - Mt 22,1-14

1. Pravieše Ježư zboróm pověst tuto

2. Rovno jest uð̌iněno královstvie nebeské clověku královi jenz uxinil svatbu synovi svému

3. i poslal panołe své zvat na hody

a nerodiechu pijifti

4. Znova posla jiné posly réci aby zvanl płisli a tka

Seova obèd dospęl jest 1 vłe hotovo jest dod'te na svatbu

5. Ale opozdichu

I jide nèkterý do sué vsi

a jiný na potzebu

6. a ti jenz ostali jemse posly

1 zbili je

7. Ale král kdyz to uslyse hněviv by

i posla zástupy 1 zahubi vražedlniky ony

a mésta sejžechu

8. Tehdy vece sluhám svým hody uxinèny sú

ale jesto zváni biechu neduostojni byli 
9. Jdéte na rozputie cestné

a kohoz koli naleznete zovte na hody

10. vyłedకe sluhy jeho

sebrachu vłechny koho nalezu

aby našel duom svatebny

11. Tehdy unide král aby vidél svatebnfky

i vidè tu ¿lověka neoděna svatebnym rúchem

12. I vece jemu

prieteli kak si sem všel nejmaje rúcha svatebného Tehdy on pomlce

13. Tehdyz vece král sluhám svým

sviezice ruce a nohy puste jeho ve tmy dolejšle

Tu bude plác a skfehet zubuom

14. Nebo mnoho jich pozváno

a málo vybráno

CXIV.: $S, R, W]$ deest $A, C, D$

1. Praviełe] $U$ Onom czya\$\$y praem. W, MLuwye\$\$ye W, R; zboróm] $\$$ uczyennyky \$wymy $W, R$; pověst] $v$ powye \$tech $W$; tuto] a $r z k a W, y$ powyedye gym a rzka R - 2. Rovno] Rownye w: jest uciněnol transp. W: jenz] ge\$to $R:$ synovi] \$ynu $R$ - 3. i] Tehdy R: zvat na hody] wolat pozwanych na \$watbu $\mathrm{W} ; \mathrm{a}$ ) $y \mathrm{~W}, \mathrm{Ale} \mathrm{R}$; nerodiechu] nerodyely $W$ - 4. Znova] Opyet $W$; posla] po\$\$lal W, R; Dosly] $\$$ iuhy $W, a$ rzka add. W, R; Ýéi aby zvani píisli a lka] rzczete gym zdat by zwany przy\$\$ly R, Powyezte zwanym W; Seova] Ay R, tot W; obéd] moy add. W, R; dospél jest] do\$pyen ge\$t y bykowe mogy y p(t)at\$two me zbyto ge\$t R, \$em prayprawy 2 podte na \$watbu wolowe mogy $y$ ptacz\$two zbyto $W_{;}$vSe] w\$\$eczko R, $w \$ \$ y c z k n o$ W; jest pod'te na svatbu] om. W - 5. Ale] Tehdy R, ony add. W, R; ooozdichu] zame\$\$kachu W, \$\$ye add. R; jide] gdu R, gydechu W: nékterý] nyekterzy

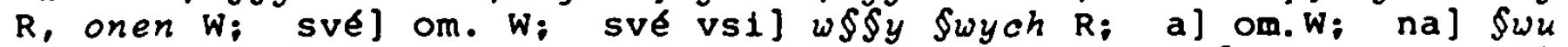
add. $W$ - 6. a ti jenz...2bili jej] Nyekterzy gymaly \$luhy geho nyekte-

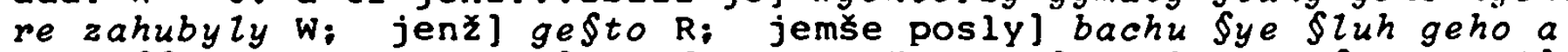
zalow\$\$y gym R - 7. Ale] Tehdy R; hnéviv by] rozhnyewa \$ye w; i] a tak R: zastupy] Swe add. R; zahubi] zahuby ty $\mathrm{W}$, zahuby te R: ony] om. R; mésta] mye§to gych W: sejzechu] §ezzye w, zezrze gych $\mathrm{R}$ - 8. Tehdy] zatyem R; jesto zváni] kterzy \$u pozwany W: zváni biechu] bychu zwany R: biechu] om. W: neduostojni byli] neby ${ }_{i}$ \$u doo\$toyny $\mathrm{W}, I$ wecze $\{$ uham $\$ w y m$ add. $\mathrm{R}-9$. Jdète] $A$ le oraem. W; rozputie cestné] rozpu\$czenye cze\$t $R$, czye§ty $W_{;}$kohoz] ktere $W_{;}$ koli] wyek add. $\mathrm{R}$; naleznete] naydete $\mathrm{W}$; zovte] zente gye $\mathrm{R}$, gye m. rec. add. W; hody] $\$ w a d b u ~ R-10$. vyšedకe] Tehdy oraem. $R, y$ praem $W$; jeho] na czye\$ty add. $W$, nazaytrze na ce\$ty add. R: sebrachu] \$ebraly $W$; vSechny] w\$\$eczkny $R, w \$ \$ y c z k n y$ W: koho nalezu] zle y dobre ktere kolwyek nalezly $\mathrm{W}$, kohoz naleznu zle y dobre $\mathrm{R}$ : našl duom svatebny] by $2 a$ swatba nap Inyena W - 11. Tehdy] Potom R; vnide krall kral wende R; videll ohledal $R$; i] Tehdy $R$, om. W; vide tu] tu varzye $\mathrm{R}$; neodéna] neodyeneho $\mathrm{W}, \mathrm{R}-12$. jemu] $k$ nymu $R_{i}$ kak si] kako W, procz\$\$ R; vsel] $\$ \$ e l$ R; svatebného] swatebnyeho R: pomlCe] pomlczew $R, m i c z y e W-13$. Tehdyz] Tehdy W: Svie-

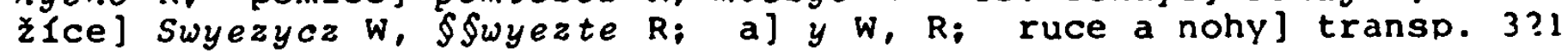


W, geho add. $R_{i}$ pustel wrzte W; jehol gey W, $R ;$ ve tmy dolejsie]

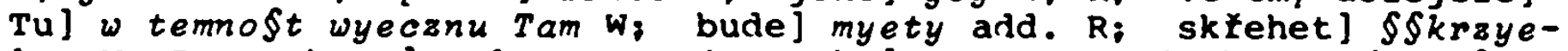
hot W, $R$; zubuom] zubow $W-14$. mnoho] mnozy W; jich Dozvano a] Su pozwany ale $W$, gełt pozwanych ale $R$; vybránol wybranych $W, R$.

CXV. Dominica XXI. post Pentecosten - J4,46-53

46. Bieł̌e jeden králik jehozto syn nemocen biełe u městě Kafarnaum

47. Ten kdyžto uslyse ze Jezús pł́lde ot Judy do Galilea prosiese jeho aby sstúpil 1 uzdravil syna jeho /

S $147 b_{1}$ nebo pocinase milieti

$\left(152 b_{1}\right)$

48. Tehdy povědě jemu Jezús

kromé uzł́s li divy a znamenie nevěr

49. Praví k nêmu králík

Hospodine vejdes dł̌́ve nez umłe

50. Pravi jemu Ježus

viz syn truoj ziv je

1 věłi clověk slovóm ješto vece Ježús I jide

51. A kdyz prichodiese

potkáchu jej panołe łkuce ze jest ziv

52. Otáza jich $v$ ktery cas lepl byl

Povęerchu

$s$ "noci s poledne ostala jeho studenice

53. urozumé otec že $v$ ten Cas povĕdél Ježús syn tvuoj żiv jest

1 uvěr 1 on a vకe celed' u Buoh

CXV.: $S, R, W]$ deest $A, C, D$

46. Bieš] U Onom czya\$\$y praem. W: jehozto] gehoz W; u městę]

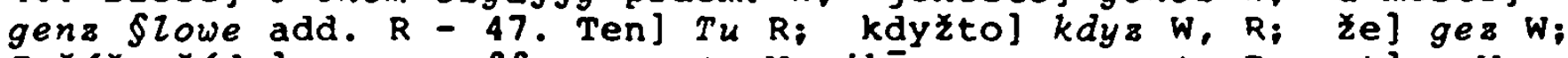
Jezús płide] ma gezy\$S przygyty $W$, ihüs ma przygyty $\mathrm{R}_{\text {; }}$ ot] $z$ W: Judy] Yudea R, zydow\$twye $W$ : do Galliea] a galylee \$\$ed $k$ nyemu $y$ $\mathrm{R}$; Prosiese jehol pro\$\$y ho W: sstúpil] w\$tupy $2 \mathrm{R}$; miletil vmyeraty $W$, Skonczenye braty $R$ - 48. Tehdy] zatyem $R$; Dovedel weczye $W$; kromej gedno W, R; divy] dyw R; uzł́s li divy a znamenie nevěłis] anamenye $y$ dywy vzrzyte newyerzyte $W$ - 49. Pravil Tehdy praem. $R$, Weczye $W, R ;$ vejdes] wendy $R$, Sendy $W$; umž] Syn moy add. $W, R$ 50. Pravi] Powyedye R; Pravi jemu Jezús] om. W; viz] gdy W, Gdyz $R ;$ i] om. W, $R$; vełi] vwyerzy $R$, wyerzy $W_{\text {; }}$ slovóm] Slowam $R$, §lowu W: vece] gemu add. W - 51. płichodiese] przygyde W, przyhody S\$ye R; potkachu jej panose] \$luhy potkachu gey W: Ykuce] a rzkucze gemu R, y powyedyechu gemu W; ze] Syn twoy W, R; jest] om. W: jest Ziv] transp. R - 52. Otazal Tehdy praem. R, y praem. W: ktery

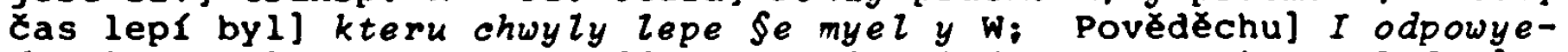
dyechu a rzkucze R, gemu add. W: s *noci (nuoczy ms.) s poledne] 
wezyera $w$ §edmu hodynu W; studenice] zymnycze R - 53. urozumé to$m u$ add. $W$; v] om. $W$; Cas] $v$ nemzto add. $W ;$ pověděl] gemu add. $R ;$ Ježus] $d y$ add. W, a raka add. $R_{;}$i] $T e h d y R_{;}$a] y $W, R_{;}$vš] w\$yeczka R; Celed'] geho add. W, R; u Buoh] Om. W, R.

CXVI. Dominica XXII. post Pentecosten - Mt 18,23-35

23. Pověděl Ježús mlazšlm svým Podobno jest královstvo nebeské đlověku královi jenž chtieše pođet uxiniti 〈s〉 svými pacholky

24. A kdyz poče jmieti počt podachu jemu jednoho jenž jmějieše deset tisicóv funtuov dáti

25. A když nejméjiese zaplacenie káza jej zastaviti

i děti 1 ženu jeho 1 položiti

26. Tehdy klekna poprosi jeho a łka otloz $\mathrm{mi}$ to pane a vకe tobe vráci

27. Smilova sé pán nad panoš svým pusti jeho 1 dluh jeho

28. Tehdy vyšed týže panoš naleze jednoho dlužníka svého jenž bieše sto peněz dlužen

a jèm dávieše jeho a łka vrat' mi dluh

29. tehdy poklekna prosieše jeho slituj se nade mnú a všecko vráti tobé

30. Ale on nerodi

Set $i$ pusti jej $v$ zalár doñavadž nevrát 1 dluhu

31. Tehdy viduce sluhy jeho smútichu sè velmè a pfíduce praviechu to dánu svému vše co sé stalo

32. Tehdy pozva panoše pán jeho i vece jemu sluho nexstny vštek dluh spustil sem tobě nebo prosil si mne

33. aby ty milostiv byl svému jako jáz tobé milostiv sem by 1

34. Rozhněvav sè pán jeho poda jeho katuom doněvadż nenavrát l poslednieho dluhu /

S $147 b_{2}$ $\left(152 b_{2}\right)$
35. Takož Otec muoj nebeský uxini vám neodpustlte li každý vás bratru svému s vašeho se věeho srdce 
23. Povĕdĕl] U Onom czya\$\$y praem. W; svým] podoben\$twy toto a raka add. R, podoben\$twye toto add. W; kralovstvo] kralow\$twye W, R; nebeské] $k$ add. $\mathrm{R}$; chtiese] chtyel $\mathrm{R}$; uXinitij polozyty W: svymi Dacholky] transp. W - 24. jmieti Dotet] poczyet kia\$ty $w$; jenz] gye\$to $R_{i}$ jméjieše] gemu add. W; funtuov] om. R - 25. nejmejiese] odkud add. W; zaplacenie] zaplatyty $R$, nawratyty $W$; jej] gym $R ; ~ i d e t i$ 1 Zenu] transp. $1432 \mathrm{~W}, \mathrm{R}$; jeho 1$]$ om. $R$; poloziti] om. W, R, $A$ to w\$\$e czo gmyegye\$\$e dolozy diwh add. $R$, w\$\$yeczko czo myegy\$\$ye y nawratyty add. W- 26 . klekna] poklekna $W$, pacholek ten gy\$ty add. $R$, \$luha add. W; otloz mi to pane] Smy $z$ ig \$ye nade mnu w, moy add. R: a] $y$ W: vłe] w\$\$yeczkno $W, g y z$ gye R; tobe vráci] nawratym tobye W - 27. Smilova] Smy Lowaw W, Tehdy praem. R; panosi svym] \$wym $\$ 2 u-$ hu $\mathrm{w}_{i}$ jeho] gey $\mathrm{w}_{\text {; }}$ i] om. R, w\$\$yczyek add. W; dluh jeho] yhned

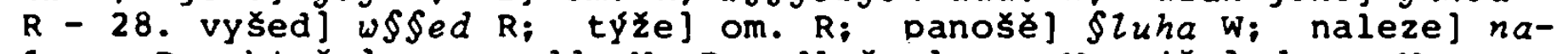
lezne $R_{i}$ biě̌e] gemu add. W, R; dlužen] om. W; jěm] drzye W, gey add. R; dávieše] dawa\$§e R; jehol gey $W, z a$ diuh add. $R ;$ mi dluh] czo\$ $\$$ diuzen $W-29$. tehdy] $y W$; poklekna] $\left\{l_{u h a}\right.$ add. $W$, on add. $R$; prosiese jeho] geho pro\$\$y geho a rzka W; slituj] smy $2 u g W, R_{;}$a] $y$ W; vSecko vrati] w\$\$yeczkno wratym $W$, w\$ye wraczy $R-3 n$. nero-

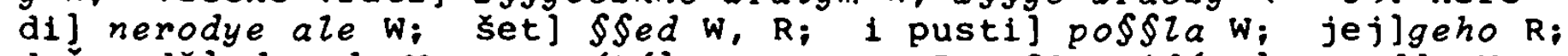
doñavadz] donydz W; nevrát 1$]$ nenauraty $R-31$. viduce] to add. W; velmé] welmy W; pŕlduce] przy\$§ed R, przy\$\$edczye W; oraviechu] prawyl R; svému...stalo] om. W; coj yakoz R; stalo] ge§t add. R - 32. Tehdy... pán] om. W; panoše pán] transp. R; jeho] om. R; Sluho...si mne] om. $R$; nexstny vititek] zly w\$\$yczyek $w_{i}$ spustil sem] Sem odpu§ty $Z$ w: prosil si mne] s mne pro\$\$y $Z$ W - 33. aby ty... sem byl] om. R; aby ty milostiv byl svému] proto ne\$my lowaty \$ye tobye nad \$wym \$luhu w: jako jaz] yakoz ya \$em (\$em rub. superscr.) i : tobe milostiv sem byl] nad tebu $\oint_{e} \oint m y$ lowal $w-34$. Rozhnevav] Tehdy praem. R, y praem. W; jeho] nan R; jeho] ho $W$; donévadz] donawadz $\mathrm{R}$, donydz $\mathrm{W}$; nenavrátl] newraty $\mathrm{W}$; poslednieho] w\$\$yeho W - 35. Takoz] Takez W, R; vám] acz add. W, R; li] om. W, R; kazdy vás] $z$ wa\$\$ kazdy W, dluhu add. R; bratru svermu] transo. W; $s$ vaseho] om. $R ;$ s vaseho se vieho srdce] $z$ frdecz wa\$\$ych $W$, \$weho add. $R$.

CXVII. Dominica XXIII. post Pentecosten - Mt 22,15-21

15. Odstúpivse zákonnlci 1 vzeli radu kak by popadli Jezise $v$ Eexi

16. 1 poslali jemu učennlky své s Erodiásovými a řkuce Mistre vieme ze prav jsi

a cěstu Bož u pravdé uxis

i nenie tobè péce do nikohého

Nebo nehledás osoby clovexie

17. Pověz nám co sè tobè Dodobno vidl

jmáme 11 cinzi dáti césarovi neb nic

18. Tehdy poznav Jezus zlost jich 1 poverde

1 co mne pokusujete pokrtnici

19. pokazte mi peniez cinžový

Tehdy oni prínesli mu peniez 
20. 1 povědĕ jim Ježus

¿1 jest obraz tento a ¿̌ie plsmo jest na nĕm

21. Pověděchu jemu ciesařóv

Tehdy povède jim Jezús

Navractez proto které sú Bozie Bohu

a které sú ciesarovy ciesarovi

CXVII.: $S, R$ ] deest $A, C, D, W$

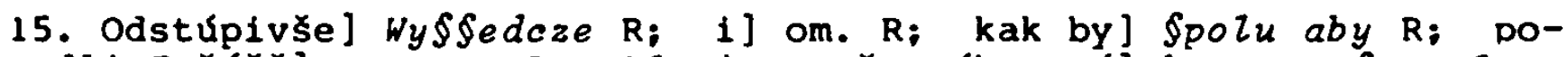
padli Ježíé] transp. $R-16$. jemu utenniky své] $k$ nyemu §we miazSye R; Erodiásovłmi] he rowamy §luhamy $R$; Mistíe] To add. R; prav]

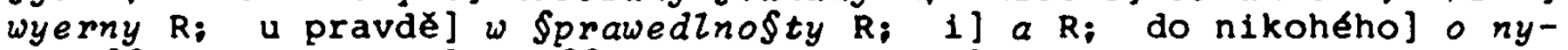
czem\$ई R; ¿lověxie] lyd\$\$ke $R-17$. Pověz] Proto Draem. R; Dodobno] om. R; jmáme $1 i$ ‘inži] geftly zle dan $R ;$ neb] czyly $R$ - 18. Doznav Ježus] transp. $R_{i}$ zlost] newyeru $R_{i}$ povědé i] wecze $R$; pokusujete pokrtn[ci] zku§§ugete lyczomyernyczy $\mathrm{R}$ - 19. pokazte] Vkazte R; ¿inžový] om. R; přinesli mu] porokowachu gemu $R-20$. povèdĕ jim] we-

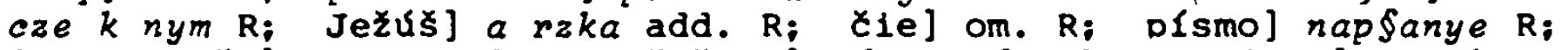
jest na nĕm] om. R - 21. Pověděchu] odpowyedyechu $R ;$ jemu] a $r z k u-$ $c z e$ add. $\mathrm{R}$; Tehdy pověde] Toho die wecze $\mathrm{R} ;$ Ježus] om. $\mathrm{R}$; Navractez proto] Protoz wratte R; které su Bozile Bohu a které sú ciesarovy ciesałovi] czoz ge\$t czye§arowo czye§arzowy a czoz ge\$t bozye bohu R.

CXVIII. Dominica XXIV. post Pentecosten - Mt 9,18-26

R $124 a_{2}$ 18. (M)luviese Ježls $k$ sboróm żidovským 0 spravedlnosti Otce svêho

Aj jedno knieže pristúpi 1 následováse jeho a tak rka Hospodine dci má umřela jest

Ale ty jdi a vloz na ni svu ruku at' ožive

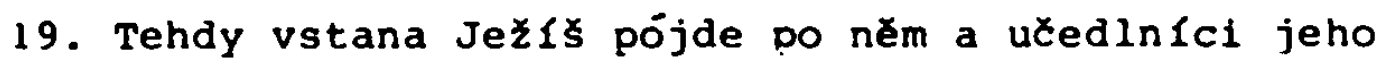
s n Im

20. A jedna žena jmějê̌e červenú nemoc dvanádcte let přistúpi k němu szadu I doť̌e sě podolka jeho

21. A potom vece sama $k$ sobe

AC jedno dotknu sè jeho rúcha ihned zdráva budu

22. Tehdy Jež́s obrativ sè $i$ vece $k$ nie věriś li nebo viera tvá ta té zarávu cini

A uzdravena jest zena $v$ tu hodinu

23. Tehdy vsed Jež́s $v$ dóm kniežecl

1 už̀ tu pisce hudce a jiný zástud veliký lida 24. I vece $k \mathrm{nim}$

Vystupte ven $z$ domu Nebo dcera jest ziva

Tehdy oni smiechu sè jemu 
25. $i$ vyndu ven $z$ domu

A pristúpi vslzi 1 dotðe se ruky jejie A ihned vsta $z$ mrtvých

26. 1 pronese sè po v̧̌em kraji Amen

CXVIII.: R] deest $A, C, D, S, W$

26. Amen ] expl. R.

CXIX. In dedicatione ecclesiae - L 19,1-10

S $147 \mathrm{~b}_{2}$ 1. Vక̌ed Ježús chodiese skrzè Jericho

$\left(152 b_{2}\right) \quad 2$. A seova muz jménem $Z$ acheus ten biese kniež obecnlkuov a bohatec veliký

3. I hledáse viděti Ježše kto by byl

1 nemožleše pro zbor nebo postavy malické biese

4. A předběhna vstúpi na dłevo aby viděl jeho nebo odtad jlti jméjiese

5. A kdyz prilde $k$ miestu veže Ježús vidě jeho

$i$ vece $k$ nèmu

Zachee skoro sejdi

nebo dnes $v$ *domu tvém musi bydliti

6. Tehdy chvátaje stúpi I prije jeho radosten

7. A kdy̌ vidiechu vక̌ichni reptáchu łkúce že k clověku hł̌iešnému navrátil sè

8. Tehdy stoje $z$ acheus vece $k$ Hospodinu Seova polovici zbožie mého Hospodine dávaji chudým Pakli sem co koho přelstil vracuji ctvero

9. vece Ježús

Nebo zajisté tomuto domovi zdravie dnes stalo sex proto aby on byl syn Abrahamuov

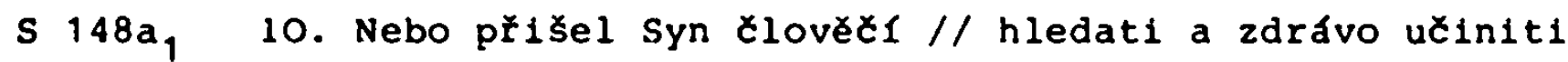
$\left(153 a_{1}\right)$ jenz zahynulo biese

CXIX.: $S, W]$ deest $A, C, D, R$ $----------$

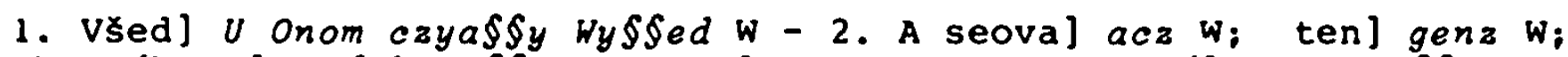
obecnlkuov] nad hrzy\$\$nym $W$; a] on add. W; veliky] a wyecz\$\$y wypowyednyk $W-3$. I] a $W$; postavy malické malytky $W-4$. A] tehdy

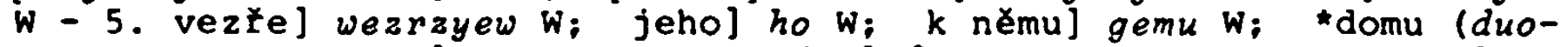
$m u$ ms.) - 6. Tehdy] on add. $W_{i}$ stupi] \$tupyty $w_{i}$ jeho radosten] raduge Sye $w$ - 7. vílchni reptáchu] reptachu w\$\$yczkny $W$ - 8. stoje] 
Stana W; Seova] $E z$ W; zbozie mého] transp. w; vracuji] y add. W

- 10. zdráo] zdrawe W; jenż gez W: biešl expl. S.

Lectiones Proprii et Commune sanctorum

CXX. De S. Andrea - Mt 4, 18-22

W 36a 18. V onom Cas 1

Chode Jeẑ́ podlé moł̌ Galilee vidél dva bratry

Simonie jemuž jmě Petr a ondžje bratra jeho

pušcejlce siet u more Nebo biesta rybary

19. I vecè jim

pod'te po mue uxinim vy rybałe lidské

20. Tehdy oni inhed ostavivకe sieti i lodi jidechu po něm

21. I jda odtad uz ł̌ jiná dva bratry

Jakuba Zebedei a Jana bratra jeho

v lodi s Zebedeem s otcem jich dospievajice sitě své

$i$ pozval jich

22. Tehdy oni inhed ostavivłe sieti i lodi jidechu no nèm

CXX.: W] deest $A, C, D, S, R$

CXXI. De S. Nicolao (?) - L 12,35-44

35. $V$ onom Xasi

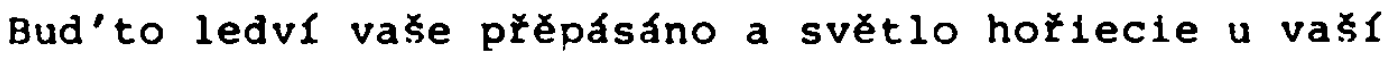
ruku

36. a vy podobni lidem đěkajlce pána suêho kdyż sè vrât 1 s hodóv

a kdyz pŕlde a potluce aby inhed otevrěli jemu

37. Blahoslaveny sluhy ty kdyžto pílde pán najde jĕ bdiec Zajisté pravi vám

že opắe sè a káze tym sêsti

a chodè bude jim sluziti

38. ac płide $v$ druhý vecier

paklı $v$ tret 1 večier płr lde a tak nalezne /

w 36b blahoslaveny sú ty sluhy

39. Ale to vězte

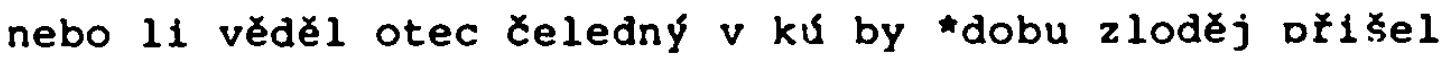

všelik by bděl i nesmell by podkopati domu jeho

40. I protoz vy bud'te hotovi Nebo $v$ niezto dobu nemnlte 
Syn とlověç pr̆ Ida

41. Tehdy jemu vecé petr Hospodine $k$ nám 11 đdies tu pověst $\succ_{i}$ ke vక̌rm

42. *Povědě mu Ježı

kto jest mudrý a věrný sefáx

jehoz ustavil pán nad svú celedr

aby jim dal $v$ cas mieru psenice

43. Blahoslavený ten sluha jehož když přlde pán nalezne tak cinlce

44. Jistè pravi vám

že nade v̌̌ sbožle ustavuji

CXXI.: W] deest A, C, D, S, R; De S. Nicolao hodie - Mt 25, 14-23 39. *dobu (tobu ms.) - 41. *dies (de§\$ ms.) - 42. *Povědě (Powyedy ms.).

CXXII. De Ss. Fabiani et Sebastiani-L6,17-23

17. $\mathrm{V}$ onom Casi

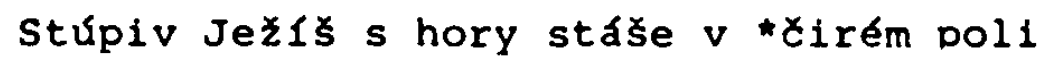

a sila ucennlkuov jeho

a mnohost lida ze vłeho Zidovstva 1 z Jeruzalema

I maritima a $z$ *Tyrska a sidona $z$ těch vlast 1

18. jesto biechu pfisli aby slyserli jeho

a uzdraveni byli z nemoci svych

a jesto biechu obkliceni duchy nexistymi uzdraveni

19. a vłeliký sbor zádăe jeho dotknuti

nebo moc od něho vychodiese 1 uzdraviese vłěckny

20. Tehdy vzveda oxi $k$ nebi vecè

* Blahoslaven 1 *chudf duchem nebo vase jest královstvie nebeské

21. *Blahoslaven 1 *jesto nynie laxn 1 nebo syti budete *Blahoslaven 1 jesto plácete neb se smát1 budete

22. Blahoslaveni budete kdyz vás nenávidèti budú lidé

a kdyz vy rozlútie a zkusie

w $37 a$

1 vyvrhú jméno // vaše jako zlé pro syna c〈l)ověłieho

23. Radujte se $i$ veselte sè $v$ onen den nebo mzda vaš mnohá jest $v$ nebesiech

CXXII.: W] deest $A, C, D, S, R$

17. * Cirém (czyerem ms.); *Tyrska (\$tyr\$ka ms.) - 20. *Blahoslaven1 
(-ye ms.. ibid. v. 21. 2x); *chud1 (-ye ms.) - 21. *jesto (ge\$to ge Sto ms.).

CXXIII. In Purificatione B. Mariae V. - L 2,22-32

22. V onom Casi

Kdyz *sú dokonány dny ocišenie Marie podlé zákona Mojziesova

nesechu jeho do Jeruzalema aby obětovali jeho Hospodinu

23. jakož psáno jest $v$ zákonè Božiem

Nebo *vకeliké *pachole otvierá *brich *svaté Bohu nazváno bude

24. aby *ali obět jakož povědíno jest $v$ zákoně Božlm dvé hrdlicátek

25. A když muž b1̧e $v$ Jeruzalemě jemuž jmě simeon a Clověk *ten pravý a bánivý

¿ěkaje utěšnien Zidovstvu

a Duch Svatý bieše $v$ ňem

26. 1 odpovědernie vzal simeon od Svatého Ducha

* jez by dřleve neuzrél smrti až by uzfél Hospodina

27. 1 pŕ Ide $v$ Duchu do chrámu

A kdyz uvedechu dietè Jeziš Rodina jeho podlé *obv¿eje zákonniho

28. 1 on vza jej na své rucé 1 chválése Boha a řka

29. Jiz pustı́ hospodine sluhu svého podlé tvého slova

*u pokoji

30. Nebo ste viděly oxi moji zdravie tvé

31. Jez si uxinil před oblič̉jem vł̌eho lidu

32. Svętlo na zjevenie pohanóm a chválu lidu tvému zidovskému

CXXIII.: W] deest $A, C, D, S, R$

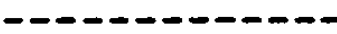

22. *sú (by $l_{y} \mathrm{~m}$. rec. superscr.)- 23. *vłeliké *Dachole (lyke pachoLe in rasura m. zec., ktere\$\$to nayprwe matky fwey mg. add. m. rec.); *bílch (in rasura m. rec.); "svaté Bohu (\$luzbu bochu mg. m. rec.) - 24. *dall (gye $w \mathrm{mg}$. add. $\mathrm{m}$. rec.) - 25. *ten (by\$\$ye mg. add. m. rec.) - 26. *jez (nez ms., n-m. rec.) - 27. *obyčjje (oblycayege ms., $-\tau$ - rad. $)-29 . * u(y$ ms. $)$. 
CXXIV. In vigilia s. Matthiae - Mt 10,5-8

5. V onom ¿asi

Poslal Jež́s dvanádcet uXennfkóv suých pravě jim Na cèstu pohanskư nenachod'te

W $37 \mathrm{~b}$

a města samaritánská / nevchod'te

6. Ale spiese děte $k$ ovciem jesto sú zhynuly $z$ domu Izrahelova

7. a chodiece kažte ŕkúce žet' blıžl se královstvie nebeské

8. Nemocné uzdravite

mrtvé 2 křiesite

pracné oxiste

běsy vypud'te

darmo ste vzeli a darmo dajte

CXXIV.: $W$ ] deest A, C, D, S, R

CXXV. De S. Matthia - Mt 11,25-30

25. V onom Casi

radoval se Jež́s v Duchu Svatém $i$ povědel

zpovidaji se tobè oť̌e Hospodine nebe 1 zemĕ

Nebo skryl s to od mudrych a chytrych

1 zjevil s to mladým

26. tako oťe že jest tobě bylo libo na tom

27. vše mi jest poddáno od otcè mého

A nikte neznal syna jedno otec

ani otcé kto znal jedno syn

A komu bude chtieti syn zjeviti

28. Pod'te ke mnĕ vక̌̌ckni ješto usilujete a břmeñ nesete

a já nakrmím vy

29. zdvihnète tiezi mu na vy

a ưte sĕ ode mne nebo tichý sem a pokorného srdcè

I naleznete pł́lbytek duśm vasım

30. nebo jeho mé jest a břiemè mé *lehké

CXXV.: W] deest $A, C, D, S, R$

(2)

30. "lehké (super -eh- m. rec. c superscr.). 


\section{Lectiones}

L 3,1-6 vide VI. Sabbato IV temporum adventus

Mt 21,33-46 vide XLII. Feria VI. post Dom. II. in Quadr.

Mc 3,1-5 vide XXIII. Dominica V. post Epiphaniam

J 14,15-21 vide LxxxIV. Sabbato in vigilia Pentecostes

CXXVI. Pro ordinandis episcopis (?) - Mc 6,7-10

พ 39a

7. $v$ onom cas 1

Sezval Ježls dvanást uCennikóv i pođè je sláti do dvú

i dáváse jim moc duchovnú

8. i káza jim aby na cěstu nice nevzeli jedno hól

ani *tobolice ni chleba

9. ni jednoho obutie

a dvú sukni neobláxili

10. a vecé $j$ im

$v$ kterýz koli dóm vejdete tu bydlte odtud nevychod'te

CXXVI.: W] deest A, C, D, S, R

8. *tobolice (toho lycaye ms.).

CXXVII. Commune plurimorum martyrum - L 21,14-19

14. $V$ onom Casi

pravil Ježís učennikóm svým

*ustanovte toho dle u vasich srdciech

nevzpominajte kterým Xinem byste odpoviedali

15. Nebo já vem dám ústa a múdrost

jemuž nebudú moci svitéziti vaši všickni prctivnici

16. Ale zrazeni budete brat 1 mi otci $i$ rodinu 1 otateli

a smrti vy poddadie

17. a budete $v$ nenávisti pro mé jmě vక̌̌m

18. a vlas nezahyne s vası hlavy /

W 39b 19. u pokoji vašem vlásti budete dušemi vašimi

CXXVII.: W] deest $A, C, D, S, R$

14. *ustanovte ( $v$ wa\$ych add. ms.). 
CXXVIII. De S8. apostolis Philippo et Jacobo - J 14,1-13

1. V onom Casi

Povědĕl Jež́ učennikóm svỵm

Nemut'te srdcè vašeho

věrlte 11 u Buoh i u mè věrte

2. $\mathbf{v}$ domu Otcě mého rozliéna bydla jsu

cot' bych nynie pravil vám

jdu uxiniti vám miesto

3. $\mathbf{i}$ opět pýldu i pojmu vy $k$ sobè tu kdez sem jaz abyste vy byli

4. a kam jdu viete $i$ cěstu viete

5. vecé jemu Thomas

Hospodine nevieme kam jdem

ak móžem cěstu věděti

6. Praví jemu Ježı́

Já sem cĕsta 1 pravda i zivot

Nikte nejde $k$ Otci jedno mnu

7. ac poznate mè tehdy i otcè poznate mého

a viec poznate ho 1 vidite ho

8. pravi jemu Filip

Hospodine ukaz nám Otcè $v$ tomti máme dosti

9. Pravl mu Jezís

Toliko Casu s vámi sem a nepoznali ste mne Filide

ktoz vědě mě vidl otcě mého

kak ty pravis ukaz nem otcé

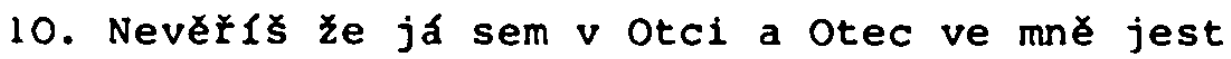

Slova jenź $k$ vám mluvi sám od sebe nemluvi

Ale Otec ve mnè bydlf ten * činl skutky

11. I nevěrís ž otec ve mnè jest a já v otci

12. Ale ponè pro ty skutky vète

zajisté pravím vám

kto u mè věrl skutky jež jă xini 1 on $x i n i t i$ bude

a viece toho uxiní nebo já $k$ otci jdu

13. a coz koli poprosite u mé jmè to uxini //

CXXVIII.: W] deest $A, C, D, S, R$

CXXVIII.---.---

10. « ¿inf (caynye ms.). 
CXXIX. De invencione S. Crucis - J 3,1-15

W 40a 1. V onom casi

Bieše clověk mezi zákonnIky jménem Nikodém

2. Ten přijide $k$ Ježrsovi $i$ vecè jemu

* Rabr viemy že od Boha přisel si

Nebo nemóz ijeden toho diva ciniti jesto ty ciars

jedno byl $l i$ by Buoh $s \mathrm{nim}$

3. Odpovědě Jež

věrně jistě pravi vám

jedno ktož znova narodil se bude nemóż vidęti crálovstuie Božieho

4. Pravi jemu Nikodemus

Kak sè móže clověk naroditi kdy̌̌ jest stár

a zda móž opét $v$ život matky své vnfti i porociti se

5. ...

6. Což narozeno z téla tělo jest

a coz narozeno $z$ duchu duch jest

7. ‘Nedivte se žet' sem Y̌ekl vám musfte se naroditi druhé

8. Duch kde chce *potiva

a hlas jeho slyšs

a nevies odkud jde Nebo kam jde

Takti jest prokni Ktǒ sĕ 2 Duchu narodil

9. Otpovědě Nikodemus jemu

Kak to móz býti

10. Povědě Jež́s

Ty s mistr zidovský a toho nevies

11. Zajisté pravi vám že což vieme *mluvímy

a což viemy svèdðı́my

a svèdexstuie naseho nepłijmete

12. Povědĕ 11 vám suětské neuvěrite

a kako povědě li vám nebeské vèulte

13. Ani kto vstúpil na nebe jedno kto $s$ nebe stúpil

Syn clověx jest na nebi

14. a jakož Mojzés povýsil hadu na pišxi

Takez mus1 syn clověl povýsen býti

15. aby každý ktož věr 1 veñ nezhynul

Ale aby jměl život věxný

CXXIX.: $W$ ] deest $A, C, D, S, R$ 
2. *Ratf (Rabii ms.) - 5. om. ms. - 7. *Nedivte (drages m. rec. superscr.) - 8. *pociva (dicha m. rec. superscr.) - 11. *mluvimy (mluwyeny ms.).

CXXX. Pro sponso et sponsa - Mt 19,3-11

3. V onom Casi

W $40 \mathrm{Ob}$

Přistúpili k Ježľ́ovi zákon / nlci pokusijlce ho a pravice

jestli lze clověku pustiti ženu sví kteruž koli vinu

4. Otpovědě jim Jež́s

Nectli ste že kto jest stvořil muže a ženu i stvoril oba

5. i povèdè

pro to opust l clovék otce a matku a přidržtí se svej ženè

1 budeta oba jedné krve

6. tehdy jiz nejsta dva Ale jako jeden zivot Protož což Buoh spojil clovĕk nerozluŁi

7. Vecéchu on 1

Což tehdy Mojžés píikázal dáti znamens hanby k zenè

i pustiti

8. Vece jim Ježrs

Nebo Mojžěs turdosti vaś přxoustil vám dustiti ženv vasě

Ale ot poxátka jest nebylo tak

9. Pravi vám já

Ktoz koli pusti zenu svu prec a jinu dojme pro smilstvo

a jinu pojme tupi dusi

a ktož pusti i pojme hřx̌r

10. Povẽděchu jemu uxennici

Jestli tak vinna Tehdy nenie slično dodlé zeny muži smilstvo ploditi

11. I vecé Ježls

Ne vక̌ickni rozuméjl tomu slovu Ale jimžto doddáno jest

$\operatorname{CxxX},:$ ] deest $A, C, D, S, R$

CXXXI. In vigilia S. Joannis Baptistae - L 1,5-17

5. V onom Casi 
Byl $v$ oněch dnech Herodiáše krále żidovského kněz jeden jemuž jmè $Z$ acharias rodu Abia

A Žena jeho ze dcer Aaronových a jme jlej Alžberta

6. a biesta oba pravá př̀ Hospodinem bydléce ve všem kázani i u pravdé Božie beze lsti

7. nejmęj Íta syna nebo bieše Elžběta zákoná a oba biešta vešla v svá léta

W $41 \mathrm{a}$

8. Sta sě když biě̌e popem Zacharias v svém zákonè // Dřĕd Bohem

9. podlé obyzeje popového

*třied(u) vnide aby oběd zažěhl vejda $v$ chrám Božl

10. a vక̌̌ckna sila lidr stáse napřed modléce sĕ

11. Tehdy zjevil se mu anděl Božl stoje na pravici oltáł obětovánie

12. I Zacharlas smúti se vida a strach veliký oŕijide nañ

13. Tehdy vecè jemu anděl Neboj se Zacharias *uslyšána jest zádost tvá

a Žena tvá Alžběta porodí tobě syna

I nazoves jej jménem Jan

14. I bude tobè radost $i$ veselé

a mnozi budu se radovati jeho narozen 1

15. nebo bude veliký pł̌d Hospodinem vína nebude ofti

a Ducha svatého bude naplnèn ješe $z$ matky zivota

16. a mnoho synóv zidovských obráti k Hosdodinu Bohu jich

17. a on pójde př̉̆ $n I m v$ duchu Eliášovẽ aby obrátil srdcè na syny otcova a nejemné viery na múdrost pravých ujednati Hospodinu lid ustaviený

CXXXI.: $W]$ deest $A, C, D, S, R$

9. "tried(u) (trzyed ms.) - 13. *uslysána (v\$\$ly§\$yana ms.).

CXXXII. De S. Joanne Baptista - L 1,57-68

57. $V$ onom Casi

Alžbětě přišel cas porozeń

1 porodi syna

58. i uslyక̌chu súsedi i př́telé ze jest ostavil Hospodin milost svi $k$ niej

1 radováchu sĕ 
59. Sta sè na osmý den

přijdu chtíce obřzovati dieté

i zváchu ho jménem otcovým zacharias

60. Otpovědé máti jeho a řkúci

nikaké Ale nazovte ho Janem

61. i řecechu $k$ niej

Neniet' ijednoho $v$ tvém rodè jenž by tiem jménem nazván byl

62. i pokýváchu 1 na jeho otcè kak by mu vzdẻl

w $41 b$

63. Tehdy / pozáda *pera 1 napsa

Jan jest jmè jeho

Podivichu se vł̌ickni

64. I otvořechu sě inhed usta jeho i jazyk jeho

i mluviese chvale Boha

65. i ửini se strach veliký na vłěch súsediech

i na vsěch horách pronesu sè slova tato $v$ Zidovstve

66. Tehdy položili mnlchu vకłickni jesto slyšxli na srdci pravice

Kaké toto dieté bude

nebo ruka Božle s nfm bise

67. Tehdy Zacharias otec jeho naplnèn svatého Ducha ororokováse a prave

68. Blahoslavený Buoh Hospodin Izrahel ze jest navšxvil 1 uxinil vykupenie lida svého

CXXXII.: W] deest $A, C, D, S, R$

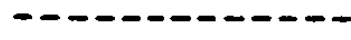

63. *pera (py\$\$adza rub. superscr.).

CXXXIII. In vigilia S8. Petri et Pauli App. - J 21,15-19

15. Vecè Ježš Petrovi

Simon Johannes miluj(es 1$\rangle$ i mé viece jich

Pravi

i ovsem Hospodine ty vieš že jă tè miluji

Vecě jemu

pasiz ovcè mé

16. Vecè mu druhé

Simon Johannes milujes 1 i mè

Pověde jemu

také Hospodine ty vies že miluji tè 
Prav1 mu Jež́s

pasiz ovcè mé

17. Povědé jemu tłet 1

Simon Johannes milujes li mè

i Dovèdĕ jemu

Hospodine ty vše znắ 1 vies že jă tě miluji

Tehdy vecè jemu Jež́s

Pasiz ovcè mé

18. zavěrné pravit' tobè

kdyz biese mladx 1 pásắse se 1 chodiese kde chtiełe kdyż sè ostarás jiny tè opáse a povede kamży rechces

19. Ale to povèdé znamenáv(a)je kteru by smrti oslavil Boha

CXXXIII.: W] deest $A, C, D, S, R$

CXXXIV. So. Petri et Pauli apostolorum - Mt 16,13-19

13. V onom Casi

พ $42 \mathrm{a}$

Płisel Ježs do kraje cisa // rova Filibova

i otáza *ư̌enníkóv *svých

Koho pravi lidé Syna Bożieho júsce

14. Tehdy oni Dověděchu

jedni Jana kftitele Božieho

A jinf Eliásè

A jin1 Jeremiałe nebo jednoho $z$ Drorokóv

15. Prav1 jim Jezis

a *koho vy mè pravite

16. Pověde Simon Petr

Ty si Kristus Syn Boha zivého

17. Tehdy odpovědĕ Jež́s

* Blaženy si Simon Bar Iona

ze tělo ani krev zjevilo tobe

jedno otec mój jenz na nebi jest

18. A já tobè pravi Petre že jsi ty Petr

a na tem kamenu stavi kostel mój

a vrata pekelná nebudu moci protiv tobe

19. A tobě dám klið̌e královstva nebeského

A coz koli zavizes na zemi bude zavázáno 1 na nebi

A což koli rozvižes na zemi bude i na nebi rozvázáno 
CXXXIV.: $W$ ] deest $A, C, D, S, R$

13. *uX̌ennikóv (vczyennyekow ms.); «svých (a rzka add. m. rec. mq.)

- 15. *koho vy mé (a czym ze wy m. rec. superscr.) - 17. «Blažený (BZaho\$Zan $\bar{y}$. rec. mg.).

CXXXV. In commemoratione S. Pauli Ap. - Mt 19,27-29

27. $V$ onom Casi

Pověděl Simon Petr k Ježlsovi

Ež my pustili vకe కli sme po tobě

coz nem pro to bude

28. Tehdy Ježls vece jim

zajisté pravi vám Jež vy ez ste po mné šli

po vskřiełenl když sede syn clovęu na stolici Bozstvie suého

stokrát dá viece vám sedete vy na stoliciech dứnadcet sudice dvojnast narod żidovsky

29. a prokn1 ktoz ostav1 dóm nebo sestry otcè mateř

zenu dědiny pro mé jmè

sto člest 1 viec vezmete a život věny dìijmete

CXXXV.: $W$ ] deest $A, C, D, S, R$

CXXXVI. S. Jacobi Apostoli - Mt 12,46-50

46. $V$ onom casi

Mluviěe Ježı k sboróm /

W $42 b$

ez matka jeho a bratrie stáchu chtiece mluviti k nèmu

47. Tehdy mu jeden povèdé

Ez matka tva a bratíle tvá stojl chtiece mluviti s tobu

48. Tehdy on vece

ké jest matka má a ké sư bratrie má

49. A ztáhna ruku na ucenniky své 1 povědè

Ež matka má a bratíle má

50. a ktor koli tučini vóli otcě mého jenż jest na nebesich

ten jest mój bratr 1 sestra 1 matka jest

CXXXVI.: $W]$ deest $A, C, D, S, R$

50. *uxini (vozynye ms.). 
W $42 b-43 a$ Lectio L 7,36-50 vide CIX. Feria VI. IV temporum sept.

CXXXVII. In Assumptione B. Mariae Virg. - L 10,38-42

W $43 a$

38. $\mathrm{V}$ onom ¿asi

v̧̌el Jež́s v jeden hrádek

a Žena jedna pìije jej v dóm svój jménem Marta

39. a bieše jeji sestra jménem Maria

jez také sediese podlé noh Bożch posluchajlce slova jeho

40. ale Marta oracovăse o ob(v)ětšenéj službě

Jez stanúci i vecé

Hospodine nenie tobě péč že sestra má ostavila mĕ samu sluziti

proto jiej pověz at' mi pomáhá

41. Tehdy pověde jiej Hospodin

Marta Marta teskliva jsi a mútís sé pro mnoho

42. proto jednoho jest potłěba

Maria lepś ‘iest vzvolila jenž ot nie nebude otjata

CXXXVII.: $W$ ] deest $A, C, D, S, R$

CXXXVIII. S. Augustini - Mt 5,13-16

13. V onom Casi

Pravil Jezís svým mladxím /

W $43 b$

vy jste suol zemé

...v Xem osolé

$k$ ni xemuz nebude potom jedno aby ven vymetali a lidmi potlacili

14. vy ste suětlost suětská

Nemóz na hož mexsto postavené schováno býti

15. Ani světlo zažhúce pod kád' Dostavie

Ale na sviecen

aby *svietilo tym jesto $v$ domu su

16. Takê̌ vaše světlo svět'

aby vaš dobrá diela vidúce

chvalu otcě vašeho jenž na nebi jest

CXXXVIII.: $W]$ deest $A, C, D, S, R$

13. Quod si sal evanuerit vulgata) om.ms. - 15. *svietilo (-tyelo ms. 
CXXXIX. In decollatione S. Joannis Bapt. - Mc 6,17-29

17. V onom Casi

Poslal Herodes 1 jal Jana $i$ pustil ho $v$ zalá

pro Herodiadem svého bratra ženu Filipovu jiz biese pojal

18. Nebo diese Jan

Nelzet' jest jmieti zeny bratra tvého

19. Tehdy Herodias nepłej 1 Ke mu i chtiese tajnè zablti ho a nemožiese

20. Ale Herodes báse sè Jana

*vèda jej pravého i svatého

i chovase ho

a rád poslúchăe ho

21. A *kdyz *bezdexny den príde

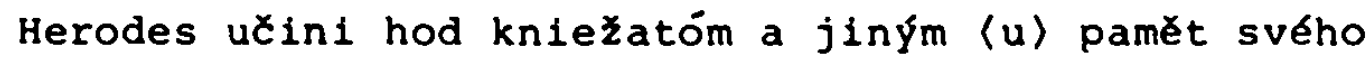
narozenie

22. A kdy̌̃ vnide dci té Herodiadis 1 metáse sè

*otcu i vserm kvasanóm

král vecé

pros na mnè co hces dám tober

23. i pł́iseže jakz chces li puol mého králoustuie

24. Kdy̌ vynide pověde materi

co uprosi

vece jiej

hlavu Janovu

25. A kdy unide inhed poce rự prositi hlavy svatého Jana u krále řkúci

Daj mi hlavu Janovu chci jej

26. leče se král pro pł́sahu 1 pro hostě nerode ji smititi

w $44 a$ 27. Ale poslav (kata) káza pł́inésti hlavu // jeho na okfine

1 stè hlavu jeho v zalári

28. 1 *pł́lnese hlavu jeho

1 da ji dievcé

a dievka da matełi svéj

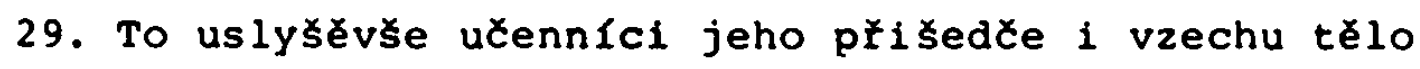
jeho 1 poloziechu to $v$ novém hrobu

CXXXIX.: $W$ ] deest $A, C, D, S, R$ 
20. *věda (weyda ms.) - 21. *kdyz *bezděxny (kazdy bezdyczny ms.) 22. *otcu (otyzu ms.) - 28. *ołinese (przyne§ty ms.).

CXL. In Nativitate B. Mariae Virg. - Mt 1,1-16

1. $\langle K\rangle$ nihy porozenie Jezu Krista syna Davidova syna Abrahamova

2. Abraham porodil Izaak

Izaak porodil Jakuba

Jakub porodil Judam a bratra jeho

3. Judas porodil Fares a Zaram z Tamar

Fares porodil Ezrom

Ezrom porodil Aram

4. Aram porodil Aminadab

Aminadab porodil Naason

Naason porodil Salmon

5. Salmon porodil Booz

Booz porodil Obeth de Ruth

Obeth porodil Jesse

Jesse porodil Davida krále

6. David kral porodil Salomona $z$ té jesto byla Urie

7. Salomon porodil Roboam

Roboam porodil Abiam

Abias porodil Asa

8. Asa porodil Jozefath

Joza porodil Joram

Jora porodil Dziam

9. Ozias porodil Jotam

Jotam porodil Akaz

Akaz porodil Ezechiam

10. Ezechias porodil Manasen

Manases porodil Amon

Amon porodil Jozlam

11. Jozlas porodil Jekoniam a bratł 1 jeho na prénesenie Babylona

12. A po "płénesení Babylona

Jekonias porodil Salatiel

Salatiel porodil zorobabel

13. Zorobabel porodil Ablud

Abiud porodil Ellachim 
Eliachim porodil Azor

14. Azor porodil Sadoch

Sadoch porodil Achim

Achim porodil Eleazar

15. Eleazar porodil Mathan

Mathan porodil Jakuba

W $44 b$

16. Jakub / porodil Jozefa muže Marie $z$ niežto narodil sè Jež́s jenz slóve Kristus

CXL.: W] deest $A, C, D, S, R$

12. "prèneseñ (przyne§§enye ms.).

CXLI. In Exaltatione S. Crucis - J12,32-36

32. $\mathrm{V}$ onom Casi

Pověděl Ježrs učennikóm svým

Já budu li povy̧̧en od zeme všecko vezmu sám k sobè

33. Ale tot' pravise znamenávaje kteru by smrti umǐl

34. o tomto jemu sboy

My sme slyšeli že Buoh věxnè je a v zákonè

A kako ty pravis musím povýsiti clovecieho syna

Kto je to syn cloverr

35. Tehdy jemu povède Ježr

Jesce málo suětla más

Chod'te dokad suétlo máte a vás tma nezviže

Kto *chodl ve tme nevi kam jlti

36. Donidz suêtlo máte věrte $v$ suêtlost abyste suětlosti synové byli

CXLI.: W] deest $A, C, D, S, R$

- - - - - - - - - -

35. *chodr (chodye ms.).

CXLII. S. Matthaei Ap. - Mt $9,9-13$

9. V onom Casi

Kdyžto *Ježř chodiese

vidè clověka sediece jménem Matự na "mýtě

$i$ vece mu pod' po mne

a vstana jide za nIm

10. I sta se kdyz j(e)diese (v) domu 


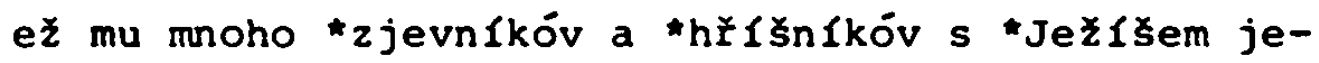
diese i s uxenniky

11. viduce to zákonnici povědiechu mladex́m jeho

prođ s hřiešnými a s vypovĕdlniky jl a Die mistr vás

12. Tehdy Ježs uslysav to vecé jim

Nenie ponacin zdravému lékał̌e Ale nemocnému

13. Ale sedce uctež co milosrdie chté a ne obet nebo neprišel sem pozvati pravých ale hr̈iešných //

CXLII.: $W$ ] deest $A, C, D, S, R$

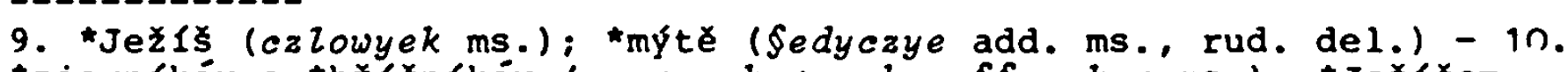

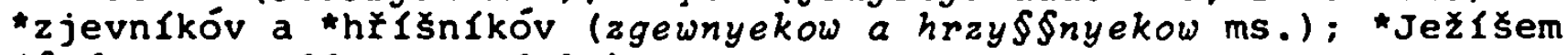
(Sedyeczye add. ms., del.).

CXLIII. In dedicatione $S$. Michaelis Archangeli Mt 18, 1-10

W 45a 1. V onom ¿asi

Pristúpili k Jež́šovi ucennici tiežlce ho

Kto sè zdá věcšl $v$ nebeském *královstur

2. I pozva Jež́s mládencè i dostavi mezi nimi 3 . i vecè Jesce pravi vám

Jedno obrátite $1 i$ sè a budete jako mládencek tento nevejdete $\mathbf{v}$ královstuie nebeské

4. Ktoz koli ponlzi se jako diete toto

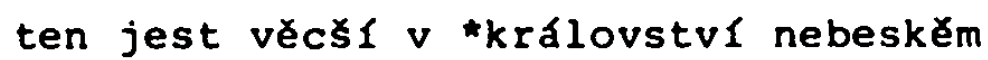

5. a kto prijime tohto mládencè $u$ mé jmè mĕ pĭijimá

6. Ale kto oblúal jednoho $z$ těchto mládencóv jesto u mé věrie

Hodno jest aby *pověsena byla đělist osliðina na jeho sıji

a potopen byl $v$ hlubokém mołi

7. hơ̌e suětu cistému ot přxlšxenie potřéba jest také aby prisila přxlustua

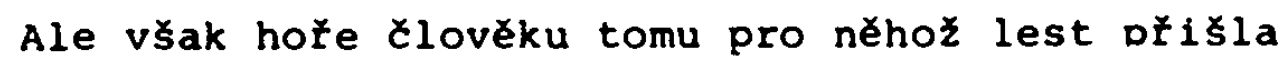

8. pakli ruka nebo noha tva té tiri umi ji povrz ot tebe *dobro ti jest tobé belhavu nebo chromu unfti v zivot než dvè rucè nebo dvè (nozè) jmajlce pušenu býti u plamen věñ

9. Pakli oko tvé té pł̌̉lšije vynmi je a povrz od sebe 
lépet' jest tobé jedno oko majlce vnfti v żivot než s oběma vnfti $v$ oheň

10. vizte abyste nepotupili ijednoho těch mládencóv Nebo pravi vám že anděli jich vidie vezdy oblicéj otcè mého jenž na nebi jest

CXLIII.: $W$ ] deest $A, C, D, S, R$

1..4. *královstul (kralow§twye ms.) - 6. *pověsena (powy§§ena ns.)

- 8. *dobro (dobra ms.).

CXLIV. S. Lucae Evange Listae - L 10,1-7

1. V onom ¿asi

Znamenal Hospodin i jiných sedmdesát abostolóv a dva

W $45 b$

i poslal je / př̀d sobu po dvu

jamže jlti jemu bieše ve vక̌ mèsta

2. 1 vecĕ jim

žeñ veliká jest ale * dělnfkóv skrovnè

protož proste u Pána té żni aby pustil żencè na suú žeñ

3. Děte ež já vy šli jako beránky mezi vlky

4. a já zapovidaji vám nésti ani miška ani tobolicè ani obuvi

ani komu po cèstè vitěl dajte

5. a v kterýz dóm vejdete

Najprvé rcète mier domu tomuto

6. a bude $1 i$ tu syn pokojný otbočine na něm pokoj vás Pakli nenie $k$ vám sè vrát 1

7. a $v$ tom domu bydlete jedlce a pijlce to což u nich jest Nebo jest dóstojen dělnlk mýta svého

CXLIV.: W] deest $A, C, D, S, R$ 2. *délnikóv (dyelnyekow ms.).

CXLV. Ss. Simonis et Judae App. - J 15,17-25

17. $V$ onom Cas1

Pověděl Jež́s učennIkóm svým

To vám ^přikazuji abyste milovali spolek 
18. ał vás suět nenávidr to vězte žet' mne prvé v nenávist mèl

19. Byste suěta byli suět což jeho miloval by

Ale *že suěta nejste

proto nenávidi vás suét

20. pomnete slovo mé *jez povèaéch vám

*nenie sluha věcšl pána svého

Jsú lit' mnè lest ư̌inili 1 vámt' učinie

Jsu lit' mé slovo schovali i vaset' schovaj 1

21. Ale to vem vše učinie pro mé jmé

Nebo nevědie ho *kto mě jest poslal

22. A bych nepr̈isel a jim nemluvil hr̈iechu bv neměli

23. ...

24. ...

Ale viděli i nenávidéli sú me 1 otcè mého

25. Ale aby naplněno bylo kázanie *jež v zákonè psáno jest

* Nebo $v$ nenávisti mẻli ste mè darmo //

CXLV.: W] deest $A, C, D, S, R$

17. "płikazuji (przy rub. superscr.) - 19. „že (ze rub. suderscr.) 20. *jez ( $n$ rub. superscr.); *nenie (nynye ms.) - 21. "kto me jest poslal (eras. ms.) - 22. nunc autem excusationem non habent de peccato suo vulgata] om. ms. - 23. om. ms. - 24. Si opera non fecissem in eis quae nemo alius fecit peccatum non haberent vulgata] om. ns. - 25. *jez (n rub. superscr.); *Nebo (eras.. m. rec. pthoz adscr.).

CXIVI. In festo Omnium Sanctorum - Mt 5, 1-12

W 46a 1. Viděv Jež́s zástupy jide na horu

A kdy̌ sediese płistúpichu $k$ nèmu mladé jeho

2. 1 otvoŕl sua ústa 1 ux̌r je je a łka

3. Blažení chudi duchem Nebo jich jest královstvie nebeské

4. Blažen I *ciš *nebo *budú vlásti *zemú

5. BlaženI jesto plaxi nebo oni utěseni budu

6. Blažen l lačn ́ nebo ż́nêvi zajisté nasyceni budu

7. Blaženi milosrdni nebo zajisté oni milosrdie dojdu

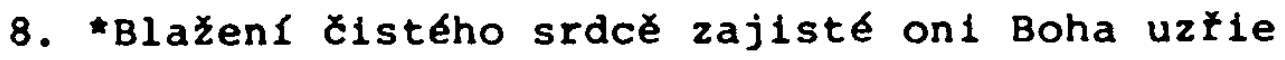

9. Blaženl pokojnl zajisté synové Božie nazváni budí

10. Blažení jesto *ruchanie a protivenstvie trol pro oraviu 
zajisté jich jest královstvie nebeské

11. Blaženi jste když vás *zlosti budu poddávati

*a vaše zlosti povědie na vy lžlce pro mè

12. radujte sè vo onen den a veselte sĕ nebo otplata vaš veliká jest na nebi

CXLVI.: W] deest $A, C, D, S, R$

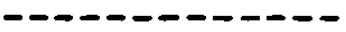

4. *cisl (eras., czy§§ij pokoin m. rec. adscr.); "nebo (gych add. ms. eras.); *budu (m. rec. adscr.); „zemu (zemuu ms., uu eras. et $\ddot{y}$ adscr.) - 6. *lačn 1 (Laczny a ziznywye ms., eras.) - 8. *Blažen1 (Blazenye ms.) - 10. *ruchanie a protivenstvie trol (anye a ptiwe $\bar{e}$ trpy in rasura $\mathrm{m}$. rec.) - 11. *zlosti budú poddávati (eras.); *a vaš̉ zlosti povědie na vy lžlce (del., zlorzeciczi budu m.rec.mg.).

Lectio L 19,1-10 vide CXIX. In dedicatione ecclesiae

CXLVII. In vigilia Apostolorum - J15,12-16

W $46 \mathrm{~b}$

12. V onom Casi

Pověděl Ježls uxennIkóm svým

To jest mé kázanie abyste milovali se jakož sem miloval vy

13. *věcsile to milost ijeden *nemá aby kto posadil dusi svú za píátely své

14. vy ste moji píltelé AC uCinfte to co píikazuji vám

15. jiz vás nenazovu panosexmi

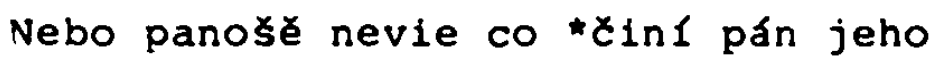

Ale vy nazval prátely

nebo v̌̌e což sem slyšal ot ntcè mého zjevil sem vám

16. Ne vy jste mne zvolili ale jáz sem vy volil

1 postavil sem vy aby sli a uzitek ostal

a byste co koli prosili otcè u mé jmĕ dá vem

CXLVII.: W] deest $A, C, D, S, R$

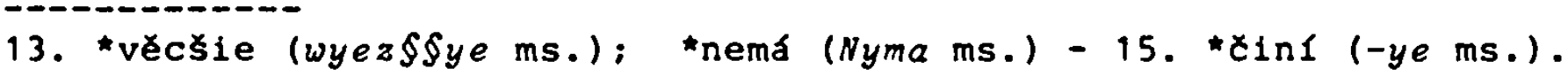

CXLVIII. Commune unius martyris - Mt 16,24-28

24. V onom Cas 1

Pověděl Jež́s učennIkóm svým

kto chce po mnè jlti otpověz sè sám sebe 
nasledujz mne

25. Nebo kto bude chtieti svu dusi schovati ztrati ji

W 47a

A kto // ztrati sví dusi pro mĕ nalezne $j i$

26. Nebo co probude ¿lověku ą zí̌̌e ves svět

a svéj dusi ujjmu *ðin

Nebo kterú Ølověk dă otměnu za duši sví

27. zajisté syn chověx pưijlti jmá v chvále otcovĕ s andèly svými

a tehdy dá otplatu každému podlé jeho cinóv

28. zajisté pravím vám

ze su tuto někteł̌l

jez neokusi smrti don̆udz neuzŕie Syna clověcieho oł́ichodlce $v$ svém *královstul

CXLVIII.: W] deest A, C, D, S, R

26. *cinf (-ye ms.) - 28. *královstvi (-ye ms.).

CXLIX. Commune plurimorum martyrum ? - Mt 10,16-22

16. V onom ¿asi

pověděl Ježrs mladðı́m svým

Ez já vy sli jako ovcè mezi vlky

Bud'te proto mudir jako hadové

a sprostnl jako holube

17. Ale chovajte se ot lidi

Nebo zradie vy na *sněmiech

$a{ }^{*} u$ modlách bicovati budu vy $v$ svych

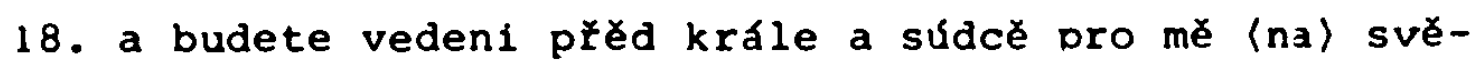
decstvie jim a lidu

19. A kdyz vy proradie

nerod'te mysliti co nebo kako by mluvil

Nebo vem dadie $v$ ten Cas co budete mluviti

20. nebo nejste vy jez mluviete

Ale Duch otcè vałeho jenż u vás smluví

21. A také *radi bratr bratra

a otec syna

1 vstanu synové protiv rodinè a usmrtie je

22. i budete $v$ nenávist vłèm oro mé jmè

Ale kto ustavi ̌en bude do skončenie ten spasen bude 
CXLIX.: W] deest $A, C, D, S, R$

17. *snëmiech (\$Senmyech ms.); *u (y ms.) - 21.*zradl (-ye ms.).

CL. Commune unius martyris - L 14,26-33

26. $V$ onom Casi

Povědẻl Ježis uxennikóm svým

AC kto jde ke mnè

W $47 \mathrm{~b}$

a nenávidie otcè suého a matky / 1 bratrie 1 sestry

1 také duše své

nenie mne dóstojen

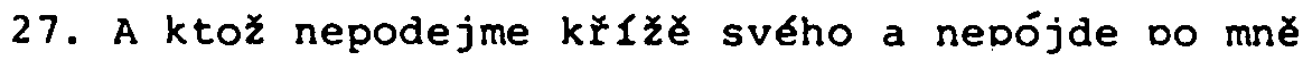
nemóz býti mój mlader

28. Nebo kterýz mezi vámi chtè *vězi staviti

a neprèmysli pokladu dřieve

jme〈l〉 $1 i$ by doskonceti

29. Ne aby založ potom nemohl dospěti

Aby ktoż by vidẻli jemu sè neposmievali 30. a łkúce

Ze tento *založiv základ i nemohl doskončti

31. Nebo který král na vojnu jda 1 pŕlda ku boji proti

jinému

nepomysli sada král

Móż li deseti tislcóv podstúpiti jenž $k$ ñemu $z$ dvanádcèti tánne tislcóv

32. nen 11 toho ale posle $z$ daleka jeste jsa a *oros 1 pokojè u nèho

33. Protoz každý takéz mezi vámi ktož sè neotpovie v̧̌eho jez vládne

nemóž býti mój mladé

CL.: W] deest $A, C, D, S, R$

28. *věz: (wyeray ms.) - 30. *založiv (zaloznu ms.) - 31.*orosi $(-$ ye ms.).

CLI. Commune plurimorum martyrum - L 21,9-14

9. V onom Casi

Kdyžto uslyşte boje a sedánie nelekajte se

Nebo mus1 to pocatek býti Ale ne inhed skonánie

10. Tehdy pravise jim 
Vstane lid proti lidu

a král proti králi

11. a zemè płèzèsti budú (u) vlastech

a mor hlad i nápasti $z$ nebe a znamenie veliká budú

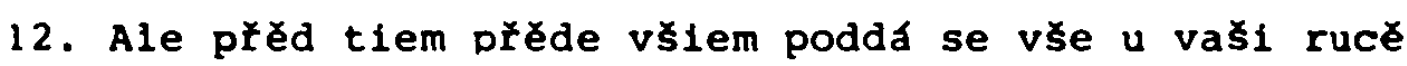
a nevěrně a lstivĕ

táhnúce *u modly táhnúce ờed krále a v strá̉è pł̌ed krále a vladał̌ 1 popravce pro mé jmè

13. přihodl sě také vám na svêdèstuie

W 48a 14. Proto nerod'te $v$ srdclch vzpominati // kak budete otpovidat 1

CLI.:W] deest $A, C, D, S, R$

12. *u (y ms.).

CLII. Commune confessoris pontificis - Mc 13,33-3?

33. $V$ onom Casi

Pověděl Ježı̌ ucennIkóm svým

hlédajte a nesperte a modlte sè

nebo neviete kdy bude cas

34. jako Łlověk jenž na put otejde ostavi dóm svój panosiem

i dá jim svú moc nade v̧̌e łemeslo

a vrátnému płikáe aby bděl a ponocoval

35. Ponocujte proto

nebo neviete kdyzto pł́lde pán domový

pł́lde pozdé neb u púlnocl nebo $v$ kury nebo ráno

36. Ne aby unáhle pł́lda nalez ny spiecie

37. a coł vám pravi všem pravi délajte oroł spiete modlte sé a ponocujte

CLII.: W] deest A, C, D, S, R

CLIII. Commune confessoris pontificis - L 11,33-36

33. V onom casi

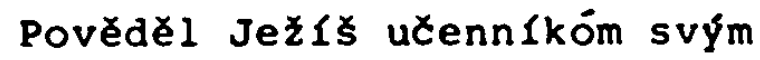

Nepostavi nikte suětla zažha v zákưtni

ani pod kad's 
ale na svicnè

aby kto vejdu suetlo videxli

34. Svètlost zivota tvého jest oko tvé

Bude li oko tvé tiché vše têlo tvé svètlé bude

Pakl1 bude neslechetné také tvé tẻlo vse temné bude

35. hlédajz proto suetlo jez $v$ tobe jest aby tma nebyla

36. Pakli tué tělo bude vse světlê nejmaje ijednéj cies-

ti temné

bude vse světlo

a jako svêtlo blýskavičné osviet tex

CLIII.: $W]$ deest $A, C, D, S, R$

CLIV. Commune virginum - Mt 25,1-13

1. V onom Casi

Pověděl Ježrs učennikóm svým pověst tuto

přijednává sě královstuie nebeské desiti ^děvicím /

W $48 b$ jež vezmúce lampy své vyక̌ly protiv ženichovi vstrueci

a nevěstè

2. Ale pět mezi nimi biese nesmyslných a pět múdrých

3. Ale pet nemudrých vzemse lampy nevzechu oleje 〈s〉 sobis

4. ale mudrých pět vzemse oleje $v$ sưdciech 1 lampy

5. otpoxivajice そenicha driemaly

6. Tehdy o puolnoci kryk veliky uciňen

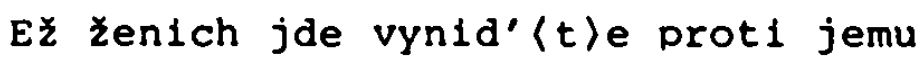

7. Tehdy vstachu v̌̌e ony dêvice

i nalichu oleje $v$ své lampy

Tehdy nedosta sè nemúdrým

8. Pověděchu

dajte nám oleję vašeho

nebo lampy nase hasnu

9. Odpověděchu múdré a ŕkúce

A snad se nedostane nám 1 vám

jdexte brzo do kupcóv a kupte sober

10. Tehdy kdyzto pójdu kupovat prijide żenich

a jezto hotovy biechu vnidu s nim

1 zaviechu vrata

11. Najpotom také pr̆fdú obmełkalé děvicè a oravíce 
Pane pane otevĭi nám

12. Tehdy on otpověder

věrnè jistě pravi vám nevěde vás

13. bdète toho dle nebo nevite dne ani hodiny

CLIV.: W] deest $A, C, D, S, R$

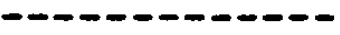

1. đěvicím (dyewyeczym ms.).

CLV. Commune plurimorum virginum martyrum - Mt 13,44-52

44. V onom Casi

Pověděl Ježlక uXennikóm svým pověst tuto

Rovno jest královstvo nebeské sbožl schovanému v zemi

jez kto nalezne clověk

jỏe prodá vకe což má 1 kự pol pole to

45. Opět rovno jest královstvo nebeské člověku kupcovému jenž hledá dobrého kamenie

46. Tehdy nalezna jeden

jâa prodá vše což má 1 kúpl jej

W $49 a$

47. A znova rovno jest // královstvo nebeské vrši dušenéj u moł̌e a všemu rybnému rodu sebranému

48. A kdyzto naplněna biese vytáhše a podlé bł̌nha sediece vybrachu dobré $v$ své sudy

Ale coz zlého ven vymetachu

49. Takéz bude na skon ̌enie světa vyndúce andêli 1 vymecr *zlé nalezníce mezi dobrými

50. 1 pustie $v$ nIstéji onñem pláoolnú tu bude plac a skǐhot zubuom

51. *urozumêli ste vsemu tomu pravie jemu ovsem Hospodine

52. povědě jim

proto každý plsał věhlasny $v$ nebeském královs:vè roven jest otci celedniemu jeł pronosi poklad svój nový 1 vetchy

CLV.: W] deest A, C, D, S, R

49. *zlé (in rasuram. rec. scripsit) - 51. *urozuméli (rub. m. rec. $\mathrm{mg}$. wecze gezy\$\$ oraem.). 
ClVI. S. Bartholomaei Apostoli - L 22, 24-30

24. V onom Cas 1

Sta sĕ pohadka mezi mladémi Bož́mi kto by $z$ nich věter by $l$

25. Tehdy jim vecè Ježrs

kralové pohanšr panujr jim

a *kto moc má nad nimi uřednici slovú

26. Ale vy ne tak

Ale kto věcšl jest bud' jako mladeı

a kto přèni bud' jako služebny

27. Nebo kto věcšl jest

jenzto sluzi nebo *jenz sed 1

já jsem mezi vámi jako jenż sluzi

28. Ale vy ste jesce se mnu ostali u mém ^pokusen

29. a já vám jednaji jakoz ujednal mnè otec mój královstvo

30. aby jedli a pili na mém stole u mém královstuě

a sedéli na dvínadcet stoliciech a súdice dvojnadcet národ zidovský

CLVI.: W] deest $A, C, D, S, R$

- - - - - - - - - -

25. *kio moc má ( $k$ tomu moc mam ms.) - 27. *jenz (ge§t ms.) - 28 . *pokusens (poku\$\$yenye ms.).

CLVII. S. Laurentii martyris - J12,21-26

W $49 b$

24. V onom Casi

Povědě Ježiš uðennikóm svým

zajisté cèle pravi vám

jedno ac zrno upadna $v$ zemu umrlo bude 25. jinak

samo ostane

Pakli umře veliký užitek ořinese

Kto miluje duši svu ztrati ji

A kto nenávidr duše sué na tomto suêter

na vě̉ny zi ivot schová ji

26. Ktož mně služ po mně jde

a kdež sem já tudieź služebnik mój bude

Bude 11 mně kto sluziti pocti jej otec mój·jenż jest na nebesiech

CLVII.: W] deest $A, C, D, S$, in $R$ vide LXV. J 12,1-36 26. na nebesiech] expl. W. 
14.1. Synopis der Texte

Anm.: Die fetten Ziffem bezeichnen die Folia des edierten inmatextes, die kursiven die Folia der Variantentexte.

A

I. Daminica I. in adventu

II. Domin. II. in adventu

III. Dam. III. in actventu

at 21,1-9

L $21,25-33$

IV. Feria IV. in IV termo.

L 1,26-38

V. Feria VI, in IV temporum

L 1,39-47

VI. Sabbato in IV temporum

VII. Dam. IV. in adventu $\mathrm{J} 1,19-28$

VIII. In vigilia Nativ.Damini ift 1,18-21

IX. Nativ. Dam. missa I.

L $2,1-14$

X. Nativ. Dam. missa II.

L 2,15-20

XI. Nativ. Dam. missa III. J 1,1-14

XII. In die

S. Stephani it 23,34-39

XIII. In die $s$. Johannis

J 21,19-24

XIV. In die

Innocentium vit 2,13-18

XV. Dam. infra

ot.Nat.Dam. I 2,33-40

XVI. In vigilia Exiphaniae

XVII. In

Eplphania Nt 2,1-12

XVIII. In octava

Epiphaniae at 3,13-17

XIX. Dom. I.post

Epiphaniam L 2,42-52

XX. Domin. II . post Epiph. J 2,1-11
C

D

$\mathbf{S}$

R

w

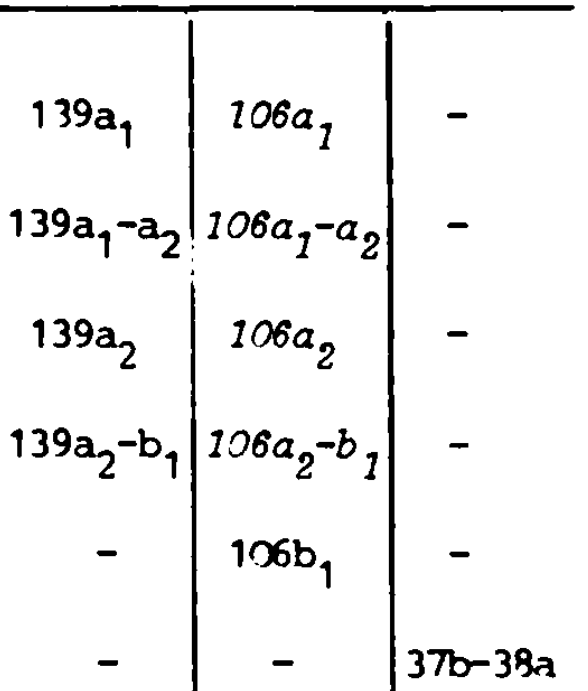

$$
139
$$

$-\quad$\begin{tabular}{c|c}
$139 b_{2}-$ & 1 \\
$14 m_{1}$ & $106 b_{2}$
\end{tabular} \mid$=$

$-\quad 1 a_{1}$

1395

$106 b_{2}-$

$107 a_{1}$

$-\quad 1 a_{1}$

$142 a$

$-\quad 1 a_{1}-a_{2}$

$140 a_{1}-a_{2}$

$107 a_{1}$

$\mathrm{a}_{1}-\mathrm{a}_{2}$

$1 a_{2}$

$1 a_{1}-b_{1}$

$140 a_{2}$

$140 a_{2}-b_{1}$

$107 a_{2}$

$1 b_{1}$

$1 b_{1}-b_{2}$

$1 b_{2}$

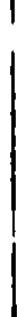

1406

$14 a_{1}-b_{2} \quad 107 b_{1}$

$140 b_{2} 107 b_{2}$

$140 b_{2}-107 b_{2}-$

$1 b$

$1 b_{2}$

\begin{tabular}{c|c}
$141 a_{1}$ & $108 a_{1}$ \\
$141 a_{1}-a_{2}$ & $108 a_{1}$ \\
$141 a_{2}$ & $108 a_{1}-a_{2}$ \\
$141 a_{2}-b_{1}$ & $108 a_{2}$
\end{tabular}

$1 b-2 a$

$1 a-1 b$

$1 a$

$2 a-2 b$ 
A

C

D

S

$\mathbf{R}$ W

XXI. Dom. III. post Epiph. ":tt 8,1-13 XXII. Dom. IV. post Epiph. Mt 8,23-27 XXIII. Dom. V. post Epiph. Mc 3,1-5 XXIV. Dom. in Septuagesima ift 20,1-16 $X X V$. Dom. in Sexagesima L $8,4-15$ XXVI. Dom. in Quinquages. L 18,31-43 XXVII. Feria IV. Cinerum Mt $6,16-21$ XXVIII. Feria VI .:Vt 5,43-4 post Quing. Mt 6,1-4 XXIX. Sabbato post Quinq. Mc 6,47-56 $X X X$. Domin. I. in Quadragesima Nt 4,1-11 XXXXI. Feria II.

post Dom. I. Mt 25,31-46 XXXII. Feria III. post Dom. I. Mt $21,10-17$ XXXIII. Feria IV. post Dom.I. Vit 12,38-50 XXXIV. Feria $V$. post Dom. I. J 8,31-47 XXV. Feria VI. post Dom.I. J 5,1-15 XXXVI. Sabbato post Dom.I. Nt 17,1-9 XXXVII . Dom. II .

in Quadr. Nt 15,21-28 XXXVIII. Fer.II. post Dom.II. J 8,21-29 XXXIX. Feria III.

post Dam.II. ' it 23,1-12

XL. Feria IV. post Dom. II. in puadr. Mt 20,17-28 XII. Feria V. post Dom. II. J 5,30-47 XLII. Feria VI.

post Dom. II.Mt 21,33-46 XIIII. Domin. I II. in Quadrag. L 11, 14-28

$2 a^{\circ}-2 b^{\circ}$ $2 a$

$2 b$

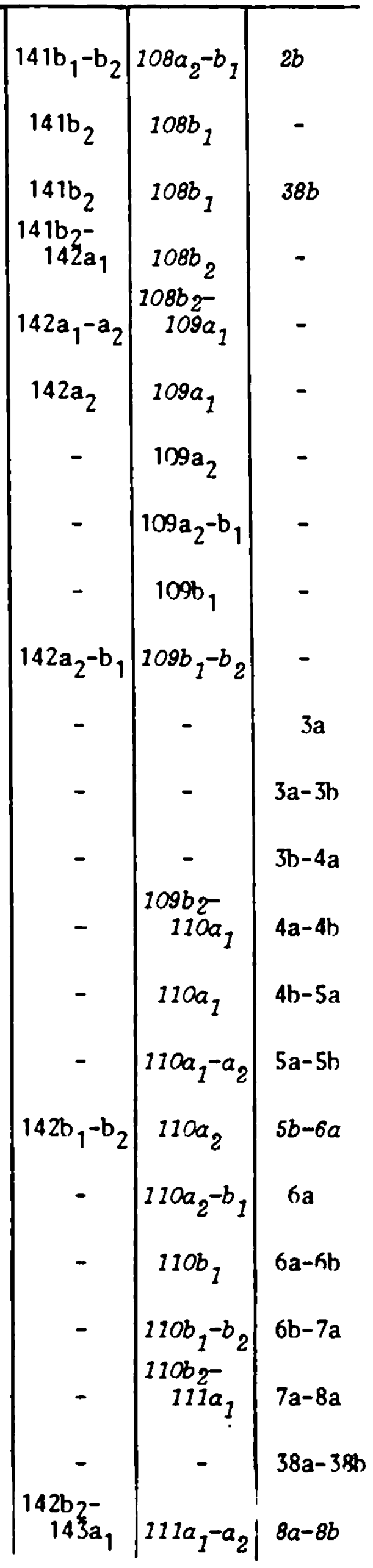


A

C

D

S

R

W

XLIV.Fer.II.post

Dom. III.

L 4, 23-30

XlV. Fer. III.post

Dan.III. Vt 18,15-22

XLVI. Fer. IV.post

Dam. III. Mt 15,1-20

XLVII. Fer.V. post

Don. III. J 6,27-35

XIVIII.Fer.VI . post

Dan. III. J 4,5-42

XIIX. Sabbato post

Dam. III. J 8,1-11

L. Daminica IV. in

Quadragesima J 6,1-14

LI . Feria II.post

Dom. IV.

J 2,13-25

LII. Fer. III . post

Don. IV.

$\mathrm{J}$ 7, 14-31

LIII. Fer. IV.post

Dom. IV. J 9,1-38

LIV. Feria V.post

Dom. IV.

J 5, 17-29

LV. Fer.VI . post

Dam. IV.

J 11,1-45

LVI. Sabbato post

Dom. IV.

J 8,12-20

LVII. Dominica V.

in Quadrages. $\mathrm{J} 8,46-59$

LVIII. Feria II.post

Dom. V.

J 7, 32-39

LIX. Feria III.post

Dan.V.

LX. Feria IV.post

Dam. V.

J $10,22-38$

LXI. Feria $V$. post Dom. $V$.

$\mathrm{J} 7,40-53$

LXII. Fer. VI .post

Dom. V. J 11,47-54

LXIII. Sabbato post

Dom. V.

J 17,1-11

LXIV. Dominica in

Palmis J 17,11-26

LXV. Fer.II.post

Dom.in Pal. J 12,1-36

LXVI.Fer.V.in Coena

Domini

J $13,1-15$

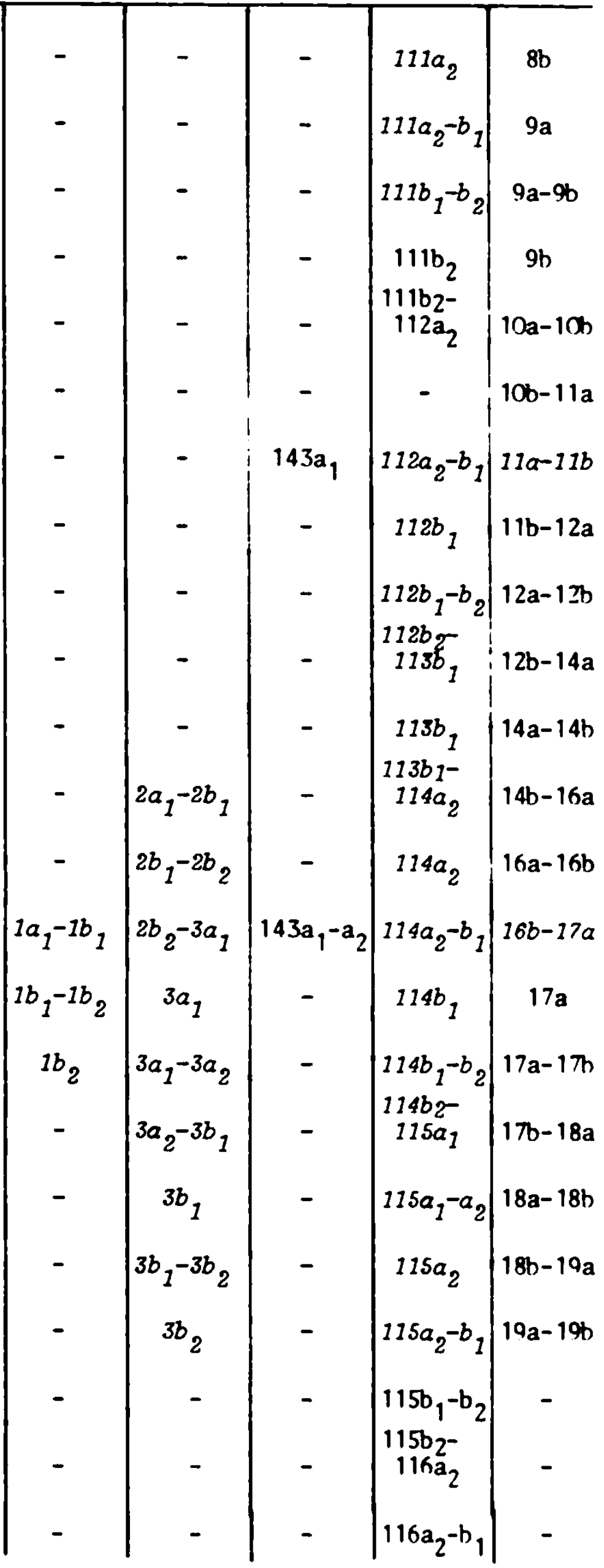


A

C.

D

$\mathrm{S}$ R W

LXVII. Feria VI.in

Parasceve $J$ 19,15-42

LXVIII. In vigilia

Paschae Yit 28,1-7

LXIX. In festo

Paschae Vc 16,1-7

LXX. Feria II.

Paschae

L $24,13-35$

LXXXI. Feria III.

Paschae

L $24,36-47$

LXXI I. Feria IV.

Paschae

J 21,1-14

LXXIII. Feria V.

Paschae

J 20,11-18

LXXIV. Feria VI.

Paschae Vit 28,16-20

LXXV. Sabbato post

Pascha

J $20,1-9$

LXXVI. Domin. in octa-

va Paschae $J 20,19-31$

LXXVI I . Dom. II . post

Pascha

J 10,11-16

LXXVI I I . Dom. I I I . post

Pascha

J $16,16-22$

LXXIX. Dom. IV. Dost

Pascha

J 16,5-14

LXXXX. Dom.V. post

Pascha

J $16,23-30$

LXXXI. In diebus

rogationum L 11,5-13

LXXXII. In Ascensione

Domini Nk 16,14-20

LXXXIII. Dom. post J 15,26-

Asc. Dom. 27, 16,1-4

LXXXIV.Sabbato in vigilia

Pentecostes J 14,15-21

LXXXV. Dominica

Pentecostes J 14,23-31

LXXXVI. Feria II .Dost

Pentecosten $\mathrm{J} 3,16-21$

LXXOVII . Feria III.post

Pentecosten $\mathrm{J} 10,1-10$

LXXXVIII. Feria IV.post

Pentecosten J 6,44-52

LXOXIX. Feria V.post

Pentecosten

L $9,1-6$

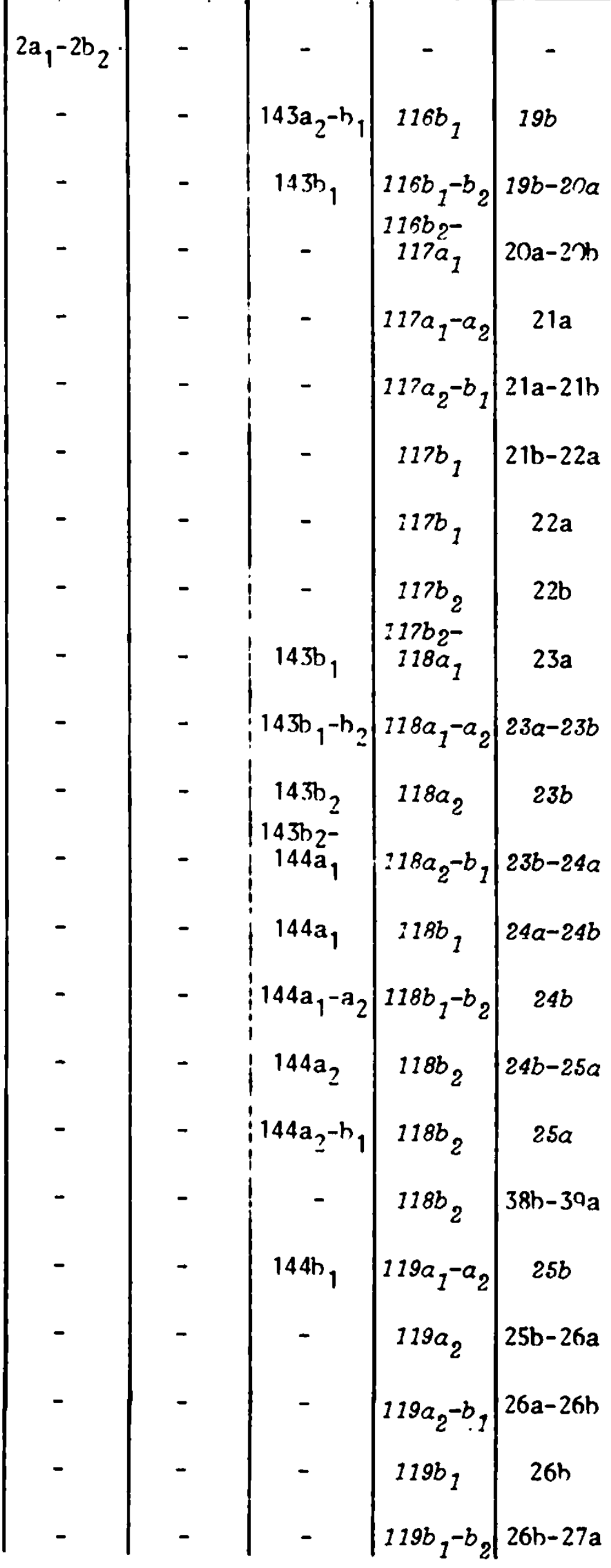


A

C

D

$\mathrm{S}$

R

W

XC. Feria VI. post

Pentecosten L 5, 17-26

XCI. Domin. I.post

Pentecost. L 16, 19-31

XCII. Corporis

Christi J 6,56-59

XCI I I . Domin. I I . post

Pentecost. L 14, 16-24

XCIV. Domin. III post

Pentecost. L 15,1-10

XCV. Domin. IV.post

Pentecost. L 6,36-42

XCVI. Domin.V.post

Pentecost. L 5,1-11

XCVII . Domin.VI . post

Pentec. If 5,20-24

XCVIII . Domin. VII . post

Pentec.

VC 8,1-9

XCIX. Domin. VI II . post

Pentec. Ift 7,15-21

C. Domin. IX.post

Pentec. L 16,1-9

CI. Domin. $X$. post

Pentec. L 19,41-47

CII. Domin.XI.post

Pentec.

L $18,9-14$

CIII. Domin.XII . post

Pentec. Mc 7,31-37

CIV. Domin.XIII . post

Pentec. L 10,23-37

CV. Domin. XW.post

Pentec. L 17,11-19

CVI. Domin. XV.post

Pentec. it 6,24-33

CVI I . Domin. XVI .post

Pentec.

L $7,11-16$

CVIII.Feria IV. Quat.

temp.sept. ik 9,16-28

CIX. Feria VI. Ruat.

temp.sept. L 7,36-50

CX. Sabbato Quat.

temp.sept. L 13,6-17

QXI . Domin.XVII post

Pentec.

L $14,1-11$

CXII. Domin.XVI II . post

Pentec. Mt 22,34-46

\begin{tabular}{|c|c|c|}
\hline - & $119 b_{2}$ & $27 a-27 b$ \\
\hline $144 b\}^{-b}$ & $120 a_{1}-a_{2}$ & $27 b-28 a$ \\
\hline - & $119 \mathrm{~b}$ & - \\
\hline $\begin{array}{r}144 b_{2}- \\
145 a_{1}\end{array}$ & $120 a_{2}$ & $28 a-28 b$ \\
\hline $145 a_{1}$ & $120 a$ & $28 b$ \\
\hline $145 a_{1}-$ & $120 b_{1}$ & $28 b-29 a$ \\
\hline $145 a_{2}-$ & $120 b_{1}-b_{2}$ & $29 a-29 b$ \\
\hline $145 b_{1}$ & $\begin{array}{r}120 b_{2-} \\
121 a_{1}\end{array}$ & $29 b-30 a$ \\
\hline $145 b_{1}$ & $121 a_{1}$ & $30 a$ \\
\hline $145 b_{1}$ & $121 a_{1}$ & $3 a a-30 b$ \\
\hline $145 b_{2}$ & $121 a_{2}$ & $30 b-31 a$ \\
\hline $\begin{array}{r}145 b_{2-} \\
146 a_{1}\end{array}$ & $121 a$ & $31 a$ \\
\hline $146 a_{1}$ & $121 b_{1}$ & $31 a-31 b$ \\
\hline $146 a$ & $121 b_{1}$ & $31 b$ \\
\hline $146 a_{2}$ & $\begin{array}{c}121 b_{2} \\
122 a_{1}\end{array}$ & $31 b-32 a$ \\
\hline $146 a$ & $122 a$ & $32 b$ \\
\hline $146 b_{1}$ & $122 a_{1}$ & $32 b-33 a$ \\
\hline $146 \mathrm{~b}$ & $122 a_{2}$ & $33 a-33 b$ \\
\hline - & $122 \mathrm{~b}_{1}$ & - \\
\hline - & $\begin{array}{l}123 a_{1} \\
12 a^{-}\end{array}$ & $42 b-43 a$ \\
\hline - & $123 a_{1}-a_{2}$ & $33 b-34 a$ \\
\hline $\begin{array}{r}146 \mathrm{~b}_{2}^{-} \\
147 \mathrm{a}_{1}\end{array}$ & $122 b$ & $34 a$ \\
\hline $147 a_{1}$ & $123 a_{2}-b_{1}$ & $34 b$ \\
\hline
\end{tabular}


A $C$

D

$\mathrm{S}$

R

$W$

CXIII. Domin.XIX.post

Pentec.

vit $9,1-8$

CXIV. Domin. XX.post

Pentec.

Mt 22,1-14

CXV. Domin. XXI .post

Pentec.

J 4,46-53

CXVI. Domin. XXII. post

Pentec.

vit 18,23-35

CXVII. Damin. XXI I I . post

Pentec. $\quad \mathrm{ftt}$ 22,15-21

CXVIII . Domin. XXIV.post

Pentec. Vt 9, 18-26

CXIX. In dedicatione

ecclesiae

CXX. De Sancto

Andrea

L $19,1-10$

CXXI. De Sancto

Vicolao

vit $4,18-22$

L $12,35-44$

CXXII. De Ss.Fabiani et

Sebastiani

L 6, 17-23

CXXIII. In Purificatione

B. Yariae

L 2,22-32

CXXIV. In vigilia $S$.

Matthiae vit 10,5-8

COXV. De Sancto

Matthia vt 11,25-30

CXXVI. Pro ordinandis

episcopis Mc 6,7-10

CXXVII. Commene plur.

martyrum L 21,14-19

CXXVIII.De Ap.Philippo et

Jacobo

J 14,1-13

CXXIX. De Inventione

S.Crucis J $3,1-15$

COXX. Pro sponso et

spansa Yt 19,3-11

CXXXI. In vig.S.Joannis

Bapt.

L $1,5-17$

CXOXII. De S. Joanne

Baptista L 1,57-68

CXXXIII. In vig.S.Petri

et Pauli J 21,15-19

COOXIV. Ss.Petri et Pauli

Apostolorum Yt 15, 13-19

COXXV. In commemoratione

S.Pauli Ap. 19,27-29

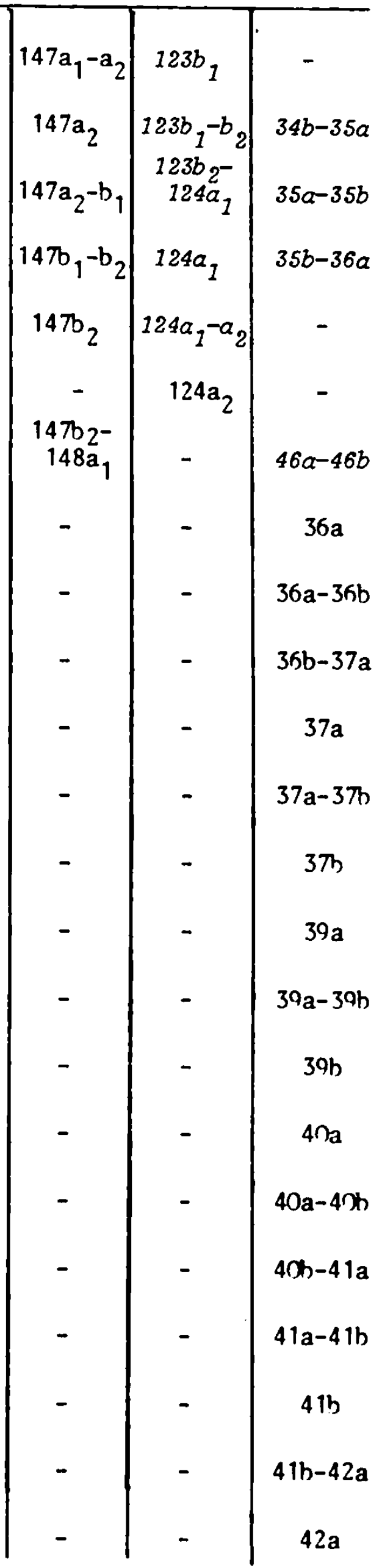




\section{Jacobi}

Apostoli Mt 12,46-50

CXOXVII. In Assumptione

B. Mariae L 10,38-42 CXOXIII. Sancti

Augustini ve 5,13-16 CXXXIX. In decollat.S.

Joan. Bapt. Yc 6,17-29

CXL. In nativitate

B. Mariae Vt 1,1-16

CXLI. In exaltatione

S. Crucis J 12,32-36

CXLII. S. Mat thaei

Apostoli V/t 9,9-13

CXIIII. In dedicatione

S.Michaeli vit 18,1-10

CXIIV. S. Lucae

Evangel.

L $10,1-7$

CXlV. Ss.Simonis et

Judae Ap. J 15, 17-25

CXLVI. Onnium

Sanctorum Yt 5,1-12

CXLVII. In vigiliis

Apostolorum J 15, 12-16

CXLVIII. Commune unius

martyris $\mathrm{Vtt} 16,24-28$

CXLIX. Comme plur.

martyrum vit 10,16-22

CL. Commune unius

martyris L 14,26-33

CLI. Commune plur.

martyrum L 21,9-14

CLII. Comme confes.

pontific. Mc 13,33-37

CLIII. Commme confes.

pontif.

L 11,33-36

QIV. Commune

virginum vt 25,1-13

CLV. Cormume plur virg.

martyrum vt 13,44-52

CIVI. S.Bartholonaei

Apost.

L 22, 24-30

CLVII. S. Laurentii

martyris $\mathrm{J} \mathrm{12,24-26}$

A

C

D

$\mathrm{S}$

R

W

$2 a-42 b$

$43 a$

$43 a-43 h$

$43 b-44 a$

$44 a-44 b$

$44 b$

$44 b$

$45 a$

$45 a-45 b$

$45 b$

$46 a$

$46 b$

$46 h-47 a$

$47 a$

$47 a-47 b$

$47 b-48 a$

$48 a$

$48 a$

$48 a-48 h$

$48 b-49 a$

$49 a$

49 
14.2. S y nopsis der p e riko o e n

Anm: Die fetten $Z$ iffern bezeichnen die Folia des edierten Grundtextes, die kursiven die Folia der Variantentexte, die römischen die Reihenfolge der Perikopen in der Edition (vgl. auch 14.1.).

Biblische Reihen-

\begin{tabular}{|c|c|c|c|c|c|c|c|c|}
\hline Stelle & folge & Seite & A & C & D & $S$ & $\mathrm{R}$ & W \\
\hline Nt $1,1-16$ & CXL. & 314 & - & - & - & - & - & $\sqrt{44 a-44 b}$ \\
\hline $18-21$ & IX. & 163 & - & - & - & $\begin{array}{c}139 \mathrm{~b}_{2-} \\
140 \mathrm{a}\end{array}$ & $106 b_{2}$ & - \\
\hline $2,1-12$ & XVII. & 170 & - & - & $1 b_{2}$ & $\begin{array}{r}140 \mathrm{~b}_{2} 1 \\
14 \mathrm{la}_{1}\end{array}$ & $\begin{array}{c}107 b_{2}- \\
108 a_{1}\end{array}$ & $1 b-2 a$ \\
\hline $13-18$ & XIV. & 167 & - & - & $1 b_{1}$ & $140 b_{1}$ & $107 b_{1}$ & - \\
\hline $19-23$ & XVI. & 169 & - & - & $1 b_{2}$ & $14 \mathrm{Cb}_{2}$ & $107 b_{2}$ & $1 b$ \\
\hline $3,13-17$ & XVIII. & 171 & - & - & - & $141 a_{1}-a_{2}$ & $108 a_{1}$ & $1 a-1 b$ \\
\hline $4,1-11$ & $x x x$. & 183 & - & - & - & $142 a_{2}-b_{1}$ & $109 b_{1}-b_{2}$ & - \\
\hline $18-22$ & $c x x$. & 300 & - & - & - & - & -20 & $36 a$ \\
\hline $5,1-12$ & CXIVI. & 318 & - & - & - & - & - & $46 a$ \\
\hline $13-16$ & CXXXVI I I & 312 & - & - & - & - & - & $43 a-43 b$ \\
\hline $20-24$ & XCVII. & 273 & - & - & - & $145 b_{1}$ & $\begin{array}{c}120 b_{2-} \\
121 a_{1}\end{array}$ & $29 b-30 a$ \\
\hline $43-48$ & XXVIII & 181 & - & - & - & - & $109 a_{2}-b_{1}$ & - \\
\hline $6,1-4$ & XXVI II & 181 & - & - & - & - & $109 a_{2}-b_{1}$ & - \\
\hline $16-21$ & XXVII. & 181 & $2 b$ & - & - & - & $109 a_{2}$ & - \\
\hline $24-33$ & CVI. & 283 & - & - & - & $146 b_{1}-b_{2}$ & $122 a_{1}-a_{2}$ & $32 b-33 a$ \\
\hline $7,15-21$ & XCIX. & 275 & - & - & - & $145 b_{1}-b_{2}$ & $121 a_{1}-a_{2}$ & $30 a-30 b$ \\
\hline $8,1-13$ & XXI. & 174 & - & - & - & $141 b_{1}-b_{2}$ & $108 a_{2}-b 1$ & $2 b$ \\
\hline $23-27$ & XXII. & 176 & - & - & - & $141 b_{2}$ & $108 b_{1}$ & - \\
\hline $9,1-8$ & CXIII. & 292 & - & - & - & $147 a_{1}-a_{2}$ & $123 b_{1}$ & - \\
\hline $9-13$ & CXLII. & 315 & - & - & - & - & - & $44 \mathrm{~b}$ \\
\hline $18-26$ & CXVIII. & 298 & - & - & - & - & $124 a_{2}$ & - \\
\hline $10,5-8$ & CXXIV. & 303 & - & - & - & - & - & $37 a-37 h$ \\
\hline $16-22$ & CXLIX. & 320 & - & - & - & - & - & $47 a$ \\
\hline $11,2-10$ & III. & 158 & - & - & - & $139 a_{2}$ & $106 a_{2}$ & - \\
\hline $25-30$ & CXXV. & 303 & - & - & - & - & - & $37 \mathrm{~b}$ \\
\hline $12,38-50$ & XOXIII. & 185 & $\begin{array}{l}1 a-1 b \\
1 a^{\circ}-1 b\end{array}$ & - & - & - & - & $3 b-4 a$ \\
\hline $46-50$ & CXXXVI. & 311 & - & - & - & - & - & $42 a-42 b$ \\
\hline $13,44-52$ & CIV. & 324 & - & - & - & - & - & $48 b-49 a$ \\
\hline $15,1-20$ & XLVI. & 202 & - & - & - & - & $111 b_{1}-b_{2}$ & $9 a-9 b$ \\
\hline $21-28$ & XXXVII. & 191 & - & - & - & $142 b_{1}-b_{2}$ & $110 a_{2}$ & $5 b-6 a$ \\
\hline $16,13-19$ & CXOXIV. & 310 & - & - & - & - & - & $41 b-42 a$ \\
\hline $24-28$ & CXLVIII & 319 & - & - & - & - & - & $46 b-47 a$ \\
\hline
\end{tabular}


Biblische Reihen-

Stelle folge

\begin{tabular}{l|l|l}
\hline vt 17,1-9 & XXXVI. & 190
\end{tabular}

18,1-10 CXLIII. 316

15-22 XLV. 201

23-35 CXVI. 296

19,3-11 COXX. 307

27-29 COOXV. 311

20,1-16 XXIV. 177

17-28 XL. 194

\begin{tabular}{l|l|l}
$21,1-9$ & I. & 157
\end{tabular}

10-17 XXXII. 185

33-46 XLII. 197

22,1-14 CXIV. 293

15-21 CXVII. 297

34-46 CXII. 291

23,1-12 XXXIX. 193

34-39 XII. 166

25,1-13 CLIV. 323

31-46 XXXI. 184

28,1-7 LXVIII. 242

16-20 LXXIV. 250

Mc 3,1-5 XXIII. 176

6,7-10 CXXVI. $\quad 304$

17-29 CXXXIX. 313

47-56 XXIX. 182

7,31-37 CIII. 279

8,1-9 XCVIII. 274

9,16-28 CVIII. 285

13,33-37 CLII. 322

16,1-7 LXIX. 243

14-20 LXXXII. 258

$\begin{array}{lll}L & 1,5-17 \quad \text { CXXXI. } & 307\end{array}$

26-38 IV. 159

39-47 V. $\quad 160$

57-68 COXXII. 308

2,1-14 VIII. 162

\begin{tabular}{l|l|l}
$15-20$ & $X$. & 164
\end{tabular}

22-32 CXXIII. 302

A

C

D

$\mathrm{S}$

S

R IN

\begin{tabular}{|c|c|c|c|}
\hline- & - & $110 a_{1}-a_{2}$ & $5 a-5 b$ \\
\hline - & - & - & $45 a$ \\
\hline - & - & $111 a_{2}-b_{1}$ & $9 a$ \\
\hline - & $147 \mathrm{~b}_{1}-\mathrm{b}_{2}$ & $124 a_{1}$ & $35 b-36 a$ \\
\hline - & - & - & $40 a-40 h$ \\
\hline - & - & - & $42 a$ \\
\hline - & $\begin{array}{r}141 \mathrm{~b}_{2}- \\
142 \mathrm{a}_{1}\end{array}$ & $108 b_{2}$ & - \\
\hline- & - & $110 b_{1}-b_{2}$ & $6 b-7 a$ \\
\hline- & $139 a_{1}$ & $106 a_{1}$ & - \\
\hline - & - & - & $3 a-3 b$ \\
\hline- & - & - & $38 a-38 b$ \\
\hline - & $147 a_{2}$ & $123 b_{1}-b_{2}$ & $34 b-35 a$ \\
\hline - & $14 \mathrm{~Tb}_{2}$ & $124 a_{1}-a_{2}$ & - \\
\hline - & $147 a_{1}$ & $123 a_{2}-b_{1}$ & $34 b$ \\
\hline- & - & $110 b_{1}$ & $6 a-6 b$ \\
\hline $1 a_{2}$ & $140 a_{2}$ & $107 a_{2}$ & - \\
\hline- & - & - & $48 a-48 h$ \\
\hline- & - & - & $3 a$ \\
\hline- & $143 a_{2}-b_{1}$ & $116 b_{1}$ & $19 b$ \\
\hline - & - & $117 b_{1}$ & $22 a$ \\
\hline- & $141 b_{2}$ & $108 b_{1}$ & $38 b$ \\
\hline- & - & - & $39 a$ \\
\hline- & - & - & $43 b-44 a$ \\
\hline- & - & $199 \mathrm{~b}_{1}$ & - \\
\hline - & $146 a_{1}-a_{2}$ & $121 b_{1}-b_{2}$ & $31 b$ \\
\hline - & $145 b_{1}$ & $121 a_{1}$ & $30 a$ \\
\hline - & - & $122 b_{1}-b_{2}$ & - \\
\hline - & - & - & $48 a$ \\
\hline - & 1435 & $116 b_{1}-b_{2}$ & $19 b-20 a$ \\
\hline - & $144 a_{2}$ & $118 b_{2}$ & $24 b-25 a$ \\
\hline- & - & - & $40 b-41 a$ \\
\hline - & $139 a_{2}-b_{1}$ & $106 a_{2}-b_{1}$ & - \\
\hline - & - & $106 b_{1}$ & - \\
\hline- & - & - & $41 a-41 b$ \\
\hline $1 a_{1}$ & $139 b_{2}$ & $\begin{array}{c}106 b_{2^{-}} \\
107 a_{1}\end{array}$ & - \\
\hline $1 a_{1}$ & $140 a_{1}$ & $107 a_{1}$ & - \\
\hline - & - & - & $37 a$ \\
\hline
\end{tabular}


Biblische Reihen-

Stelle

folge

Seite A

C

$\mathrm{S}$

$\mathrm{R}$

W

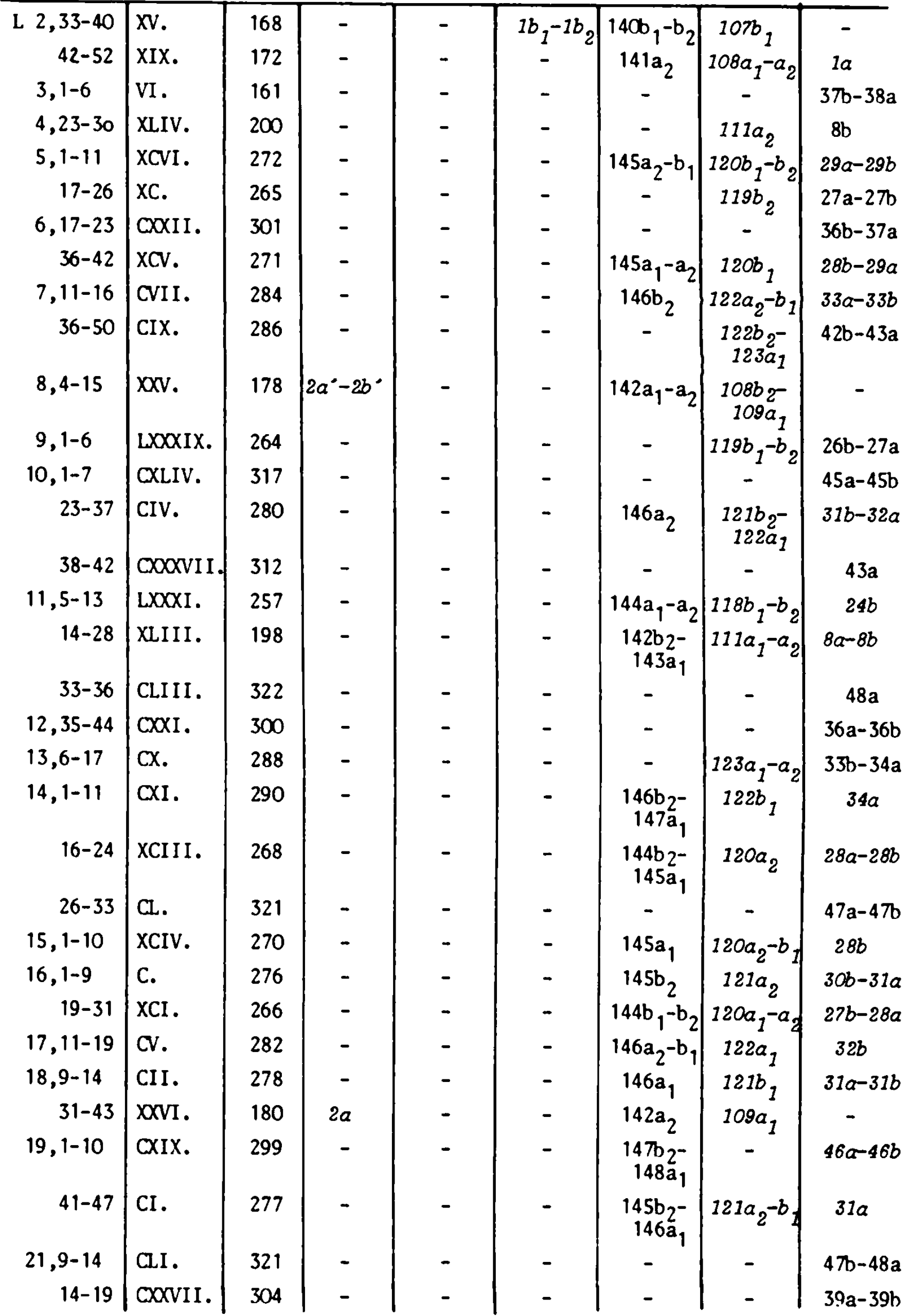


Biblische Reihen-

Stelle folge

Seite A

C

D

$\mathrm{S}$

$\mathbf{R}$

W

\begin{tabular}{|c|c|c|c|c|c|c|c|c|}
\hline L $21,25-33$ & II. & 158 & - & - & - & $139 a_{1}-a_{2}$ & $106 a_{1}$ & - \\
\hline $22,24-30$ & CIVI. & 325 & - & - & - & - & - & $49 a$ \\
\hline $24,13-35$ & $L X X X$. & 244 & - & - & - & - & $\begin{array}{c}116 b_{2} \\
117 a_{1}\end{array}$ & $20 a-20 b$ \\
\hline $36-47$ & LXXI. & 246 & - & - & - & - & $117 a_{1}-a_{2}$ & $21 a$ \\
\hline J $1,1-14$ & XI. & 165 & - & - & $1 a_{1}-1 a_{2}$ & $140 a_{1}-a_{2}$ & $107 a_{1}-a_{2}$ & - \\
\hline $19-28$ & VII. & 161 & - & - & - & $139 \mathrm{~b}_{1}-\mathrm{b}_{2}$ & $106 b_{1}$ & - \\
\hline $2,1-11$ & $x x$ & 173 & - & - & - & $141 a_{2}-b_{1}$ & $108 a_{2}$ & $2 a-2 b$ \\
\hline $13-25$ & LI. & 210 & - & - & - & - & $112 b_{1}$ & $11 b-12 a$ \\
\hline $3,1-15$ & CXXIX. & 306 & - & - & - & - & - & $40 a$ \\
\hline $16-21$ & LXOXVI. & 262 & - & - & - & - & $119 a_{2}$ & $25 b-26 a$ \\
\hline $4,5-42$ & XIVIII. & 204 & - & - & - & - & $\begin{array}{l}111 \mathrm{~b}_{2}^{-} \\
112 \mathrm{a}_{1}\end{array}$ & $10 a-10 b$ \\
\hline $46-53$ & CXV. & 295 & - & - & - & $147 a_{2}-b_{1}$ & $\begin{array}{c}123 b_{2}- \\
124 a_{1}\end{array}$ & $35 a-35 b$ \\
\hline $5,1-15$ & $X X X V$ & 188 & - & - & - & - & $110 a_{1}$ & $4 b-5 a$ \\
\hline $17-29$ & LIV. & 217 & - & - & - & - & $113 b_{1}$ & $14 a-14 b$ \\
\hline $30-47$ & XLI. & 195 & - & - & - & - & $\begin{array}{c}110 b_{2}^{-} \\
111 a_{1}\end{array}$ & $7 a-8 a$ \\
\hline $6,1-14$ & L. & 209 & - & - & - & $143 a_{1}$ & $112 a_{2}-b_{1}$ & $11 a-11 b$ \\
\hline $27-35$ & XLVII. & 204 & - & - & - & - & $111 b_{2}$ & $9 b$ \\
\hline $44-52$ & LXXXVII & 264 & - & - & - & - & $119 \mathrm{~b}_{1}$ & $26 b$ \\
\hline $56-59$ & XCII. & 268 & - & - & - & - & $119 b_{2}$ & - \\
\hline $7,1-13$ & LIX. & 227 & - & $1 b_{2}$ & $3 a_{1}-3 a_{2}$ & - & $114 b_{1}-b_{2}$ & $17 a-17 b$ \\
\hline $14-31$ & LII. & 211 & - & - & - & - & $112 b_{1}-b_{2}$ & $12 a-12 b$ \\
\hline $32-39$ & LVIII. & 226 & - & $1 b_{1}-1 b_{2}$ & $3 a_{1}$ & - & $114 b_{1}$ & $17 a$ \\
\hline $40-53$ & $\mathrm{LXI}$ & 230 & - & - & $3 b_{1}$ & - & $115 a_{1}-a_{2}$ & $18 a-18 h$ \\
\hline $8,1-11$ & XLIX. & 208 & - & - & - & - & - & $10 b-11 a$ \\
\hline $12-20$ & LVI. & 223 & - & - & $2 b_{1}-2 b_{2}$ & - & $114 a_{2}$ & $16 a-16 b$ \\
\hline $21-29$ & XXXVIII & 192 & - & - & - & - & $110 a_{2}-b$ & ha \\
\hline $31-47$ & XXXIV. & 187 & $1 b^{\circ}$ & - & - & - & $\begin{array}{c}109 b_{2^{-}} \\
110 a_{1}\end{array}$ & $4 a-4 b$ \\
\hline $46-59$ & LVII. & 224 & - & $1 a_{1}-1 b_{1}$ & $2 b_{1}-3 a_{1}$ & $143 a_{1}-a_{2}$ & $114 a_{2}-b_{1}$ & $16 b-17 a$ \\
\hline $9,1-38$ & LIII. & 213 & - & - & - & - & $\begin{array}{l}112 b_{2} \\
113 b_{1}\end{array}$ & $12 b-14 a$ \\
\hline $10,1-10$ & LXXXVII I & 263 & - & - & - & - & $119 a_{2}-b_{1}$ & $26 a-26 b$ \\
\hline $11-16$ & LXXVII & 253 & - & - & - & $143 \mathrm{~b}_{1}-\mathrm{b}_{2}$ & $118 a_{1}-a_{2}$ & $23 a-23 b$ \\
\hline $22-38$ & $L X$. & 228 & - & - & $3 a_{2}-3 b_{1}$ & - & $\begin{array}{c}114 b_{2}^{-} \\
115 a_{1}\end{array}$ & $17 b-18 a$ \\
\hline $11,1-45$ & LV. & 218 & - & - & $2 a_{1}-2 b_{1}$ & - & $\begin{array}{r}113 b_{1} \\
114 a_{2}\end{array}$ & $14 b-16 a$ \\
\hline
\end{tabular}


Biblische Reihen-

\begin{tabular}{|c|c|c|c|c|c|c|c|c|}
\hline telle & folge & Seite & A & C & D & $S$ & $R$ & $w$ \\
\hline$J 11,47-54$ & LXII. & 232 & - & - & $3 b_{1}-3 b_{2}$ & - & $115 a_{2}$ & $18 b-19 a$ \\
\hline $12,1-36$ & LXV. & 235 & - & - & -6 & - & $\begin{array}{r}115 b_{2-}^{2} \\
116 a_{2}\end{array}$ & - \\
\hline $24-26$ & CIVII. & 325 & - & - & - & - & - & $49 b$ \\
\hline $32-36$ & CXLI. & 315 & - & - & - & - & - & $44 b$ \\
\hline $13,1-15$ & LXVI. & 239 & - & - & - & - & $116 a_{1}-b_{1}$ & - \\
\hline $14,1-13$ & CXXVIII & 305 & - & - & - & - & - & $39 \mathrm{~b}$ \\
\hline $15-21$ & LXXXIV. & 260 & - & - & - & - & $118 b_{2}$ & $38 b-39 a$ \\
\hline $23-31$ & LXXXV. & 261 & - & - & - & $144 b_{1}$ & $119 a_{1}-a_{2}$ & $25 b$ \\
\hline $15,12-16$ & CXLVII. & 319 & - & - & - & - & $\begin{array}{lll}1 & 4 \\
- & \end{array}$ & $46 \mathrm{~b}$ \\
\hline $17-25$ & CXlv. & 317 & - & - & - & - & - & $45 b$ \\
\hline $26-27$ & LXXXXI II & 259 & - & - & - & $144 a_{2}$ & $118 b_{2}$ & $25 a$ \\
\hline $16,1-4$ & LXXXII I I & 259 & - & - & - & $144 a_{2}-b_{1}$ & $118 b_{2}$ & $25 a$ \\
\hline $5-14$ & LXXIX. & 255 & - & - & - & $\begin{array}{r}143 b_{2-}^{-} \\
144 a_{1}\end{array}$ & $118 a_{2}-b_{1}$ & $23 b-24 a$ \\
\hline $16-22$ & LXXVIII & 254 & - & - & - & $143 b_{2}$ & $118 a_{2}$ & $23 b$ \\
\hline $23-30$ & LXXX. & 256 & - & - & - & $144 a_{1}$ & $118 b_{1}$ & $24 a-24 b$ \\
\hline $17,1-11$ & LXIII. & 233 & - & - & $3 b_{2}$ & - & $115 a_{2}-b_{1}$ & $19 a-19 b$ \\
\hline $11-26$ & LXIV. & 234 & - & - & - & - & $115 b_{1}-b_{2}$ & - \\
\hline $19,15-42$ & LXVII. & 240 & - & $2 a_{1}-2 b_{2}$ & - & - & - & - \\
\hline $20,1-9$ & LXXV. & 251 & - & - & - & - & $117 b_{2}$ & $22 \mathrm{~b}$ \\
\hline $11-18$ & LXXIII. & 249 & - & - & - & - & $117 b_{1}$ & $21 b-22 a$ \\
\hline $19-31$ & LXXVI. & 252 & - & - & - & $143 b_{1}$ & $\begin{array}{r}117 b_{2} \\
118 a_{1}\end{array}$ & $23 a$ \\
\hline $21,1-14$ & LXXII. & 247 & - & - & - & - & $117 a_{2}-b_{1}$ & $21 a-21 b$ \\
\hline $15-19$ & CXXXIII & 309 & - & - & - & - & - & $41 \mathrm{~b}$ \\
\hline $19-24$ & XIII. & 166 & - & - & $1 a_{2}-1 b_{1}$ & $140 a_{2}-b$ & $107 a_{2}$ & - \\
\hline
\end{tabular}




\section{LITERATURVERZEICHNIS}

BAUER, J., Phénomènes centraux et périphériques dans 1'évolution du système syntactique de la langue tchèque, in: Travaux linquistiques de Praque 2 (1966) 225-238.

BAUER, J., Starođeská věta a starođeské souvět l na základě srounávacim, in: Syntactica slavica, Brno 1972, 107-121.

BAUER, J., Syntactica slavica, Brno 1972.

BAUER, J., Vývoj Zeského souvět1, Praha 1960.

BAUER, J., zur Auffassung des sprachlichen Zeichens, in: Zeichen und System der Sprache II, Berlin 1962, $11 \mathrm{ff}$.

BAUER, J., Vliv fečtiny a latiny na vývoj syntaktické stavby slovanských jazykú, in: Syntactica slavica, Brno 1972, 58-59.

Biblia sacra luxta Vulgatam versionem, ed. R. WEBER, Stuttgart 1969. BRIQUET, Ch., Les filigranes IV, Paris 1907.

CEJNAR, J., Odraz znělostnı asimilace sykavek $v$ spřežkových oravo-

pisných systémech $v$ češtině, slovo a slovesnost 30 (1969) 150-156.

CERNÝ, F., Dva evangelistáre (Rezension zur Edition von F. Menčlk), Listy filologické 21 (1894) 477.

CERNY, F., Olomoucký evangeliár, Praha 1902.

CERvY, F., Fragmenta Bołkova, Casopis Cesk hho musea 73 (1899) 505-506. COSERIU, E., Thesen zum Thema ,Sprache und Dichtung', in: Beitrăge

zur Textlinguistik, München 1971, 183-188.

DANES, F., Vztah centra a periférie jakožto jazykové universále, Jazykovédné aktuality 1965/II-III, 1-6.

DANES, F., The Relation of Centre and Periphery as a Lanquage Universal, in: Travaux linguistiques de Praque 2 (1966) 9-21. DANHELKA, J., Textologie a lingvistika, in: Miscellanea linquistica, Ostrava 1971, 211-215.

DOBROVSKY, J., Geschichte der bohmischen Sprache und 1 iteren Literatur, Prag 1818.

DOBROVSKY, J., Uber den ersten Text der böhmischen Bibelübersetzung,

in: Neuere Abhandlungen d. k. bohmischen Gesellschaft d. Wissenschaften, Bd. III, Prag 1795, 240-266.

DokoupIL, V., Soupis rukopisi knihouny benediktinu v Rajhrade, Praha $1966,144-145$.

DOSTÁL, A., Historická mluvnice Ceská II, Tvaroslovi 2 (Casován̊), Praha 1967. 


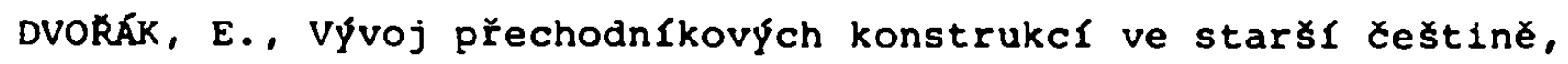
Praha 1970.

EHRISMAN, G., Geschichte der deutschen Literatur bis zum Ausgang des Mittelalters, II/2/2, München 1935.

FILIPEC, J., Probleme des Sprachzentrums und der sprachperipherie im System des Wortschatzes, in: Travaux linguistiques de Prague 2 (1966) 257-276.

FLAJSHANS, V., klaret a jeho druzina, I, II, Praha 1926, 1928. FLAJSHANS, V., K otázce o vlivu clrkevní slovanstiny na starou cestinu, Casopis Ceského musea 69 (1895) 487-498.

FLAJSHANS, V., Nejstarకł památky jazyka a pisemnictví ceského, Praha 1903.

FLAJSHANS, V., Vliv literatury staroslovenské na staroceskou, Listy filologické 21 (1894) 372-378, 463-469.

FRIND, A., Die Kirchengeschichte Böhmens II, Prag 1866. GEBAUER, J., Historická mluvnice jazyka Ceského I, HIáskoslovi, Praha - VIdeñ 1894.

GEBAUER, J., Historická mluvnice jazyka Łeského III/1, SkloňovánI, Praha - Videñ 1896.

GEBAUER, J., Historická mluvnice jazyka Ceského III/2, Casován1, Praha 1909.

GEBAUER, J., Historická mluvnice jazyka Ceského IV, Skladba, heraus-

gegeben aus dem Nachlass von F. TrávnlČek, Praha 1929.

GEBAUER, J., Płispěvky k historii Ceského pravopisu, Praha 1871. GEBAUER, J., SlounIk staroðeský I, II, Praha 1903, 1916.

GRACIOTTI, S., La bibbia paleoboema della Biblioteca di Brera, Milano 1964.

GREGOR der Grosse, 40 Homilien in Evangelia - Besědy na evangelije papy Grigorija Velikago (vgl. Quellenverzeichnis im slovnik jazyka staroslověnskêho /Bes/, Praha 1966, LXVII); zitiert nach einer Abschrift von Prof. Mares.

HAMM, J., Die Verschiebung der Velarkonsonanten, wiener slavistisches Jahrbuch 15 (1969) 38-58.

HAMM, J., Glose u Radonovoj bibliji, Slovo 1 (1952) 19-32. HAMM, J., Hrvatski glagoljasi u Pragu, zbornik za slavistiku

1 (1970) 84-99.

HANUS, I. J., Maly výbor ze starođeské literatury, Praha 1863. HAUSENBLAS, K., Vývoj predmétového genitivu v Ceštinè, Praha 1958. HAVRANEK, B., Genera verbi v slovanskych jazyclch, I, II, Praha 1928, 1937. 
HAVRÁNEK, B., Vývoj spisouného jazyka Ceského, in: Ceskoslovenská vlastivèda II (Jazyk), Praha 1936, 1-144.

HORALEK, K., Evangeliắe a Ctveroevangelia, Praha 1954.

HORALEK, K., Zum Begriff der phonologischen Korrelation, in: Phonologie der Gegenwart, wien 1967.

HRABAK, J.. Starకł Ceská literatura, Praha 1964.

HRABÁK, J.., et coauct., Dẻjiny Ceské literatury I, Praha (ČAV) 1959. JAKUBEC, J., Dějiny literatury Ceské I, Praha $19 ? 9$.

JANǍCEK, K., Dvĕ poznámky $k$ starođeským evangeliárúm, in: (Fest-

schrift) Pocta F. Trávnickovi a F. Wollmanovi, Brno 1948, $132-185$.

JANÁCEK, K., K otázce jednotného pưvodu starođeských evanqeliárú, Casopis Matice moravské 56 (1932) 445-449.

JANACEK, K., Rezension der Monographie von J. Vałica, Staroðeské evangeliáze, Casopis Matice moravské 55 (1931)491-509.

JIRECEK, J., o Ceském prvotnIm pł̌ekladu sv. evangeli1, in: Rozoravy Kralovské Ceské společnosti nauk V, Praha 1859, Bd. 10, 161-196. JIRECEK, J., O zvlástnostech Čstiny ve starych rukopisech moravských, in: Rozpravy KCSN VII, Praha 1887, Bd. ?, besonders die Seiten 16-18.

KELLNER, K. A. H., Heortologie oder die geschichtliche Entwicklung des Kirchenjahres und der Heiligenfeste, Freiburg (3.Aufl.) 1911.

KONÁREK, M. , Historická mluvnice Ceská I, Hláskosloví, Praha

(2. Aufl.) 1962 .

KOMÁREK, M., Zur Entwicklung der konsonantischen Mouillierungskorrelation im Tschechischen, in: Travaux linguistiques de Praque

4 (1971) 25-36.

KOPECNÝ, F., BYti - verbum existentiae (VE), kopula (VC) a pomocné sloveso (VA), přecházejlcl v morfém v čestinĕ, slovenstinĕ, polstině, Slavia 42 (1973) 135-148.

KOPECNÝ, F., K symetril a asymetril v jazyce, Nałe řę 55 (1972) 68-72.

KOTT, F., Dva evangelistá̌e (Rezension), Casopis Ceského musea

67 (1893) 632-634.

KR̃ŽKOVA, H., VÝvoj opisného futura v jazyclch slovanských, zvlástĕ $\checkmark$ rustinè, Praha 1960.

KURZ, J., UČebnice jazyka staroslověnského, Praha 1969. KVfCALA, J., Rezension zu V. Vondrák, Die Spuren..., in: Ceské museum filologické 1 (1894) 77-87. 
KYAS, V., Prunl Ceský překlad bible, in: Rozpravy CSAV 81 (1971), Heft 1, Praha 1971.

LAMPRECHT, A. , Vývoj fonologického systému ceského jazyka, Brno 1966. LEVY, J., Ceské teorie překladu, Praha 1957.

Lexikon für Theologie und Kirche, Freiburg (Herder-Verlag), 1961. LUNT, H.G., Old Church Slavonic Grammar, s'Gravenhage 1955.

MACHEK, V., Etymologický slovnik jazyka Ceského, Praha 1968 (2.Aufl.) MARES, F. V., Analytische Phonologie, The slavic Word (1970), oreprint, 1-33.

MARES, F. V., Ceská redakce clrkevni slovanకtiny v suětle Besĕd kehơ̌e Velikého (Dvojeslova), Slavia 32 (1963) 418, 445-451. MARES, F. V., Das Lautsystem im Licht der analytischen Dhonoloqie, in: Phonologica 1972, Nithchen-Salzburg, 267-281

MARES, F. V., Levínský nápis - epigrafický doklad cyrilice v Cechách, Slavia 22 (1953) 473-483.

MARTIMORT, G. , Handbuch der Iiturgiewissenschaft I, II, Freiburq 1965.

MENCfK, F., Dva evangelistáre, Praha 1893. MĚrKa, V., Ctenie knězě Benesovy, Prostějov 1918. MICHÁLEK, E., Ceský právní jazyk údobl Díedhusitského a doby Husovy, in: Rozpravy CSAV, Praha 1970, Heft 2.

NEJEDLY, 2., Déjiny předhusitského zpěvu v Cechách, Praha 1904. NĚMEC, I., Hláskoslovné předpoklady produktivity slovotvorných formantú, slovo a slovesnost 32 (1971) 217-224.

NĔMEC, I., Vývojové postupy Ceské slovn 1 zásoby, Praha 1968. OBERPFALCER-JfLEK, F. , Rod jmen v Cestiné, Praha 1933.

PATERA, A., Ctenie zimnieho Casu, in: Sblrka pramenú literárnich I/1, 7, Praha 1905.

PATERA, A., Nově nalezené zbytky starođeského evangelistáře, Anselma a Umucenf sv. Jiłr ze XIV. stoleti, Casopis Ceského musea 74 (1900) 504-507.

PATERA, A., zbytky evangelí ze XIV. stoleti, Ceské museum filologické l (1895) 46-48.

PATERA, A., Korespondence J. Dobrovského I., Vzájemné dopisy J. Dobrovského a F. Durycha $z$ let 1777-1800, in: sb1rka pramenú, skud. II, Nr. 2, Praha 1895.

PATERA, A., Soupis rukopisu metropolitni knihovny kapituly pražské, I - II, Praha 1910, 1922.

PETRUS, abbas de Aula Regia, Chronicon Aulae Reqiae (Kronika zbra- 
slavská), in: Fontes rerum Bohemicarum IV, Praha 1884, 70. PICCARD, G., Die Ochsenkopfwasserzeichen, 1-3, stuttgart 1966. POHL, H. D., Ein Beitrag zur serbokroatischen Morphonologie: nepostojano $a$, Niener Slavistisches Jahrbuch 21 (1975) 219-236. POLfVKA, J., Rezension zu V. Vondrák, Die Spuren..., Casopis Ceského musea 68 (1894) 468-470.

POLfVKA, J., Ještě slovo $k$ otázce o vlivu cirkevni slovanstiny na starou Cestinu, Casopis Ceského musea 69 (1895) 501-502. ROCHER-SKÁLA, K., Gramatický rod a vývoj Ceských deklinac1 jmenných, Praha 1934.

ROST, H., Die Bibel im Mittelalter, Augsburg 1939. SCHROPFER, J., Hussens Traktat ,Orthographia Bohemica', 'viesbaden 1968.

SCHWARZENBERG, K., Katalog der kroatischen, polnischen und tschechischen Handschriften der Ysterreichischen Nationalbibliothek, wien 1972.

SGALL, P., K programu lingvistiky textu, slovo a slovesnost 34 (1973) 39-43.

SKALICKA, V., O tzv. vnitíním modelu v jazyce, slovo a slovesnost 34 (1973) 22-26.

SKALICKA, V., Vývoj České deklinace, Praha 1941.

slownik polsczyzny XVI. wieku, Wroclaw - Warszawa - Kraków - Gdańsk 1973.

SMETÁNKA, E., o stár̆ staročeského žaltáfe, Listy filoloqické 30 (1903) 438-441.

Staročeský slovník, Autorenkollektiv unter Leitung von B. Havránek und I. Němec; Ưvodni stati, soupis pramenú a zkratek; bis jetzt Hefte 1-7, Praha CSAV $1968 \mathrm{ff}$.

Staroslověnský slovník - Lexicon linquae palaeoslovenicae, Praha $1966 \mathrm{ff}$.

SKKARKA, A., Nejstarక̌l Ceská duchovnl lyrika, praha 1949.

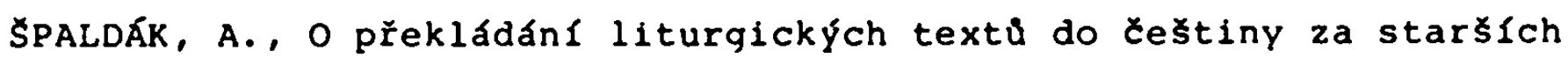
dob, Casopis Ceského musea 114 (1940) 154-180.

TADRA, F., Kulturni styky Cech s cizinou až do valek husitských, Praha 1897.

TITZ, K., Nejstarš vrstva Ceských slov clrkevnlch a kulturnich, Slavia 9 (1930-31) 19-35.

TRAVNfCEK, F., Historická mluvnice Ceská III, Skladba (Hochschullehrbuch), Praha 1956.

TRAVNICEK, F., Historická mluvnice Ceskoslovenská, Praha 1935. 
TRÁVNfCEK, F., Neslovesné vêty v Cestinè, I, II, Brno 1930, 1931. TRÁVNfCEK, F., Studie o Ceském vidu slovesném, Praha 1923. TRUBETzKOY, N. S., Grundzüge der Phonologie, Gottingen (3.Aufl.)

1962 .

VACHEK, J., Dynamika fonologického systému soủasné Cestiny, Praha 1968.

VASICA, J., Starođeské evangeliắe, in: Rozpravy CaV, tr. III, ¿.68, Praha 1931.

VǍ̃̂Y, V., Historická mluvnice Ceská II, Tvarosloví I (Skloñovánf), Praha 1964.

VINTR, J., Rezension des Buches, Editor a text', Wiener slavistisches Jahrbuch 19 (1973) 138.

VINTR, J., Rezension zu E. Michálek, Ceský pránni jazyk..., Nałe ł̌ę 54 (1971) 308-310.

VINTR, J., Die Symmetrie im phonologischen system des Alttschechischen, Wiener Slavistisches Jahrbuch 20 (1974) 152-163.

VINTR, J., Dynamisches Raummodell des alttschechischen phonoloqischen Systems, wiener Slavistisches Jahrbuch 21 (1975) 290-299. VINTR, J., Das alttschechische Pater noster, Ave und Credo in einer Handschrift der wiener Nationalbibliothek, wiener Slavistisches Jahrbuch 17 (1972) 303-309.

VLCEK, J., Déjiny Ceské literatury I, 3. Aufl., Praha 1940. VONDRAK, V., Die Spuren der altkirchenslavischen Evangelienübersetzung in der altböhmischen Literatur, in: Sitzungsberichte d. k. Akademie d. Wiss. in wien, phil.-hist. Classe, Bd.CXXIX, 1-38 (als selbst. Druck noch 1894).

VONDRÁK V., K námitkám stran vlivu clrkevni slovanstiny na starou Cestinu, Casopis Ceského musea 69 (1895) 498-501.

VONDRÁK, V., K otázce o vlivu clrkevní slovanłtiny na starou ceštinu, Casopis Ceského musea 69 (1895) 301-314.

VRASTIL, J., VYzzam nejstarłlch staroceských souvislých textu evangelijnlch pro otázku o vlivu bible staroslovenské na staroceskou, in: slovanské studie (Vajs' Festschrift), Praha 1948, 169-173.

Výbor z Ceské literatury husitské doby II, Praha 1964. VYSKOCIL, P., Staroslovenské sztvorizz bqdQ, slavia 25 (1956) 260-61. WALTHER, W., Die deutsche Bibelübersetzung des Mittelalters, Braunschweig 1889.

WEBER, R., siehe Biblia... 


\section{PERSONENREGISTER}

Agnes, Abtissin

Anna, engl. Königin

Anselm, $\mathrm{Hl}$.

Balbinus, B.

Baver, J.

Birkfellner, $G$.

Briquet, $\mathrm{Ch}$.

Cejnar, J.

Cerný, F.

Conradus, de Saxonia

Coseriu, E.

Danes, F.

Daňhelka, J.

Dokoupil, $\mathrm{V}$.

Dobrovský, J .

Dostál, A.

Durych, F.

Dvořák, E.

Ehrisman, G.

Filipec, $J$.

Flajłhans, $V$.

Frind, $A$.

Gebauer, J.
3.2 .

3.2 .

3.3 .2 .9 .1 .2 .

3.2 .

$4.3 .1 .1 \ldots 4.3 .3 .1 \ldots 6.1 \ldots 7 .$,

$7.0 .1 \ldots 7.0 .2 \ldots 7.1 \ldots 7.2$.

0 .

3.3 .4 .

$0 . .4 .2 .2 .1$.

$3.2 ., 4.1 .1 \ldots 13.1$.

3.3 .4 .

1.2 .1 .

5.1 .

1.2 .1 .

13.1 .

$1.1 \ldots 3.3 .6,4.1 \ldots 4.1 .1 \ldots$

$4.5 .1 \ldots 4.5 .3 \ldots 13.1$.

8.2 .1 .

3.3 .6 .4 .1 .1 .

4.3.1.2.2.

4.1 .

6.1 .

4.1 .1 .13 .1 .

3.2 .

$4.1 .1 \ldots 4.3 .1 .1 .2 ., 4.3 .1 .2 .2 .$,

$4.3 .2 .1 .2 ., 4.3 .3 .1,4.3 .3 .2 ., 4.4 .1 .$,

$6.0 .2 ., 7.0 .2 \ldots 7.1 \ldots 7.2 ., 8.1 .1 \ldots$

$8.1 .2 ., 8.2 .1 \ldots 8.2 .2 ., 9.1 .6 ., 9.2 .1 \ldots$

9.2.3.1.1., 10.1.

3.3 .2 .9 .1 .2 .

4.2.1.

$3.3 .1,3.3 .4,7.1,8.1 .2$.

$0 ., 3.2 \ldots 4.4 .1 \ldots 9.2 .6 .2$.

3.3 .1 .4 .1 .1 .

13.1 .

8.1 .1 .

$4.2 .2 .1 ., 6.0 .2, .7 ., 7.0 .2 .7 .2 \ldots, 10.1$. 
Horálek, K.,

Hrabák, J.

Hus, Johannes

Jakubec, J.

Janatek, $K$.

Jirecek, J.

Kačna, Adelige

Komárek, $M$.

kopečny, F.

kott, F.

K亡̌lzková, $H$.

Kunigunde, Äbtissin

Kurz, J.

Kvicala, J.

Kyas, V.

Lamprecht, A.

Levý, $J$.

Lunt, H.G.

Machek, V.

Mares, F. V.

Mencik, F.

Měrka, $\mathrm{V}$.

Michálek, E.

Nejedly, $\mathrm{Z}$.

Nĕmec, I.

Oberpfalcer-Jilek, $\boldsymbol{F}$.

Palacký, F.

Patera, A.

Petrus, abbas de Aula Regia

Piccard, G.

Pol Ivka, J.

Preinerstorfer, $R$.

Rocher-Skála, $K$.

Safaŕlk, P. J.

Schropper, J.

Schwarzenberg, $K$.
9.2 .3 .1 .

$3.2 ., 4.1 .1$.

$9 \cdot 2 \cdot 3 \cdot 1.1$.

$3.2,4.1 .1$.

$4.1 .1,4.4 .1$.

4.1 .1 .9 .1 .6 .

3.2 .

9.2 .1 .9 .2 .3 .1 .1$.

$6.3 ., 8.2 .2$.

4.1.1.

8.2.2.

3.2 .

7.1 .

4.1 .1 .

$4.1 .1 \ldots 4.2 .1 \ldots 4.4 .1$.

9.1 .4 .9 .1 .6 .9 .2 .1$.

7.2 .

8.2.2.

$4.4 .1,4.4 .2,4.4 .5 .2$.

$0 ., 1.2 .1 \ldots 3.2 \ldots 4.1 .1 \ldots 7.1 \ldots$

$9.2 .2 \ldots 9.2 .3 .1 \ldots 9.2 .4 .4 \ldots$

9.2 .5 .2 .

$1.1,3.3 .4 \ldots 4.0 .2,4.1 .1 \ldots$

$10.6 ., 13.1$.

3.2 .

6.0 .2 .

3. 2 .

$6.0 .2,6.1 \ldots 6.2,6.2 .1,6.3$.

9.2 .6 .6 .

8.1 .1 .

4.1.1.

$1.1,3.3 .6,4.1 .1,4.2 .1,13$.

3. 2 .

3.3. 4 .

$4.1 .1,4.4 .5 .2$.

0 .

8. 1.1 .

4. 1.1 .

10. 1 .

13.1 . 


\begin{tabular}{|c|c|}
\hline $\begin{array}{l}\text { Sembera, A. V. } \\
\text { skalicka, V. }\end{array}$ & $\begin{array}{l}4.1 .1 . \\
8.1 .1 .9 .2 .4 .1\end{array}$ \\
\hline Skarka, A. & 3.2 \\
\hline Spaldak, A. & 4.1 .1$. \\
\hline Stıtný, Tomás & 4.1 .1 .7 .1 \\
\hline Tadra, F. & 3.2 \\
\hline Tobias, von Bechyně & 3.2 \\
\hline Trávniðek, F. & $7.0 .2 \ldots, 8.1 .1 \ldots 8.2 .1 \ldots, 9.2 .1$ \\
\hline Trubetzkoy, N. S. & 9.2 .4 .1 \\
\hline Vachek, J. & 9.2 .4 .1$. \\
\hline Vasica, J. & $\begin{array}{l}1.1,3.3 ., 3.3 .1,3.3 .2,, 3, .3 .3 ., \\
3.3 .4,3.3 .5 ., 3.3 .6 ., 3.4 .3 .5 ., 4.0 .2 ., \\
4.1,4.1 .1,4.2 .1 ., 4.2 .2 ., 4.4 .5 .1 ., \\
4.4 .5 .2 ., 4.5 .3 ., 7.2,, 12 ., 13.1 .\end{array}$ \\
\hline vázný, V. & 8.1 .1 \\
\hline Vintr, J. & $1.2 .1 \ldots, 3.2 \ldots, 6.0 .2,9.2$ \\
\hline vlcek, J. & 3.2 .4 .1 .1 \\
\hline Vondrák, V. & $4.1 .1 \ldots 4.4 .5 .2$ \\
\hline Vraštil, J. & 4.4 .2 \\
\hline Vyskoðil, P. & 8.2 .2 \\
\hline Weber, R. & $4.2 .1 \ldots 13.2$ \\
\hline Wenzel, II., Rönig & 3.2 \\
\hline Wiclif, J. & 3.2 \\
\hline Wytrzens, G. & 0 \\
\hline
\end{tabular}




\section{SACHREGISTER}

Achse der Sonanten

Adj. denom.

akzessorische Elemente

Alcuinbibel

Alexandreis

'Allophoneme'

Altpolnisch

Alveolare

analytische Phonologie

Aoristformen, alttsch. bych

Assibilierung

Assimilation, regressive

Benediktiner

Bewegungen im phonol. System

Bibelkommentar, lat.-alttsch.

Buchstabenzahlenwerte, kyrill.

Bystrá

Commune Sanctorum

Credo

Dativ, adnom.

Depalatalisation

Dialektismen

Diphthongierung

Dual

Ebene der Vokale

Ebene der Konsonanten

Evangeliar - Olmiitzer

- Ctenie knězě Benesovy

- Entstehung

- relat. Chronologie

- lat. Original

- Verhältnis zum aksl.

Evangelienübersetzung

- altkirchens lavische

- allemanische

- deutsche
$9.2 .5 .1 \ldots 9.2 .5 .5 \ldots 9.2 .6 .5$.

4.3.4.2.

$9.2 .4 .4 \ldots 9.2 .5 .2 \ldots 9.2 .6 .2$.

4.2 .1 .4 .5 .1 .

$1.1,3.2,4.4 .1$.

11.4 .

4.4.5.2.

$9.2 .3 .1 \ldots 9.2 .3 .2 \ldots 9.2 .4 .5 .3 \ldots$

9.2 .6 .5 .

$9.2 .3 .1 \ldots 9.2 .4 .4$.

$4.3 .1 .2 .1,4.3 .2 .1 ., 8.2 ., 8.2 .2$

$9.1 .4 .9 .1 .5 ., 9.1 .6$.

$9.1 .4 .9 .1 .5 ., 9.1 .6$.

3.2 .

9.2 .6 .

3.3 .6 .

7.1 .

3.3 .6 .

3.3 .6 .12 .

3.2 .

7.1 .

9.1 .5 .

9.1 .6 .

$9.1 .2 \ldots 9.1 .4 \ldots 9.1 .5 ., 9.1 .6$.

7.2 .

9.2 .5 .1 .

9.2 .5 .1 .

3.2 .

3.2 .

3.5 .

$3.2,4.1 .1,4.5 .3 ., 12$.

$4.2 .1 \ldots 4.5 .1$.

$4.1 .1 \ldots 4.5 .1$.

4.1 .

4.1 .

$3.2,4.1$. 
Evangelienübersetzung,

- mündliche Uberlieferung

$1.1,4.1$

- russisch-ksl.

$3.2,4.5 .1$.

Falsum des Johannesevangeliums,

alttsch. Ubersetzung

4.1.1.

Farbe der Phoneme

$9.2 .4 .4 \ldots, 9.2 .4 .5 .3 ., 9.2 .5 .1 \ldots$

9.2 .6 .2 .

Fest d.Hl.Dreifaltigkeit

3.5 .

Figuren im Raumodell

$9.2 .5 .3 ., 9.2 .5 .6$.

Filiationsschema

$4.2 .1,4.2 .2 .1 \ldots 4.5 . \Xi, 12$.

Finalsătze, alttsch.

4.3.2.2.1.

Fronleichnamsfest

3.5 .

Futur

- alttschechisches

$4.3 .2 .1 .1 ., 4.3 .2 .1 .2$.

- analytisches

8.2.2.

- II. (exactum)

4.3 .2 .1 .1 .8 .2 .2 .

Genitiv

- absol. alttsch.

$4 \cdot 3 \cdot 1.1 .2$.

- partitivus

7.1 .

- possesivus

$4.3 .4 .2 ., 7.1$.

Gen. / Akk . - Formen

Grund(bau)elemente d. Phonems

7.2 .8 .1 .2 .

$9.2 .4 .4 \ldots 9.2 .4 .5 .8 \ldots, 7.2 .4 .6 .$,

9.2 .5 .2 .

Hilfsverb byt $i$

- stämme, modal.,temp.Funk.

8.2.2.

- budiech-Formen

8.2 .2 .

1.1 .

Hospodine pomiluj ny

3.3 .6 .

Hymnarium, lat.-alttsch.

$4.5 .1,4.5 .3$.

Hyparchetypen

4.3.4.1.

Imperativ, alttsch. negat.

$4.3 .1 .2 .1 \ldots 4.3 .2 .1 .8 .2$.

Imperfektformen, alttsch.

Infinitive, mährische Kurzformen

7.1 .

Ingressiva

6.2 .1 .

Interpunktion

13.2 .

j-Achse

$9.2 \cdot 5 \cdot 6$.

Jerlaute

9.2 .6 .5 .

Johannesevangelium, falsif.

alttsch. Ubersetzung

Jotierung

4.1.1.

$9.1 .2 \ldots 9.1 .3 ., 9.1 .5 ., 9.1 .6 \ldots$

$9.2 .6 .5 ., 13.2$. 
Kategorie der Belebtheit/

Unbe lebtheit

7.2 .

- des Stammes $\rightarrow$ Genus

6.2 .1 .

Klarets Worterbücher

4.4.5.2.

Klöster

- Ardagger

3.3 .4 .

- Brevnov

$3.2,4.5 .3 ., 12$.

- Emaus

Fn. 57

- Lambach

3.3 .6 .

- Rajhrad

- Seitenstetten

$3.3 .3 ., 3.3 .5$.

3.3 .4 .

- Sv. Jiłl (S. Georg) Prag

$3.2,12$.

Konditional, alttsch.

- des Futurs

Konditionalsutze, alttsch.

Konjugationsendungen (1.Pers.

Sg.Prăs. $-m$ vs. $-u$ )

4.3 .3 .1 .8 .2 .2 .

8.2 .2 .

$4.3 .2 .2 .3 ., 8.2 .2$.

8.2 .

konjunktionslose satze

$4.3 \cdot 1.1 .3$.

konsonantisches Viereck

9.2 .5 .3 .99 .2 .5 .6 .

Kunigunde-Lied (PIsen̆ Kunhutina)

Labiale

3.2 .

$9.2 .3 .1 ., 9.2 .3 .2 \ldots 9.2 .4 .5 .3 .$,

9.2 .6 .5 .

Labialisierung

$9.1 .2 \ldots 9.1 .4 \ldots 9.2 .3 .2 ., 9.2 .4 .6$

$9.2 .6 .3 ., 13.2$.

Latinismen

$4.3 .4 .4,4.4 .5 .1,, 12$.

Legenden, älteste alttsch.

1.1 .

Liturgie, slavische

3.2 .

m(Mouillierung) -Mitte

9.2 .6 .5 .

Mariengebet, alttsch.

3.3 .4 .

- Edition

13.1 .

Modalität

8.2.2.

'modus narrativus', alttsch.

8.2.2.

Monophthongierung

Moravismen

Mouillierungskorrelation

$9.1 .2 \ldots 9.1 .3 \ldots 9.1 .4 \ldots 9.1 .5 \ldots$

9.1 .6 .

$4.4 .5 .2 \ldots 8.1 .2,9.1 .4 \ldots 9.1 .5$.

$9.1 .1 .9 .1 .2 \ldots, 9.1 .3 ., 9.1 .4 \ldots$

$9.1 .5 ., 9.1 .6 \ldots 9.2 .3 .2 \ldots$

$9.2 .4 .5 .3 \ldots 9.2 .4 .5 .4 ., 9.2 .4 .6 \ldots$

$9.2 .6 .2 ., 9.2 .6 .3 ., 9.2 .6 .5$. 
Myslice

Nachahmungen d. lat. Konstrukt.

Nom./Akk .-Formen

Nonnen

Numeralia, alttsch.

oberitalienisches Papier

Orthographie, alttsch.

Palăos lovenismen

Palatale

Paraphrasierung

Partizipien, alttsch.

- Präs.

- Prät.

- Perf.

- absolutive

Passivformen

Pater noster

Perfektformen, alttsch.

Perikopentitel

Phoneme, potentielle

Pronomina

- Archaismen

Proprium de tempore

Proprium sanctorum

Psalter, alttsch.

Relationen d. Systemelemente

russische Priester

Satznegation

Sektoren im Raummodell

slovakismen

\section{Sonanten}

- Achse s. Achse d. Sonanten

- silbische

Sorbonne-Bibel

Sprachsystem, Definition

Stimmbeteiligung

Supinformen
3.3. 4 .

$4.3 \cdot 4 \cdot 4$.

$7.2 ., 8.1 .2$.

3.2 .

7.1 .

3.3 .4 .

$4.2 .2 .1 \ldots 9.1 .6 \ldots 10$.

4.4.5.2. 8.1.2.

$9.2 .3 .1 \ldots 9.2 .3 .2 \ldots 9.2 .4 .5 .3 \ldots$

9.2 .6 .5 .

4.1 .

$4.3 .1 .1 ., 4.3 .3 .1$.

$4.3 .1 .2 .1,4.3 .3 .1$.

4.3.1.1., 4.3.2.1.2.

$4.3 \cdot 1.2 .1$.

$4.3 \cdot 1.2 .2$.

7.2 .

3.2 .

4.3 .2 .1 .4 .3 .2 .1 .2 .

13.2 .

9.2 .4 .5 .9 .

7.1 .

8.1.3.

$3.3 .6,4.4 .1 \ldots 4.4 .6,12$.

$3.3 .6,3.5,4.4 .1 \ldots 4.4 .4 .1 \ldots$

$4.4 .6,4.5 .1 \ldots 9.1 .6 \ldots 12$.

1.1 .

9.2.4.3.

$3.2 ., 4.4 .5 .2$.

7.2 .

9.2.5.2.

9.1 .6 .

9.2 .3 .1 .1$.

4.2 .1 .4 .5 .1 .

5 .

9.2 .5 .2 .9 .2 .6 .3 .

7.1 . 
Svatý Václave-Lied

1.1 .

Symmetrie, vertik., horizont.

9.2 .5 .6 .

Systemmodell

9.2 .4 .2 .

- arithmetisches

9.2 .4 .3 .

- geometrisches

9.2 .4 .3 .

- inneres

9.2 .4 .1 .

- dynamisches

$9.2 .6 \cdot 1 .-4$.

- im Raum

9.2.5.1.

Temporalsätze, alttsch.

Teilebenen, im Raummodell

4.3.1.1.4., 4.3.2.2.2.

9.2 .5 .1 .

Textcharakteristik, innere und aussere

2.1 .

Textreproduktionen

13.2 .

textstrukturelle Analyse

1.2 .

Transkription

Velare

$10.2,13.2,13.3 ., 13.5$.

$9.2 .3 .1 ., 9.2 .3 .2 ., 9.2 .4 .5 .3 .$,

9.2 .6 .5 .

vertikale struktur

11,12 .

Vita palaeoslovenica

s. Venceslai rec. (Nikorskiana) 4.4.5.2.

Vokale

$9.1 .4 \ldots 9.1 .5 ., 9.1 .6$.

$$
\text { - lange }
$$

vokalische Varianten

9.2.3.1.

$9.2 .3 .1 \ldots 9.2 .3 .2 ., 9.2 .4 .5 .8 \ldots$,

$9.2 .4 .5 .9 ., 9.2 .4 .6$.

vokalisches Dreieck

$9.2 .5 .3 ., 9.2 .5 .6$.

Vulgata, benutzte Ausgabe

13.2 .

Wasserzeichen

$3.3 .4 \ldots, 3.3 .5,3.3 .6,12$.

Wiener (Jagić)-Glossen

3.2 . Fn. 5 .

Wortfolge, alttsch.

7.2 . 


\section{WORTREGISTER}

(wichtigere wörter, die in der studie behandelt, ev. erklürt wurden)

Tschechisch:

\begin{tabular}{|c|c|c|c|}
\hline aj & 4.4 .1 & jiti po + Lok. & 4.4 .4 .1 \\
\hline běs & 4.4 .1 .6 .1 & kazatel & 4.4 .1 .6 .2 .2 \\
\hline běsový & 6.1 & každý & 4.4 .3$. \\
\hline \multirow[t]{2}{*}{ biskup } & $4.4 .1 .6 .1 \ldots$ & kázen & 4.4 .1 \\
\hline & 6.2 .2 & ké & 8.1 .3$. \\
\hline blahoslaviti & 4.4 .4 .1 & kněz & $4.4 .1 \ldots 6.1 \ldots$ \\
\hline blažiti & 4.4 .4 .1 & & 6.2 .2$. \\
\hline Cas & 4.4 .2$. & kněžský & 6.1 \\
\hline cele & 4.4 .1 & kostel & 4.4 .1 \\
\hline celost & 4.4 .1 & královstvie & 4.4 .1 \\
\hline chrám & $4.4 .1 . .6 .2 .2$ & kvasěnín & 6.1 \\
\hline chvala & 4.4 .1 & 11 coměrn $1 k$ & 4.4 .1 \\
\hline chvalu vzdáti & 4.4 .4 .1 & malomocenstvie & 4.4 .2 \\
\hline chvile & 4.4 .2 & malomocný & 4.4 .2 \\
\hline chvostišer & 4.2 .1 & mězený prstek & 4.4 .5 .1 \\
\hline ¿1 & 7.1 & mile & 4.4 .2 \\
\hline cierkev & 4.4 .1 & $\operatorname{mir}$ & 4.4 .1 \\
\hline cistota & 4.4 .4 .1 & mistr & $4.4 .1 \ldots 6.2 .2$. \\
\hline cizozemenin & 6.1. & mladel & 4.4 .1 \\
\hline diábel & 4.4 .1 .6 .1 & $\bmod 1 a$ & $4.4 .1 \ldots 6.2 .2$ \\
\hline diábelský & 6.1. & modliti sĕ & 4.4 .4 .1 \\
\hline doba & 4.4 .2$. & nacin & 4.4 .5 .2 \\
\hline dobre ciniti & 4.4 .4 .1 & následovati & 4.4 .4 .1 \\
\hline$e^{z}$ & 4.4 .1 & navštieviti & 4.4 .4 .1 \\
\hline hlożie & 4.4 .2 & nazievati & 4.4 .4 .1 \\
\hline hodina & 4.4 .2 & nedéle & 4.4 .2 \\
\hline hon & 4.4 .2 & nemocný & 4.4 .2 \\
\hline hospodár & 4.4 .2 & nikte & 4.4 .3 \\
\hline Hospodin & 4.4 .1 .6 .1 & nizádny & 4.4 .3 \\
\hline hřiešñk & 4.4 .1 & nuzný & 4.4 .2 .6 .2 .2 \\
\hline ijeden & $4.4 .3 . .7 .1$ & obecnIk & 4.4 .1 \\
\hline iżadný & 4.4 .3 & obida & 6.1 \\
\hline jalový & $4.4 \cdot 5.1$ & oblisditi & 4.4 .4 .2 \\
\hline jeden & 7.1 & ocistiti & 4.4 .4 .1 \\
\hline jistex & 4.4 .1$. & $\begin{array}{l}\text { odplata Jose } \\
\text { Downloaded from PubFactory at }\end{array}$ & 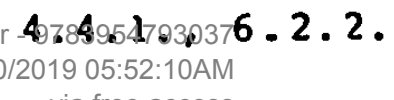 \\
\hline
\end{tabular}




\begin{tabular}{|c|c|c|c|}
\hline oslaviti & 4.4 .4 .1 & sêova & 4.4 .1 \\
\hline osvětiti & 4.4 .4 .1 & s1pek & 4.4 .2 \\
\hline otec Čledinný. & & skeřupina & 4.4 .2$. \\
\hline o. Celednr, & & skola & $4.4 .1 \ldots 6.2 .2$. \\
\hline o. domovitý & 4.4 .2 & skř̉hot zubōm & 7.1 \\
\hline ova & 4.4 .1 & slavenie & 4.4 .4 .1 \\
\hline Pán & 4.4 .1 .6 .1 & slovo & 4.4 .1 \\
\hline pavlaka, pavlačný & $4 \cdot 4 \cdot 5.2$ & sobota & 4.4 .2 \\
\hline pIsaŕ & 4.4 .1 & spasitel & 4.4 .1 \\
\hline podobenstvie & 4.4 .1 & spravedlnost & 4.4 .1 .6 .2 .2$. \\
\hline podolek & $4.4 \cdot 5.2$ & strr & 4.4 .2$. \\
\hline podrah & $4 \cdot 4 \cdot 5 \cdot 2$ & stred & 4.4 .5 .2 \\
\hline pokloniti sè & 4.4 .4 .1 & teder & 4.4 .1 \\
\hline pokňư̌ený & 4.4 .1 & tehdy & 4.4 .1 \\
\hline pokňurnIk & 4.4 .1 & tet, ted & 8.1 .3$. \\
\hline pokoj & 4.4 .1 & tirati & 4.4 .4 .2 \\
\hline pokrtnik & 4.4 .1 & tíñti & 4.4 .4 .2 \\
\hline pokrytec & 4.4 .1 & tot' & 4.4 .1 \\
\hline pokrytý & 4.4 .1 & týrati & 4.4 .4 .2 \\
\hline pomodliti sè & 4.4 .4 .1 & týřeti & 4.4 .4 .2 \\
\hline ponatin & 4.4 .5 .2 & ucenik/uðedln lk & 4.4 .1 \\
\hline \multirow[t]{2}{*}{ pop } & $4.4 .1 \ldots 6.1 \ldots$ & utexitel & 4.2 .1$. \\
\hline & 6.2 .2 & věrnè & 4.4 .1 \\
\hline popový & 6.1 & \multicolumn{2}{|c|}{ veš, všicek, vštek, } \\
\hline porúęti sẻ & 4.4 .4 .1 & \multicolumn{2}{|c|}{ vseliký, všelikaký 4.4.3. } \\
\hline povèst & 4.4 .1 & věst & 4.4 .1 \\
\hline požehnati & 4.4 .4 .1 & viera & 4.4 .1 .6 .2 .2 \\
\hline pracný & 4.4 .2$. & vitél dáti & 4.4 .4 .1 \\
\hline pravda & $4.4 .1 ., 6.2 .2$ & viz & 4.4 .1$. \\
\hline přikázanie & 4.4 .1 & vodné tele & 4.4 .2 .6 .2 .2 \\
\hline prikazatel & 4.4 .1 .6 .2 .2 & vypovědln lk & 4.4 .1 \\
\hline priklad & 4.4 .1 & vaieti křest & 6.2 .1 \\
\hline prislovie & 4.4 .1 & zabř̀̃denie & 4.4 .2$. \\
\hline prokn1 & 4.4 .3 & zajisté & 4.4 .1 \\
\hline prositi & 4.4 .4 .1 & zakonn Ik & 4.4 .1$. \\
\hline rost & 4.4 .2 & zákony & 4.4 .5 .1 \\
\hline rovenstvie & 4.4 .1 & zavěrné & 4.4 .1 \\
\hline rozputie cestné & 4.4 .5 .2 & zbluzovati & 4.4 .4 .2 \\
\hline rybitev & 4.4 .2 & zdravie vdáti & 4.4 .4 .1 \\
\hline sen (Pron.) & 8.1 .3$. & 2 jêvn $1 k$ & 4.4 .1 \\
\hline
\end{tabular}



z jěvný hĭiešnı́k
4.4 .1 .
zadny
4.4.3.
zvon ryby
4.4.5.2.
zivot
4.4 .2 .6 .2 .2 .

A l t $k$ i $r h$ e $n$ s 1 a $i s c h$ :
I i cemèrz
4.4.1.
zatskati
$4 \cdot 4 \cdot 5 \cdot 1$.
podragz
4.4.5.2.

P $\circ$ l n i s c h :

dzwono

4.4.5.2.

De uts c h :

Jïnger

4. 4. 1 .

knurren

4. 4.1 .

L a te $1 \mathrm{n}$ :

adorare

amen

benedicere

byssus

clarificare

daemoni um

discipulus

Dominus

ecce

ecclesia

ethnicus

exitus viarum

extremum digiti

favus

fimbria

gazofilacium

gloria

hora

hydropicus

hypocrita

iustitia

lepra

leprosus
4. 4. 4. 1 .

4.4.1.

4.4.4.1.

4.4.5.2.

4.4 .4 .1 .

4.4.1.,6.1.

4. 4.1 .

4.4 .1 .6 .1 .

4. 4.1 .

4. 4.1 .

4. 4.1 .

4.4.5.2.

4.4.5.1.

4.4 .5 .2 .

4.4.5.2.

4.4.5.1.

4.4 .1 .

4.4 .2 .

$4.4 .2,6.2 .2$.

4.4 .1 .

4.4 .1 .6 .2 .2 .

4.4.2., 6.2.2.

4.4 .2 .6 .2 .2 . mandatum

mysterium

nemo

non est opus

omnis

oportunus

parabola

paralyticus

pars piscis

pater familias

pax

Pharisaeus

phylacterium

piscator

pontifex

porticus

praeceptor

proverbium

publicanus

ourpura

rabbi

puteus
4.4 .1 .

4.4 .1 .

4. 4.3 .

4.4.5.2.

4.4 .3 .

4.4.5.1.

4.4 .1 .

4.4.2.

4.4.5.2.

4.4.2.

4.4.1.

4.4.1.

4.4.5.2.

4. 4.2 .

$4.4 .1 .6 . \pi \ldots$

6.2 .2 .

4.4.5.1.

4.4 .1 .6 .2 .2 .

4.4 .1 .

4.4. 1 .

4.4.5.2.

6.2 .2 .

4.4 .5 .1 . 


$\begin{array}{llll}\text { sabbatum } & 4.4 .2 . & \text { similitudo } & 4.4 .1 . \\ \text { sacerdos } & 4.4 .1 .6 .1 . & \text { stadium } & 4.4 .2 . \\ \text { salutare } & 6.2 .2 . & \text { sterilis } & 4.4 .5 .1 . \\ \text { sanctificare } & 4.4 .4 .1 . & \text { stridor dentium } & 7.1 . \\ \text { scandalizare } & 4.4 .4 .1 . & \text { synagoga } & 4.4 .1 .66 .2 .2 \\ \text { scorpio } & 4.4 .4 .2 . & \text { temptator } & 4.4 .1 . \\ \text { scriba } & 4.4 .2 . & \text { veritas } & 4.4 .1 .6 .2 .2 \\ \text { sermo } & 4.4 .1 . & \text { vigilia } & 4.4 .2 . \\ \text { sequi } & 4.4 .1 . & \text { zelus } & 4.4 .5 .1 .\end{array}$

REGISTER DER BIBELZITATE

\begin{tabular}{|c|c|c|c|}
\hline Mt $\quad 1,2-26$ & 4.3 .4 .4 & 5,1 & 4.4 .1 \\
\hline 11 & 4.4 .5 .1 & $1-12$ & 4.5 .1 \\
\hline 18 & $8.2 .2 \ldots 10.6$ & 2 & 4.4 .1 \\
\hline 19 & 8.2 .2 & 4 & 10.8 \\
\hline 20 & $4.3 \cdot 1.1 .2$ & 10 & 9.1 .6$. \\
\hline 2,1 & 4.2 .2 .1 & 13 & 4.4 .1$. \\
\hline 4 & $4 \cdot 4 \cdot 1$ & 20 & 4.4 .1$. \\
\hline 7 & $4.3 .1 .1 .3 ., 10.6$ & 22 & 4.2 .1 .4 .4 .3 \\
\hline 8 & $4.3 \cdot 1.2 .1$ & 23 & $4 \cdot 4 \cdot 4 \cdot 3$. \\
\hline 11 & $4.3 .1 .1 .1 ., 4.4 .4 .1 \ldots$ & 44 & 4.4 .4 .1 \\
\hline & $4 \cdot 4 \cdot 5 \cdot 1$. & 46 & 4.4 .1$. \\
\hline 15 & 4.3 .1 .2 .2 & 47 & 4.4 .1 .4 .4 .4 .1$. \\
\hline 16 & 4.4 .5 .1 & 6,1 & 4.4 .1$. \\
\hline 18 & 4.3 .1 .2 .1 & 2 & 4.4 .1 \\
\hline 20 & 9.1 .5 & 16 & 7.2 \\
\hline 23 & 4.3 .1 .1 .2 & 24 & $4.4 .1 . .9 .1 .4$ \\
\hline 3,15 & 4.4 .1 & 26 & $4.1 ., 4.4 .4 .3$. \\
\hline 16 & 4.3 .1 .2 .2 .7 .2 & & 9.1 .4$. \\
\hline 17 & $4.2 .1 ., 8.1 .2$ & 29 & 4.4 .1$. \\
\hline $4,1-11$ & 4.4 .1 & 33 & 4.4 .1$. \\
\hline 3 & 4.4 .1 & 7,15 & 4.4 .1 \\
\hline 6 & 10.6 & 16 & 4.4 .2 \\
\hline 9 & 4.4 .4 .1 & 17 & 10.8. \\
\hline 20 & 4.3 .1 .1 .1 & 8,2 & $4.4 .2 ., 4.4 .4 .1$ \\
\hline 21 & 4.4 .2 & 3 & 4.4 .2 \\
\hline
\end{tabular}




\begin{tabular}{|c|c|c|c|}
\hline Mt 8,6 & 9.1 .6$. & $16,13-19$ & 4.5 .1$. \\
\hline 12 & 7.1 & 15 & $4 \cdot 3 \cdot 3 \cdot 1$ \\
\hline 9.2 & 4.4 .2 & 18 & 4.4 .1$. \\
\hline 10 & $4.3 .1 .1 .4 . .4 .4 .1$ & 27 & $4.3 .2 .1 .2 ., 4.4 .1$ \\
\hline 11 & 4.4 .1 & 17,5 & 4.2 .1 \\
\hline 12 & $4 \cdot 4 \cdot 5 \cdot 2$ & 6 & $4 \cdot 3 \cdot 1 \cdot 2 \cdot 1$ \\
\hline 23 & 9.1 .5 & 7 & $4.3 \cdot 4 \cdot 1$ \\
\hline 10,8 & 4.4 .2 & 18,6 & 4.4 .4 .2 \\
\hline 16 & 4.4 .1$. & 7 & 4.2 .2 .2 \\
\hline 11,3 & 4.3 .2 .1 .2 & 8 & 4.4 .4 .2 \\
\hline 4 & $4 \cdot 3 \cdot 1 \cdot 2 \cdot 1$ & 9 & 4.4 .4 .2$. \\
\hline 7 & $4.2 .2 .2 ., 4.3 .1 .1 .2$ & 15 & $4.3 .2 .1 .1 \ldots 8.2 .2 \ldots$ \\
\hline 8 & $4.2 .2 .2 .4 .3 .1 .2 .2 \ldots$ & & 4.3 .2 .2 .3 \\
\hline & 4.3 .4 .2 & 17 & 4.4 .1 .9 .1 .5 \\
\hline 9 & 4.2 .2 .2 & 23 & 4.4 .1$. \\
\hline 30 & 4.2 .2 .1$. & 24 & 4.4 .2 \\
\hline 12,38 & 4.4 .1 & 19.27 & 4.4 .1 .8 .1 .2 \\
\hline $38-39$ & 13.1 & $27-29$ & 4.5 .1 \\
\hline 39 & 10.8 & 29 & 4.4 .3 \\
\hline 42 & 4.4 .5 .1 & 20,1 & 4.4 .2$. \\
\hline $42-47$ & 13.1 & 2 & 4.2 .1$. \\
\hline 44 & 4.2 .1 & 6 & 10.6 \\
\hline 46 & 4.4 .1$. & 8 & 8.2 .2$. \\
\hline $46-50$ & 4.5 .1 & 11 & 4.4 .2 \\
\hline 50 & 13.1 & 13 & 7.1 \\
\hline 13,45 & $4 \cdot 4 \cdot 5 \cdot 1$ & 20 & 4.4 .4 .1 \\
\hline 50 & 4.3 .4 .2 .7 .1 & 21 & 7.2 \\
\hline 52 & $4.4 .1 ., 4.4 .2$ & 22 & 4.3 .2 .1 .2 .9 .1 .6$. \\
\hline 14.28 & 8.1 .2$. & 21,1 & $4.2 .1 \ldots 4.3 .2 .2 .2 \ldots$ \\
\hline 15,1 & 4.4 .1$. & & 4.3 .4 .4 .99 .1 .4$. \\
\hline 3 & 9.1 .6$. & 3 & 9.1 .4 .9 .1 .5 \\
\hline 7 & 4.4 .1 & 4 & 4.3 .1 .2 .2 \\
\hline 12 & 4.4 .4 .2 & 5 & 4.2 .2 .1 .10 .6 \\
\hline 14 & 7.2 .9 .1 .6 & 6 & 4.3 .1 .2 .1$. \\
\hline 15 & 4.4 .1$. & 9 & $4.3 .2 .1 .2 ., 10.6$ \\
\hline 20 & 4.3 .1 .2 .2 & 12 & 4.3 .4 .2 \\
\hline 21 & 4.3 .4 .2$. & 15 & 4.4 .1$. \\
\hline 26 & 4.3 .4 .2 & 17 & 4.2 .1 .4 .3 .1 .1 .3$. \\
\hline 16,13 & 4.2 .2 .2 .44 .3 .3 .1$. & 33 & 9.1 .6$. \\
\hline
\end{tabular}




\begin{tabular}{|c|c|}
\hline Mt $21,33-46$ & 4.5 .1 \\
\hline 35 & $4.3 \cdot 1 \cdot 1.1$ \\
\hline 38 & 8.1 .2$. \\
\hline 41 & $4 \cdot 3 \cdot 4 \cdot 3$ \\
\hline 45 & 4.4 .1 \\
\hline 22,7 & 4.3 .1 .1 .3 \\
\hline 9 & 4.4 .5 .2 \\
\hline 10 & 7.2. \\
\hline 12 & 6.2 .1$. \\
\hline 13 & 7.1 \\
\hline 16 & 4.4 .1$. \\
\hline 17 & 4.3 .4 .4 \\
\hline 18 & $4.3 .1 .1 .1 ., 4.4 .1$ \\
\hline 19 & 4.4 .4 .2 \\
\hline 36 & 4.4 .1 \\
\hline 38 & 4.4 .1 \\
\hline 41 & $4.3 .1 .1 .1 ., 4.3 .4 .4$. \\
\hline 23,5 & $4 \cdot 4 \cdot 5 \cdot 2$ \\
\hline 6 & 4.4 .1 \\
\hline 9 & 9.1 .6$. \\
\hline 11 & 4.4 .2 \\
\hline 34 & 4.4 .1 \\
\hline 35 & $4 \cdot 3 \cdot 4 \cdot 4$ \\
\hline 24,3 & 4.2 .1 \\
\hline 25,3 & 4.3 .1 .1 .1$. \\
\hline 28,5 & 4.3 .4 .1 \\
\hline 6 & 4.4 .1 \\
\hline 20 & 4.3 .4 .3$. \\
\hline
\end{tabular}

Mc 6,50

53

55

7,31

32

33

35

8,1

4

8

9,22

24

13,35

16,5

14

16

17

18

20
4. 3. 4. 1 .

4. 4.2 .

4.3.3.1.

4.2.2.2.

9.1 .4 .

7.2 .

4.2.2.2.

4.3.1.1.2.

4.4.1.

4.4.4.3.

4.3.1.2.3.

9.1 .5 .

4.4.2.

9.1 .6 .

4.3.1.1.2.1.,

$4.3 .3 .1 \ldots 4.3 .4 .2$.

6.2 .1 .7 .2 .

4.2 .1 .

6.2 .1 .

4.3.1.1.1..

4.3 .1 .1 .4 .
L $\quad 1,5-17$ 4.5.1.

2,2
26

29

48

49

4.4.1.

9.1 .5 .

4.3.4.2.

4.3 .4 .4 .

17-29 4.5.1.

226.1.

66.1.

94.3 .1 .1 .1$.

$4.3 .1 .2 .1 \ldots 4.4 .2$.

4.3.3.1.
7

27

36

39

40

64

10

14

28

32

34

4.4 .5 .1 .

9.1 .4 .

4.4.5.1.

9.1 .5 .

4.4.4.1.

4.4.4.1.

4.2 .1 .

$4.3 .4 .1 ., 9.1 .3$.

4. 4.1 .

4.4 .4 .1 .

4.4 .1 .

$4.4 .4 .1 ., 4.4 .5 .1 .$,

6.1 .

36

7.1 .

42

4.3.1.1.3.

43

4.3.1.1.1.,9.1.6. 


\begin{tabular}{|c|c|c|c|}
\hline 2,44 & 4.3 .3 .1 .9 .1 .6 & L $\quad 10,6$ & 4.4 .1 \\
\hline 45 & 4.3 .1 .2 .3 & 23 & 7.2 \\
\hline 46 & 4.3 .1 .2 .1 & 24 & 8.1 .2 \\
\hline 49 & 8.2 & 30 & 6.2 .1 \\
\hline 3,1 & 4.3 .1 .1 .2 & 37 & $4 \cdot 3 \cdot 3.2$ \\
\hline 4 & 9.1 .6$. & 11,5 & $4.3 .4 .4 .4 .4 .1 .$. \\
\hline 4,25 & 4.4 .1 & & 9.1 .6$. \\
\hline 27 & $4.4 .2 ., 7.2$. & 7 & 4.3 .4 .1 \\
\hline 29 & 9.1 .5$. & 8 & $4.2 .1 \ldots 10.8$ \\
\hline 5,2 & 4.2 .2 & 12 & 4.4 .2 \\
\hline 3 & 4.4 .2 & 13 & $4.3 .1 .2 .2 ., 4.4 .1$ \\
\hline 4 & $4.2 .2 .2 ., 4.4 .2$ & 14 & $4.3 .1 .2 .3 ., 4.4 .1$. \\
\hline 5 & 4.2 .2 .2 .4 .4 .1 & & 7.2 \\
\hline 11 & 4.3 .1 .1 .2 & 15 & 4.3 .4 .2 .4 .4 .1 \\
\hline 17 & 4.4 .1 & 18 & 4.3 .3 .1 .4 .4 .1$. \\
\hline 18 & 4.4 .2 & 25 & 4.2 .1 \\
\hline 21 & 4.4 .1 & 28 & 9.1 .6$. \\
\hline 24 & 4.4 .2 & 12,36 & $4.3 .1 .2 .2 ., 6.2 .1$ \\
\hline 6,17 & 4.2 .2 .2 & 39 & 4.4 .2 \\
\hline 36 & 4.4 .1 & 42 & 9.1 .6 \\
\hline 37 & $4 \cdot 3 \cdot 4 \cdot 1$ & 13,7 & 9.1 .5 \\
\hline 39 & 4.4 .1$. & 8 & $4.1 ., 9.1 .6$ \\
\hline 40 & 9.1 .4$. & 10 & 4.4 .1 \\
\hline 41 & 10.6 & 13 & 7.2 \\
\hline 42 & 4.4 .1 & 15 & 4.4 .1 \\
\hline 7,42 & $4.1 ., 4.3 .1 .1 .4$ & $15-16$ & 4.2 .2 .2 \\
\hline 49 & 6.1 & 16 & 4.2 .2 .1 \\
\hline 8,4 & 4.2 .1 .4 .4 .1$. & 14,2 & 4.4 .2 \\
\hline 8 & 4.3 .1 .2 .3 .1 & 4 & 4.4 .4 .3 \\
\hline 10 & 4.4 .1 & 5 & 4.4 .5 .1 .7 .1$. \\
\hline 12 & 9.1 .5$. & & 9.1 .6$. \\
\hline 13 & 4.3 .4 .2 & 7 & 4.4 .1 \\
\hline 9,1 & $4.3 .1 .1 .3 . .4 .4 .1$ & 10 & 4.4 .1 \\
\hline 5 & 4.2 .2 .1 & 11 & 4.4 .3$. \\
\hline 35 & 4.2 .1 & 16 & 4.4 .1$. \\
\hline $10,1-9$ & 4.5 .1 & 18 & $4.3 .4 \cdot 4$. \\
\hline 2 & 10.8 & 19 & 9.1 .6 .10 .8 \\
\hline 4 & $4.4 .4 .1 ., 4.3 .4 .1$ & 21 & 4.2 .1 .4 .4 .2 \\
\hline 5 & 4.4 .1 .9 .1 .6$. & 24 & 7.1 .8 .1 .2$. \\
\hline
\end{tabular}




\begin{tabular}{|c|c|c|c|c|}
\hline 14,27 & 4.4 .1 & L & 21,19 & 4.4 .2 \\
\hline 28 & $4 \cdot 3 \cdot 1 \cdot 2 \cdot 3 \cdot 1$ & & 25 & $4.3 .4 .2 ., 9.1 .4$ \\
\hline 15,1 & 4.4 .1 & & 27 & 4.3 .1 .2 .2 \\
\hline 2 & 4.4 .1 & & 28 & 4.3 .1 .1 .2 .1 \\
\hline 3 & 4.4 .1$. & & 30 & 9.1 .5 \\
\hline 6 & 6.2 .1 & & 31 & $4 \cdot 3 \cdot 3 \cdot 1$ \\
\hline 7 & $4.3 .1 .2 .2 ., 7.1$ & & 22.24 & 4.4 .1 . \\
\hline 9 & 6.2 .1 & & 24,13 & 4.4 .2 \\
\hline 10 & 4.3 .1 .2 .2 & & 16 & 4.4 .4 .2 \\
\hline 16,1 & 4.2 .1 .4 .2 .2 .1$. & & 17 & 7.2 \\
\hline & 4.4 .1 & & 18 & $4 \cdot 3 \cdot 4 \cdot 3$. \\
\hline 6 & $4.2 .1,4.4 .2 \ldots, 7.1$ & & 23 & $4.3 .1 .1 .1 ., 9.1 .6$ \\
\hline 7 & $4.4 .2 ., 9.1 .4$ & & 26 & 4.4 .1 \\
\hline 8 & 4.2 .2 .1 & & 27 & 4.2 .1 .4 .3 .1 .2 .1 \\
\hline 19 & $4.4 .1 \ldots, 4.4 .5 .2$ & & 30 & $4 \cdot 4 \cdot 4 \cdot 1$ \\
\hline 21 & $4.2 .1 ., 7.2 ., 9.1 .5$ & & 36 & $4 \cdot 3 \cdot 4 \cdot 1$ \\
\hline 22 & 7.2 & & 37 & 4.3 .3 .1$. \\
\hline 24 & $4 \cdot 4 \cdot 5.1$ & & 39 & $4 \cdot 3 \cdot 3 \cdot 1$ \\
\hline 25 & 10.6 & & 41 & 4.3 .1 .1 .2 \\
\hline 30 & 9.1 .6$. & & 42 & 4.4 .5 .2 \\
\hline 31 & $4.3 .2 .2 .3 ., 7.2$. & & & \\
\hline 17,12 & 4.4 .2 & & & \\
\hline 13 & 4.4 .1 & $\mathrm{~J}$ & 1,7 & $4.2 .1 ., 8.1 .2$. \\
\hline 14 & 4.4 .1 & & 9 & 9.1 .4 \\
\hline 15 & $4 \cdot 3 \cdot 3 \cdot 1$ & & 10 & 4.4 .1 \\
\hline 18 & 6.1 & & 14 & 4.4 .1$. \\
\hline 18,9 & 4.4 .4 .3 & & 24 & 4.4 .1 \\
\hline 10 & 4.4 .1 & & 2,3 & 4.3 .1 .1 .3 \\
\hline 12 & 4.4 .2 & 1 & 4 & $4.3 \cdot 4 \cdot 4$. \\
\hline 14 & $4.2 .1 ., 4.4 .3$ & & 11 & 4.4 .1 \\
\hline 35 & 4.2 .1 & & 17 & 4.4 .5 .1$. \\
\hline 19,2 & $4 \cdot 4 \cdot 1$ & & 19 & 7.1 \\
\hline 5 & 9.1 .4 & & $3,1-15$ & 4.5 .1 \\
\hline 42 & 4.2 .1 & & 3 & 4.3 .2 .1 .1 .8 .2$. \\
\hline 43 & 4.2 .2 .1 & & 8 & 4.4 .3 \\
\hline 44 & 4.2 .1 & & 16 & 4.4 .1 \\
\hline 45 & $4 \cdot 4 \cdot 4 \cdot 3$ & & 20 & 7.2 . \\
\hline 21,9 & $4.3 .4 .1 ., 4.4 .5 .1$ & & 21 & 4.4 .1$. \\
\hline 15 & 4.3 .4 .4 & & 4,6 & 4.4 .2 . \\
\hline
\end{tabular}




\begin{tabular}{|c|c|c|c|}
\hline $\mathrm{J} \quad 4,8$ & 4.3 .2 .2 .1 & 7,23 & 9.1 .5 \\
\hline 11 & 4.4 .5 .1 & 24 & 4.3 .4 .1 \\
\hline 12 & $4.2 .1 . .4 .4 .5 .1$ & 32 & 4.4 .1$. \\
\hline 23 & 4.4 .1 & 33 & 9.1 .2$. \\
\hline 24 & 9.1 .6$. & 35 & $4.3 .2 .1 .2 ., 4.3 .4 .4$. \\
\hline 28 & 8.1 .2$. & 36 & 9.1 .2$. \\
\hline 41 & 4.4 .1 & 39 & 4.3 .2 .1 .2 .9 .9 .3 \\
\hline 52 & $4.4 .2 ., 9.1 .4$ & 45 & 4.4 .2 \\
\hline 5,2 & 4.4 .5 .1 & 46 & 4.4 .2 \\
\hline 4 & 8.2 .2 & 48 & 9.1 .6$. \\
\hline 9 & 4.4 .2 & 49 & $4.4 .4 \cdot 3$ \\
\hline 13 & $4.3 \cdot 1 \cdot 1.1$ & 8,2 & 4.4 .2 \\
\hline $17-29$ & 4.5 .1 & 3 & 9.1 .6$. \\
\hline 19 & 4.3 .1 .2 .2 & 4 & 9.1 .6$. \\
\hline 21 & 4.2 .2 .2 & 7 & 4.2 .2 .1 \\
\hline 28 & 9.1 .6$. & 12 & $4.2 .2 .1 ., 4.4 .4 .1$ \\
\hline 29 & 4.3 .4 .2 .9 .1 .6 & 16 & 9.1 .3$. \\
\hline 30 & 4.2 .2 .1 & 20 & 4.4 .5 .1 \\
\hline 31 & 8.2 & 25 & 8.2. \\
\hline 33 & $4.3 \cdot 4.2$ & 32 & 4.4 .1 \\
\hline 35 & 9.1 .6$. & 37 & 4.4 .1 \\
\hline 36 & 4.1 & 42 & $4.3 .2 .2 .3 ., 10.8$ \\
\hline 39 & 4.2 .2 .1$. & 43 & 4.4 .1 \\
\hline 44 & 4.2 .2 .1 & 46 & $4.3 .2 .2 .3 ., 9.1 .2$ \\
\hline 46 & 4.3 .2 .2 .3 & $46-59$ & 4.5 .1 \\
\hline 47 & $9.1 .6 \ldots, 10.8$ & 47 & 9.1 .6$. \\
\hline 6,4 & 4.3 .4 .2 & 48 & 4.4 .1$. \\
\hline 10 & 7.1 & 51 & 4.4 .1$. \\
\hline 12 & $9.1 .4 ., 9.1 .6$. & 54 & 9.1 .3$. \\
\hline 27 & 9.1 .5 & 55 & 4.3 .2 .1 .1$. \\
\hline 31 & 7.1 & & $4.3 .2 .2 .3 ., 8.2 .2$ \\
\hline 45 & 4.4 .1 & 59 & $4 \cdot 3 \cdot 2 \cdot 2.1$ \\
\hline 56 & 4.4 .1 & 9.7 & 4.2 .2 .2 \\
\hline $56-59$ & $3.5 ., 4.5 .1$ & 10 & 9.1 .5 . \\
\hline 7,4 & 7.2 & 11 & 10.8 \\
\hline 6 & 9.1 .6$. & 31 & 9.1 .5 . \\
\hline 13 & 7.2 & 10,1 & 4.4 .1 \\
\hline $14-31$ & 4.5 .1 & 6 & 4.4 .1 \\
\hline 20 & 4.4 .1$. & 23 & 4.4 .5 .1 \\
\hline
\end{tabular}




\begin{tabular}{|c|c|}
\hline 10,30 & 7.2 . \\
\hline 31 & 4.4 .4 .3$. \\
\hline 36 & 4.4 .4 .1 \\
\hline $11,1-45$ & 4.5 .1 \\
\hline 8 & 4.4 .1 \\
\hline 9 & 4.4 .2 . \\
\hline 10 & 7.2 . \\
\hline 11 & 9.1 .5 . \\
\hline 13 & 4.3 .4 .2 \\
\hline 18 & 4.4 .2 \\
\hline 21 & 4.4.1. \\
\hline 22 & 9.1 .3$. \\
\hline 28 & 4.3 .2 .2 .2$. \\
\hline 29 & 4.3 .2 .2 .1 \\
\hline 31 & 4.3 .2 .1$. \\
\hline 32 & $4.3 .2 .2 .2 ., 4.4 .1$. \\
\hline 33 & 4.2 .1 \\
\hline 34 & $4.3 .2 .1,, 4.4 .1,7.2$ \\
\hline 35 & 4.3 .2 .1 \\
\hline 36 & $4.3 .2 .1 . .6 .2 .1$ \\
\hline 39 & $4.2 .1,4.4 .1,7.1$ \\
\hline 41 & 4.2 .1 \\
\hline 43 & $4.3 .2 .2 .2 ., 6.2 .1$ \\
\hline 47 & 4.4 .1 \\
\hline 51 & 4.3 .2 .1 .2 \\
\hline 52 & 9.1 .3$. \\
\hline 54 & 9.1 .5$. \\
\hline 12,1 & 8.1 .2 . \\
\hline 4 & 4.3 .2 .1 .2 \\
\hline 18 & 4.3 .3 .1$. \\
\hline 19 & 4.4 .4 .1$. \\
\hline 20 & 4.4 .4 .1 \\
\hline 23 & 4.4 .4 .1$. \\
\hline 24 & $\begin{array}{l}4.3 .2 .1 .1 ., 8.2 .2 ., \\
9.1 .6 ., 9.1 .5 .\end{array}$ \\
\hline 25 & $4.3 .2 .1 .1 .8,8.2 .2$ \\
\hline 26 & 4.4 .2$. \\
\hline 28 & 4.4 .4 .1$. \\
\hline 33 & 4.3 .2 .1 .2$. \\
\hline
\end{tabular}

J 13,5

9.1.5.

6

9.1.5.

10

4.2.2.2.

11

14,9

9.1.5.

15

18

21

23

24

27

28

30

31

15,19

20

21

16,1

2

5

6

8

10

12

13

14

16

17

23

25

27

28

29

30

17,1

3

4-5

5
8.1.2.

4.4.1.

9.1 .4 .

4.4.1.

4.4.1.

4.4.1.

$4.4 .1,9.1 .6$.

4.3.2.2.3.

4.3.4.2., 6.2.1.

4.4.1.

4.3.2.2.3.

4.1 .

8.1.2.

4.4.4.2.

4.2.2.1., 4.3.3.1.,

$4.4 .1 ., 9.1 .6$.

4.4.1.

4.4 .4 .3 .

4.4.1.

4.4.1.,9.1.4.

9.1.1., 10.6 .

4.3.2.1.2., 6.2.1.

4.3.2.1.2.,4.4.4.1.

9.1.4.

4.4.1.,9.1.4.

4.4.1.

4.4.1.

6.2 .1 .

9.1 .4 .

4.4.1.

4.4.5.2.

4.4 .4 .1 .

8.1.2.

4.4.4.1.

8.1.2. 


\begin{tabular}{|c|c|}
\hline $\mathrm{J} \quad 17,10$ & 4.4 .4 .1 \\
\hline 14 & $4.3 \cdot 1.1 .2$. \\
\hline 17 & 4.4 .4 .1 \\
\hline 19 & 4.4 .4 .1 \\
\hline 20 & 4.3 .2 .1 .2 \\
\hline 19,15 & 4.4 .1 \\
\hline 18 & 9.1 .2$. \\
\hline 21 & $4.3 .4 .1 ., 4.4 .1$ \\
\hline 23 & 9.1 .2$. \\
\hline 31 & 4.4 .2 \\
\hline 38 & 4.3 .4 .2 \\
\hline 39 & 4.4 .2 \\
\hline 40 & 9.1 .2$. \\
\hline 20,13 & 4.4 .1 \\
\hline 17 & 4.3 .4 .1 \\
\hline 19 & $4.4 .1 \ldots 8.2 .2 \ldots, 9.1 .4 \ldots 9.1 .6$ \\
\hline 21 & 4.4 .1 \\
\hline 26 & $4.3 .1 .1 .5 ., 4.4 .1$ \\
\hline 28 & 4.4 .1 \\
\hline 21,11 & 4.2 .2 .2 \\
\hline 12 & 4.2 .2 .2 .4 .3 .1 .2 .1 \\
\hline 19 & 4.4 .4 .1 \\
\hline
\end{tabular}




\section{FAKSIMILIA}

Handschriftenmuster

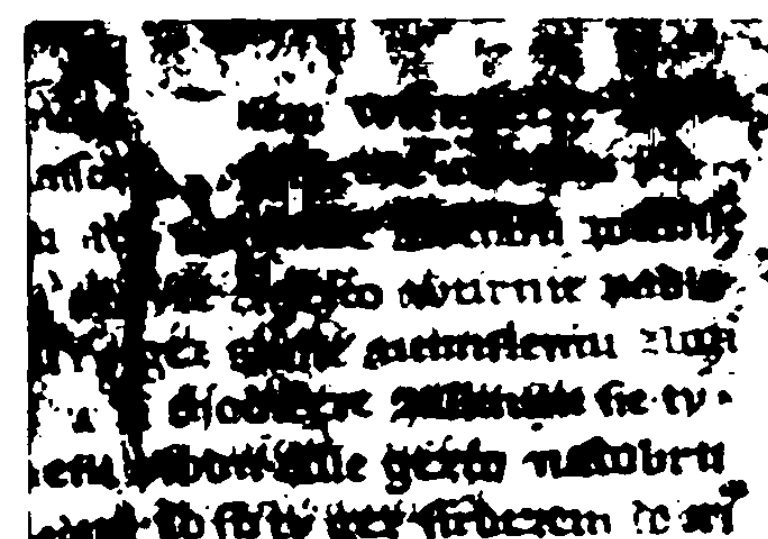

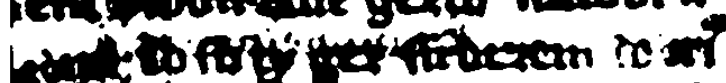

$$
2 b^{\prime}(L 8,12-15)
$$

$1 a^{\prime}$ (Mt $\left.12,44-47\right)$

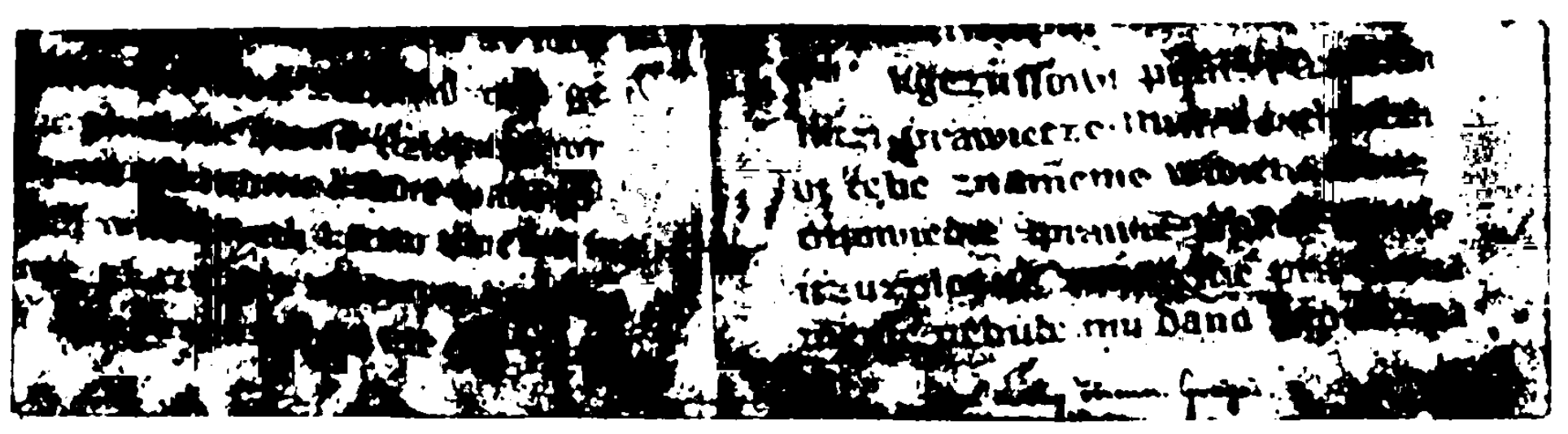

$2 b \quad($ Mt $6,18-21)$

1 a (Mt $12,38-39)$

Fragment A; Nationalmuseum Prag, Sign. 1 AC 47 


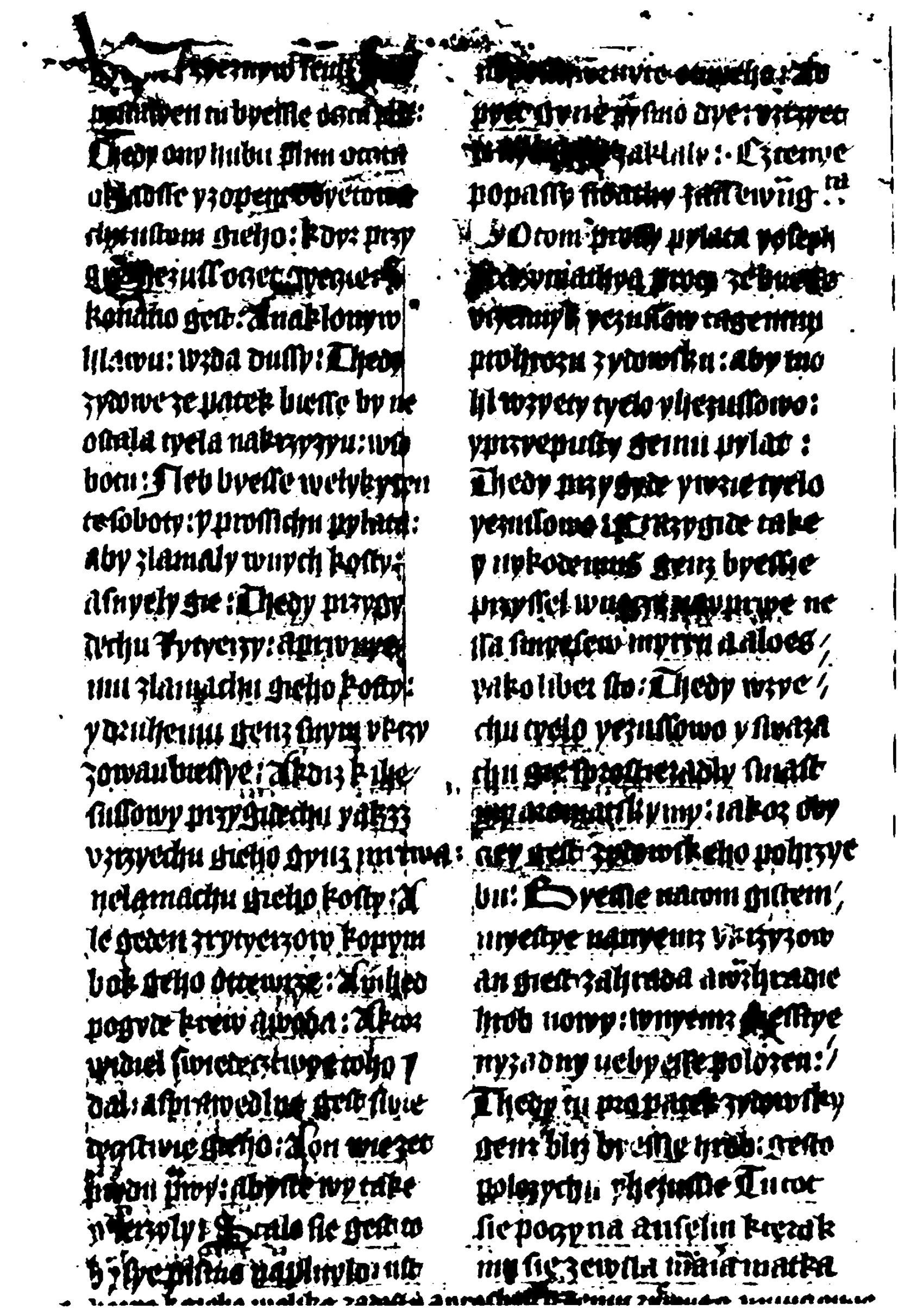

Fragment C; Nationalmuseum Prag, S1gn. 1 AC 67 , fol. 2b 


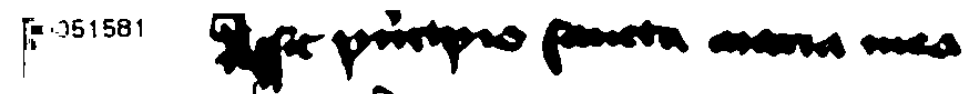

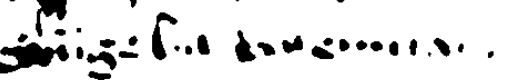

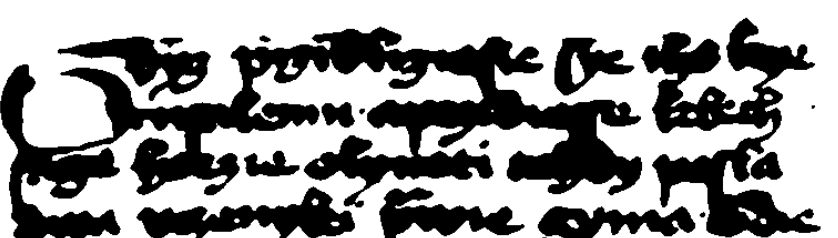

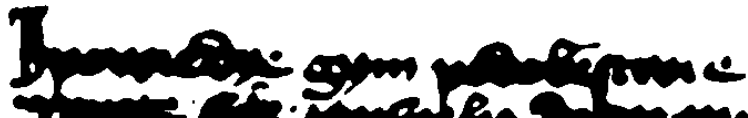

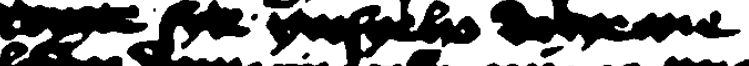
P.

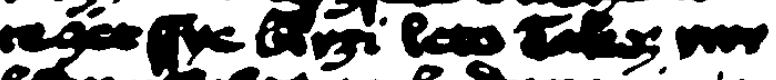

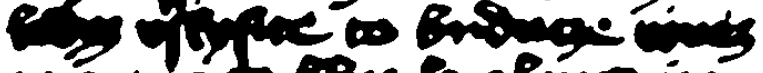
inne

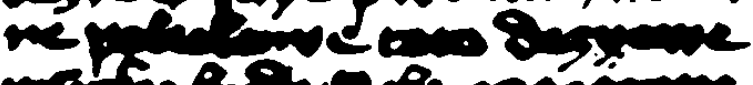

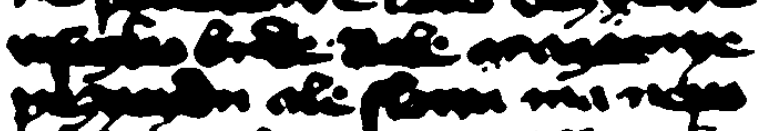

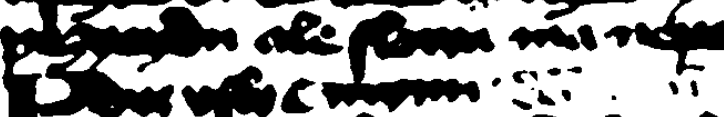

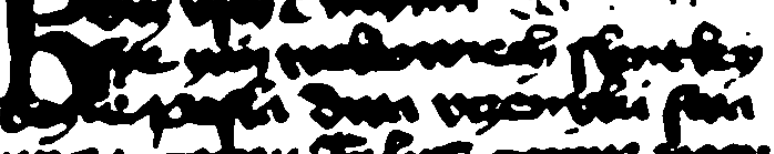

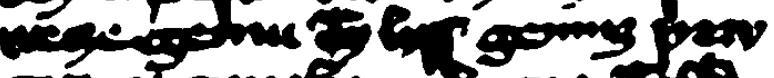

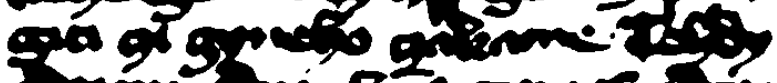

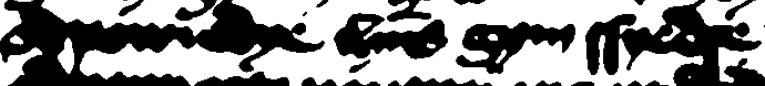
tow in imatrich

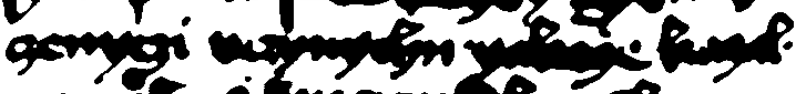

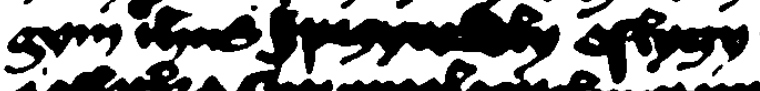
a ancher

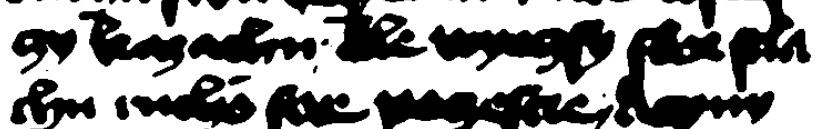

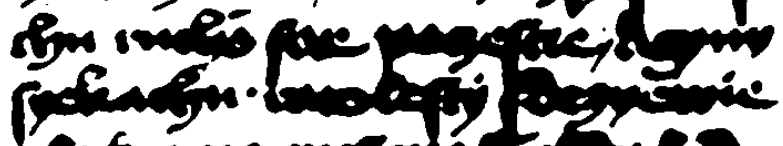

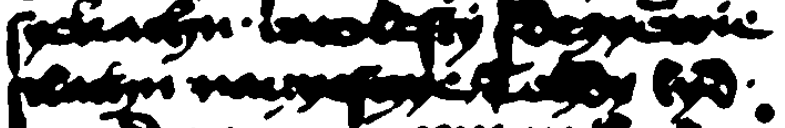
m

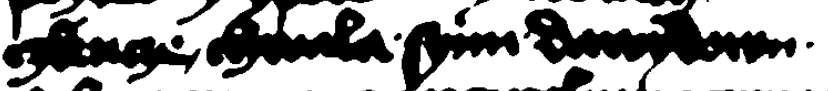

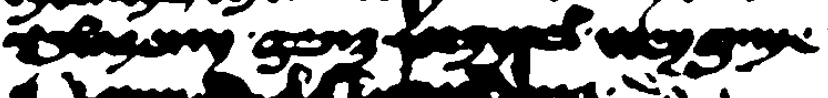

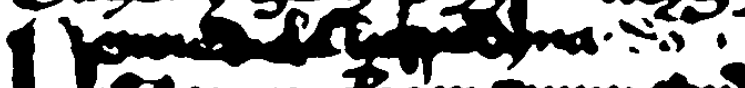

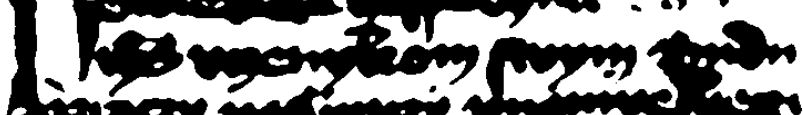
S ymans mernon jive ensumen

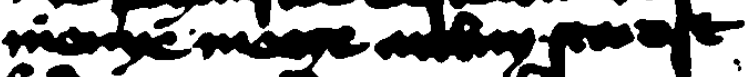

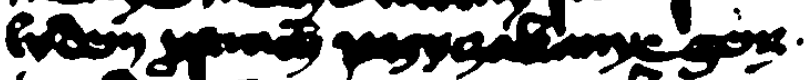

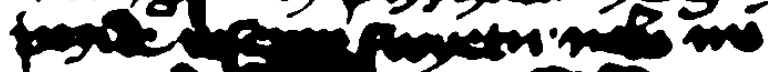
5y we -

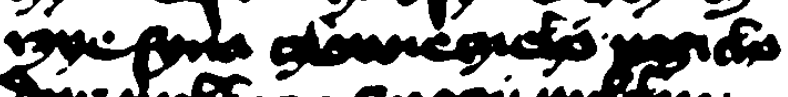

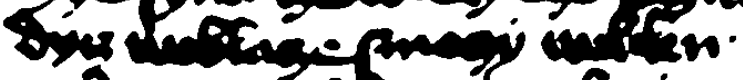

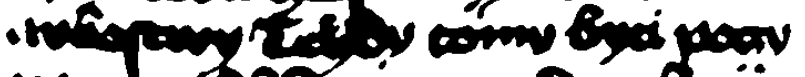

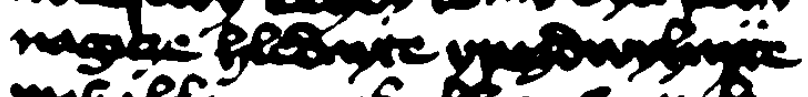

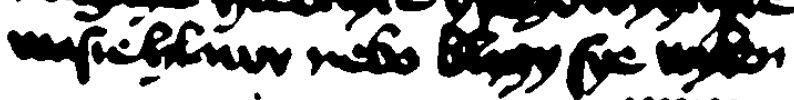

rines

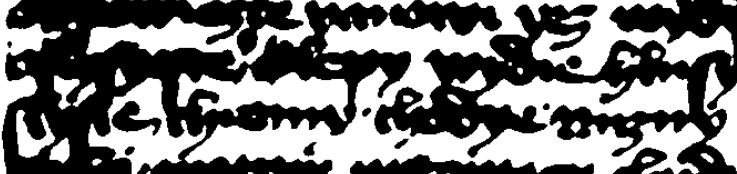

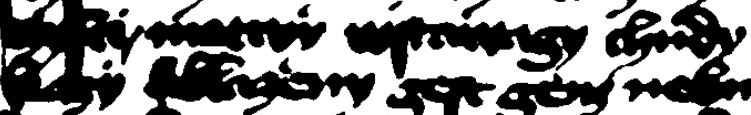

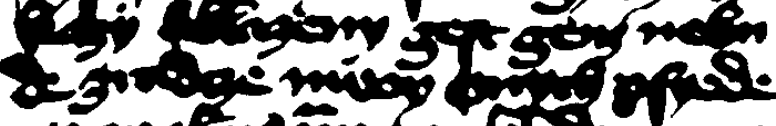

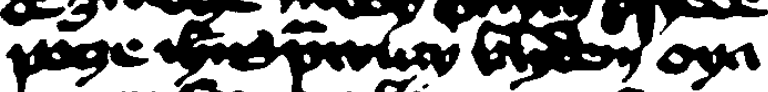

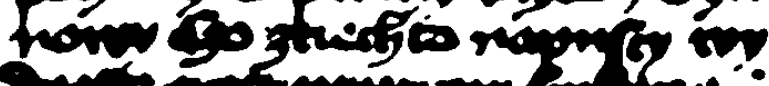
"is

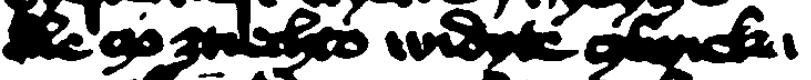

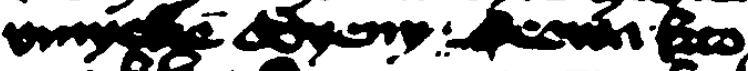

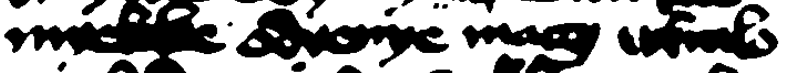

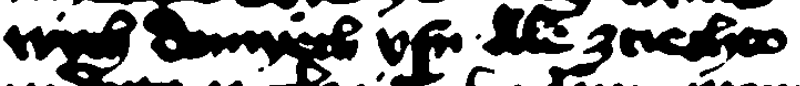

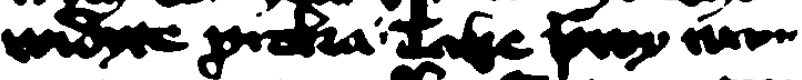

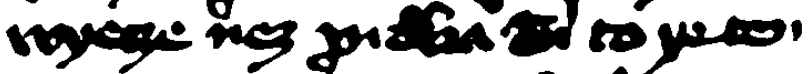

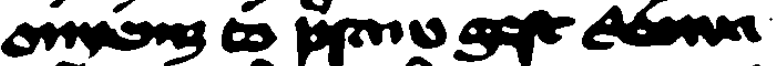

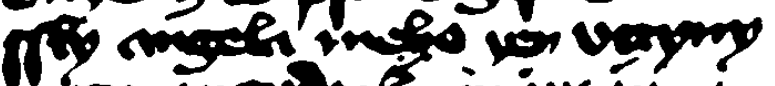

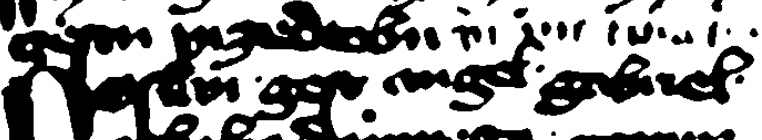

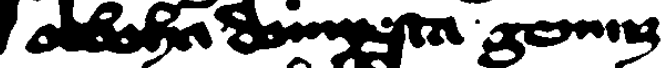

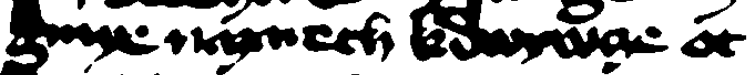
\%

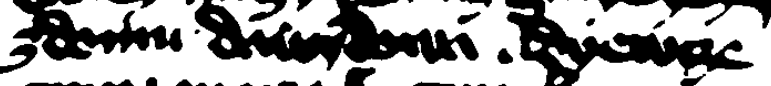

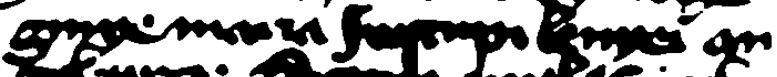
\& Fune so

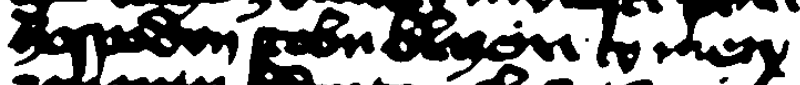

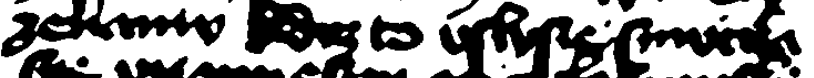
he on

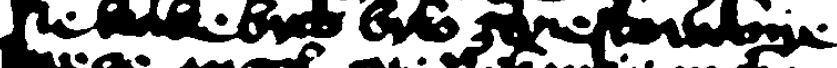

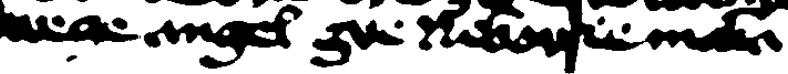

Seitenstettener Evangeliar, Sign. der Stiftsbibliothek CCLXXII;

fol. 139a (neuere Foliation - 144a); 4t 21,1-9; L 21,25-33; 


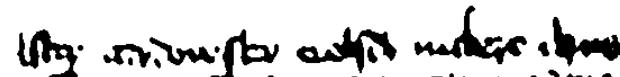

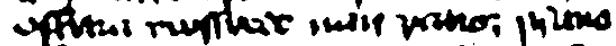

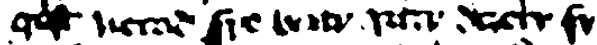

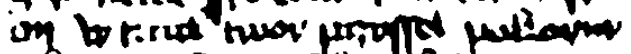

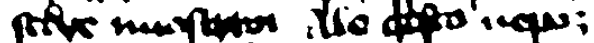

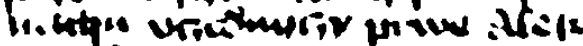

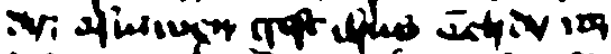

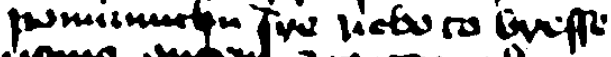

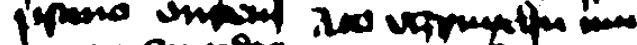

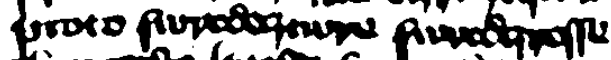

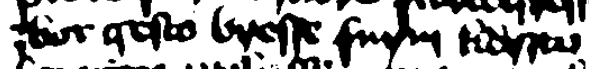

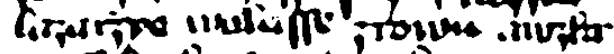

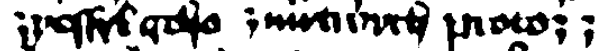

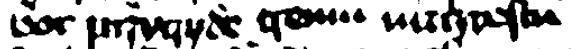

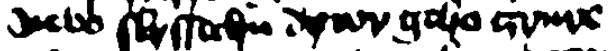

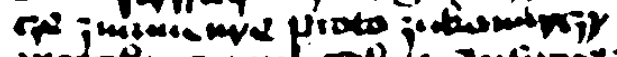

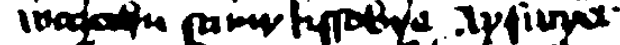

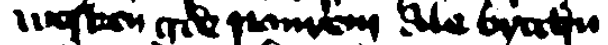

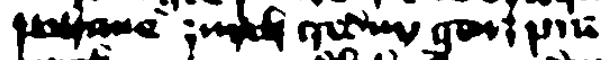

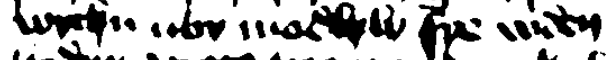

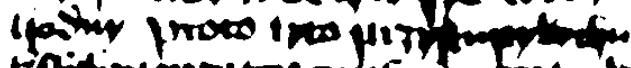

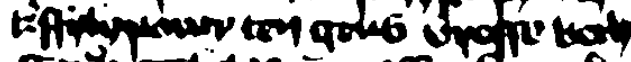

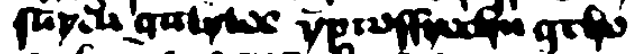

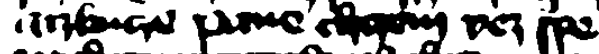

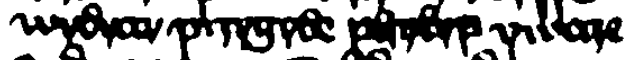

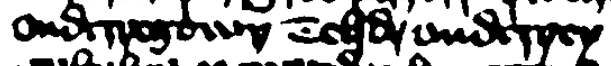
upheans purvasyan get

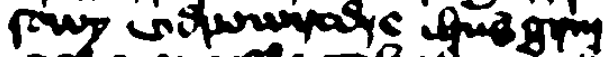

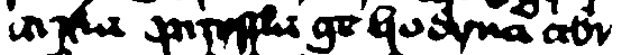

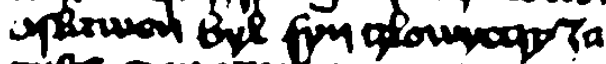
gifto appirux prixay whim

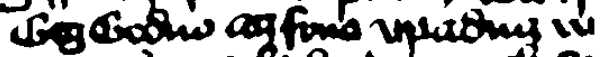
jomw tom zots envix grmath pa

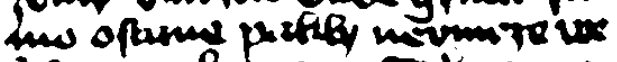

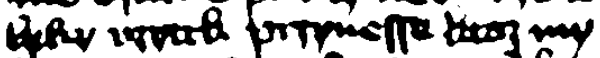

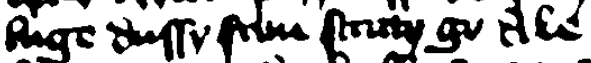

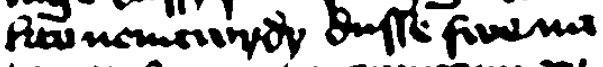
tomes firveted nalupomy iv

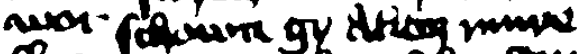

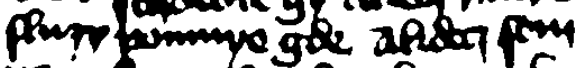

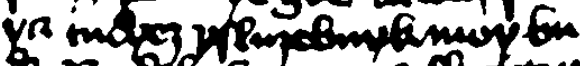

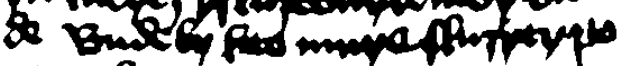
ntegres onter moy gery man

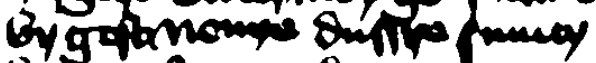
hiflegof waor sxm dequ'

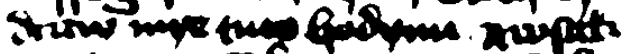

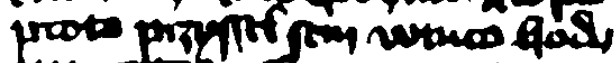

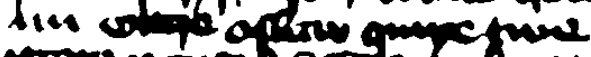

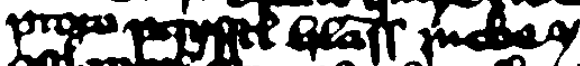

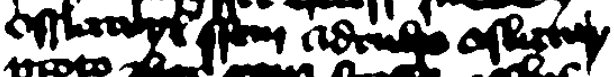

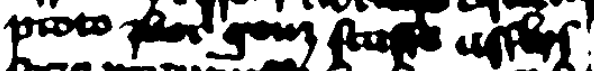

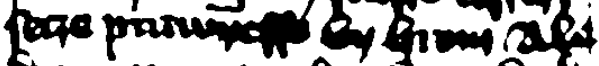

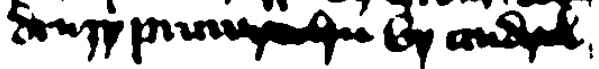

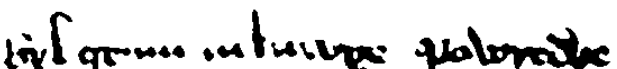

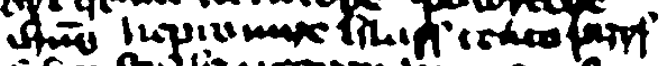
if gef ille pronvy livane of

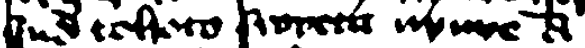

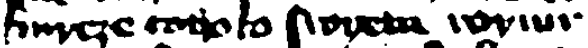

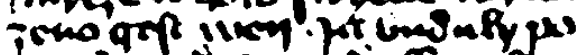

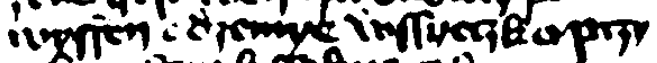

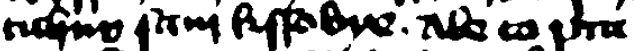

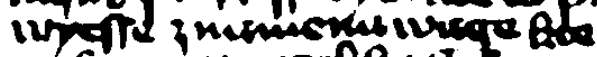

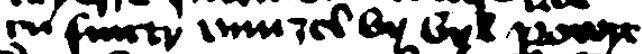

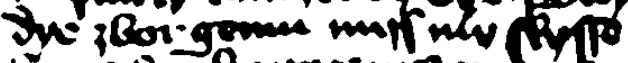

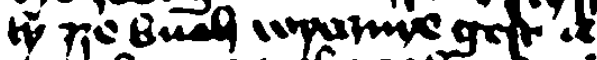

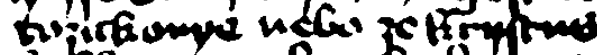

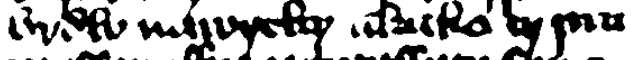

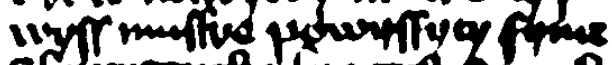

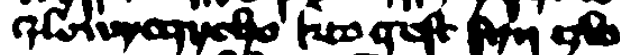

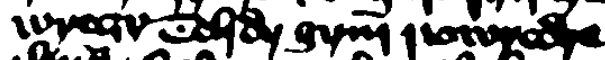

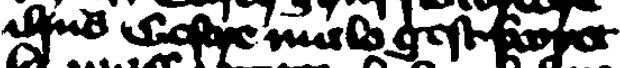

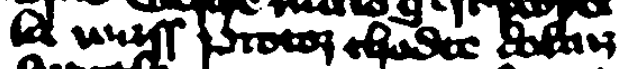

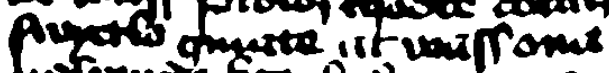

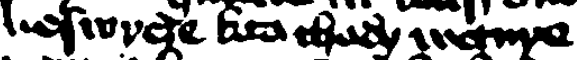

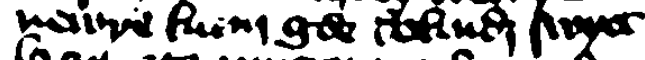

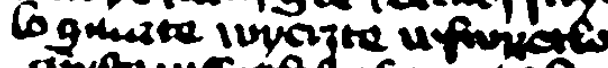

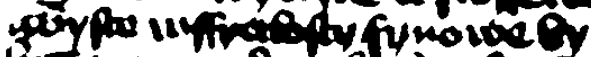

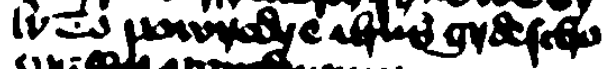

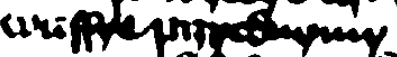

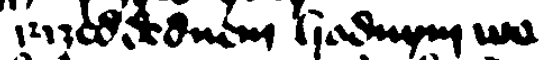

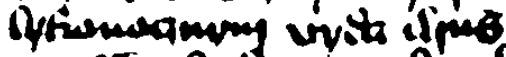

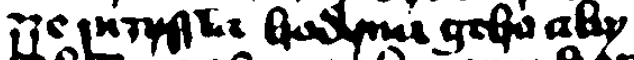

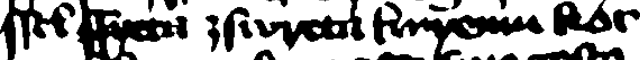

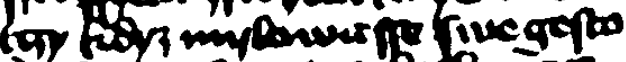

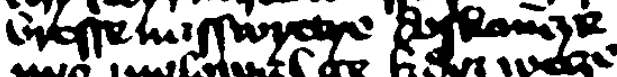

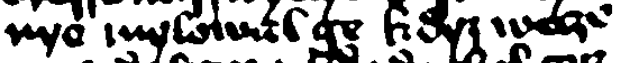

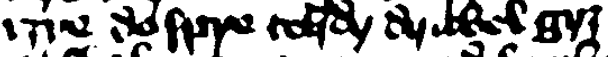

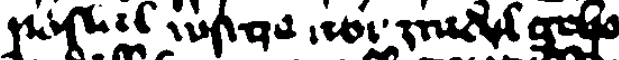

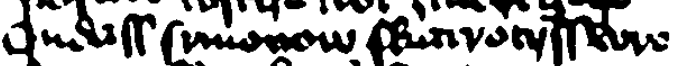

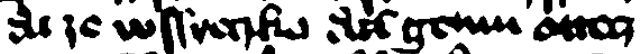

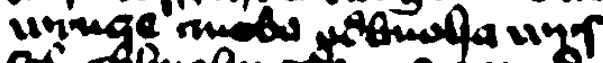

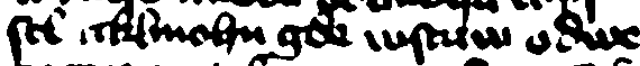

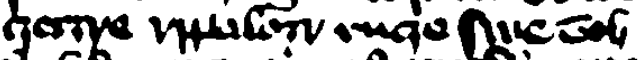

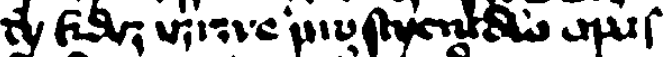

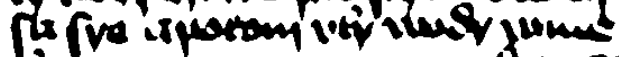

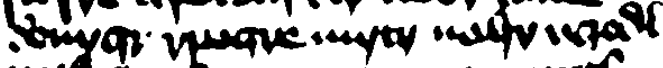

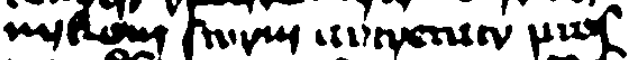

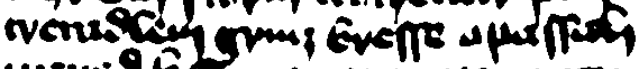

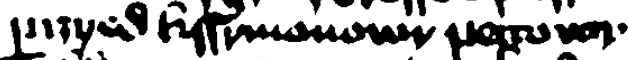

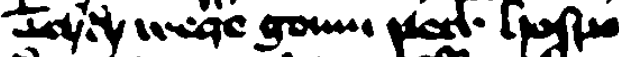

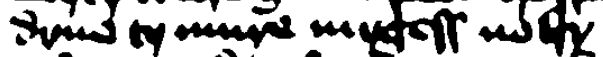

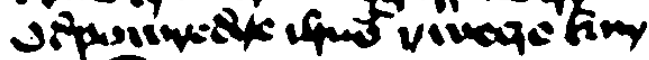

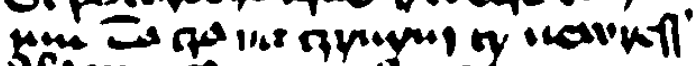

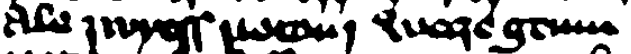

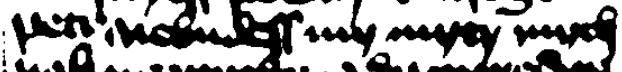

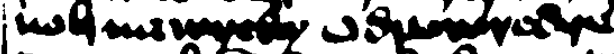

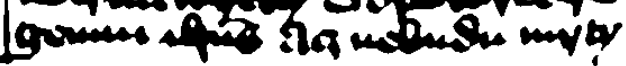

Rajhrader Evangeliar, Univ.Bibl. Brünn, Sign. R 364;

fol. 116a; J 12,13-36; J 13,1-8 
ir

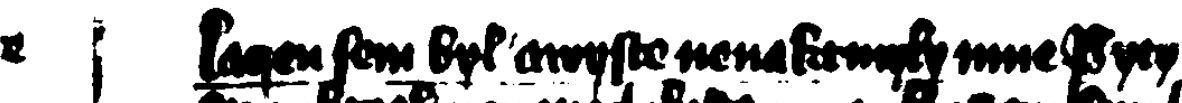

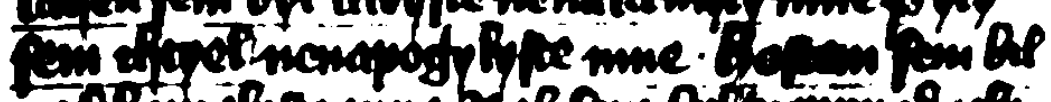

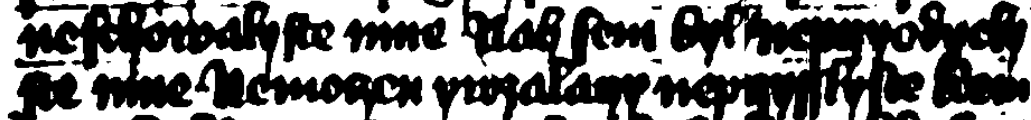

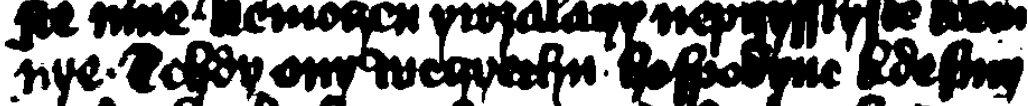

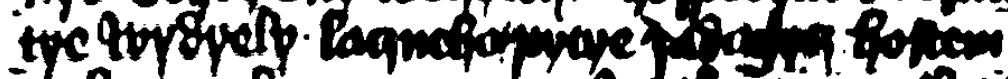

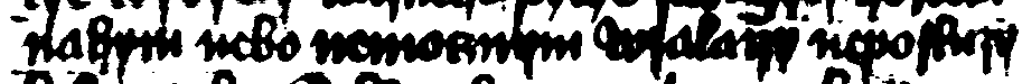

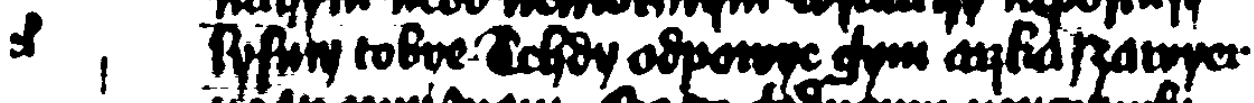

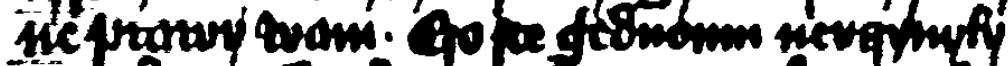

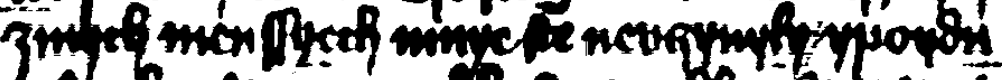

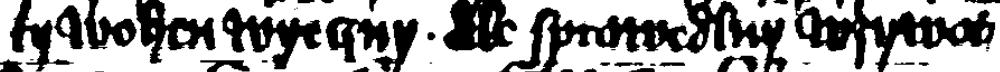

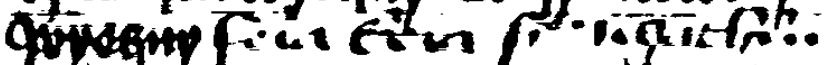

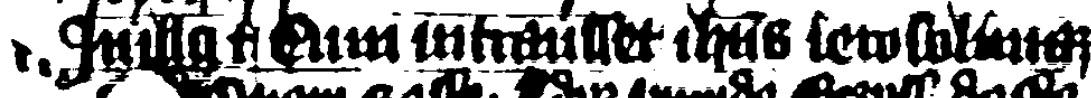

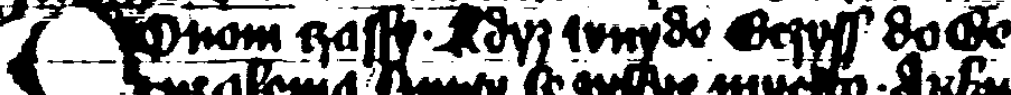

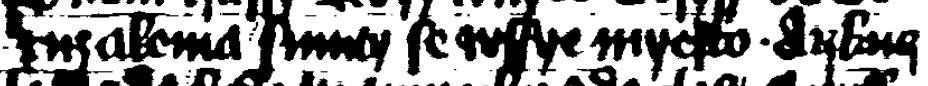

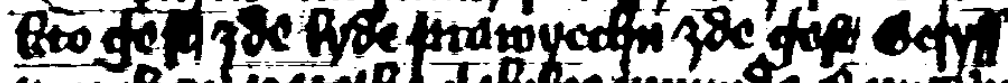

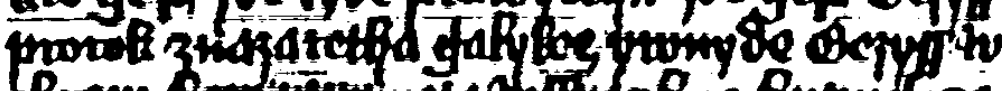

9

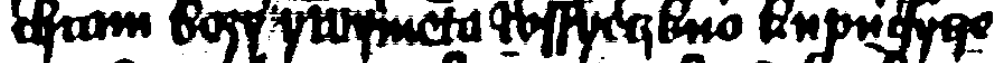

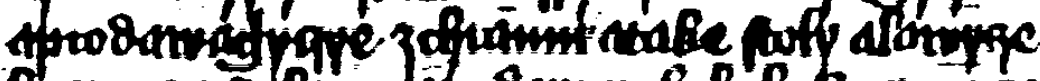

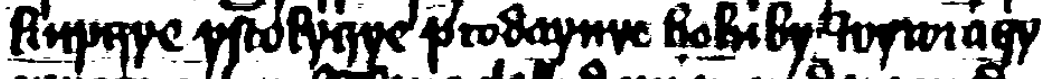

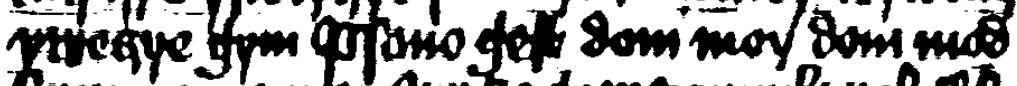

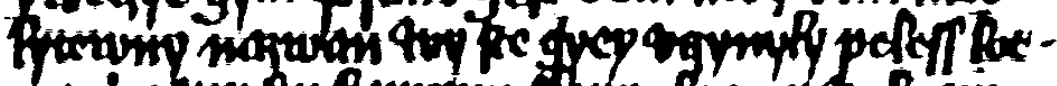

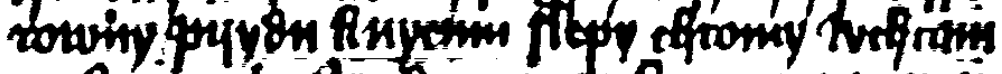

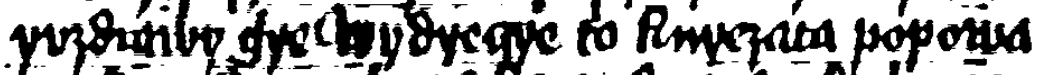

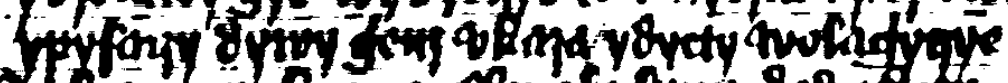

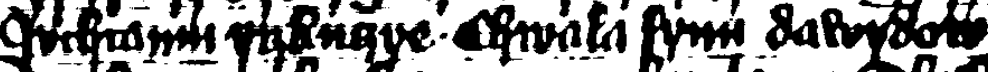

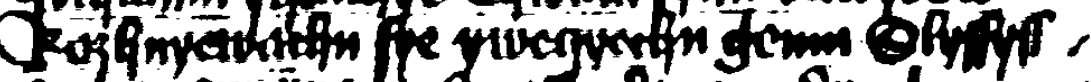

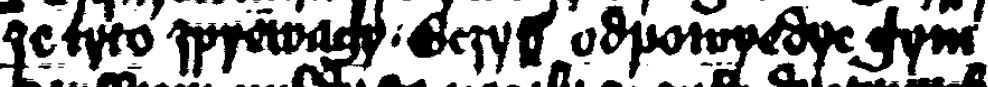

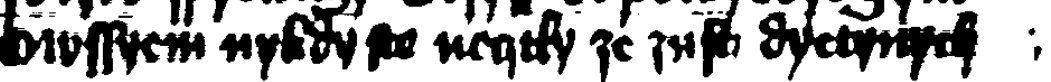




\section{SLAVISTISCHE BEITR ̈̈GE}

83. Baumann, $W_{.:}$Die Sage von Heinrich dem Löwen bei den Slaven. 1975. $185 \mathrm{~S}$.

84. Everts-Grigat, S.: V. V. Majakovskij: Pro éto. Ubersetzung und Interpretation. 1975. $262 \mathrm{~S}$.

85. Mirsky, S.: Der Orient im Werk Velimir Chlebnikovs. 1975. VIII, $112 \mathrm{~s}$.

86. Ditterich, M.: Untersuchungen zum altrussischen Akzent anhand von Kirchengesangshandschriften. 1975. $147 \mathrm{~S}$.

87. Cummins, G. M.: The Language of the Old Czech Legenda o svaté Katefine. 1975. VIII, $371 \mathrm{~S}$.

88. Földeak, H.: Neuere Tendenzen der sowjetischen Science Fiction. 1975. VI, $208 \mathrm{~s}$.

89. Drews, P.: Devétsil und Poetismus. Künstlerische Theorie und Praxis der tschechischen literarischen Avantgarde am Beispiel vitézslav Nezvals, Jaroslav Seiferts und Jiłí Wolkers. 1975. $330 \mathrm{~S}$.

90. Schönle, P. W.: Zur Wortbildung im modernen Russisch. 1975. VIII, $195 \mathrm{~S}$.

91. Okuka, M.: Sava Mrkalj als Reformator der serbischen Kyrilliza. Mit einem Nachdruck des Salo debeloga jera libo Azbukoprotres. 1975. $123 \mathrm{~S}$.

92. Neuhäuser, R.: The Romantic Age in Russian Literature: Poetic and Esthetic Norms. An Anthology of Original Texts (18001850). 1975. VIII, $300 \mathrm{~S}$.

93. Döring, J. R. (Hrg.): Literaturwissenschaftliches Seminar: Zur Analyse dreier Erzählungen von Vl. I. Dal'. Mit einem methodologischen Geleitwort von Johannes Holthusen.1975. 203 S.

94. Alexander, R.: Torlak Accentuation. 1975. XVI, $806 \mathrm{~S}$.

95. Schenkowitz, G.: Der Inhalt sowjetrussischer Vorlesestoffe für Vorschulkinder. Eine quantifizierende Corpusanalyse unter Benutzung eines Computers. 1976. $767 \mathrm{~S}$.

96. Kitch, F. C. M.: The Literary Style of Epifanij Premudryj. Pletenije sloves. 1976. $298 \mathrm{~S}$.

97. Eschenburg, B.: Linguistische Analyse der Ortsnamen der ehemaligen Komitate Bács und Bodrog-von der ungarischen Landnahme (896) bis zur Schlacht von Mohács (1526). 1976. $156 \mathrm{~s}$. $3 \mathrm{Kt}$.

98. Lohse, H.: Die Ikone des hl. Theodor Stratilat zu Kalbensteinberg. Eine philologisch-historische Untersuchung. 1976.XX,242 S.

99. Erbslöh, G.: "Pobeda nad solncem". Ein futuristisches Drama von A. Kručenych. Ubersetzung und Kommentar. (Mit einem Nachdruck der Originalausgabe.) 1976. $121 \mathrm{~s}$.

100. Koszinowski, K.: Die von präfigierten Verben abgeleiteten substantive in der modernen serbokroatischen Standardsprache. Eine Untersuchung zu den Präfixen do, iz, na, za. 1976. $271 \mathrm{~S}$.

101. Leitner, A.: Die Erzählungen Fedor Sologubs. 1976. $249 \mathrm{~S}$. 102. Lenga, G.: Zur Kontextdeterminierung des Verbalaspekts im modernen Polnisch. 1976. VIII, $233 \mathrm{~S}$.

103. Zlatanova, R.: Die Struktur des zusammengesetzten Nominalprädikats im Altbulgarischen. 1976. VIII, $220 \mathrm{~S}$.

104. Krupka, P.: Der polnische Aphorismus. Die "Unfrisierten Gedanken" von Stanisław Jerzy Lec und ihr Platz in der polnischen Aphoristik 1976. 197 S.

105. Pogacnik, J.: Von der Dekoration zur Narration. Zur Entstehungsgef schichte der slovenischen Literatur. 1977. $165 \mathrm{~S}$.

106. Bojić, V.: Jacob Grimm und Vuk Karadžić. Ein Vergleich ihrer Sprac auffassungen und ihre zusammenarbeit auf dem Gebiet der serbischen Grammatik. 1977. 257 S. 